UNIVERSIDADE DE SĀO PAULO

INSTITUTO DE GEOCIENCIAS

\title{
FOSFATOS PRIMÁRIOS E SECUNDÁRIOS NOS PERFIS DE INTEMPERISMO SOBRE OS MACIÇOS ALCALINO-CARBONATÍTICOS DE JUQUIÁ (SP), ANITÁPOLIS (SC) E TAPIRA (MG)
}

\author{
Viviane Carillo Ferrari
}

Orientadora: Profa. Dra. Maria Cristina Motta de Toledo

TESE DE DOUTORAMENTO

Programa de Pós-Graduação em Geoquímica e Geotectônica 


\section{FOSFATOS PRIMÁRIOS E SECUNDÁRIOS NOS PERFIS DE INTEMPERISMO SOBRE OS MACIÇOS ALCALINO-CARBONATÍTICOS DE JUQUIÁ (SP), ANITÁPOLIS (SC) E TAPIRA (MG)}

\section{VIVIANE CARILLO FERRARI}

Orientadora: Prof ${ }^{\text {a. }}$ Dr ${ }^{\text {a. }}$ Maria Cristina Motta de Toledo

TESE DE DOUTORAMENTO

COMISSÃO JULGADORA

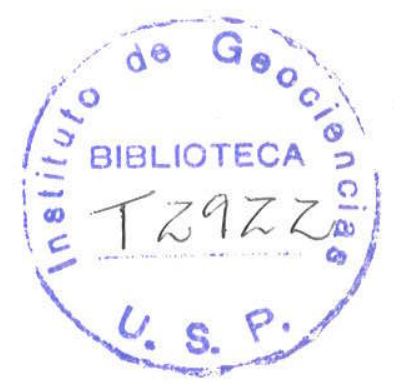

Nome

Assinatura

Presidente: $\quad \operatorname{Prof}^{\mathrm{a} \cdot} \mathrm{Dr}^{\mathrm{a} .}$ Maria Cristina Motta de Toledo

Examinadores:

Dr. Arnaldo Alcover Neto

Prof. Dr. José Carlos Gaspar

Prof ${ }^{\text {a. }} \cdot \mathrm{Dr}^{\mathrm{a}}$. Lília Mascarenhas Sant'Agostino

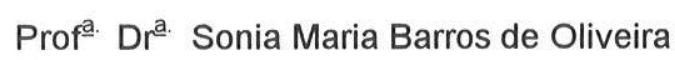

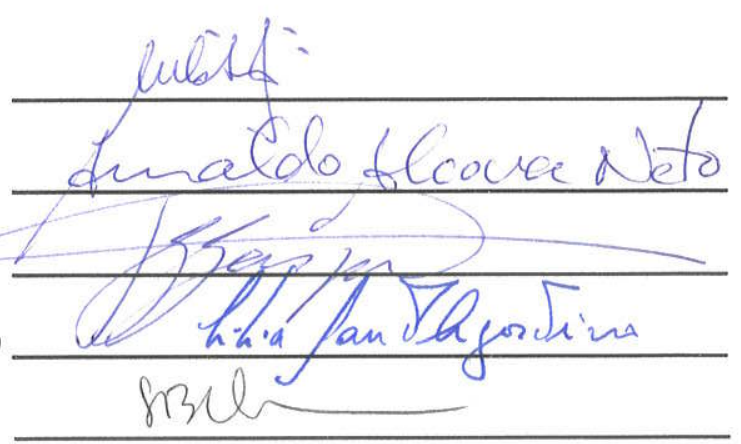

SÃO PAULO

2000 
UNIVERSIDADE DE SÃO PAULO

INSTITUTO DE GEOCIÊNCIAS

FOSFATOS PRIMÁRIOS E SECUNDÁRIOS NOS PERFIS DE INTEMPERISMO SOBRE OS MACIÇOS ALCALINO-CARBONATÍTICOS DE JUQUiÁ (SP), ANITÁPOLIS (SC) E TAPIRA (MG)

Viviane Carillo Ferrari

Orientadora: Maria Cristina Motta de Toledo

TESE DE DOUTORAMENTO

Programa de Pós-Graduação em Geoquímica e Geotectônica

SÃO PAULO

2000

DEDALUS - Acervo - IGC

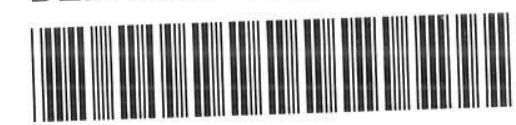

30900004578 
"aos meus queridos José e Augusto pelos laços de carinho “ 


\section{AGRADECIMENTOS}

À Pfa. Dra. Maria Cristina Motta de Toledo pela orientação e estímulo para a realização deste trabalho.

Ao Pf. Dr. François Fontan, co-orientador desta pesquisa, pelas sugestões e correções.

À equipe do Laboratório de Mineralogia e Cristalografia da Universidade Paul Sabatier pelo apoio durante o meu estágio em Toulouse, em especial Jean Pol Fortunèe.

Ao pesquisador Leroy da Universidade de Lille pelo acompanhamento das interpretações dos espectros Raman.

Ao pessoal do Laboratório de Física dos Sólidos da Universidade Paul Sabatier por viabilizar a realização das análises ao micro-espectômetro Raman.

Aos pesquisadores Milton L.L. Formoso, Vitor Pereira, Arnaldo Alcover Neto, Sara Lenharo, Helmut Born e François Soubiès por colocarem a disposição parte dos materiais aqui estudados.

Ao Dr. Luiz Antonio F. de Barros e pessoal técnico da FERTIFOS pelo acesso à mina de Tapira e pela colaboração prestada.

Ao pesquisador Flávio Machado de Carvalho pela discussões sobre a DRX e o Método Rietveld.

À colega Verônica Gabriel dos Santos pelo auxilio nas preparações das amostras e análises no ATD, sempre com muita eficiência.

Ao Centro de Aperfeiçoamento de Professores do Ensino Superior - CAPES que através do acordo CAPES-COFECUB viabilizou minha estadia em Toulouse.

À fundação de Amparo à pesquisa do Estado de São Paulo - FAPESP que financiou as idas ao campo, materiais e análises 


\section{ÍNDICE}

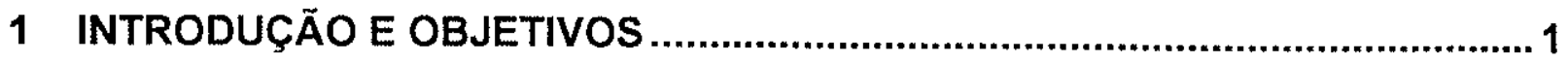

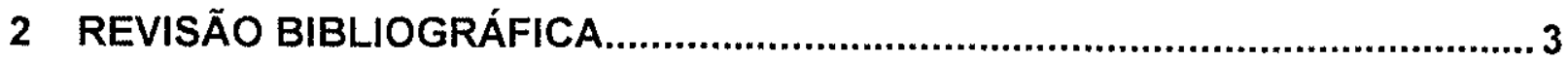

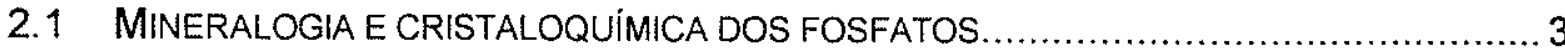

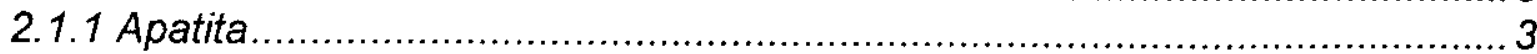

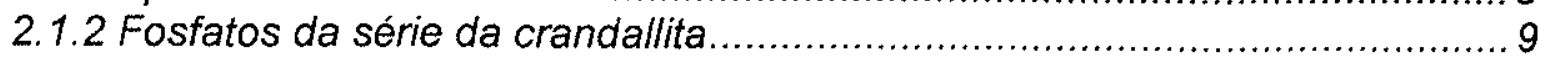

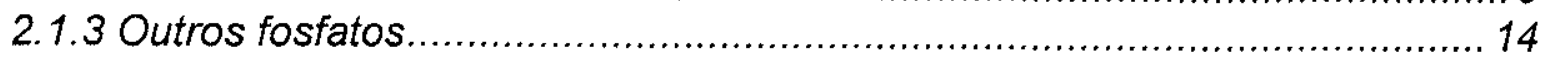

2.2 ALTERAÇÃO DE FOSFATOS PRIMÁRIOS E FORMAÇÃO DE FOSFATOS

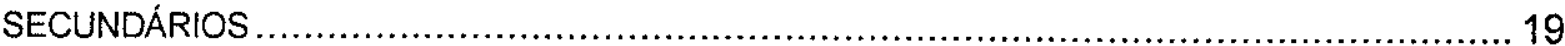

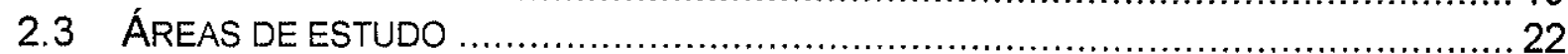

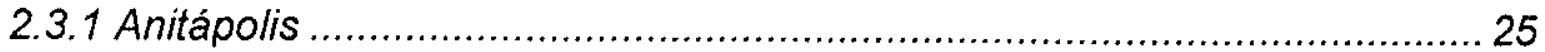

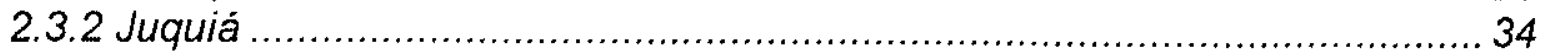

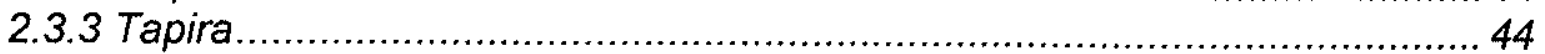

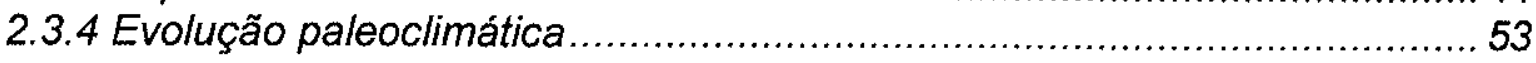

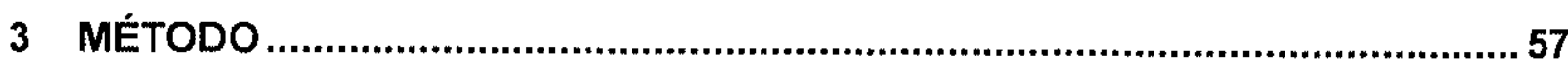

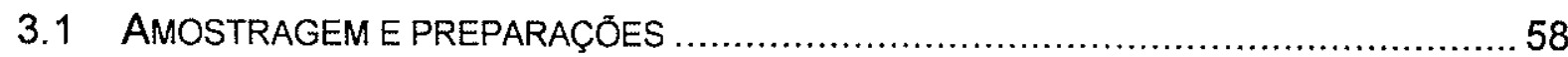

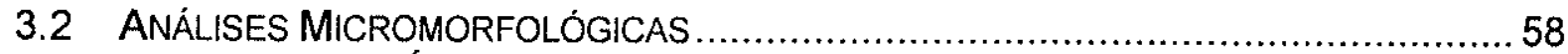

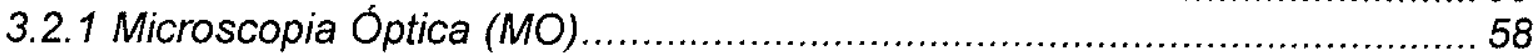

3.2.2 Microscopia Eletrônica de Varredura (MEV) e microanálises $X(E D S)$..... 59

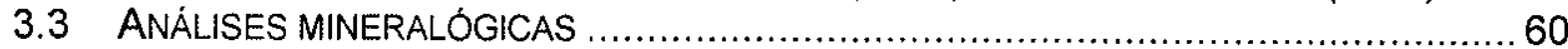

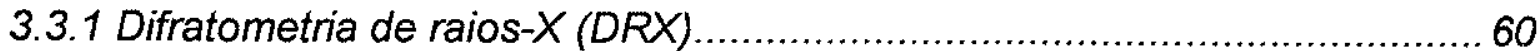

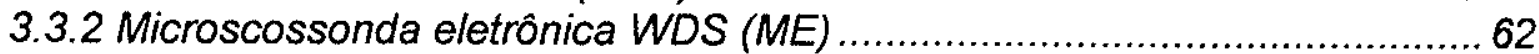

3.3.3 Análises Termo diferencial e Termo gravimétrica (ATD/ATG) ..................64 64

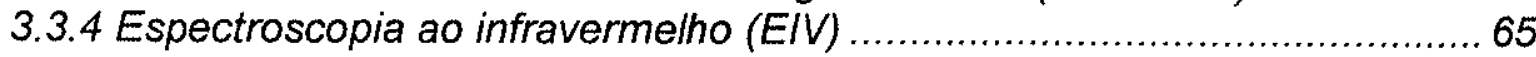

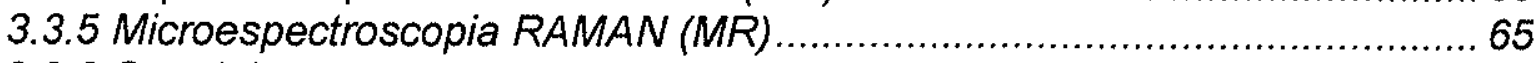

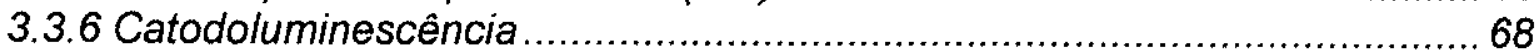

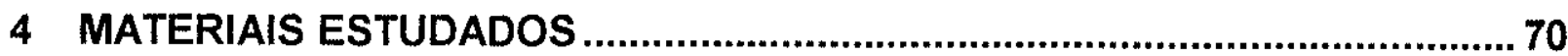

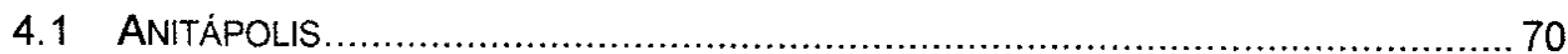

4.1.1 Perfil sobre piroxenito com bolsões de glimmerito................................ 70

4.1.2 Perfil sobre piroxenitos em contato com sienitos.................................... 71

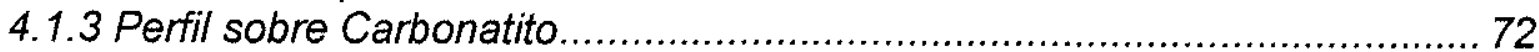

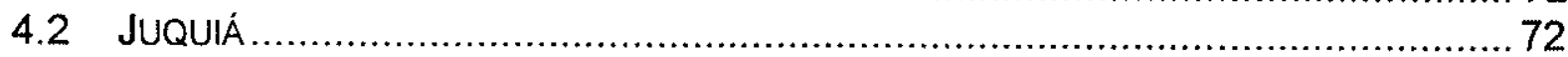

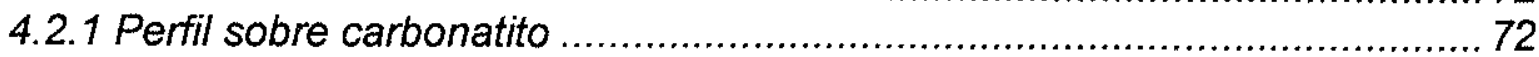

4.2.2 Perfil sobre rocha alcalino-silicática (setor 2) ..................................... 73

4.2.3 Perfil sobre zona de transição carbonatito/rochas alcalino-silicáticas

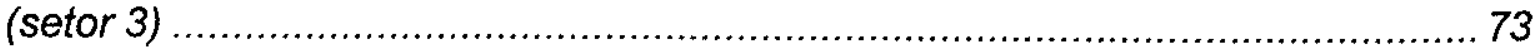

4.2.4 Horizonte aloterítico próximo ao corpo carbonatítico (setor 4) .................. 74

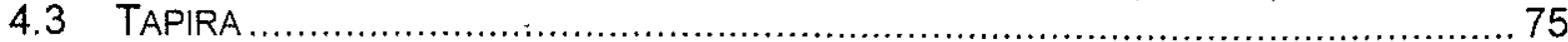

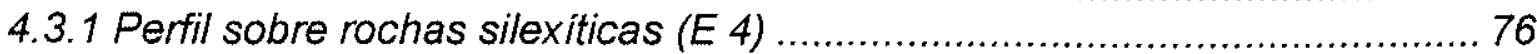

4.3.2 Perfis sobre rochas piroxeníticas (E 2, $E$ 3 e $E$ 5) .............................. 77 


\section{ASPECTOS MINERALÓGICOS, MORFOLÓGICOS, GEOQUÍMICOS E}

CRISTALOQUÍMICOS DOS FOSFATOS

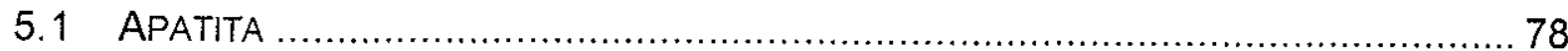

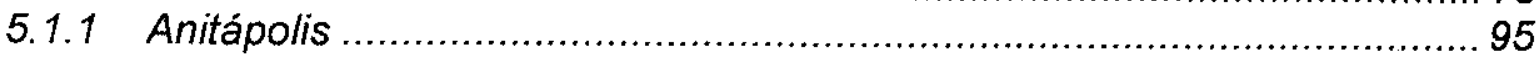

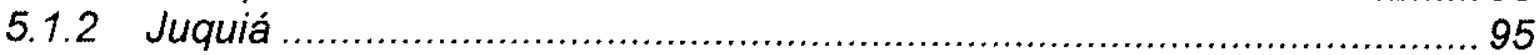

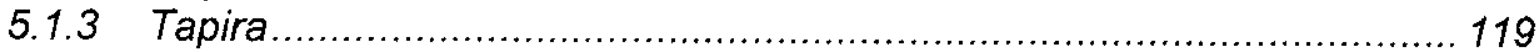

5.1.4 Sintese comparativa das apatitas das três áreas .............................. 139

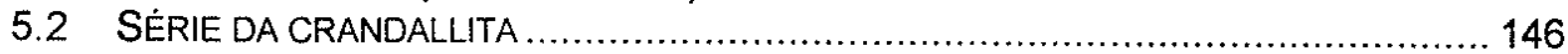

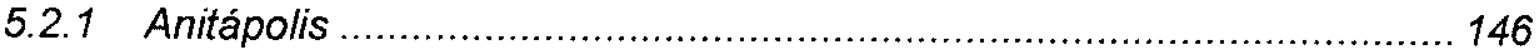

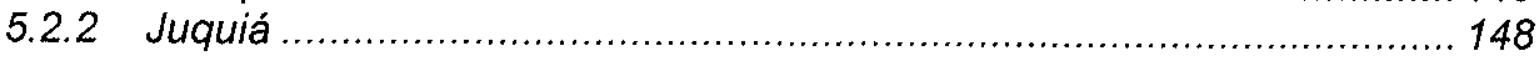

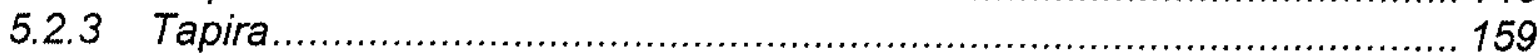

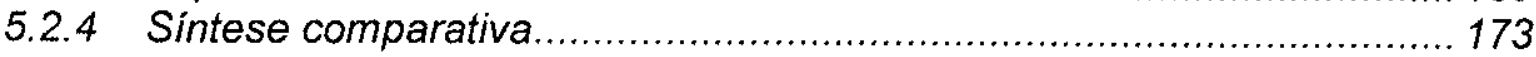

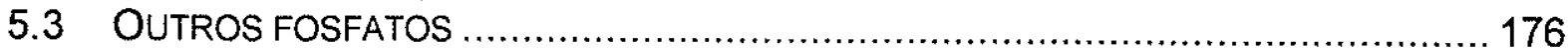

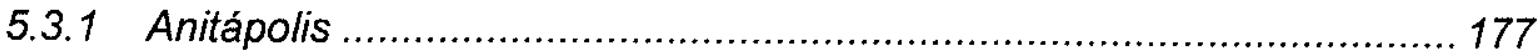

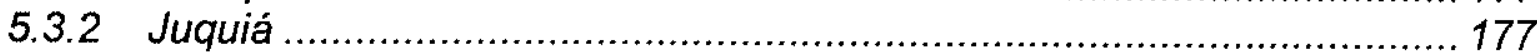

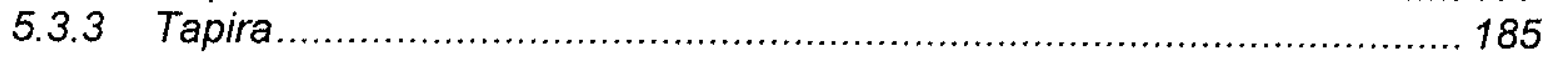

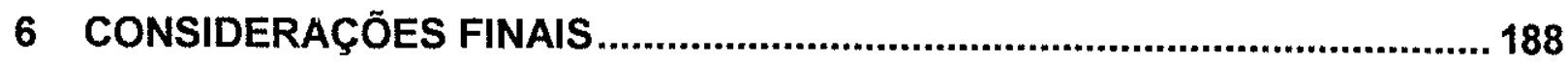

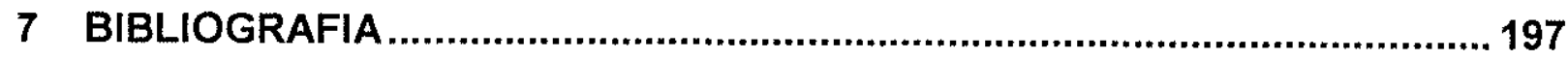

ANEXO 1 MÉTOdO DE RIETVELD APLICADO Ȧ DIFRAÇÃO DE RAIOS-X .......................209

ANEXO 2 COMPOSIÇÃO QUIMICA DAS APATITAS DE ANITÁPOLIS OBTIDA À ME E EXPRESSA EM \% EM ÓXIDOS E EM NÚMERO DE ÁTOMOS POR FÓRMULA UNITÁRIA

ANEXO 3 COMPOSIÇÃO QUIMICA DAS APATITAS DE JUQUIÁ OBTIDA À ME E EXPRESSA EM \% EM ÓXIDOS E EM NÜMERO DE ÁTOMOS POR FÓRMULA UNITÁRIA

ANEXO 4 COMPOSIÇÃO QUIMICA DAS APATITAS DE TAPIRA OBTIDA À ME E EXPRESSA EM \% EM ÓXIDOS E EM NÚMERO DE ÁTOMOS POR FÓRMULA UNITÁRIA 


\section{LISTA DE FIGURAS}

Figura 1 Estrutura da apatita segundo Montel, 1968, elaborado com o auxílio do programa ORTEP3 desenvolvido por Farrugia, 1997 ................................... 4

Figura 2 Estrutura da crandallita segundo Blount (1974), elaborado com o auxílio do programa ORTEP3, programa desenvolvido por Farrugia (1997) ..... 12

Figura 3 Mapa de localização dos complexos alcalinos estudados. Fonte: Rodrigues \& Lima (1984).

Figura 4 Superfície e mapa de sombras elaborados a partir do Modelo digital do terreno da área do Complexo alcalino-carbonatítico de Anitápolis. Mapa base: Carta topográfica Folha SG-22-Z-D-IV-4, escala 1:50.000 (IBGE 1978)......

Figura 5 Mapa geológico do Complexo alcalino-carbonatítico de Anitápolis (Vergara, 1980).

Figura 6 Superfície e mapa de sombras elaborados a partir do Modelo digital do terreno da área do Complexo alcalino-carbonatítico de Juquiá. Mapa base: Carta topográfica Folha SG-23-V-A-1-4, escala 1:50.000 (IBGE, 1974). 35

Figura 7 Mapa geológico do Complexo Alcalino-carbonatítico de Juquiá (Born, 1971 e Macciotta et al., 1988).

Figura 8 Superfície e mapa de sombras elaborados a partir do Modelo digital do terreno da área do Complexo alcalino-carbonatítico de Tapira. Mapa base: Carta topográfica Folha SE-23-Y-C-VI, escala 1:100.000 (IBGE 1970).

Figura 9 Mapa geológico do Complexo Alcalino-carbonatítico de Tapira (Alves, 1960, apud Henrich, 1966).

Figura 10 Esquema dos procedimentos analíticos adotados

Figura 11 Perfis esquemáticos representativos da trincheira TGB e da frente de lavra experimental do depósito residual de Anitápolis.

Figura 12 Esquema do manto de alteração sobre o maciço de Juquiá, com indicação dos setores amostrados

Figura 13 Esquema da seção amostrada com indicação dos materiais encontrados e locais de amostragem. Esquema apresentado por Alcover Neto (1994).

Figura 14 Perfis esquemáticos representativos das frentes de lavra E 2, E3, E 4 e $E$ com a localização dos setores amostrados em Tapira.

Figura 15 Variação dos parâmetros cristalográficos a e $c$ das apatitas de Anitápolis, calculados pelo método dos mínimos quadrados utilizando o programa de refinamento de parâmetros de cela LCLSQ (Burnham, 1991). Fap - Fluorapatita sintética (JCPDS 15-876) Hap - Hidroxiapatita sintética (JCPDS 9-432)

Figura 16 Difratogramas de amostras com apatita primária e supérgena de Anitápolis. M: mica, 1: posições das reflexões de Bragg da apatita.

Figura 17 Gráfico da variação, em número de átomos p.f.u., dos principais cátions substituintes do cálcio, da razão $\mathrm{Ca} / \mathrm{P}$ e do $\mathrm{F}$ de diferentes tipos de 
apatita de Anitápolis. Os cálculos de fórmula estrutural foram efetuados com base em 10 cátions a partir de dados da ME.

Figura 18 Diagramas binários mostrando as relações entre vários dos constituintes das apatitas de Anitápolis, em número de átomos p.f.u.

(fórmula estrutural calculada na base 10 cátions a partir de dados da ME)

Figura 19 Diagramas ternários mostrando as variações de conteúdo em $\mathrm{Ca} /(\mathrm{P}$ $+\mathrm{Si}) / \mathrm{F} \mathrm{e}(\mathrm{Na}+\mathrm{Sr}+\mathrm{Mg}+\mathrm{ETR}) /(\mathrm{P}+\mathrm{Si}) / \mathrm{F}$ para os diferentes tipos de apatitas de Anitápolis. ETR $=\mathrm{Ce}+\mathrm{La}$.

Figura 20 Difratogramas das amostras de apatitas primárias e supérgenas de Juquiá. 1 : posições das reflexões de Bragg da apatita. 103

Figura 21 Variação dos parâmetros cristalográficos a e $c$ das apatitas de Juquiá, pelo método dos mínimos quadrados utilizando o programa de refinamento de parâmetros de cela LCLSQ (Burnham, 1991). Fap Fluorapatita sintética (JCPDS 15-876) Hap - Hidroxiapatita sintética (JCPDS 9-432).

Figura 22 Gráfico do refinamento Rietveld para a apatita supérgena prismática, mostrando os padrões observado, calculado e o resíduo.

Figura 23 Gráfico do refinamento Rietveld para a apatita supérgena fibrosa, mostrando os padrões observado, calculado e o resíduo.

Figura 24 Diagramas ternários mostrando as variaçōes de conteúdo em $\mathrm{Ca} /(\mathrm{P}$ $+\mathrm{Si}) / \mathrm{Fe}(\mathrm{Na}+\mathrm{Sr}+\mathrm{Mg}+\mathrm{ETR}) /(\mathrm{P}+\mathrm{Si}) / \mathrm{F}$ para os diferentes tipos de apatitas de Anitápolis. ETR $=\mathrm{Ce}+\mathrm{La}$.

Figura 25 Gráfico da variação, em número de átomos p.f.u., dos principais cátions substituintes do cálcio, da razão $\mathrm{Ca} / \mathrm{P}$ e do $\mathrm{F}$ de diferentes tipos de apatita de Juquiá. Os cálculos de fórmula estrutural foram efetuados com base em 10 cátions a partir de dados da ME.

Figura 26 Diagramas binários mostrando as relações entre vários constituintes das apatitas de Juquiá, em número de átomos p.f.u. (fórmula estrutural calculada na base 10 átions).

Figura 27 Variação dos parâmetros cristalográficos a e $c$ das apatitas de

Tapira, calculados pelo método dos mínimos quadrados utilizando o programa de refinamento de parâmetros de cela LCLSQ (Burnham, 1991). Fap - Fluorapatita sintética (JCPDS 15-876) Hap - Hidroxiapatita sintética (JCPDS 9-432)

Figura 28 Difratogramas de amostras mistas de apatita primária e supérgena com diferentes porcentagens. qz: quartzo, dol: dolomita, cc: calcita, | : posições das reflexões de Bragg da apatita.

Figura 29 Gráfico da variação, em número de átomos p.f.u., dos principais cátions substituintes do cálcio, da razão $\mathrm{Ca} / \mathrm{P}$ e do $\mathrm{F}$ de diferentes tipos de apatita de Tapira. Os cálculos de fórmula estrutural foram efetuados com base em 10 cátions a partir de dados da ME.

Figura 30 Diagramas binários mostrando a relação dos constituintes das apatitas de Tapira, em número de átomos p.f.u. (fórmula estrutural calculada na base 10 cátions). 
Figura 31 Diagramas ternários mostrando as variações de conteúdo em $\mathrm{Ca} /(\mathrm{P}$ $+\mathrm{Si}) / \mathrm{F},(\mathrm{Na}+\mathrm{Sr}+\mathrm{Mg}) /(\mathrm{P}+\mathrm{Si}) / \mathrm{F} \mathrm{e} \mathrm{Ca} /(\mathrm{P}+\mathrm{Si}) / \mathrm{ETR}$ para os diferentes tipos de apatitas de Tapira. ETR $=\mathrm{Ce}+\mathrm{La}$.

Figura 32 Difratogramas de amostras de fosfato da série crandallita de Juquiá comparado a um padrão calculado da gorceixita dada por Radoslovich \& Slade (1980). goe: goethita, K: caulinita, Ap: apatita.

Figura 33 Diagramas ternários mostrando as variações de conteúdo em $\mathrm{Ca} / \mathrm{Sr}$ / Ba, Ba / Al / (P+Si), Ca / ETR / Ba e Ca / Al / P+Si de fosfatos não apatíticos de Juquiá. (fórmula estrutural calculada na base 10,5 O para fórmula da crandallita anidra)

Figura 34 Diagramas binários mostrando a relação dos constituintes dos fosfatos da série da crandallita de Juquiá, em número de átomos p.f.u. (fórmula estrutural calculada na base 10,5 O para fórmula da crandallita anidra).

Figura 35 Difratogramas das amostras com fosfatos da série da crandallita de Tapira em comparação com padrões da gorceixita e da florencita.

Figura 36 Diagramas ternários mostrando as variações de conteúdo em $\mathrm{Ca} / \mathrm{P}$ / Al, Ca / ETR / BaO e Ca / SrO / Ba de fosfatos não apatíticos de Tapira. (fórmula estrutural calculada na base 10,5 O para fórmula da crandallita anidra) 169

Figura 37 Diagramas binários mostrando as relações dos constituintes dos fosfatos da série da crandallita de Tapira, em número de átomos p.f.u. (fórmula estrutural calculada na base 10,5 O para fórmula da crandallita anidra).

Figura 38 Gráficos de variação dos teores em principais elementos e ocupações do sítios cristaloquímicos $\mathrm{A}$ dos fosfatos da série da crandallita de Juquiá e Tapira (dados da tabela 32), em número de átomos p.f.u.

Figura 39 Gráficos de variação dos teores dos principais elementos e ocupações dos sítios cristaloquímicos $X$ e $B$ dos fosfatos da série da crandallita de Juquiá e Tapira, (dados da tabela 32), em número de átomos p.f.u. 


\section{LISTA DE FOTOS}

Foto 1 Cristais de apatita primária $(p)$ sãs em pavê com borda de maior birrefringência (b) e massa dolomítica (do) nos espaços intercristalinos, em carbonatito são, Anitápolis. Amostra GPF-3a, MO (LP).

Foto 2 Cristais de apatita primária com fraturas $(p)$ associados a apatita supérgena do tipo fibroso (s2), em piroxenito alterado de Anitápolis. Amostra AN9e. MO (LP).

Foto 3 grão de apatita alterada (p), em piroxenito alterado de Anitápolis. Amostra AN7. MEV (BEI).

Foto 4 Feição de alteração na superfície do grão de apatita $(p)$ com apatita supérgena criptocristalina (s1) em piroxenito alterado de Anitápolis. Amostra AN1.4. MEV (BEI).

Foto 5 Grãos de apatita primária residual $(p)$ rodeados por fibras de apatita supérgena (s2), piroxenito alterado no perfil TGB de Anitápolis. Amostra AN9e. a: $M E V(B E I)$ e b: MO (LN).

Foto 6 Grão de apatita primária residual $(p)$, fraturada e com impregnações ferruginosas em material pedogeneizado do perfil TGB de Anitápolis. Amostra AN10C. MO (LN).

Foto 7 Cristais de apatita primária sã $(p)$ com borda de maior birrefringência (b) estão associados a cristais menores sem esta borda. Juquiá. Amostra FJ88. MO (LP).

Foto 8 Apatita primária alterada $(p)$ com borda de maior birrefringência (b) parcialmente dissolvida e recoberta por fibras de apatita supérgena tipo fibrorradial (s2). Juquiá. Amostra FJ-42. MO (LP).

Foto 9 Apatita primária (p) com borda alterada (b) e núcleo são. Juquiá. Amostra JU48. MO (LN).

Foto 10 Cristais de apatita primária residual sã ( $p$ ), euedrais, associados a pequenos cristais alongados de apatita supérgena (s1). Juquiá. Amostra JU1B. MEV (SEI),

Foto 11 Feições de dissolução "em ripa" da apatita primária residual ( $p$ ). Juquiá. Amostra JU14. MEV (SEI).

Foto 12 Feições de dissolução em pequenos "golfos" na apatita primária $(p)$ associada a apatita supérgena criptocristalina. Juquiá. Amostra JU34. MEV (SEl).

Foto 13 Apatita primária $(p)$ parcialmente alterada revestida por apatita supérgena criptocristalina ( $\mathrm{s} 1$ ). Amostra JU14. Juquiá. MEV (SEI). 99

Foto 14 a: Cristais de apatita com linha de crescimento (pl) em carbonatito alterado com vazios deixados pela dissolução do carbonato preenchido por apatita supérgena criptocristalina (s1). Juquiá. Amostra JU37.1. MO (LP). b: Detalhe destas apatitas primárias imersas em massa de cristais 
criptocristalino (s1), algumas delas encontram-se parcialmente dissolvidas.

Juquiá. Amostra JU37.1 MEV (SEI).

Foto 15 a: Cristais de apatita primária sã (p) com borda de maior birrefringência

(b) em massa de cristais fibrorradiais de apatita supérgena (s2). Juquiá.

Amostra JU32.1. MO (LP). b: Cristais fibrosos de apatita supérgena (s2) ao lado de um cristal de apatita primária sã residual (p). Juquiá. Amostra JU21B. MEV (SEl).

Foto 16 a: Cristais fibrorradiados de apatita supérgena (s2) em contato com massa de apatita supérgena microprismática (s3). Juquiá. Amostra JU10. MO (LP). b: Detalhe da massa de apatita supérgena microprismática (s3), formada por prismas de apatita revestidos de material argiloferruginoso (cor esbranquiçada). Juquiá. Amostra JU10. MEV (BEI).

Foto 17 a: Cristais fibrorradiais de apatita supérgena (s2) formando camadas marcadas por diferenças de comprimento das fibras e cores de birrefringência. Juquiá. Amostra JU37.1. MO (LP). b: Detalhe da camada de apatita supérgena fibrosa (s2) com o topo formado por cristais prismáticos mais desenvolvidos (s4). Juquiá. Amostra JU37.1. MEV (SEI) .... 102

Foto 18 a: Cristais de apatita supérgena prismática (s4) ao redor de um cristal tabular de barita, nota-se pequenos cristais de apatita incrustados em cavidades de sua superfície. Juquiá. Amostra JU21. MEV (BEl). b: cristais de apatita supérgena prismática com terminação piramidal (s4) preenchendo cavidades de cristais de barita parcialmente dissolvidos. Juquiá. Amostra JU40. MO (LP).

Foto 19 Cristais de apatita primária $(p)$ anédrica imbricados em textura tipo pavê cortados por vênulas de calcita (cc). Tapira. Amostra TA46. MO (LP).... 121

Foto 20 Detalhe da vênula de calcita $(c c)$ que corta a apatita primária $(p)$ anédrica. Tapira. Amostra TA46. MEV.

Foto 21 Cristais de apatita primária sã $(p)$ de forma prismática alongada (borda de maior birrefringência de espessura muito fina e descontínua) e de piroxênio (px), imersos em massa dolomítica de cor mais clara cortada por um volume de mineral verde (?). Tapira. Amostra TA33. MO (LP)

Foto 22 Cristal de apatita hidrotermal (h) anédrica alterada com fratura preenchida por fosfatos da série da crandallita tipo microcristalino cor clara (fsc1). Os espaços entre as apatitas residuais são constituídos por microglóbulos ( $\mathrm{fsc} 2$ ) misturados a plasma de alteração de micas. Tapira. Amostra TAF49. MO (LP).

Foto 23 Detalhe da mica vermiculitizada junto a microglóbulos de fosfatos da série da crandallita ( $f s c 2$ ), que ocorrem ao redor das apatitas hidrotermais anédricas. Tapira. Amostra TA49. MEV (BEl).

Foto 24 Apatita hidrotermal anédrica alterada (h) com núcleo de aspecto estriado e borda mais sã. Tapira. Amostra TA1. MO (LP).

Foto 25 Detalhe da superfície da apatita hidrotermal anédrica alterada. Tapira. Amostra TA1. MEV (BEl).

Foto 26 Cristal de apatita hidrotermal anédrica com sulcos de dissolução e com microporosidade. Tapira. Amostra TA2a. MEV (BEl). 
Foto 27 Fraturas da apatita hidrotermal (h) anédrica com recristalização de apatita supérgena fibrosa (s) muito fina. Tapira. Amostra 49.1. MO (LP).

Foto 28 Apatitas supérgenas fibrosas em descontinuidades da rocha, ao redor de grãos de apatita primária $(p)$ anédrica com bordas dissolvidas e ferruginizadas. Tapira. Amostra TA-SC-4b. MO (LN).

Foto 29 Cristais de apatita prismática supérgena, em pavê, cristalizada entre cristais de apatita hidrotermal (h) anédrica. Tapira. Amostra TA19. MO (LN)... 126

Foto 30 Detalhe dos cristais de apatita prismática supérgena entre grãos de apatita hidrotermal anédrica (h). Amostra TA19. Tapira. MEV (BEl). 126

Foto 31 Fosfatos da série da crandallita (fsc) de aspecto muito fino sobre a superfície da apatita primária $(p)$ alterada. Elementos identificados por EDS: $\mathrm{P}, \mathrm{Al}, \mathrm{Ca}, \mathrm{Sr}, \mathrm{Ba}$ e Fe. Anitápolis. Amostra AN7.4. MEV (BEI).

Foto 32 Agregados globulares de fosfatos da série da crandallita com núcleo mais escuro ( $f s c n$ ) e bordas incolores ( $f s c b$ ). Juquiá. Amostra JU8. MEV (BEI).

Foto 33 Detalhe dos agregados globulares de fosfatos da série da crandallita (fsc). Juquiá. Amostra JU8. MO (LN).

Foto 34 Apatita primária $(p)$ alterada com fissuras (intraminerais e interminerais) revestidas por cristais de fosfatos da série da crandallita trigonais cutânicos (fsc). Juquiá. Amostra T4Agb. MO (LP).

Foto 35 Agregados microcristalinos de fosfato da série crandallita (fsc) de forma granular a trigonal. Juquiá. Amostra JU40. MEV (BEI).

Foto 36 Cristal de pirocloro (pir) com superfície de textura granular imerso em material rico em fosfato da série crandallita. Juquiá. Amostra JU7. MEV (BEI).

Foto 37 Cristal de anatásio alterado com fissuras revestidas por fosfato da série da crandallita (fsc1) microcristalino cor de birrefringência cinza esbranquiçada. Tapira. Amostra TA50c1. MO (LP).

Foto 38 Detalhe do material de fosfato da série crandallita (fsc1) que reveste as fissuras do anatásio. Tapira. Amostra TA50c1. MEV (BEI).

Foto 39 Revestimento cutânico de fosfato da série da crandallita (fsc1) em descontinuidades do plasma goethítico (goe) e agregados microcristalinos misturado ao plasma ferruginoso (fsc2). Tapira. Amostra TA8.1. MO (LP) 163

Foto 40 Detalhe do material cutânico constituído por cristais romboédricos a tetraédricos de fosfato da série da crandallita (fsc). Tapira. Amostra TA8.1. $\operatorname{MEV}(\mathrm{BEI})$.

Foto 41 Apatita primária ( $p$ ) com superfície revestida por fosfatos da série da crandallita (fsc3) enriquecidos em ETR. Tapira. Amostra TA5.1. MEV (BEI)... 164

Foto 42 Feição "box-work" dos fosfatos da série da crandallita (fsc3) rico em ETR. Tapira. Amostra TA1.2. MEV (BEI).

Foto 43 Detalhe da parede do box-work (região do retângulo na foto 42 ), onde aparecem cristais fusiformes e globulares sobre a parede de cristais em roseta todos fosfatos da série crandallita com ETR. Tapira. Amostra TA1.2. 
MEV (BEI)

Foto 44 Agregados criptocristalinos de fosfatos de TR (ftr) entre cristais de apatita primária $(p)$ e de piroxênio $(p x)$. Anitápolis. Amostra AN7.4. MEV (SEI). 182

Foto 45 Wavellita acicular $(w)$ com diferentes dimensões. Juquiá. Amostra T2Agb. MO (LP), 182

Foto 46 Wavellita acicular (w). Juquiá. Amostra JUT'15. MEV (BEI). 183

Foto 47 Cristais de turquesa $(\mathrm{t})$ associados à agregados microcristalinos de fosfato da série da crandallita (fsc). Juquiá. JUT'15. MEV (BEI).

Foto 48 Agregados de cristais muito finos de fosfato de ETR associados à agregados microcristalinos de fosfato da série da crandallita (fsc) do pseudomorfo micáceo. Juquiá. Amostra JU21d. MEV (SEI).

Foto 49 Apatita primária $(p)$ inclusa em anatásio (an) e rhabdofânio (rh) no contato entre os dois minerais. Tapira. Amostra TA6.1. MO (LP).

Foto 50 Rhabdofânio (rh) crescido sobre anatásio (an). Tapira. Amostra TA2.1. MEV (BEI)

Foto 51 Fosfato de ETR (ftr) em fissura da apatita primária alterada (p). Tapira. Amostra TA6.1. MEV (SEI). 


\section{LISTA DE TABELAS}

Tabela 1 Substituições na estrutura da apatita, exemplificada pela fluorapatita......... 3

Tabela 2 Parâmetros de cela das principais variedades de apatitas ........................ 6

Tabela 3 Composição química (\% em óxidos) de apatitas de várias origens apresentadas por Roeder et al. (1987), análises a microssonda eletrônica.......... 7

Tabela 4 Composição química (em \%) de alguns fosfatos da série da crandallita analisados à microssonda eletrônica.

Tabela 5 Grupos espaciais dos fosfatos da série da crandallita

Tabela 6 Parâmetros de cela unitária de minerais da série da crandallita e fosfatos similares de origem sintética, apresentados por vários autores. .......... 13

Tabela 7 Análises químicas de wavellitas (Correia Neves et al., 1976).................. 14

Tabela 8 Análises químicas de turquesas...................................................... 15

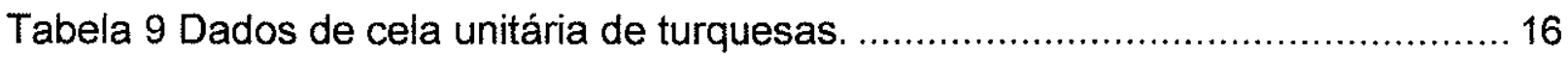

Tabela 10 Composição química de fosfatos de terras raras da jazida de talco e clorita de Trimouns (Ariege, França), Parseval et al. (1996)............................. 17

Tabela 11 Parâmetros de cela da monazita e xenotima...................................... 17

Tabela 12 Composição química (em \%) de rhabdofânios analisados à

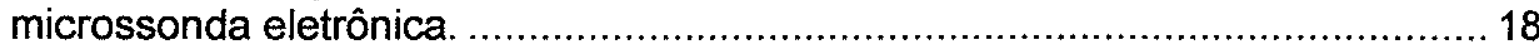

Tabela 13 Dados geográficos e geológicos das três áreas de estudo..................... 23

Tabela 14 Condições de análise utilizadas na DRX ...........................................61

Tabela 15 Elementos analisados à microssonda para os diferentes minerais fosfáticos

Tabela 16 Condições de análise das apatitas à microespectroscopia Raman.

Tabela 17 Parâmetros cristalográficos a e $c$ de apatitas de Anitápolis.

Tabela 18 Análises à microssonda eletrônica (em \% em peso dos óxidos) e cálculos de fórmulas estruturais das apatitas de Anitápolis.

Tabela 19 Dados de quantidades de $\mathrm{OH}$ (\% em peso e átomos p.f.u.), peso molecular (PM) e carga da fórmula estrutural considerando três alternativas: a - todo flúor $(F)$ nos canais $\left(F_{p}=0\right), b$ - parte do flúor $\left(F_{p}\right)$ acompanhando o $\mathrm{CO}_{3}{ }^{2-}\left(\mathrm{F}_{\mathrm{p}}=0,4 \mathrm{C}\right)$ e $\mathrm{c}$ - parte do flúor $\left(\mathrm{F}_{\mathrm{p}}\right)$ acompanhando o $\mathrm{CO}_{3}\left(\mathrm{~F}_{\mathrm{p}}=\mathrm{C}\right)$. $\mathrm{OH}$ foi calculado pela diferença da fração molar no sítio dos ânions monovalentes $\left(\mathrm{OH}=2-\mathrm{F}-\mathrm{F}_{\mathrm{p}}\right)$, para cada caso $\mathrm{a}, \mathrm{b}$ e $\mathrm{c}$. (A partir dos dados da tabela anterior, para apatitas de Anitápolis).

Tabela 20 Análises detalhadas de elementos terras-raras à ME (\% em peso dos óxidos) de apatitas de Anitápolis.

Tabela 21 Parâmetros cristalográficos a e $c$ de apatitas de Juquiá. 105

Tabela 22 Resultados do refinamento Rietveld das apatitas supérgenas de Juquiá. 
Tabela 23 Análises à microssonda eletrônica (em \% em peso dos óxidos) e cálculos de fórmulas estruturais das apatitas de Juquiá.

Tabela 24 Dados de quantidades de $\mathrm{OH}$ (\% em peso e átomos p.f.u.), peso molecular (PM) e carga da fórmula estrutural considerando três alternativas: a - todo fiúor $(F)$ nos canais $\left(F_{p}=0\right), b$ - parte do flúor $\left(F_{p}\right)$ acompanhando o $\mathrm{CO}_{3}{ }^{2-}\left(\mathrm{F}_{\mathrm{p}}=0,4 \mathrm{C}\right)$ e $\mathrm{c}$ - parte do flúor $\left(\mathrm{F}_{\mathrm{p}}\right)$ acompanhando o $\mathrm{CO}_{3}\left(\mathrm{~F}_{\mathrm{p}}=\mathrm{C}\right)$. $\mathrm{OH}$ foi calculado pela diferença da fração molar no sítio dos ânions monovalentes $\left(\mathrm{OH}=2-\mathrm{F}-\mathrm{F}_{\mathrm{p}}\right)$, para cada caso $\mathrm{a}$, b e c . (A partir dos dados da tabela anterior, para apatitas de Juquiá).

Tabela 25 Análises detalhadas de elementos terras-raras à ME (\% em peso dos óxidos) de apatitas de Juquiá.

Tabela 26 Parâmetros cristalográficos a e $c$ de apatitas de Tapira 128

Tabela 27 Análises à microssonda eletrônica (em \% em peso dos óxidos) e cálculos de fórmulas estruturais das apatitas de Tapira.

Tabela 28 Dados de quantidades de $\mathrm{OH}$ (\% em peso e átomos p.f.u.), peso molecular (PM) e carga da fórmula estrutural considerando três alternativas: a - todo flúor $(F)$ nos canais $\left(F_{p}=0\right), b$ - parte do flúor $\left(F_{p}\right)$ acompanhando o $\mathrm{CO}_{3}{ }^{2-}\left(\mathrm{F}_{\mathrm{p}}=0,4 \mathrm{C}\right)$ e $\mathrm{c}$ - parte do flúor $\left(\mathrm{F}_{\mathrm{p}}\right)$ acompanhando o $\mathrm{CO}_{3}\left(\mathrm{~F}_{\mathrm{p}}=\mathrm{C}\right)$. $\mathrm{OH}$ foi calculado pela diferença da fração molar no sítio dos ânions monovalentes $\left(\mathrm{OH}=2-\mathrm{F}-\mathrm{F}_{\mathrm{p}}\right)$, para cada caso $\mathrm{a}$, b e c. (A partir dos dados da tabela anterior, para apatitas de Tapira).

Tabela 29 Análises detalhadas de elementos terras-raras à ME (\% em peso dos óxidos) de apatitas de Tapira.

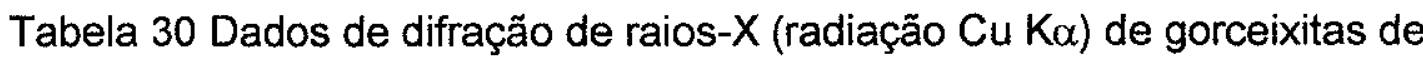
Juquiá.

Tabela 31 Composição química dos fosfatos da série da crandallita de Juquiá, expressa em \% em peso dos óxidos e em número de átomos por fórmula unitária na base de 10,5 $\mathrm{O}$.

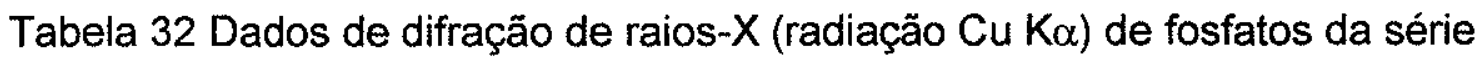
da crandallita de Tapira.

Tabela 33 Composição química dos fosfatos da série da crandallita de Tapira, expressa em \% em peso dos óxidos e em número de átomos por fórmula unitária na base de 10,5 $\mathrm{O}$.

Tabela 34 Composição química das wavellitas de Juquiá, em \% em peso dos óxidos e em número de átomos por unidade de fórmula estrutural na base $\mathrm{Al}+\mathrm{Fe}=3$

Tabela 35 Dados de difração de raios-X (radiação $\mathrm{Cu} K \alpha$ ) da wavellita de Juquiá comparada com a wavellita de Trauira (Costa et al., 1980).

Tabela 36 Composição química das turquesas de Juquiá expressa em \% em peso dos óxidos e em número de átomos por unidade de fórmula estrutural na base sítio $\mathrm{B}=6$ (modelo de composição anidra: $\mathrm{A} \mathrm{B}_{6}\left(\mathrm{XO}_{4}\right)_{4} 4 \mathrm{O}^{2-}$ )

Tabela 37 Dados de difração de raios-X (radiação $\mathrm{Cu} K \alpha$ ) da wavellita de Juquiá comparada com a turquesa da Macedônia, Grécia (Sclavounos et al, 1992 apud Foord \& Taggart, 1998, ficha JCPDS 6-214). 
Esta pesquisa explorou a mineralogia, a geoquímica e a cristaloquímica de fosfatos primários e secundários nos perfis lateríticos desenvolvidos nos Complexos Alcalino-carbonatíticos de Juquiá (SP), Tapira (MG) e Anitápolis (SC). Os estudos dão continuidade aos trabalhos já efetuados nas áreas, procurando aplicar técnicas da micromorfologia (MO, MEV, ME, MR, CL) e de identificação mineralógica DRX e ATD. Os resultados obtidos podem contribuir aos estudos de caracterização tecnológica de fosfatos e ao diagnóstico de problemas de tratamento de minério fosfático; além disso, foram relacionados aos controles da sua gênese, como tipos litológicos presentes e sua distribuição relativa, associações de fosfatos primários, disponibilidades geoquímicas, clima e relevo.

A mineralogia dos fosfatos nos perfis lateríticos desenvolvidos sobre os Complexos Alcalino-carbonatíticos é marcada pela presença da apatita residual, que apresenta algumas feições de alteração nos materiais mais evoluídos. Apatitas primárias sãs, de composição hidroxi-fuorapatita, sofrem durante o intemperismo perdas de cátions substituintes do cálcio $(\mathrm{Sr}$ e $\mathrm{Na})$ e uma carbonatação sempre acompanhada pelo aumento em flúor tendendo a composições próximas à da carbonato flúor-hidroxiapatita. Evidências deste comportamento foram observadas em Tapira e Juquiá. Em Anitápolis observou-se uma menor variação nas composições das apatitas primárias ao longo do perfil, o que mostra uma evolução diferenciada em relação as outras áreas. O aumento da porosidade que decorre da dissolução dos minerais leva à formação dos fosfatos supérgenos apatíticos e principalmente os aluminosos da série da crandallita. Observou-se que as apatitas supérgenas são dominantemente carbonatadas e mais enriquecidas em flúor do que as apatitas primárias, mostrando que no ambiente supérgeno a variedade carbonatofluorapatita é a mais estável. Além da formação de fosfatos supergenos, a alteração intempérica causa modificações físicas e químicas nas apatitas primárias, que podem ser o fator responsável por perturbações nos processos industriais de concentração do minério fosfático para o caso de Tapira, que é a única área em que ocorre o aproveitamento econômico da apatita. 
As fases crandallíticas ocorrem em materiais de alteração supérgena do perfil, onde as apatitas foram parcial ou totalmente dissolvidas e dominam os produtos de alteração de rochas alcalino-silicátitcas, situação observada em Juquiá e Tapira. Em Anitápolis estes fosfatos são muito raros. A composição dos fosfatos da série crandallita mostrou, em Tapira, uma variação nos teores de $\mathrm{Ba}, \mathrm{Ca}, \mathrm{Sr}$ e ETR no sítio A. Neste local foram encontradas variedades intermediárias entre a gorceixita e a goyazita (com ETR) em materiais ferruginosos, e entre a crandallita e a gorceixita em materiais apatíticos. Nos materiais onde ainda estão presentes as apatitas primárias, esta variação pode estar relacionada às diferenças geoquímicas do meio onde foram formadas. Juquiá apresentou uma menor variação na composição dos minerais da série da crandallita no sítio catiônico, dominado quase que exclusivamente pelo $\mathrm{Ba}$ (salvo o tipo que ocorre em pseudomorfos micáceos que apresentam uma dominância do $\mathrm{Ca}$ em relação ao $\mathrm{Ba}$ e maiores irregularidades na ocupação dos sítios).

A ocorrência de outros fosfatos nos perfis estudados é mais restrita e limitada em cada área: turquesa e wavellita em Juquiá e rhabdofânio em Tapira. Estes minerais aqui interpretados como produtos de neoformação supérgena preenchem fissuras nos materiais mais evoluidos do perfil. $O$ rhabdofânio de Tapira ocorre em materiais ricos em anatásio. A wavellita e a turquesa de Juquiá ocorrem na alterita sobre a zona de transição entre o carbonatito e a rocha alcalino-silicática. A composição dos minerais supérgenos analisados, fosfatos da série da crandallita, wavellita, turquesa e rhabdofânio mostrou ser controlada pelas disponibilidades geoquimicas do meio onde foram formados. 


\section{Abstract}

This research investigates the mineralogy, geochemistry and crystalochemistry of primary and supergene phosphates in lateritic profiles developed over Alkaline-carbonatites Complexes of Juquiá (SP) Tapira (MG) and Anitápolis (SC). The study applies micromorphology techniques (MEV, ME, $M R, C L)$ and mineralogical identification DRX and ATD. The obtained data can contribute with studies of technological characterization. Otherwise the data had been correlated with the genesis controls of the phosphates (litologic types and its relative distribution, associations of primary phosphates, geochemistry sources, climate and relief).

The phosphate mineralogy in lateritic profiles developed over Alkalinecarbonatítes Complexes is marked by the presence of residual apatite, that presents some alteration features. Fresh primary apatites of composition hidroxyfuorapatite, alter during weathering by losses of substitute calcium cations ( $\mathrm{Sr}$ and $\mathrm{Na}$ ) and by a carbonate increase accompanied by the increase in $F$, with a trend to compositions near the carbonate flluorhydroxyapatite. Evidences of this behavior were observed in Tapira and Juquiá. In Anitápolis a smaller variation was observed in the compositions of the primary apatites along the profile, which shows a differential evolution comparing to the other areas. The porosity increase due to mineral weathering leads to the formation of supergene phosphate apatites and mainly the aluminous phosphates of the crandallite series. It was observed that supergene apatites are carbonated and more $\mathrm{F}$ enriched than the primary ones, showing that in the supergene condition the carbonatefluorapatite is more stable. Weathering causes also physical and chemical modifications in primary apatites, which may be responsible for problems in industrial procedures to the concentration of phosphatic ore in Tapira, the only area where apatite is mined, between the three areas here treated.

The crandallitic phases are present in materials of supergene origin where apatite was partially or totally dissolved. They dominates the weathering products of alkaline-silicatic rocks. This situation was observed in Juquiá and Tapira. In Anitápolis these phosphates are rare. The phosphate composition of 
crandallite series shows, at Tapira, a variation in $\mathrm{Ba}, \mathrm{Ca}, \mathrm{Sr}$ and ETR in site $\mathrm{A}$; there were found intermediary varieties between gorceixite and goyazite (with ETR) in ferruginous material, and among the crandallite and the gorceixite in apatitic material. In materials where primary apatite is still present, this variation can be related to geochemical differences of the profile where they were formed. Juquiá presents smaller variation in the composition of minerals from crandallite series in the cationic site, which is dominated by $\mathrm{Ba}$ (except for the type in phlogopite pseudomorphs, where there is more $\mathrm{Ca}$ than $\mathrm{Ba}$ and larger irregularities in site occupation).

The occurrence of other phosphates in the studied profiles is more restricted and limited in each area: turquoise and wavellita in Juquiá and rhabdophane in Tapira. These minerals have been interpreted as supergene neoformation; they fill fissures in the well developed materials of the profile. Rhabdophane was found in rich anatase materials. Wavellita and turquoise were found in the alterite formed on transition zone between carbonatite and alkaline-silicatic rocks. The composition of analyzed phosphate supergene minerals, crandallite, wavellite, turquoise, and rhabdophane, showed to be controlled by geochemical availability of the profile where they were formed. 


\section{Introdução e objetivos}

O presente trabalho teve como objetivo caracterizar a mineralogia, a micromorfologia e a cristaloquímica dos fosfatos de três maciços alcalinocarbonatíticos brasileiros (Anitápolis, SC, Juquiá, SP e Tapira, MG), relacionando os aspectos de alteração intempérica (alteração dos fosfatos primários e formação dos fosfatos secundários) de cada maciço ao conjunto de características que nela poderiam influenciar (tipos litológicos presentes e sua distribuição relativa, associações dos fosfatos primários, disponibilidades geoquímicas, clima e relevo). Esta pesquisa deu continuidade a trabalhos anteriores que foram ou mais gerais ou mais ligados aos aspectos econômicos, no caso de Anitápolis e Tapira, ou menos abrangentes em termos de amostragem, no caso de Juquiá.

Foram estudados materiais dos três maciços mencionados, incluindo rochas sãs e em várias fases de alteração sobre os diversos tipos litológicos, coletados para este trabalho ou anteriormente, nas frentes de lavra (Juquiá e Tapira) ou de pesquisa (Anitápolis), e ainda em furos de sondagem (Anitápolis e Tapira).

Foram também estudados concentrados apatíticos de Tapira e Juquiá preparados nos laboratórios da Escola Politécnica - USP por Lenharo (1994) e cedidos pelo Prof. Dr. Helmut Born. Outros materiais de Anitápolis, Juquiá e Tapira já estudados em trabalhos anteriores foram colocados a disposição respectivamente pelos pesquisadores Dr. Vitor Paulo Pereira (Anitápolis), Dr. Arnaldo Alcover Neto e Cláudia Nogueira dos Santos (Juquiá) e Dr. François Soubiès (Tapira).

Os fosfatos primários, encontrados em rochas de complexos carbonatíticos são representados principalmente pela apatita e raarmente pela monazita. Já os fosfatos supérgenos, encontrados nos mantos de alteração destas rochas, são freqüentemente representados pelas apatitas, pelos fosfatos da série da crandallita e ainda outros fosfatos aluminosos.

A apatita é o principal mineral de minério dos depósitos fosfáticos (ígneos, sedimentares ou de origem orgânica). As maiores concentrações de apatita do mundo provêm de rochas sedimentares, porém, no Brasil, $90 \%$ da produção de fosfatos está nos complexos alcalino-carbonatíticos, principalmente nos mantos de alteração residul que apresentam teores de $\mathrm{P}_{2} \mathrm{O}_{5}$ bem maiores do que as rochas sãs. 
Os fosfatos produzidos são utilizados principalmente na fabricação de fertilizantes, detergentes e alimentação. A crescente demanda de fosfato e a diminuição da produção mundial e da qualidade dos minérios tornam importantes os estudos que otimizem o aproveitamento de minérios fosfáticos.

o estudo dos minérios residuais mostra que a apatita, apesar de ser relativamente resistente ao intemperismo pode se alterar, chegando à desestabilização e formação de novas fases fosfatadas. $O$ aproveitamento econômico dos minérios pode ser afetado quando as apatitas sofrem modificações morfológicas ou cristaloquímicas ou ainda por sua associação a outros minerais supérgenos.

Além da apatita, as rochas de complexos alcalinos-carbonatíticos podem apresentar outros minerais fosfatados primários como a monazita, que, embora ocorrendo de forma mais restrita, é de grande interesse econômico. É um mineral rico em ETR e muito estável que pode se acumular nos perfis lateríticos formando importantes jazidas. Além disso sua estrutura de grande estabilidade em superfície tem sido estudada como possível imobilizadora de elementos radioativos indesejáveis no ambiente (McCarty et al., 1978).

Nos mantos residuais os fosfatos aluminosos da série da crandallita são os principais minerais supérgenos formados pela alteração de rochas alcalinocarbonatíticas ricas em fósforo (Toledo, 1999). Podem incorporar em sua estrutura elementos indesejáveis no ambiente do mesmo modo que as monazitas. Em alguns países os fosfatos aluminosos são utilizados na fabricação de fertilizantes o que não ocorre no Brasil (Gilkes \& Palmer, 1979). 


\section{Revisão bibliográfica}

\subsection{Mineralogia e cristaloquímica dos fosfatos}

Neste item será apresentada uma revisão bibliográfica sobre a mineralogia e cristaloquímica dos fosfatos de interesse para este trabalho, de ocorrência nas rochas dos complexos alcalino-carbonatíticos estudados e seus mantos de intemperismo. São dominantemente representados pelas apatitas, fosfatos da série da crandallita e fosfatos de terras raras (monazita e rhabdofânio s.s.) e mais raramente wavellita e turquesa.

\subsubsection{Apatita}

A estrutura geral da apatita é dada pela fórmula $A_{10}\left(X_{4}\right)_{6} Y_{2}$ com átomos arranjados no grupo espacial de simetria P6 3 /m (Náray-Szabó, 1930, Mehmel, 1930 , Bragg et al., 1965, Sudarsanan et al., 1972, Hughes et al., 1989). Segundo Beevers \& Mclntyre (1946, apud Hogarth, 1989) o cálcio ocupa duas posições distintas na estrutura da fluorapatita (Figura 1): Cal coordenado com nove átomos de oxigênio, e Call coordenado com seis átomos de oxigênio e um $\mathrm{F}$. Cada átomo de $\mathrm{O}$ é ligado a um átomo de P, um átomo de Cal e dois átomos de Call.

\begin{tabular}{|l|l|l|}
\hline Posição cristaloquímica & \multicolumn{1}{|c|}{ Ion constituinte } & \multicolumn{1}{|c|}{ lons de substituinte } \\
\hline $\mathrm{A}$ & $\mathrm{Ca}_{2}{ }^{+}$ & $\begin{array}{l}\mathrm{Na}^{+}, \mathrm{K}^{+}, \mathrm{Ag}^{+} \\
\mathrm{Sr}^{2+}, \mathrm{Mn}^{2+}, \mathrm{Mg}^{2+}, \mathrm{Zn}^{2+}, \mathrm{Cd}^{2+}, \mathrm{Ba}^{2+}, \mathrm{Fe}^{2+} \\
\mathrm{Sc}^{3+}, \mathrm{Y}^{3+}, \mathrm{TR}^{3+}, \mathrm{Bi}^{3+}, \mathrm{Al}^{3+} \\
\mathrm{Pb}^{4+}, \mathrm{U}^{4+}\end{array}$ \\
\hline $\mathrm{XO}_{4}$ & & $\begin{array}{l}\mathrm{CO}_{3}{ }^{2-}, \mathrm{SO}_{4}{ }^{2-}, \mathrm{COO}_{4}{ }^{2-} \\
\mathrm{CO}_{3} \cdot \mathrm{F}^{3-}, \mathrm{CO}_{3} \cdot \mathrm{OH}^{3-} \\
\mathrm{AsO}_{4}{ }^{4}, \mathrm{VO}_{4}{ }^{4}, \mathrm{SiO}_{4}{ }^{4}\end{array}$ \\
\hline $\mathrm{Y}$ & $\mathrm{PO}_{4}{ }^{3-}$ & $\mathrm{OH}^{-}, \mathrm{Cl}^{-}, \mathrm{Br}^{--}$ \\
& & $\mathrm{O}^{2-}$ \\
\hline
\end{tabular}

Tabela 1 Substituições na estrutura da apatita, exemplificada pela fluorapatita.

A apatita tem significativa capacidade de incorporar vários íons de raios iônicos grandes e grupos aniônicos em sua estrutura (Tabela 1) como mostrou Nathan (1984). 
Além destas substituições podem ocorrer substituições conjugadas na apatita, que visam o equilíbrio elétrico da estrutura, apresentadas por Hogarth (1989):

$$
\begin{aligned}
& \mathrm{REE}^{3+}+\mathrm{Na}^{+}=2 \mathrm{Ca}^{2+} \\
& \mathrm{REE}^{3+}+\mathrm{Si}^{4+}=\mathrm{Ca}^{2+}+\mathrm{P}^{5+} ; \\
& 2 \mathrm{P}^{5+}=(\mathrm{Si}, \mathrm{C})^{4+}+\mathrm{Si}^{6+} ; \\
& \mathrm{P}^{5+}+\mathrm{O}^{2-}=(\mathrm{Si}, \mathrm{C})^{4+}+(\mathrm{OH}, \mathrm{F})^{-} \\
& \mathrm{P}^{5+}+\mathrm{F}^{-}=\mathrm{C}^{4+}+
\end{aligned}
$$

Fleet \& Pan (1994) acrescentaram mais dois tipos de substituições:

$\mathrm{REE}^{3+}+\mathrm{O}^{2-}=\mathrm{Ca}^{2+}+\mathrm{A}^{1-}$, onde $\mathrm{A}=\mathrm{F}, \mathrm{OH}, \mathrm{Cl}$

$2 \mathrm{REE}^{3+}+\square=3 \mathrm{Ca}^{2+}$, onde $\square$ são vazios no sítio de substituição.

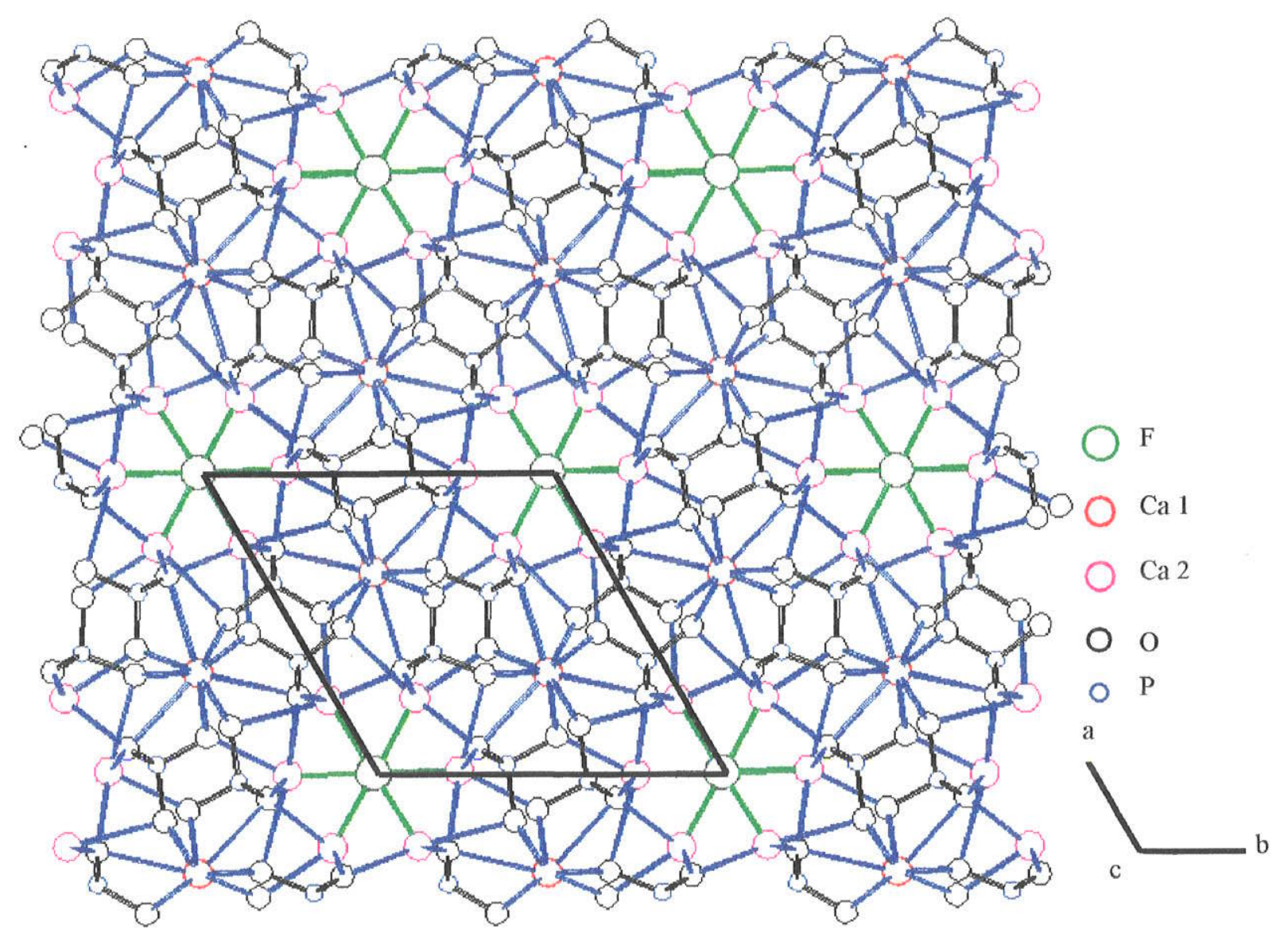

Figura 1 Estrutura da apatita segundo Montel, 1968, elaborado com o auxílio do programa ORTEP3 desenvolvido por Farrugia, 1997.

Estudos à espectroscopia ao infravermelho (EIV) e à microespectroscopia Raman (MR) revelaram que o íon carbonato pode ocupar duas posições diferentes na estrutura das apatitas, permitindo classificá-las em dois tipos: apatita do tipo $\mathrm{A}$ quando $0 \mathrm{CO}_{3}{ }^{2-}$ substitui os ânions monovalentes dos canais e apatita do tipo $\mathrm{B}$ quando $0 \mathrm{CO}_{3}{ }^{2-}$ substitui íons no sítio do fosfato, (Walleys, 1964, Bonel \& Montel, 
1964 e 1966, Trombe et al., 1967 todos apud Massuyes et al.,1969; LeGeros, 1965 e Dowker \& Elliot 1979 ambos apud Mayer et al. 1988 e Regnier, et al., 1994).

Regnier et al. (1994) admitiu que o ín $\mathrm{F}$ acompanha a substituição do $\mathrm{PO}_{4}{ }^{3-}$ por $\mathrm{CO}_{3}{ }^{2-n}$ na estrutura da apatita de forma a balancear as cargas. Este flúor estaria fora dos canais e situado em posições intersticiais da estrutura. Em acordo com os autores outros trabalhos desenvolvidos em materiais brasileiros como os de Toledo et al., (1999) e Toledo (1999) mostram a importância do flúor no mecanismo de carbonatação das apatitas

A proporção de flúor que acompanha $0 \mathrm{CO}_{3}{ }^{2-}$ na carbonatação da apatita foi proposta por alguns autores. Altschuler (1973) propõe que o valor da proporção molar $\mathrm{F}^{-} \mathrm{CO}_{3}{ }^{2-}$ seja 1, diferente de McClellan (1980) que sugere um valor de 0.4 .

No sítio do íon fosfato pode ocorrer a substituição de $\mathrm{SiO}_{4}{ }^{4-}$ de acordo com Sommerauer \& Katz-Lehnert (1985) e Roeder et al. (1987, apud Hogarth, 1989), Rønsbo (1989), Hughes et al. (1991b) e Liu \& Comodi (1993). Esta substituição pode ser acompanhada por substituições acopladas como $\mathrm{REE}^{3+}+\mathrm{Na} \Leftrightarrow \mathrm{Ca}^{2+}+\mathrm{Ca}^{2+} \mathrm{e}$ $\mathrm{REE}^{3+}+\mathrm{Si}^{4+} \Leftrightarrow \mathrm{Ca}^{2+}+\mathrm{P}^{5+}$ (Roeder et al., 1987, Rønsbo, 1989 e Fleet \& Pan, 1995a) A substituição de $\mathrm{PO}_{4}{ }^{3-}$ por $\mathrm{SO}_{4}{ }^{2-}$ é uma outra possibilidade mas também necessita de substituiçōes acopladas (e.g. $\mathrm{Na}^{+}$) para compensar as diferenças de carga e garantir a neutralidade da estrutura. Segundo Hogarth (1989) apatitas de carbonatito em geral apresentam teores de $\mathrm{SO}_{3}$ muito baixos, da ordem de $0,0 \mathrm{X}$ a $0, X \%$. Em contrapartida, "francolitas" de fosforitos podem alcançar teores de até $5 \%$ em peso em $\mathrm{SO}_{3}$ (Vasileva et al., 1958, Whippo \& Murowchick, 1967 ambos, apud Trombe \& Montel, 1980, Lehr et al., 1968 e McArthur 1978).

$\mathrm{O}$ teor de $\mathrm{F}$ de apatitas de carbonatito é muito variável, podendo ou não estar em excesso estequiométrico. $O$ sítio aniônico monovalente pode ser ocupado pelos ions $\mathrm{F}^{-}, \mathrm{OH}^{-}, \mathrm{Cl}^{-}$e $\mathrm{CO}_{3}^{2-}$. Outros íons ainda podem entrar no sítio como $\mathrm{I}^{-}, \mathrm{Br}^{-}, \mathrm{O}^{2-}$ (Tabela 1).

O sítio dos cátions pode apresentar diversos elementos (Tabela 1) substituindo - $\mathrm{Ca}$, dentre eles os elementos mais freqüentes são: $\mathrm{Na}$, Mn, Sr e ETR (La e Ce principalmente). O percentual em peso destes elementos e a presença de vazios no sítio do $\mathrm{Ca}$ podem ser influenciados pelas substituições ocorridas nos sítios aniônicos que necessitam de compensações de cargas. $O$ meio pode também controlar este percentual, como é o caso do $\mathrm{Sr}$ encontrado em maior quantidade nas 
apatitas de carbonatito com relação as apatitas de rochas ígneas ácidas e rochas sedimentares (Hogarth, 1989).

As substituições iônicas podem causar modificações na estrutura da apatita refletindo em suas propriedades ópticas, físicas e químicas como índice de refração, morfologia, densidade, grau de cristalinidade, parâmetros cristalográficos e solubilidade.

Apatitas carbonatadas mostram um maior índice de refração, maior solubilidade (LeGeros et al., 1968, Lehr et al., 1968 e Altschuler, 1973), menor cristalinidade, formas mais granulares que aciculares e menor dimensão dos cristalitos (LeGeros et al., op. cit.).

Os parâmetros de cela encontrados para os diferentes tipos de apatitas, classificadas segundo seus constituintes aniônicos, mostram uma maior variação na dimensão do eixo a com relação ao eixo $c$ (Tabela 2).

\begin{tabular}{lllll}
\hline & $a(\AA)$ & $c(\AA)$ & Composição & Referência \\
\hline Clap & 9,598 & 6,776 & síntese & JCPDS 24-0214 \\
Hap & 9,418 & 6,884 & síntese & JCPDS 9-0432 \\
Fap & 9,3684 & 6,8841 & síntese & JCPDS 15-876 \\
Dahllita & 9,419 & 6,89 & Hap + C & McConnell (1973) \\
Francolita & 9,36 & 6,90 & Fap + C & McConnell (1973) \\
\hline
\end{tabular}

Hap: hidroxiapatita, Fap: fluorapatita, Clap

Tabela 2 Parâmetros de cela das principais variedades de apatitas

A carbonatação das apatitas do tipo $\mathrm{B}$ causa uma diminuição do eixo a e expansão do eixo c (LeGeros, 1965, apud Nelson \& Williamson, 1982, McClellan \& Lehr, 1969 e Vignoles \& Bonel, 1978). Por outro lado, Legeros \& Legeros (1984) observaram que a entrada de $\mathrm{F}^{-}$em apatitas de tecido ósseo humano provoca a contração do eixo a sem modificação da dimensão do eixo $c$ e aumenta a sua estabilidade. Liu \& Comodi (1993) observaram que o ín $\mathrm{OH}^{-}$nos canais causa um aumento nos dois parâmetros. LeGeros \& LeGeros (1984) observaram o mesmo comportamento na substituição do Ca por um cátion de raio maior ( $\mathrm{Sr}, \mathrm{Ba}, \mathrm{Ce}$ e La). Por isto a relação entre as diferenças no parâmetros de cela e a composição das apatitas deve ser feita com cautela devendo ser consideradas todas as substituições isomórficas possíveis de ocorrer no tipo estudado. 
Tabela 3 Composição química (\% em óxidos) de apatitas de várias origens apresentadas por Roeder et al. (1987), análises a microssonda eletrônica.

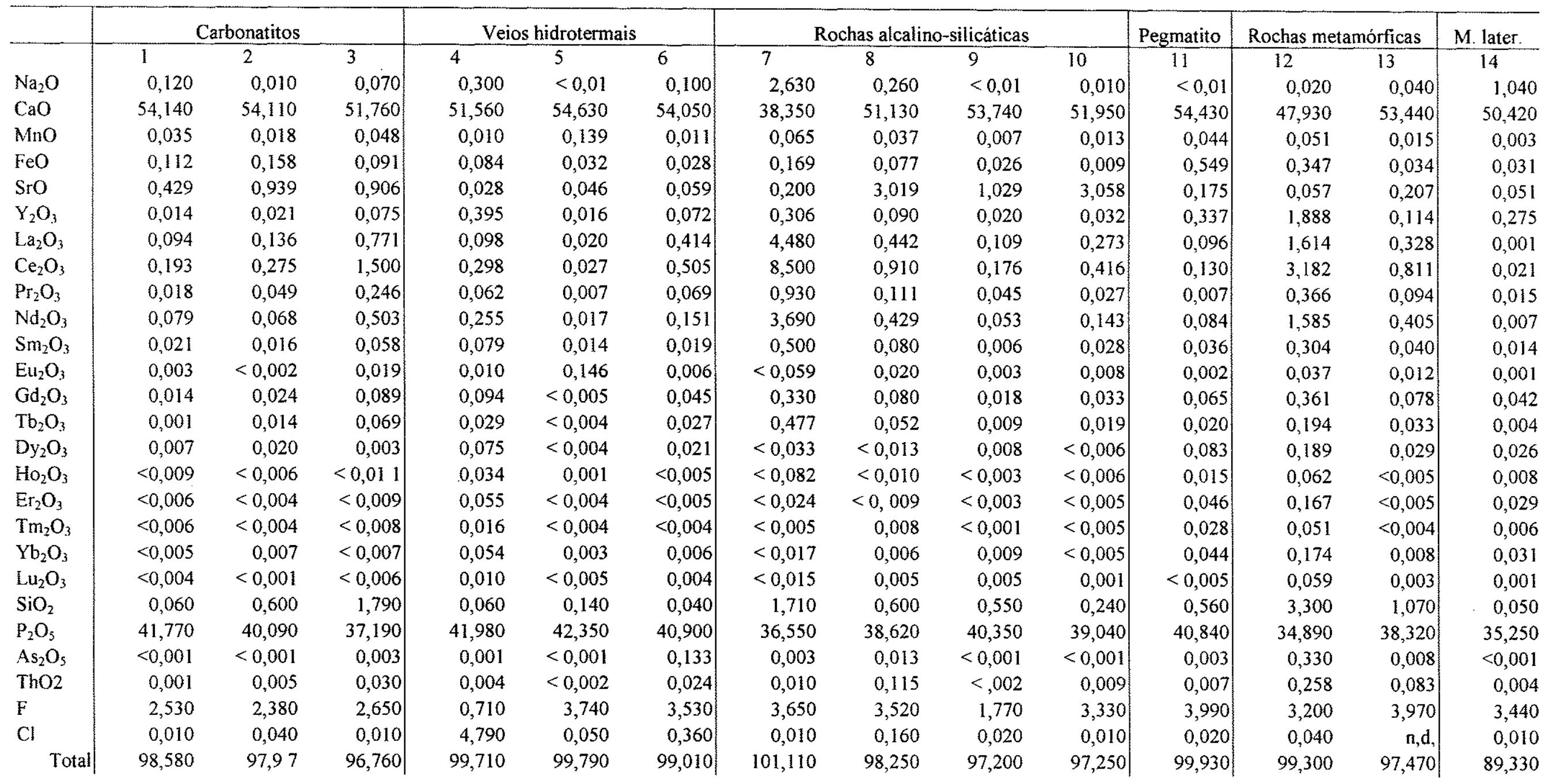




\section{Tabela 3 (continuação)}

1- apatita de beforsito Blue River, British Columbia, Canadá

2- apatita de aglomerados de nefelinito e carbonatito, Kerimasi, Tanzânia

3- apatita de sovito, Oka, Quebec, Canadá

4- cloroapatita de veios em rochas gabróicas, Snarum, Noruega

5- apatita hidrotermal, Llallaqua, Bolivia.

6- apatita hidrotermal, Durango, México.

7-apatita de riebeckita sienito peralcalino, Pajarito, Novo México, EUA

8- apatita de shonquinito associado a carbobatito, Mt. Pass, Califórnia, EUA

9- apatita de piroxenitos do complexo carbonatítico de Tapira, Minas Gerais, Brasil

10- apatita da zona de ijolito do complexo anelar alcalino de Khibina, Peninsula Kola, antiga URSS.

11- apatita de pegmatito granítico, Timmins, Ontário, Canadá.

12- fluorapatita de rochas metassedimentares, Mineville, Nova York, EUA.

13- apatita de skarnito, Huddersfield Township, Quebec, Canadá

14- apatita supérgena brotrioidal, em materiais lateríticos sobre carbonatito, Austrália.

A composição das apatitas é controlada tanto por fatores de gênese como fatores cristaloquímicos que podem agir em conjunto no momento da cristalização ou transformação destes minerais. Vários trabalhos foram publicados abordando a variação da composição da apatita em diferentes materiais como carbonatitos (Roeder et al. 1987, Hogarth, 1989, Walter, 1991, Torres, 1996, Dawson et al. 1996, Toledo, 1999), fosforitos (Lehr et al., 1968, McClellan \& Lehr, 1969, McArthur, 1978, McClellan,1980, McArthur, 1985) e rochas graníticas (Banfield \& Eggleton, 1989), alguns destes trabalhos estudam o comportamento da apatita na alteração. A Tabela 3 mostra a composição química de apatitas de diferentes origens (hidrotermal, metamórfica, ígnea e supérgena) apresentadas por Roeder et al. (1987).

As variedades de apatita de complexos alcalino-carbonatíticos já estudados possuem composições próximas às da fluorapatita e hidroxiapatita (apatitas primárias) e carbonatoapatita (apatitas supérgenas e residuais alteradas).

Muitos dos estudos sobre a cristaloquímica das substituições possiveis na estrutura da apatita são feitos a partir de sínteses (Freund \& Nobel, 1977, Latil \& Maury, 1977, Vignoles \& Bonel, 1978, Fleet \& Pan, 1995a, 1995b e 1997, entre outros), materiais biológicos (Arends \& Davidson, 1975, Nelson \& Williamson, 1982, Elliot et al., 1985, Mayer et al., 1988, Tsuda \& Arends, 1994, Penel et al., 1997 e 1998, entre outros) e em apatitas naturais (McClellan, 1980, Hughes et al., 1991). A comparação de apatitas sintéticas e naturais revelou diferenças estruturais destas últimas possivelmente atribuiveis a presença de impurezas ou vazios na rede cristalina das apatitas naturais (Sudarsanan et al., 1972). 


\subsubsection{Fosfatos da série da crandallita}

Os minerais da família alunita-jarosita apresentam a fórmula estrutural geral $\mathrm{AB}_{3}\left(\mathrm{XO}_{4}\right)_{2}(\mathrm{OH})_{6}$ (Palache et al. 1951, Botinelly, 1976, Struntz 1978, Randohr \& Struntz, 1978, todos apud Scott, 1987). A posição A pode ser ocupada por íons de diferentes valências como $\mathrm{Na}^{+}, \mathrm{K}^{+}, \mathrm{Ag}^{+}, \mathrm{NH}^{4+}, \mathrm{H}_{3} \mathrm{O}^{+}, \mathrm{Ca}^{2+}, \mathrm{Mn}^{2+}, \mathrm{Pb}^{4+}, \mathrm{Ti}^{4+}, \mathrm{Mg}^{2+}$, $\mathrm{Sr}^{2+}, \mathrm{Ba}^{2+}, \mathrm{ETR}^{3+}$ ou $\mathrm{U}^{4+}$. A posição $\mathrm{B}$ é preenchida por $\mathrm{Al}^{3+}$ ou $\mathrm{Fe}^{3+}$, e mais raramente $\mathrm{Cu}^{2+}$ e $\mathrm{Zn}^{2+}$. Comumente a posição $\left(\mathrm{XO}_{4}\right)$ é ocupada por $\mathrm{SO}_{4}{ }^{2-}, \mathrm{PO}_{4}{ }^{3-}$, $\mathrm{AsO}_{4}{ }^{3-}, \mathrm{CO}_{3}{ }^{2-}, \mathrm{SbO}_{4}{ }^{3-}, \mathrm{CrO}_{4}{ }^{2-}$ ou $\mathrm{SiO}_{4}{ }^{2-}$. A posição $(\mathrm{OH})_{6}$ pode ser ocupada parcialmente por halogêneos.

A valência dos íons constituintes dos minerais da familia alunita-jarosita permite definir três grupos (Palache et al. 1951, apud Scott, 1987): a) grupo da alunita: dois ânions bivalentes no sítio $\left(\mathrm{XO}_{4}\right)$ e usualmente um cátion monovalente no sítio $A, b)$ grupo da beudantita ou woodhouseita com um ânion bivalente e um trivalente no sítio $\left(\mathrm{XO}_{4}\right)$ e cátions bivalentes no sítio $\left.\mathrm{A}, \mathrm{c}\right)$ grupo da plumbogummita, crandallita ou goyazita com dois ânions trivalentes no sítio $\left(\mathrm{XO}_{4}\right)$ e cátions bivalentes ou trivalentes no sítio $A$. Scott (1987) propõe uma classificação com base na relação Al e Fe no sítio $B$; se o mineral apresenta $A l>F e$ pertence ao super-grupo da alunita e se Fe>Al pertence ao super-grupo da jarosita. Jambor \& Birch (1993) sugerem o uso de triângulos As-P-S para cada cátion da posição $\mathrm{A}(\mathrm{Pb}, \mathrm{Sr}, \mathrm{Ba}, \mathrm{Sr}$ ou $\mathrm{Ca}$ ) levando em conta a relação FelAl.

Os termos da série da crandallita são classificados segundo o cátion na posição A, Ca: crandallita; Sr: goyazita; Pb: plumbogummita; Ba: gorceixita; ETR: florencita. São muitos os trabalhos que apresentam as composições de minerais naturais próximas das composições dos termos extremos deste grupo, Tabela 4 , mostrando que os minerais naturais dificilmente formam composiçöes ideais (Botinelly, 1976, Scott 1987, Blanchard, 1989, Schwab et al., 1990a, Atencio \& Clark, 1996):

Segundo Blount (1974) a estrutura da crandallita apresenta folhas orientadas perpendicularmente ao eixo $c$ que são constituídas por octaedros $\mathrm{Al}(\mathrm{OH})_{4} \mathrm{O}_{2}$ ligados entre si em anéis hexagonais ou trigonais. Estas folhas octaédricas são intercaladas a folhas tetraédricas de fosfato unidas por pontes de hidrogênio. Os cátions da posição A situam-se nas grandes cavidades entre as folhas, Figura 2. 


\begin{tabular}{|c|c|c|c|c|c|c|c|c|c|c|c|c|c|c|}
\hline & \multicolumn{2}{|c|}{ Crandallita } & \multicolumn{3}{|c|}{ Goyazita } & \multicolumn{4}{|c|}{ Gorceixita } & \multicolumn{5}{|c|}{ Florencita } \\
\hline & 1 & 2 & 3 & 4 & 5 & 6 & $7 \mathrm{a}$ & $7 \mathrm{~b}$ & 8 & 9 & 10 & $11 a$ & $11 \mathrm{~b}$ & 12 \\
\hline $\mathrm{Na}_{2} \mathrm{O}$ & 0,00 & & & & & 0,06 & 0,03 & 0,04 & & & & & & \\
\hline $\mathrm{K}_{2} \mathrm{O}$ & 0,00 & & & & & 0,1 & 0,26 & 0,27 & & & & & & \\
\hline $\mathrm{CaO}$ & 7,66 & 13,54 & 3,1 & 0,45 & & 0,76 & 1,45 & 1,29 & & & 0,2 & 0,5 & 0,4 & \\
\hline $\mathrm{SrO}$ & 2,31 & & 9,9 & 18,65 & 22,51 & 1,81 & 4,34 & 4,77 & & & & & & \\
\hline $\mathrm{MgO}$ & 0,13 & & & & & & n.d. & n.d. & & & 0,9 & & & \\
\hline $\mathrm{FeO}$ & 1,12 & & & & & & & & & & & & & \\
\hline $\mathrm{BaO}$ & & & n.a. & 0,26 & & 23,52 & 17,84 & 20,09 & 29,99 & & & & & \\
\hline $\mathrm{PbO}$ & & & & 0,04 & & & 0,73 & 1,52 & & & & & & \\
\hline $\mathrm{TR}_{2} \mathrm{O}_{3}$ & 10,02 & & 13,0 & & & & 1,14 & 1,28 & & 32,12 & 31,2 & 30 & 28,4 & 31,99 \\
\hline $\mathrm{Al}_{2} \mathrm{O}_{3}$ & 33,37 & 36,94 & 32,5 & 31,58 & 33,11 & 31,25 & 31,83 & 33,14 & 29,91 & 30,56 & 32,0 & 31,3 & 32,0 & 29,81 \\
\hline $\mathrm{Fe}_{2} \mathrm{O}_{3}$ & & & & 0,82 & & 3,76 & 0,36 & 0,42 & & & & & & \\
\hline $\mathrm{SiO}_{2}$ & & & & & & 0,95 & n.d. & n.d. & & & 1,4 & - & 0,5 & \\
\hline $\mathrm{P}_{2} \mathrm{O}_{5}$ & 28,45 & 34,28 & 27,8 & 27,57 & 30,73 & 26,19 & 27,55 & 26,89 & 27,76 & 28,12 & 29,1 & 27,2 & 28,6 & 27,67 \\
\hline $\mathrm{SO}_{3}$ & 0,52 & & 2,3 & & & & 0,67 & 0,94 & & & & & & \\
\hline $\mathrm{H}_{2} \mathrm{O}^{*}$ & & 15,22 & 11,4 & 20,63 & 13,63 & 11,07 & 13,02 & 8,48 & 12,33 & & & & & 10,53 \\
\hline Total & 83,58 & 99,98 & 100,0 & 100,00 & 99,98 & 99,47 & 99,22 & 99,13 & 99,99 & 90,8 & 94,8 & 89,0 & 89,9 & 100,00 \\
\hline
\end{tabular}

\section{Tabela 4 Composiçăo química (em \%) de alguns fosfatos da série da crandallita analisados à microssonda eletrônica.}

1 crandallita-(Ce), dumortierita quartzito, Macaúbas (BA, Brasil), Visser et al. (1997)

2 crandallita ideal $\mathrm{CaAl}_{3}\left(\mathrm{PO}_{4}\right)_{2}(\mathrm{OH})_{5} . \mathrm{H}_{2} \mathrm{O}$

$3 \mathrm{Nd}$ goyazita, depósito de bauxita, microssonda eletrônica, Vlasenica, Maksimovié \& Pantó (1985)

4 goyazita (média de 6 análises), zona oxidada do minério de $\mathrm{Pb}-\mathrm{Zn}$, Broken Hill, New South Wales (Austrália), Pring et al. (1995)

5 goyazita ideal $\mathrm{SrAl}_{3}\left(\mathrm{PO}_{4}\right)_{2}(\mathrm{OH})_{5} \cdot \mathrm{H}_{2} \mathrm{O}$

6 gorceixita (média de 10 análises) Diamantina (MG, Brasil)

$7 \mathrm{a}, 7 \mathrm{~b}$ gorceixita osso fóssil, Santon Inácio (PA, Brasil) (a: média de 5 análises; b: média de 4 análises), Coutinho et al. (1999)

8 gorceixita ideal $\mathrm{BaAl}_{3}\left(\mathrm{PO}_{4}\right)_{2}(\mathrm{OH})_{5} \cdot \mathrm{H}_{2} \mathrm{O}$

9 florencita, folhelho fossilifero (Canadá), McKenzie Montains, Pouliot \& Hofmann (1981)

10 florencita, metassedimentos, depósito Shituru (Shaba, Zaire), Lefebvre \& Gasparini (1980)

$11 \mathrm{a}$ e $11 \mathrm{~b}$ florencita, areias diamantiferas, Diamantina (MG, Brasil), Lefebvre \& Gasparrini (1980)

12 florencita ideal $\mathrm{CeAl}_{3}\left(\mathrm{PO}_{4}\right)_{2}(\mathrm{OH})_{6}$

${ }^{*} \mathrm{H}_{2} \mathrm{O}$ obtida por perda ao fogo 
Fosfatos da família alunita - jarosita pertencem em geral ao grupo espacial romboédrico R-3m (Hendricks, 1937, Wang, 1965 ambos apud Blount, 1974 e Blount, 1974). Estudos mais recentes mostram que os fosfatos da série da crandallita podem cristalizar-se em outros grupos espaciais R3m ou R-3m (romboédricos) ou Cm (monoclínico) (Tabela 5).

\begin{tabular}{|lll|}
\hline goyazita & $\begin{array}{l}\text { R3m ou R-3m } \\
\text { R-3m }\end{array}$ & $\begin{array}{l}\text { Kato, 1971 } \\
\text { Blackburn \& Dennen, 1997 }\end{array}$ \\
\hline gorceixita & R3m & $\begin{array}{l}\text { Radosiovich \& Slade, 1980 } \\
\text { Goreau \& Raveau, 1980 } \\
\text { R-3m } \\
\text { Blackburn \& Dennen, 1997 }\end{array}$ \\
\hline $\begin{array}{l}\text { cátions trivalentes } \\
\text { na posição A }\end{array}$ & $\mathrm{Cm}$ & Radoslovich, 1980 \\
\hline $\begin{array}{l}\text { crandallita; florencita } \\
\text { e plumbogummita }\end{array}$ & $\mathrm{R} 3 \mathrm{~m}$ & Blackburn \& Dennen, 1997 \\
\hline
\end{tabular}

Tabela 5 Grupos espaciais dos fosfatos da série da crandallita.

Menchetti \& Sabelli (1976) observaram que os parâmetros de cela variam com as substituições isomórficas em minerais sintéticos da família alunita - jarosita. A substituição do Al por Fe causa uma expansão no eixo a sem alteração da dimensão do eixo $c$. A substituição do cátion da posição A pode alterar somente a dimensão do eixo c. Já McKie (1962) estudando plumbogummita natural demonstrou que o aumento do valor médio do raio iônico dos cátions na posição $A$ causa um aumento dos parâmetros de cela a e $c$.

Os valores dos parâmetros de cela dos termos da série da crandallita (Tabela 6) mostram uma menor variação do parâmetro de cela a do que do parâmetro $c$. Segundo Gilkes \& Palmer (1983) este fato pode estar ligado à maior rigidez do plano 001 e à presença de pontes de hidrogênio, que são ligações mais fracas, na direção do eixo $c$.

A substituição de íns bivalentes pelo trivalente $\mathrm{Ce}$ pode ser balanceada seja pela substituição $\mathrm{PO}_{4}$ por $\mathrm{SO}_{4}$ ou pela protonação do ânion fosfato. Este mecanismo modifica o comprimento da ligação $\mathrm{P}-\mathrm{O}$ a ponto de modificar o grupo espacial transformando a estrutura R-3m em Cm (Radoslovich, 1982). Scott (1987) separa o grupo da florencita do grupo da plumbogummita com base nestas diferenças estruturais. 


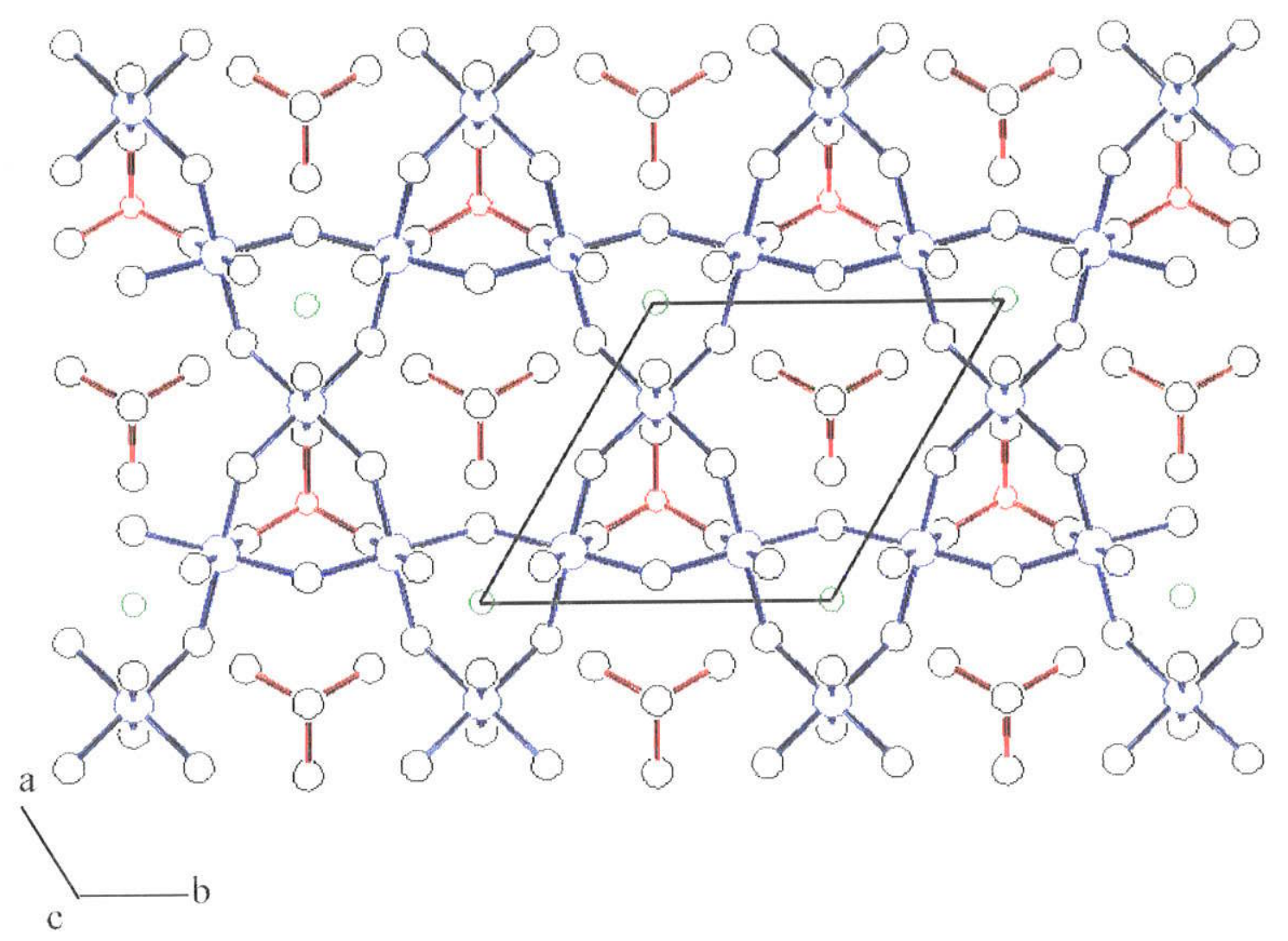
$\mathrm{Oa}$
$\circ \mathrm{P}$
$\mathrm{O} \mathrm{O}$
$\bigcirc \mathrm{Al}$

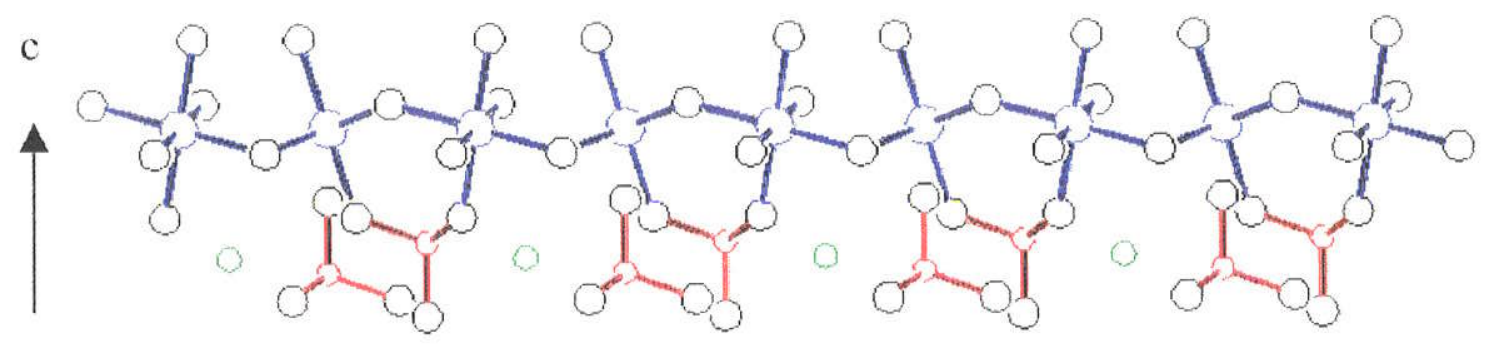

Figura 2 Estrutura da crandallita segundo Blount (1974), elaborado com o auxílio do programa ORTEP3, programa desenvolvido por Farrugia (1997). 
Tabela 6 Parâmetros de cela unitária de minerais da série da crandallita e fosfatos similares de origem sintética, apresentados por vários autores.

\begin{tabular}{|c|c|c|c|c|c|}
\hline \multirow{3}{*}{$\begin{array}{l}\text { Materiat } \\
\text { Crandallita sintética }\end{array}$} & \multicolumn{3}{|l|}{ Referência } & $a(A)$ & $\mathrm{c}(\mathrm{A})$ \\
\hline & \multicolumn{3}{|l|}{ Slade (1974) } & 6,989 & 16,159 \\
\hline & \multicolumn{3}{|l|}{ Gilkes \& Palmer (1983) } & 7,007 & 16,216 \\
\hline \multirow{6}{*}{ Crandallita natural } & \multicolumn{3}{|l|}{ Fransolet \& Deliens (1997) } & 6,999 & 16,671 \\
\hline & \multicolumn{3}{|l|}{ Blount (1974) } & 7,005 & 16,192 \\
\hline & \multicolumn{3}{|l|}{ Radoslovich (1969) * } & 7,003 & 16,166 \\
\hline & \multicolumn{3}{|c|}{ Blanchard (1971) } & 7,013 & 16,196 \\
\hline & \multicolumn{3}{|c|}{ Mitchell \& Knowiton (1971) * } & 7,000 & 16,194 \\
\hline & \multicolumn{3}{|c|}{ Palmer $(1979)^{*}$} & 7,005 & 16,192 \\
\hline \multirow[t]{2}{*}{ Goyazita sintética } & \multicolumn{3}{|l|}{ Schwab et al. $\left(1990^{\mathrm{a}}\right)$} & 7,024 & 16,611 \\
\hline & \multicolumn{3}{|c|}{ Gilkes \& Palmer (1983) } & 7,013 & 16,650 \\
\hline \multirow[t]{4}{*}{ Goyazita natural } & \multicolumn{3}{|c|}{ Kato \& Radoslovich (1968) ** } & 7,021 & 16,505 \\
\hline & \multicolumn{3}{|c|}{ Guilleman $(1955)^{*}$} & 6,981 & 16,487 \\
\hline & \multicolumn{3}{|c|}{ McKie (1962) (Goiazita com Ce) } & 6,982 & 16,540 \\
\hline & \multicolumn{3}{|c|}{ Palache et al. (1951) *** } & 6,97 & 16,51 \\
\hline Gorceixita sintética & \multirow{2}{*}{\multicolumn{3}{|c|}{ Kato \& Radoslovich (1968) ** }} & 7,059 & 17,275 \\
\hline \multirow[t]{7}{*}{ Gorceixita natural } & & & & 7,017 & 16,696 \\
\hline & \multicolumn{3}{|c|}{ Radoslovich \& Slade (1980) (1) } & 7,036 & 17,282 \\
\hline & \multicolumn{3}{|c|}{ Kresten \& Chyssler (1978) **** } & 7,017 & 16,744 \\
\hline & \multicolumn{3}{|c|}{ Taylor et al. (1984) } & 7,02 & 17,29 \\
\hline & \multicolumn{3}{|l|}{ McKie (1962) } & 6,999 & 16,540 \\
\hline & McKie (1962) (Mrima Hill & & & 7,022 & 17,030 \\
\hline & McKie (1962) (Serra Leão & & & 7,028 & 17,030 \\
\hline Plumbogumita sintética & Schwab et al. (1990a) & & & 7,033 & 16,789 \\
\hline & Baker $(1963)^{* * * *}$ & & & 7,010 & 16,740 \\
\hline Plumbogumita natural & Slansky (1977) & & & 7,017 & 16,750 \\
\hline & Förtsch (1968) **** & & & 7,018 & 16,784 \\
\hline Florencita sintética & Schwab et al. (1990b) La & & & 6,994 & 16,331 \\
\hline & Schwab et al.. (1990b) Ce & & & 6,965 & 16,227 \\
\hline & Schwab et al. (1990b) $\operatorname{Pr}$ & & & 6,970 & 16,185 \\
\hline & Schwab et al. (1990b) Nd & & & 6,972 & 16,116 \\
\hline & Schwab et al. (1990b) Sm & & & 6,947 & 15,982 \\
\hline & Schwab et al. (1990b) Eu & & & 6,948 & 15,934 \\
\hline & Schwab et al. (1990b) Gd & & & 6,938 & 15,898 \\
\hline Florencita sintética com $\mathrm{Sr}$ & Schwab et al. (1990b) $\mathrm{Sr}_{0,3}$ & $y_{0,7}$ & & 7,019 & 16,601 \\
\hline & Schwab et al. (1990b) $\mathrm{Sr}_{0,5}$ & $r_{0,5}$ & & 7,019 & 16,591 \\
\hline & Schwab et al. (1990b) $\mathrm{Sr}_{0,7}$ & $L_{0,25}$ & & 7,015 & 16,594 \\
\hline Florencita natural & Pouliot \& Hofmann (1981) & & & 6,990 & 16,250 \\
\hline & McKie (1962) & & & 6,949 & 16,233 \\
\hline Florencita natural com Sr & McKie (1962) & & & 6,971 & 16,420 \\
\hline & $a(A)$ & $\mathrm{b}(\mathrm{A})$ & $c(A)$ & $\beta^{\circ}$ & \\
\hline $\begin{array}{l}\text { Gorceixita natural } \\
\text { calculada como monoclínica (1) }\end{array}$ & 12,1892 & 7,0306 & 7,0364 & 125,30 & \\
\hline $\begin{array}{l}\text { Gorceixita natural } \\
\text { calculada como ortorrômbica (1) }\end{array}$ & 7,0333 & 7,0478 & 9,9465 & & \\
\hline
\end{tabular}

*, apud Gilkes \& Palmer, 1983, **apud Kato (1971),

***, apud Scott, 1987, ****, apud Schwab et al. (1990a) 


\subsubsection{Outros fosfatos}

A wavelita é um fosfato básico, hidratado, de alumínio; sua fórmula estrutural ideal é $\mathrm{Al}_{3}(\mathrm{OH}, \mathrm{F})_{3}\left(\mathrm{PO}_{4}\right)_{2}$. $5 \mathrm{H}_{2} \mathrm{O}$. São propostos diferentes grupos espaciais para a wavellita, todos pertencentes ao sistema ortorrômbico: Pcmm (Morgan, 1950, apud Gomes, 1968), Pmmn (Gordon, 1950, apud Correia Neves et al., 1976) ou Pnma (Correia Neves et al., 1976). Os parâmetros cristalográficos apresentados no registro do JPCDS (ficha 25-0020) são $a=9,621 \AA, b=17,363 \AA$ e $c=6,994 \AA$, que diferem pouco dos valores encontrados para as wavellitas da llha de Itacupim (PA, Da Costa et al., 1980), com $a=9.620(5), b=17.328(8)$ e $c=6.991(3)$.

São possiveis algumas substituições como o Fe e o Mn por Al (Gomes, 1978) e o $\mathrm{F}$ por $\mathrm{OH}$ (Dana, 1959). Outros elementos menos comuns podem estar presentes, como $\circ \mathrm{Zn}$ e o $\mathrm{Cu}$. A composição de wavellitas naturais pode se afastar da composição ideal apresentando déficit em $P$ e Al (Correia Neves et al., 1976) (Tabela 7).

\begin{tabular}{|c|c|c|c|}
\hline & 1 & 2 & 3 \\
\hline $\mathrm{CaO}$ & & 0,30 & \\
\hline $\mathrm{MgO}$ & 0,085 & 0,20 & \\
\hline $\mathrm{BeO}$ & 0,085 & & \\
\hline $\mathrm{TIO}_{2}$ & 0,006 & & \\
\hline $\mathrm{CuO}$ & 0,012 & & \\
\hline $\mathrm{ZnO}$ & 0,002 & & \\
\hline $\mathrm{Al}_{2} \mathrm{O}_{3}$ & 35,80 & 36,10 & 37,14 \\
\hline $\mathrm{Fe}_{2} \mathrm{O}_{3}$ & 0,54 & & \\
\hline $\mathrm{P}_{2} \mathrm{O}_{5}$ & 32,50 & 33,00 & 34,46 \\
\hline $\mathrm{H}_{2} \mathrm{O}^{*}$ & 29,98 & 26,20 & 28,40 \\
\hline $\mathrm{F}$ & 0,80 & 3,60 & \\
\hline $\mathrm{O} \equiv \mathrm{F}$ & 0,34 & 1,52 & \\
\hline Total & 99,47 & 97,88 & 100,00 \\
\hline
\end{tabular}

Tabela 7 Análises químicas de wavellitas (Correia Neves et al., 1976).

1 Conselheiro da Mata

2 Carandaí

3 composição ideal da wavellita.

* dado fornecido como perda ao fogo.

A turquesa, $\mathrm{Cu} \mathrm{Al} 6\left[(\mathrm{OH})_{2} / \mathrm{PO}_{4}\right]_{4} 4 \mathrm{H}_{2} \mathrm{O}$, constitui um dos termos do grupo homônimo, cuja fórmula geral é dada por $\mathrm{A}_{0-1} \mathrm{~B}_{6}\left(\mathrm{PO}_{4}\right)_{4-x}\left(\mathrm{PO}_{3} \mathrm{OH}\right)_{x}(\mathrm{OH})_{8} \cdot 4 \mathrm{H}_{2} \mathrm{O}$ onde $\mathrm{x}=0-2, \mathrm{~A}=\mathrm{Fe}^{2+}, \mathrm{Cu}^{2+}, \mathrm{Ca}^{2+}, \mathrm{Zn}^{2+},=$ (vazio); $\mathrm{B}=\mathrm{Al}^{3+}, \mathrm{Fe}^{3+}, \mathrm{Cr}^{2+}$ (Foord \& Taggart Jr., 1998). 
Aheylita, $\left(\mathrm{Fe}^{2+}, \mathrm{Zn}\right) \mathrm{Al}_{6}\left(\mathrm{PO}_{4}\right)_{4}(\mathrm{OH})_{8} \cdot 4 \mathrm{H}_{2} \mathrm{O}$,
chalcosiderita $\mathrm{Cu}^{2+} \mathrm{Fe}_{6}^{3+}\left(\mathrm{PO}_{4}\right)_{4}(\mathrm{OH})_{8} \cdot 4 \mathrm{H}_{2} \mathrm{O}$,
coeruleolactita $\left(\mathrm{Ca}, \mathrm{Cu}^{2+}\right) \mathrm{Al}_{6}\left(\mathrm{PO}_{4}\right)_{4}(\mathrm{OH})_{8} \cdot 4-5 \mathrm{H}_{2} \mathrm{O}$,
faustite $\left(\mathrm{Zn} \mathrm{Cu}^{2+}\right) \mathrm{Al}_{6}\left(\mathrm{PO}_{4}\right)_{4}(\mathrm{OH})_{8} \cdot 4 \mathrm{H}_{2} \mathrm{O}$ e
planerita $\square \mathrm{Al}_{6}\left(\mathrm{PO}_{4}\right)_{2}\left(\mathrm{PO}_{3} \mathrm{OH}\right)_{2}(\mathrm{OH})_{8} \cdot 4 \mathrm{H}_{2} \mathrm{O}$ são os outros termos do grupo da turquesa.

A deficiência em cátions no sítio $A$ nos fosfatos do grupo pode causar a protonação do grupo fosfato, para manter o balanço de cargas, desenvolvendo no máximo dois grupos $\left(\mathrm{PO}_{3} \mathrm{OH}\right)$, como é visto na fórmula da planerita. Análises de turquesas naturais, locais e referência na Tabela 8 , revelaram um desvio da composição ideal com excesso de água e déficit no sítio $\mathrm{A}$, sendo raras as turquesas de pureza elevada (e.g. Schaller, 1912, apud Foord \& Taggart Jr., op. cit.). Baseados em análises obtidas e de outras da literatura, Foord \& Taggart Jr. (op. cit.) observaram a existência de solução - sólida entre a chalcosiderita e a turquesa e entre a planerita e a turquesa.

\begin{tabular}{|c|c|c|c|c|c|}
\hline & 1 & $2 a$ & $2 b$ & 3 & 4 \\
\hline $\mathrm{BaO}$ & 0,26 & - & - & - & - \\
\hline $\mathrm{FeO}$ & - & - & - & 0,23 & - \\
\hline $\mathrm{CuO}$ & 9,09 & 9,00 & 8,81 & 3,08 & 9,78 \\
\hline $\mathrm{ZnO}$ & - & - & 0,14 & - & - \\
\hline $\mathrm{Al}_{2} \mathrm{O}_{3}$ & 35,7 & 36,50 & 37,7 & 37,75 & 37,60 \\
\hline $\mathrm{Fe}_{2} \mathrm{O}_{3}$ & 1,27 & 0,21 & 0,28 & 0,86 & - \\
\hline $\mathrm{P}_{2} \mathrm{O}_{5}$ & 34,00 & 34,13 & 34,5 & 35,75 & 34,90 \\
\hline $\mathrm{As}_{2} \mathrm{O}_{5}$ & 0,14 & - & - & - & - \\
\hline $\mathrm{H}_{2} \mathrm{O}^{+}$ & - & - & 18,2 & 21,21 & 17,72 \\
\hline $\mathrm{H}_{2} \mathrm{O}_{\text {total }}$ & 19,41 & 20,12 & - & - & - \\
\hline $\mathrm{H}_{2} \mathrm{O}^{-}$ & & & 0,45 & 0,12 & 0,00 \\
\hline Total & 99,87 & 99,96 & 100,08 & 98,75 & 100,00 \\
\hline
\end{tabular}

Tabela 8 Análises químicas de turquesas.

1 Grécia (Sklavounos et al., 1992, apud Foord \& Taggart Jr., 1998)

2a Lynch Station, Virgínia (Schaller, 1912, apud Foord \& Taggart Jr., 1998);

2b Lynch Station, Virginia (Foord \& Taggart Jr., 1998);

3 planerita - turquesa Dug Hill, Arkansas (Foord \& Taggart Jr., 1998).

4 Turquesa ideal $\mathrm{Cu} \mathrm{Al} 6\left(\mathrm{PO}_{4}\right)_{4}(\mathrm{OH})_{8} \cdot 4 \mathrm{H}_{2} \mathrm{O}$

A turquesa é um mineral triclínico do grupo espacial $\mathrm{P}_{1}$; as dimensões dos parâmetros cristalográficos da cela unitária variam segundo sua composição química (Tabela 9). O grau de ocupação do sítio $A$ pode ser observado nos difratogramas de 
raios-X da turquesa (Foord \& Taggart Jr., 1998). Quanto maior o grau de ocupação deste sítio a reflexão 010 torna-se mais definida e a reflexão $\overline{2} \overline{1} 1$ desaparece. Podese assim identificar termos mais próximos da turquesa ou da planerita.

\begin{tabular}{|c|c|c|c|}
\hline & 1 & 2 & 3 \\
\hline a & 7,52 & $7,409(1)$ & 7,526 \\
\hline$b$ & 10,24 & $9,914(2)$ & 9,946 \\
\hline$c$ & 7,70 & $7,635(1)$ & 7,779 \\
\hline$\alpha$ & 111,3 & 111,356 & 112,42 \\
\hline$\beta$ & 115,12 & 114,973 & 116,56 \\
\hline$\gamma$ & 69,32 & 69,532 & 68,54 \\
\hline V & - & $460,64(9)$ & 467,8 \\
\hline
\end{tabular}

Tabela 9 Dados de cela unitária de turquesas.

1 Grécia: turquesa sem déficit no sítio A (Sklavounos et al., 1992, apud Foord \& Taggart Jr., 1998);

2 Lynch Station, VA: turquesa com 0,9 de ocupação do sítio A (Foord \& Taggart Jr., 1998); 3 planerita - turquesa Dug Hill, Arkansas (Foord \& Taggart Jr., 1998).

() desvio padrão

As fases de fosfatos de lantanídeos $(\mathrm{Ln})$ e de $\mathrm{Y}, \operatorname{TR}\left(\mathrm{PO}_{4}\right)$, comumente encontradas na natureza são xenotima e monazita. A monazita incorpora os elementos terras raras maiores e mais leves (ETRL: La ao Cd) enquanto a xenotima incorpora os elementos terras raras menores e mais pesados (ETRP: Tb-Lu) e Y. Segundo Fleischer et al. (1990) o grupo estrutural das monazitas é representado por arseniatos, fosfatos e silicatos de fórmula geral $\mathrm{AB} \mathrm{O}$, onde $\mathrm{A}=\mathrm{Bi}, \mathrm{Ca}, \mathrm{Ce}, \mathrm{La}, \mathrm{Nd}$, Th, e U e B $=$ As, $\mathrm{P}$ e Si.

Durante sínteses de monazita observou-se que a entrada de tório na estrutura da monazita é acompanhada pelas substituições de $\mathrm{Ca}^{2+}$ por $\mathrm{Ln}^{+3}$ ou de $\mathrm{Si}^{4+}$ por $\mathrm{P}^{5+}$ e a entrada de urânio somente causaria a substituição de $\mathrm{Ca}^{2+}$ por $\mathrm{Ln}^{+3}$ (McCarthy et al., 1978). Parseval et al. (1996) estudaram a composição de minerais de terras raras à microssonda eletrônica, observando que a monazita se aproxima da composições de monazitas de outras localidades e que a xenotima- $(Y)$ quando comparada com a xenotima de composição ideal apresenta teores elevados de $\mathrm{Gd}$ (Tabela 10). 


\begin{tabular}{|l|l|l|}
\hline & $\begin{array}{l}\text { Monazita- } \\
(\mathrm{Ce})\end{array}$ & Xenotima-(Y) \\
$\mathrm{CaO}$ & n.d. & n.d. \\
$\mathrm{Y}_{2} \mathrm{O}_{3}$ & n.d. & 45,22 \\
$\mathrm{La}_{2} \mathrm{O}_{3}$ & 18,12 & n.d. \\
$\mathrm{Ce}_{2} \mathrm{O}_{3}$ & 31,66 & n.d. \\
$\mathrm{Pr}_{2} \mathrm{O}_{3}$ & 2,62 & n.d. \\
$\mathrm{Nd}_{2} \mathrm{O}_{3}$ & 12,09 & n.d. \\
$\mathrm{Sm}_{2} \mathrm{O}_{3}$ & 1,20 & n.d. \\
$\mathrm{Eu}_{2} \mathrm{O}_{3}$ & n.d. & 0,17 \\
$\mathrm{Gd}_{2} \mathrm{O}_{3}$ & 0,59 & 3,60 \\
$\mathrm{~Tb}_{2} \mathrm{O}_{3}$ & n.d. & 0,79 \\
$\mathrm{Dy}_{2} \mathrm{O}_{3}$ & n.d. & 6,14 \\
$\mathrm{Ho}_{2} \mathrm{O}_{3}$ & n.d. & 1,12 \\
$\mathrm{Er}_{2} \mathrm{O}_{3}$ & n.d. & 3,29 \\
$\mathrm{Tm}_{2} \mathrm{O}_{3}$ & n.d. & 0,36 \\
$\mathrm{Yb}_{2} \mathrm{O}_{3}$ & n.d. & 2,29 \\
$\mathrm{SiO}_{2}$ & n.d. & n.d. \\
$\mathrm{P}_{2} \mathrm{O}_{5}$ & 26,68 & 36,42 \\
$\mathrm{Total}$ & 95,17 & 99,82 \\
\hline
\end{tabular}

Tabela 10 Composição química de fosfatos de terras raras da jazida de talco e clorita de Trimouns (Ariege, França), Parseval et al. (1996).

$\mathrm{Ni}$ et al. (1995) estudando amostras sintéticas e naturais apresentaram o detalhamento da estrutura destes fosfatos de terras raras. A monazita (La, $\mathrm{Ce}$, $\mathrm{Nd}) \mathrm{PO}_{4}$ é monoclínica $\left(P 2_{1} / n\right)$ e difere da xenotima $\left(\mathrm{YPO}_{4}\right)$ que é romboédrica $(/ 4, / a m d)$. O arranjo atômico fundamental da monazita e xenotima é descrito por cadeias [001] formadas pela alternância de poliedros de ETR e tetraedros de fosfato. Na monazita o componente TR é coordenado a 9 átomos de oxigênio que difere da xenotima coordenado a 8 átomos.

Os parâmetros de cela variam com o valor do ângulo $\beta$ e o tamanho do raio iônico do elemento terra rara na posição catiônica (Montel et al., 1989). A monazita(Ce) apresenta uma dimensão maior do parâmetro $c$ quando comparada a xenotima(Y), Tabela 11.

$$
\begin{array}{llll} 
& \multicolumn{1}{c}{\frac{1}{\text { a }}} & \frac{2}{6,7902(10)} & \\
\text { b } & 7,0203(7) & & 6,8951(6) \\
\text { c } & 6,4674(7) & & 6,0276(6)
\end{array}
$$

Tabela 11 Parâmetros de cela da monazita e xenotima.

1 monazita do carbonatito de Kangankunde, Malawi, $\left(\mathrm{Ce}_{0.51} \mathrm{La}_{0.29} \mathrm{Nd}_{0.14} \mathrm{Pr}_{0.05} \mathrm{Sm}_{0.01}\right)_{\Sigma 1.00}\left(\mathrm{PO}_{4}\right)$

2 xenotima ( $-Y)$ do granitóide de Nanling, China,

$\left(\mathrm{Y}_{0,77} \mathrm{Dy}_{0,07} \mathrm{Er}_{0,05} \mathrm{Yb}_{0,03} \mathrm{Gd}_{0,02} \mathrm{Ho}_{0,02} \mathrm{Ca}_{0,01}\right)_{\Sigma 0,97}\left(\mathrm{P}_{1,01} \mathrm{Si}_{0,01}\right)_{\Sigma 1,02} \mathrm{O}_{4}$. (Ni et al., 1995). 
Os minerais do grupo do rhabdofânio apresentam uma fórmula estrutural do tipo $\mathrm{XZO}_{4} \cdot \mathrm{nH}_{2} \mathrm{O}$, onde $\mathrm{X}=\mathrm{Ca}, \mathrm{Pb}, \mathrm{Fe}^{3+}, \mathrm{Ce}, \mathrm{La}, \mathrm{U}$ e Th, $\mathrm{Z}=\mathrm{P}, \mathrm{S}$, Si e $\mathrm{n}$ varia de 1 a 2, as espécies, que fazem parte do grupo são:

rhabdofânio: ( $\mathrm{Nd}, \mathrm{Ce}, \mathrm{La}) \mathrm{PO}_{4} \cdot \mathrm{H}_{2} \mathrm{O}$

brockita: $(\mathrm{Ca}, \mathrm{Th}, \mathrm{Ce}) \mathrm{PO}_{4} \cdot \mathrm{H}_{2} \mathrm{O}$

grayita: (Th, $\mathrm{Pb}, \mathrm{Ca}) \mathrm{PO}_{4} \cdot \mathrm{H}_{2} \mathrm{O}$

ningyoite: $(\mathrm{U}, \mathrm{Ca}, \mathrm{Ce})_{2}\left(\mathrm{PO}_{4}\right)_{2} \cdot \mathrm{nH}_{2} \mathrm{O}$

tristramita: $\left(\mathrm{Ca}, \mathrm{U}^{4+}, \mathrm{Fe}^{3+}\right) \mathrm{PO}_{4} \cdot \mathrm{H}_{2} \mathrm{O}$

Análises à microssonda eletrônica, apresentadas na literatura consultada, revelaram que as proporções dos elementos terras raras são variáveis nos rhabdofânios da literatura, e que o Ca e Sr podem substituir os ETR (Tabela 12).

\begin{tabular}{|c|c|c|c|c|c|c|}
\hline & 1 & 2 & 3 & 4 & 5 & 6 \\
\hline $\mathrm{Na}_{2} \mathrm{O}$ & & & 0,3 & 0,3 & 0,3 & \\
\hline $\mathrm{CaO}$ & 0,26 & 0,24 & 8,5 & 8,6 & 8,4 & 8,65 \\
\hline $\mathrm{SrO}$ & & & 2,2 & 2,2 & 2,5 & 0,46 \\
\hline $\mathrm{Fe}_{2} \mathrm{O}_{3}$ & 0,38 & 0,32 & & & & 0,33 \\
\hline $\mathrm{La}_{2} \mathrm{O}_{3}$ & 12,19 & 11,07 & 10,3 & 10,2 & 10,1 & 11,87 \\
\hline $\mathrm{Ce}_{2} \mathrm{O}_{3}$ & 11,85 & 13,26 & 25,4 & 25,2 & 25,0 & 17,28 \\
\hline $\mathrm{Pr}_{2} \mathrm{O}_{3}$ & 1,02 & 0,85 & 1,8 & 1,9 & 2,0 & \\
\hline $\mathrm{Nd}_{2} \mathrm{O}_{3}$ & 21,18 & 15,74 & 6,5 & 6,4 & 6,7 & 6,85 \\
\hline $\mathrm{Sm}_{2} \mathrm{O}_{3}$ & 3,49 & 2,93 & 0,8 & 0,8 & 0,7 & \\
\hline $\mathrm{Eu}_{2} \mathrm{O}_{3}$ & 1,78 & 1,59 & & & & \\
\hline $\mathrm{Gd}_{2} \mathrm{O}_{3}$ & 3,24 & 3,46 & 0,5 & 0,4 & 0,4 & \\
\hline $\mathrm{Tb}_{2} \mathrm{O}_{3}$ & 0,34 & 0,33 & & & & \\
\hline $\mathrm{Dy}_{2} \mathrm{O}_{3}$ & 1,69 & 1,68 & 0,7 & 0,7 & 0,7 & \\
\hline $\mathrm{Ho}_{2} \mathrm{O}_{3}$ & 0,40 & 0,44 & 0,1 & 0,1 & 0,1 & \\
\hline $\mathrm{Er}_{2} \mathrm{O}_{3}$ & 1,12 & 1,13 & & & & \\
\hline $\mathrm{Tm}_{2} \mathrm{O}_{3}$ & 0,51 & 0,42 & & & & \\
\hline $\mathrm{Yb}_{2} \mathrm{O}_{3}$ & 0,40 & 0,76 & & & & 0,62 \\
\hline $\mathrm{Y}_{2} \mathrm{O}_{3}$ & 4,02 & 8,33 & & & & \\
\hline $\mathrm{TR}_{2} \mathrm{O}_{3}+\mathrm{Y}_{2} \mathrm{O}_{3}$ & 63,23 & 61,99 & 46,1 & 45,7 & 45,7 & \\
\hline $\mathrm{ThO}_{2}$ & - & 0,10 & & & & \\
\hline $\mathrm{U}_{3} \mathrm{O}_{8}$ & 0,42 & 0,18 & & & & \\
\hline $\mathrm{P}_{2} \mathrm{O}_{5}$ & 28,59 & 28,02 & 28,4 & 28,4 & 28,3 & 28,22 \\
\hline $\mathrm{SO}_{3}$ & & & 2,2 & 2,4 & 1,9 & \\
\hline F & & & 0,7 & 0,6 & 0,6 & \\
\hline $\mathrm{F} \equiv \mathrm{O}$ & & & 0,3 & 0,2 & 0,2 & \\
\hline Total & 92,88 & 90,85 & 88,1 & 88,0 & 87,5 & \\
\hline $\mathrm{H}_{2} \mathrm{O}^{*}$ & 7,12 & 9,15 & 11,3 & 11,6 & 12,1 & \\
\hline
\end{tabular}

Tabela 12 Composição química (em \%) de rhabdofânios analisados à microssonda eletrônica.

1 e 2 rhabdofânio-(Ce), Cornwall, Inglaterra (JCPDS 35-0614), Atkin et al. (1983);

3, 4 e 5 rhabdofânio-(Ce) cálcico, Dorfman, M. et al. (1988)

6 rhabdofânio calcifero (Soubiès, 1990 e 1991) 
Nota-se que o teor de $\mathrm{Ce}_{2} \mathrm{O}_{3}$ é maior do que os de $\mathrm{La}_{2} \mathrm{O}_{3}$ nos rhabdofânios ricos em $\mathrm{CaO}$. As variedades estudadas por Atkin et al. (1983) apresentam um importante teor em $\mathrm{Nd}_{2} \mathrm{O}_{3}$, o que não é observado nas estudadas por Dorfman, et al. (1988). Variações na composição destes minerais refletem sobretudo as condições do meio em que se formaram, segundo Bowles \& Morgan (1984) estas condiçōes seriam mais importantes do que os fatores de estrutura do cristal.

A estrutura do rhabdofânio é hexagonal, $P 6_{2} 22$ com parâmetros de cela $a=6.960$ e $c=6.372 \AA$ (rhabdofânio - (Ce), Atkin et al., 1983) ou $a=7.03$ e $c=6.44 \AA$ (rhabdofânio - (Ce), calcífero, Dorfman, et al. 1988).

Estes minerais ocorrem em produto de alteração hidrotermal de pegmatitos ou de alteração intempérica de apatita (Sawka et al., 1986 e Banfield et al., 1989 ambos apud Soubiès et al., 1990) e de allanita (Meintzer et al., 1988 e Khadem Allah \& Soubiès, 1990 ambos apud Soubiès et al., 1990). Soubiès et al. (1990 e 1991) encontraram rhabdofânios neoformados nas cavidades do anatásio estágio inicial de alteração intempérica de rochas do complexo alcalino-carbonatítico de Tapira.

\subsection{Alteração de fosfatos primários e formação de fosfatos secundários}

A alteração intempérica de depósitos fosfáticos de diferentes origens (ígnea, sedimentar e orgânica) leva muitas vezes à acumulação relativa dos fosfatos primários (primário aqui entendido como o material inicial que sofre o intemperismo). Este fenômeno vem sendo amplamente estudado nas últimas décadas, sendo investigados os fatores responsáveis pelo enriquecimento supérgeno (ambiente geoquímico, características dos materiais originais, condições climáticas e litológicas) e os produtos fosfáticos do intemperismo (supérgenos).

Os perfis de alteração sobre materiais com fosfatos podem ser marcados pela dissolução dos fosfatos iniciais, com lixiviação ou fixação do fósforo com formação dos fosfatos secundários; esta evolução depende das condições locais, que incluem os aspectos climáticos e topográficos, além das características texturais, estruturais, mineralógicas e geoquímicas da rocha original. Estes fatores determinam as condições físico-químicas do meio e, consequentemente, o comportamento dinâmico do fósforo (Zanin, 1989). O fósforo pode se acumular no perfil intempérico em ambiente alcalino, em geral, na forma de apatita primária residual, ou em ambiente substancialmente ácido fixado na forma de fosfatos de alumínio e/ou ferro. A eliminação do fósforo se dá em ambientes moderadamente ácidos. 
Segundo Vieillard et al. (1979) e Schwab et al. (1989) o comportamento dinâmico do fósforo é controlado por parâmetros como $\mathrm{pH}$, atividade do $\mathrm{H}_{3} \mathrm{PO}_{4}$ e a atividade dos cátions envolvidos nas novas fases $(\mathrm{Na}, \mathrm{Ca}, \mathrm{Sr}, \mathrm{Ba}, \mathrm{Al}, \mathrm{Fe}, \mathrm{ETR}, \mathrm{Pb}$ e ainda outros), e que são, por sua vez, função dos aspectos petrográficos, mineralógicos e geoquímicos das rochas envolvidas, bem como dos aspectos morfológicos e climáticos da área em questão.

Após a dissolução dos fosfatos primários, principalmente minerais da família da apatita, o fósforo é liberado nas diferentes formas dissociadas de ácido fosfórico (Vieillard, 1978) podendo recristalizar-se dando origem a novas estruturas, apatíticas e não apatíticas (onde se destacam os fosfatos da família das crandallita).

No ambiente de intemperismo o fósforo acaba por influenciar na disponibilidade química de outros elementos, fixa os cátions formando fosfatos secundários, ou pode participar na formação de apatitas secundárias na base do perfil. Assim, embora seja considerado residual em escala de perfil o fósforo sofre reciclagens e pode migrar durante o intemperismo. Minerais provenientes de neoformações a partir do fósforo liberado de apatitas alteradas foram encontrados em carbonatitos intensamente alterados como monazita secundária, florencita, goyazita e gorceixita (Rose et al.,1958, Goetzee \& Edwards, 1959, McKie, 1962, Deans, 1966, todos apud Altschuler, 1973).

O intemperismo sobre rochas alcalino-carbonatíticas ricas em apatita primária, representada pela fluorapatita ou hidróxi-fluorapatita, leva à formação de apatitas supérgenas do tipo carbonatoapatita e de fosfatos aluminosos principalmente da série da crandallita. Antes de liberar o fósforo e outros elementos para o meio, a apatita pode sofrer modificações químicas, como o aprisionamento ou liberação de elementos químicos. Evidências destas modificações foram encontradas nas bordas de apatitas em alteração enriquecidas em Al de rochas glimmeríticas e carbonatítica de Ipanema (Florêncio \& Toledo, 1997). Ainda as apatitas podem perder substituintes catiônicos e aniônicos como observado em apatitas de Catalão I (Toledo et al., 1998).

Flicoteaux \& Lucas (1984) mostraram que com o intemperismo laterítico a carbonato-fluorapatita perde $\mathrm{CO}_{2}$, e que a presença de carbonatos controla a evolução da apatita, fazendo com que este mineral pare de evoluir, alcançando somente o estágio de fluorapatita. Em depósitos sedimentares associados a calcário e marga, somente com a dissolução total dos carbonatos a apatita começa a 
desaparecer, o ambiente deficiente em cálcio torna-se mais ácido, e então o cálcio é removido da apatita levando a sua completa dissolução. McArthur (1985) observou que em amostras intemperizadas a apatita contém um menor teor em $\mathrm{Sr}, \mathrm{Na}$ e $\mathrm{SO}_{4}{ }^{2-}$ em relação ao $\mathrm{P}_{2} \mathrm{O}_{5}$ quando comparadas às apatitas da rocha fresca.

Segundo alguns autores, a apatita começa a se desestabilizar em ambientes moderadamente ácidos, sendo totalmente dissolvida, em pH de 5,5 a 6,5 (Lucas et al., 1980, Flicoteaux \& Lucas, 1984, Zanin, 1989 e Lottermoser, 1990, entre outros). Apatitas supérgenas vão se formar nos estágios iniciais da alteração e sua composição é determinada pelas condições geoquímicas do meio como foi apresentado por McArthur (1985) para as "francolitas" presentes em fosforitos.

Gusev et al. (1976) estudaram a variação da composição e a ordem de remoção dos elementos da apatita durante o intemperismo. Para o estudo foram analisados fosforitos frescos e alterados e flúor-hidroxiapatitas de origem ígnea atacadas experimentalmente por ácido cítrico. Os resultados destes estudos mostraram que no intemperismo o flúor é o primeiro elemento a ser eliminado da apatita seguido pelo Ca e pelo P. Altschuler (1973) já assinalava a ocorrência de dissolução incongruente durante o ataque ácido de apatitas a $25^{\circ}$ e $70^{\circ} \mathrm{C}$ notando uma maior liberação de $\mathrm{Ca}$ e conseqüente diminuição da razão $\mathrm{CaO} / \mathrm{P}_{2} \mathrm{O}_{5}$.

Lucas et al. (1980) concluiram que com a intensificação do intemperismo outros minerais são atacados liberando alumínio e ferro para o meio e que de acordo com sua disponibilidade estes elementos combinam-se com o fosfato. Em ambiente argiloso o alumínio é mais disponível formando fosfatos de composição aluminocálcica e aluminosa. Num meio pobre em alumínio como os fosforitos de Negev o ferro é o elemento disponivel levando a formação de diferentes tipos de fosfatos de ferro. Estes autores encontraram a seguinte sucessão evolutiva para os fosfatos:

flúor-carbonatoapatita $\rightarrow$ millisita $\mathrm{Ca}+$ crandallita $\mathrm{Sr} \rightarrow$ crandallita $\mathrm{Ca}$ $(\rightarrow$ wavellita), em materiais mais evoluídos pode ocorrer fosfatos com ferro como a Fe-millisita.

Vieillard et al.(1979) citaram o papel geoquímico do fosfato no intemperismo laterítico mostrando que a presença de fosfatos na rocha mãe altera o comportamento geoquímico usual, nos perfis lateríticos, do cálcio, silício, alumínio e ferro observado no intemperismo de rochas puramente silicáticas sob mesmas condições climáticas. $O$ cálcio é prontamente lixiviado em rochas silicáticas mas é mantido por longo tempo em formações fosfatadas. 'A caulinita dominante em 
alteritas de rochas silicáticas é rara em seqüências fosfáticas intemperizadas. A presença de fosfatos de alumínio de baixa solubilidade mantém baixa a fração molar de diásporo dentro da goethita. Somente quando os fosfatos aluminosos são destruídos o valor desta fração aumenta para $15-25 \%$ na goethita, o que é usualmente encontrado em crostas ferruginosas (ferricrete).

A riqueza de minerais aluminosos ricos em bário (gorceixita) freqüentemente encontrada nos materiais mais evoluídos do perfil de alteração sobre rochas fosfáticas pode ser explicada pela sua maior estabilidade quando comparados a outros fosfatos aluminosos. Frondel (1958) observou que a diferença de solubilidade dos minerais da série da crandallita depende de sua composição; os mais solúveis seriam os fosfatos com $\mathrm{Ca}$ seguido pelos fosfatos com $\mathrm{Sr}$ e por último os fosfatos com Ba. Estas observaçōes estão em acordo com estudos experimentais posteriores de Schwab et al. (1980), que indicam a gorceixita como fase mais estável dessa série.

\section{3 Áreas de estudo}

Os complexos alcalino-carbonatíticos brasileiros estão relacionados à separação dos continentes que começou a 160 M.a. Dentre os maciços distribuídos na borda da bacia do Paraná (Figura 3) foram escolhidos três: Anitápolis (SC), Juquiá (SP) e Tapira (MG). Para cada maciço foi feito um levantamento de informações sobre a geologia, petrologia e mineralogia (Tabela 13).

Os complexos escolhidos para o estudo estão situados em zonas climáticas dominadas pelo clima tropical úmido, sendo Juquiá a área de maior incidência de chuvas. Os dados climáticos apresentados são atuais e entre as três áreas estudadas somente Tapira apresenta um regime de chuvas com estação seca definida. O relevo dos complexos é positivo em Juquiá e Tapira e negativo em Anitápolis. Os tipos litológicos mais freqüentes são piroxenitos, carbonatitos nefelinasienitos e foscorito, sendo que em Juquiá.

Todas as áreas possuem concentraçöes importantes em fosfato, sendo que apenas Anitápolis $(\mathrm{SC})$ não chegou a produzir minério.

O fosfato primário dos depósitos estudados é a apatita e mais raramente fosfatos de terras raras (monazita e rhabdofânio). Outros fosfatos aparecem nos materiais lateríticos como fosfatos da série da crandallita em Juquiá e Tapira, wavelita (em Juquiá e Anitápolis), turquesa (em Juquiá) e fosfatos de ETR representado pelo rhabdofânio (em Tapira). Um fosfato de escândio, de ocorrência 
rara, a kolbeckita, $\mathrm{ScPO}_{4} \times \mathrm{XH}_{2} \mathrm{O}$, foi encontrado em Tapira (Melfi et al., 1991, Soubiès et al., 1992).

\begin{tabular}{|c|c|c|c|}
\hline PRINCIPAIS CARACTERISTICAS & ANITÁPOLIS (SC) & JUQUIÁ (SP) & TAPIRA (MG) \\
\hline $\begin{array}{l}\text { CLIMA } \\
\text { P: pluviometria média anual }(\mathrm{mm}) \\
\text { T: temperatura médias anual }\left({ }^{\circ} \mathrm{C}\right)\end{array}$ & $\begin{array}{c}\text { P: } 1696 \\
\text { (sem estação seca) } \\
T: 17\end{array}$ & $\begin{array}{c}P: 1300 \text { a } 1500 \\
\text { (sem estação seca) } \\
T:>20\end{array}$ & $\begin{array}{c}P: 1735 \\
\text { (com estação seca) } \\
T: 22\end{array}$ \\
\hline RELEVO & $\begin{array}{l}\text { depressão regional; } \\
\text { cotas de } 700 \mathrm{~m}\end{array}$ & $\begin{array}{c}\text { relevo de morrotes; } \\
\text { cotas entre } 100 \mathrm{e} \\
120 \mathrm{~m}\end{array}$ & $\begin{array}{l}\text { platôs de altitude; } \\
\text { cotas de } 850 \mathrm{~m}\end{array}$ \\
\hline IDADE K-Ar (M.a.) & \multicolumn{2}{|c|}{$\sim 130$} & 70 \\
\hline ÁREA $(\mathrm{km} 2)$ & 6 & 13 & 33 \\
\hline FORMA & circular & \multicolumn{2}{|c|}{ oval } \\
\hline ESTRUTURA & \multicolumn{3}{|c|}{ fraturas radiais concêntricas } \\
\hline ENCAIXANTE & $\begin{array}{l}\text { granitos pré- } \\
\text { cambrianos }\end{array}$ & \multicolumn{2}{|c|}{ metassedimentos pré-cambrianos } \\
\hline \multirow{2}{*}{ LITOLOGIA } & \multicolumn{3}{|c|}{ carbonatito-piroxenito-nefelina sienito-foscorito } \\
\hline & ijolito & peridotito & ijolito \\
\hline CARBONATITO & $\begin{array}{l}\text { veios e bolsões } \\
\text { sövito, dolomita }\end{array}$ & $\begin{array}{l}\text { plug de beforsito } \\
\text { (contínuo) }\end{array}$ & $\begin{array}{l}\text { veios e bolsões } \\
\text { sövito, dolomita } \\
\text { sövito, beforsito }\end{array}$ \\
\hline ROCHA APATÍTICA & $\begin{array}{c}\text { rochas ultramáficas, } \\
\text { nefelina sienitos, } \\
\text { urtitos }\end{array}$ & Carbonatito & $\begin{array}{c}\text { rochas } \\
\text { ultramáficas, } \\
\text { silexito, foscorito }\end{array}$ \\
\hline $\begin{array}{c}\text { ESPESSURA MÉDIA DO MANTO } \\
\text { DE INTEMPERISMO (m) }\end{array}$ & $\sim 30$ & $\sim 50$ & $\sim 90$ (até $200 \mathrm{~m}$ ) \\
\hline $\begin{array}{c}\text { FOSFATOS } \\
\text { (mineral de minério em negrito) }\end{array}$ & apatita, monazita & $\begin{array}{l}\text { apatita, gorceixita, } \\
\text { wavellita e turquesa }\end{array}$ & $\begin{array}{c}\text { apatita, gorceixita, } \\
\text { florencita, } \\
\text { rhabdofânio, } \\
\text { monazita, } \\
\text { kolbeckita }\end{array}$ \\
\hline OUTRAS MINERALIZAÇỎES & \multicolumn{2}{|c|}{ Fe (magnetita) } & $\begin{array}{l}\mathrm{Fe} \text { (magnetita) } \\
\mathrm{Ti} \text { (anatásio) } \\
\mathrm{Nb} \text { (pirocloro) }\end{array}$ \\
\hline
\end{tabular}

Tabela 13 Dados geográficos e geológicos das três áreas de estudo.

Referências da tabela 13:

Geologia geral: Amaral et al., 1967, Rodrigues \& Lima, 1984, Ulbrich \& Gomes, 1981, Almeida, 1983 Anitápolis: Kahn, 1988, Pereira, 1991, Pereira et al., 1997, Costa, 1987, Ziesemer \& Kahn. , 1980, Furtado, 1989, Vergara, 1980, Hasui \& Cordani, 1968

Juquiá: Alcover Neto, 1991, Born, 1971, Walter, 1991, Walter et al. 1989, Walter et al. 1995, Lenharo, 1994, Felissíssimo Jr., 1976, Flicoteaux e Walter, 1988, Alcover Neto \& Toledo, 1993, Lenharo, 1994, Macciotta et al., 1988,

Tapira: Cruz \& Cheney, 1976, Melfi et al. 1991, Lindenmayer, 1978, Lenharo 1994, Geisel Sobrinho, 1974, Brod, 1993 


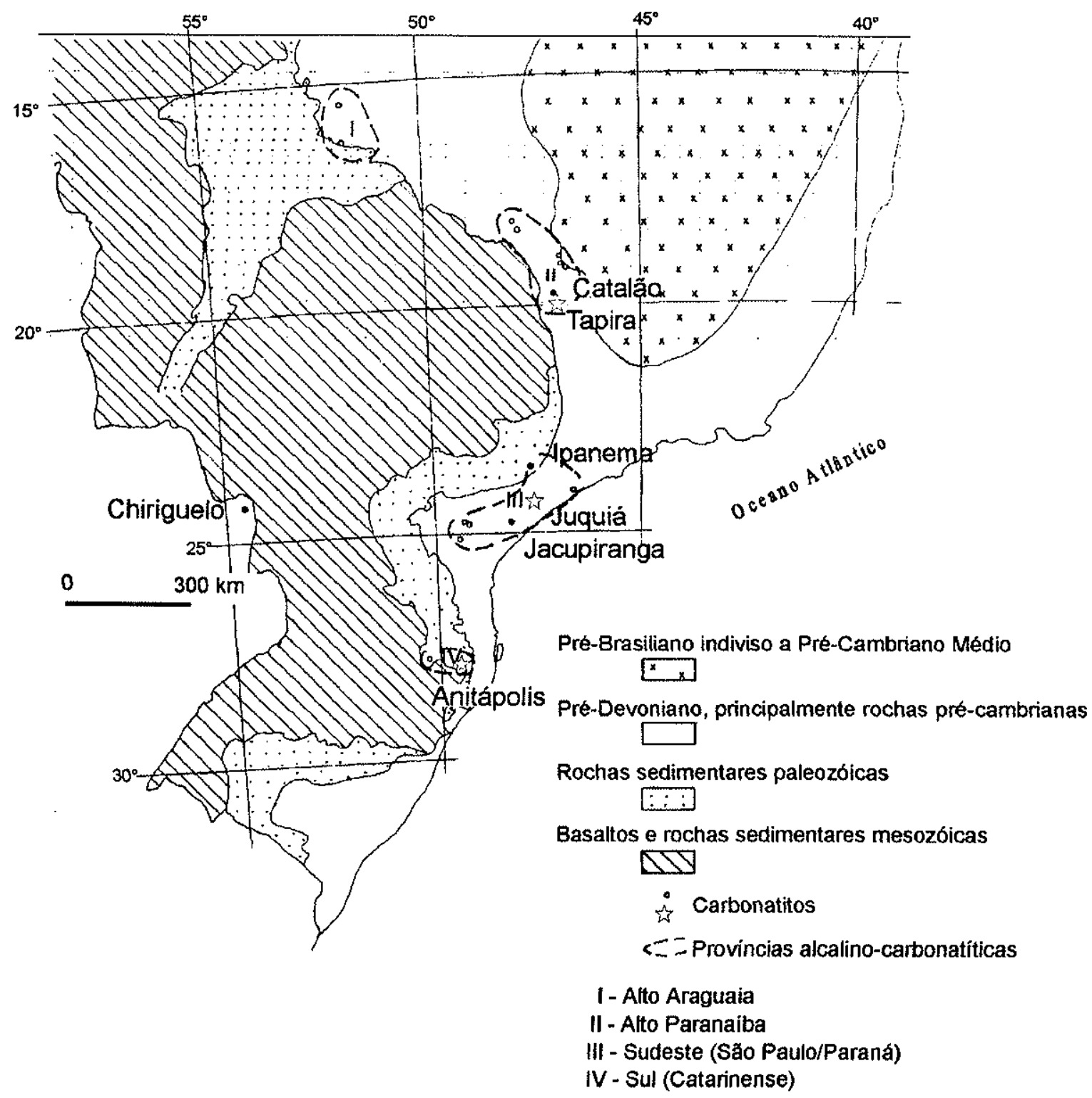

Figura 3 Mapa de localização dos complexos alcalinos estudados. Fonte: Rodrigues \& Lima (1984). 


\subsubsection{Anitápolis}

\section{Localização}

O maciço alcalino-carbonatítico de Anitápolis ocorre na porção oeste do Estado de Santa Catarina localizado a $60 \mathrm{~km}$ da cidade de Florianópolis, com coordenadas geográficas aproximadas de $49^{\circ} 05^{\prime}$ de longitude oeste e $27^{\circ} 49^{\prime}$ de latitude sul.

\section{Fisiografia, Clima e Vegetação}

O maciço representa uma depressão do relevo da região com cotas em torno de $700 \mathrm{~m}$; as áreas mais internas e erodidas coincidem com as seqüências ultramáficas da intrusão (Figura 4) . O rio Pinheiros Altos corta a área na direção NNW; é condicionado por falhamentos e fraturas regionais e desenvolve importantes depósitos aluviais de até $17 \mathrm{~m}$ de profundidade.

Segundo a classificação de Köppen, o clima é do tipo cfa, mesotérmico, superúmido com verão quente e ocorrência de chuvas em todos os meses do ano. A pluviometria média anual da região do período de 1946 a 1977 foi de $1696 \mathrm{~mm}$. As temperaturas registradas em 1979 indicam médias mensais máxima e mínima de $22,3^{\circ} \mathrm{C}$ e $11,5^{\circ} \mathrm{C}$, respectivamente, com valores absolutos máximo de $36^{\circ} \mathrm{C}$ em dezembro e mínimo de $-4^{\circ} \mathrm{C}$ em julho (IBGE, 1979 e Adubos Trevo, 1979 e 1980, apud Kahn, 1988).

Atualmente a vegetação nativa encontra-se praticamente toda devastada, só preservada em áreas mais acidentadas; pertence ao domínio da mata Atlântica. 

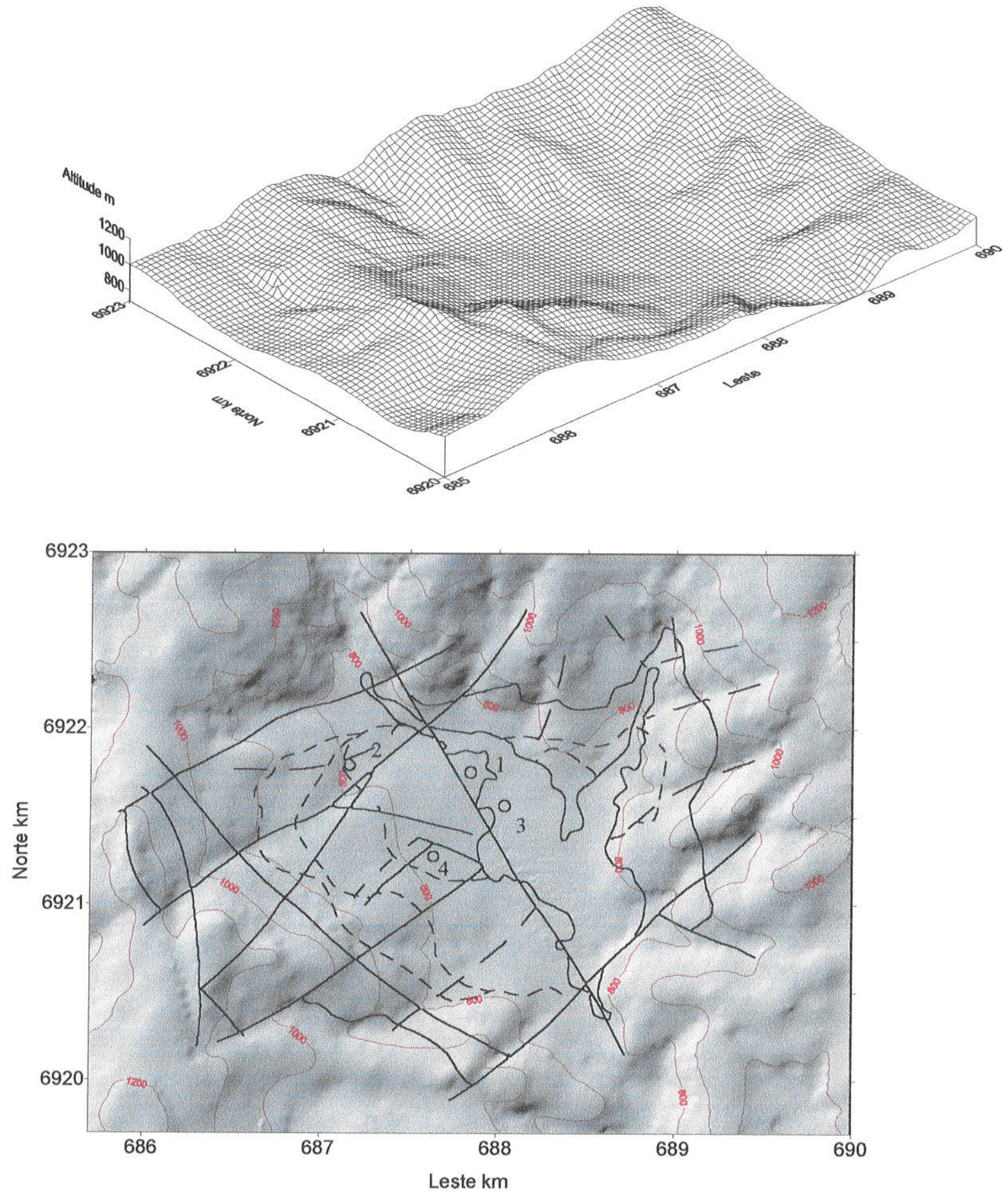

Figura 4 Superfície e mapa de sombras elaborados a partir do Modelo digital do terreno da área do Complexo alcalino-carbonatítico de Anitápolis. Mapa base: Carta topográfica Folha SG-22-Z-D-IV-4, escala 1:50.000 (IBGE 1978).

1 = frente de lavra experimental; 2 = trincheira TGB; 3 = carbonatito; 4 = galeria GPF

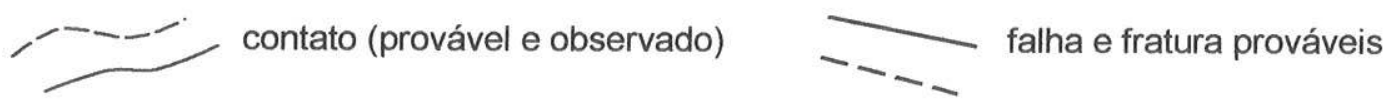




\section{Geologia}

O Complexo Alcalino de Anitápolis já conhecido desde o início deste século, só foi sistematicamente estudado a partir de 1976 pela CPRM, cujas pesquisas foram realizadas pelas Indústrias Luchsinger Madörin S.S. a partir de 1977. A síntese dessas pesquisas foi publicada por Ziesemer \& Kahn (1980), ressaltando a importância do minério residual, com base em estudos mineralógicos e químicos para os elementos maiores. Trabalhos mais recentes (Rodrigues, 1985, Rodrigues et al., 1986) discutem detalhadamente a mineralogia, petrografia e evolução petrogenética das rochas inalteradas.

Em superfície, este maciço forma um corpo subcircular, com aproximadamente $6 \mathrm{~km}^{2}$ de área, encaixado em rochas granitóides de composição sienítica a monzogranítica de idade brasiliana (Figura 5). Segundo Rodrigues et al. (1986) o maciço é intrusivo nas rochas graníticas da Suite Pedras Grandes do Embasamento Cristalino.

A intrusão das rochas alcalinas do maciço apresenta duas direções preferenciais de lineamentos estruturais, uma aproximadamente N-S, representando os de maior extensão, e outro, $\mathrm{N} 60^{\circ} \mathrm{E}$. Além destes lineamentos principais, observase uma nítida disposição de fraturas do tipo radial periférico.

A idade do maciço de Anitápolis situa-se no limite Jurássico-Cretáceo. Determinações sistemáticas K/Ar em biotita feitas em diversos tipos litológicos deste maciço forneceram valores entre 104 e $131 \mathrm{Ma}$ (Amaral et al., 1967), de $136 \mathrm{Ma}$. e de $133 \mathrm{Ma}$. (Gomes, 1987). Estes resultados cronológicos diferem daqueles obtidos por Baitelli (1992, apud Pereira et al., 1997) que, através da análise dos traços de fissão de urânio em apatitas do maciço alcalino-carbonatítico de Anitápolis, concluiu que os diferentes eventos portadores de apatitas apresentam idades entre 100 e 198 Ma. 


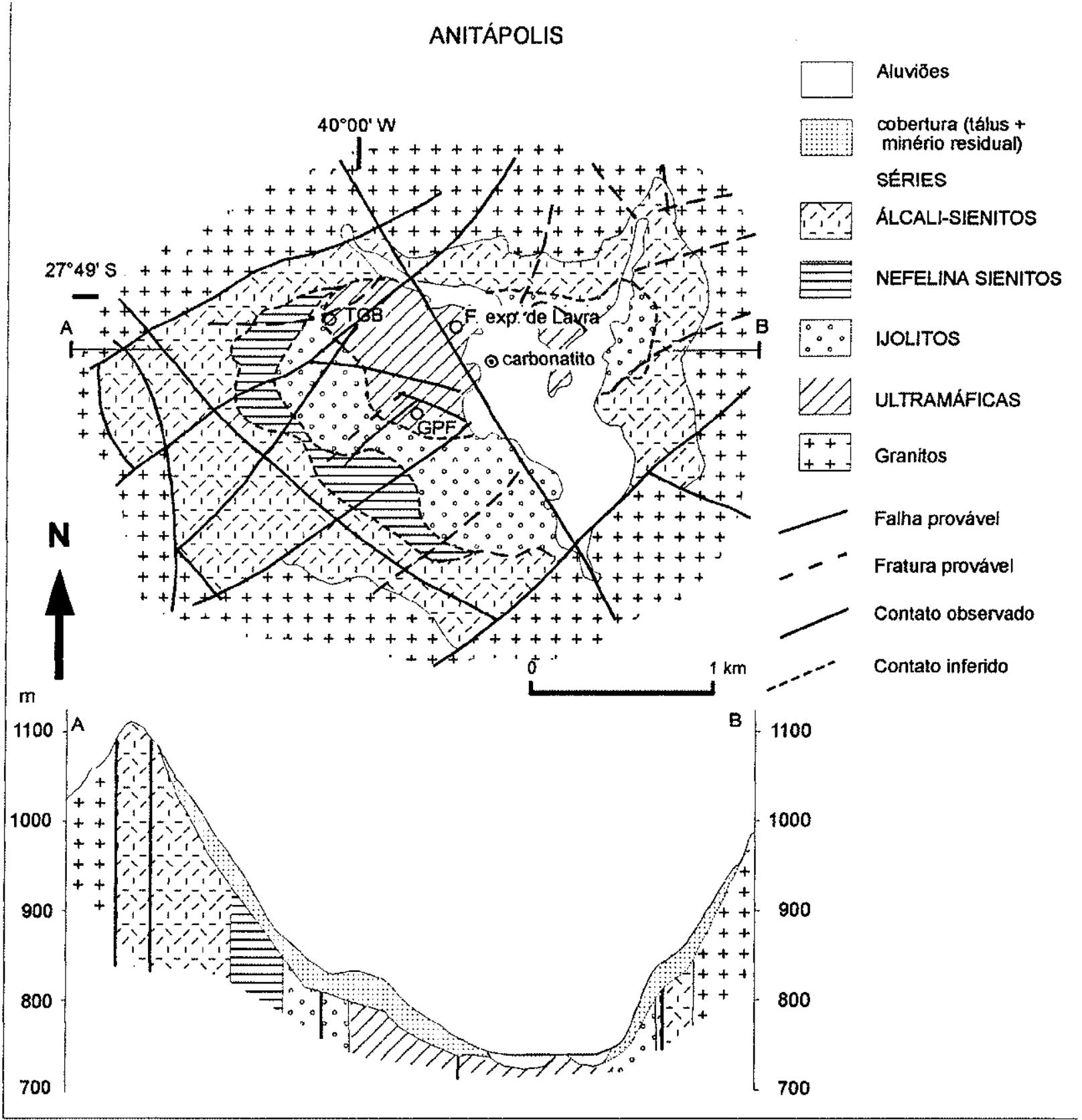

Figura 5 Mapa geológico do Complexo alcalino-carbonatítico de Anitápolis (Vergara, 1980).

Nos trabalhos realizados em Anitápolis foi verificada a presença de múltiplos eventos, causando a alteração das rochas do próprio maciço e dos granitos encaixantes, originando rochas heterogêneas. A presença de carbonatitos, foscoritos, glimmeritos, nelsonitos entre outros tipos litológicos foram relacionados a eventos hidrotermais tardios. Rodrigues (1985) a partir de dados obtidos e integrados aos de Vergara (1979) elaborou um mapa geológico para o maciço, que apresenta quatro zonas grosseiramente concêntricas (fig. 2). A zona externa é constituída por rochas do grupo dos álcali-sienitos, a zona intermediária externa contém predominantemente nefelina-sienitos, a zona intermediária interna é formada 
por ijolitos e melteigitos enquanto que na zona interna predominam rochas ultramáficas. Todas as variedades de rochas encontram-se cortadas por veios carbonatíticos.

Os álcali-sienitos são constituídos essencialmente de feldspatos e piroxênios, variando de termos leucocráticos a melanocráticos. Os piroxênios de composição egirínica tendem a formar agregados, às vezes isoorientados preenchendo fraturas ou espaços entre os cristais de feldspatos. Os alcali-sienitos são interpretados como o resultado do processo de fenitização sobre os granitos encaixantes.

Nefelina-sienitos ocorrem mais para o centro do maciço e são constituídos essencialmente por feldspato potássico, nefelina e piroxênio, com quantidades subordinadas de apatita, biotita, albita e titanita. A textura desse tipo de rocha é raramente homogênea.

Nas rochas da série dos ijolitos predominam as variedades mesocráticas (ijolitos); sua mineralogia é formada por nefelina e piroxênio, com pequenas porções de anfibólio, titanita e apatita em um arranjo extremamente variado onde são freqüentes manchas e faixas irregulares ora com predomínio de piroxênio, ora de nefelina.

As ultramáficas são divididas por Rodrigues (1985) em dois tipos básicos: aqueles com predomínio de biotita e piroxênios (piroxenitos, biotititos, biotita piroxenitos, piroxênio biotititos) e os compostos predominantemente por magnetita e olivina, denominado pelo autor de magnetita dunitos. Este último encontra-se intensamente afetado pelo hidrotermalismo que ocasiona a transformação total da olivina em serpentina, argilo minerais e carbonato. $O$ autor interpreta estas rochas como xenólitos trazidos do manto à superfície durante a ascensão do magma biotita piroxenítico.

Os carbonatitos são principalmente representados por sovitos, embora ocorram em menores quantidades dolomita-sovito e beforsitos. Apatita, magnetita, flogopita, pirocloro, esfalerita e anfibólio estão presentes como acessórios entre os grãos de carbonato ou concentrados em lâminas subparalelas de espessura submilimétrica a milimétrica.

No maciço de Anitápolis a apatita está presente em todas as rochas e concentrada nas ultramáficas e nos carbonatitos com grande quantidade de magnetita. A apatita, segundo IPT (1979), estaria ligada tanto nas rochas magmáticas como nas metassomáticas. A reserva total de fosfato do maciço de 
Anitápolis estimada por Vergara (1977) é de 330 milhões de toneladas de fosfato para um teor de $6,5 \%$ de $\mathrm{P}_{2} \mathrm{O}_{5}$ em média, considerada como uma reserva pequena quando comparada a outros maciços alcalinos do mundo (Cook, 1984).

Para Rodrigues (1985) as séries dos álcali-sienitos, nefelina sienitos e parte dos ijolitos foram geradas por ação metassomática de caráter sódico; o metassomatismo intenso originou nefelina sienitos e ijolitos reomórficos, com texturas magmáticas. Por outro lado o metassomatismo potássico teria efeito apenas localizado, com formação de biotita ao longo de clivagens e fraturas.

Pozza \& Garcia (1974), ao realizar o projeto Anitápolis constataram anomalias radiométricas numa faixa de $800 \mathrm{~km}^{2}$, com o maciço de Anitápolis ocupando a porção central da área. Nessa faixa foi constatada a presença de 197 diques, constituídos principalmente por fonólitos e tinguaitos. De acordo com esses autores, os diques têm preferência pela direção NS e secundariamente NW e NE.

Furtado (1989) descreve ainda foscoritos e outras rochas como magnetitabiotita piroxenito ou apatita-piroxênio biotitito. Pereira et al. (1997) mencionou a existência de silicitos (rochas hidrotermais quartzosas relacionadas ao magmatismo alcalino) que estão associados aos granitos encaixantes. Em escala não mapeável aparecem os glimmeritos, veios apatíticos e nelsoníticos entre outros tipos litológicos que evidenciam a existência de múltiplos eventos hidrotermais, responsáveis pela concentração econômica de fosfato apatítico.

\section{Manto de intemperismo}

Segundo Vergara (1979) o manto de intemperismo possui uma espessura média de aproximadamente $30 \mathrm{~m}$ (entre $10-50 \mathrm{~m}$ ) e é subdividido em três níveis: nível A, nível B e nível C. Ziesemer \& Kahn (1980) apresentaram outra divisão: zona de tálus (nível A), zona intermediária (nível B) e zona mais compacta (nível C). Costa (1987) retoma a classificação de Ziesemer \& Kahn (op. cit.) dividindo o manto em horizontes: horizonte de tálus, horizonte intermediário e horizonte compacto.

O nível $A$ (tálus) é formado por um depósito de encosta $(5-20 \mathrm{~m}$ de espessura). Cobre quase toda a região e é constituído por blocos e seixos predominantemente de rochas alcalinas, imersos em matriz síltico-argilosa. A espessura do tálus, a dimensão dos blocos e a relação blocos/matriz diminui em relação às porçōes mais centrais e inferiores do maciço. 
Sob este nivel, há dois outros formados pela alteração intempérica das rochas alcalinas (nível B e C). O nivel B ou zona (10-20m) é constituído por um material intemperizado, com estruturas e texturas originais da rocha preservadas, e o nivel $\mathrm{C}$ representados principalmente por piroxenitos pouco alterados.

O manto de intemperismo apresenta feldspatos, goethita oxihidróxidos amorfos de ferro, caulinita / esmectita, e conteúdos menores de fosfatos secundários, vermiculita, magnetita e quartzo (derivado da alteração das rochas encaixantes). A apatita e, subordinadamente, o piroxênio e $O$ anfibólio ocorrem no níveis $B$ e $C$, podendo ocorrer localizadamente na base do tálus (Vergara, 1980) e na região de transição entre o tálus e os níveis inferiores (Costa, 1987).

Costa (1987) considera a jazida residual de Anitápolis de natureza laterítica inicial, formada em condições climáticas moderadas, onde a evolução mineralógica e geoquímica foi dificultada pelo intemperismo físico. A mineralogia e geoquímica do perfil refletem a natureza ultramáfica da rocha mãe e o caráter coluvionar do topo do perfil.

A evolução mineralógica pela ação do intemperismo em perfis da jazida foi sugerida por Pereira (1991). É marcada pela destruição das estruturas originais da rocha, acumulação de minerais resistentes ao intemperismo e formação de plasma de alteração que é remobilizado no perfil. Nos horizontes de alteração observa-se a seguinte sequeencia evolutiva: 1. alteração mineralógica com pouca ou nenhuma modificação de volume: piroxênio ou anfibólio $\rightarrow$ esmectita; flogopita ou biotita $\rightarrow$ vermiculita, 2. alteroplasmação com a neoformação de argilo minerais e liberação de óxidos e hidróxidos de manganês, pseudomorfose das micas pelo ferro, dissolução das apatitas; os materiais sofrem aí modificações volumétricas e destruição da estrutura da rocha original, 3. pedoplasmação com a dissolução e migração do plasma secundário e formação de apatitas supérgenas nos poros e 4 . remobilizações policíclicas de óxidos e hidróxidos de manganês depositados sobre os fosfatos supérgenos.

Com a evolução, os materiais perdem $\mathrm{Si}, \mathrm{Ca}, \mathrm{K}, \mathrm{Na}$ e $\mathrm{Rb}$ e se concentram em $\mathrm{Fe}, \mathrm{Mn}, \mathrm{Mg}$ e $\mathrm{P}$ (Pereira, 1991). Os ETR sofrem um fracionamento; os ETRL se concentram nas fases mineralógicas tardias tendo o plasma fosfático teores anômalos de Ce possivelmente fixado nas fases manganesíferas a ele associada. 


\section{Fosfatos de Anitápolis}

Apatitas

Furtado (1989) analisou à microssonda apatitas de foscoritos, identificando-as como sendo fluorapatita. Estes minerais estão presentes na maior parte das amostras analisadas e constituem tanto a matriz com um arranjo de mosaico como inclusões em olivinas. O tamanho dos grãos varia entre 0,1 e 1,5 mm, sendo mais freqüentes valores em torno de $0,5 \mathrm{~mm}$. Nas camadas de apatitas onde o bandamento é mais acentuado ocorrem os maiores tamanhos de grãos, com o alongamento segundo o eixo $\mathrm{C}$ e extinção às vezes ondulante. Nas amostras onde a olivina conserva seu idiomorfismo, constata-se que os grãos de apatita apresentam pequena quantidade de inclusões fluidas. Nas amostras em que não aparecem mais vestígio de olivina original a quantidade de inclusões é maior, mas sempre menor do que as apatitas presentes nos carbonatitos sovíticos. Nestas mesmas amostras a apatita pode conter inclusões de anfibólio.

Outra variedade de apatita presente nos foscoritos é a carbonatoapatita. Ao microscópio óptico (MO) é distinguida das fluorapatitas tanto pela sua maior birrefringência como pelo seu modo de ocorrência, pois forma capas com contornos idiomórficos em torno dos grãos de fluorapatita xenomórfica. A carbonatoapatita ocorre em amostras onde a olivina está mais intensamente transformada, e onde a apatita está em contato com carbonatos ou bowlingita (Furtado et al. 1986).

As apatitas do maciço alcalino-carbonatítico de Anitápolis apresentam grãos de diferentes tamanhos e formas, sendo comuns as apatitas milimétricas (até $5 \mathrm{~mm}$ ).

Nos trabalhos de Pereira (1991) e Pereira et al. (1997) foram estudadas apatitas de flogopita-piroxenito, glimmerito, veios apatíticos tardios, carbonatito sovítico e do fosfato secundário apatítico. Estes autores identificaram a presença de hidróxi-carbonatofluorapatita ou carbonato-hidroxifluorapatita, através de determinações de flúor por reação nuclear ressonante e cromatografia iônica; os teores de cloro foram dosados por colorimetria e os teores de carbonato e hidroxila determinados qualitativamente por EIV.

O cálculo dos parâmetros cristalográficos efetuados por Pereira (1991) através da DRX revelaram que as apatitas dos veios hidrotermais são mais desenvolvidas ao longo do eixo cristalográfico c. Segundo Rahal (1987), apud Pereira (1991) apatitas com estas características se formam de um resfriamento mais rápido do líquido. 
O estudo dos ETR (Pereira, 1991) revelou: 1. enriquecimento dos ETRL em relação aos ETRP em todas apatitas analisadas; 2. ausência de anomalia negativa de Eu; 3. apatitas dos veios hidrotermais tardios são mais ricas em ETR que as apatitas ígneas; 3. Razões $L a / Y b$ e ETRL/ETRP de apatitas aumentam significativamente da fácies flogopita-piroxenito e dos glimmeritos para os veios apatíticos tardios.

Foi observado ainda que durante a alteração supergênica há uma concentração localizada de Ce no perfil laterítico, sempre associado às apatitas supérgenas. A presença de óxido de manganês amorfo também é responsável pelo acúmulo desse elemento, cuja concentração varia nos diferentes microssistemas.

Com base no conteúdo total de ETR ou mesmo das razões ETRL/ ETRP, não foi possível saber se as apatitas supérgenas são provenientes da alteração de apatitas de um veio hidrotermal, havendo perda destes elementos durante a gênese de apatitas supérgenas, ou se são provenientes da fácies flogopita piroxenito ou de um glimmerito que concentrou os ETR durante a laterização.

Análises de apatitas (em piroxenito, glimmerito e veio hidrotermal) feitas por Pereira (1991) por absorção atômica mostraram a presença de $\mathrm{Mg}(100-600$ ppm), $\mathrm{Zn} \mathrm{(16-36} \mathrm{ppm),} \mathrm{Cu} \mathrm{(4} \mathrm{-} 13$ ppm), Fe (304-553 ppm), Mn (168-366 ppm) e Na (2372 $2838 \mathrm{ppm}$ ) (Pereira, 1991). Também foram analisados $\circ \mathrm{Ni}, \circ \mathrm{K}$ e $\circ \mathrm{S}$ que apresentaram teores abaixo de $0,02 \%$.

Segundo o mesmo autor apatitas de sienitos da trincheira TGB apresentam cor de catodoluminescência salmão (cor de ativação $\mathrm{Mn}^{3+}$ ), cujo espectro apresenta picos do $\mathrm{Mn}^{2+}$ e do $\mathrm{Sm}^{3+}$. Apatitas de carbonatito sovítico da trincheira GPF apresentaram cor de catodoluminescência azul (cor de ativação do Eu), com tons mais claros nas bordas dos grãos.

Pereira (1991) observou a presença de apatitas supérgenas formadas em fissuras da alterita próximo a um veio hidrotermal que corta o sienito alterado, na zona superior do nivel $B$. Estas apatitas formam agulhas micrométricas diferenciadas em dois tipos, euédricas e mal cristalizadas. São formadas pela desestabilização do plasma fosfático secundário seguida pela dissolução e reprecipitação.

Não existe nenhuma informação da composição química das apatitas supérgenas. 


\section{Outros fosfatos}

Pereira (1991) citou a presença de apatitas supérgenas de hábito fibroso associadas a grãos de apatitas parcialmente dissolvidos e argiliplasma fosfático. Mostra que a apatita supérgena se forma num estágio mais evoluído da alteração, a partir da dissolução deste argiliplasma originado pela alteração da apatita e outros minerais primários.

Nos trabalhos de Vergara (1980), Ziesemer \& Kahn (1980), Costa (1987) e Kahn (1988), foi citada a presença de fosfatos amorfos de alumínio e ferro, wavelita, gorceixita e/ou goyazita em materiais intemperizados.

Kahn (1988) observou que os fosfatos supérgenos não apatíticos, detectados pela razão $\mathrm{CaO} / \mathrm{P}_{2} \mathrm{O}_{5}$, estão concentrados em frações menores que $0,037 \mathrm{~mm}$ do minério residual. Estes fosfatos supérgenos ocorrem mais freqüentemente em porçöes mais superficiais do perfil (tálus e capeamento estéril), não amostradas no presente estudo.

Segundo Ziesemer \& Kahn (1980) fosfatos de alumínio amorfos ocorrem nos níveis superficiais do solo (zona de tálus) e formam agregados muito finos impregnados por ferro.

Costa (1987), estudando um perfil intempérico desenvolvido sobre rocha ultrabásica através de amostras de um furo de sondagem, observou a presença de wavelita no horizonte intermediário, situado logo abaixo do horizonte de tálus.

\subsubsection{Juquiá}

\section{Localização}

O complexo alcalino-carbonatítico de Juquiá está localizado no sudeste do estado de São Paulo, no município de Registro, distando aproximadamente $170 \mathrm{~km}$ de São Paulo pela rodovia $\mathrm{Br}-116$. Suas coordenadas geográficas aproximadas são $47^{\circ} 42^{\prime}$ de longitude oeste e $24^{\circ} 24^{\prime}$ de latitude sul.

\section{Fisiografia, Clima e Vegetação}

O complexo está situado numa área denominada província Costeira na zona de morrarias costeiras (Almeida, 1964), caracterizada por um relevo de morrotes em meia laranja com altitudes médias entre 100 e $120 \mathrm{~m}$. O complexo destaca-se na paisagem com a elevação do morro do Serrote que atinge a altitude aproximada de $210 \mathrm{~m}$ (Figura 6). 

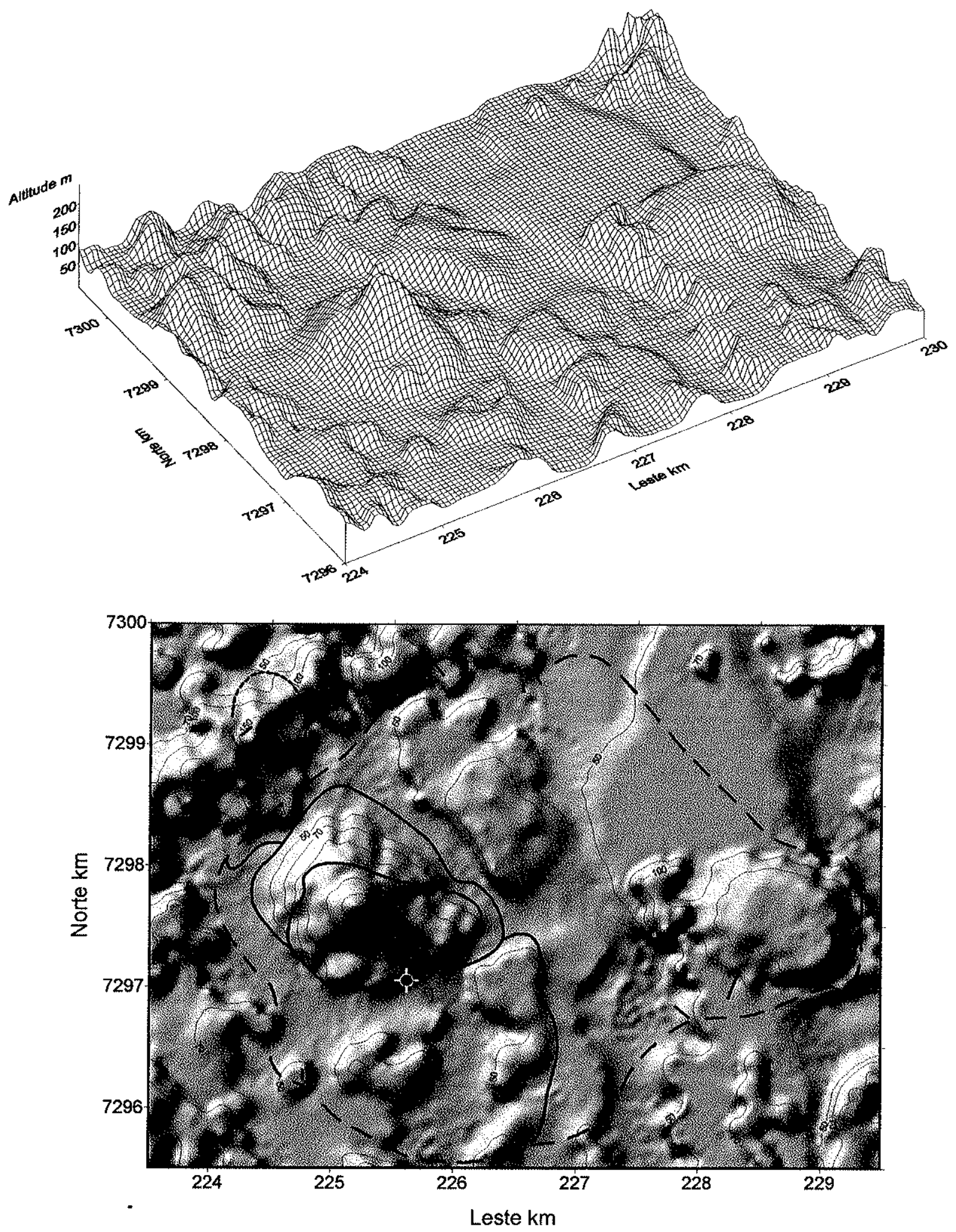

Figura 6 Superficie e mapa de sombras elaborados a partir do Modelo digital do terreno da área do Complexo alcalino-carbonatítico de Juquiá. Mapa base: Carta topográfica Folha SG-23-V-A-1-4, escala 1:50.000 (IBGE, 1974).

$1=$ frente de lavra de explotação
limites do maciço

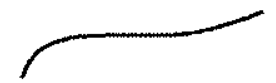
contato litológico
diques básicos 
O clima atual segundo Köppen é do tipo cfa (mesotérmico subtropical úmido sem estação seca, com verão quente). As temperaturas médias anuais são superiores a $20^{\circ} \mathrm{C}$ e a pluviosidade média anual varia entre $1300 \mathrm{~mm}$ e $1500 \mathrm{~mm}$ (Ponçano et al., 1981, apud Alcover Neto, 1991). A vegetação dominante na área é do tipo floresta perenifólia costeira (Lima 1966, apud IBGE, 1977).

\section{Geologia}

O complexo alcalino carbonatítico de Juquiá encontra-se intrudido nas rochas do embasamento pré-cambriano do Maciço de Joinville (Bistrichi et al. 1981, apud Alcover Neto, 1991), no setor do Complexo costeiro. Neste setor predominam rochas magmatíticas com xistos, anfibolitos, gnaisses, quartzitos e rochas calcossilicatadas que apresentam um aumento geral do grau do metamorfismo de NW par SW.

Datações pelo método KJAr em rochas do embasamento efetuadas por Born (1971) revelaram idades de mais de $650 \mathrm{Ma}$ (Pré-cambriano Superior). Hasui et al. (1981, apud Alcover Neto, 1991) considerou uma idade brasiliana para o Complexo Costeiro e uma gênese caracterizada por eventos policíclicos sobre rochas arqueanas.

Regionalmente, área é dominada por lineamentos NE-NW que segundo Algarte (1972, apud Ulbrich \& Gomes 1981) e Ferreira et al. (1981, apud Alcover Neto 1991) foram condicionados pelo fissuramento de Guapiara de direção NW, formando uma zona de fraqueza paralela ao Arco de Ponta Grossa. Próximo à intrusão de Juquiá, Born (1971) observou a presença de fraturas radiais e concêntricas com direções N2OW e N60E.

O Complexo Costeiro é parcialmente recoberto pelo sedimentos fanerozóicos indivisos, sendo algumas áreas de Juquiá cobertas por sedimentos pliopleistocênicos da Formação Pariquera-Açu definida por Bigarella e Mousinho (1965, apud Alcover Neto, 1991).

O Complexo alcalino-carbonatítico de Juquiá com rochas alcalinas datadas do Cretáceo Inferior (127 Ma segundo Amaral et al., 1967), pertence a um grupo de intrusões alcalino-carbonatíticas de idade média de $130 \mathrm{Ma}$. (Ulbrich \& Gomes, 1981) e faz parte da subprovíncia alcalina Guapiara (Ferreira et al., 1984, apud Alcover Neto, 1991) e da Província de Ponta Grossa (Almeida, 1983). Freqüentemente na região ocorrem diques de dioritos pórfiros e quartzo dioritos (Almeida, 1983). A idade destes diques giram em torno de 120 e $130 \mathrm{Ma}$ (Amaral et al., 1966 e Melfi, 1967, apud Alcover Neto, op. cit.). 
A estrutura do complexo é anelar e concêntrica, constituida por ijolitos e sienitos que cortam uma massa principal de rochas ultrabásicas. Todas as rochas contornam um núcleo de carbonatito (Figura 7) (Born, 1971 e Maciotta et al., 1988). $\mathrm{Na}$ região, o embasamento gnáissico é constituído por biotita, anfibólio, microclínio, andesina, oligoclásio e quartzo. Os minerais acessórios são: alanita epidoto, zircão, apatita e opacos indiscriminados. Estas rochas sofreram um metamorfismo regional de fácies anfibólio.

As circulações de fluidos quentes nas rochas do embasamento originaram fenitos no contato com a intrusão. Born (1971) menciona a raridade de afloramentos de fenitos na região. Os fenitos estudados por ele apresentaram uma quantidade muito restrita de minerais sódicos considerando a composição dos fluidos empobrecida em $\mathrm{Na}$ e a presença importante do $\mathrm{K}$. O autor sugere que a intrusão se deu de maneira muito rápida dificultando a formação de minerais típicos dos processos de fenitização.

Os piroxenitos dominam a superfície aflorante da intrusão de Juquiá e estão situados na periferia entre os ijolitos e o embasamento gnáissico e fenitos. Como minerais principais aparecem as olivinas que podem estar totalmente alteradas em serpentinas e piroxênios ( $40-80 \%$ ); dentre eles a augita é dominante, com menores proporções os hiperstênios e enstatitas. Ocorrem ainda magnetitas e andesinas. Como acessórios estão presentes a nefelina, apatita e perovskita.

Basicamente os ijolitos são compostos por aegerina-augita e nefelina. É comum a presença subordinada de magnetita, pirrotita, perovskita, calcita e cancrinita. Os dois últimos são formados a partir da alteração intempérica da nefelina.

Os sienitos encontram-se isoladamente no Morro Casa de Pedra e numa zona mais restrita do complexo (Figura 7). Sua composição mineralógica é homogênea, contendo ortoclásio, biotita, augita, aegirina, nefelina, cancrinita e calcita. Como minerais acessórios aparecem magnetita, ilmenita, pirrotita, apatita e zircão. A passagem de piroxenito a ijolitos é progressiva que é marcada pelo enriquecimento em nefelina.

O Complexo alcalino-carbonatítico de Juquiá é cortado por diques de composição feldspática ou lamprofirítica. Os diques cortam diferentes litologias como ijolitos e carbonatitos. 
O último termo da seqüência intrusiva é o carbonatito. Born (1971) através do estudo de furos de sondagem distinguiu dois tipos de carbonatitos: um interno de composição beforsítica rico em anquerita e com monazita hidrotermal; outro externo de composição beforsítica rico em apatita, micas e magnetita. $\mathrm{O}$ carbonatito externo apresenta zonas enriquecidas em pirocloro.

Walter (1991) considerou que as rochas aflorantes da intrusão representam um corte do conduto vulcânico. Melcher (1966, apud Born, 1971) estimou uma erosão de $1500 \mathrm{~m}$ do corpo rochoso da intrusão.

JUQUIÁ

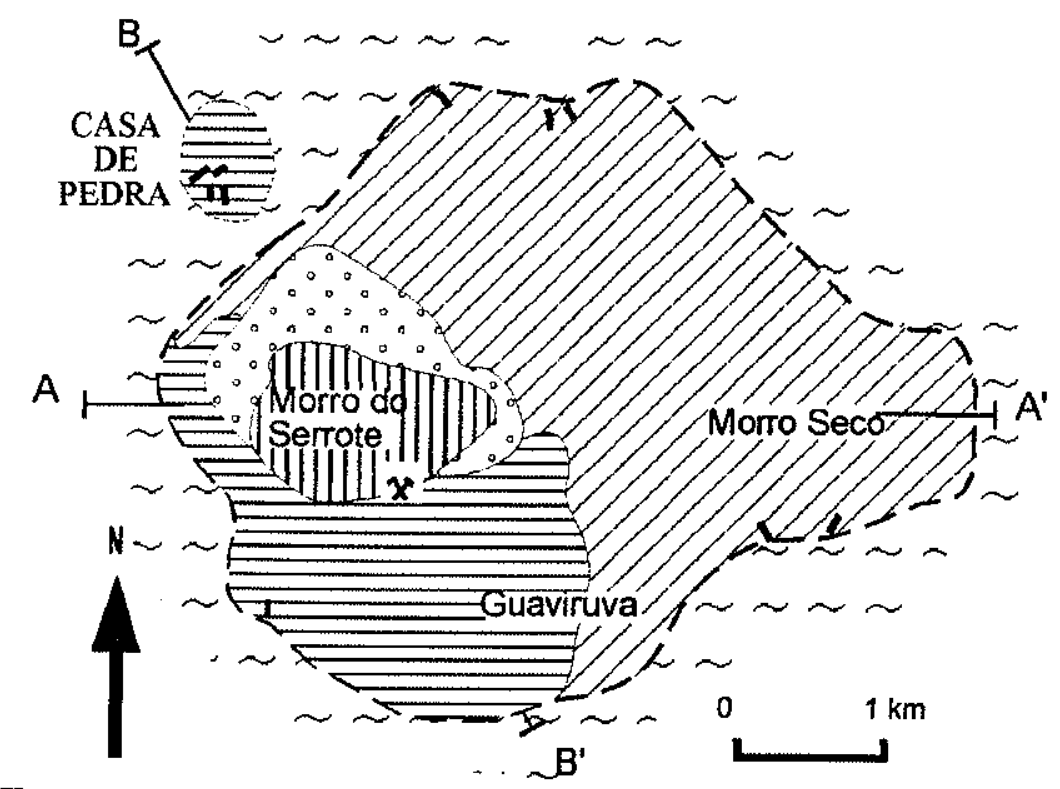

Manto de intemperismo

III] Mg-carbonatito

i. ljolitos, melteigitos e urtitos

Nefelina sienitos, essexitos e sienodioritos

Ol - clinopiroxenitos, clinopiroxenitos e ol-alcali gabros

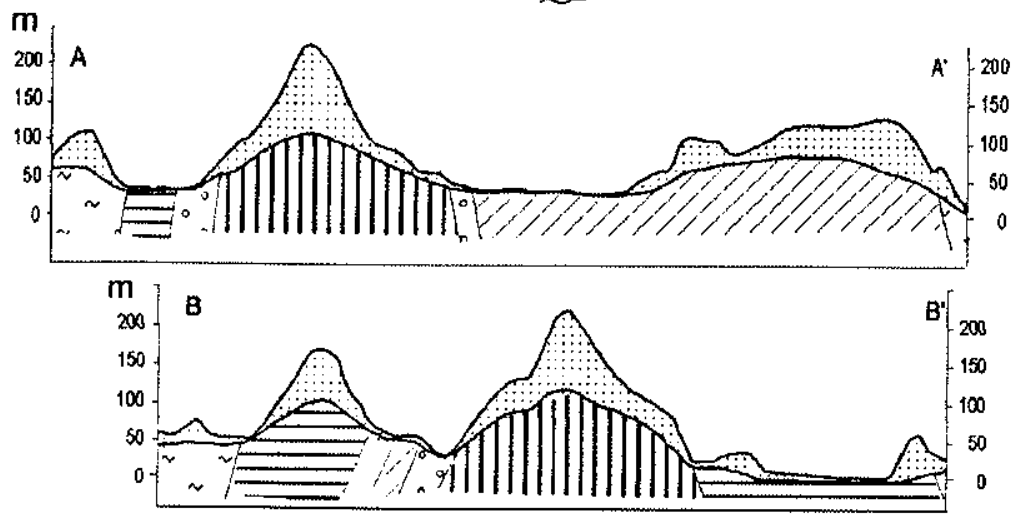

Embasamento gnáissico

Contato provável

Contato inferido

I

Diques fonoliticos e

ankaratriticos

Figura 7 Mapa geológico do Complexo Alcalino-carbonatítico de Juquiá (Born, 1971 e Macciotta et al., 1988).

\section{Manto de intemperismo}

O manto de intemperismo sobre o Morro do Serrote possui aproximadamente $50 \mathrm{~m}$ de espessura.

Segundo de Knetch \& Felicíssimo (1939), apud Alcover Neto (1991) o topo do Morro do Serrote é constituído de um material argiloferruginoso com eventuais 
concentrações de ferro e manganês. Em sua superfície são encontrados blocos milimétricos de material magnetítico poroso alterando para produtos ferruginosos supérgenos (goethita e hematita) compactos ou terrosos. Em materiais alterados observou-se a presença de concentrações de apatitas supérgenas.

Born (1971) observou diferenças mineralógicas e de teores em $\mathrm{P}_{2} \mathrm{O}_{5}$ no manto de intemperismo desenvolvido nos dois tipos de carbonatito. No carbonatito externo o manto apresenta minerais residuais como a magnetita, barita e pirocloro e interno. No carbonatito interno os minerais residuais encontrados no manto foram o quartzo, a magnetita e raros zircões. Óxidos de ferro e de manganês estão presentes em ambos os solos.

Manto de intemperismo desenvolvido sobre o carbonatito interno apresenta teor de $\mathrm{P}_{2} \mathrm{O}_{5}$ mais elevado ( $\left.14000 \mathrm{ppm}\right)$ do que nos mantos sobre carbonatitos externos (7500 ppm) e sobre rochas alcalinas (2500 ppm).

Walter (1991) estudou um perfil de alteração desenvolvido numa área de carbonatito externo. Em sua descrição reconhece no perfil de alteração dois horizontes e um solo de cobertura. O primeiro horizonte é formado pelo carbonatito são que é rico em apatita e dolomita. Os cristais de apatita marcam uma estrutura fluidal na rocha. No segundo horizonte o carbonatito se encontra muito alterado e observa-se uma maior porosidade deixada pela dissolução dos carbonatos. A estrutura fluidal é conservada em todo o perfil estudado levando o autor considerar a alteração isovolumétrica. As apatitas aparecem tanto preenchendo fissuras como depositadas em veios de barita que cortam o perfil.

Alcover Neto \& Toledo (1993) estudaram o manto de alteração desenvolvido sobre o carbonatito externo de Born (1971), rochas alcalinas silicatadas e a zona de transição entre estas duas rochas. Um perfil de alteração esquemático foi elaborado onde pode-se diferenciar quatro fácies: carbonatito em início de alteração, isalterita inicial, isalterita evoluída e zonas alteradas da transição entre o carbonatito e as rochas silicáticas alcalinas encaixantes. $O$ carbonatito são evolui para fácies isalteríticas tanto lateralmente como verticalmente.

Aqueles autores observaram junto aos materiais desenvolvidos sobre 0 carbonatito e as rochas alcalinas silicatadas a presença de materiais argilosos ricos em caulinita e goethita, e localizadamente crandallita e apatita. No topo do Morro do Serrote foi mencionada a presença de um solo com espessura que chega a mais de $10 \mathrm{~m}$ constituído por blocos ferruginosos endurecidos e fragmentos de couraça. Foi 
elaborado um perfil que mostra as subdivisões da isalterita do carbonatito, das rochas alcalinas silicáticas e da zona de transição. No início da alteração ocorre a dissolução parcial dos cristais de carbonatos primários, formação de óxidos e hidróxidos de ferro e manganês, precipitados nos espaços deixados pela dissolução de minerais primários, principalmente carbonatos e a formação de pseudomorfoses. Eventualmente calcita secundária pode precipitar em camadas com superfície brotrioidal, na base do perfil de alteração, localizadamente.

\section{Fosfatos de Juquiá}

Apatitas primárias

Apatitas primárias tratadas neste trabalho são as gerações formadas antes do intemperismo, podendo ter diferentes origens: magmáticas, tardi-magmáticas e hidrotermais. Estudo de bolsões de carbonatito externo inalterado revelou a presença de três tipos de apatitas primárias (Walter, 1991, Walter et al., 1990, 1995).

Apatita tipo - 1 (ou Ap)

É caracterizada por grãos ovóides agrupados (100 a $200 \mu \mathrm{m})$ muitas vezes formando uma textura em mosaico e por pequenos cristais (30 a $90 \mu \mathrm{m})$ com eixos alongados com a estrutura do fluxo magmático.

Estudos à microssonda efetuados por Walter (1991) revelaram que as apatitas primárias apresentam baixos teores de $\mathrm{Na}$ (em média $0,11 \%$ em óxido) e $\mathrm{Sr}$ (em média $0,51 \%$ em óxido) podendo apresentar em algumas análises pequenas quantidades de $\mathrm{Mg}$, $\mathrm{Fe}$, Al e $\mathrm{Mn}(0,05$ a 0,5\% em óxidos) e raramente $\mathrm{Ba}$ e $\mathrm{Pb}(0,1 \mathrm{a}$ $0,3 \%$ em óxidos). A apatita tipo - 1 apresenta um maior teor em ETRL com uma pequena anomalia negativa em $\mathrm{Ce}$ e um declínio acentuado de ETRP. Apatitas do tipo -1 apresentam a composição Sr-flúor-hidroxiapatita com baixo conteúdo de carbonato.

Esta geração de apatitas, ainda segundo Walter (1991), é contemporânea com à Fe-dolomita e cristalizou-se de um magma residual carbonatítico, portanto são magmáticas. Alcover Neto (1991) e Walter (1991) concordam que as apatitas de dimensões menores são posteriores às de dimensões maiores.

Lenharo (1994) analisando concentrados ricos em apatitas primárias, observou duas composições químicas distintas: hidróxi-fluorapatita com contribuição subordinada de $\mathrm{Sr}$ (rocha medianamente alterada) e hidróxi-Sr-fluorapatita (rocha pouco alterada). Os parâmetros cristalográficos a e $c$ médios obtidos para estas 
apatitas foram 9,39/6,89 e 9,38/6,89 respectivamente. Ao EIV as apatitas primárias apresentaram bandas de $\mathrm{CO}_{3}{ }^{2-}$ com baixa resolução e bandas do $\mathrm{OH}$ de forma bem definida.

As apatitas primárias de Juquiá podem apresentar feições de alteração. Walter (1991) observou ao MO a dissolução parcial da borda de maior birrefringência de apatitas primárias do tipo pavê da rocha alterada. Alcover Neto (1991) analisando apatitas primárias (tipo 1 e 2) alteradas ao microscópio eletrônico de varredura (MEV) pode diferenciar três formas de desestabilização: a) desmonte em ripas; b) dissolução localizada e c) dissolução generalizada formando um material muito poroso, tipo couve-flor de composição heterogênea, fosfática e ferruginosa. A variação da composição destas apatitas não foi estudada.

Apatita tipo - 2 (Aa)

É bem desenvolvida em algumas zonas do carbonatito e representa uma borda de espessura variável ao redor do núcleo de apatita tipo - 1 . Em geral quanto maior a espessura da borda, menor a área do núcleo da apatita; o limite entre a borda e o núcleo é brusco. Podem ocorrer em fraturas que atravessam o grão de apatita, apresenta características ópticas diferentes das do núcleo, atribuídas a defeitos ou diferenças de estrutura cristalina.

Esta borda, de maior birrefringência, é mais rica em Na (em média 2,25\%) e Sr (em média 1,15\%) que o núcleo do cristal de apatita; as diferenças químicas são bruscas ao longo do limite morfológico e óptico. Apresentam também um maior conteúdo em ETR do que as apatitas do tipo - 1 mostrando um enriquecimento em ETRP (Dy, Er e Yb). Walter (1991) classificou a apatita tipo - 2 como uma carbonatofluorapatita.

A apatita tipo - 2 está relacionada a um evento magmático tardio ou hidrotermal confirmado por dados isotópicos de oxigênio (Walter et al., 1995). Bordas em apatitas foram descritas por Hogarth (1989) e interpretadas como um sobrecrescimento que antecede o fraturamento da rocha.

Apatita tipo - 3

Outra apatita de ocorrência esporádica nas amostras estudadas por Walter (1991) e Walter et al. (1995), aparece em cavidades como uma fina camada (2 - 10 $\mu \mathrm{m}$ de espessura) sobrepostas às bordas de apatita tipo - 2. Esta camada de apatita 
possui a mesma morfologia e cor de birrefringência da borda (apatita tipo - 2 ) só que não apresenta a mesma orientação óptica desta.

Apresenta altos teores de $\mathrm{Sr}$ (em média 4,14\% de $\mathrm{SrO}$ ) comparados aos da apatita tipo - 2 (em média $1,15 \%$ de SrO) e da apatita tipo - 1, o conteúdo de $\mathrm{OH}$ e $\mathrm{CO}_{2}$ não foi determinado devido às suas dimensões reduzidas e escassez.

\section{Apatitas Supérgenas}

Três tipos morfológicos de apatitas supérgenas foram encontrados no perfil intempérico (Alcover, 1991): a) depósitos de apatita fibrosa em fraturas transminerais; b) cristais idiomórficos milimétricos (pirâmides hexagonais geminadas) sobre os depósitos brotrioidais e c) cristais prismáticos micrométricos vítreos de base hexagonal com aspecto de "geodo", sobre superfícies de fissuras.

Walter (1991) também identificou apatitas supérgenas em horizontes da base do perfil de alteração classificando-as em cinco tipos: Ag, Ar, At, Afm, Aft. As apatitas do tipo $\mathrm{Ag}$ crescem nas porosidades dos produtos ferruginosos e sobre os grãos de apatita tipo pavê com ou sem borda de maior birrefringência. As apatitas do tipo Ar são cristais retangulares finamente estriados com fibras paralelas entre si. As apatitas do tipo At são prismáticas e transparentes e ocorrem em espaços intersticiais da alterita. As apatitas do tipo Afm são fibrosas e de aspecto leitoso e revestem as paredes das cavidades. As apatitas do tipo Aft são prismáticas e transparentes e ocorrem sobre apatitas do tipo Afm. Além desses tipos, Walter (1991) descreveu um tipo de apatita pouco comum de aspecto esbranquiçado formando pequenas ilhas no material micáceo.

As apatitas supérgenas analisadas à microssonda eletrônica (ME) por Walter (1991) em geral mostraram uma composição química caracterizada por baixos teores de $\mathrm{Na}, \mathrm{Mn}, \mathrm{Si}, \mathrm{S}, \mathrm{Fe}$ e Al e teores mais significativos de $\mathrm{Sr}, \mathrm{Mg}$ e Ba que não se diferenciam muito entre os diferentes tipos morfológicos.

Lenharo (1994), estudando ao MO concentrados de apatitas identificou em quatro tipos de apatitas supérgenas: prismática hexagonal radial, microcristalina, criptocristalina e linhas de crescimento em grão de apatita. $O$ estudo à DRX permitiu diferenciar 3 espécies de apatitas supérgenas com valores de a e c comparáveis aos de variantes da carbonatoapatita referidas na literatura. A partir de análises químicas totais observou a presença de $\mathrm{Na}, \mathrm{Sr}$ e $\mathrm{CO}_{2}$ e subordinadamente de $\mathrm{Si}, \mathrm{Al}, \mathrm{Mg}, \mathrm{Mn}$ e $S$ nas espécies de apatitas supérgenas classificadas como $\mathrm{Na}$-Sr-carbonatoapatita e 
sílica-fluor-carbonatoapatita com $\mathrm{Sr}, \mathrm{Na}$ e Mg. Estas análises também revelaram um aumento do conteúdo em $\mathrm{CO}_{2}$ e uma diminuição do conteúdo em $\mathrm{P}_{2} \mathrm{O}_{5}, \mathrm{Sr}$ e ETR das apatitas supérgenas com relação às apatitas primárias. $O$ exame de apatitas ao MEVIEDS mostrou variações nos teores de ETR, Sr, Si, Al, Fe e Ti na região com linhas de crescimento sequenciais e paralelas. O estudo ao EIV mostrou que o grupo $\mathrm{OH}^{-}$está ausente ou ocorre de forma muito subordinada e o grupo $\mathrm{CO}_{3}{ }^{2-}$ ocorre de forma muito proeminente nos concentrados de apatita supérgenas. Em alguns destes concentrados houve $O$ desaparecimento das bandas fortes de $\mathrm{PO}_{4}$ que foi relacionada à substituição do $\mathrm{PO}_{4}$ pelo $\mathrm{CO}_{3}{ }^{2-}$ (carbonatoapatita tipo $\mathrm{B}$ ). $\mathrm{O}$ estudo por catodoluminescência revelou que as apatitas supérgenas hexagonais são reprecipitadas e que massas avermelhadas de oxihidróxidos que envolvem grãos de apatitas possuem espectro de emissão que sugerem origem hidrotermal, que pode indicar tanto uma nova variedade de apatita como o resultado de uma mistura que compõe o grão.

O estudo do comportamento dos elementos terras raras nas apatitas supérgenas fibrosas durante o intemperismo do fosfato (Walter, 1991 e Flicoteaux et al., 1990) revelou um empobrecimento em ETR, com um empobrecimento preferencial de ETRP com relação às apatitas primárias.

\section{Outros fosfatos}

Walter (1991) encontrou dois modos de ocorrência de gorceixita em bolsões de rocha alcalino-silicática alterada constituídos por ilhas de material apatítico e cortados por veios de barita. Um modo está associado a estruturas micáceas (pseudomorfose de flogopita) e outro ocorre junto a matriz rica em goethita formando pequenos glóbulos cinzentos à luz natural.

A DRX da matriz confirmou a presença de fosfatos da série da crandallita. Análises químicas destes fosfatos à microssonda, realizados pela mesma autora, revelaram a presença de $\mathrm{BaO}(13,85$ a $24,13 \%)$, $\mathrm{SrO}\left(0.2\right.$ a 3,12\%) e $\mathrm{Fe}_{2} \mathrm{O}_{3}(1,14$ a $14,89 \%), \mathrm{Al}_{2} \mathrm{O}_{3}(16,28$ a $32,19 \%)$. Alguns pontos analisados nas folhas de flogopitas substituídas apresentaram teores anômalos de $\mathrm{TiO}_{2}$ (atinge 28,66\%) nesses pontos o teor de $\mathrm{Al}_{2} \mathrm{O}_{3}$ é mais baixo $(16,28 \%)$. A composição destes fosfatos aliada aos dados de DRX permitiram classificar estes minerais como gorceixita.

A presença de gorceixita em pseudomorfos de flogopita é comum (Toledo, 1999) admitindo-se que a gorceixita seja formada a partir da dissolução da flogopita (fonte de $\mathrm{Al}$ ), das apatitas primárias (fonte de $\mathrm{P}$ ) e da barita (fonte de $\mathrm{Ba}$ ). 
Walter (1991) identificou minúsculas agulhas de wavelita preenchendo fissuras em toda a rocha alcalino-silicática alterada. Os cristais de wavelita recobrem tanto apatitas do tipo Ap e Aa como gorceixitas. Não foram feitas análises químicas para a wavelita tendo sido feita sua identificação por DRX. A wavelita origina-se da dissolução da flogopita e das apatitas (Ap, Aa e Ah) formando-se após a geração da gorceixita, em etapa sem participação do bário.

Alcover Neto (1991) observou a presença de fosfato de ETR secundário considerado como evolução direta da apatita primária. Walter (1991) e Alcover Neto (op. cit.) confirmaram em Juquiá a seqüência evolutiva geral apatita I $\rightarrow$ apatita II $\rightarrow$ fosfato Al proposta por Vieillard et al. (1979), Lucas et al. (1980), Flicoteaux \& Lucas (1984) e Schwab et al. (1989).

\subsubsection{Tapira}

\section{Localização e Fisiografia}

A jazida de fosfato de Tapira está situada a $35 \mathrm{~km}$ a sudeste de Araxá, no oeste do estado de Minas Gerais. Suas coordenadas geográficas aproximadas são $46^{\circ} 49^{\prime}$ de longitude oeste e $19^{\circ} 54^{\prime}$ de latitude sul.

É uma região dominada por altos platôs de altitudes médias de $850 \mathrm{~m}$ correspondentes a um peneplano que se formou no Terciário e vem sendo dissecado (Cruz e Cheney, 1976) (Figura 8). São cobertos por uma vegetação tipo cerrado e dominados por um clima atual do tipo tropical caracterizado por alternância de uma estação úmida (novembro - março) e uma estação seca o resto do ano. A pluviometria média anual é de $1400 \mathrm{~mm}$ e a temperatura média é de $22^{\circ} \mathrm{C}$.

\section{Geologia}

O Complexo alcalino-carbonatítico de Tapira faz parte da Província Alto Paranaíba (Almeida, 1983) com estruturas circulares que se alinham numa extensão aproximada de $1200 \mathrm{~km}$ na direção NW-SE. Ocorre encaixado em quartzitos do Grupo da Canastra (Barbosa et al., 1970). O corpo intrusivo tem forma subcircular, com um alongamento maior no sentido NS e possui diâmetro maior da ordem de 6 km (Figura 9).

A idade estimada pela datação K/Ar em biotitas de rocha ultrabásica foi de 70 Ma. (Hasui \& Cordani, 1968). A intrusão é a mais recente das aqui estudadas. Seu contato com as rochas quartzíticas encaixantes é vertical e irregular (Cruz \& Cheney, 1976). 

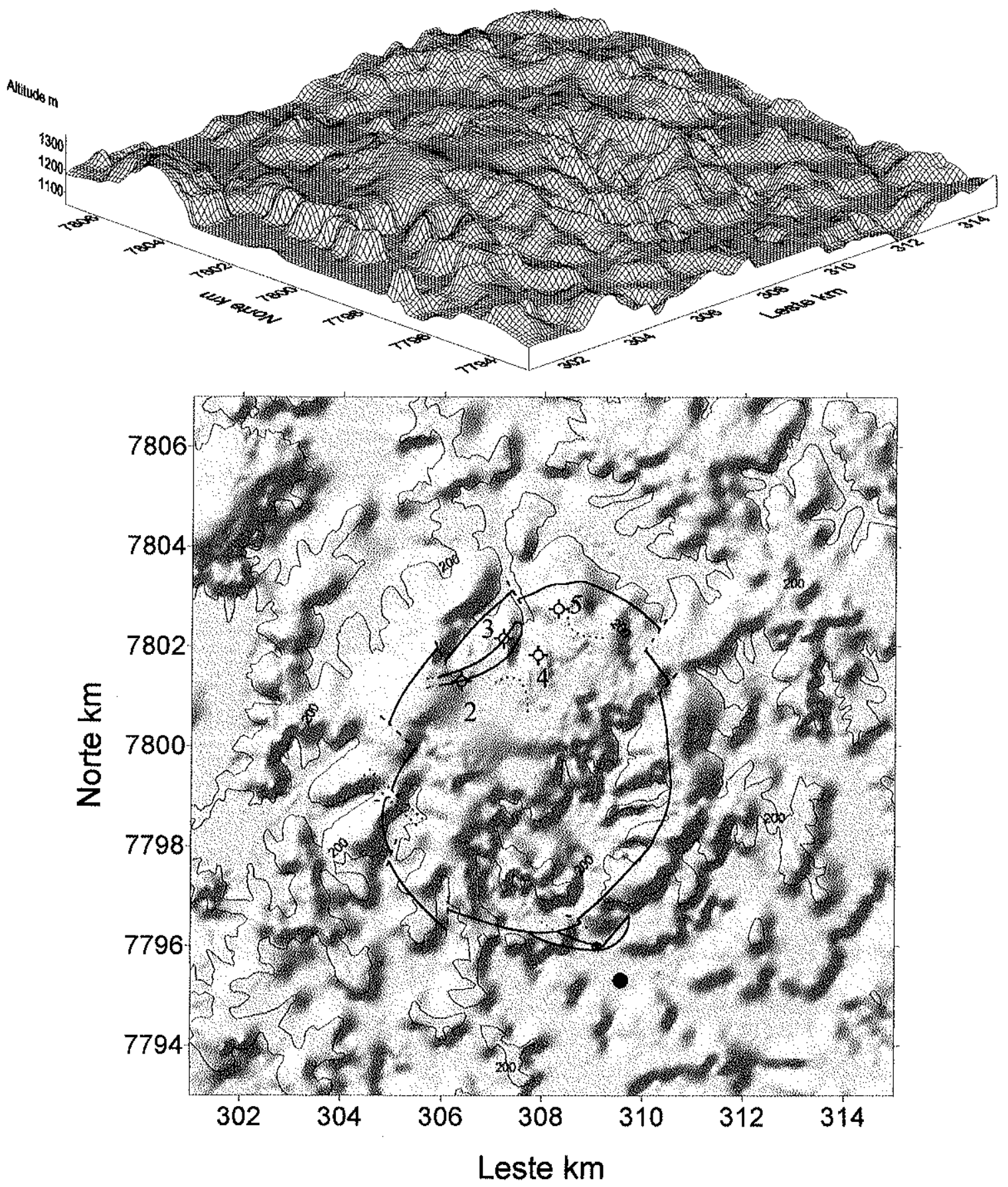

Figura 8 Superfície e mapa de sombras elaborados a partir do Modelo digital do terreno da área do Complexo alcalino-carbonatítico de Tapira. Mapa base: Carta topográfica Folha SE-23-Y-C-VI, escala 1:100.000 (IBGE 1970).

2,34 e 5 = frentes de lavra de explotação limites do maciço -' falhas contato litológico 
Não existe um mapa geológico detalhado da intrusão de Tapira; o primeiro mapa sintético foi publicado por Alves (1960, apud Heinrich, 1980). (Figura 9).

Segundo Cruz \& Cheney (1976) a intrusão é dominada por rochas ultrabásicas $(80 \%)$ em grande parte representadas por piroxênitos, seguidas por rochas alcalinas potássicas félsicas $(5 \%) \mathrm{com}$ predomínio de sienito e traquitos, e por fim carbonatitos sovíticos $(3 \%)$ e silexitos $(12 \%)$. As unidades litológicas são complexas havendo gradações que dificultam a separação, assim, os autores optaram por construir mapas de isoporcentagens mineralógicas ao invés de mapas geológicos. A granulometria das rochas do complexo varia de muito fina a grosseira.

As rochas ultrabásicas apresentam piroxênio ou olivina como minerais principais e magnetita, apatita, perovskita, melanita, biotita, flogopita, calcita, pirita e ilmenita como acessórios. Perovskita, apatita, magnetita e biotita podem ocorrer em segregações quase monominerálicas ou em rochas com dois ou três destes minerais. Dominantemente os piroxenitos contêm o diopsídio augítico e os dunitos a forsterita; algumas destas rochas têm composição próxima de foscoritos do tipo de Palabora na África do Sul (Cruz \& Cheney, 1976). Podem ainda ocorrer peridotitos que são termos entre os piroxênitos e os dunitos.

As rochas ultrabásicas são cortadas por bolsões de silexitos e corpos de carbonatito. Os silexitos são interpretados por Cruz \& Cheney, (1976) como sendo relacionados a zonas de silicificação, com a deposição da calcedônia, a partir de soluções ricas em sílica provenientes da solubilização dos silicatos, os autores não especificam os ambientes. em que se deram estes processos. Soubiès et al.(1990 e 1991) e Heinrich, (1980) observaram que o fenômeno de silicificação não seria meteórico, mas seria contemporâneo à colocação dos corpos de carbonatito. Os carbonatitos são sovíticos com mais de $90 \%$ de calcita em forma de veios ou massa contínua. 


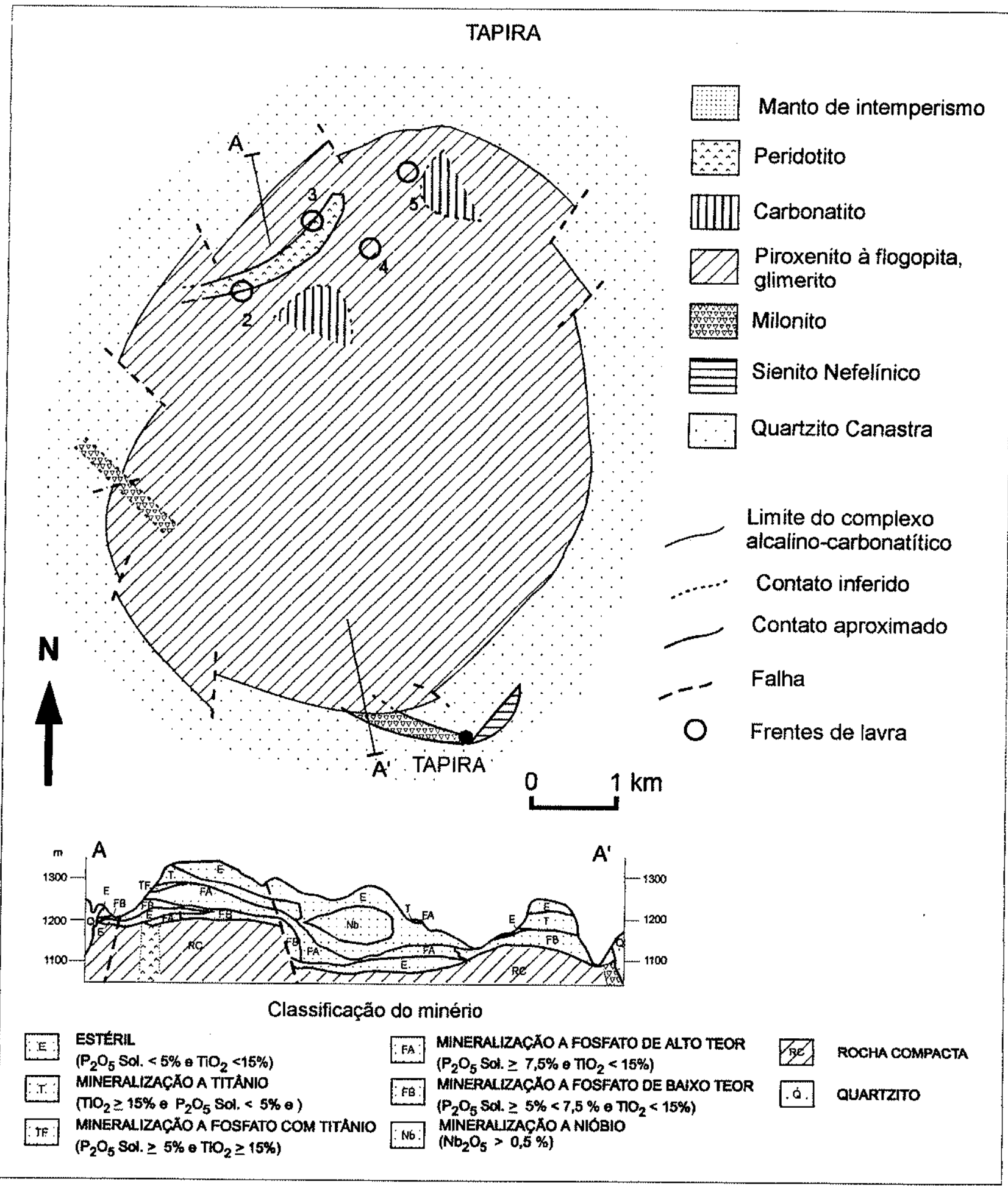

Figura 9 Mapa geológico do Complexo Alcalino-carbonatítico de Tapira (Alves, 1960, apud Heinrich, 1966).

\section{Manto de intemperismo}

O manto de intemperismo atinge uma profundidade de $200 \mathrm{~m}$ com médias de $90 \mathrm{~m}$. O intemperismo de rochas ultramáficas deu origem depósitos residuais de apatita, de pirocloro e de anatásio. 
A gênese da jazida é considerada como o resultado de enriquecimento supérgeno causado pela alteração intempérica de rochas ultramáficas anomalamente enriquecidas em titânio e fósforo (Grossi-Sad \& Torres, 1971, Cruz \& Cheney, 1976, Lindenmayer, 1978 e Vaz de Melo, 1983). O processo de mineralização foi desenvolvido a partir do Terciário e favorecido por um clima tropical, pela estrutura bem fraturada e pela heterogeneidade da rocha matriz e da granulometria (Cruz \& Cheney, 1976). Por outro lado acredita-se que também a erosão mecânica tenha sido limitada não prejudicando as acumulações minerais (Lindenmayer, 1978 e Soubiès et al., 1991).

Foram diferenciadas cinco zonas no manto de intemperismo correlacionadas ao grau de intemperismo, em ordem crescente de profundidade: capeamento estéril, minério de titânio, minério de titânio e fosfato, minério de fosfato e rocha estéril parcialmente intemperizada (CBPM, 1984 e DNPM, 1984, apud Cruz \& Cheney, 1976). Estas zonas foram delimitadas pelos teores de $15 \%$ para $\mathrm{TiO}_{2}$ e $5 \%$ para $\mathrm{P}_{2} \mathrm{O}_{5}$. Sucessivamente foram observadas do topo para a base:

zona latossólica: $20 \mathrm{~m}$ de espessura, estrutura pedológica e textura argilosa, constituída dominantemente por caulinita, goethita, gibbsita, hematita, fosfatos aluminosos secundários e anatásio. Pode apresentar um nivel concrecionário tipo carapaça em profundidade. Esta zona foi classificada como estéril $\left(\mathrm{P}_{2} \mathrm{O}_{5}\right.$ solúvel < $5 \%$ e $\mathrm{TiO}_{2}<15 \%$ )

zona rica em titânio: $40 \mathrm{~m}$ de espessura e estruturas originais da rocha parcialmente preservadas. Segue a mineralogia da zona latossólica, porém com maior riqueza de anatásio amarelado e uma fração fina mais restrita. As micas aparecem transformadas em vermiculitas e um pouco de perovskita é ainda observada $\left(\mathrm{P}_{2} \mathrm{O}_{5}\right.$ solúvel $<5 \%$ e $\left.\mathrm{TiO}_{2} \geq 15 \%\right)$.

zona rica em titânio e fosfato: $15 \mathrm{~m}$ de espessura, podendo estar ausente na frente da lavra. As estruturas originais são bem preservadas. Zona rica em apatita primária, parcialmente dissolvida associada a perovskita quase toda alterada para anatásio. Também estão presentes as micas em grande parte vermiculitizadas e a magnetita titanifera parcialmente alterada em maghemita ou hematita $\left(\mathrm{P}_{2} \mathrm{O}_{5}\right.$ solúvel $\geq 5 \%$ e $\mathrm{TiO}_{2} \geq 15 \%$ ).

zona rica em fosfato: Com cerca de $80 \mathrm{~m}$ de espessura em contato com a rocha fresca, é constituída por piroxenitos e peridotitos intemperizados. Ocorrem principalmente apatitas e perovskitas frescas, magnetita titanifera, olivina 


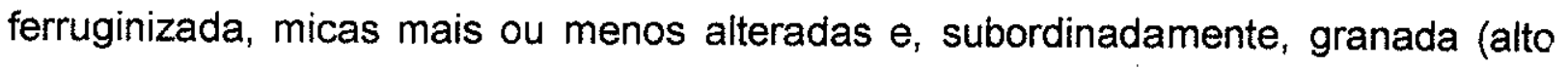
grau de mineralização: $\mathrm{P}_{2} \mathrm{O}_{5}$ solúvel $\geq 7,5 \%$; baixo grau de mineralização: $\mathrm{P}_{2} \mathrm{O}_{5}$ solúvel $\geq 5$ e $<7,5 \%$, em ambas $\mathrm{TiO}_{2}<15 \%$ ). Os setores silissificados são comuns nesta zona e os veios de carbonatito se concentram nas proximidades da rocha fresca.

Soubiès et al. (1991) caracterizaram diferentes estágios no processo de alteração. No estágio inicial ocorrem, nesta ordem: 1. dissolução parcial da apatita ao longo de fraturas e neoformação de apatita supérgena; 2. transformação total (pseudomorfismo) da perovskita para anatásio microbotrioidal; 3. formação de geodos de fosfatos da família do rhabdofânio nas cavidades da estrutura microbotrioidal no anatásio e 4. evolução destes fosfatos secundários para gorceixita e florencita, os quais podem invadir os anatásios substituindo-os ou então precipitar no plasma ferruginoso, em vias de formação. Soubiès et al. (1992) relacionou os três primeiros eventos deste estágio a uma alteração de hidrotermal e o quarto a uma alteração supérgena.

Num estágio mais evoluído ocorrem: 1. Argilização, formando uma alterita grossa com predomínio de argilo minerais do tipo 2/1 (esmectitas, interestratificados vermiculita-esmectita) e de goethita associados à caulinita, cujos teores aumentam na alterita fina (topo), 2. desestabilização do anatásio, que desaparece no topo da alterita, 3. dissolução da apatita, ausente já na base da alterita, e 4. neoformação de uma série de fosfatos aluminosos sendo a crandallita (mineral mais rico em alumínio) dominante nos horizontes do latossolo. Junto ao plasma ferruginoso Soubiès et al. (1992) identificaram um fosfato de escândio, kolbeckita $\left(\mathrm{ScPO}_{4} \cdot \times \mathrm{H}_{2} \mathrm{O}\right)$, cuja filiação não pode ser muito bem estabelecida.

Os mesmos autores reconheceram que durante os processos de intemperismo, Ti, ETR e $P$ são fixados e $\mathrm{K}, \mathrm{Na}, \mathrm{Mg}$ e Ca são lixiviados. Logo no início da alteração observa-se uma forte associação entre o ETR e Ti em diferentes escalas. Inicialmente ETR fixado na perovskita e posteriormente nos fosfatos de ETR formados junto ao anatásio pseudomórfico sobre a perovskita. Nos materiais mais evoluídos a riqueza de $\mathrm{Ca}$ e aluminização progressiva do meio reflete na natureza dos minerais de terras raras neoformados: $1^{0}$ estágio: fosfato de ETR não aluminoso

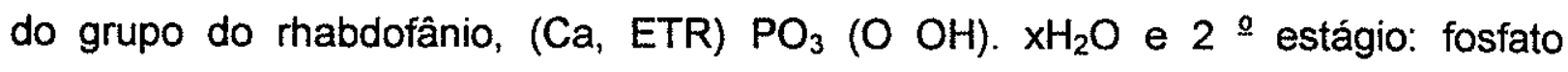
aluminoso com ETR da série da crandallita, de composição entre a florencita e a crandallita, (Ca, ETR) $(\mathrm{Al} \mathrm{Fe})_{3}\left(\mathrm{PO}_{4}\right)\left(\mathrm{PO}_{3}\right)(\mathrm{OH})(\mathrm{OH})_{6}$. 
Melfi et al. (1991) e Soubiès et al. (1991) observaram a seguinte seqüência evolutiva para os fosfatos no manto de intemperismo: apatita $1^{\text {ária }} \rightarrow$ apatita $2^{\text {ária }} \rightarrow$ rhabdofânio calcífero $\rightarrow$ florencita calcífera.

Vieira (1997) estudando furos de sondagens efetuou análises químicas globais e MO em 118 amostras, observaram que os teores de $P$ tendem a diminuir nos níveis mais altos do perfil. $O$ aumento de $P$ geralmente é acompanhado pelo aumento $\mathrm{Ca}$ e está relacionado a formação de apatita supérgena e fosfatos crandalíticos. A apatita só foi encontrada em profundidades maiores do que $41 \mathrm{~m}$, os minerais associados foram: 41,1 e 72,10 m, material alterado, está associada a hidróxidos de $\mathrm{Fe}^{3+}$ e $\mathrm{Mn}^{4+}$, vermiculita, argilo minerais, magnetita, ilmenita, anatásio e barita, 72,1 e 133,7 m, material pouco alterado, vermiculita, magnetita, ilmenita, perovskita, piroxênio, anfibólio e carbonato, abaixo de $134 \mathrm{~m}$, rocha fresca, piroxênio, perovskita, flogopita, magnetita, carbonato e sulfeto.

\section{Fosfatos de Tapira}

\section{a) Apatitas primárias}

Soubiès et al. (1991) observaram que as apatitas primárias apresentam valores com totais de óxidos analisados à ME menores que $100 \%$; este fato foi em parte atribuído à abundância de inclusões fluidas no mineral ou, mais provavelmente, à presença de elementos não analisados. Um cálculo sobre a base $5(\mathrm{Ca}+\mathrm{Na}+\mathrm{Sr})$ indica 2,9 $(\mathrm{P}+\mathrm{Si})$ por malha do mineral ao invés de 3 . Como o $S$ não foi detectado é provável que a substituição $\left(\mathrm{CO}_{3}{ }^{2-} \mathrm{OH}\right) \rightarrow\left(\mathrm{PO}_{4}\right)$ possa ocorrer. Apatitas apresentam um déficit no sítio do ânion monovalente, com $3,1 \%$ em $\mathrm{F}$ e $0,001 \%$ em $\mathrm{Cl}$, sugerindo outra substituição na fluorapatita, a presença de $\mathrm{OH}^{-}$neste sítio, o que teria contribuído para os totais baixos.

Segundo estes autores, em Tapira, a apatita primária na rocha alterada apresenta aproximadamente a mesma composição do que as apatitas na rocha fresca, e são classificadas como uma flúor-hidróxi-carbonatoapatita.

Segundo Lenharo (1994) as apatitas primárias de concentrados de Tapira apresentam hábito granular e subordinadamente prismático, com superfície lisa ou irregular marcadas por sulcos e estrias de dissolução, originando um aspecto mamelonar. Estas apatitas podem apresentar inclusões (não discriminadas).

Cremillion et al. (1975) estudaram concentrados de apatitas de rochas fosfáticas de Tapira cujos resultados de análises químicas globais mostraram que 
todas as apatitas são do tipo carbonato-flúor-hidroxiapatita, $\mathrm{Sr}$ e $\mathrm{Na}$ parcialmente substituindo o cálcio; e o carbonato parcialmente substituindo $\left(\mathrm{PO}_{4}{ }^{3-}\right)$ e/ou $\left(\mathrm{OH}^{-}\right)$. Os dados de DRX mostraram parâmetros a e $c$ situados entre a fluorapatita e a hidroxiapatita. Análises à EIV revelaram a presença de $\mathrm{OH}^{-}$em substituição ao $\mathrm{F}^{-}$e a ocorrência de carbonato substituído tanto no sítio $\mathrm{PO}_{4}{ }^{3-}$ como no sítio dos halogêneos. Isto parece inédito para apatitas minerais pois a presença de $\mathrm{CO} 3$ no sítio dos halogênios na estrutura da apatita só é encontrada em materiais sintéticos ou materiais biológicos. Os parâmetros cristalográficos a e $c$ médios dos concentrados apatíticos estudados são 9,402 $\AA$ e $6,889 \AA$ respectivamente.

b) Apatitas secundárias (de alteração hidrotermal)

Cruz et al., 1975 já apontavam a presença de apatitas secundárias na periferia de grãos de apatita primária, sem contudo analisá-las quimicamente e propor uma origem para estas. Soubiès et al. (1991) identificaram apatitas microfibrosas que ocorrem como fibras orientadas perpendicularmente às paredes dos vazios, formando camadas sucessivas de fibras, foram relacionadas a um estágio inicial de alteração intempérica. Segundo Soubiès et al. (1992) a dissolução parcial das apatitas primárias e precipitação da apatita secundária estariam relacionadas à intensa alteração hidrotermal que precedeu à alteração meteórica.

Análises à ME destas apatitas apresentadas por Soubiès et al. (1990 e 1991) revelaram um empobrecimento em ETR, Si e Sr e um enriquecimento em flúor em relação às apatitas magmáticas. Os cálculos de fórmula estrutural, sobre a base $26(\mathrm{O}, \mathrm{F}, \mathrm{Cl}, \mathrm{OH})$, revelaram excesso de flúor ( $3,099 \mathrm{pfu})$, o que foi explicado pela possivel presença de fluorita entre as fibras de apatitas ou menos provável pela presença de flúor na estrutura aniônica ( $F$ substituindo $O$ ). Cabe aqui ressaltar a possibilidade de um teor de flúor superestimado durante a análise, que ocorre quando não se considera a sobreposição da raia $L \alpha$ do fósforo com a raia $K \alpha$ do flúor. Como o $\mathrm{P}$ está muito próximo da apatita teórica $(6,037 \mathrm{pfu})$ foi descartada a presença de $\mathrm{CO}_{3}{ }^{2-}$ na estrutura desta apatita. Cálculos com base na soma de cátions no sítio do cálcio fixada em 10 pfu resultaram em valores de $F(3,24 \mathrm{pfu})$ e de $P(5,58 \mathrm{pfu})$ próximos aos obtidos por Soubiès et al. (op. cit.).

Segundo os autores, a formação de apatitas ricas em flúor poderia estar ligada a processos hidrotermais através de uma reação de hidrólise entre a apatita primária e soluções fortemente acidas ou alcalinas. 
Lenharo (1994) identificou três tipos de apatitas secundárias: em prismas radiais, microcristalinas e criptocristalinas. Os cálculos de parâmetros de cela unitária da apatita supérgena em amostras mistas (apatitas supérgena e primária), foram considerados pouco precisos $(a=9,371 \pm 0,001 \AA$ e $c=6,873 \pm 0,002 \AA$, em média). Observou-se uma diminuição nos valores destes parâmetros com relação aos encontrados para as apatitas primárias $(a=9,406 \pm 0.001 \AA$ e $c=6,892 \pm$ $0,001 \AA$ em média). $O$ quimismo dos concentrados ricos em apatitas secundárias não mostraram nenhum enriquecimento relativo. Análises químicas, DRX e EIV efetuadas em concentrados apatíticos de materiais alterados mostraram que 0 ín carbonato possivelmente está associado às apatitas secundárias.

c) Outros fosfatos

Cruz et al. (1975) observaram que a apatita sofre uma dissolução e é progressivamente substituída por fosfatos aluminosos da série da crandallita. Materiais relacionados a um estágio mais avançado de intemperismo apresentaram agregados finos crandalíticos preenchendo cavidades em cristais de anatásio.

Soubiès et al. (1991) identificaram, junto à fácies final de alteração (zona 2 rica em titânio), cristais de fosfatos aluminosos da série da crandallita de composição química intermediária entre a crandallita e a florencita. Caracterizam-se pela justaposição de cristais romboédricos $(5 \mu \mathrm{m})$ com seções triangulares e de coloração acinzentadas (LN e LP). Eles ocorrem tanto em vazios como ao redor dos cristais de anatásio e em certos poros do plasma ferruginoso como incrustações cristalinas rendadas. Para os cálculos de fórmula estrutural, ○ $\mathrm{Ti}$ e $\circ \mathrm{Si}$ foram considerados como pertencentes ao anatásio, a dosagem do Ba considerada incerta e parte do Al foi atribuída a presença de alumínio amorfo ou gibbsita (não detectadas no estudo). Os autores admitem a hipótese deste mineral pertencer à família de minerais chamados de "crandallita triclínica" definidos por Cowgill \& Hutchinson (1963) e Blount (1974). A DRX efetuada em misturas (fosfato aluminoso da série da crandallita + anatásio + fosfato do grupo do rhabdofânio) mostram mostraram espectros característicos da florencita mas não foram considerados de boa qualidade para garantir a identificação do mineral.

O rhabdofânio foi identificado por Soubiès et al. (1991) concentrado na fácies intermediária zona 3 - rica em titânio e fosfato) em descontinuidades internas a de cristais de anatás:o. Foram descritos como cristais aciculares minúsculos $(\sim 10 \mu \mathrm{m}$ de comprimerto) arranjados em feixes, de coloração amarelo-esverdeada (LN), 
birrefringência baixa e extinção reta. Segundo Soubiès et al. (1992) estes rhabdofânios seriam formados durante a alteração hidrotermal que afetou parte das rochas do complexo de Tapira.

As análises dos cristais de rhabdofânio revelaram riqueza em Ca e ETR, ausência quase total de $U$ e Th, diferenciando o rhabdofânio de Tapira de outras espécies de rhabdofânio.

\subsubsection{Evolução paleoclimática}

Levando em consideração que muitos dos processos de gênese dos perfis lateríticos podem ser influenciados pelo clima, foram levantadas da literatura algumas informações sobre a evolução paleoclimática das áreas de estudo.

A literatura que aborda a evolução paleoclimática no Brasil é baseada em modelos qualitativos derivados de concepções lógicas da interação de fenômenos que condicionam os elementos climáticos; interpretação de depósitos não datados que identificam processos relacionados a determinadas condições climáticas; ou de uma malha ainda pouco densa de informaçōes datáveis que indicam condições climáticas pretéritas.

$\mathrm{Na}$ última década, alguns autores começaram a associar a gênese de formações lateríticas com mudanças climáticas desencadeadas pela deriva dos continentes. BARDOSSY \& ALEVA 1990, foram os primeiros a explorar esta linha de raciocínio, seguidos pelos trabalhos de TARDY et al. 1991, e TARDY e ROQUIN 1998. Estes autores utilizaram os mapas qualitativos de paleoprecipitação de PARRISH et al. 1982, elaborados a partir de reconstruções paleocontinentais e informações paleogeográficas. Os modelos assumem que durante o Cenozóico e o Mesozóico, a circulação atmosférica não era radicalmente diferente de sua configuração atual; assim, adota padrões de distribuição de temperatura e precipitação pluviométrica semelhantes aos atuais, mas adaptados as condiçōes paleogeográficas (posição latitudinal, proximidade do oceano e altitude) da época analisada.

Utilizando estes modelos, TARDY et al.1991, fazem uma primeira aproximação da distribuição dos ambientes favoráveis a formação de bauxitas (clima tropical com zonas muito úmidas) e ferricretes (clima tropical, relativamente menos úmido e com estações contrastantes) na América do Sul. De acordo com os mapas apresentados pelos autores, a partir do Eoceno Médio, a regiāo de Tapira ficou numa zona 
favorável a formação de ferricretes. Na mesma época, as regiões de Juquiá e Anitápolis, ficaram expostas a um ambiente favorável a formação de bauxitas.

Em 1998, Tardy e Roquin publicam uma nova aproximação. Segundo os mapas apresentados pelos autores, a partir do Eoceno Médio, todas as áreas estudadas (Tapira, Juquiá e Anitápolis) ficaram expostas a um clima favorável a formação de ferricretes. Os mapas mostram que ferricretes estavam em formação mesmo na zona equatorial e na margem atlântica, conseqüência de um clima global muito quente. Bauxitas só estavam em formação nas zonas mais altas com climas relativamente mais frios.

Segundo os modelos apresentados, atualmente as regiōes de Tapira e Anitápolis não favorecem a formação nem de bauxitas nem de ferricretes, apenas Juquiá possui condições climáticas favoráveis a formação de bauxitas.

Não é objetivo deste trabalho elaborar modelos paleoclimáticos, no entanto, algumas consideraçōes devem ser feitas a respeito da segunda aproximação apresentada por Tardy e Roquin. Segundo BERNER et al. (1983), baseados nos trabalhos de MANABE \& STOUFFER (1980) e BUDYKO (1977), o aumento da temperatura global deve trazer uma alteração de todo o ciclo hidrológico, aumentando a drenagem continental (consequencia do aumento da precipitação). A relação entre a temperatura e a drenagem também foi identificada por PROBST \& TARDY (1989) em grandes bacias hidrográficas do globo. Levando em conta estas considerações, generalizar a formação de ferricretes em função de uma temperatura global elevada é arriscada, visto que os modelos globais apontam para um aumento das precipitações. BARDOSSY \& ALEVA 1990 mostram em seu trabalho, que não existe um consenso a respeito de uma temperatura máxima que limite a formação de bauxitas, as limitações estão sempre associadas a déficits hídricos. Sendo assim, a primeira aproximação elaborada pelos autores é mais coerente.

Durante o Quaternário, alternâncias entre períodos de biostasia e resistasia transformaram as paisagens estabelecidas no Terciário Superior. O clima semi-árido permitiu a expansão da caatinga em direção a diversos compartimentos dos planaltos intertropicais brasileiros, em áreas hoje dotadas de matas ou cerrados, predominavam formações vegetais abertas (Ab'Saber 1977). Segundo o autor, as variações climáticas quaternárias associadas a baixas temperaturas e umidade, desencadearam mudanças agressivas de processos morfogenéticos que foram capazes de destruir paisagens estabelecidas no Terciário Superior. Aos períodos de 
Biostasia sucederam-se períodos de resistasia, alternando-se portanto, sistemas morfoclimáticos de longa duração com sistemas de degradação rápida. O clima semi-árido permitiu a expansão da caatinga em direção a diversos compartimentos dos planaltos intertropicais brasileiros. Em seu trabalho, o autor elaborou um mapa das condições ambientais dominantes na América do Sul entre 18.000 e 13.000 anos.

Depois de Ab'Saber, Clapperton (1993) elaborou uma síntese do Quaternário continental na América do Sul e chegou a um mapa quase idêntico ao do autor brasileiro. Para Clapperton, embora algumas evidências estratigráficas datáveis indiquem que durante o máximo glacial do Quaternário ocorreu uma grande expansão de climas áridos na América do Sul, os cenários fisiográficos continentais propostos por Ab'Saber (1977) e por ele, são em grande parte especulativos. Considerando os mapas propostos pelos autores, regiōes de cerrados com enclaves de caatinga formavam a paisagem dominante na região de Tapira. Áreas semiáridas com caatingas e floras similares (com cactáceas) dominavam as paisagens de Juquiá e Anitápolis. Estas paisagens evoluiam para cenários parecidos com o atual durante os interglaciais.

Considerando os parágrafos anteriores, podemos estabelecer uma possível seqüência evolutiva para as áreas de estudo. Durante o Eoceno Médio, a região de Tapira esteve numa zona de clima tropical contrastante (estação seca e estação úmida) onde os processos de lateritização favoreciam a formação de ferricretes. Não sabemos se estas condiçōes prevaleceram em seguida, no entanto, durante as glaciações do Quaternário, processos de lateritização foram interrompidos por períodos mais frios e secos. Nestes períodos, onde a vegetação mais aberta recobria o solo, as formações lateríticas (pretéritas) foram remobilizadas pela erosão.

A seqüência não é muito diferente para as regiões de Juquiá e Anitápolis. Durante o Eoceno Médio, as regiões foram submetidas a um clima tropical úmido favorável a formação de bauxitas. Em Juquiá, estas condições devem ter sido preservadas mesmo após o Eoceno Médio. A partir das glaciações Quaternárias, períodos áridos e frios impediram o desenvolvimento dos perfis, e devem ter erodido parte dos mantos de alteração formados anteriormente.

Um fato registrado por BARDOSSY \& ALEVA 1990, permite algumas considerações a respeito da presença de ferricretes em perfis lateríticos. Segundo 
os autores, experiências em áreas de mineração têm mostrado que onde a cobertura florestal foi retirada, em cerca de 40 a 50 anos, até 1 metro de crosta ferruginosa (duricrust) pode ser formada sobre perfis bauxíticos, o processo de endurecimento é irreversível e leva à posterior destruição da vegetação. Considerando este fato, pode-se admitir, que a presença de fragmentos de couraças observados em perfis nas áreas de estudo, podem ter sua origem nas alternâncias entre períodos de biostasia e resistasia ocorridos no Quaternário. Neste caso, na transição de um período de resistasia (frio e seco com cobertura vegetal aberta) para um período de biostasia (quente e úmido propiciando a instalação de uma cobertura florestal), remanescentes de coberturas lateríticas poderiam formar ferricretes. 


\section{Método}

Alguns procedimentos foram adotados para se caracterizar as fases fosfatadas presentes no manto de intemperismo e obter dados para as interpretações genéticas dos materiais. Numa primeira etapa foi feito um estudo da bibliografia obtendo-se informações contidas em trabalhos anteriores nos mantos intempéricos dos complexos estudados. Estes estudos serviram de base para a seleção dos materiais a serem estudados na ótica dos estudos micromorfológicos, utilizando-se de técnicas como a microscopia óptica (MO), microscopia eletrônica de varredura (MEV), microssonda eletrônica (ME) e catodoluminescência (CL) em materiais indeformados.

O estudo de amostras indeformadas é muito importante para o entendimento dos fenômenos de alteração e de neoformação observados no ambiente laterítico. Os procedimentos adotados no estudo estão representados na Figura 10.

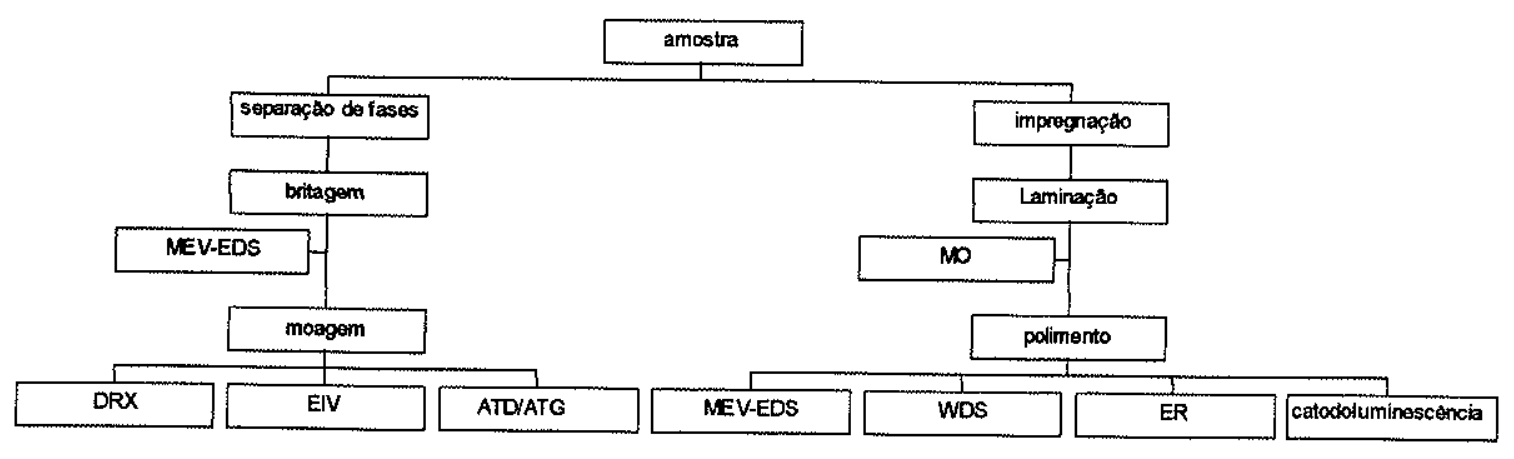

Figura 10 Esquema dos procedimentos analíticos adotados

O exame ao MO e ao MEV permitiu a seleção dos materiais para a caracterização mineralógica e evolutiva das fases fosfatadas. Foi priorizada a utilização de técnicas analíticas microlocalizadas como a ME e microespctroscopia Raman (MR), importantes para as determinaçöes de amostras com minerais muito finos e heterogêneos comumente encontrados nos materiais estudados. Técnicas analíticas globais como a espectroscopia ao infravermelho (EIV) foram aplicadas somente em amostras puras.

A difratometria de raios- $X$ foi útil na seleção dos materiais, identificação das fases mineralógicas e no estudo dos parâmetros cristalográficos das fases fosfatadas. 


\subsection{Amostragem e preparações}

A amostragem foi dirigida em função dos trabalhos anteriores, escolhendo-se aquelas áreas mais ricas em fosfatos e aquelas que apresentassem fosfatos não apatíticos (grupo da crandallita, rhabdofânio...). Foram amostrados materiais em diferentes estágios de alteração e, quando possível, foram coletadas amostras da rocha sã subjacente ao manto de intemperismo. A quantidade de amostras variou em função da heterogeneidade dos materiais.

As amostras foram coletadas de frentes de lavra experimentais ou de explotação e nomeadas com duas letras iniciais da área (AN: Anitápolis, JU: Juquiá e TA: Tapira) e numeradas continuamente. Algumas letras foram incluídas entre as iniciais do nome da área e o número como $\mathrm{C}$ : concreção, $\mathrm{M}$ : matriz, $\mathrm{T}$ : transição. Amostras coletadas em trabalhos anteriores conservou-se o nome que em geral não seguem as mesmas regras adotadas no presente estudo.

As amostras sofreram preparações e sub-amostragens de acordo com o destino: pulverização e peneiramento (DRX e EIV), impregnação e laminação (MO), fragmentação (MEV), polimento de lâminas e revestimento de carbono (ME e MEV).

Além dessas amostras, foram também coletados materiais representantes do rejeito e do concentrado final na usina de beneficiamento. A coleta destes materiais visou à busca de informações sobre a possivel presença diferencial dos tipos de apatita num e noutro material. 0 estudo detalhado deste material, incluindo concentrados e rejeitos intermediários no processo industrial foi objeto de um Trabalho de Formatura (Santos, 1998) desenvolvido em colaboração com esta pesquisa. 0 mesmo não foi feito nas outras áreas, pois não há processos de concentração.

\subsection{Análises Micromorfológicas}

\subsubsection{Microscopia Óptica (MO)}

Foi utilizado um microscópio LEITZ Ortoplan-pol, do laboratório do NUPEGEL/USP e um microscópio OLYMPUS do laboratório de mineralogia da UPS - Toulouse, ambos acoplados a um aparelho fotográfico.

Foram efetuados estudos mineralógicos em amostras contendo fácies ricas em fosfatos, previamente impregnadas e laminadas. À microscopia óptica (MO) puderam ser selecionadas as lâminas com fases ricas em fosfatos a serem analisadas à microssonda eletrônica. 
O exame ao MO visou o estudo petrográfico das rochas sãs e alteradas; o reconhecimento das filiações mineralógicas, das modificações micromorfológicas das fases fosfatadas com a evolução do intemperismo (estudo de materiais com diferentes graus de alteração); e a seleção de seções e áreas representativas das diferentes fases morfológicas para as análises microlocalizadas.

Nem todas as fases fosfatadas puderam ser diferenciadas à MO, por apresentar dimensões muito reduzidas dos cristais (aspecto criptocristalino) e estar intrinsecamente associadas à outras fases mineralógicas. Nestes casos o uso da MEV (EDS) auxiliou na diferenciação e caracterização das fases.

No caso das apatitas foi possivel o estudo das feições de alteração como fraturas, textura, coloração diferenciada nas bordas dos grãos e cavidades de dissolução. Os diminutos cristais de fosfatos da série da crandallita puderam ser diferenciados do plasma de alteração mas não se pode distinguir os tipos da série.

As descrições das lâminas delgadas basearam-se nos trabalhos de micromorfologia de autores como Delvigne (1988 e 1998), Stoops et al. (1978) entre outros.

\subsubsection{Microscopia Eletrônica de Varredura (MEV) e microanálises X (EDS)}

As análises à MEV foram efetuadas no laboratório do NUPEGEL (IAG-USP) equipado com um aparelho marca JEOL modelo JSM-T330A, acoplado a um sistema EDS marca NORAN e um aparelho fotográfico para filmes de $135 \mathrm{~mm}$. O equipamento permite a visualização morfológica (imagens de elétrons secundários e de elétrons retroespalhados) e registro fotográfico.

Fragmentos de amostras com até $3 \mathrm{~cm}$ de diâmetro e $1 \mathrm{~cm}$ de altura puderam ser analisados. As amostras foram montadas em uma lâmina com a superfície, o mais plana possivel, recoberta uniformemente com uma película de material condutor (carbono ou ouro) para efetuar as observaçōes micromorfológicas e as análises químicas qualitativas (EDS). Lâminas revestidas de um material condutor também foram analisadas.

Muitos são os trabalhos que se utilizam da MEV para análises micromorfológicas, aplicando sobretudo ao estudo da alteração e neoformação de fases minerais, como pirocloros, piroxênios, apatitas (Pereira, 1991, Alcover Neto, 1991 e 1996 e Toledo, 1999). 
As análises ao MEV foram úteis no estudo das relações espaciais interminerais, na caracterização morfológica e no auxilio da identificação das diferentes fases mineralógicas encontradas na microscopia óptica.

\subsection{Análises mineralógicas}

\subsubsection{Difratometria de raios-X (DRX)}

A DRX permitiu a seleção prévia de materiais ricos em fosfatos, a partir do emprego de uma rotina de análise qualitativa. Fases naturalmente concentradas em fosfatos foram analisadas ao DRX por um método de aquisição mais acurado, que permitiu o estudo dos parâmetros de cela da estrutura dos fosfatos, mesmo em amostras polifásicas. A Tabela 14 mostra as condições de análise ao DRX adotados nas etapas de identificação e dos refinamentos de parâmetros cristalográficos dos diferentes fosfatos e da estrutura da apatita supérgena.

Pequenas quantidades de mostras de wavelita e turquesa foram analisadas utilizando a câmara de difração de raios- $X$ Debye-Scherrer.

O cálculo das dimensões das células unitárias das apatitas, fosfatos da série da crandallita, wavellita, turquesa e rhabdofânio foi efetuado a partir de um programa computacional de refinamento de cela baseado no método dos mínimos quadrados: LCLSQ (Burnham, 1991).

Utilizou-se o método Rietveld (Rietveld 1968, 1969), descrito no Anexo 1, para refinar as estruturas de apatitas supérgenas e calcular os parâmetros de cela do rhabdofânio. O refinamento dos parâmetros de cela do rhabdofânio foi efetuado atravez do programa XND (Bérar, 1989) baseado no método Rietveld.

Dois tipos de apatitas supérgenas (fibrosa e prismática) foram escolhidas para o refinamento de estrutura pelo método de Rietveld. As condições de aquisição de dados na DRX adotadas no método Rietveld foram diferentes daquelas empregadas no refinamento dos parâmetros de cela, diminuindo o passo ${ }^{\circ} 2 \theta$ e utilizando $10 \mathrm{~s}$ por passo ao invés de $1 \mathrm{~s}$ para 10 passagens (Tabela 14). Ao final do refinamento foram coletadas informações de ocupação dos sítios cristalográficos, as posições atômicas permitindo o estudo das substituições iônicas. 
DRX

\begin{tabular}{llll}
\hline & \multicolumn{3}{c}{ DRX } \\
\cline { 2 - 3 } condições de análise & Identificação $^{\text {a }}$ & $\begin{array}{l}\text { Cálculo dos parâme- } \\
\text { tros cristalográficos }^{b}\end{array}$ & $\begin{array}{l}\text { Refinamento de } \\
\text { estrutura }\end{array}$ \\
& & 6 & 5 \\
Ângulo inicial $\left({ }^{\circ} 2 \theta\right)$ & 5 & 120 & 140 \\
Ângulo final $\left({ }^{\circ} 2 \theta\right)$ & 90 & 0,04 & 0,02 \\
Passo $\left({ }^{\circ} 2 \theta\right)$ & 0,04 & $10^{*}$ & 10 \\
\hline
\end{tabular}

Tabela 14 Condições de análise utilizadas na DRX.

* foram adquiridas em 10 passagens com is por passo, a intensidade de cada ponto é somada no final.

a laboratório do NUPEL/IAG-USP equipado de um difratômetro PHILLIPS PW 3020

- laboratório de mineralogia da Universidade Paul Sabatier, equipado de um difratômetro PHILLIPS

' Laboratório de Mineralogia (IGc-USP) equipado de um difratômetro Siemens modelo D5000.

Inicialmente pensou-se em refinar todos os tipos que foram amostrados para a DRX, mas testes com o método de Rietveld em amostras com mais de uma fase, mostraram desvios muito grandes entre os padrões calculado e observado, e resultaram em refinamentos muito instáveis, devido a qualidade inferior dos dados de DRX (passo de aquisição $0,04^{\circ} \theta$ ). Na impossibilidade de refazer as análises com modo de aquisição mais acurado em todas as amostras (passo $0,02^{\circ} \theta$ ), foram selecionadas para o estudo duas amostras de apatita mais puras e que representassem um único tipo morfológico.

As apatitas supérgenas de Juquiá (tipos fibroso e tipo prismático) foram as escolhidas para o refinamento da estrutura. A amostra de apatita supérgena fibrosa apresentou traços de crandallita $(<0,5 \%)$, como esta fase interfere muito pouco nos picos das apatitas foi excluída do modelo inicial do refinamento. Já a amostra de apatita prismática apresentou cerca de $2 \%$ de barita que precisou ser refinada com o modelo.

Análises à microssonda indicaram que estas apatitas são ricas em flúor e que o $\mathrm{CO}_{3}$ e $\mathrm{OH}^{-}$estão presentes em maior quantidade nas apatitas supérgenas do tipo fibroso $(0,85$ e 1,19 pfu, respectivamente) e quase ausente no tipo prismático $(0,13$ e $0,35 \mathrm{pfu}$, respectivamente). Estas diferenças permitem testar dois modelos estruturais variando as ocupações dos sítios do fósforo, onde ocorre a substituição $\mathrm{CO}_{3}$ por $\mathrm{PO}_{4}$, e dos canais aniônicos, onde estão os átomos de $\mathrm{F}, \mathrm{OH}$.

$O$ refinamento da estrutura das apatitas foi efetuado utilizando os seguintes programas: LSCQ: indexação das posições de Bragg e cálculo dos parâmetros de cela, Powdercell (Kraus \& Nolze, 1996): estudo das misturas, checagem dos 
modelos iniciais, DBWS 9807 (Young et al., 1995, versão distribuída no curso sobre o método Rietveld coordenado pelo Pf. Dr. Carlos Paiva Santos): refinamento da estrutura. GSAS (Larson \& Von Dreele, 1987): checagem dos modelos obtidos no refinamento.

Durante o refinamento foram liberados inicialmente os parâmetros instrumentais fator de escala, deslocamento da amostra, coeficientes da linha de base, coeficientes do perfil dos picos e orientação preferencial, sendo fixados os parâmetros de assimetria e zero do goniômetro. A função da linha de base utilizada no DBWS foi a polinomial de quinta ordem. A orientação preferencial foi refinada com o modelo March-Dollase e a função do pico utilizada foi a pseudo-voigt com assimetria.

Numa etapa posterior foram refinados os parâmetros estruturais das fases partindo-se de um modelo inicial da fluorapatita natural (Hughes et al., 1989). Durante o refinamento foram liberados os parâmetros de cela, as ocupaçōes e posições atômicas $(x, y e z)$; os deslocamentos térmicos isotrópicos $(\beta)$ foram fixados.

\subsubsection{Microscossonda eletrônica WDS (ME)}

As análises da composição química dos diferentes minerais foram efetuadas no Laboratório de Mineralogia da Universidade Paul Sabatier de Toulouse, equipado de uma microssonda elêtrônica modelo CAMEBAX SX50. Foram elaborados programas de análises adaptados à composição química da fase analisada. Os elementos analisados para apatitas, fosfatos aluminosos da série da crandallita, rhabdofânio, florencita, wavelita e turquesa estão na Tabela 15.

As análises foram efetuadas em lâminas delgadas e polidas de fases previamente identificadas à MO. Cada tipo de apatita foi analisado à ME procurandose obter para cada cristal no mínimo três pontos de análise sempre observando eventuais variações de composição entre os pontos.

Análises com totais baixos não foram desprezadas no presente estudo pois sugerem a presença de constituintes não analisados como $\mathrm{CO}_{3}{ }^{2-} \mathrm{e} \mathrm{OH}^{-}$, considerando não haver a influência de efeitos da preparação e porosidade do local analisado.

Elementos encontrados como traços foram investigados durante as análises dos fosfatos como $\mathrm{S}, \mathrm{K}, \mathrm{V}, \mathrm{Cd}, \mathrm{Pb}, \mathrm{U}$ e Th. Os elementos terras raras ( $\mathrm{Ce}, \mathrm{La}, \mathrm{Nd}$, $\mathrm{Gd}, \mathrm{Sm}, \mathrm{Dy}, \mathrm{Yb} Y$ ) foram dosados em alguns tipos de apatitas, utilizando um 
programa de aquisição com tempo de contagem mais longo de modo a baixar os limites de detecção destes elementos. As condições de análise foram ajustadas em $15 \mathrm{kV}, 40 \mathrm{nA}, 60$ s de contagem para os picos dos elementos e 30 s para o fundo.

Para os cálculos das correções no programa de análise de ETR foi necessário fixar uma composição modelo para as apatitas selecionando-se o os teores de $\mathrm{F} e$ Sr como parâmetros de composição mais característicos.

As análises à microssonda permitiram o cálculo de fórmula estrutural dos diferentes fosfatos (apatita, fosfatos da série da crandallita, rhabdofânio, wavellita e turquesa). Foram testados para cada mineral diferentes tipos de cálculos da fórmula estrutural, baseados no número de átomos de oxigênio (ou ânions $\mathrm{F}, \mathrm{OH}, \mathrm{Cl}$ ), fixando número de átomos no sítio catiônico, ou no sítio do fósforo, conforme as fórmulas estruturais dos minerais.

A escolha do método de cálculo e guiou-se pela estequiometria alcançada nas fórmulas estruturais resultantes, grau do conhecimento sobre os constituintes do sítio a ser considerado como base dos cálculos. Assim as seguintes fórmulas estruturais foram adotadas no presente estudo:

Apatita: (Ca, Sr, $\mathrm{Na}, \mathrm{Mg}, \mathrm{Mn}, \mathrm{Ba}, \mathrm{La}, \mathrm{Ce})_{10}\left(\mathrm{PO}_{4}, \mathrm{SiO}_{4}\right)_{6-\mathrm{z}}\left(\mathrm{CO}_{3}\right)_{\mathrm{z}} \mathrm{F}_{\mathrm{X}}\left(\mathrm{OH}, \mathrm{F}_{1-\mathrm{x}}\right)_{2}$, base 10 cátions. $\mathrm{CO}_{3}$ calculado por diferença no sítio do fósforo $(\mathrm{P}+\mathrm{Si}+\mathrm{C}=6)$ e $\mathrm{OH}$ calculado por diferença no canal aniônico, considerando três possibilidades: parte do flúor $\left(x=z\right.$ ou $x=0,4 z$ ) acompanhando $\mathrm{CO}_{3}$ ou todo $\mathrm{F}$ nos canais $(x=0)$.

Fosfatos da série da crandallita: fórmula anidra da série crandallita: $\left(\mathrm{Ca}^{2+}\right.$, $\left.\mathrm{Sr}^{2+}, \mathrm{Ba}^{2+}, \mathrm{La}^{3+}, \mathrm{Ce}^{3+}\right)\left(\mathrm{Al}^{3+}, \mathrm{Fe}^{3+}\right)_{3}\left(\mathrm{PO}_{4}\right)_{2} \mathrm{O}_{2,5}$, base $10,5 \mathrm{O}$, seguindo os trabalhos Lottermoser (1990) e Taylor et. al. (1984).

Wavellita: $\left(\mathrm{Al}^{3+}, \mathrm{Fe}^{3+}\right)_{3}(\mathrm{OH}, \mathrm{F})_{3}\left(\mathrm{PO}_{4}\right)_{2} \cdot 5 \mathrm{H}_{2} \mathrm{O}$, base $\mathrm{Al}^{3+}+\mathrm{Fe}^{3+}=3$.

Turquesa: $\left(\mathrm{Cu}^{2+}, \mathrm{Ca}^{2+}\right)\left(\mathrm{Al}^{3+}, \mathrm{Fe}^{3+}\right)_{6}\left(\mathrm{PO}_{4}\right)_{4} 4 \mathrm{O}^{2-}$ (anidra), base $\mathrm{Al}^{3+}+\mathrm{Fe}^{3+}=6$, segundo Foord \& Taggart (1998).

Rhabdofânio: ( $\left.\mathrm{Ca}, \mathrm{Ti}, \mathrm{Fe}^{3+}, \mathrm{ETR}, \mathrm{Y}, \mathrm{U}, \mathrm{Th}\right) \mathrm{PO}_{4} \cdot \mathrm{nH}_{2} \mathrm{O}, \mathrm{n}$ calculado por diferença e ETR= La, Ce, Pr, Nd, Sm, Gd, Yb, base $\mathrm{P}=1$, segundo Dorfman et al.(1988) e Soubiès et. al. (1991). 


\begin{tabular}{|c|c|c|c|c|c|c|}
\hline mineral & \multicolumn{6}{|c|}{ elementos dosados } \\
\hline apatita & $F_{1}$ & Al, Si, P, C & $\mathrm{Ca}_{1}$ & $\mathrm{Mn}, \mathrm{Fe}, \quad \mathrm{Sr}$ & $\mathrm{Ba}, \mathrm{La}, \mathrm{Ce}$ & \\
\hline $\begin{array}{l}\text { fosfatos da série da } \\
\text { crandallita }\end{array}$ & $F_{1}$ & $\mathrm{Al}, \mathrm{Si}, \mathrm{P}$, & $\mathrm{Ca}$ & $\mathrm{V}, \mathrm{Mn}, \mathrm{Fe}, \mathrm{Cu}, \mathrm{Sr}$ & $\mathrm{Nb}, \mathrm{Ba}, \mathrm{La}, \mathrm{Ce}$ & $U$ \\
\hline wavelita & F. & $A \mathrm{I}, \mathrm{Si}, \mathrm{P}_{1}$ & $\mathrm{Ca}$ & $\mathrm{Fe}_{1}$ & $\mathrm{Ba}, \mathrm{La}, \mathrm{Ce}$ & \\
\hline turquesa & $F$ & $\mathrm{Al}, \mathrm{Si}, P_{1}$ & $\mathrm{Ca}_{1}$ & $\mathrm{Fe}, \mathrm{Cu}, \mathrm{Sr}$, & $\mathrm{Ba}, \mathrm{La}, \mathrm{Ce}$ & \\
\hline rhabdofánio & & $\mathrm{Al}, \mathrm{Si}, \mathrm{P}$, & $\mathrm{Ca}, \mathrm{Ti}$, & Sr, Y, & $\mathrm{Ba}, \mathrm{La}, \mathrm{Ce}, \mathrm{F}$ & $, \mathrm{Nd}, \mathrm{Sm}, \mathrm{Gd}, \mathrm{Yb}, \mathrm{U}, \mathrm{Th}$ \\
\hline
\end{tabular}

Tabela 15 Elementos analisados à microssonda para os diferentes minerais fosfáticos.

\subsubsection{Análises Termo diferencial e Termo gravimétrica (ATD/ATG)}

Amostras pulverizadas de fosfatos crandalíticos, previamente deferrificadas, foram submetidas às análises térmicas no equipamento de ATD/ATG dos laboratórios IGc - USP e LMC-UPS. As amostras foram aquecidas à uma rampa de $10^{\circ}$ por minuto em uma atmosfera de ar sintético até $900^{\circ} \mathrm{C}$.

As análises ATD/ATG foram efetuadas nas amostras de fosfatos que puderam ser purificadas ou aquelas naturalmente puras. Dentre as amostras de apatitas somente as supérgenas de Juquiá foram estudadas. Todas as amostras de fosfatos da série da crandallita tiveram de ser deferrificadas, resultando em amostras mais puras.

Nas amostras de apatitas foram investigadas as diferenças de perda de massa, visando à indicação da presença de $\mathrm{OH}+\mathrm{CO}_{3}$ na estrutura das apatitas.

Os dados de ATD/ATG foram utilizados na caracterização das diferentes amostras de fosfatos da série da crandallita e comparados com minerais da literatura. Diferentes minerais da série podem ter as mesmas características termogravimétricas 0 que impede a determinação mineralógica pelo método. Estudos efetuados em materiais de síntese mostram que as temperaturas de desidratação podem indicar o tipo de substituição catiônica na estrutura dos minerais da série da crandallita.

Gilkes \& Palmer (1983) observaram que com o aumento da participação do $\mathrm{Sr}$ no sítio $A$ a temperatura de desidratação oscila, diminui de 470 para $420^{\circ} \mathrm{C}$ de uma crandallita pura para uma crandallita com $20 \%$ molar de Sr e torna a aumentar para $420^{\circ} \mathrm{C}$ para uma goyazita. Schwab et al. (1990a) observaram que as crandallitas com cátions bivalentes apresentam desidratação em duas etapas enquanto que crandalitas com cátions trivalentes apresentariam uma desidratação em duas 
etapas. Ainda observaram que as temperaturas de desidratação variam conforme o ETR no sítio A. Estes estudos são efetuados em materiais de síntese e dificilmente podem ser aplicados aos estudos dos materiais naturais. Mesmo assim já é um bom indício de que o comportamento térmico dos fosfatos da série da crandallita pode estar relacionado com as substituições catiônicas.

\subsubsection{Espectroscopia ao infravermelho (EIV)}

A técnica foi empregada em amostras de apatitas pulverizadas onde a qualidade das análises é controlada pelo grau de pureza das amostras. Assim só foram encaminhadas para a EIV amostras onde foi possivel a concentração dos fosfatos. O espectrômetro utilizado foi colocado a disposição pelo laboratório da Universidade Paul Sabatier, sendo as análises acompanhadas pelo pesquisador François Martin do laboratório de mineralogia e cristalografia em Toulouse.

Os espectros de infravermelho mostram em geral as bandas do carbonato, fosfato, hidroxila e água, existindo trabalhos que relacionam as amplitudes destas bandas aos teores de $\mathrm{CO}_{3} \in \mathrm{OH}$. Para as francolitas Lehr et al. (1968) propuseram um cálculo de um indice de $\mathrm{CO}_{2}$ com base na relação dos picos da banda das ligações $\mathrm{C}-\mathrm{O}$ e P.O, que é dados por

Índice de $\mathrm{CO} 2=0,5(\mathrm{D} 1+\mathrm{D} 2) / \mathrm{D} 3$, onde $\mathrm{D} 1$ e $\mathrm{D} 2$ são as intensidades dos dubletos da absorção v3 da ligação $C-O\left(1800 \mathrm{~cm}^{-1}\right)$ e D3 é a intensidade da banda de vibração da ligação P-O (entre 605 e $600 \mathrm{~cm}^{-1}$ ). Posteriormente, Nathan (1984) relacionou este índice ao teor de $\mathrm{CO}_{2}$ propondo a fórmula:

Índice de $\mathrm{CO}_{2}=0,032+0,226 \% \mathrm{CO}_{2}$

Santos \& Clayton (1995) adaptaram o método de Lehr et al. (1968) às apatitas de alta temperatura propondo uma relação de áreas dos picos das bandas das ligações $\mathrm{P}-\mathrm{O}$ e $\mathrm{C}-\mathrm{O}$ ao invés da relação dos valores de intensidade destas bandas.

Os cálculos de $\mathrm{CO}_{2}$ das apatitas foram efetuados neste trabalho segundo 0 método de Lehr et al. (1968) (índice de $\left.\mathrm{CO}_{2}\right)$ e de Scheib et al. (1984) $\left(\% \mathrm{CO}_{2}\right)$.

\subsubsection{Microespectroscopia RAMAN (MR)}

A microespectroscopia Raman (MR) se aplica ao estudo cristaloquímico das apatita, através de informações sobre a presença e quantidade de ânions como $\mathrm{CO}_{3}^{2-}$ e $\mathrm{OH}^{-}$. Exemplos destes estudos são freqüentemente encontrados em trabalhos sobre apatitas de materiais biológicos onde são estudados modelos de 
substituição química como $\mathrm{OH}$ por $\mathrm{CO}_{3}$ (apatita do tipo A) e $\mathrm{PO}_{4}$ por $\mathrm{CO}_{3}$ (apatita do tipo B).

Modos vibracionais do fosfato variam conforme a localização dos íons $\mathrm{CO}_{3}{ }^{2-}$ na estrutura da apatita. Penel et al. (1998) observaram que nos espectros da hidroxiapatita pura ocorre um desvio da banda $v 1964 \mathrm{~cm}^{-1}$ em relação a da apatita carbonatada do tipo $B(960 \mathrm{~cm}-1)$. As bandas $v 1$ não se alteram com o grau de carbonatação da apatita tipo B. A carbonatoapatita do tipo A apresenta duas bandas uma à $957 \mathrm{~cm}^{-1}$ e outra à $947 \mathrm{~cm}^{-1}$ sendo a primeira a mais intensa.

No domínio da banda $v 2$ do grupo $\mathrm{PO}_{4}$ a apatita do tipo B apresenta a diferenciação de dois picos 432 e 445 enquanto as apatitas do tipo A apresentam um pico largo mal resolvido a 440. Apatitas biológicas apresentam bandas à 432 e 450 ou 452.

$\mathrm{O}$ domínio de $\mathrm{v} 3$ do grupo $\mathrm{PO}_{4}$ é o mais afetado pela carbonatação (e pela entrada de $F$ na Hap como visto em Penel et al., 1997), nas carbonatoapatitas do tipo B duas bandas são observadas 1046 e 1070, sendo a banda 1070 também está relacionada ao ion $\mathrm{CO}_{3}{ }^{2-}$ e sua intensidade aumenta com o grau de carbonatação da apatita do tipo B. A calibragem do teor de $\mathrm{CO}_{3}$ das apatitas pode ser feita nesta região relacionando uma constante a razão dos valores de intensidade destes dois picos.

Tsuda \& Arends (1994) observaram variações de intensidade dos picos dos grupos $\mathrm{PO}_{4}$ quando cristais de apatitas são analisados em diferentes posições em relação à direção de polarização do lazer que incide sobre a amostra, da direção de reemissão Raman e da posição do eixo c do cristal analisado, quando ele é perfeitamente paralelo ao plano da lâmina estudada.

Boulingui (1995) analisou à MR apatitas de carbonatito em amostras pulverizadas sem a necessidade de estudo de polarização. Existem vários exemplos da aplicação do método micro-Raman com estudo de polarização em materiais sintéticos e biológicos, sendo Toledo (1999) quem o aplicou pela primeira vez em apatitas minerais.

Métodos de dosagem do $\mathrm{CO}_{3}{ }^{2-}$ a MR tem sido propostos para apatitas biológicas. O método de Nelson \& Williamson (1982) e Mul et al. (1988) baseia-se nas larguras a meia altura de pico a $965 \mathrm{~cm}^{-1}$ aplicando uma relação direta entre a largura do pico e o teor de $\mathrm{CO}_{3}{ }^{2-}$, considera que a carbonatação diminui o grau de cristalinidade das apatitas. O método parte do princípio de que a entrada do 
carbonato é única causa responsável pela diminuição da cristalinidade, o que pode não ser totalmente verdadeiro para alguns tipos de apatitas, especialmente as naturais onde outros fatores podem diminuir a cristalinidade.

Penel et al. (1998) estudando apatitas do tipo B propõem um outro método que relaciona desvios nas posições e variações de intensidade dos picos das ligações $C$ $\mathrm{O}$ e P-O com a quantidade de $\mathrm{CO}_{3}{ }^{2-}$ no sítio $\mathrm{B}$. O estudo foi efetuado em amostras de granulação muito fina onde não foi necessário usar estudo de polarização.

Neste trabalho os cálculos do teor em $\mathrm{CO}_{3}{ }^{2-}$ das apatitas a partir de espectros RAMAN foram efetuados por G. Leroy (INSERM-Lile, França) utilizando o método de Penel et al. (1998). Foram efetuadas análises dos espectros visando à localização do $\mathrm{CO}_{3}{ }^{2-}$ (sítio do $\mathrm{PO}_{4}{ }^{3}$ ou canais aniônicos) e a confirmação dos teores de $\mathrm{CO}_{3}$ calculados a partir de dados da microssonda. $\mathrm{O}$ grupamento $\mathrm{OH}$ - também foi investigado.

Foram escolhidas lâminas com apatitas de eixo c paralelo à seção e efetuadas análises à MR (polarização laser paralela a reemissão laser) em três posições distintas: cristais paralelos, a $45^{\circ}$ e perpendiculares à direção da polarização do laser e da reemissão Raman. Em todas as análises a polarização laser foi colocada na mesma direção da reemissão Raman. Os cristais escolhidos foram aqueles mais representativos do tipo micromorfológico e já analisados à microssonda eletrônica.

As análises microlocalizadas à MR possibilitaram o estudo de diferentes gerações de apatitas, especialmente aquelas de difícil concentração que não foram analisadas ao EIV. Como a obtenção de espectros ideais para os cálculos de teor de $\mathrm{CO}_{3}$ depende da orientação do cristal, só puderam ser estudadas apatitas com eixos cristalográficos identificados à MO, como cristais euhedrais de forma alongada.

\begin{tabular}{|l|l|}
\hline Equipamento & Dillor modelo XY \\
\hline excitação lazer & $\lambda=514,5 \mathrm{~nm}$ \\
\hline Potência & $25 \mathrm{~mW}$ \\
\hline acumulação & 200 segundos \\
\hline intervalo de aquisição $(\mathrm{P}-\mathrm{O}, \mathrm{C}-\mathrm{O})$ & $300 \mathrm{a} 700 \mathrm{~cm}^{-1}$ e $800 \mathrm{a} 1200 \mathrm{~cm}^{-1}$ \\
\hline intervalo de aquisição $(\mathrm{O}-\mathrm{H})$ & $3300 \mathrm{a} 3600 \mathrm{~cm}^{-1}$ \\
\hline
\end{tabular}

Tabela 16 Condições de análise das apatitas à microespectroscopia Raman.

Foi utilizado um microespectrômetro para a verificação do $\mathrm{OH}$ e $\mathrm{CO}_{3}{ }^{2-}$ na estrutura da apatita, conforme a rotina dada na Tabela 16. 


\subsubsection{Catodoluminescência (CL)}

Foi utilizado o equipamento CITL, Cold Cathode Luminescence, $8200 \mathrm{mk}^{3}$, acoplado à um microscópio do laboratório de Mineralogia e Cristalografia da Universidade Paul Sabatier, Toulouse, França. As análises foram acompanhadas pela pesquisadora Claudia Nogueira Santos que desenvolve pesquisa em fosfatos de minério e que na ocasião estava aplicando a técnica de catodoluminescência $(\mathrm{CL})$ à caracterização destes fosfatos.

O estudo teve como objetivo a observação da variação das cores de luminescência das diferentes apatitas e a tentativa de correlação com o tipo de apatita. O maior aumento possível no microscópio utilizado foi de $6 \mathrm{X}$, o que impediu o estudo de apatitas de granulometria fina e a observação de detalhes em alguns tipos de apatitas.

Os método de $\mathrm{CL}$ é muito útil no estudo do comportamento dos ETR pois o fenômeno à ele associado ocorre devido a presença de substituições na estrutura dos minerais, sendo os principais elementos ativadores $\mathrm{Mn}^{2+}, \mathrm{Sm}^{3+}, \mathrm{Dy}^{3+}, \mathrm{Tb}^{3+}, \mathrm{Eu}^{3+}$ e $\mathrm{Eu}^{2+}$. O método é muito sensível à concentração destes elementos (menos de $100 \mathrm{ppm}$ ) que podem ser detectados pela mudança de cor de CL. A interpretação dos espectros de $\mathrm{CL}$ obtidos é feita através da comparação com espectros de apatitas sintéticas ou naturais saturadas com elementos ativadores.

A CL permite estudar o estado de oxidação do elemento Eu em minerais e apatitas podendo ser inferida as condições do meio de formação desses minerais, razões $\mathrm{Eu}^{2+} / \mathrm{Eu}_{\text {total }}$ são utilizadas como indicadores de condições oxidantes ou redutoras do meio (Moroshkin \& Gorobets, 1985 apud Hogarth, 1989). A cor de luminescência de apatitas do carbonatito é azul, ao contrário das igneas e metamórficas, e está relacionada a emissão $\mathrm{Eu}^{2+}$ a 410-430 $\mu$ (Mariano \& Ring, 1975 e Mariano, 1976 ambos apud Marshall, 1988).

Apatitas de diferentes origens foram estudadas por Campbell \& Henderson (1977) observando diferentes cores para apatitas de diferentes origens. Foram classificados nos seguintes tipos morfológicos: tipo 1, sedimentar, sem muitas substituições químicas, cor $\mathrm{CL}$ amarelo-cinza; tipo 2 , grãos anédricos, cor $\mathrm{CL}$ rosa/creme/cinza, ricos em ETR, produto da transformação do tipo 1 por fluídos derivados de fonte carbonatítica profunda; tipo 3 , grãos de veio, posteriores ao tipo 2, ricos em ETR e $\mathrm{Sr}$, cor $\mathrm{CL}$ amarela/creme, tipo 4 grãos grandes e euédricos , apatita pura, com CL creme/cinza, em veios de fluorita de origem incerta. 
Roeder et al. (1987) observaram que a técnica CL é bastate útil na identificação de diferentes estágios de crescimento do cristal e no estudo do comportamento dos ETR nos carbonatitos. Os autores estudando apatitas de diferentes origens (ígnea, hidrotermal e intempérica) propuseram a relação de altura entre os picos de Sm e Dy para indicar o enriquecimento de ETR leves ou pesados, observaram que a presença de $\mathrm{Mn}^{2+}$ causa um alargamento dos picos Sm e Dy, a ausência desse alargamento na apatita intempérica seria atribuída a presença de $\mathrm{Mn}^{4+}$.

Nasraoui (1996) estudou à CL apatitas de tipos litológicos do complexo carbonatítico de Lueshe (Antigo Zaire) e apatitas residuais na base de perfis de alteração laterítica. Observou que a presença da raia $\mathrm{Eu}^{2+}$ dá indicações das condições oxidantes durante a cristalização das apatitas. $O$ autor considera as interpretações a partir de cores de CL subjetivas e que a análise dos espectros das raias seria mais conveniente.

Apesar de reconhecer a importância da CL, Murray \& Oreskes (1997) observaram que as cores de $\mathrm{CL} e$ as intensidades dos espectros podem variar com o envelhecimento das lâminas e com a orientação do cristal na lâmina prejudicando a eficácia do método. 


\section{Materiais estudados}

O acesso aos materiais representativos dos diferentes estágios do intemperismo foi diferenciado em cada área estudada. As frentes de lavra em Tapira e em Juquiá expuseram grande parte do manto de alteração, enquanto que, em Anitápolis, só puderam ser estudados poucos perfis em antigos cortes dos trabalhos de pesquisa mineral.

\subsection{Anitápolis}

As amostras escolhidas para o estudo dos fosfatos foram coletadas em frentes de lavra experimental do minério residual em um afloramento natural de carbonatito. Os perfis amostrados são os mesmos adotados no trabalho de Pereira (1991) que colocou à disposição deste trabalho, amostras anteriormente coletadas e concentrados apatíticos, também utilizados.

A localização das amostras estudadas está indicada na Figura 11. Basicamente os materiais são produto do intemperismo de rochas piroxeníticas (frente de lavra experimental) e de rochas sieníticas (trincheira TGB) ambas cortadas por veios apatíiticos. $O$ carbonatito se encontra próximo às margens do Rio Pinheiros Altos. Todos os locais estudados estão marcados no mapa geológico do maciço de Anitápolis (Figura 5). A seguir serão apresentadas as características dos materiais estudados ; entre parênteses são mencionadas as amostras mais representativas.

\subsubsection{Perfil sobre piroxenito com bolsões de glimmerito}

O perfil está situado na frente de lavra (Figura 5), tendo sido denominado Perfil A por Pereira (1991). Os materiais no perfil A (setor 1) encontram-se pouco alterados e muito friáveis. Observou-se a presença de piroxenito praticamente são (piroxênio, flogopita magnetita, apatita) (AN2) e veios apatíticos (AN1) de cor amarelo esbranquiçada e granulação grosseira (1 a $5 \mathrm{~mm}$ ). Faz contato com um glimmerito de granulação grosseira de cor avermelhada (AN3).

Amostras coletadas por Pereira (1991) localizadas na frente de lavra foram também estudadas: glimmerito alterado (PD3) do perfil $D$ (setor 2), rochas alteradas da fácies zeóita (A7) e da fácies flogopita e piroxenito (A1) ambas do perfil A (setor 1). Estes perfis estão situados em diferentes bancadas 


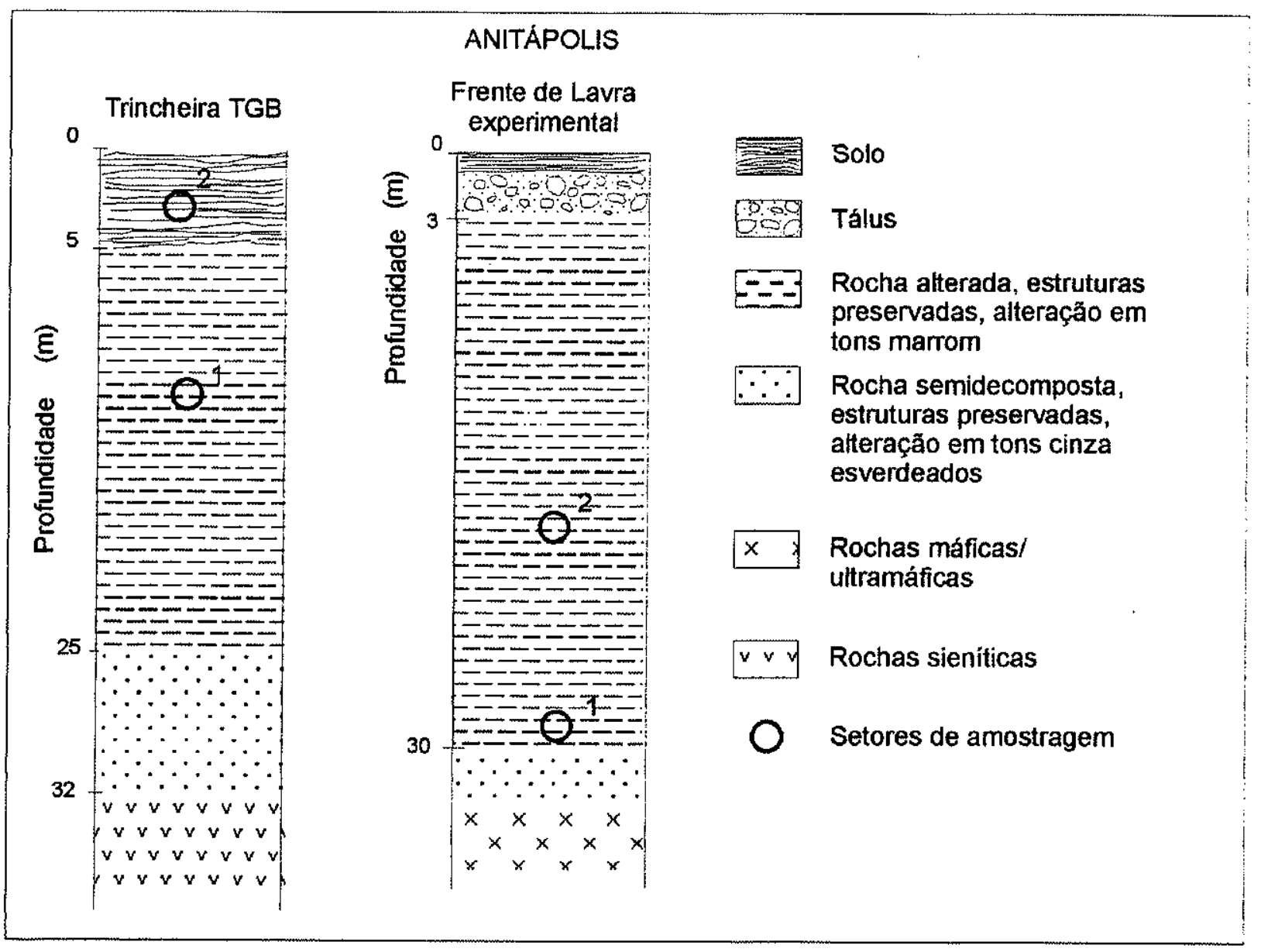

Figura 11 Perfis esquemáticos representativos da trincheira TGB e da frente de lavra experimental do depósito residual de Anitápolis.

\subsubsection{Perfil sobre piroxenitos em contato com sienitos}

Foram estudadas amostras de um perfil da trincheira TGB já estudadas por Pereira (1991). No setor 1 da TGB dominam piroxenitos alterados (AN4, AN5, AN6, AN7) e muito alterados (AN8) cortados por veios apatíticos (AN9) e bolsões de sienito (DRX: Ortoclásio, clinocloro). A apatita ocorre em todos os materiais. Neste setor foi observada a única ocorrência de apatita supérgena dos materiais estudados em Anitápolis (AN9). Estas apatitas são fibrosas e revestem todas as cavidades e fraturas da alterita do piroxenito. O setor 2, localizado no topo do perfil da TGB, é recoberto por um material aloterítico pedogeneizado (AN10).

Foram integrados ao conjunto de amostras da trincheira TGB lâminas e concentrados da coleção de Pereira (1991) provenientes de um veio apatítico hidrotermal (TGB4, setor 1) e do material argiloferruginoso com manganês e apatita (TGB5 e TGB6, ambos do setor 1). 


\subsubsection{Perfil sobre Carbonatito}

O carbonatito são ocorre tanto na superfície em afloramentos na margem do rio Pinheiros Altos (AN11) e trincheira GPF (amostra GPF3, Pereira, 1994), como em profundidade, presente nos testemunhos de sondagem PA PEM-1 (amostra AN7, Pereira, 1994).

\subsection{Juquiá}

A localização dos materiais estudados em Juquiá pode ser seguida na figura 12, que mostra um perfil esquemático do maciço de Juquiá, evidenciando os diferentes setores: rochas sãs (carbonatíticas ou silicáticas), alteradas com ou sem preservação das estruturas.

Assim foram estudados perfis de alteração desenvolvidos sobre carbonatito (setores 0 e 1), sobre rochas alcalino-silicáticas (setor 2) e sobre a zona de transição entre estas duas litologias (setor 3). Ainda foram amostrados materiais aloteríticos mais próximos (setor 4) e mais afastados (setor 5) do corpo carbonatítico. O perfil de transição também foi estudado pela pesquisadora Claudia Nogueira dos Santos em seu trabalho de iniciação científica, suas amostras foram integradas ao presente estudo.

\subsubsection{Perfil sobre carbonatito}

Rocha sã (setor 0 )

O perfil de alteração desenvolve-se sobre um carbonatito (A-15 e FJ88) que apresenta uma estrutura fluidal marcada por bandas de proporção variada de apatita e dolomita. Como minerais acessórios aparecem flogopita e magnetita e, raramente, pirocloro e titanita.

\section{Rocha alterada (setor 1)}

A isalterita (JU14, JU33, JU48 e JU24) apresenta uma estrutura fluidal da rocha original bem preservada que é marcada por bandas com diferentes proporções de apatita e dolomita. Bandas mais claras e maciças de composição apatítica se alternam com bandas mais escuras e ricas em cavidades romboédricas (originalmente dolomiticas). Estas cavidades são freqüentemente preenchidas por material ferruginoso ( e manganesífero) e apatitas supérgenas. 


\subsubsection{Perfil sobre rocha alcalino-silicática (setor 2)}

Neste perfil não aflora a rocha sã, sendo só estudados materiais muito alterados (JUX, JUY e JUZ). A alterita é bastante argilosa e rica em gorceixita, associada a oxihidróxidos de ferro e manganês. A amostra JUX está situada mais próxima ao corpo carbonatitico e a JUZ mais afastada, a JUY encontra-se entre as duas.

\subsubsection{Perfil sobre zona de transição carbonatito/rochas alcalino- silicáticas (setor 3)}

A zona de transição situa-se entre as rochas alcalino - silicáticas e 0 carbonatito. Estão presentes neste perfil corpos de carbonatito com estrutura fluidal pouco alterados ao lado de produtos argiloferruginosos, mais evoluídos, provenientes da alteração de rochas alcalino-silicáticas (JU8, JUT, JUT').

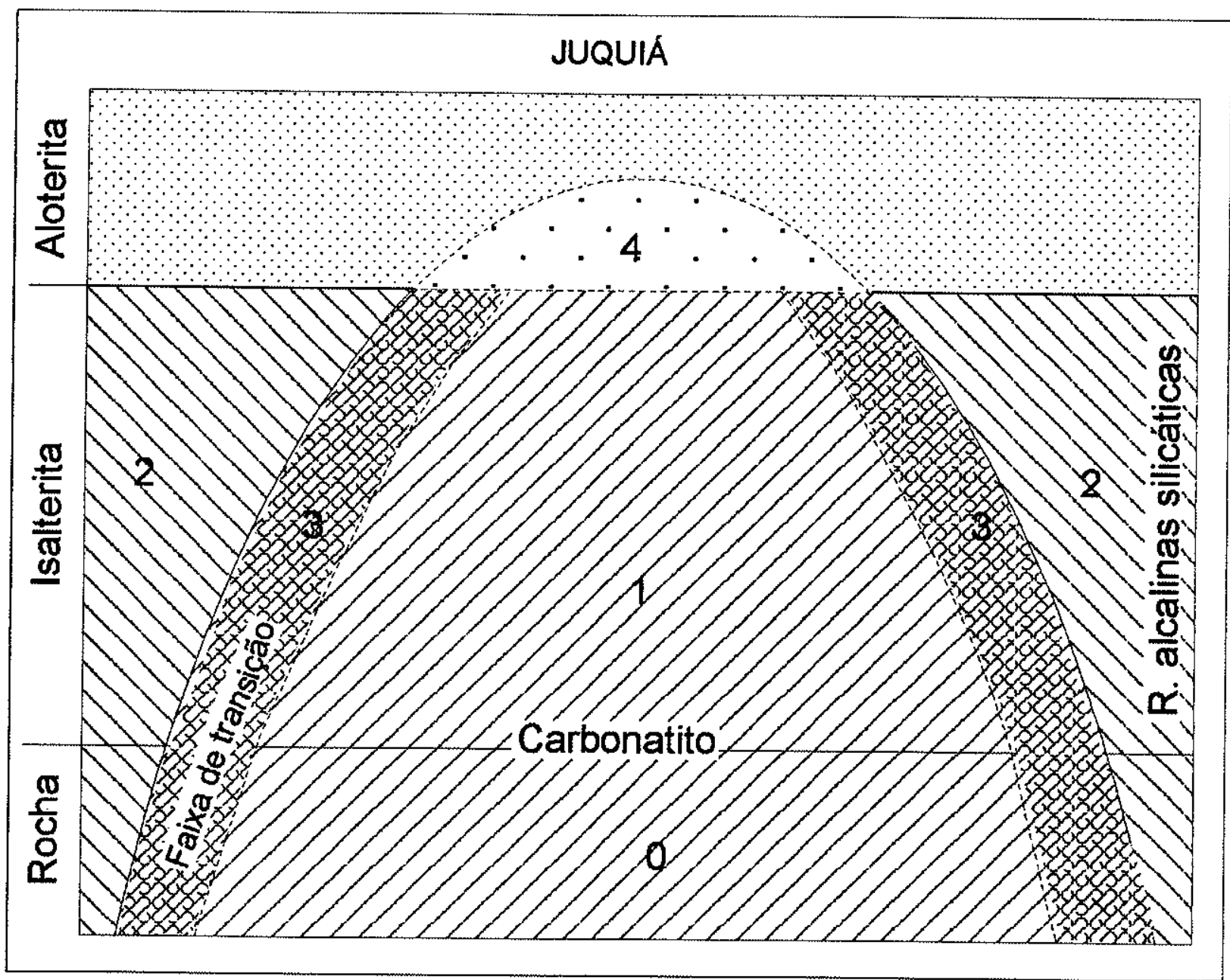

Figura 12 Esquema do manto de alteração sobre o maciço de Juquiá, com indicação dos setores amostrados 


\subsubsection{Horizonte aloterítico próximo ao corpo carbonatítico (setor 4)}

Ocorre sobrejacente aos perfis estudados; apresenta uma matriz terrosa rica em concreções ferruginosas, material endurecido de aspecto nodular. Tanto a matriz (JUM) como as concreções apresentam fosfatos aluminosos(JUC).

JUQUIÁ

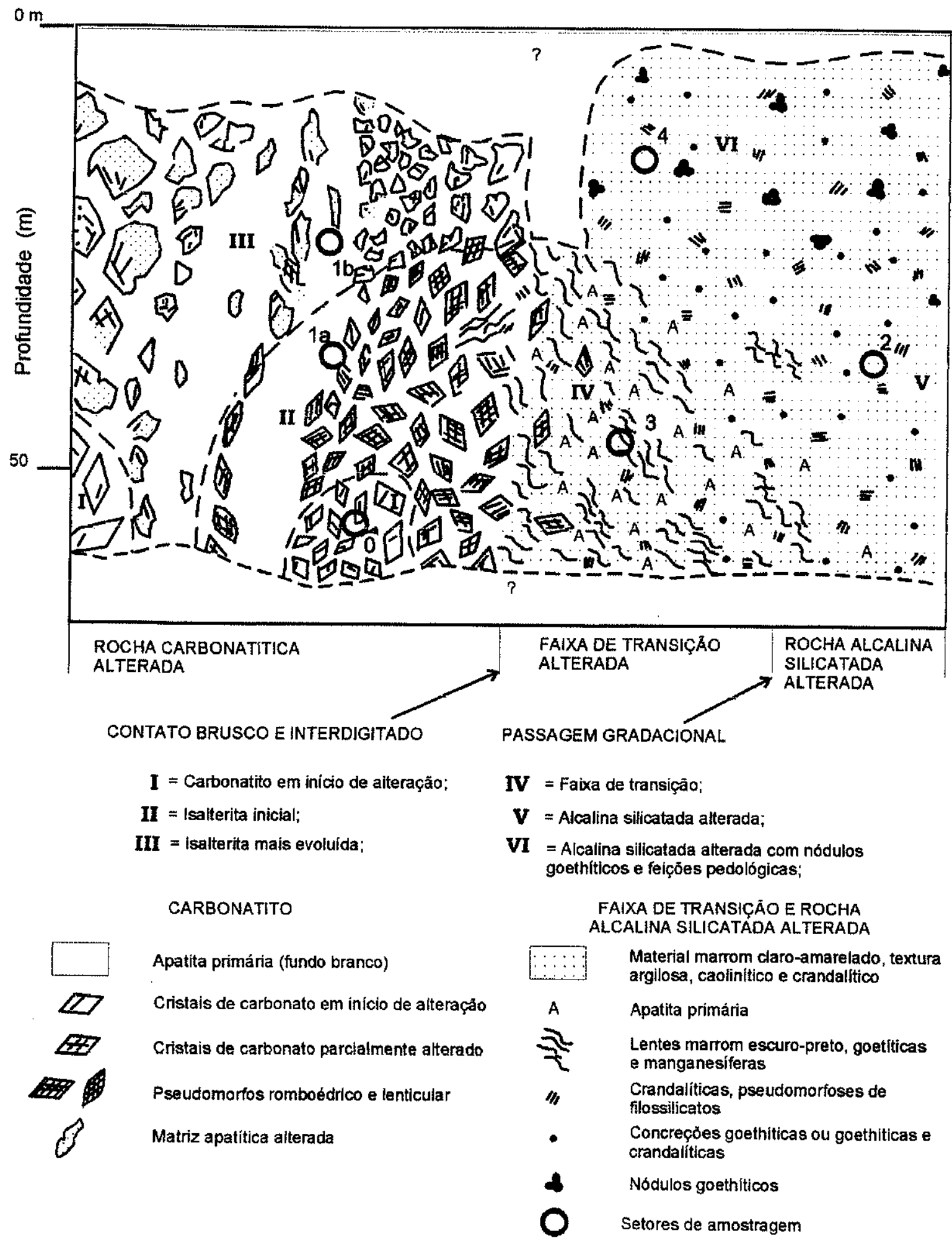

Figura 13 Esquema da seção amostrada com indicação dos materiais encontrados e locais de amostragem. Esquema apresentado por Alcover Neto (1994). 


\subsection{Tapira}

$O$ depósito residual de Tapira, classificado segundo os teores em $\mathrm{P}_{2} \mathrm{O}_{5}$ e $\mathrm{TiO}_{2}$, vem sendo explotado em frentes de lavra denominadas espigões ( $E$, E 2, E 3, E 4 e E 5). Todos os perfis estudados estão localizados ao norte do complexo alcalino (Figura 9) e as amostras foram coletadas em bancadas com altura média de $13 \mathrm{~m}$.

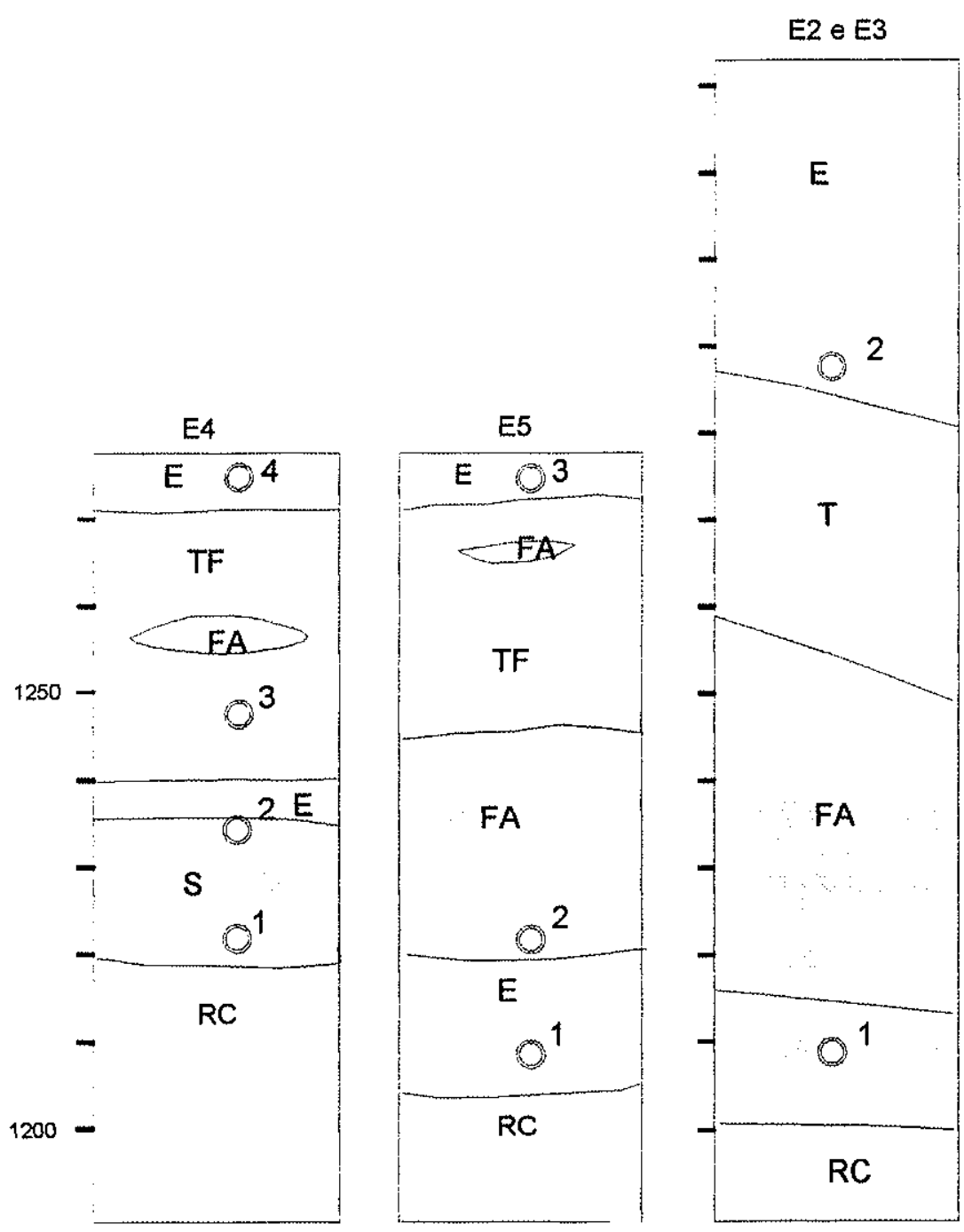

Classificação do minério

E ESTÉRIL

$\left(\mathrm{TIO}_{2}<15 \% \mathrm{EP}_{2} \mathrm{O}_{5} \mathrm{SOL} .<5 \%\right)$

$T$ MINERALIZAÇẤO A TITÂNIO

$\left(\mathrm{P}_{2} \mathrm{O}_{5} \mathrm{SOL}\right.$. $\left.<5 \% \mathrm{ATIO}_{2} \geq 15 \%\right)$

MINERALIZAÇĀO A FOSFATO COM

TF TITÂNIO $\left(\mathrm{P}_{2} \mathrm{O}_{5}\right.$ Sol. $>5 \%$ e TiO $\left.2 \geq 15 \%\right)$

FA MINERALIZAÇÄO A FOSFATO DE ALTO TEOR $\left(\mathrm{P}_{2} \mathrm{O}_{5} \mathrm{SOL} . \geq 7,5 \% \mathrm{E} \mathrm{TiO}_{2}<15 \%\right)$
FB MINERALIZAÇÃO A FOSFATO DE BAIXO TEOR $\left(\mathrm{P}_{2} \mathrm{O}_{5} \mathrm{SOL} .25 \% \mathrm{E} \mathrm{TiO}_{2}<15 \%\right)$

Nb MINERALIZAÇÃO A NIÓBIO $\left(\mathrm{N}_{2} \mathrm{O}_{5}>0,5 \%\right.$

RC ROCHA COMPACTA

$S$ MATERIAL SILEXÍTICO EIOU SEMI-

COMPACTO

SETORES AMOSTRADOS

Figura 14 Perfis esquemáticos representativos das frentes de lavra E 2, E3, E 4 e E 5 com a localização dos setores amostrados em Tapira. 


\subsubsection{Perfil sobre rochas silexíticas (E 4)}

Bancada $1222 \mathrm{~m}$ (setor 1): No topo da bancada ocorre um material isalterítico onde são observadas duas fases, uma mais resistente rica em quartzo e oxihidróxidos de ferro, anatásio e apatita, cortada por vênulas de calcita (TA19, TA20, TA21,TA23, TA24) e outra, mais friável, micácea e de cor amareloesverdeada, que é rica em mica, apatita, magnetita e anatásio (TA22). Ainda na base da bancada ocorre um material ferruginoso, aloterítico e laminar que é rico em goethita e gorceixita (TA25).

Bancada 1235m (setor 2): Nesta bancada, materiais alteríticos de rocha silexítica fazem contato brusco com materiais coluvionares e a superfície do contato é irregular. O material coluvionar apresenta camadas de material friável de cor cinzaesverdeada ricas em anatásio e caulinita e pouco quartzo (TA13) intercaladas a camadas de um material preto rico em matéria orgânica (TA14). O material coluvionar é recoberto por um solo de coloração castanha-amarelada rico em caulinita e goethita (TA15, TA16). Sobre a alterita ocorre um material friável grosseiro rico em anatásio e oxihidróxidos de ferro (TA18) cortado por um material caolinítico muito fino (TA17).

Bancada1248m (setor 3): É constituída por um material apatítico friável de granulação fina a média. Apresenta cor amarela com manchas esbranquiçadas e pontos pretos. Neste material ocorrem apatitas, micas, magnetita e anatásio. A apatita caracteriza-se por uma granulometria média e um aspecto leitoso. Estes minerais encontram-se bem alterados e associados a oxihidróxidos de ferro e argilo minerais ( TA1, TA2, TA3, TA4, TA5, TA6).

Bancada 1274m (setor 4): Observa-se a presença de um material muito evoluído, aloterítico, de cor avermelhada e rico em gorceixita (TA8) e um bolsão de cor rósea mosqueada e textura argilosa rica em argilo minerais do tipo caulinita (TA7, TA9). Um veio de material de cor castanha-amarelada, rico em caulinita , anatásio, gorceixita e goethita (TA10) corta todos os materiais da bancada. Um material concrecionar aloterítico rico em anatásio, caulinita, goethita e com pouca gorceixita (TA11, TA12) ocorre em contato lateral com o material aloterítico. Neste setor a apatita não foi encontrada. 


\subsubsection{Perfis sobre rochas piroxeníticas (E 2, E 3 e E 5)}

\section{E 2}

Bancada 1209m (setor 1): Caracteriza-se pela presença de rochas frescas piroxeníticas cortadas por veios de diferentes litologias: silexitos, rocha básica e carbonatito (TA45).

\section{E 3}

Bancada 1209m (setor 1): No local ocorre uma rocha carbonatítica sã (calcita, magnetita, mica), de cor cinza esbranquiçada com bolsões de silexito alaranjado. A rocha é cortada por calcita secundária brotrioidal (TA46).

Bancada $1287 \mathrm{~m}$ (setor 2): Ocorre sienito muito alterado, friável e grosseiro (sanidina e ortoclásio) de cor é cinza esbranquiçada. É cortado por um veio argiloso cor castanha e outro veio de cor esbranquiçada mosqueado nas cores verde e laranja (caulinita, apatita e gorceixita) (TA48). No mesmo local ocorre um material rico em anatásio, de cor esverdeada e granulação média a grosseira (TA49, TA50) que é cortado por veios sieníticos (ortoclásio e apatita).

\section{E 5}

Bancada $1209 \mathrm{~m}$ (setor 1): No local dominam rochas piroxeníticas (piroxênio, micas , apatita, anatásio, perovskita, calcita) de coloração verde, pouco resistente e sãs (TA27, TA28, TA29, TA31, TA33, TA34, TA35, TA36, TA38, TA39, TA40) cortadas por veios de diferentes litologias: silexito (TA26, TA30, TA32, TA37), carbonatito e rocha ultrabásica.

Bancada $1222 \mathrm{~m}$ (setor 2): Observa-se a presença de uma rocha piroxenítica (piroxênio, micas, apatitas) cortada por veio de rocha básica (TA41).

Bancada $1274 \mathrm{~m}$ (setor 3 ): Dois tipos de materiais são encontrados: na base ocorre um material aloterítico concrecionar (TA42) e no topo um material de aspecto terroso e pulverulento de cor vermelho amarelada (TA43, TA44). 


\section{Aspectos mineralógicos, morfológicos, geoquímicos e cristaloquímicos dos fosfatos}

Neste capítulo serão mostrados de forma integrada os resultados das várias análises (MO, MEV, ME, IV, MR e CL) das fases fosfatadas encontradas nos perfis estudados, organizados por área e por natureza dos dados. Houve sempre a preocupação de relacionar a composição com o tipo morfológico de cada mineral fosfático.

Os estudos mineralógicos e micromorfológicos encontram-se ilustrados respectivamente por difratogramas e fotografias, enquanto que os aspectos de composição química e cristaloquímica são ilustrados por tabelas, gráficos e espectros. No caso das tabelas de dados de composição química das apatitas, por serem muito extensas, optou-se por colocá-las em anexo (2: Anitápolis, 3: Juquiá e 4: Tapira), encontrando-se no texto tabelas resumidas indicativas das composições encontradas por área e por tipo morfológico.

Para todos os minerais, os dados de composição em porcentagem em peso dos óxidos foram utilizados para cálculo das respectivas fórmulas estruturais, o que é explicado para cada caso. Para a exploração dos dados, foram utilizados gráficos ternários e binários tanto com as porcentagens em peso dos óxidos, como com os dados expressos em número de átomos por fórmula unitária (p.f.u.).

\subsection{Apatita}

As apatitas encontradas nos perfis de alteração de cada complexo alcalinocarbonatítico puderam ser classificadas em três tipos: apatita primária (sã e alterada), apatita de alteração não intempérica (hidrotermal ou tardi-magmática), denominada aqui genericamente de apatita hidrotermal e apatita supérgena.

\subsubsection{Anitápolis}

\section{Mineralogia e micromorfologia das apatitas de Anitápolis}

As análises globais à DRX de amostras coletadas no manto de intemperismo do complexo de Anitápolis indicaram apenas a presença de apatitas, não sendo encontrados outros fosfatos.

Amostras ricas em apatita foram analisadas ao microscópio óptico e ao MEV. As características micromorfológicas encontradas permitiram a diferenciação dos seguintes tipos de apatita: 


\section{Apatita primária}

1 - apatita primária sã

As apatitas deste tipo ocorrem em piroxenito pouco alterado (1A7), e carbonatito são (AN11A, GPF-3A). Ao MO os cristais de apatitas apresentam-se incolores, com cor de birrefringência baixa, normal para apatitas, com seções ovóides de diâmetro entre 0,1 e 0,3 mm (Foto 1). O imbricamento destes cristais dá origem a uma textura em pavê. No carbonatito da trincheira GPF foram observados cristais de apatita com inclusões de piroxênio fibroso, o que não foi encontrado nos piroxenitos da frente de lavra e da trincheira TGB, que apresentam apenas inclusões fluidas.

2 - apatita primária alterada: a- fraturada e b- estriada

Grãos de apatita com sinais de alteração (fraturas e estrias) e de forma irregular são encontrados em piroxenitos (amostras TGB-4A, TGB-5B, PD3, AN1 e AN7), em bolsões apatíticos alterados (AN9) e no material aloterítico pedogeneizado (AN10C). Nestes materiais, os cristais de piroxênio apresentam porções ferruginizadas e os cristais de flogopita estão parcialmente transformados em argilominerais (vermiculita). Ao MO e MEV foram observadas diferentes feições de alteração como fraturas, bordas dissolvidas e estrias nas apatitas.

Cristais alterados de apatita primária no piroxenito alterado apresentam fraturas, e impregnações de ferro (Foto 2 e Foto 5) e uma textura em pavê. Grãos residuais de apatita primária, na alterita de rochas piroxeníticas, apresentam feições de dissolução (Foto 3 e Foto 4). No material pedogeneizado, os grãos de apatita são arredondados, fraturados e impregnados por óxido de ferro (Foto 6). Não foram observados cristais de apatita provenientes de carbonatito alterado.

A apatita "estriada" (TGB-4A) ocorre em porções mais alteradas do piroxenito. Estas apatitas apresentam-se mais fraturadas e sem borda de maior birrefringência; seu interior pode apresentar porções estriadas dando um aspecto fosco ao grão observado ao MO em luz natural.

\section{Apatita hidrotermal}

\section{3 - borda de maior birrefringência}

Alguns cristais de apatita apresentam uma borda de cor de birrefringência de ordem maior do que a do núcleo; esta borda de espessura irregular pode abranger mais de $50 \%$ da área do cristal. Cristais com borda de maior birrefringência foram encontrados tanto no piroxenito pouco alterado (1A7) como no carbonatito (GPF-3A) 
(Foto 1), sendo ausentes em materiais muito alterados onde ocorrem as apatitas supérgenas. A ocorrência destas bordas apenas em apatitas de rocha sem sinais de intemperismo e sem fases mineralógicas supérgenas sugere que sua formação tenha se originado por alteração das apatitas primárias em condições anteriores ao intemperismo (hidrotermais ou tardi-magmáticas). Após 0 estudo de sua composição, o que é apresentado no próximo item, decidiu-se classificá-las como hidrotermais.

\section{Apatita supérgena}

4 a - apatita tipo fibrorradiada

Cristais de apatita supérgena fibrorradiados (Foto 5) foram encontrados junto a um bolsão apatítico marcado por uma riqueza em cavidades. Estes cristais formam películas que revestem estas cavidades, que podem ser fraturas ou vazios de dissolução. Em geral as fibras de apatita apresentam comprimento de dimensões reduzidas $(10 \mu \mathrm{m})$ e estão impregnadas por óxidos-hidróxidos de ferro.

$4 \mathrm{~b}$ - apatita tipo criptocristalino

Agregados muito finos de cristais de apatita criptocristalina foram encontrados em amostras de piroxenito alterado. Estes agregados em geral revestem as descontinuidades superficiais dos cristais de apatita primária alterada, e só puderam ser identificados ao MEV (Foto 4). 


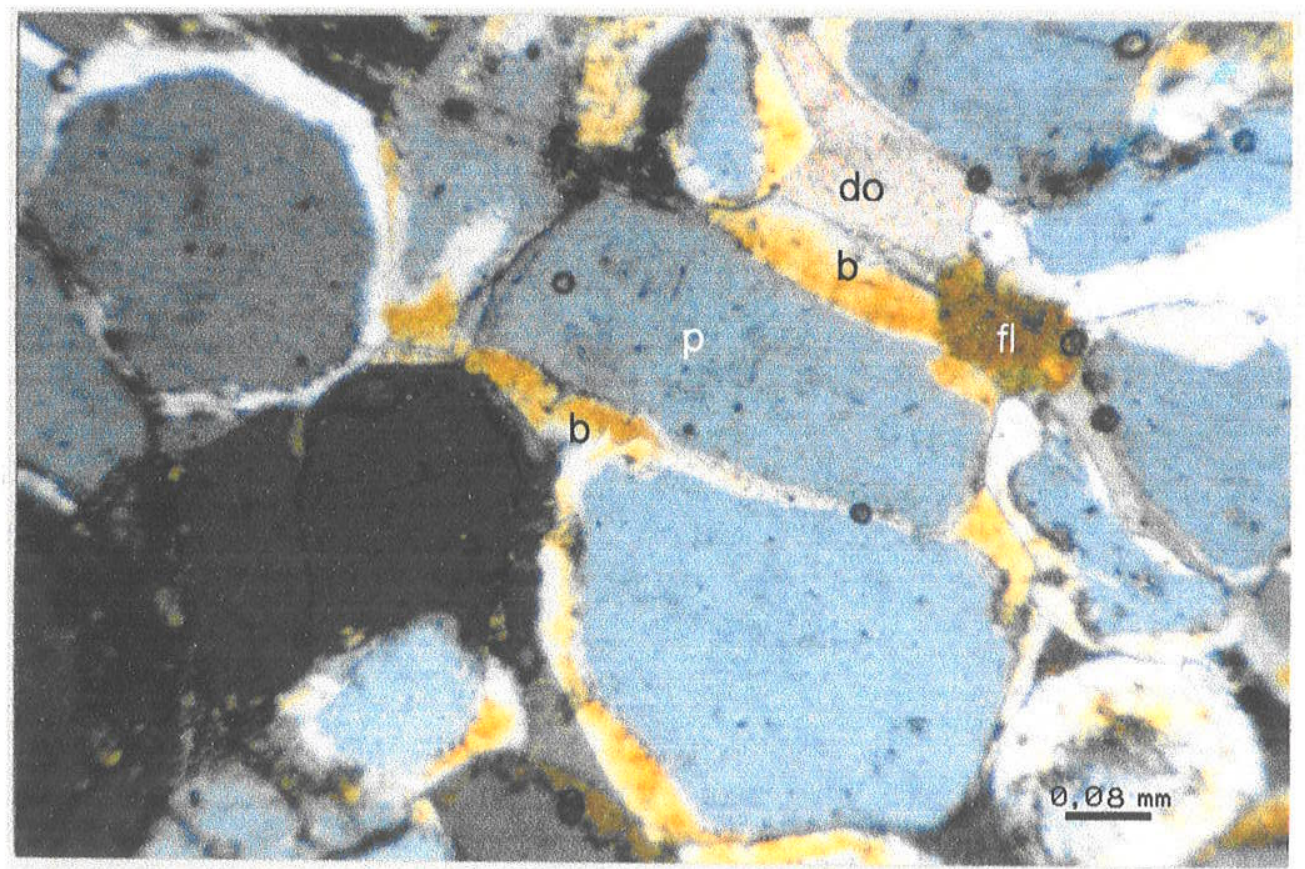

Foto 1 Cristais de apatita primária ( $p$ ) sãs em pavê com borda de maior birrefringência (b) e massa dolomítica (do) nos espaços intercristalinos, em carbonatito são, Anitápolis. Amostra GPF-3a, MO (LP).

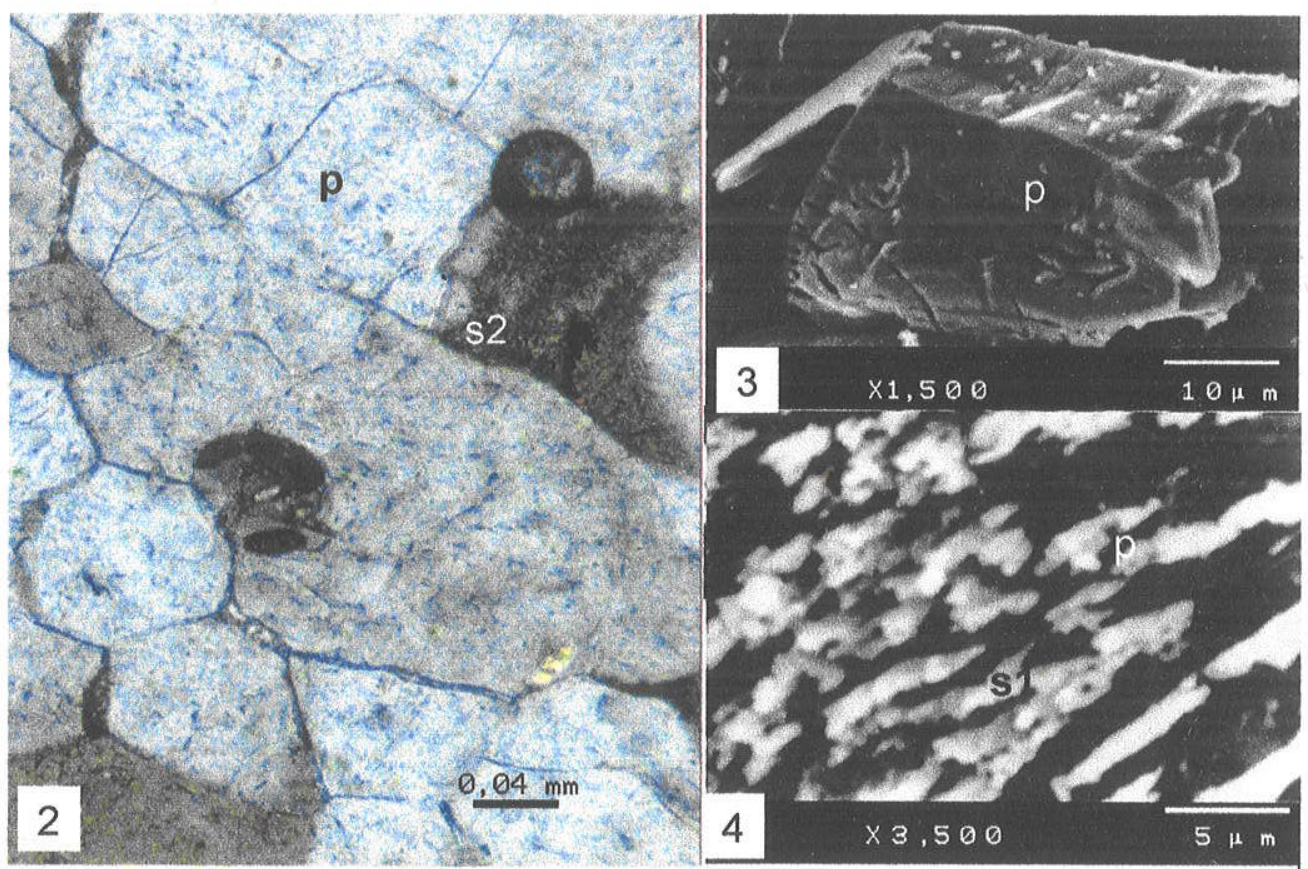

Foto 2 Cristais de apatita primária com fraturas (p) associados a apatita supérgena do tipo fibroso (s2), em piroxenito alterado de Anitápolis. Amostra AN9e. MO (LP).

Foto 3 grão de apatita alterada ( $p)$, em piroxenito alterado de Anitápolis. Amostra AN7. MEV (BEI).

Foto 4 Feição de alteração na superfície do grão de apatita (p) com apatita supérgena criptocristalina (s1) em piroxenito alterado de Anitápolis. Amostra AN1.4. MEV (BEI). 


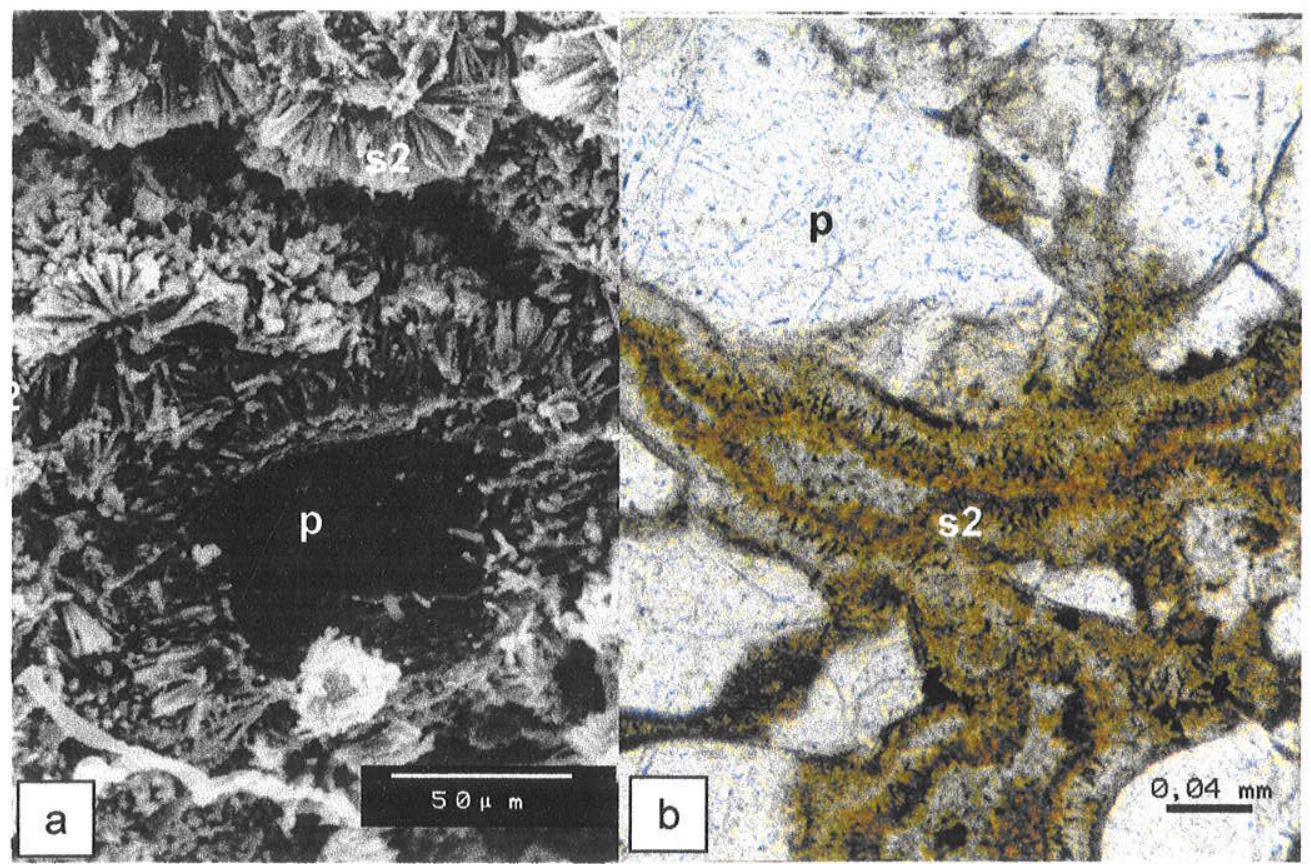

Foto 5 Grãos de apatita primária residual $(p)$ rodeados por fibras de apatita supérgena (s2), piroxenito alterado no perfil TGB de Anitápolis. Amostra AN9e. a: MEV (BEI) e b: MO (LN).

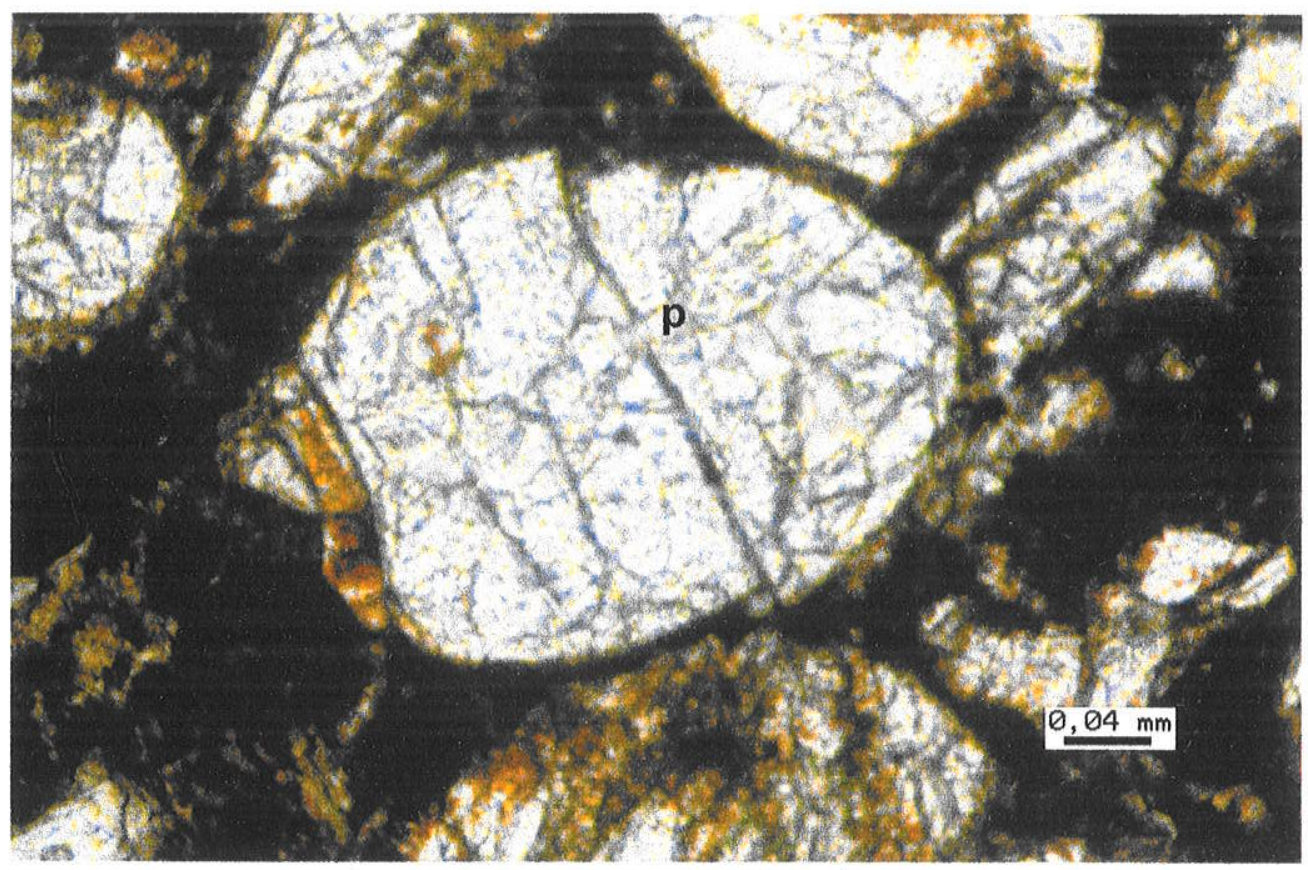

Foto 6 Grão de apatita primária residual (p), fraturada e com impregnações ferruginosas em material pedogeneizado do perfil TGB de Anitápolis. Amostra AN10C. MO (LN). 
A partir de dados de DRX foram calculados os parâmetros cristalográficos a e $c$ (através de um programa de refinamento dos parâmetros de cela, LCLSQ, que utiliza o método dos mínimos quadrados) de amostras enriquecidas em apatita, incluindo os seguintes tipos de apatitas: apatitas primárias (com ocorrência de bordas de maior birrefringência originadas em alteração profunda, provavelmente hidrotermal), apatitas primárias com sinais de alteração (bordas dissolvidas, fraturas, aspecto estriado) e apatitas supérgenas, assim reconhecidas por sua morfologia e modo de ocorrência no perfil (Tabela 17).

A estrutura das apatitas primárias de Anitápolis apresenta valores de a e $C$ intermediários entre os da hidroxiapatita (JCPDS 9-432) e os da fluorapatita (JCPDS 15-876), sendo mais próximos aos valores desta última.

Os dados mostram que a estrutura da apatita alterada não sofre importantes modificações em relação à apatita sã, e que a apatita supérgena exibe aproximadamente os mesmos valores de a e $c$ que as apatitas primárias (Figura 15).

Os difratogramas de raios - $\mathrm{X}$ (Figura 16) mostram um alargamento dos picos das apatitas supérgenas com relação aos encontrados em amostras de apatitas primárias e a presença de mica associada a apatita supérgena. $\mathrm{O}$ alargamento dos picos pode estar associado ao baixo grau de cristalinidade, possivelmente relacionado. pelo menos em parte, à substituição de $\mathrm{CO}_{3}{ }^{2-}$ pelo $\mathrm{PO}_{4}{ }^{3-}$, como já foi encontrado em estudos de apatitas carbonatadas de materiais biológicos (LeGeros \& LeGeros. 1984).

Outra possibilidade é a ocorrência de uma outra fase de apatita misturada a apatita supérgena, que não foi possível ser estudada aplicando o Método Rietveld dada a baixa qualidade dos dados de DRX disponíveis (passo ${ }^{\circ} 2 \theta$, muito grande).

Além do alargamento, as intensidades relativas dos dois difratogramas aqui apresentados são diferentes entre si. Sabe-se que as intensidades estão ligadas a estrutura e composição dos minerais mas também pode estar ligada a preparação da amostra como a orientação e dimensão das partículas. O método Rietveld aplicado a este caso mostrou que algumas reflexões podem estar ligadas à orientação dos cristais durante a preparação da amostra. Isto está em acordo com o esperado pois as apatitas supérgenas apresentam um hábito fibroso que favorece a orientação das partículas durante a preparação da amostra. 


\begin{tabular}{|c|c|c|c|c|}
\hline materiai & amostra & Tipo de apatita & [a]A & {$[c] \AA$} \\
\hline $\begin{array}{l}\text { veio hidrotermal apatítico } \\
\text { pouco alterado }\end{array}$ & A1 & \multirow{2}{*}{$\begin{array}{c}\text { primária tipo pavê sã com borda } \\
\text { de maior birrefringência }\end{array}$} & $9,385(2)$ & $6.885(3)$ \\
\hline $\begin{array}{l}\text { fácies zeólita pouco } \\
\text { alterada }\end{array}$ & $A 7$ & & $9,390(2)$ & $6.886(2)$ \\
\hline piroxenito muito alterado & TGB-6 & \multirow[t]{3}{*}{ primária tipo pavê alterada } & $9,384(2)$ & $6.892(2)$ \\
\hline glimmerito muito alterado & PD3 & & $9,393(1)$ & $6.881(1)$ \\
\hline \multirow{2}{*}{$\begin{array}{l}\text { veio hidrotermal apatítico } \\
\text { muito alterado }\end{array}$} & PB4 & & $9,386(1)$ & $6.885(2)$ \\
\hline & AN9.1.1 & supérgena fibrosa & $9,386(2)$ & $6.883(2)$ \\
\hline \multicolumn{3}{|c|}{ Fluorapatita (JCPDS 15-876) } & 9,368 & 6.884 \\
\hline \multicolumn{3}{|c|}{ Hidroxiapatita (JCPDS 9-432) } & 9,418 & 6.8841 \\
\hline
\end{tabular}

( ) desvio padrão

Tabela 17 Parâmetros cristalográficos a e $c$ de apatitas de Anitápolis.

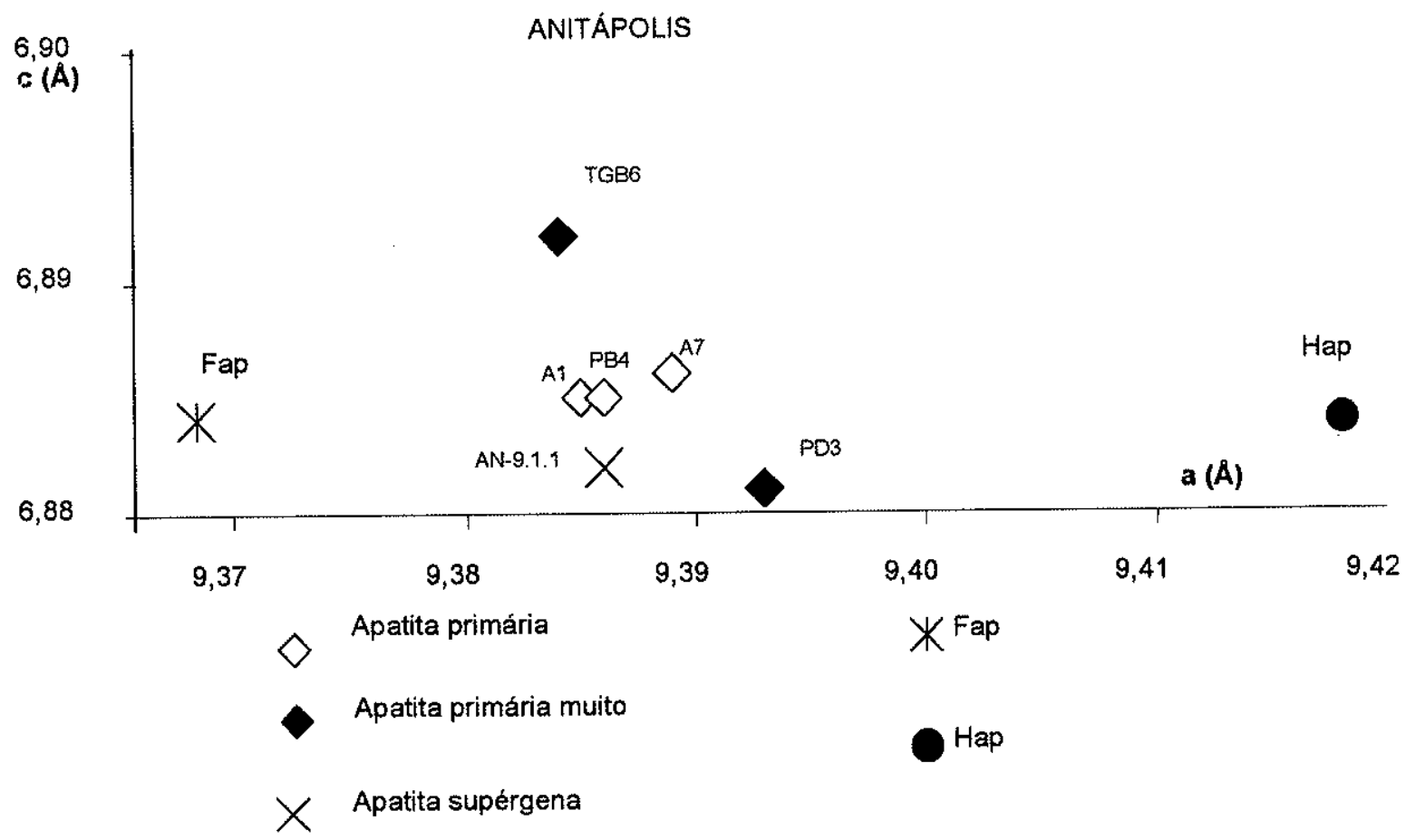

Figura 15 Variação dos parâmetros cristalográficos a e c das apatitas de Anitápolis, calculados pelo método dos mínimos quadrados utilizando o programa de refinamento de parâmetros de cela LCLSQ (Burnham, 1991). Fap - Fluorapatita sintética (JCPDS 15-876) Hap - Hidroxiapatita sintética (JCPDS 9-432) 


\section{Anitápolis}

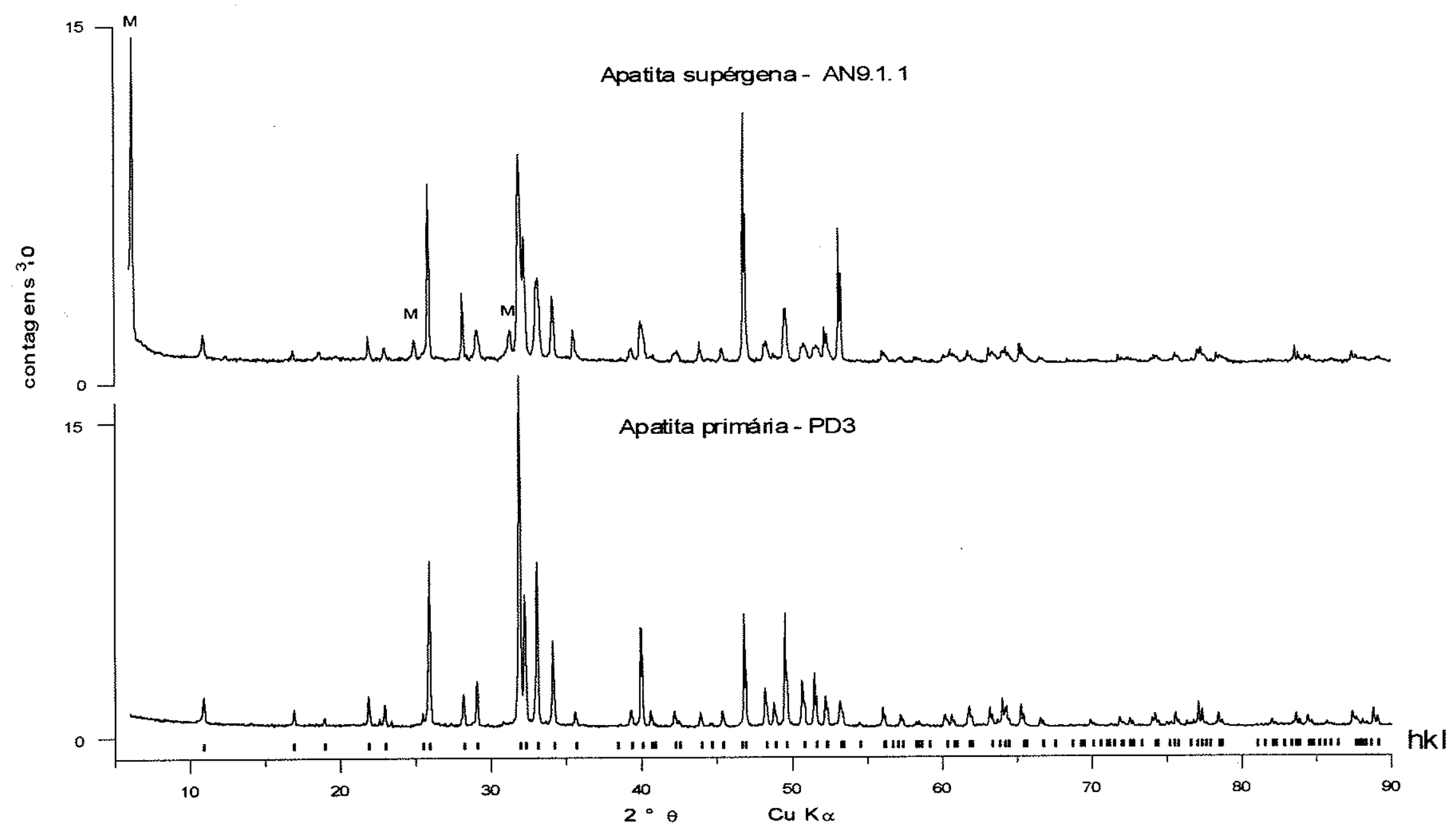

Figura 16 Difratogramas de amostras com apatita primária e supérgena de Anitápolis. M: mica, | : posições das reflexões de Bragg da apatita. 


\section{Aspectos químicos e cristaloquímicos das apatitas}

Os diferentes tipos de apatitas de Anitápolis foram analisados à ME (Tabela 18, Tabela 19 e Tabela 20, Figura 18 e Figura 19 e Anexo 1). A maioria das análises de apatitas primárias sãs apresentaram totais próximos de $98 \%$, enquanto que apatitas de alteração considerada não intempérica apresentaram totais entre 88 e $95 \%$. As apatitas fraturadas apresentam uma maior variação nos valores dos totais entre $95 \mathrm{e}$ $100 \%$. Pontos situados na borda de apatitas alteradas apresentaram totais mais baixos (93 e 94\%). As apatitas supérgenas do tipo fibrosa mostraram totais entre 81 e $86 \%$ valores considerados muito baixos em relação aos valores encontrados para as apatitas supérgenas já analisadas na literatura e no presente estudo. Esta discrepância pode ser devida à dimensão muito reduzida das fibras, sendo a porosidade intercristalina incluída nos volumes atingidos pelo feixe eletrônico.

Os totais aparecem relacionados positivamente com o fósforo, a exceção das análises de apatita supérgena que forma uma população distinta e é visualizada no gráfico, o diagrama binário Total $\times \mathrm{F}$ (Figura 18) mostra bem a individualização dos diferentes tipos morfológicos de apatita.

Os valores do número de átomo p.f.u. de $\mathrm{Cl}, \mathrm{Al}, \mathrm{Mg}, \mathrm{Fe}, \mathrm{Mn}, \mathrm{Ba}, \mathrm{La}$ e $\mathrm{Ce}$ são em geral muito baixos $(0$ a 0,02$)$ nas apatitas analisadas, salvo nas apatitas hidrotermais que apresentaram valores maiores de $\mathrm{Mn}(0,06$ a 0,02$)$ e $\mathrm{Fe}(0,08$ a $0,15)$ e nas apatitas supérgenas com valores de $\mathrm{Cl}$ (até 0,16$)$, $\mathrm{Al}(0,03$ a 0,07$)$ e $\mathrm{Fe}_{2} \mathrm{O}_{3}(0,02$ a 0,07$)$. Valores anômalos do número de átomo p.f.u. de $\mathrm{Fe}$ e de $\mathrm{Al}$ encontrados na apatita supérgena podem estar ligados a outras fases dada a dimensão das fibras deste tipo e sua intrínseca associação a produtos ferruginosos. Já os teores de cloro na apatita supérgena devem ser devidos à resina infiltrada entre as fibras, não havendo nenhum motivo geoquímico para sua real presença nestas apatitas, sendo difícil obter análises sem a sua influência.

O número de átomo de $\operatorname{Sr}(0,02$ a 0,05$)$ e $\mathrm{Na}(0,03$ a 0,13$)$ das apatitas primárias sãs diferem pouco das apatitas alteradas fraturadas ( $\mathrm{Na}$ : 0,02 a 0,11 e $\mathrm{Sr}$ : 0,04 e 0,07 ) e estriadas ( $\mathrm{Na}: 0,00$ a 0,10 e $\mathrm{Sr}: 0,04$ e 0,06). A borda de maior birrefringência possui valores anômalos de número de átomos de $\mathrm{Na}$ p.f.u. $(0,60$ a $1,20)$ e $\operatorname{Sr}(0,08$ a 0,15$)$ quando comparada com o núcleo dos cristais de apatita primária analisados. Em todos os tipos de apatitas de Anitápolis o Na domina sobre o Sr no sítio catiônico. 
Os pontos de análise de todos os tipos mostram uma nitida correlação entre o número de átomos p.f.u. de $\mathrm{Na}$ e o de $\mathrm{Ca}$, como o $\mathrm{Sr}$ apresenta uma menor variação dos valores de número de átomos p.f.u. não foi possível verificar a mesma correlação no gráfico $\mathrm{Sr} \times \mathrm{Ca}$.

Foram analisados à ME os ETR ( $\mathrm{La}, \mathrm{Ce}, \mathrm{Nd}$ e $\mathrm{Gd}$ ) para os diferentes tipos de apatita, utilizando de um programa de aquisição mais lento e aplicando as devidas correções relativas à uma composição típica das apatitas primárias, os resultados das análises estão na Tabela 20. Os diferentes tipos de apatita mostraram teores muito baixos de $\operatorname{ETR}\left(0,02\right.$ a $0,44 \%$ em $\left.\mathrm{TR}_{2} \mathrm{O}_{3}\right)$ e uma maior riqueza em $\mathrm{Ce}_{2} \mathrm{O}_{3}(0,01$ a $0,22 \%$ ) em relação aos outros ETR analisados. Houve pouca diferenciação dos tipos: apatita primária sã teores de $\mathrm{Gd}_{2} \mathrm{O}_{3}$ e $\mathrm{La}_{2} \mathrm{O}_{3}$ são praticamente ausentes nas apatitas supérgenas e hidrotermais e presentes nas apatitas primárias sã e alterada fraturada (até $0,11 \%$ de $\mathrm{Gd}_{2} \mathrm{O}_{3}$ e até $0,17 \%$ de $\mathrm{La}_{2} \mathrm{O}_{3}$ ). $\mathrm{O} \mathrm{Nd}_{2} \mathrm{O}_{3}$ ocorre em todos os tipos, sendo mais acentuado na apatita alterada fraturada $(0,10$ a $0,15 \%)$.

As razões $\mathrm{Ca} / \mathrm{P}_{2} \mathrm{O}_{5}$ encontradas para os tipos de apatita analisados estão quase sempre acima dos valores encontrados para uma fluorapatita padrão $(1,32)$. Estes valores são bem mais elevados na apatita supérgena (entre 1.43 e 1.47) e alguns pontos da apatita primária alterada. $\mathrm{O}$ gráfico binário da Figura 18 mostra uma correlação negativa entre os totais da análise e a razão $\mathrm{CaO} / \mathrm{P}_{2} \mathrm{O}_{5}$; os diferentes tipos de apatita primária (sã, fraturada e estriada) não se diferenciam neste gráfico. Os únicos tipos diferenciados no gráfico foram a apatita supérgena e a hidrotermal, esta última com menores valores de total da análise e razão menor $\mathrm{CaO} / \mathrm{P}_{2} \mathrm{O}_{5}$.

Si está presente em pequenas quantidades nas apatitas primárias e não varia com o grau de alteração dos materiais; aparece em maior quantidade nas apatitas supérgenas. Nestas apatitas o aumento no teor de Si é acompanhado por um aumento em $\mathrm{Al}$ o que não é observado nas apatitas primárias; talvez isto possa indicar a presença de argilominerais ou plasma de alteração aluminossilicático entre os cristais de apatita supérgena, embora isto não tenha sido observado ao MO nos pontos analisados.

$\mathrm{O}$ cálculo dos teores de $\mathrm{CO}_{3}{ }^{2-}$ por diferença na ocupação do sítio do $\mathrm{PO}_{4}$ nas fórmulas estruturais $(\mathrm{C}+\mathrm{P}+\mathrm{Si}=6)$ mostrou que as apatitas primárias são sempre empobrecidas em $\mathrm{CO}_{3}{ }^{2-}$ e que as apatitas com sinais de alteração possuem pontos de análises onde estes teores são elevados. Apatitas supérgenas apresentaram 
teores em $\mathrm{CO}_{3}{ }^{2-}$ mais elevados, calculados desta forma, do que as apatitas primárias e mais baixos do que as apatitas hidrotermais. $O$ cálculo por diferença, no entanto, não deve ser considerado livre de problemas $e$, por esta razão, outros procedimentos foram adotados para abordar melhor a questão.

A presença de $\mathrm{CO}_{2}$ nas apatitas de Anitápolis foi pesquisada também por IV e por MR. Foram analisados ao IV concentrados de carbonatito são (A7) e de veio de apatitito que corta o piroxenito alterado (PD3). $O$ conteúdo em $\mathrm{CO}_{2}$ das amostras $\mathrm{A} 7$ e PD3, calculado segundo método presente nos trabalhos de Lehr et al. (1968) e Scheib (1984), são muito próximos, 0,34 e 0,48\%, respectivamente. Estes valores estão no intervalo de valores aqui encontrados para cristais de apatita primária (sã: 0,38 a 1,67 e alterada: 0,17 a 3,13).

Das apatitas analisadas à MR, somente as apatitas hidrotermais mostraram a presença de $\mathrm{CO}_{2}$. Assim, os teores de $\mathrm{CO}_{2}$ médios calculados por diferença a partir de dados da microssonda não puderam ser confirmados pelas análises à MR.

As apatitas supérgenas e pontos analisados na borda de cristais de apatitas alteradas estriadas apresentaram um maior conteúdo em $\mathrm{F}^{-}$, refletidos nos maiores valores da razão $\mathrm{F} / \mathrm{P}_{2} \mathrm{O}_{5}$ (próximos da razão 0,89 da fluorapatita estequiométrica) e nos gráficos binários $\mathrm{F} \times \mathrm{Ca}$ e $\mathrm{F} \times$ Total \% (Figura 18).

Os cálculos do número de $\mathrm{OH}^{-}$p.f.u., os valores da carga da fórmula estrutural e do peso molecular são dados na Tabela 19. Os cálculos da presença de $\mathrm{OH}^{-}$nas fórmulas estruturais de apatita dependem, obviamente, da quantidade de Fconsiderada como integrante do canal, já que uma parte pode estar fora dos canais, acompanhando $o$ ânion carbonato, conforme discutido anteriormente. Considerando que todo o carbonato que substitui o fosfato é acompanhado por $F$ fora dos canais $\left(F_{p}=C\right)$ as fórmulas estruturais ficam melhor mais balanceadas (como é o caso da apatita primária e supérgena). Para apatita hidrotermal a fórmula fica mais balanceada quando é empregado o cálculo que considera todo o flúor no canal da estrutura.

No geral, a apatita supérgena apresentou um empobrecimento em $\mathrm{OH}^{-}$com relação à apatita primária sã (ambas considerando $\mathrm{F}_{\mathrm{p}}=\mathrm{C}$ ). Apatita hidrotermal, por apresentar baixo teor de flúor, deve ser a mais hidroxilada (composição próxima da hidroxiapatita). As análises ao IV efetuadas somente em amostras de apatita primária (que representavam amostras mais puras) mostraram picos discretos para a 
hidroxila, porém não foi possível calcular seus teores utilizando os espectros observados.

Foram observadas por catodoluminescência lâminas de carbonatito são (GPF3a), de piroxenito alterado (TGB4a) e apatitito (AN9e). As apatitas primárias apresentaram cores distintas variando com o grau de alteração da rocha. No carbonatito os cristais de apatita primária apresentaram um zoneamento da cor de luminescência, sendo o núcleo esverdeado com tons mais escuros tornando-se mais claros em direção à borda $e$, depois, marrom. $\mathrm{Na}$ alterita, as apatitas primárias apresentaram cores de luminescência salmão, eventualmente com cores alaranjadas em forma de manchas ou faixas seguindo bordas ou fraturas. As apatitas supérgenas apresentaram cor marrom. Cores alaranjadas são também encontradas em produtos ferruginosos presentes em fraturas no material alterado. 


\begin{tabular}{|c|c|c|c|c|c|c|c|c|c|c|c|c|c|c|c|}
\hline \multirow{2}{*}{$\begin{array}{l}\text { Tipo } \\
\text { Amostra }\end{array}$} & \multirow{2}{*}{\multicolumn{3}{|c|}{1}} & \multirow{2}{*}{\multicolumn{3}{|c|}{$2 a$}} & \multirow{2}{*}{\multicolumn{3}{|c|}{$2 \mathrm{~b}$}} & \multirow{2}{*}{\multicolumn{3}{|c|}{3}} & \multirow{2}{*}{\multicolumn{3}{|c|}{4}} \\
\hline & & & & & & & & & & & & & & & \\
\hline & $\frac{\text { GPF } 3 A}{44}$ & $\frac{\text { GPF3A }}{36}$ & $\frac{\text { GPF } 3 A}{37}$ & $\frac{\text { AN10C }}{1}$ & $\frac{\text { AN1OC }}{4}$ & $\frac{\text { AN1OC }}{6}$ & $\frac{\text { TGB4A }}{2}$ & $\frac{\text { TGB4A }}{8}$ & $\frac{\text { TGB4A }}{10}$ & $\frac{\text { GPF3A }}{27}$ & $\frac{\text { GPF } 3 A}{33}$ & $\frac{1 \mathrm{~A} 7}{39}$ & $\frac{\text { AN9E }}{8}$ & $\frac{\text { AN9E }}{22}$ & $\frac{\text { ANSE }}{24}$ \\
\hline $\mathrm{Na}_{2} \mathrm{O}$ & 0.29 & 0,15 & 0,17 & 0.23 & 0,23 & 0,37 & 0,31 & 0,22 & 0,13 & 3,28 & 3,80 & 1,90 & 0,00 & 0,15 & 0,18 \\
\hline $\begin{array}{l}\mathrm{CaO} \\
\mathrm{MgC}\end{array}$ & $\begin{array}{r}54,80 \\
0,00\end{array}$ & $\begin{array}{r}55,67 \\
0,00\end{array}$ & $\begin{array}{r}55,56 \\
0,00\end{array}$ & $\begin{array}{r}54,93 \\
0,01\end{array}$ & $\begin{array}{r}54,35 \\
0,09\end{array}$ & $\begin{array}{r}55,52 \\
0,02\end{array}$ & $\begin{array}{r}54,64 \\
0,00\end{array}$ & $\begin{array}{r}55,34 \\
0,00\end{array}$ & $\begin{array}{r}55,60 \\
0,00\end{array}$ & $\begin{array}{r}48,74 \\
0,06\end{array}$ & $\begin{array}{r}48.23 \\
0.04\end{array}$ & $\begin{array}{r}51,99 \\
0,06\end{array}$ & $\begin{array}{r}46,48 \\
0,01\end{array}$ & $\begin{array}{r}47,97 \\
0,06\end{array}$ & $\begin{array}{r}49,90 \\
0,00\end{array}$ \\
\hline MnO & 0,12 & 0,03 & 0,05 & 0,15 & 0,10 & 0,05 & 0,00 & 0,00 & 0,01 & 0,87 & 1,06 & 0,43 & 0,00 & 0.01 & 0,04 \\
\hline $\mathrm{FeO}$ & 0,06 & 0,08 & 0,02 & 0,15 & 0,06 & 0,05 & 0,04 & 0,00 & 0,06 & 1,08 & 0,91 & 0,61 & 0,09 & 0,27 & 0,42 \\
\hline StO & 0,45 & 0,46 & 0,37 & 0,49 & 0,48 & 0,56 & 0,50 & 0,46 & 0,39 & 1,08 & 0,94 & 1,60 & 0,18 & 0,22 & 0,14 \\
\hline $\mathrm{BaO}$ & 0,00 & 0,00 & 0,00 & 0,00 & 0,00 & 0,00 & 0,00 & 0,00 & 0,00 & 0,19 & 0,34 & 0,00 & 0,00 & 0,00 & 0,00 \\
\hline $\mathrm{Al}_{2} \mathrm{O}_{3}$ & 0,00 & 0,02 & 0,00 & 0,04 & 0,00 & 0,01 & 0,07 & 0,05 & 0,00 & 0,00 & 0,00 & 0,00 & 0,23 & 0,18 & 0.16 \\
\hline $\mathrm{La}_{2} \mathrm{O}_{3}$ & 0,05 & 0,20 & 0,06 & 0.13 & 0,00 & 0,10 & 0,00 & 0,00 & 0,02 & 0,00 & 0,06 & 0,00 & 0,00 & 0,04 & 0,11 \\
\hline $\mathrm{Ce}_{2} \mathrm{O}_{3}$ & 0,00 & 0.21 & 0,03 & 0,00 & 0,11 & 0,03 & 0,08 & 0,00 & 0,01 & 0,00 & 0,13 & 0,01 & 0,00 & 0,00 & 0,00 \\
\hline $\mathrm{SiO}_{2}$ & 0,05 & 0,19 & 0.13 & 0,23 & 0,29 & 0,31 & 0,14 & 0,18 & 0,11 & 0,01 & 0,08 & 0,06 & 0,14 & 0,03 & 0,07 \\
\hline $\mathrm{P}_{2} \mathrm{O}_{5}$ & 41,30 & 39,15 & 40,50 & 41,91 & 39,05 & 37,58 & 40,35 & 38,47 & 40,37 & 34,23 & 34,38 & 38,60 & 32,44 & 31,29 & 34,13 \\
\hline$F$ & 1,96 & 1,86 & 1,87 & 2,20 & 1,93 & 1,95 & 2,20 & 2,08 & 2,02 & 0,89 & 0,87 & 0,73 & 2,82 & 3,22 & 2,75 \\
\hline $\mathrm{Cl}$ & 0,06 & 0,00 & 0,00 & 0,03 & 0,02 & 0,01 & 0,04 & 0,06 & 0,00 & 0,02 & 0,01 & 0,00 & 0,12 & 0,09 & 0,02 \\
\hline & 98,87 & 97,87 & 98,60 & 100,28 & 96,49 & 96,19 & 98,07 & 96.66 & 98,60 & 87,17 & 87,06 & 94,09 & 82,51 & 83,37 & 87.74 \\
\hline $\mathrm{O}=\mathrm{F}, \mathrm{Cl}$ & 0,83 & 0,78 & 0,79 & 0,93 & 0,81 & 0,82 & 0,93 & 0,88 & 0,85 & 0,37 & 0,37 & 0,31 & 1,19 & 1,36 & 1,16 \\
\hline TOTAL & 98,04 & 97,08 & 97,82 & 99,35 & 95,67 & 95,37 & 97,14 & 95,78 & 97,75 & 86,80 & 86.70 & 93,79 & 81,32 & 82,02 & 86,58 \\
\hline $\begin{array}{l}\mathrm{CO}_{2} \\
\mathrm{CO} 2 \text { (MER) }\end{array}$ & 0,60 & $\begin{array}{l}2,13 \\
0 \%\end{array}$ & 1,23 & 0,17 & $\begin{array}{l}1,64 \\
-\end{array}$ & 3,13 & 1,03 & 2,38 & 1,30 & 5,64 & $\begin{aligned} & 5,67 \\
> & 0 \%\end{aligned}$ & 2.92 & 2,11 & $\begin{array}{l}4,05 \\
0 \%\end{array}$ & 2,94 \\
\hline $\begin{array}{l}\mathrm{Na} \\
\mathrm{Ca} \\
\mathrm{Mg}\end{array}$ & $\begin{array}{l}0,094 \\
9,832 \\
0,001\end{array}$ & $\begin{array}{l}0,049 \\
9,867 \\
0,001\end{array}$ & $\begin{array}{l}0,055 \\
9,893 \\
0,001\end{array}$ & $\begin{array}{l}0,075 \\
9,825 \\
0,002\end{array}$ & $\begin{array}{l}0,074 \\
9,827 \\
0,023\end{array}$ & $\begin{array}{l}0,119 \\
9,802 \\
0,005\end{array}$ & $\begin{array}{l}0,101 \\
9,839 \\
0,001\end{array}$ & $\begin{array}{l}0,070 \\
9,884 \\
0,001\end{array}$ & $\begin{array}{l}0,041 \\
9,909 \\
0,001\end{array}$ & $\begin{array}{l}1,042 \\
8,560 \\
0,014\end{array}$ & & & $\begin{array}{l}0,001 \\
9,960 \\
0,003\end{array}$ & $\begin{array}{l}0,056 \\
9,855 \\
0,018\end{array}$ & $\begin{array}{l}0,062 \\
9,845 \\
0,000\end{array}$ \\
\hline Mn & 0,016 & 0,004 & 0,007 & 0,022 & 0,014 & 0,007 & 0,000 & 0,000 & 0,001 & 0,121 & 0.146 & 0,059 & 0,000 & 0,001 & 0,006 \\
\hline $\mathrm{Fe}$ & 0,009 & 0,011 & 0,003 & 0,021 & 0,008 & 0,006 & 0,006 & 0,000 & 0,008 & 0,148 & 0,124 & 0,084 & 0,015 & 0,043 & 0,065 \\
\hline Sr & 0,044 & 0,044 & 0,036 & 0,048 & 0,047 & 0,053 & 0,048 & 0,044 & 0,038 & 0,103 & 0,089 & 0,152 & 0,020 & 0,024 & 0,015 \\
\hline $\mathrm{Ba}$ & 0,000 & 0,000 & 0,000 & 0,000 & 0,000 & 0,000 & 0,000 & 0,000 & 0,000 & 0,012 & 0,022 & 0,000 & 0,000 & 0,000 & 0,000 \\
\hline $\mathrm{Al}$ & 0,001 & 0,004 & 0,001 & 0,008 & 0,001 & 0,002 & 0,014 & 0,010 & 0,001 & 0,001 & 0,001 & 0,001 & 0,054 & 0,040 & 0,035 \\
\hline La & 0,003 & 0,012 & 0,004 & 0,008 & 0,000 & 0,006 & 0,000 & 0,000 & 0,001 & 0,000 & 0,004 & 0,000 & 0,000 & 0,003 & 0,007 \\
\hline $\mathrm{Ce}$ & 0,000 & 0,013 & 0,002 & 0,000 & 0,007 & 0,002 & 0,005 & 0,000 & 0,000 & 0,000 & 0,008 & 0,000 & 0,000 & 0,000 & 0,000 \\
\hline Si & 0,008 & 0,032 & 0,021 & 0,038 & 0,048 & 0,051 & 0,024 & 0,031 & 0,019 & 0,001 & 0,013 & 0,009 & 0,027 & 0,006 & 0,013 \\
\hline$P$ & 5,855 & 5,483 & 5,698 & 5,923 & 5,579 & 5,242 & 5.740 & 5.429 & 5,684 & 4,750 & 4,732 & 5,332 & 5.493 & 5,079 & 5,320 \\
\hline c & 0,136 & 0,485 & 0,281 & 0,039 & 0,373 & 0,707 & 0,236 & 0,540 & 0,297 & 1,249 & 1,255 & 0,658 & 0,480 & 0,915 & 0,666 \\
\hline $\mathrm{F}$ & 1,040 & 0,975 & 0,981 & 1,160 & 1,032 & 1,015 & 1,172 & 1.096 & 1,062 & 0,460 & 0.448 & 0,379 & 1,785 & 1.953 & 1,604 \\
\hline $\mathrm{Cl}$ & 0,016 & 0,000 & 0,000 & 0,008 & 0,006 & 0,002 & 0,013 & 0,016 & 0,000 & 0,005 & 0,002 & 0,000 & 0,041 & 0,028 & 0,006 \\
\hline
\end{tabular}

Tabela 18 Análises à microssonda eletrônica (em \% em peso dos óxidos) e cálculos de fórmulas estruturais das apatitas de Anitápolis.

Composição química, obtida à ME, dos diferentes tipos de apatita estudados em Anitápolis, expressa em \% em peso de óxidos e em número de átomos por fórmula unitária calculada na base 10 cátions. São apresentados os pontos de análise mais representativos dos tipos: 1-apatita primária sã, 2-apatita primária alterada a-fraturada e b- estriada, 3-borda de maior birrefringência, 4- apatita supérgena fibrorradial. A tabela completa das análises encontra-se no Anexo. Cálculos de $\mathrm{CO}_{2}$ efetuados pela diferença no sítio do fósforo $(\mathrm{P}+\mathrm{Si}+\mathrm{C}=6)$. 
Tabela 18 (continuação)

\begin{tabular}{|c|c|c|c|c|c|c|c|c|c|c|c|c|c|c|c|}
\hline \multirow{2}{*}{$\begin{array}{l}\text { Tipo } \\
\text { Amostra }\end{array}$} & \multicolumn{3}{|c|}{1} & \multicolumn{3}{|c|}{$2 a$} & \multicolumn{3}{|c|}{$2 b$} & \multicolumn{3}{|c|}{3} & \multicolumn{3}{|c|}{4} \\
\hline & GPF3A & GPF3A & GPF3A & AN10C & AN10C & AN10C & TGB4A & TGB4A & TGB4A & GPF 3A & GPF 3A & $1 \mathrm{~A} 7$ & AN9E & AN9E & AN9E \\
\hline No & 44 & 36 & 37 & 1 & 4 & 6 & 2 & 8 & 10 & 27 & 33 & 39 & 8 & 22 & 24 \\
\hline$" \% \mathrm{OH}^{4}$ & 1,63 & 1,76 & 1,74 & 1,42 & 1,65 & 1,70 & 1,41 & 1,55 & 1,60 & 2,75 & 2,77 & 2,81 & 0,37 & 0,08 & 0,68 \\
\hline$\% \cup H^{1 .}$ & 1,12 & 2,083 & 1,92 & 1,44 & 1,90 & 2,18 & 1,57 & 1,92 & 1,80 & 3,60 & 3,63 & 3,25 & 0,69 & 0,71 & 1,14 \\
\hline$\% \mathrm{OH}^{1}$ & 1,85 & 2,56 & 2,20 & 1,48 & 2,28 & 2,89 & 1,80 & 2,5 & 2,1 & 4,86 & 4,90 & 3,91 & 1,2 & 1,64 & 1,81 \\
\hline$O H^{: 3}$ pfu & 0,944 & 1,025 & 1,018 & 0,832 & 0,962 & 0,983 & 0,815 & 0,888 & 0,938 & 1,535 & 1,549 & 1,620 & 0,174 & 0,019 & 0,390 \\
\hline$O H^{b}$ pru & 0,998 & 1,219 & 1,131 & 0,847 & 1,111 & 1,265 & 0,910 & 1,104 & 1,057 & 2,034 & 2,051 & 1,884 & 0,366 & 0,385 & 0,656 \\
\hline$O H^{c}$ pfu & 1,080 & 1,510 & 1,299 & 0,871 & 1,335 & 1,689 & 1,051 & 1,428 & 1,235 & 2,784 & 2,804 & 2,279 & 0,654 & 0,934 & 1,056 \\
\hline P.M. ${ }^{a}$ & 1003 & 993 & 998 & 1005 & 995 & 983 & 1000 & 989 & 997 & 954 & 952 & 981 & 995 & 979 & 986 \\
\hline P.M. ${ }^{\mathrm{D}}$ & 1004 & 996 & 999 & 1005 & 997 & 988 & 1002 & 993 & 999 & 962 & 961 & 985 & 998 & 985 & 991 \\
\hline P.M. ${ }^{C}$ & 1005 & 1001 & 1002 & 1005 & 1001 & 995 & 1004 & 998 & 1002 & 975 & 973 & 992 & 1003 & 994 & 998 \\
\hline carga $^{a}$ & 0,047 & 0,472 & 0,233 & $-0,005$ & 0,307 & 0,603 & 0,181 & 0,499 & 0,259 & 0,209 & 0,069 & 0,060 & 0,643 & 0,982 & 0,717 \\
\hline carga & $-0,008$ & 0,278 & 0,121 & $-0,021$ & 0,158 & 0,320 & 0,087 & 0,283 & 0,140 & $-0,291$ & $-0,433$ & $-0,204$ & 0,451 & 0,616 & 0,451 \\
\hline carga $^{c}$ & $-0,090$ & $-0,013$ & $-0,048$ & $-0,044$ & $-0,065$ & $-0,104$ & $-0,055$ & $-0,041$ & $-0,038$ & $-1,040$ & $-1,186$ & $-0,599$ & 0,162 & 0,067 & 0,051 \\
\hline
\end{tabular}

Tabela 19 Dados de quantidades de $\mathrm{OH}$ (\% em peso e átomos p.f.u.), peso molecular (PM) e carga da fórmula estrutural considerando três alternativas: a - todo flúor $(F)$ nos canais $\left(F_{p}=0\right)$, b - parte do flúor $\left(F_{p}\right)$ acompanhando $0 \mathrm{CO}_{3}{ }^{2-}\left(F_{p}=0,4 C\right)$ e $c-p a r t e$ do flúor $\left(F_{p}\right)$ acompanhando o $\mathrm{CO}_{3}\left(\mathrm{~F}_{\mathrm{p}}=\mathrm{C}\right)$. $\mathrm{OH}$ foi calculado pela diferença da fração molar no sítio dos ânions monovalentes $\left(\mathrm{OH}=2-\mathrm{F}-\mathrm{F}_{\mathrm{p}}\right)$, para cada caso a, b e c. (A partir dos dados da tabela anterior, para apatitas de Anitápolis)

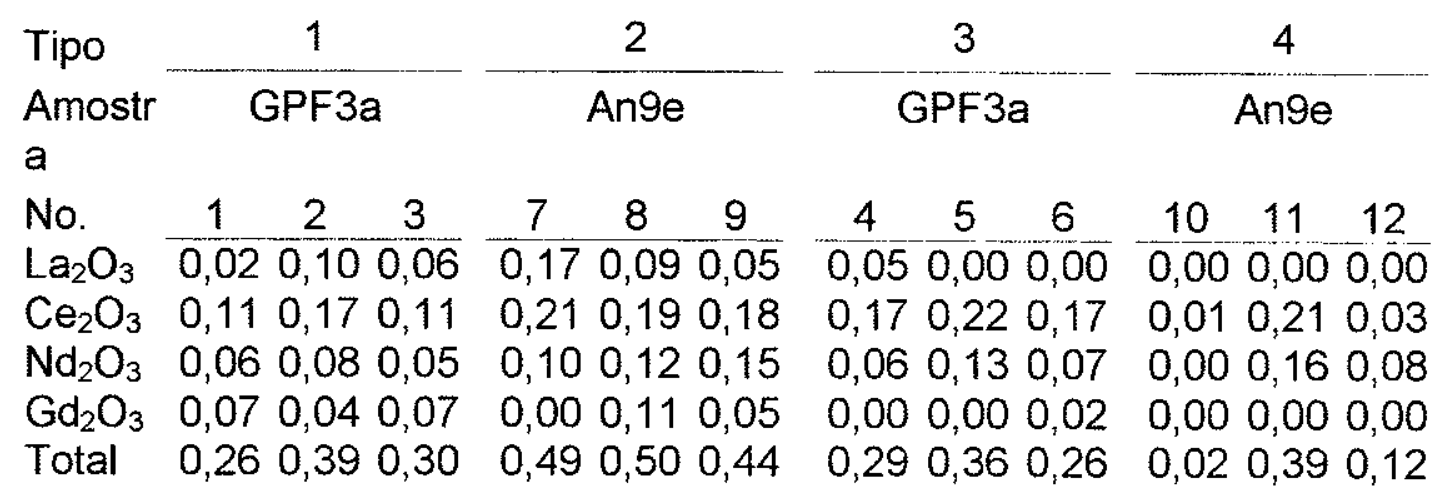

Tabela 20 Análises detalhadas de elementos terras-raras à ME (\% em peso dos óxidos) de apatitas de Anitápolis. 


\section{ANITÁPOLIS}

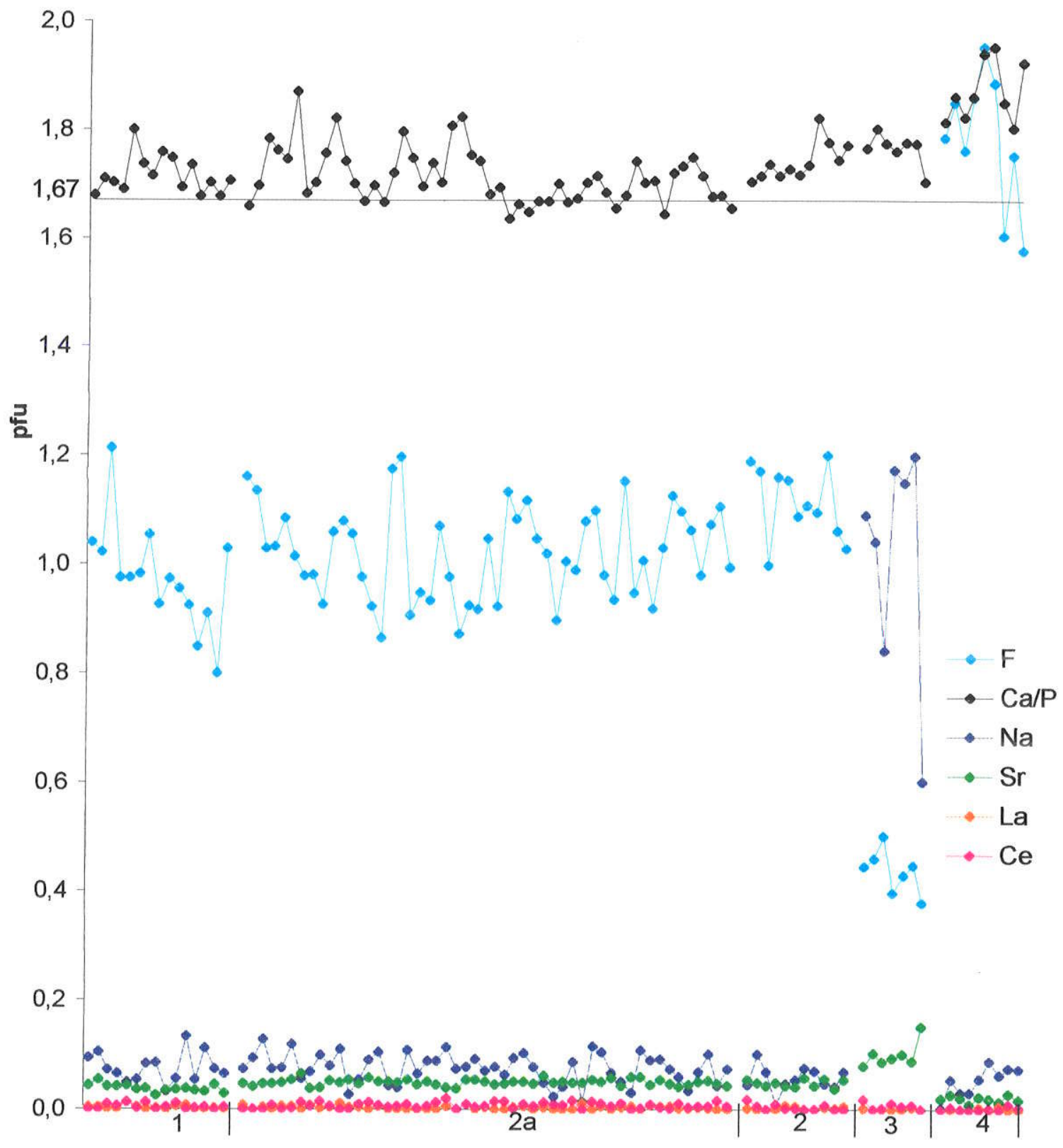

Figura 17 Gráfico da variação, em número de átomos p.f.u., dos principais cátions substituintes do cálcio, da razão $\mathrm{Ca} / \mathrm{P}$ e do $\mathrm{F}$ de diferentes tipos de apatita de Anitápolis. Os cálculos de fórmula estrutural foram efetuados com base em 10 cátions a partir de dados da ME.

1-apatita primária sã, 2-apatita primária alterada a- fraturada e b- estriada, 3- borda de maior birrefringência, 4- apatita supérgena fibrorradial. 
ANITÁPOLIS
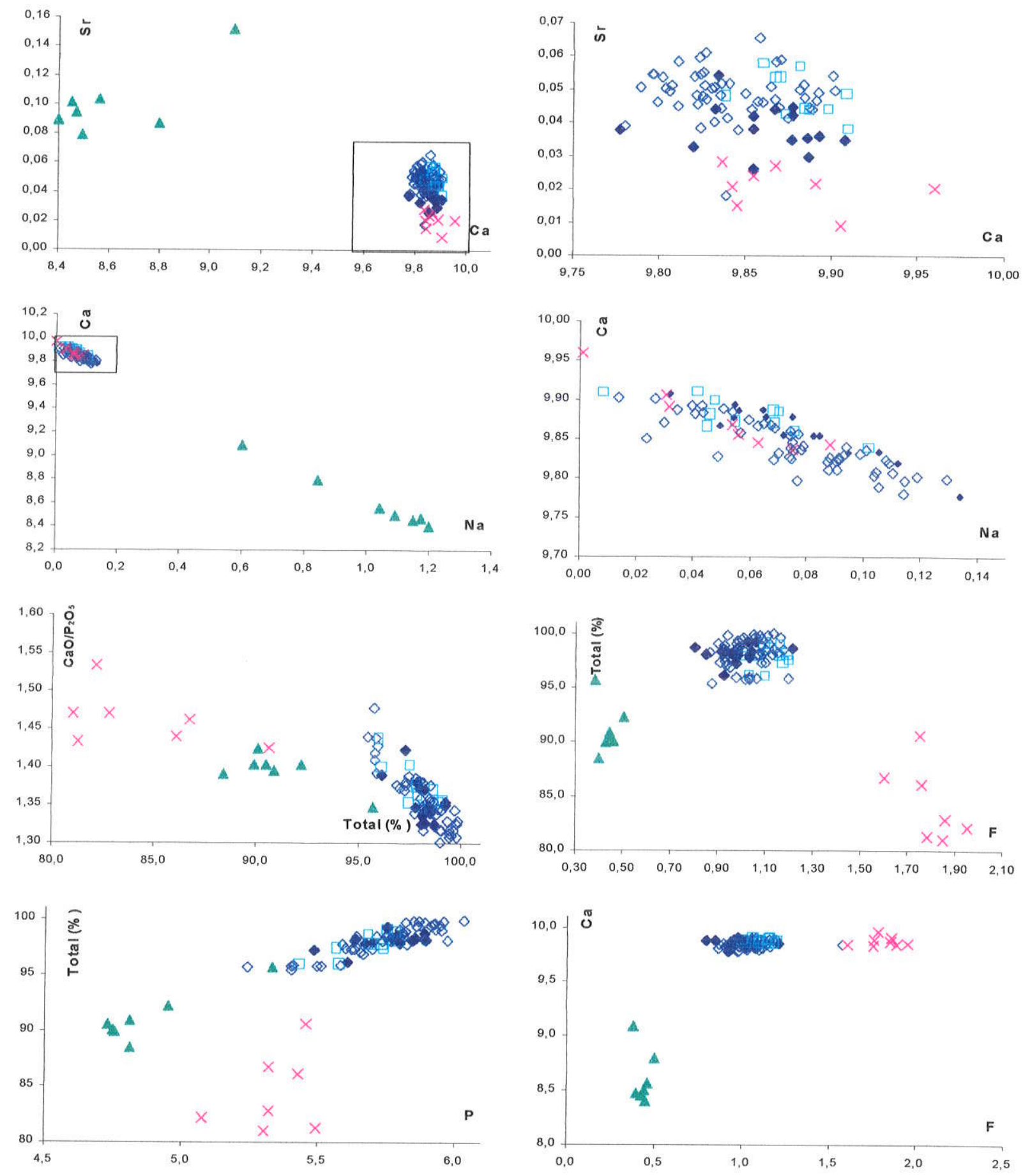

Apatitas primárias

Apatitas pré-meteóricas

Apatitas supérgenas

- 1-apatita primária sãipo pavê sã

$\Delta$ 4- borda de maior birrefringência

$\times \quad 5$ - apatita supérgena fibrorradial

$\diamond \quad$ 2-apatita primária fraturada

$\square$ 3-apatita primária com feiçäo estriada

Figura 18 Diagramas binários mostrando as relações entre vários dos constituintes das apatitas de Anitápolis, em número de átomos p.f.u. (fórmula estrutural calculada na base 10 cátions a partir de dados da ME). 

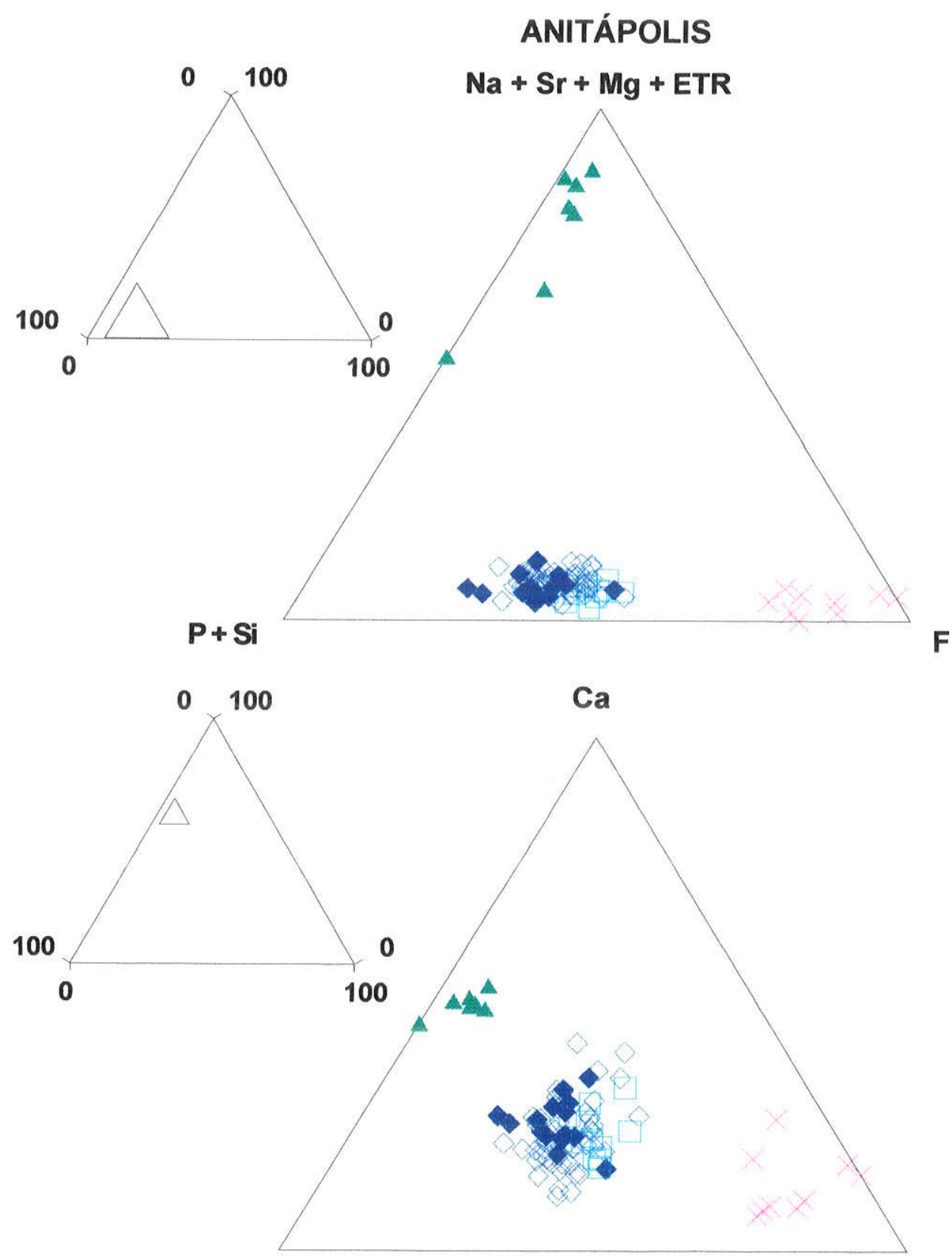

$\mathrm{P}+\mathrm{Si}$

Apatitas hidrotermais

3- borda de maior birrefringência

$\mathbf{F}$

Apatitas primárias

- 1-apatita primária sã

$\diamond \quad 2$ a-apatita primária fraturada

2 b- apatita primária com

feição estriada

\section{F}




\subsubsection{Juquiá}

\section{Mineralogia e micromorfologia das apatitas}

Ao contrário de Anitápolis, em Juquiá o estudo por DRX mostrou a presença de outros fosfatos além da apatita, mas apenas no perfil de alteração. Entre os minerais primários, apenas a apatita representa os fosfatos.

Os estudos ao MO e ao MEV permitiram a classificação das apatitas segundo suas morfologias e modo de ocorrência. Foram observados cristais de apatita primária da rocha fresca e do material de intemperismo (residuais) e de apatita supérgena freqüentemente encontrada no carbonatito alterado e na zona de transição entre o carbonatito e as rochas alcalino-silicáticas. Ainda pode ser notada a alteração anterior ao intemperismo (hidrotermal ou tardi-magmática) dos cristais de apatita primária nos materiais inalterados, ainda com carbonatos. Onde os carbonatos foram eliminados a apatita residual apresenta fraturas e feições de dissolução; tais feições serão detalhadas a seguir com a apresentação de fotos e descrições. Como em Anitápolis, o reconhecimento do caráter primário ou secundário, intempérico ou não, das apatitas, foi feito com base em suas características de ocorrência, morfológicas e situaçăo das amostras que as contêm.

\section{Apatitas primárias}

1- Apatita tipo pavê em rocha sã (Aa15, FJ42a)

Cristais de apatita primária ocorrem tanto no carbonatito são como no alterado; em geral são ovóides, transparentes e podem apresentar inclusões fluidas alongadas. Os cristais de apatitas, de dimensões variadas, formam uma textura tipo pavê e em geral possuem uma borda de maior birrefringência similar à encontrada na apatita primária de Anitápolis (Foto 7). A apatita primária aparece associada à dolomita em proporções variáveis, formando faixas alternadas de maior concentração apatítica, o que resulta num bandamento da rocha.

2- Apatita tipo pavê em material alterado (JU14c1) e 3-muito alterado (FJ42a, JU17, JU15a1, JU10C)

Cristais de apatita primária alterada são encontrados na alterita do carbonatito que apresenta cavidades romboédricas deixadas pela dissolução da dolomita. Nos cristais de apatita alterados ainda se observa a presença de uma borda de maior birrefringência porém com sinais de dissolução localizada (Foto 8). Os materiais 
associados a este tipo podem apresentar fraturas preenchidas por apatitas supérgenas do tipo hialino. No material alterado rico em argilominerais, gorceixita $e$ vênulas de apatitas supérgenas fibrosas, estas apatitas apresentam-se bem alteradas, observando-se ao MO uma maior opacidade dos cristais (Foto 34).

As feições de alteração como bordas de diferente textura, superficie com sinais de dissolução e interior fraturado foram observadas também ao MEV (Foto 8, Foto 9 , Foto 10, Foto 11, Foto 12 e Foto 13).

\section{Apatita hidrotermal}

4 a= Apatita prismática com linhas de crescimento em carbonatito são (FJ88) e $4 \mathrm{~b}$ - em carbonatito alterado (JU37.1, JU48, JU14c1)

Encontrada no carbonatito são e alterado, sua dimensão é menor do que a primária tipo pavê; apresenta linhas de crescimento concêntricas e cor de birrefringência mais alta do que as apatitas primárias. Formam cristais prismáticos que podem estar agregados em buquê ou isolados. Na rocha, são associados a massas dolomíticas e cristais de apatita tipo pavê com borda de maior birrefringência e na isalterita podem estar envoltos por apatitas supérgenas ou produtos ferruginosos (Foto 14).

5- Apatita recristalizada na superfície da apatita tipo pavê (com $\underline{\mathrm{Sr}}$ alto) (JU40, JU48, JU14c1)

Encontrada em carbonatito são e alterado, forma um massa que preenche os espaços intercristalinos nas superficies externas das bordas de maior birrefringência. Pode apresentar linhas de crescimento e uma terminação de forma hexagonal. 0 mesmo tipo foi descrito por Walter (1991) que o considerou relacionado a um evento tardi-magmático.

6- Borda de maior birrefringência ao redor da apatita tipo pavê (Aa15, FJ88, FJ42a, JU17) e pouco alterada (JU14c1, JU10Ca)

Quando observada em carbonatito são, a borda dos cristais de apatita em pavê exibe uma textura lisa, cor de birrefringência mais forte e apresenta uma espessura irregular podendo atingir um volume de até quase a totalidade da volume original destes cristais (Foto 7, Foto 8 e Foto 15). Em carbonatito pouco alterado ainda é possivel observar esta borda, apesar de sua cor de birrefringência já não se distinguir tão claramente da cor do núcleo do cristal de apatita; neste caso, a borda é visualizada pela sua textura de aparência rugosa e feições de dissolução. 
Segundo Walter (1991) os dois últimos tipos são de origem hipógena, formados por um evento tardi-magmático e derivados de um mesmo fluido.

\section{Apatita supérgena}

7 - Apatita supérgena tipo microprismática (JU10b, JU43b)

Constitui um material de alta resistência, de granulometria muito fina, de cor caramelo a chocolate e que é encontrado nas cavidades do carbonatito alterado. Este material contém apatitas microprismáticas incolores, sem orientação dos cristais, misturadas a produtos argiloferruginosos que muitas vezes mascaram suas propriedades ópticas (Foto 16). Ao MO e a olho nu observa-se uma laminação marcada pela alternância de cor. Uma única camada de apatita tipo fibroso leitoso pode estar presente entre as paredes das cavidades e esta massa apatítica microcristalina que a preenche.

8 a - Apatita supérgena tipo fibroso leitosa (JU37.1, JU10b, JU17, JU23, JUT10Ca, JUT10a, JU15a1, JUT7)

Tipo mais comum e abundante encontrado no carbonatito alterado e alterita de rochas silicáticas, apresenta camadas de cristais fibrosos dispostos perpendicularmente às descontinuidades das alteritas de carbonatitos, formando uma estrutura tipo botrioidal (Foto 16 e Foto 17). As camadas podem apresentar diferenças, com lâminas transparentes e leitosas alternadas.

8 b - Apatita supérgena tipo fibrorradial (JU37.1, JU17, JU23, JUT10a, FJ42a)

Constituem cristais aciculares radialmente dispostos, com aproximadamente $10 \mu \mathrm{m}$ de comprimento preenchendo as microcavidades dos produtos ferruginosos (Foto 8). Este tipo é encontrado na alterita do carbonatito e na zona de transição.

9 - Apatita supérgena tipo prismática: a- sobre a apatita fibrosa brotrioidal de fissuras (JU40, JU23, JU37.1) e b- em fissuras não revestidas por apatita supérgena (JU14c1)

Ocorre no carbonatito alterado. É transparente e prismática, com forma piramidal e dimensões sub-milimétricas a milimétricas (Foto 17 e Foto 18). Forma drusas de cristais prismáticos que revestem descontinuamente a superficie dos botrióides de apatita leitosa, de cristais de barita e das paredes de fraturas. 


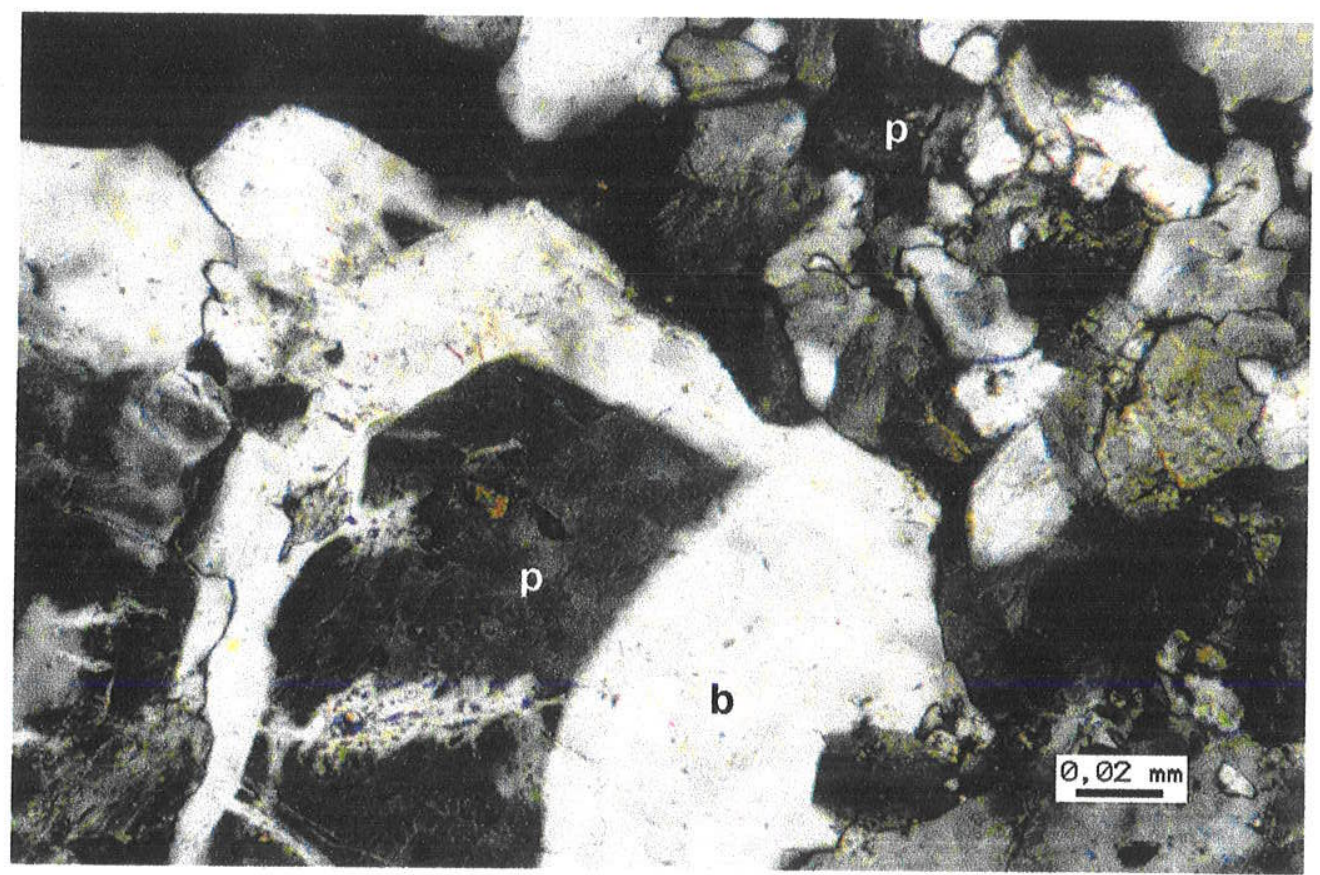

Foto 7 Cristais de apatita primária sã (p) com borda de maior birrefringência (b) estão associados a cristais menores sem esta borda. Juquiá. Amostra FJ-88. MO (LP).

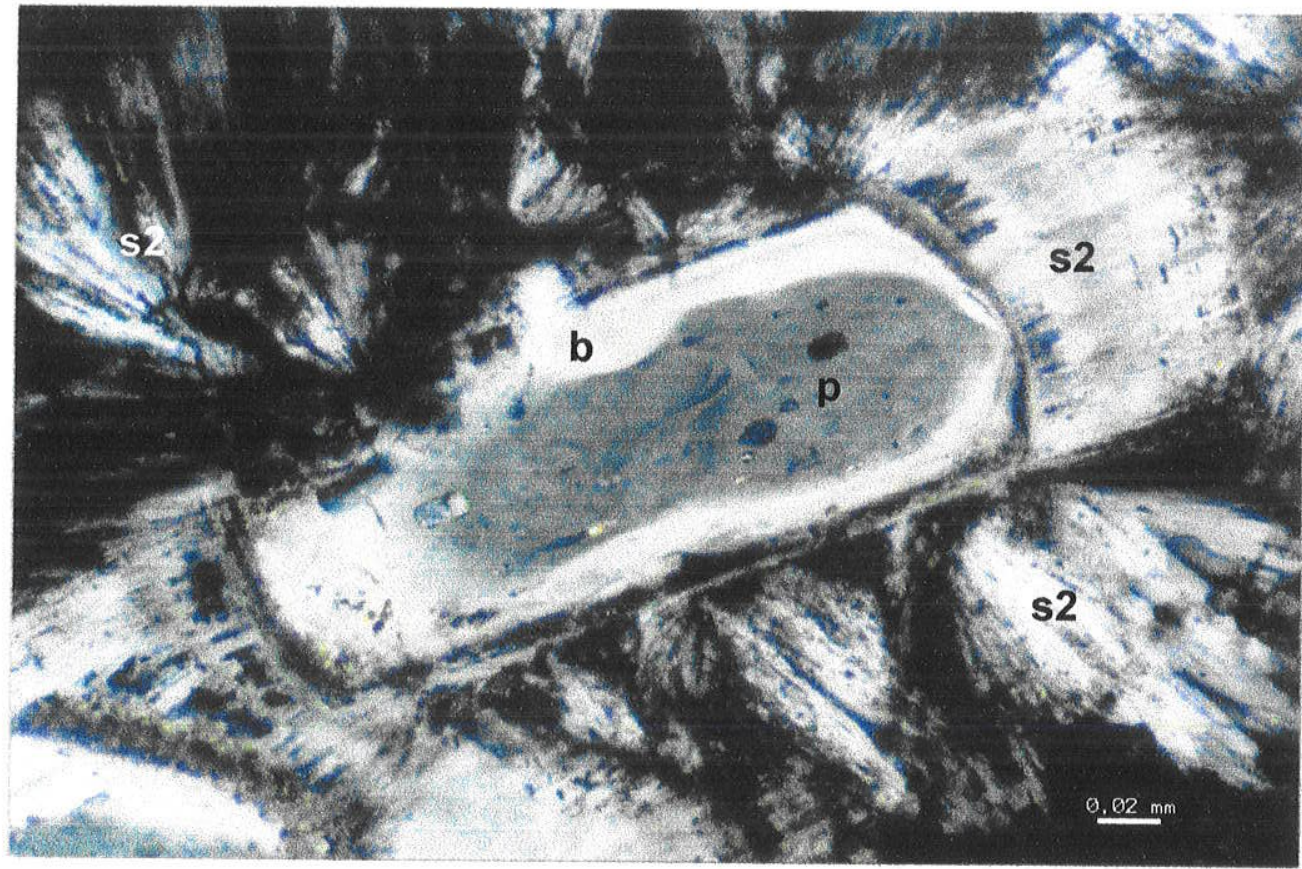

Foto 8 Apatita primária alterada (p) com borda de maior birrefringência (b) parcialmente dissolvida e recoberta por fibras de apatita supérgena tipo fibrorradial (s2). Juquiá. Amostra FJ-42. MO (LP). 

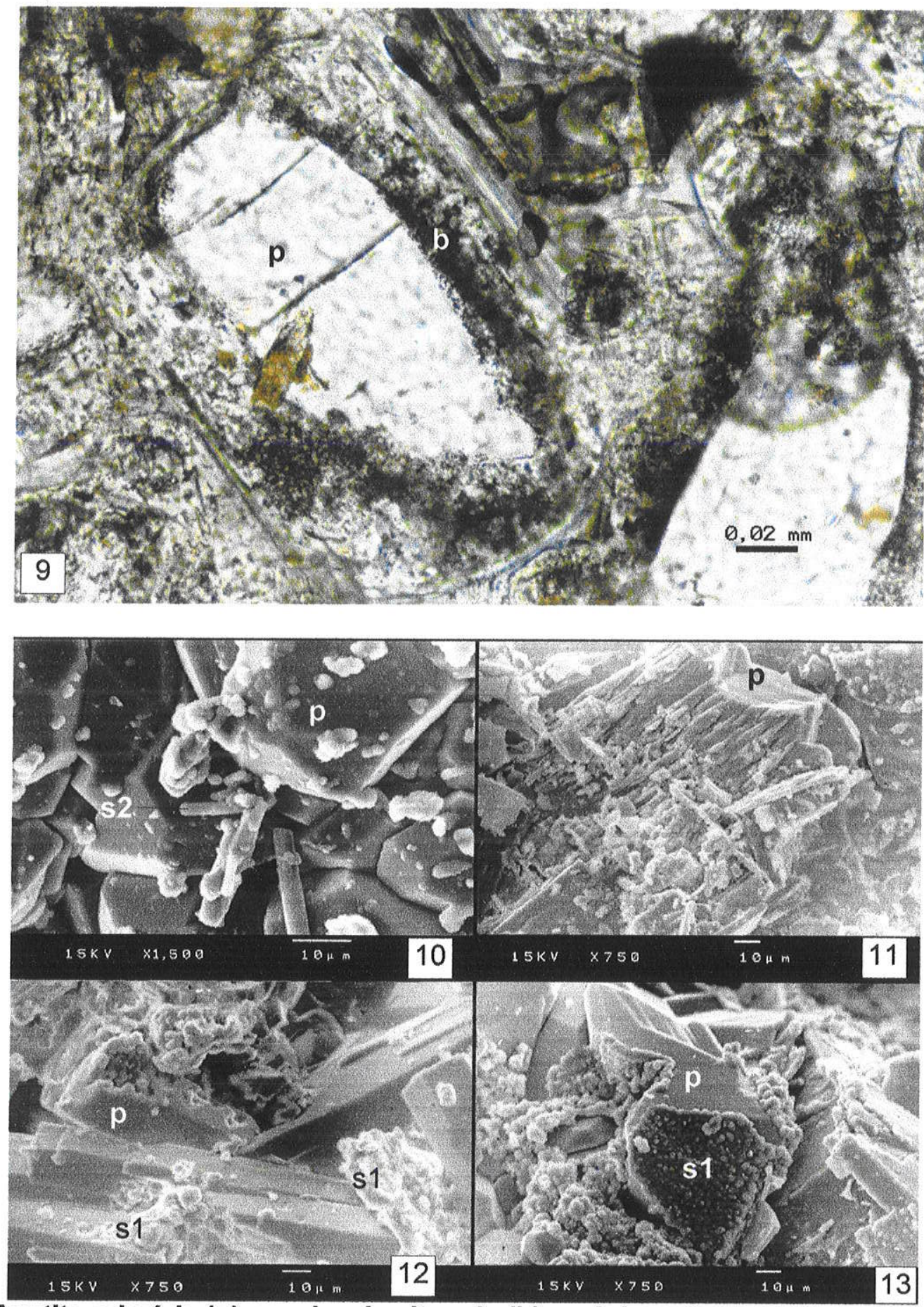

Foto 9 Apatita primária ( $p$ ) com borda alterada (b) e núcleo são. Juquiá. Amostra JU48. MO (LN).

Foto 10 Cristais de apatita primária residual sã (p), euedrais, associados a pequenos cristais alongados de apatita supérgena (s1). Juquiá. Amostra JU1B. MEV (SEI),

Foto 11 Feições de dissolução "em ripa" da apatita primária residual (p). Juquiá. Amostra JU14. MEV (SEI).

Foto 12 Feições de dissolução em pequenos "golfos" na apatita primária (p) associada a apatita supérgena criptocristalina. Juquiá. Amostra JU34. MEV (SEI).

Foto 13 Apatita primária $(p)$ parcialmente alterada revestida por apatita supérgena criptocristalina (s1). Amostra JU14. Juquiá. MEV (SEI). 

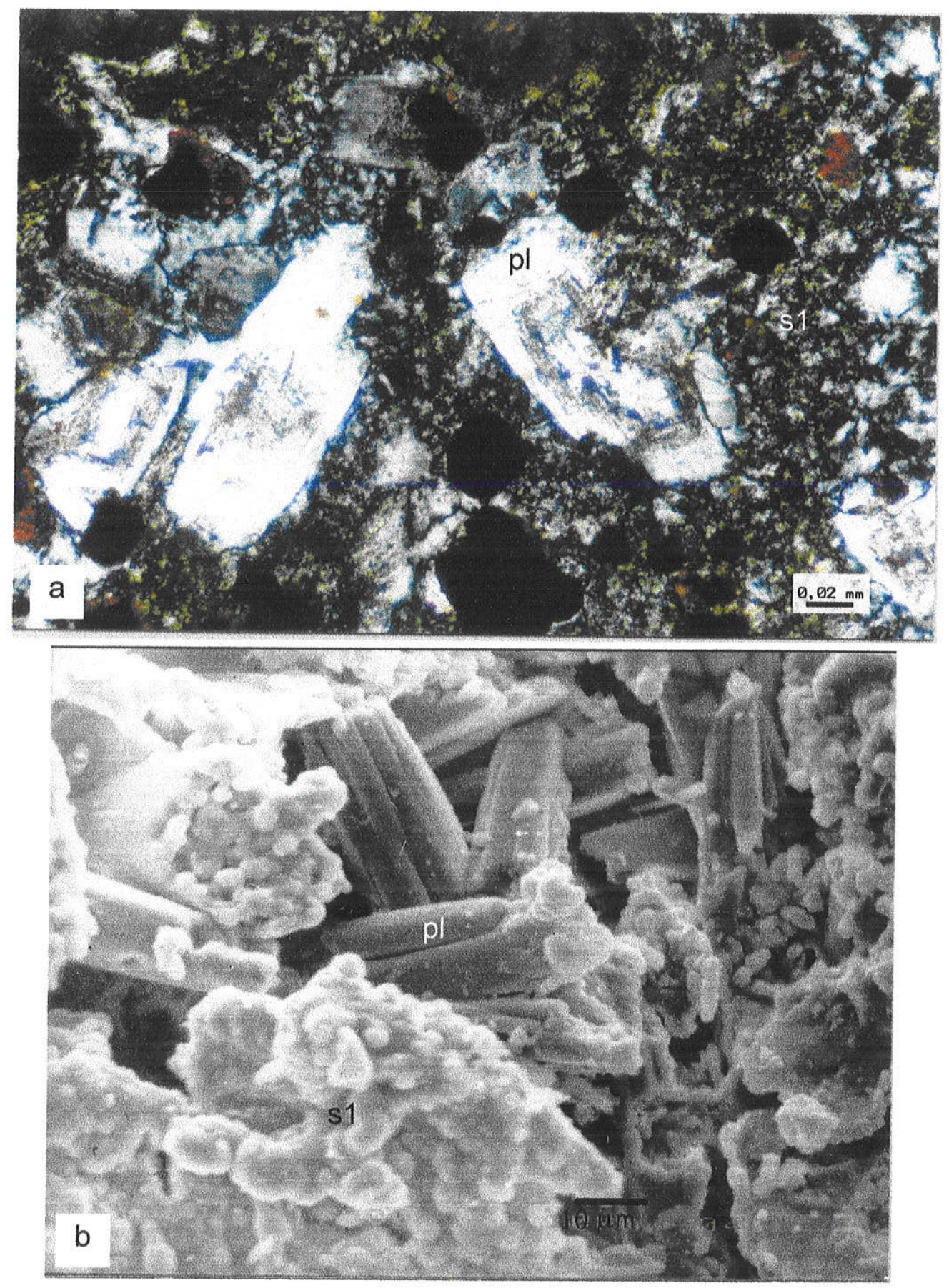

Foto 14 a: Cristais de apatita com linha de crescimento (pl) em carbonatito alterado com vazios deixados pela dissolução do carbonato preenchido por apatita supérgena criptocristalina (s1). Juquiá. Amostra JU37.1. MO (LP). b: Detalhe destas apatitas primárias imersas em massa de cristais criptocristalino (s1), algumas delas encontram-se parcialmente dissolvidas. Juquiá. Amostra JU37.1 MEV (SEI). 


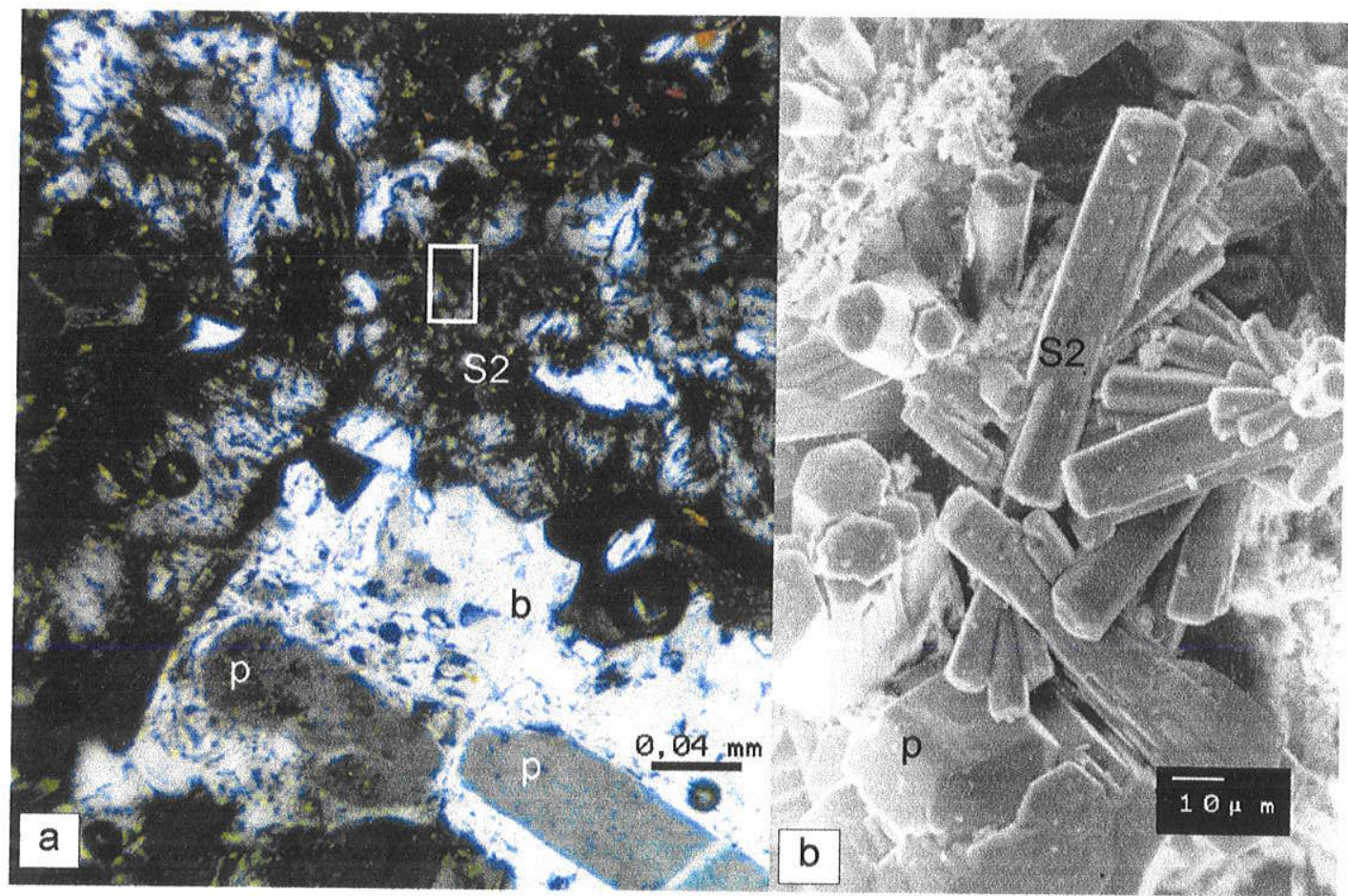

Foto 15 a: Cristais de apatita primária sã (p) com borda de maior birrefringência (b) em massa de cristais fibrorradiais de apatita supérgena (s2). Juquiá. Amostra JU32.1. MO (LP). b: Cristais fibrosos de apatita supérgena (s2) ao lado de um cristal de apatita primária sã residual (p). Juquiá. Amostra JU21B. MEV (SEI).

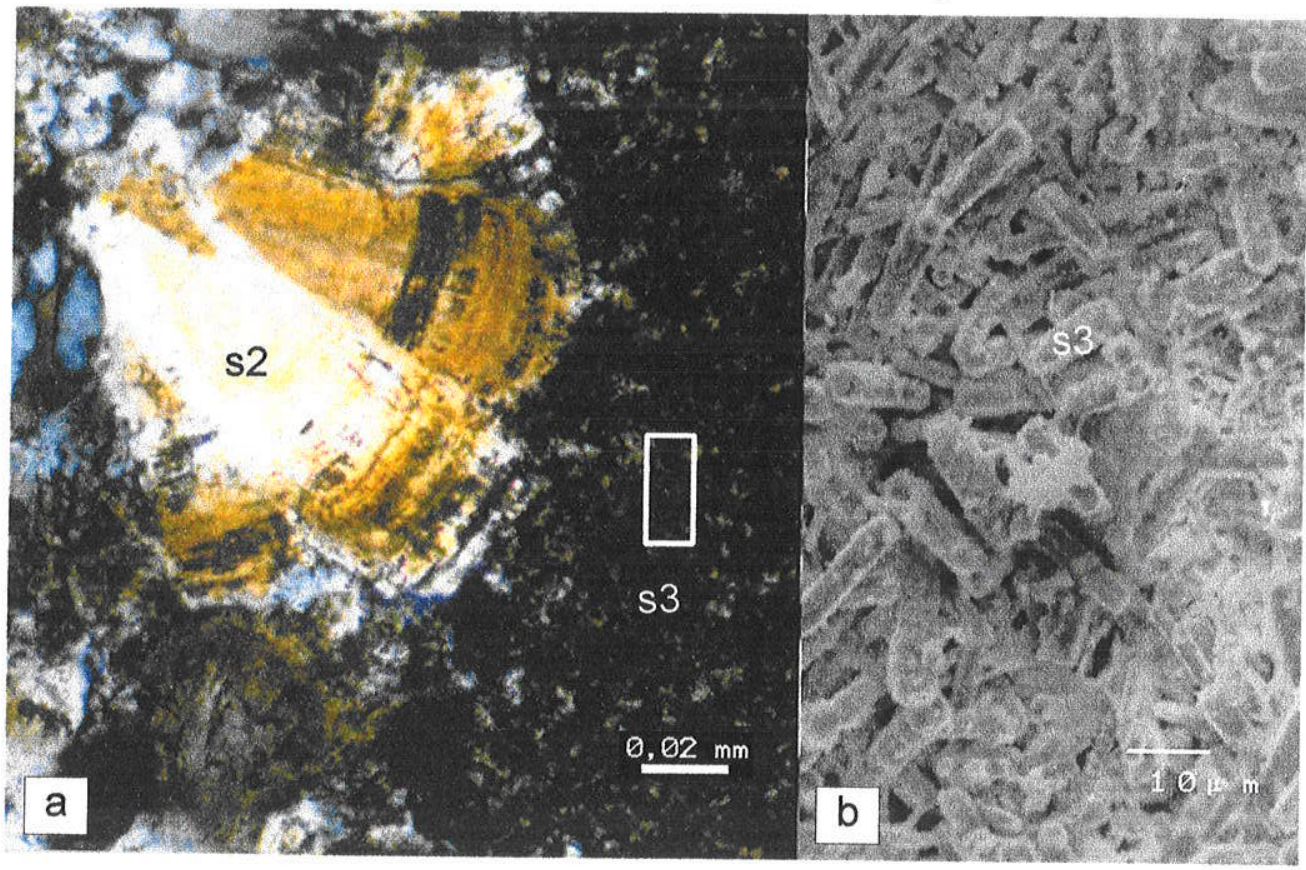

Foto 16 a: Cristais fibrorradiados de apatita supérgena (s2) em contato com massa de apatita supérgena microprismática (s3). Juquiá. Amostra JU10. MO (LP). b: Detalhe da massa de apatita supérgena microprismática (s3), formada por prismas de apatita revestidos de material argiloferruginoso (cor esbranquiçada). Juquiá. Amostra JU10. MEV (BEI). 


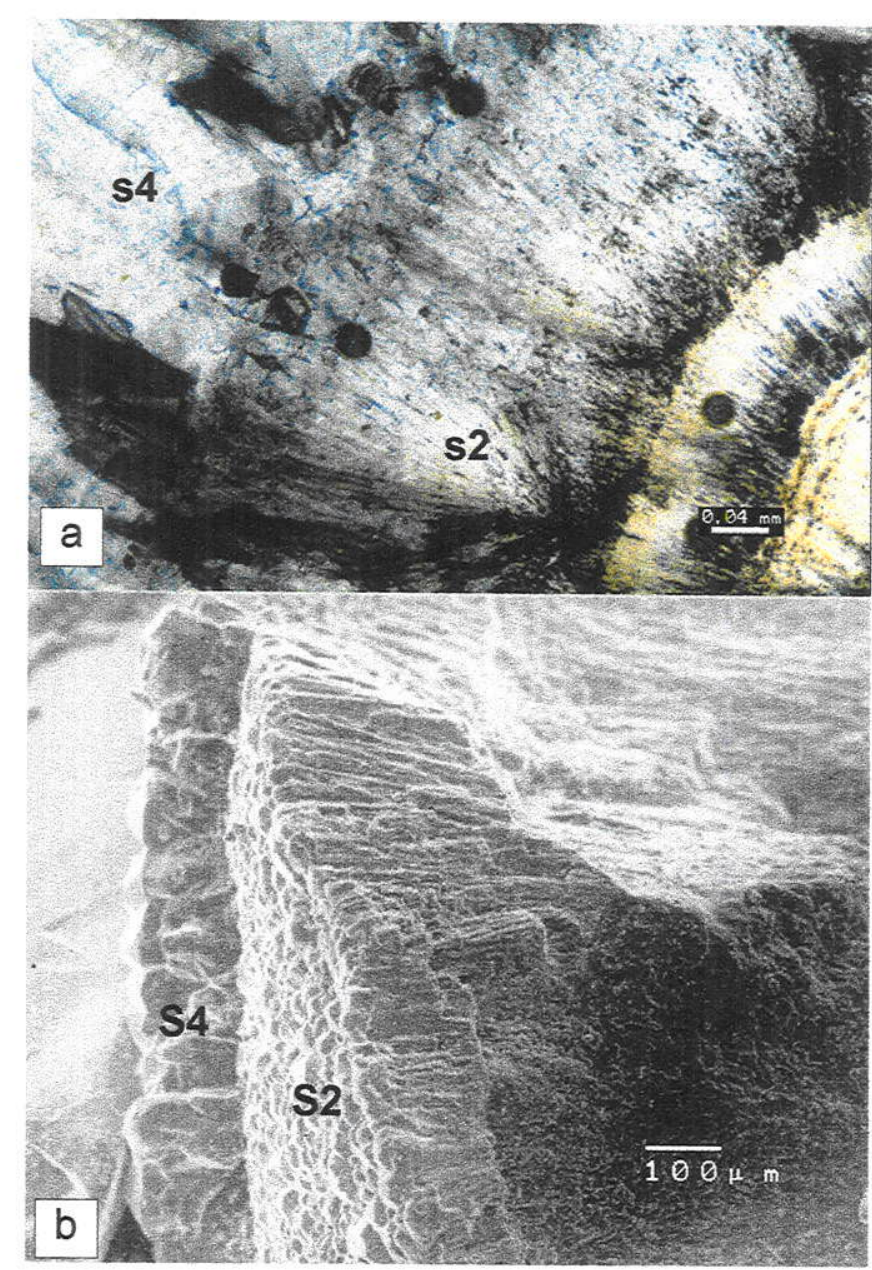

Foto 17 a: Cristais fibrorradiais de apatita supérgena (s2) formando camadas marcadas por diferenças de comprimento das fibras e cores de birrefringência. Juquiá. Amostra JU37.1. MO (LP). b: Detalhe da camada de apatita supérgena fibrosa (s2) com o topo formado por cristais prismáticos mais desenvolvidos (s4). Juquiá. Amostra JU37.1. MEV (SEI).

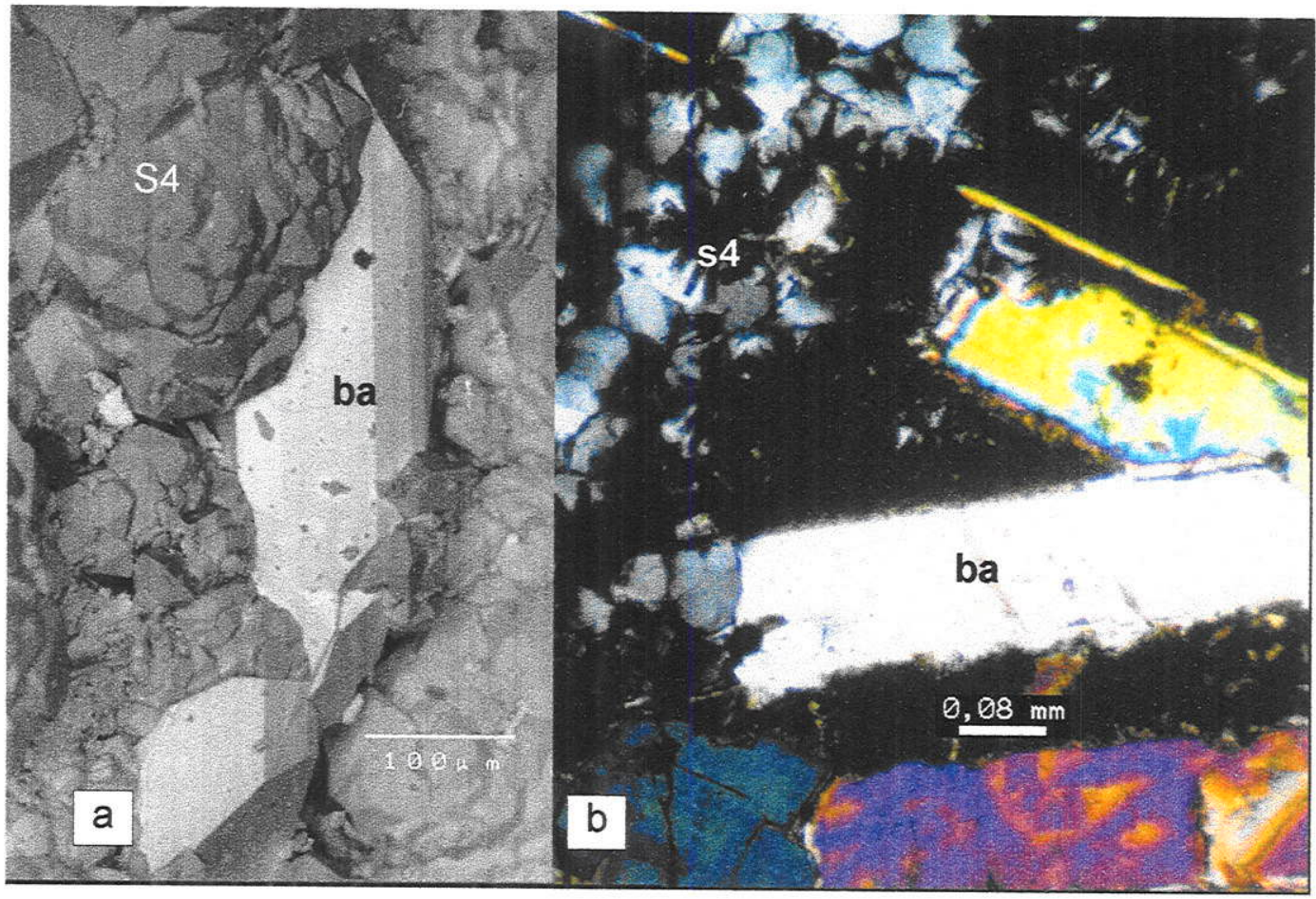

Foto 18 a: Cristais de apatita supérgena prismática (s4) ao redor de um cristal tabular de barita, nota-se pequenos cristais de apatita incrustados em cavidades de sua superfície. Juquiá. Amostra JU21. MEV (BEI). b: cristais de apatita supérgena prismática com terminação piramidal (s4) preenchendo cavidades de cristais de barita parcialmente dissolvidos. Juquiá. Amostra JU40. MO (LP). 


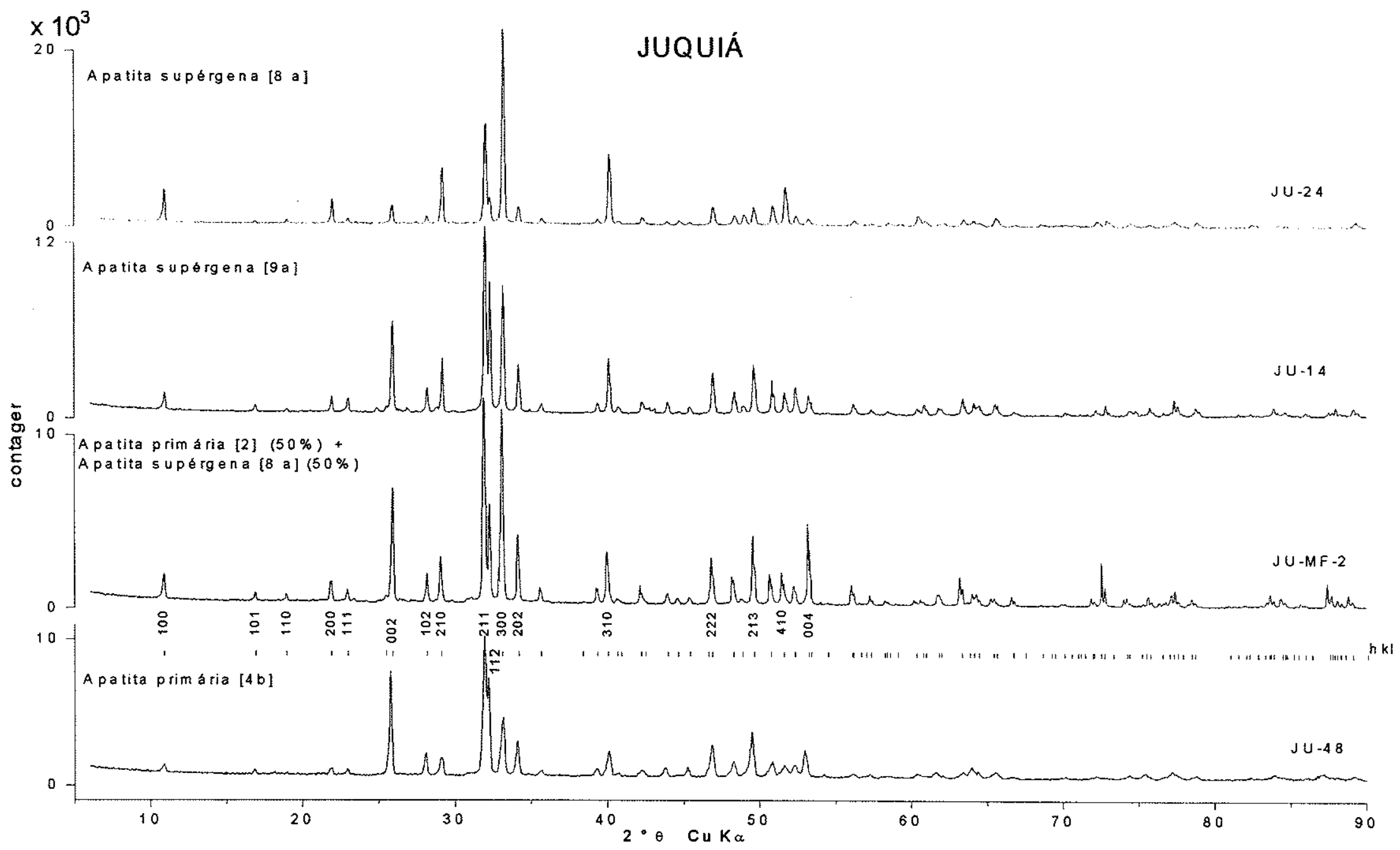

Figura 20 Difratogramas das amostras de apatitas primárias e supérgenas de Juquiá. |: posições das reflexões de Bragg da apatita.

2- apatita tipo pavê em material alterado, 4 b- Apatita prismática com linhas de crescimento carbonatito alterado, 7 - Apatita supérgena tipo microprismático, 8 a- Apatita supérgena tipo fibroso leitosa e 9 a- Apatita supérgena tipo prismática sobre a apatita fibrosa brotrioidal de fissuras. 
O estudo à DRX (Tabela 21 e Figura 21) permitiu diferenciar as apatitas supérgenas (tipos: fibroso, microprismático e prismático) das apatitas primárias. Os cálculos de parâmetros de cela unitária feitos com auxílio do programa de refinamento de cela LCLSQ (Burnham, 1991) baseado no método dos minimos quadrados, permitiram verificar que a apatita hidrotermal com linhas de crescimento e as apatitas supérgenas possuem parâmetros a menores do que os da fluorapatita padrão (JCPDS 15-876), enquanto que as apatitas primárias de materiais muito alterados possuem valores de a entre a fluorapatita padrão e a hidroxiapatita padrão (JCPDS 9-432). Os parâmetros $c$ encontrados para quase todas as apatitas oscilam em torno dos valores encontrados para os padrões de hidroxiapatita e fluorapatita.

A apatita hidrotermal com linhas de crescimento no carbonatito pouco alterado apresentaram um valor de a menor do que o da fluorapatita padrão e um valor de $c$ muito mais elevado em relação aos dos padrões.

Segundo McClellan \& Lehr (1969) a entrada do ânion bivalente como o $\mathrm{CO}_{3}{ }^{2-}$ no lugar do ânion trivalente $\mathrm{PO}_{4}{ }^{3-}$ pode causar uma diminuição do eixo a e aumento do eixo $c$ (afeta duas vezes mais o parâmetro a do que o c). Por outro lado Legeros \& Legeros (1984) observaram que a assimilação do F- na estrutura da apatita causa uma contração do eixo a, sem modificação no eixo do c (novamente o eixo a é mais sensível a mudanças do que o eixo c). Assim é difícil dizer se as mudanças observadas no valor do parâmetro a são devido a substituições no sítio aniônico monovalente ou no sítio aniônico do $\mathrm{PO}_{4}{ }^{3-}$ em uma espécie carbonatofluorapatita.

Os parâmetros das apatitas das amostras JU-MM-3, JU-MF-2 e JU-MC-4 aqui apresentados são próximos aos calculados por Lenharo (1994) e Walter (1991), os valores obtidos mostram uma diminuição do eixo a nas apatitas supérgenas com relação às apatitas primárias, pouca variação do eixo c e uma ampla variação dos valores do parâmetro de cela a (entre 9,33 e 9,39Å), como foi observado por Lenharo (op. cit.).

Os padrões da amostras com apatita primária diferem dos da apatita supérgena mostrando picos com diferentes valores de intensidade (Figura 20). As causas da existência de picos mais intensos para tipo e menos intensos para outro pode estar relacionada a substituições que ocorrem nos sítios da estrutura da apatita que podem ser estudadas com o método Rietveld (Rietveld, 1968 e 1969). No presente estudo este método foi aplicado a apatitas supérgenas de amostras mais 
puras. O resultado do refinamento será dado no próximo item, onde é apresentado o estudo do carbonato na estrutura da apatita.

\begin{tabular}{|c|c|c|c|c|}
\hline \multicolumn{5}{|c|}{ Juquiá } \\
\hline material & amostra & apatita & [a] $\hat{A}$ & {$[c] \AA$} \\
\hline glimmerito alterado & JU-MM-3* & \multirow{2}{*}{ Primária (sã e alterada) } & $9,382(2)$ & $6,890(2)$ \\
\hline carbonatito alterado & $J U-M F-2^{\star \star}$ & & $9,392(1)$ & $6,885(1)$ \\
\hline carbonatito pouco alterado & JU48 & $\begin{array}{l}\text { hidrotermal com linhas de } \\
\text { crescimento }\end{array}$ & $9,365(2)$ & $6,908(2)$ \\
\hline carbonatito alterado & JU-MC-4 & \multirow[t]{3}{*}{ supérgena tipo fibroso } & $9,346(1)$ & $6,894(1)$ \\
\hline \multirow[t]{3}{*}{ carbonatito alterado } & JU33.1 & & $9,364(2)$ & $6,887(2)$ \\
\hline & JU24 & & $9,357(2)$ & $6,881(2)$ \\
\hline & JU10,6 & supérgena tipo microprismático & $9,346(1)$ & $6,891(1)$ \\
\hline carbonatito alterado & JU14.1 & supérgena tipo prismático & $9,363(1)$ & $6,885(2)$ \\
\hline \multicolumn{3}{|c|}{ Fluorapatita (JCPDS 15-876) } & 9,368 & 6,884 \\
\hline \multicolumn{3}{|l|}{ Hidroxiapatita (JCPDS 9-432) } & 9,418 & 6,8841 \\
\hline
\end{tabular}

${ }^{\star} 40 \%$ de apatita primária, ${ }^{\star \star} 50 \%$ de apatita primária, ${ }^{\star \star \star} 5 \%$ de apatita primária

Tabela 21 Parâmetros cristalográficos a e $c$ de apatitas de Juquiá.

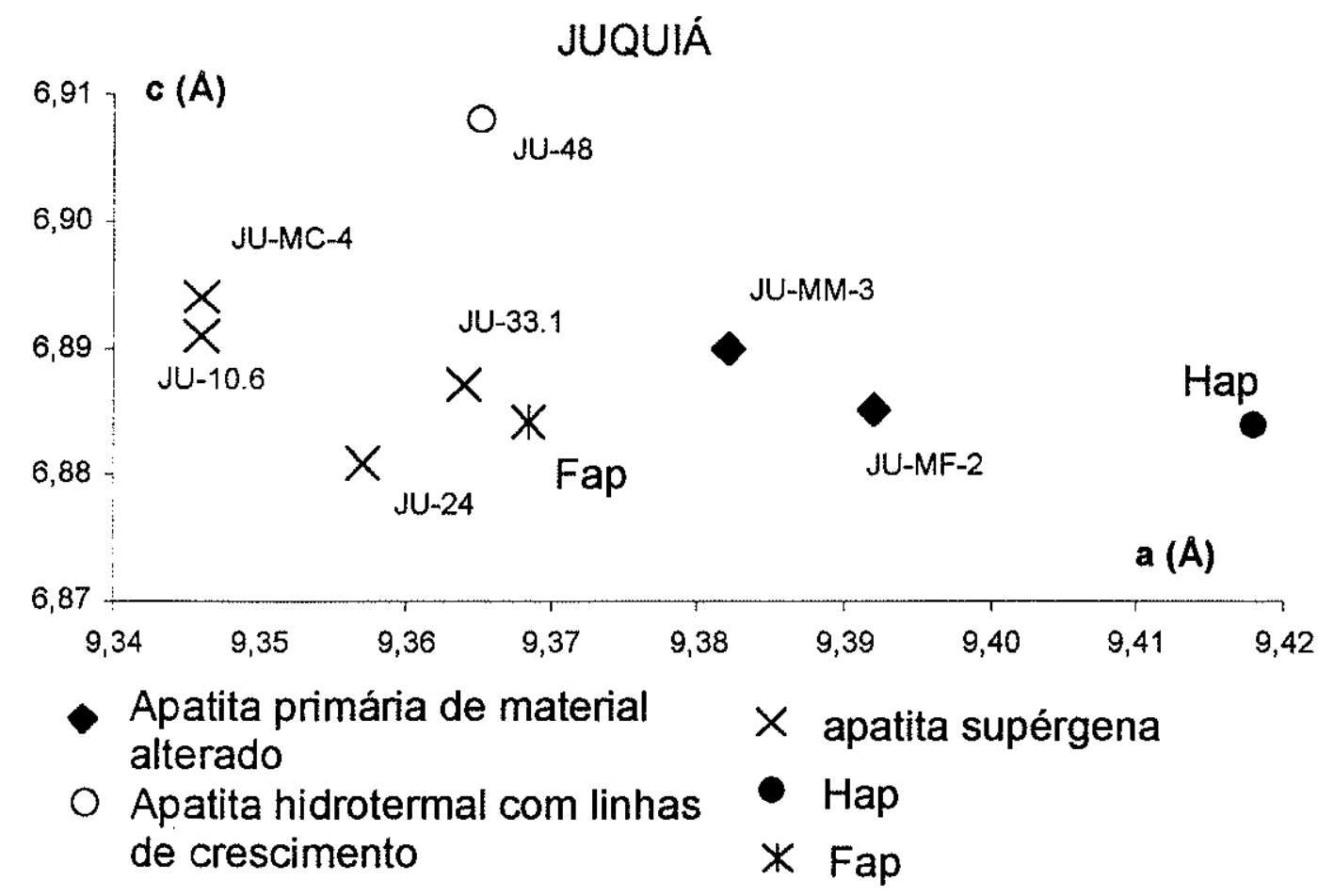

Figura 21 Variação dos parâmetros cristalográficos a e c das apatitas de Juquiá, pelo método dos mínimos quadrados utilizando o programa de refinamento de parâmetros de cela LCLSQ (Burnham, 1991). Fap - Fluorapatita sintética (JCPDS 15-876) Hap Hidroxiapatita sintética (JCPDS 9-432) 


\section{Aspectos químicos e cristaloquímicos das apatitas}

A composição química e alguns aspectos cristaloquímicos das apatitas foram estudados por diversas técnicas, como já descrito anteriormente. Neste item, os resultados serão apresentados de forma integrada, visando à caracterização, do melhor modo possivel, dos diferentes tipos morfológicos descritos no estudo mineralógico e micromorfológico.

A sintese das análises à microssonda eletrônica de diferentes apatitas encontradas em Juquiá encontra-se nas Tabela 23, Tabela 24 e Tabela 25, Figura 24 e Figura 26, sendo que as análises completas estão no Anexo 2. Grande parte das análises de cristais apatita primária apresentaram totais próximos de $100 \%$. Já as bordas de maior birrefringência ficaram com totais entre 89,5 e $96,3 \%$. A borda de apatitas primária alterada e a apatitas tipo anhedral localizadas nas descontinuidades da rocha apresentaram totais próximos de 100\%. Dos tipos de apatita supérgena analisados somente o tipo hialino apresentou totais muito próximos de $100 \%$.

Os totais podem ser significativos dos seguintes fatores: 1- constituintes não analisados, principalmente $\mathrm{OH}^{-}$e $\mathrm{CO}_{3}{ }^{2-}$, para as apatitas primárias sem problemas de alteração que atrapalhem o polimento; 2- porosidades imperfeições típicas de cristais de muito pequenos ou com descontinuidades físicas que não permitem uma preparação ideal para analise à ME. Isto pode ser estimado ao microscópio óptico e na própria tela da microssonda. Portanto quando o total é $<100 \%$ e o cristal estava bem preparado, a diferença para $100 \%$ foi interpretada como uma presença de $\mathrm{OH}^{-}$ elou $\mathrm{CO}_{3}{ }^{2-}$.

Os valores do número de átomos de $\mathrm{Mg}$ p.f.u. na maioria dos tipos analisados ficaram entre 0 e 0,02 ; em alguns tipos apresentaram alguns pontos com valores maiores como a borda de alteração hidrotermal (até 0,08 ), a apatita supérgena tipo fibrosa (até 0,13 ) e a supérgena tipo prismática (até 0,07 ). 0 número de átomos de Mn p.f.u. ficou quase sempre abaixo de 0,02 podendo ultrapassar este valor em raros pontos das apatitas hidrotermais com linhas de crescimento (até 0,06) e sobreposta à superfície da apatita primária (até 0,06). Valores do número de átomos de Fe p.f.u. maiores que 0,02 são freqüentemente encontrados nos diferentes tipos de apatita pré-meteórica. Alguns pontos analisados na apatita supérgena apresentaram um número de átomos p.f.u. anômalos de $\mathrm{Al}$, principalmente nos tipos de textura muito fina (tipo fibroso e tipo microprismático) e apatita primária alterada 
rica em feições de dissolução; isto sugere que $\circ$ alumínio poderia estar presente em fases aluminosas que revestem os micro-poros do material e não na estrutura da apatita.

O $\mathrm{Sr}$ nas apatitas primárias aparece em quantidades consideráveis e atinge valores bem elevados na apatita hidrotermal, onde são sempre inversamente proporcionais aos teores de $\mathrm{Na}$ (Figura 25). $\mathrm{O} \mathrm{Sr}$ aparece em maior quantidade que - Na na maioria das vezes na estrutura das apatitas primárias (sã e alterada). Somente nas apatitas hidrotermais o $\mathrm{Na}(0,13$ a 1,14 p.f.u.) mais freqüentemente prevalece o $\mathrm{Sr}(0,06$ a 0,79 p.f.u.). As apatitas supérgenas apresentaram $\mathrm{Na}$ e $\mathrm{Sr}$ em pequenas proporção no sítio catiônico sendo o tipo prismático (em fissuras não revestidas por apatita supérgena fibrosa) os que apresentam o sítio catiônico menos substituído ( $\mathrm{Na}$ a até 0,01 e $\mathrm{Sr}$ : até 0,01 ). Nos outros tipos de apatitas supérgenas o $\mathrm{Sr}$ em geral apresenta um maior número de átomos p.f.u. do que o $\mathrm{Na}$.

$O$ detalhamento dos ETR mostrou que a apatita hidrotermal, do tipo prismático com linhas de crescimento, apresenta teores mais elevados de $\mathrm{Ce}_{2} \mathrm{O}_{3}$ (Tabela 25). $\mathrm{O}$ teor de $\mathrm{Nd}_{2} \mathrm{O}_{3}$ é mais elevado em relação aos outros ETR na apatita primária sã. $\mathrm{O}$ mesmo acontece com um dos pontos analisados da apatita supérgena tipo fibrorradial. Quando se faz uma relação entre os ETR analisados o Ce sempre é o elemento de maior teor entre os ETR analisados. Os totais de ETR da apatita supérgena do tipo prismático são mais elevados que os da apatita supérgena dos tipos fibrosa e fibrorradial.

Os cálculos do teor de $\mathrm{CO}_{2}$ que foram feitos por diferença a 6 átomos na posição do $\mathrm{PO}_{4}$ e depois, foram recalculados em $\%$ em peso de $\mathrm{CO}_{2}$ equivalente àquele número de átomos de $\mathrm{C}$ que completava o sítio do $\mathrm{P}$, mostraram composições distintas para a apatita supérgena; a variedade prismática hialina é pobre em carbonato (entre 0,37 e 1,89\%) enquanto que as outras variedades apresentam teores mais altos de $\mathrm{CO}_{2}(0,7404,33 \%)$. Apatitas do tipo hialino apresentaram, em geral, teores de flúor acima de $3 \%$ e teor de $\mathrm{CO}_{2}$ em próximo de $0 \%$. Análises de apatita do tipo fibroso freqüentemente apresentaram totais baixos e teores de $\mathrm{CO}_{2}$ maiores que os da apatita do tipo hialino.

A avaliação dos teores de $\mathrm{CO}_{2}$ por MR mostrou que a apatita hidrotermal é a mais rica em $\mathrm{CO}_{2}$ seguida pela apatita supérgena do tipo fibroso e borda de maior birrefringência da apatita primária. $O$ estudo dos espectros Raman das amostras de 
apatita supérgena do tipo prismático (que reveste apatita fibrosa brotrioidal) e das de apatita primária sã não indicou a presença de $\mathrm{CO}_{2}$.

Apenas as amostras de apatita supérgena do tipo fibroso foram analisadas ao IV, que indicou, pelos cálculos segundo Lehr et al. 1967 e Scheib (1984), um teor de $2,57 \%$ de $\mathrm{CO}_{3}{ }^{2-}$. Este resultado é inferior ao teor encontrado por MR. Ainda não puderam ser analisados os concentrados preparados para os outros tipos de apatitas (apatitas primárias, apatita supérgena prismática hialina).

Existe uma correlação muito forte entre os resultados obtidos pelos cálculos através das análises à ME e pelas análises à MR. Muitos dos teores obtidos a partir da MR estão dentro dos teores estimados por cálculos estequimétricos de dados da ME.

Análises de apatita primária em materiais mais alterados sempre apresentam teores de flúor e razão $\mathrm{F} / \mathrm{P}_{2} \mathrm{O}_{5}$ ligeiramente maiores do que as apatitas da rocha sã. Cristais de apatita supérgena freqüentemente apresentam teores mais altos em flúor do que os da apatita primária e hidrotermal; alguns pontos analisados na apatita alterada apresentaram uma composição muito próxima dos da apatita supérgena.

$\mathrm{O} \mathrm{CO}_{2}$ na estrutura da apatita pode ser estudado aplicando o refinamento Rietveld, como o que é feito em apatitas biológicas (Wilson et. Al., 1999). As únicas apatitas estudadas foram as apatitas supérgenas tipo fibroso e prismático. Os resultados do refinamento estão na Tabela 22, onde são mostrados, para cada tipo de apatita parâmetros de rede; posições, taxas de ocupação e os fatores de temperatura isotérmica dos átomos. Os gráfico com os padrões calculados e observado mostram um bom ajuste.

O resultado do refinamento indica que a apatita supérgena do tipo fibroso apresenta um maior déficit no sítio do fósforo com uma taxa de ocupação de $80 \%$ enquanto que o tipo prismático apresenta o sítio do fósforo mais ocupado com uma taxa igual a $96 \%$.. A presença do $\mathrm{CO}_{2}$ foi calculada pela diferença no sítio do fósforo levando a resultados bem próximos do encontrado nos cálculos a partir dos dados da microssonda.

Foram analisadas à catodoluminescência lâminas de amostras ricas em apatita tipo primária e supérgena: JU14C1, JU371, JUT2agB e JUT4Cg. Os cristais de apatita primária de Juquiá freqüentemente apresentam-se manchados com cores de luminescência salmão (JU14C1) e ocre (JU37.1). A borda de maior birrefringência apresenta tons alaranjados. A apatita supérgena prismática apresentou uma cor 
verde com distribuição mais homogênea e a apatita supérgena fibrosa brotrioidal apresentou uma cor verde mais intensa. A apatita supérgena microprismática não apresentou cores de luminescência.

REFINAMENTO DA ESTRUTURA

Parâmetros iniciais: referência: Huges et al., 1989 Am. Min. 74: 870-876

\begin{tabular}{|c|c|c|c|c|}
\hline a & 9,3973 & & & \\
\hline$c$ & 6,8782 & & & \\
\hline ATOMO & $x$ & Y & Z & Oc. \\
\hline $\mathrm{Ca}$ & 0,6667 & 0,3333 & 0,0010 & 0,9900 \\
\hline $\mathrm{Ca}$ & $-0,0071$ & 0,2423 & 0,2500 & 0,9860 \\
\hline$P$ & 0,3690 & 0,3985 & 0,2500 & 1,0080 \\
\hline 0 & 0,4849 & 0,3273 & 0,2500 & 0,9880 \\
\hline 0 & 0,4667 & 0,5875 & 0,2500 & 0,9880 \\
\hline 0 & 0,2575 & 0,3421 & 0,0705 & 0,9890 \\
\hline$F$ & 0,0000 & 0,0000 & 0,2500 & 0,9060 \\
\hline
\end{tabular}

Resultados:

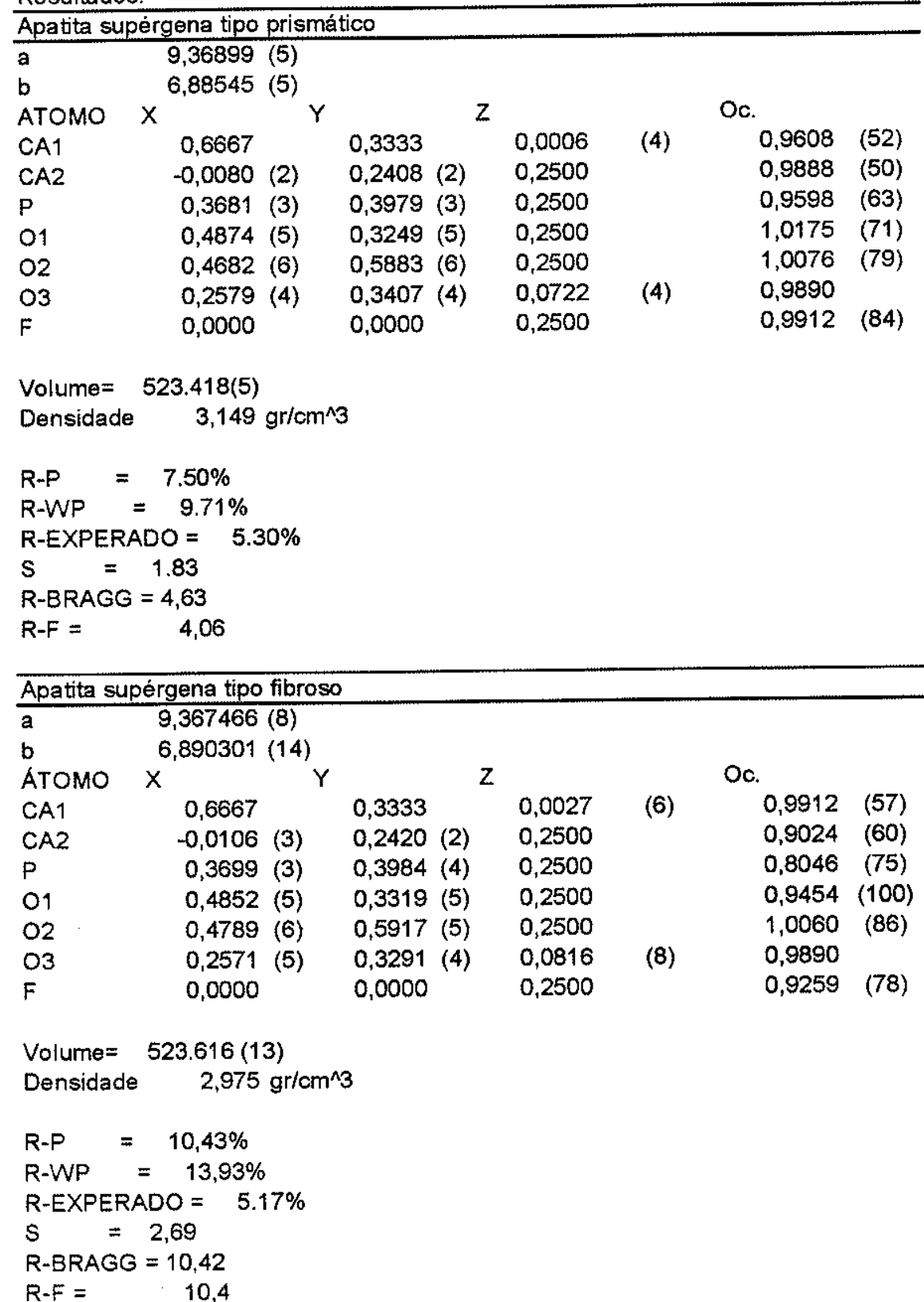

Tabela 22 Resultados do refinamento Rietveld das apatitas supérgenas de Juquiá. 


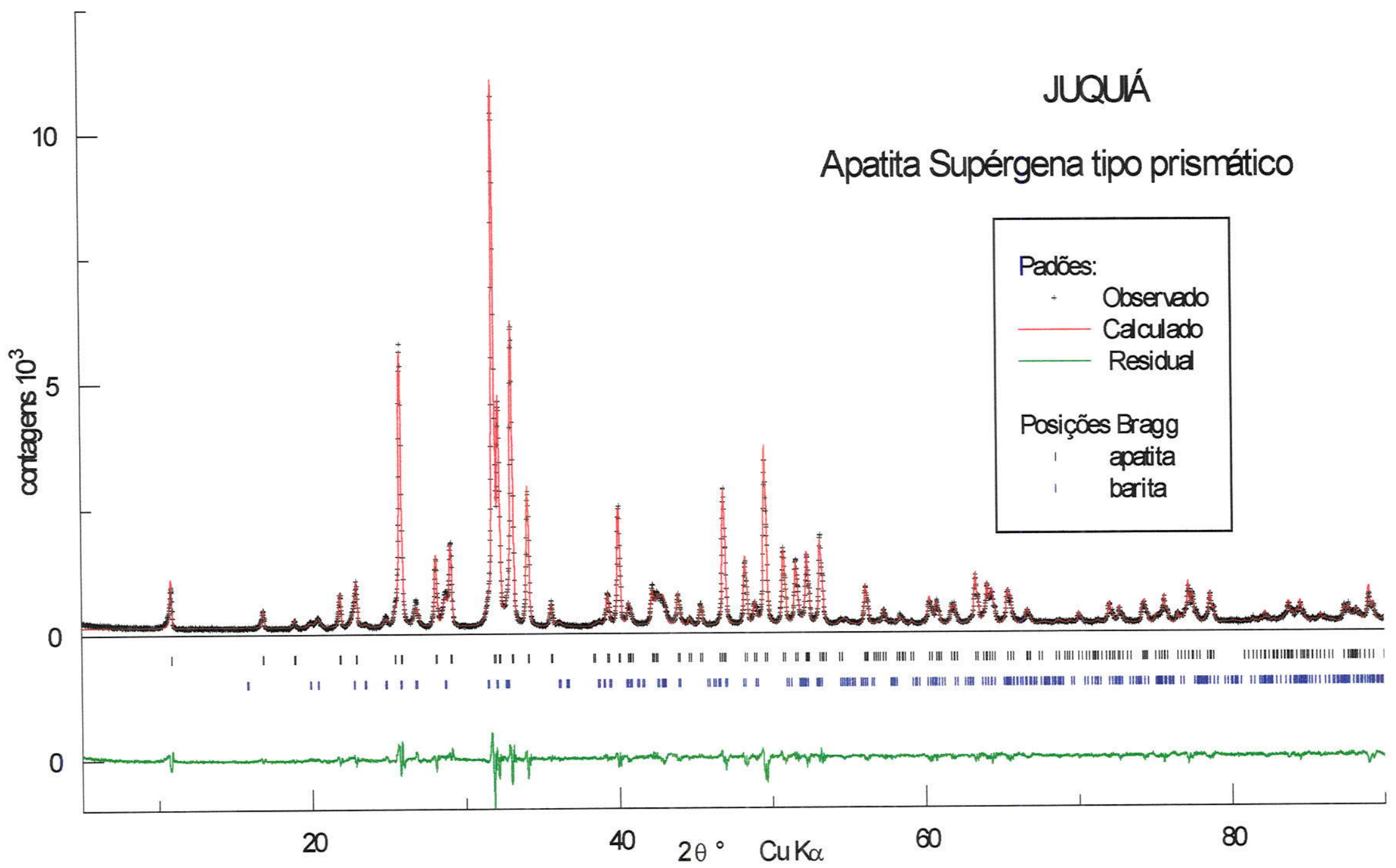

Figura 22 Gráfico do refinamento Rietveld para a apatita supérgena prismática, mostrando os padrões observado, calculado e o resíduo. 


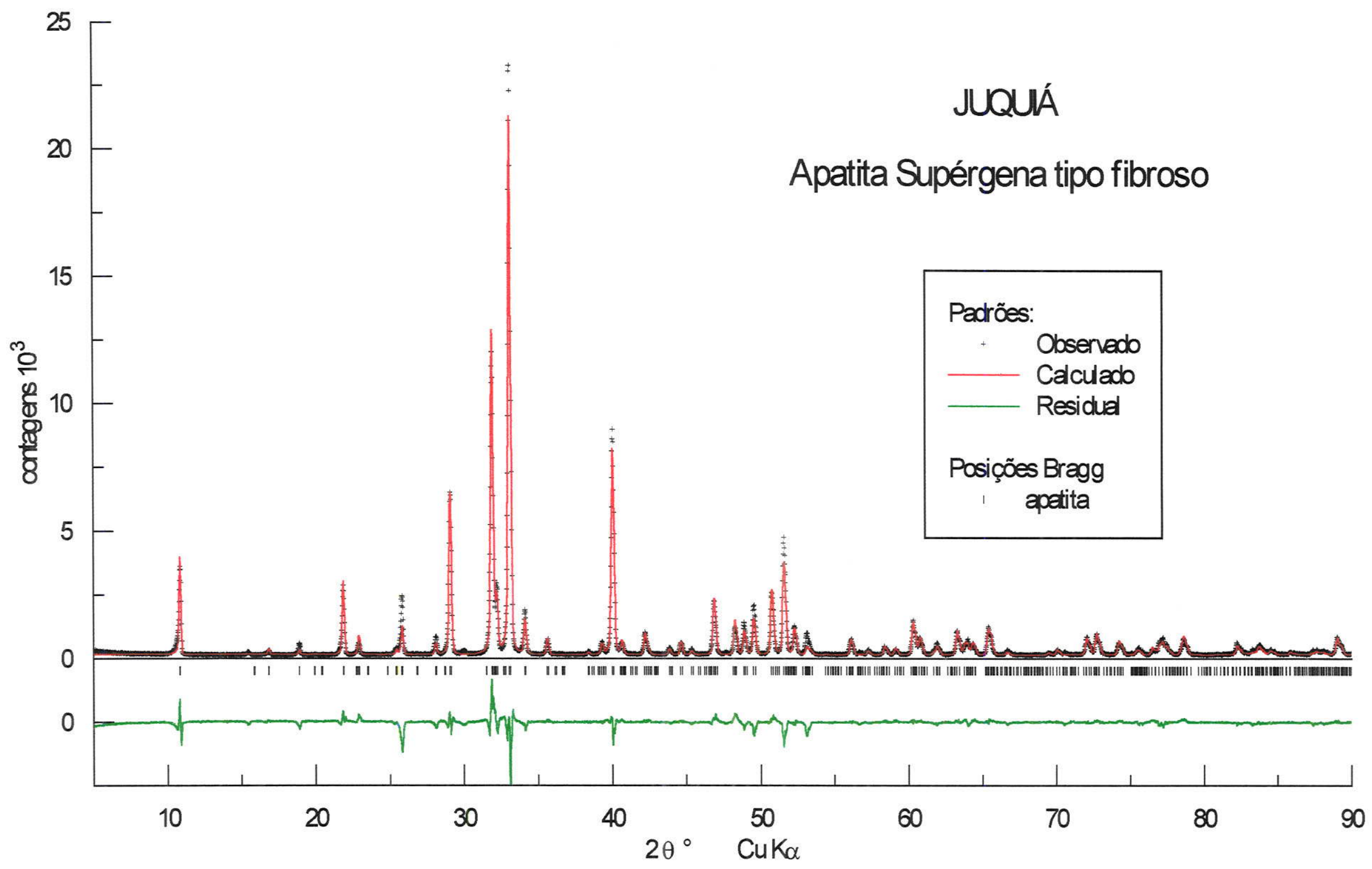

Figura 23 Gráfico do refinamento Rietveld para a apatita supérgena fibrosa, mostrando os padrões observado, calculado e o resíduo. 


\begin{tabular}{|c|c|c|c|c|c|c|c|c|c|c|c|c|c|c|c|}
\hline \multirow{3}{*}{$\begin{array}{l}\text { tipo } \\
\text { A mostra } \\
\text { No }\end{array}$} & \multicolumn{3}{|c|}{1} & \multicolumn{2}{|c|}{$2 a \quad 2 b$} & \multicolumn{2}{|l|}{$2 \mathbf{b}$} & \multicolumn{2}{|l|}{3} & \multicolumn{3}{|c|}{$4 a$} & \multicolumn{3}{|c|}{$4 b$} \\
\hline & A -15 & $A-15$ & $A-15$ & JU14c1 & JU14c 1 & JU14c1 & JU17 & JU17 & JUT 15a1 & FJ88 & FJ88 & FJ88 & JU48 & IU 48 & JU48 \\
\hline & 5 & 4 & 3 & 21 & 53 & 57 & 45 & 54 & 19 & 28 & 34 & 35 & 31 & 21 & 23 \\
\hline $\mathrm{Na}_{2} \mathrm{O}$ & 0,25 & 0,10 & 0,16 & 0,14 & 0,22 & 0,14 & 0,16 & 0,19 & 0,05 & 2,83 & 0,75 & 1,11 & 1,00 & 1,93 & 3,01 \\
\hline $\mathrm{CaO}$ & 55,22 & 56,22 & 54,92 & 55,91 & 54,41 & 54,21 & 55,09 & 55,08 & 55,65 & 50,67 & 49,98 & 49,34 & 51,27 & 52,85 & 51,16 \\
\hline $\mathrm{MgO}$ & 0,02 & 0,00 & 0,00 & 0,00 & 0,00 & 0,00 & 0,03 & 0,00 & 0,06 & 0,03 & 0,00 & 0,04 & 0,02 & 0,00 & 0,00 \\
\hline MnO & 0,00 & 0,07 & 0,00 & 0,00 & 0,03 & 0,00 & 0,00 & 0,10 & 0,15 & 0,21 & 0,16 & 0,34 & 0,13 & 0,30 & 0,09 \\
\hline $\mathrm{FeO}$ & 0,00 & 0,00 & 0,05 & 0,00 & 0,00 & 0,06 & 0,00 & 0,04 & 0,01 & 0,37 & 0,29 & 0,17 & 0,13 & 0,22 & 0,24 \\
\hline SrO & 0,46 & 0,93 & 0,95 & 0,73 & 0,68 & 0,67 & 0,82 & 0,64 & 0,78 & 1,64 & 5,29 & 5,68 & 3,69 & 0,63 & 1,23 \\
\hline $\mathrm{BaO}$ & 0,00 & 0,02 & 0,00 & 0,00 & 0,00 & 0,00 & 0,00 & 0,08 & 0,00 & 0,07 & 0,67 & 1,06 & 0,26 & 0,00 & 0,09 \\
\hline $\mathrm{Al}_{2} \mathrm{O}_{3}$ & 0,03 & 0,00 & 0,00 & 0,00 & 0,00 & 0,00 & 0,02 & 0,00 & 0,00 & 0,00 & 0,00 & 0,00 & 0,03 & 0,00 & 0,01 \\
\hline $\mathrm{La}_{2} \mathrm{O}_{3}$ & 0,06 & 0,00 & 0,11 & 0,00 & 0,02 & 0,06 & 0,00 & 0,18 & 0,00 & 0,10 & 0,00 & 0,05 & 0,00 & 0,08 & 0,14 \\
\hline $\mathrm{Ce}_{2} \mathrm{O}_{3}$ & 0,00 & 0,15 & 0,12 & 0,00 & 0,10 & 0,03 & 0,19 & 0,01 & 0,19 & 0,19 & 0,38 & 0,21 & 0,04 & 0,00 & 0,03 \\
\hline $\mathrm{SiO}_{2}$ & 0,00 & 0,00 & 0,00 & 0,04 & 0,00 & 0,03 & 0,00 & 0,09 & 0,08 & 0,00 & 0,01 & 0,03 & 0,07 & 0,05 & 0,05 \\
\hline $\mathrm{P}_{2} \mathrm{O}_{5}$ & 40,00 & 40,09 & 40,44 & 41,55 & 41,67 & 41,47 & 42,49 & 41,92 & 41,16 & 35,95 & 36,27 & 34,84 & 38,05 & 37,87 & 36,20 \\
\hline F & 2,08 & 2,13 & 2,14 & 3,05 & 1,86 & 2,46 & 2,32 & 2,24 & 2,46 & 1,11 & 1,98 & 1,70 & 1,06 & 1,91 & 1,74 \\
\hline $\mathrm{Cl}$ & 0,00 & 0,03 & 0,01 & 0,01 & 0,02 & 0,01 & 0,02 & 0,00 & 0,05 & 0,00 & 0,00 & 0,00 & 0,00 & 0,00 & 0,01 \\
\hline & 97,87 & 99,64 & 98,74 & 101,29 & 98,81 & 99,00 & 100,98 & 100,38 & 100,59 & 90,35 & 95,02 & 93,46 & 94,75 & 93,91 & 90,99 \\
\hline $\mathrm{O}=\mathrm{F}, \mathrm{Cl}$ & 0,88 & 0,90 & 0,90 & 1,28 & 0,78 & 1,03 & 0,98 & 0,94 & 1,04 & 0,47 & 0,83 & 0,71 & 0,45 & 0,80 & 0,73 \\
\hline TOTAL & 96.99 & 98,74 & 97,84 & 100,01 & 98,03 & 97,97 & 100,00 & 99,44 & 99,55 & 89,88 & 94,19 & 92,74 & 94,30 & 93,11 & 90,26 \\
\hline $\begin{array}{l}\mathrm{CO}_{2} \\
\mathrm{CO}_{2}(\mathrm{MR})\end{array}$ & 1,55 & $0^{1,95}$ & 1,21 & 0,83 &.$^{0,17}$ & 0,12 & 0,00 &.$^{0,29}$ & 0,98 & 4,67 & $\begin{aligned} & 3,37 \\
& 4 \text { a } 5\end{aligned}$ & 4,42 & 2,46 & $\begin{array}{r}3,36 \\
-\end{array}$ & 4,62 \\
\hline $\mathrm{Na}$ & 0,081 & 0,032 & 0,052 & 0,045 & 0,071 & 0,046 & 0,052 & 0,061 & 0,016 & 0,894 & 0,247 & 0,363 & 0,327 & 0,611 & 0,945 \\
\hline $\mathrm{Ca}$ & 9,866 & 9,860 & 9,835 & 9,885 & 9,849 & 9,872 & 9,850 & 9,840 & 9,860 & 8,843 & 9,098 & 8,912 & 9,251 & 9,252 & 8,878 \\
\hline $\mathrm{Mg}$ & 0,005 & 0,000 & 0,000 & 0,000 & 0,001 & 0,001 & 0,007 & 0,000 & 0,015 & 0,007 & 0,001 & 0,010 & 0,005 & 0,000 & 0,000 \\
\hline Mn & 0,000 & 0,010 & 0,000 & 0,000 & 0,005 & 0,000 & 0,000 & 0,014 & 0,021 & 0,029 & 0,024 & 0,049 & 0,019 & 0,042 & 0,012 \\
\hline $\mathrm{Fe}$ & 0,000 & 0,000 & 0,007 & 0,000 & 0,000 & 0,009 & 0,000 & 0,006 & 0,001 & 0,050 & 0,041 & 0,024 & 0,018 & 0,030 & 0,032 \\
\hline $\mathrm{Sr}$ & 0,045 & 0,088 & 0,092 & 0,070 & 0,067 & 0,066 & 0,079 & 0,062 & 0,075 & 0,155 & 0,521 & 0,555 & 0,361 & 0,060 & 0,116 \\
\hline Ba & 0,000 & 0,001 & 0,000 & 0,000 & 0,000 & 0,000 & 0,000 & 0,005 & 0,000 & 0,004 & 0,044 & 0,070 & 0,017 & 0,000 & 0,006 \\
\hline $\mathrm{Al}$ & 0,006 & 0,000 & 0,000 & 0,000 & 0,001 & 0,001 & 0,004 & 0,000 & 0,000 & 0,000 & 0,001 & 0,001 & 0,006 & 0,000 & 0,002 \\
\hline l.a & 0,004 & 0,000 & 0,007 & 0,000 & 0,001 & 0,004 & 0,000 & 0,011 & 0,000 & 0,006 & 0,000 & 0,003 & 0,000 & 0,005 & 0,008 \\
\hline$C e$ & 0,000 & 0,009 & 0,007 & 0,000 & 0,006 & 0,002 & 0,012 & 0,001 & 0,012 & 0,011 & 0,023 & 0,013 & 0,002 & 0,000 & 0,002 \\
\hline $\mathrm{Si}$ & 0,000 & 0,000 & 0,000 & 0,007 & 0,000 & 0,005 & 0,000 & 0,015 & 0,013 & 0,000 & 0,002 & 0,006 & 0,012 & 0,008 & 0,008 \\
\hline $\mathrm{p}$ & 5,647 & 5,556 & 5,722 & 5,805 & 5,961 & 5,967 & 6,003 & 5,917 & 5,762 & 4,958 & 5,217 & 4,972 & 5,425 & 5,239 & 4,964 \\
\hline C & 0,353 & 0,444 & 0,278 & 0,189 & 0,039 & 0,028 & 0,000 & 0,068 & 0,224 & 1,042 & 0,782 & 1,022 & 0,563 & 0,753 & 1,028 \\
\hline F & 1,097 & 1,103 & 1,132 & 1,592 & 0,995 & 1,321 & 1,225 & 1,182 & 1,287 & 0,572 & 1,064 & 0,906 & 0,565 & 0,987 & 0,892 \\
\hline $\mathrm{Cl}$ & 0,000 & 0,008 & 0,003 & 0,003 & 0,007 & 0,002 & 0,006 & 0,000 & 0,014 & 0,000 & 0,000 & 0,000 & 0,000 & 0,000 & 0,003 \\
\hline
\end{tabular}

Tabela 23 Análises à microssonda eletrônica (em \% em peso dos óxidos) e cálculos de fórmulas estruturais das apatitas de Juquiá.

Composição química, obtida à $M E$, dos diferentes tipos de apatita estudados em Juquiá, expressa em \% em peso de óxidos e em número de átomos por fórmula unitária calculada na base 10 cátions. São apresentados os pontos de análise mais representativos dos tipos: 1- Apatita tipo pavê em rocha sã, 2 a- borda da apatita tipo pavê em material alterado, 2 b- núcleo da apatita tipo pavê em material alterado 3- Apatita tipo pavê em material muito alterado, 4 a- Apatita prismática com linhas de crescimento carbonatito são, 4 b- Apatita prismática com linhas de crescimento carbonatito alterado. A tabela com todas as análises encontra-se no Anexo 2. 
Tabela 23 (continuação)

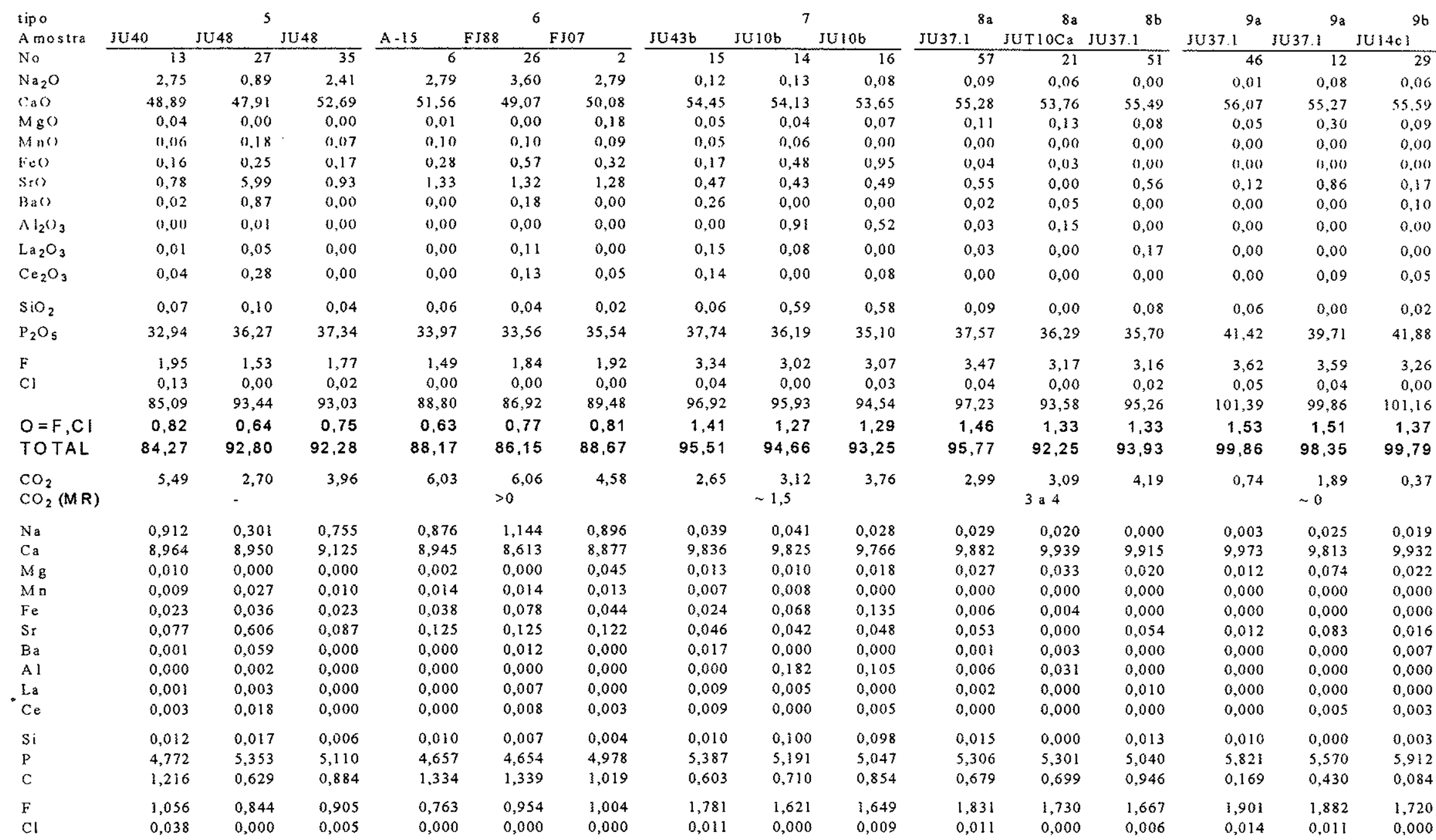

Composição química, obtida à ME, dos diferentes tipos de apatita estudados em Juquiá, expressa em \% em peso de óxidos e em número de átomos por fórmula unitária calculada na base 10 cátions. São apresentados os pontos de análise mais representativos dos tipos: 5- Apatita recristalizada na superfície da apatita tipo pavê (com Sr alto), 6- Borda de maior birrefringência ao redor da apatita tipo pavê, 7-Apatita supérgena tipo microprismático, 8 a- Apatita supérgena tipo fibroso leitosa, 8 b- Apatita supérgena tipo fibrorradial, 9 aApatita supérgena tipo prismática sobre a apatita fibrosa brotrioidal de fissuras, $9 \mathrm{~b}$ - Apatita supérgena tipo prismática milimétrica em fissuras não revestidas por apatita tipo fibroso leitosa. 


\begin{tabular}{|c|c|c|c|c|c|c|c|c|c|c|c|c|c|c|c|}
\hline \multirow{3}{*}{ tipo } & \multirow{2}{*}{\multicolumn{3}{|c|}{1}} & & & & \multirow{2}{*}{\multicolumn{3}{|c|}{3}} & \multirow{2}{*}{\multicolumn{3}{|c|}{$4 a$}} & \multirow{2}{*}{\multicolumn{3}{|c|}{$4 b$}} \\
\hline & & & & $2 a$ & $2 b$ & $2 b$ & & & & & & & & & \\
\hline & A-15 & A-15 & A-15 & JU14c1 & JU14e 1 & JU14c1 & JU17 & JU17 & JUT 15al & F J88 & FJ88 & FJ88 & JU48 & JU48 & JU48 \\
\hline No & 5 & 4 & 3 & 21 & 53 & 57 & 45 & 54 & 19 & 28 & 34 & 35 & 31 & 21 & 23 \\
\hline$\% \mathrm{OH}^{3}$ & 1,54 & 1,53 & 1,47 & 0,69 & 1,69 & 1,14 & 1,30 & 1,38 & 1,21 & 2,52 & 1,58 & 1,86 & 2,44 & 1,77 & 1,96 \\
\hline$\% \mathrm{OH}^{b}$ & 1,78 & 1,83 & 1,66 & 0,82 & 1,72 & 1,16 & 1,30 & 1,43 & 1,36 & 3,23 & 2,10 & 2,54 & 2,81 & 2,28 & 2,67 \\
\hline$\% \mathrm{OH}^{\circ}$ & 2,13 & 2,27 & 1,94 & 1,01 & 1,76 & 1,19 & 1,30 & 1,49 & 1,58 & 4,28 & 2,86 & 3,54 & 3,37 & 3,04 & 3,71 \\
\hline $\mathrm{OH}^{\mathrm{a}} \mathrm{pfu}$ & 0,903 & 0,897 & 0,868 & 0,408 & 1,005 & 0,679 & 0,775 & 0,818 & 0,713 & 1,428 & 0,936 & 1,094 & 1,435 & 1,013 & 1,108 \\
\hline $\mathrm{OH}^{\mathrm{b}} \mathrm{pfu}$ & 1,044 & 1,075 & 0,980 & 0,483 & 1,020 & 0,690 & 0,775 & 0,845 & 0,803 & 1,845 & 1,249 & 1,503 & 1,661 & 1,314 & 1,520 \\
\hline $\mathrm{OH}^{\mathrm{c}} \mathrm{pfu}$ & 1,256 & 1,341 & 1,146 & 0,596 & 1,043 & 0,706 & 0,775 & 0,886 & 0,937 & 2,470 & 1,718 & 2,117 & 1,998 & 1,766 & 2,136 \\
\hline P.M. ${ }^{8}$ & 995 & 996 & 1002 & 1003 & 1008 & 1009 & 1011 & 1008 & 1004 & 964 & 1007 & 1000 & 1000 & 974 & 962 \\
\hline P.M. & 997 & 999 & 1004 & 1005 & 1008 & 1009 & 1011 & 1008 & 1005 & 971 & 1012 & 1007 & 1003 & 979 & 969 \\
\hline P.M..$^{c}$ & 1001 & 1003 & 1006 & 1006 & 1008 & 1009 & 1011 & 1009 & 1008 & 982 & 1020 & 1017 & 1009 & 986 & 979 \\
\hline $\operatorname{carg} a^{a}$ & 0,294 & 0,413 & 0,237 & 0,141 & $-0,031$ & $-0,013$ & $-0,042$ & 0,018 & 0,206 & 0,167 & 0,559 & 0,676 & 0,257 & 0,147 & 0,096 \\
\hline carga ${ }^{b}$ & 0,152 & 0,236 & 0,126 & 0,066 & $-0,046$ & $-0,024$ & $-0,042$ & $-0,009$ & 0,116 & $-0,250$ & 0,247 & 0,267 & 0,032 & $-0,155$ & $-0,315$ \\
\hline $\operatorname{carg} a^{c}$ & $-0,059$ & $-0,031$ & $-0,041$ & $-0,048$ & $-0,069$ & $-0,041$ & $-0,042$ & $-0,050$ & $-0,019$ & $-0,875$ & $-0,222$ & $-0,346$ & $-0,306$ & $-0,607$ & $-0,932$ \\
\hline $\mathrm{CaO} / \mathrm{P}_{2} \mathrm{O}_{5}$ & 1,381 & 1,402 & 1,358 & 1,346 & 1,305 & 1,307 & 1,297 & 1,314 & 1,352 & 1,409 & 1,378 & 1,416 & 1,347 & 1,396 & 1,413 \\
\hline $\mathrm{F} / \mathrm{P}_{2} \mathrm{O}_{5}$ & 0,052 & 0,053 & 0,053 & 0,073 & 0,045 & 0,059 & 0,055 & 0,053 & 0,060 & 0,031 & 0,055 & 0,049 & 0,028 & 0,050 & 0,048 \\
\hline $\mathrm{SrO} / \mathrm{P}_{2} \mathrm{O}_{5}$ & 0,012 & 0,023 & 0,023 & 0,018 & 0,016 & 0,016 & 0,019 & 0,015 & 0,019 & 0,045 & 0,146 & 0,163 & 0,097 & 0,017 & 0,034 \\
\hline tipo & & 5 & & & 6 & & & 7 & & $8 a$ & $8 a$ & $8 b$ & $9 a$ & $9 a$ & $9 \mathrm{~b}$ \\
\hline A mostra & $\mathrm{JU} 40$ & JU48 & $\mathrm{JU} 48$ & A-15 & FJ88 & FJ07 & $\mathrm{JU} 43 \mathrm{~b}$ & JU10b & JU10b & IU37.1 & JUT $10 \mathrm{Ca}$ & JU37.1 & JU37.1 & JU37.1 & $\mathrm{JU} / 4 \mathrm{cl}$ \\
\hline No & 13 & 27 & 35 & 6 & 26 & 2 & 15 & 14 & 16 & 57 & 21 & 51 & 46 & 12 & 29 \\
\hline$\because \mathrm{OH}^{\mathrm{a}}$ & 1,68 & 1,93 & 1,93 & 2,21 & 1,87 & 1,76 & 0,37 & 0,65 & 0,61 & 0,29 & 0,47 & 0,58 & 0,17 & 0,20 & 0,47 \\
\hline$\% O \mathrm{OH}^{\mathrm{b}}$ & 2,53 & 2,35 & 2,53 & 3,14 & 2,81 & 2,46 & 0,78 & 1,13 & 1,19 & 0,75 & 0,94 & 1,23 & 0,28 & 0,49 & 0,53 \\
\hline$\% \mathrm{OH}^{c}$ & 3,77 & 2,96 & 3,43 & 4,49 & 4,17 & 3,50 & 1,39 & 1,85 & 2,05 & 1,44 & 1,65 & 2,19 & 0,45 & 0,93 & 0,62 \\
\hline olf pfu & 0,944 & 1,156 & 1,095 & 1,237 & 1,046 & 0,996 & 0,219 & 0,379 & 0,351 & 0,169 & 0,270 & 0,333 & 0,099 & 0,118 & 0,280 \\
\hline$O H^{b} p f u$ & 1,431 & 1,408 & 1,449 & 1,770 & 1,582 & 1,403 & 0,460 & 0,663 & 0,693 & 0,440 & 0,549 & 0,711 & 0,166 & 0,290 & 0,314 \\
\hline $\mathrm{OH}^{\mathrm{c}} \mathrm{pfu}$ & 2,160 & 1,785 & 1,979 & 2,570 & 2,385 & 2,014 & 0,822 & 1,089 & 1,206 & 0,847 & 0,969 & 1,279 & 0,268 & 0,548 & 0,365 \\
\hline P.M. ${ }^{2}$ & 954 & 1016 & 967 & 951 & 950 & 961 & 992 & 990 & 984 & 986 & 983 & 978 & 1003 & 996 & 1006 \\
\hline P.M. ${ }^{\text {D }}$ & 962 & 1021 & 973 & 960 & 959 & 968 & 996 & 995 & 990 & 991 & 988 & 984 & 1004 & 999 & 1006 \\
\hline P.M. & 974 & 1027 & 982 & 973 & 972 & 979 & 1002 & 1002 & 999 & 998 & 995 & 994 & 1006 & 1003 & 1007 \\
\hline $\operatorname{carga} a^{a}$ & 0,269 & 0,356 & 0,123 & 0,458 & 0,210 & 0,126 & 0,570 & 1,219 & 1,138 & 0,658 & 0,770 & 0,951 & 0,152 & 0,400 & 0,068 \\
\hline carga & $-0,217$ & 0,104 & $-0,230$ & $-0,076$ & $-0,326$ & $-0,282$ & 0,329 & 0,935 & 0,796 & 0,386 & 0,491 & 0,573 & 0,084 & 0,228 & 0,034 \\
\hline $\operatorname{carg} a^{\circ}$ & $-0,947$ & $-0,274$ & $-0,761$ & $-0,876$ & $-1,129$ & $-0,893$ & $-0,033$ & 0,509 & 0,283 & $-0,021$ & 0,071 & 0,005 & $-0,017$ & $-0,030$ & $-0,016$ \\
\hline $\mathrm{CaO} / \mathrm{P}_{2} \mathrm{O}_{5}$ & 1,484 & 1,321 & 1,411 & 1,518 & 1,462 & 1,409 & 1,443 & 1,496 & 1,529 & 1,471 & 1,481 & 1,554 & 1,354 & 1,392 & 1,327 \\
\hline $\mathrm{F} / \mathrm{P}_{2} \mathrm{O}_{5}$ & 0,059 & 0,042 & 0,047 & 0,044 & 0,055 & 0,054 & 0,089 & 0,084 & 0,087 & 0,092 & 0,087 & 0,089 & 0,087 & 0,090 & 0,078 \\
\hline $\mathrm{SrO} / \mathrm{P}_{2} \mathrm{O}_{5}$ & 0,024 & 0,165 & 0,025 & 0,039 & 0,039 & 0,036 & 0,012 & 0,012 & 0,014 & 0,015 & 0,000 & 0,016 & 0,003 & 0,022 & 0,004 \\
\hline
\end{tabular}

Tabela 24 Dados de quantidades de $\mathrm{OH}$ (\% em peso e átomos p.f.u.), peso molecular (PM) e carga da fórmula estrutural considerando três alternativas: a - todo flúor $(F)$ nos canais $\left(F_{p}=0\right)$, b - parte do flúor $\left(F_{p}\right)$ acompanhando $\circ \mathrm{CO}_{3}{ }^{2-}\left(F_{p}=0,4 C\right)$ e $c-p a r t e$ do flúor $\left(F_{p}\right)$ acompanhando $\circ \mathrm{CO}_{3}\left(\mathrm{~F}_{\mathrm{p}}=\mathrm{C}\right)$. $\mathrm{OH}$ foi calculado pela diferença da fração molar no sítio dos ânions monovalentes $\left(\mathrm{OH}=2-\mathrm{F}-\mathrm{F}_{\mathrm{p}}\right)$, para cada caso a, b e c. (A partir dos dados da tabela anterior, para apatitas de Juquiá) 


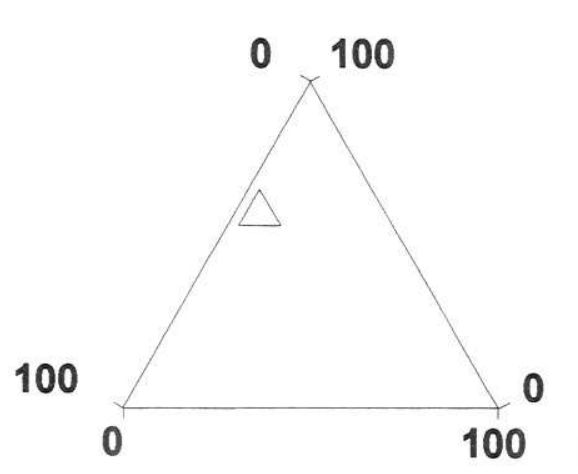

$+\mathbf{S i}$

\section{Ca}

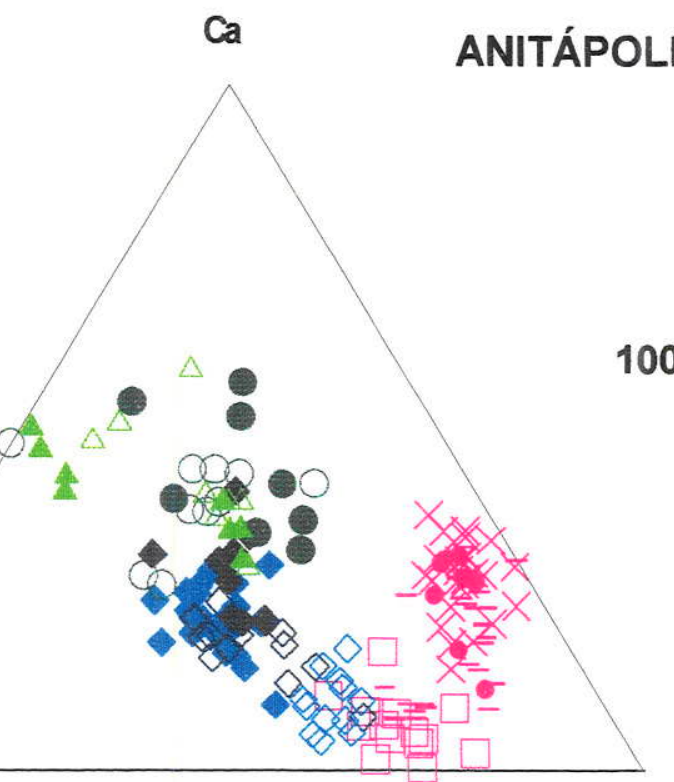

100

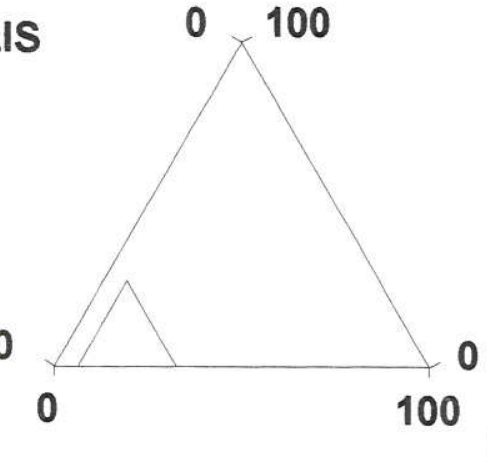

$\mathrm{Na}+\mathrm{Sr}+\mathrm{Mg}+\mathrm{ETR}$

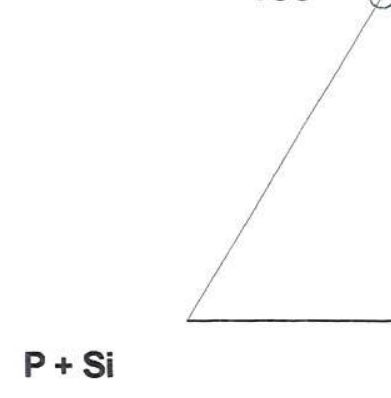

Apatitas primárias

- 1 - tipo pavê em rocha sã

$\diamond 2$ - tipo pavê em material alterado 3 - muito alterado detalhamento do grão

- 2 a-núcleo

$\diamond 2$ b - borda
Apatitas hidrotermais

$\triangle 4 a-t i p o$ prismático com linhas de crescimento em carbonatito são

4 $4 b$ - tipo prismático com linhas de crescimento em carbonatito alterado

- 5 - Apatita recristalizada na superfície da apatita tipo pavê (com $\mathrm{Sr}$ alto)

- 6 - borda de maior birrefringência
F

Figura 24 Diagramas ternários mostrando as variações de conteúdo em $\mathrm{Ca} /(\mathrm{P}+\mathrm{Si}) / \mathrm{F}$ e $(\mathrm{Na}+\mathrm{Sr}+\mathrm{Mg}+\mathrm{ETR}) /(\mathrm{P}+\mathrm{Si}) / \mathrm{F}$ para os diferentes tipos de apatitas de Anitápolis. ETR $=\mathrm{Ce}+\mathrm{La}$. 


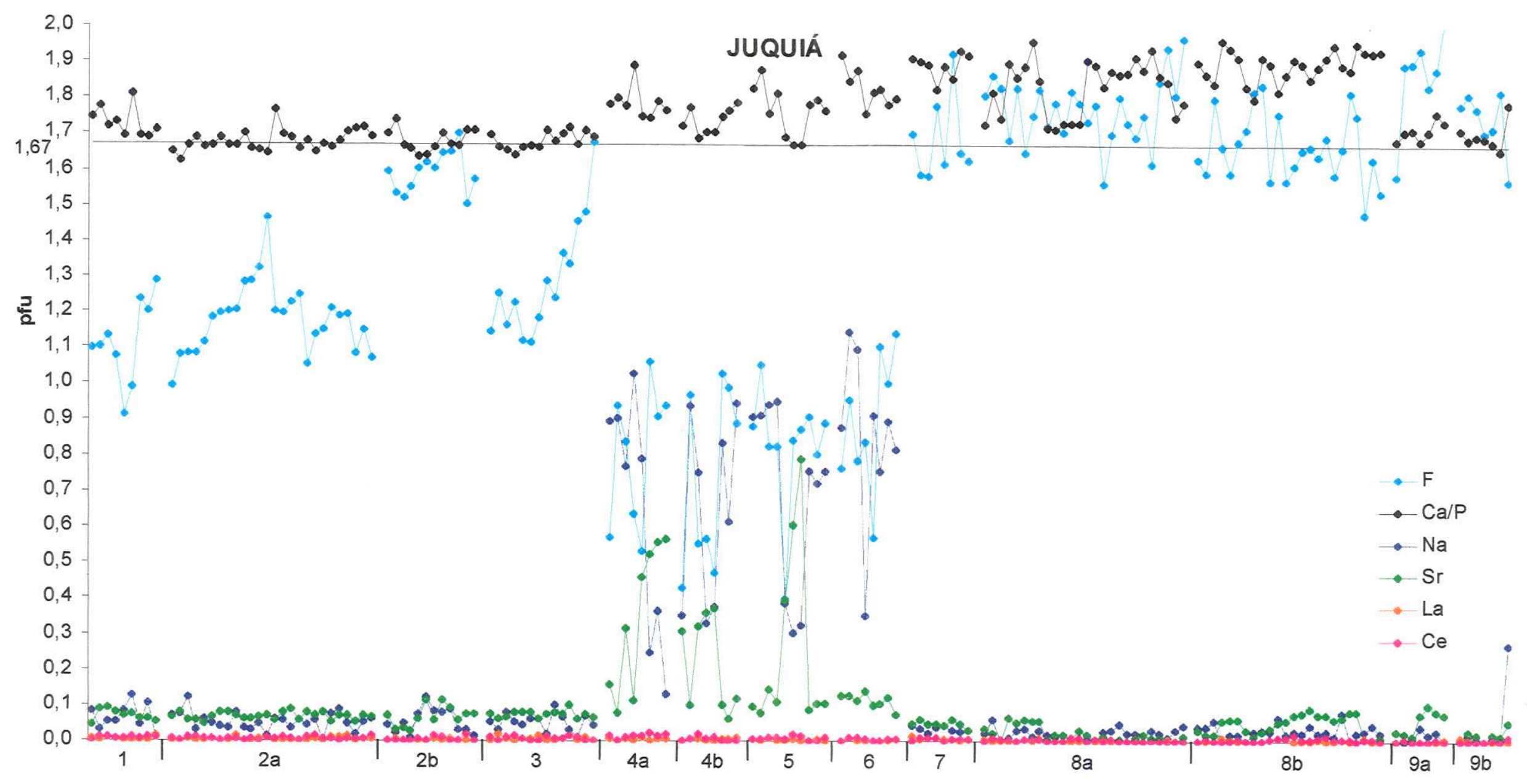

Figura 25 Gráfico da variação, em número de átomos p.f.u., dos principais cátions substituintes do cálcio, da razão Ca/P e do F de diferentes tipos de apatita de Juquiá. Os cálculos de fórmula estrutural foram efetuados com base em 10 cátions a partir de dados da ME. Legenda dos tipos de apatita na próxima página. 


\begin{tabular}{|c|c|c|c|c|c|c|c|c|c|c|c|c|c|c|c|}
\hline \multirow{3}{*}{$\begin{array}{l}\text { Tipo } \\
\text { Amostra } \\
\text { No. }\end{array}$} & \multicolumn{3}{|c|}{1} & $4 a$ & \multicolumn{3}{|c|}{6} & \multicolumn{3}{|c|}{$8 a$} & \multicolumn{3}{|c|}{$8 b$} & \multicolumn{2}{|c|}{$9 b$} \\
\hline & & $142 a$ & & FJ88 & & Ju42a & & & Ju37.1 & & & Ju42a & & JU14C1 & $14 \mathrm{C} 1$ \\
\hline & 1 & 2 & 3 & 16 & 4 & 5 & 6 & 10 & 11 & 12 & 7 & 8 & 9 & 1 & 2 \\
\hline $\begin{array}{l}\mathrm{La}_{2} \mathrm{O}_{3} \\
\mathrm{Ce}_{2} \mathrm{O}_{3} \\
\mathrm{Nd}_{2} \mathrm{O}_{3} \\
\mathrm{Gd}_{2} \mathrm{O}_{3}\end{array}$ & $\begin{array}{l}0,04 \\
0,10 \\
0,10 \\
0,00\end{array}$ & $\begin{array}{l}0,09 \\
0,08 \\
0,17 \\
0,02\end{array}$ & $\begin{array}{l}0,00 \\
0,17 \\
0,03 \\
0,00\end{array}$ & $\begin{array}{l}0,07 \\
0,00 \\
0,00 \\
0,00\end{array}$ & $\begin{array}{l}0,09 \\
0,10 \\
0,01 \\
0,03\end{array}$ & $\begin{array}{l}0,07 \\
0,20 \\
0,00 \\
0,01\end{array}$ & $\begin{array}{l}0,00 \\
0,00 \\
0,00 \\
0,03\end{array}$ & $\begin{array}{l}0,02 \\
0,00 \\
0,08 \\
0,02\end{array}$ & $\begin{array}{l}0,00 \\
0,00 \\
0,00 \\
0,00\end{array}$ & $\begin{array}{l}0,00 \\
0,00 \\
0,00 \\
0,00\end{array}$ & $\begin{array}{l}0,00 \\
0,03 \\
0,00 \\
0,00\end{array}$ & $\begin{array}{l}0,00 \\
0,02 \\
0,00 \\
0,01\end{array}$ & $\begin{array}{l}0,02 \\
0,12 \\
0,05 \\
0,00\end{array}$ & $\begin{array}{l}0,07 \\
0,10 \\
0,00 \\
0,04\end{array}$ & $\begin{array}{l}0,00 \\
0,45 \\
0,00 \\
0,00\end{array}$ \\
\hline
\end{tabular}

Tabela 25 Análises detalhadas de elementos terras-raras à ME (\% em peso dos óxidos) de apatitas de Juquiá.

Legenda da figura 25 e tabela 25

1- Apatita tipo pavê em rocha sã,2 a- borda da apatita tipo pavê em material alterado, 2 b- núcleo da apatita tipo pavê em material alterado 3- Apatita tipo pavê em material muito alterado, 4 a- Apatita prismática com linhas de crescimento carbonatito são, 4 bApatita prismática com linhas de crescimento carbonatito alterado, 5- Apatita recristalizada na superfície da apatita tipo pavê (com Sr alto), 6- Borda de maior birrefringência ao redor da apatita tipo pavê, 7- Apatita supérgena tipo microprismático, 8 a- Apatita supérgena tipo fibroso leitosa, 8 b- Apatita supérgena tipo fibrorradial, 9 a- Apatita supérgena tipo prismática sobre a apatita fibrosa brotrioidal de fissuras, $9 \mathrm{~b}$ - Apatita supérgena tipo prismática milimétrica em fissuras não revestidas por apatita tipo fibroso leitosa. 


\section{JUQUIÁ}
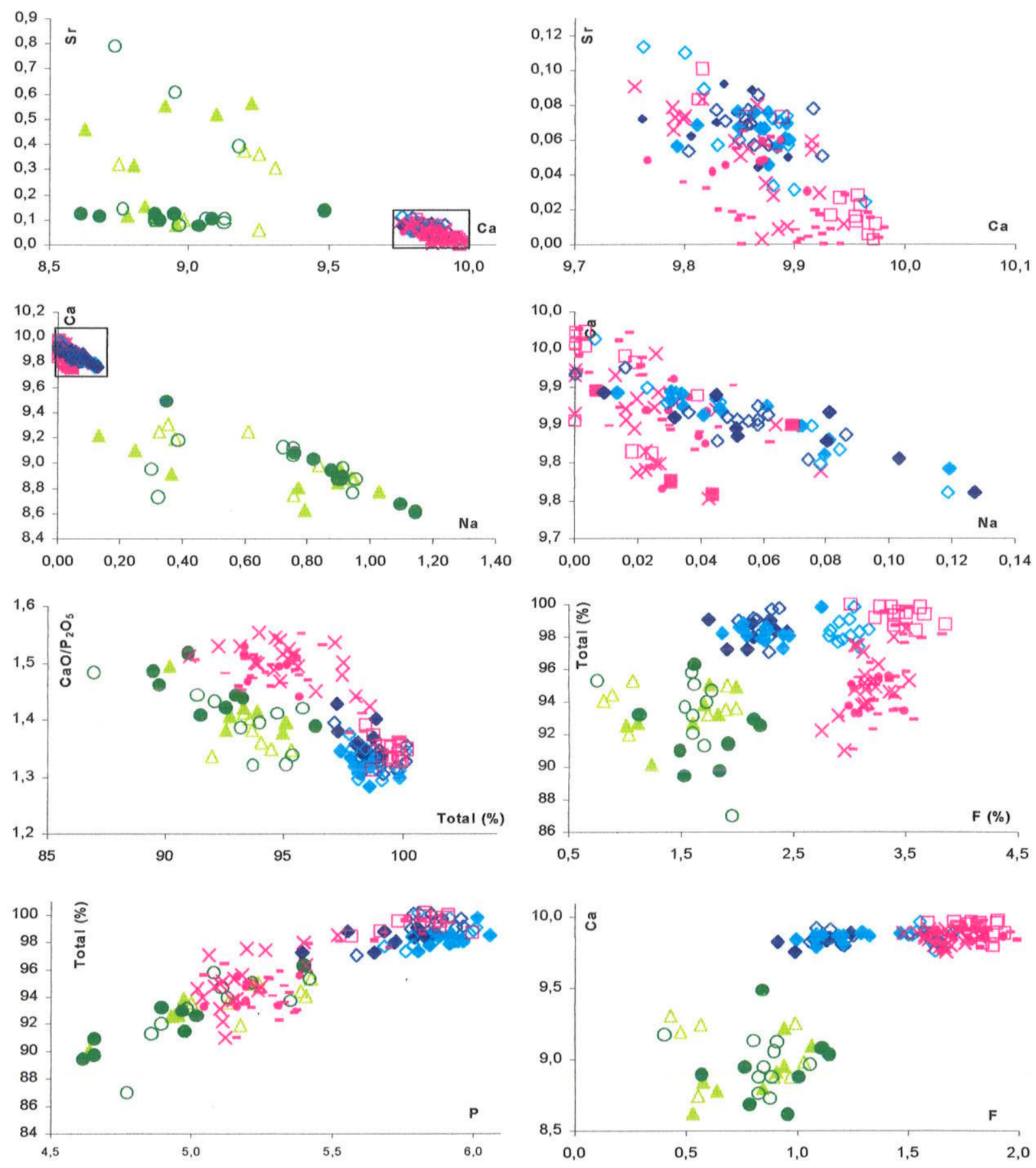

Apatitas primárias

1- tipo pavê em rocha sã

$\diamond$ 2- tipo pavê em material alterado

detalhamento do grão alterado:

2a- núcleo

$2 \mathrm{~b}$ - borda
Apatitas pré-meteóricas

4a- tipo prismático com linhas de crescimento - carbonatito são

$4 \mathrm{~b}$ - tipo prismático com linhas de - 8 a- tipo fibroso leitosa crescimento - carbonatito alterado

5- Apatita recristalizada na superficie da apatita tipo pavê (com Sr alto)
Apatitas supérgenas

7- tipo microprismático

(1)

$\times \quad 8$ b- tipo fibrorradial

9- tipo prismática (a e b)

6- borda de maior birrefringência

Figura 26 Diagramas binários mostrando as relações entre vários constituintes das apatitas de Juquiá, em número de átomos p.f.u. (fórmula estrutural calculada na base 10 átions). 


\subsubsection{Tapira}

\section{Mineralogia e micromorfologia das apatitas}

Como para as áreas anteriores, as características das apatitas de Tapira permitiram que fossem classificadas em três grupos maiores, de acordo com critérios morfológicos relacionados às etapas de fosfatogênese nos maciços: apatitas primárias, apatitas hidrotermais (de alteração anterior ao intemperismo) e apatitas supérgenas.

\section{Apatita primária}

A apatita primária ocorre essencialmente em rochas piroxeníticas e subordinadamente em veios de carbonatito e no silexito, em amostras localizadas na base do perfil de alteração. Dois tipos morfológicos de apatita primária foram observados: cristais prismáticos e cristais anédricos.

1-Apatita prismática primária sã (TA33b)

O exame microscópico de amostras de piroxenito inalterado mostra cristais de apatita prismática (em torno de $0,2 \mathrm{~mm}$ de comprimento) associados à piroxênios e porções dolomíticas (Foto 21). Não foi encontrada nos materiais mais intemperizados estudados.

A seguir serão apresentados tipos que ocorrem em materiais no estágio inicial da alteração intempérica (com porções inalteradas) e mais evoluídos (mais friáveis).

2- Apatita primária anédrica (TA-CC-3, TA46B, TA60, TA40a, TA-SC-2, TA-SC4 e TA-SC-6)

Os cristais deste tipo apresentam-se praticamente sãos em materiais pouco alterados (TA-CC3). Nos materiais alterados estes cristais apresentam fraturas, sinais de início de alteração, como bordas de contorno irregular e ferruginizadas; e dimensões milimétricas a submilimétricas (Foto 19 e Foto 20). Estes cristais podem estar associados a calcita, flogopita, piroxênio, magnetita e perovskita parcialmente (ou totalmente) alterada para anatásio. Ocorrem em materiais em estágio inicial de alteração quee apresentam estrutura original da rocha preservada, marcada pelo preenchimento por apatita supérgena fibrosa de cavidades deixadas pela dissolução dos carbonatos e sílicatos (Foto 28). 


\section{Apatita hidrotermal}

3- Apatita anédrica (TA19, TA2A, TA49)

Os grãos de apatita hidrotermal anédrica apresentam mesmas características morfológicas que as da apatita primária, sendo inicialmente confundido com esta. A classificação hidrotermal só foi indicada após análises à microssonda (altos teores de ETR). $\mathrm{Na}$ alterita podem apresentar-se parcialmente dissolvidos com descontinuidades preenchidas cristais prismáticos muito finos de apatita supérgena imbricados em textura tipo pavê (TA19) (Foto 29 e Foto 30). Ao MO observam-se que em alguns grãos aparecem manchas mais escuras no interior do grão e sulcos de dissolução que acompanham fraturas (aspecto estriado) (Foto 22, Foto 24, Foto 25 e Foto 26). As fraturas podem estar revestidas por uma fina camada de apatita supérgena (Foto 27 ).

4- borda de maior birrefringência

A borda de maior birrefringência foi encontrada apenas na rocha fresca (TAF33) em cristais prismáticos, em geral não é muito desenvolvida nos materiais estudados e ocorre de forma descontínua (Foto 21). Este tipo não foi analisado à ME.

\section{Apatita supérgena}

5- Apatita com textura fina em pavê sä intercrescida na apatita primária anédrica

Cristais prismáticos muito finos foram encontrados em silexitica alterada nas descontinuidades da apatita primária do tipo anédrica (tipo 3), como fraturas e golfos de corrosão (Foto 29 e Foto 30 ).

\section{6-Apatita tipo fibrosa}

Cristais de apatita supérgena ocorrem em volumes apatíticos, onde as apatitas primárias ocorrem associadas ao anatásio que cortam o piroxenito, revestindo os espaços deixados pela dissolução de outros minerais como piroxênio e carbonato e nas fraturas da apatita primária. Formam finas camadas com textura fibrosa, constituídas por fibras que crescem perpendicularmente a superficie das descontinuidades (Foto 28 e Foto 22 ). 


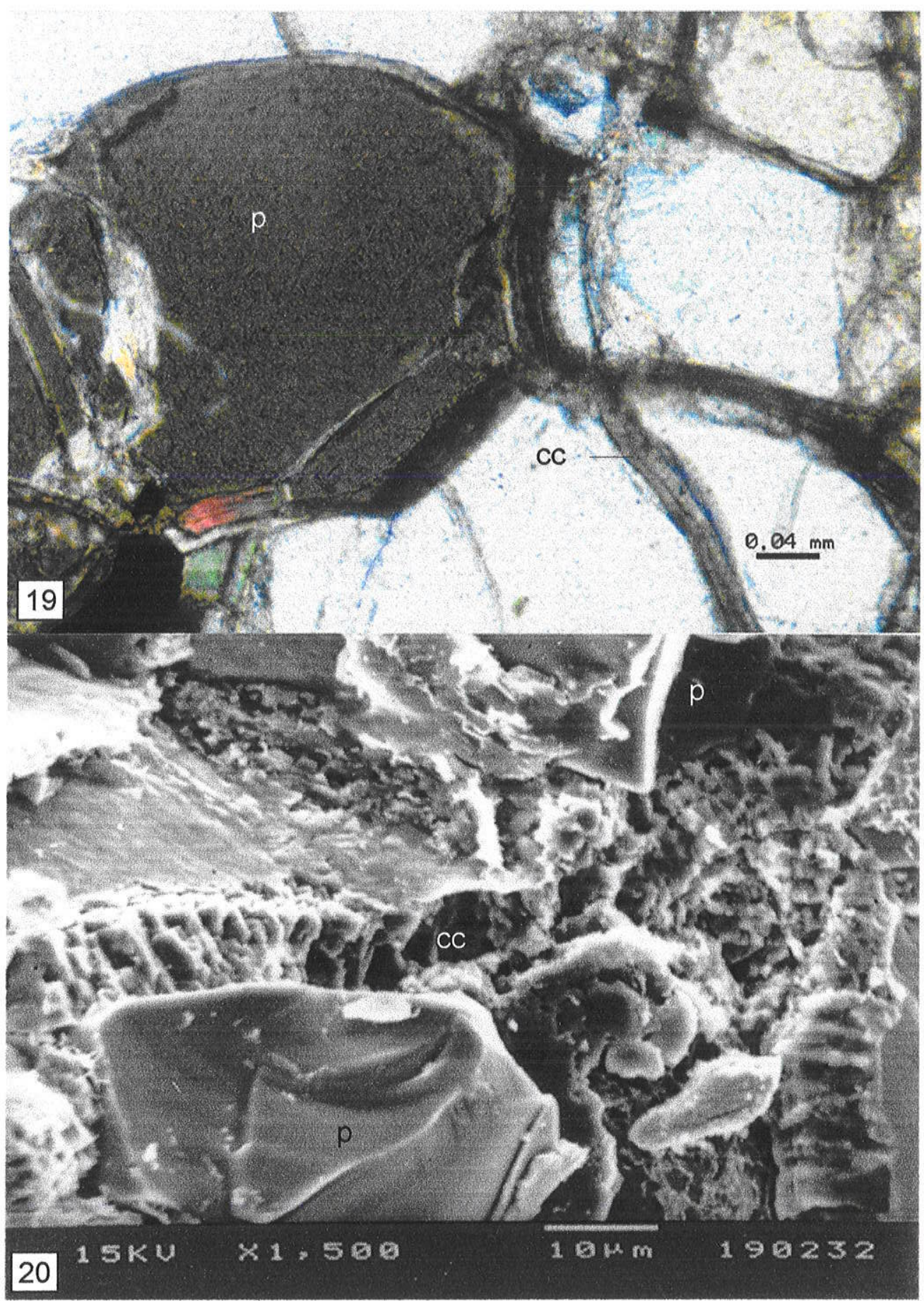

Foto 19 Cristais de apatita primária (p) anédrica imbricados em textura tipo pavê cortados por vênulas de calcita (cc). Tapira. Amostra TA46. MO (LP).

Foto 20 Detalhe da vênula de calcita (cc) que corta a apatita primária (p) anédrica. Tapira. Amostra TA46. MEV. 


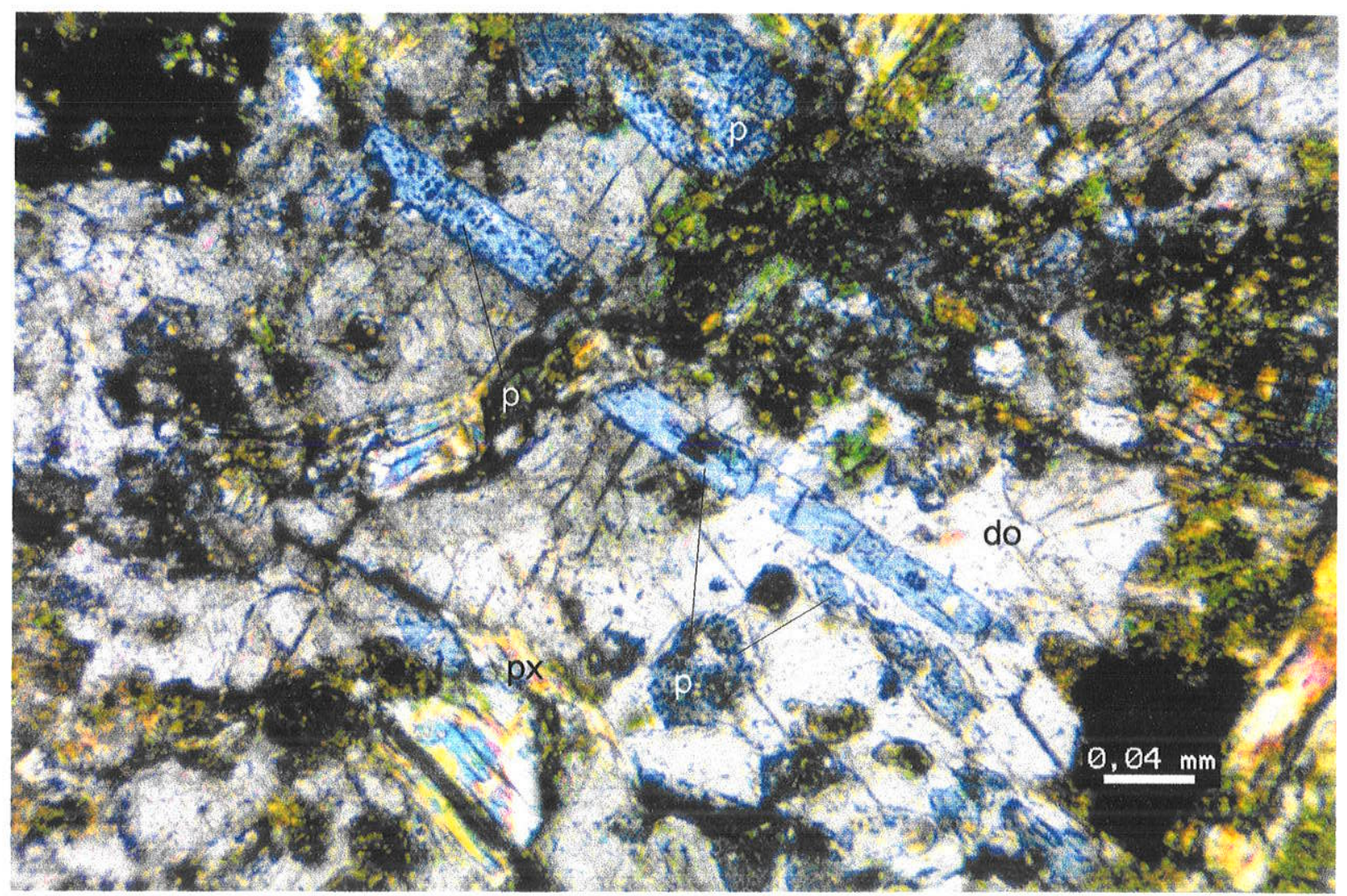

Foto 21 Cristais de apatita primária sã $(p)$ de forma prismática alongada (borda de maior birrefringência de espessura muito fina e descontínua) e de piroxênio (px), imersos em massa dolomítica de cor mais clara cortada por um volume de mineral verde (?).Tapira. Amostra TA33. MO (LP). 


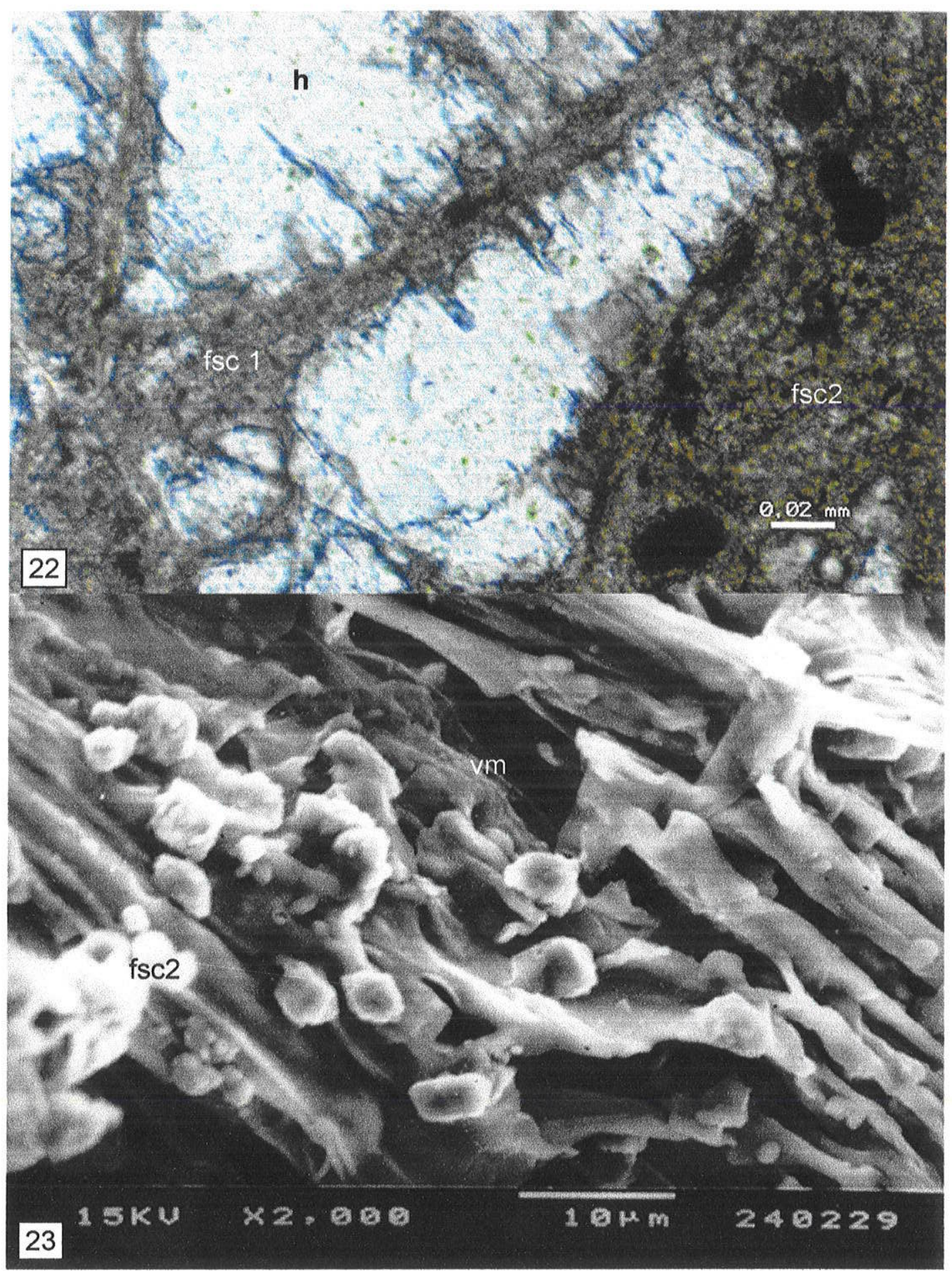

Foto 22 Cristal de apatita hidrotermal (h) anédrica alterada com fratura preenchida por fosfatos da série da crandallita tipo microcristalino cor clara (fsc1). Os espaços entre as apatitas residuais são constituídos por microglóbulos (fsc2) misturados a plasma de alteração de micas. Tapira. Amostra TAF49. MO (LP).

Foto 23 Detalhe da mica vermiculitizada junto a microglóbulos de fosfatos da série da crandallita (fsc2), que ocorrem ao redor das apatitas hidrotermais anédricas. Tapira. Amostra TA49. MEV (BEI). 


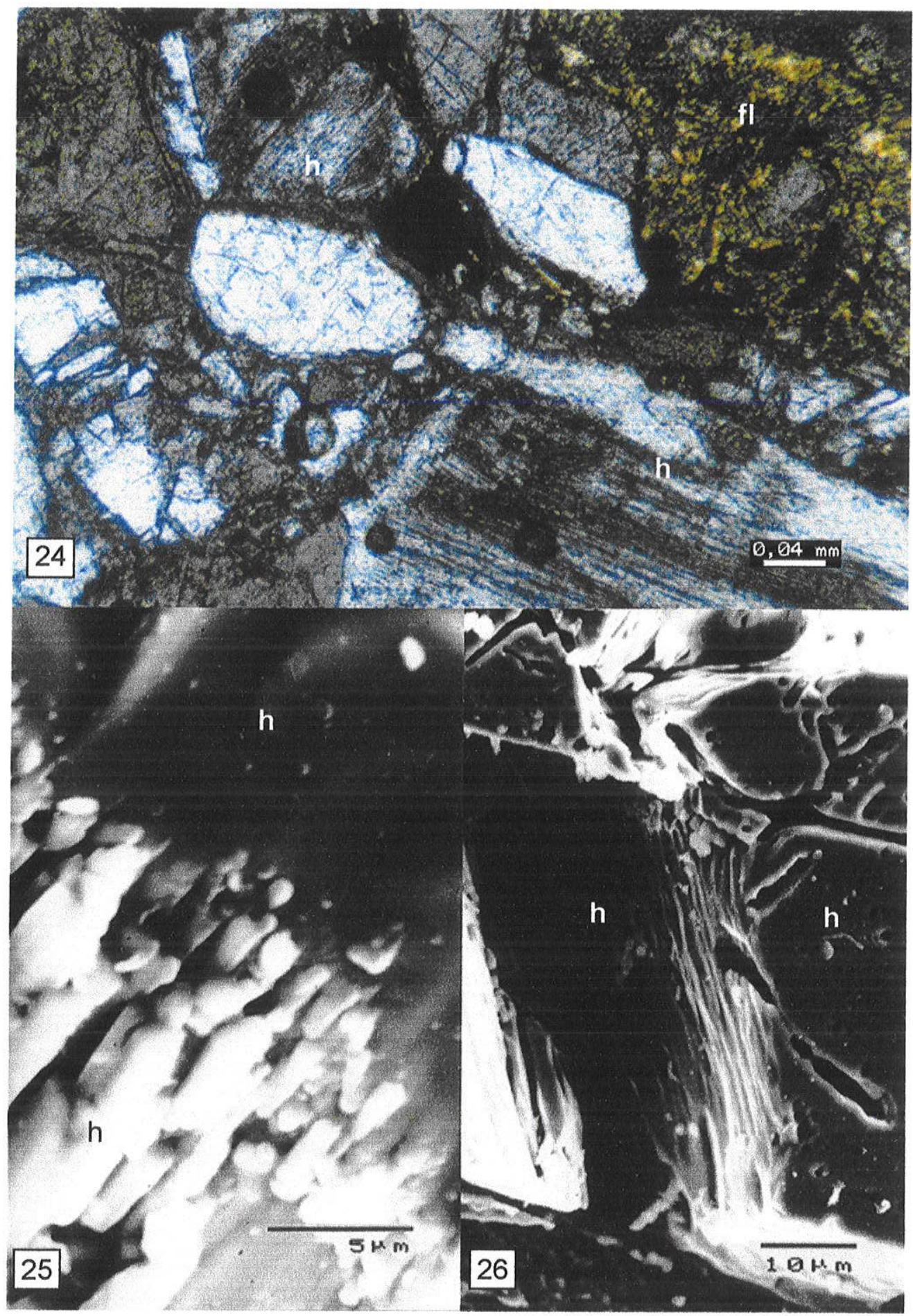

Foto 24 Apatita hidrotermal anédrica alterada (h) com núcleo de aspecto estriado e borda mais sã. Tapira. Amostra TA1. MO (LP).

Foto 25 Detalhe da superfície da apatita hidrotermal anédrica alterada. Tapira. Amostra TA1. MEV (BEI).

Foto 26 Cristal de apatita hidrotermal anédrica com sulcos de dissolução e com microporosidade. Tapira. Amostra TA2a. MEV (BEI). 


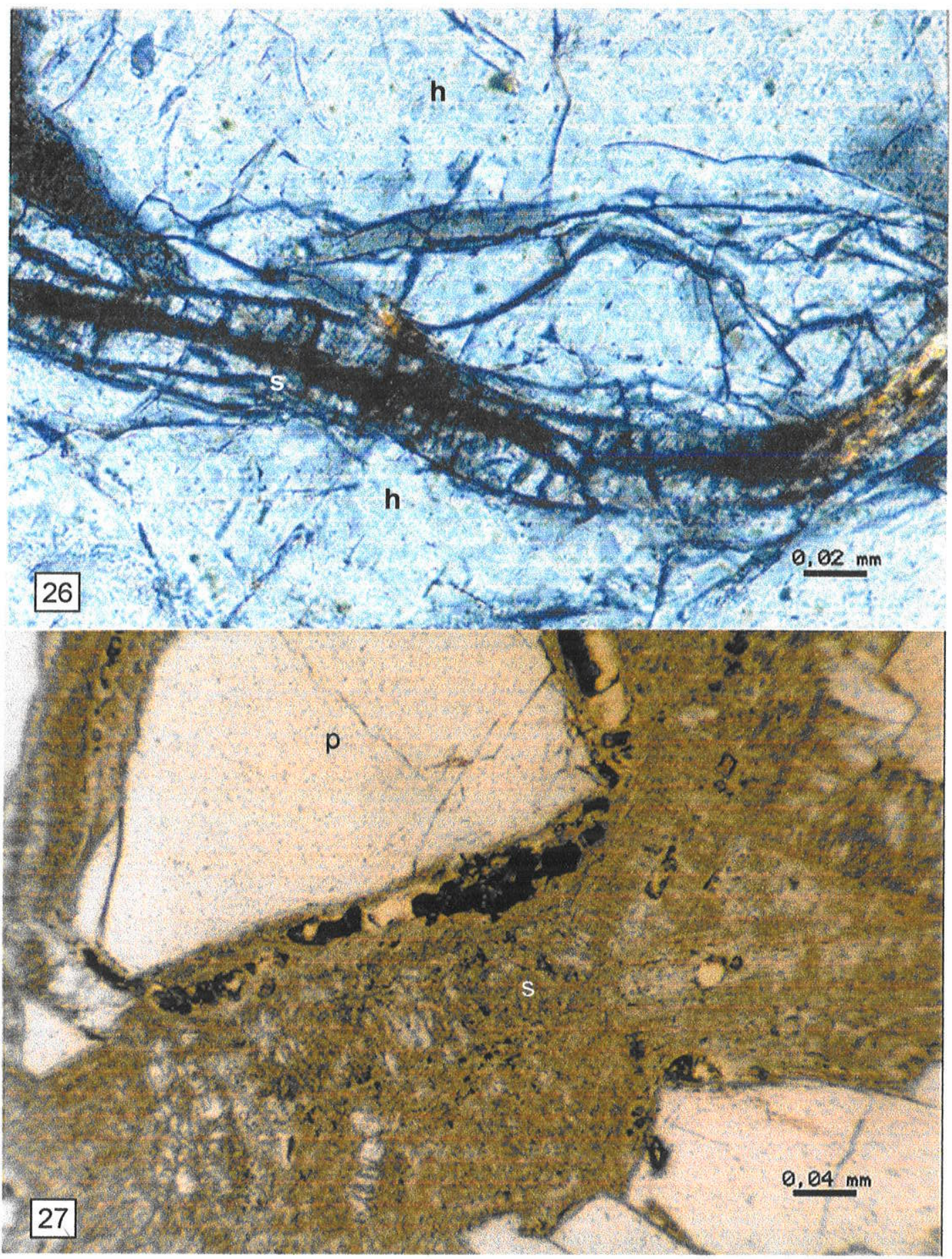

Foto 27 Fraturas da apatita hidrotermal (h) anédrica com recristalização de apatita supérgena fibrosa (s) muito fina. Tapira. Amostra 49.1. MO (LP).

Foto 28 Apatitas supérgenas fibrosas em descontinuidades da rocha, ao redor de grãos de apatita primária $(p)$ anédrica com bordas dissolvidas e ferruginizadas. Tapira. Amostra TA-SC-4b. MO (LN). 


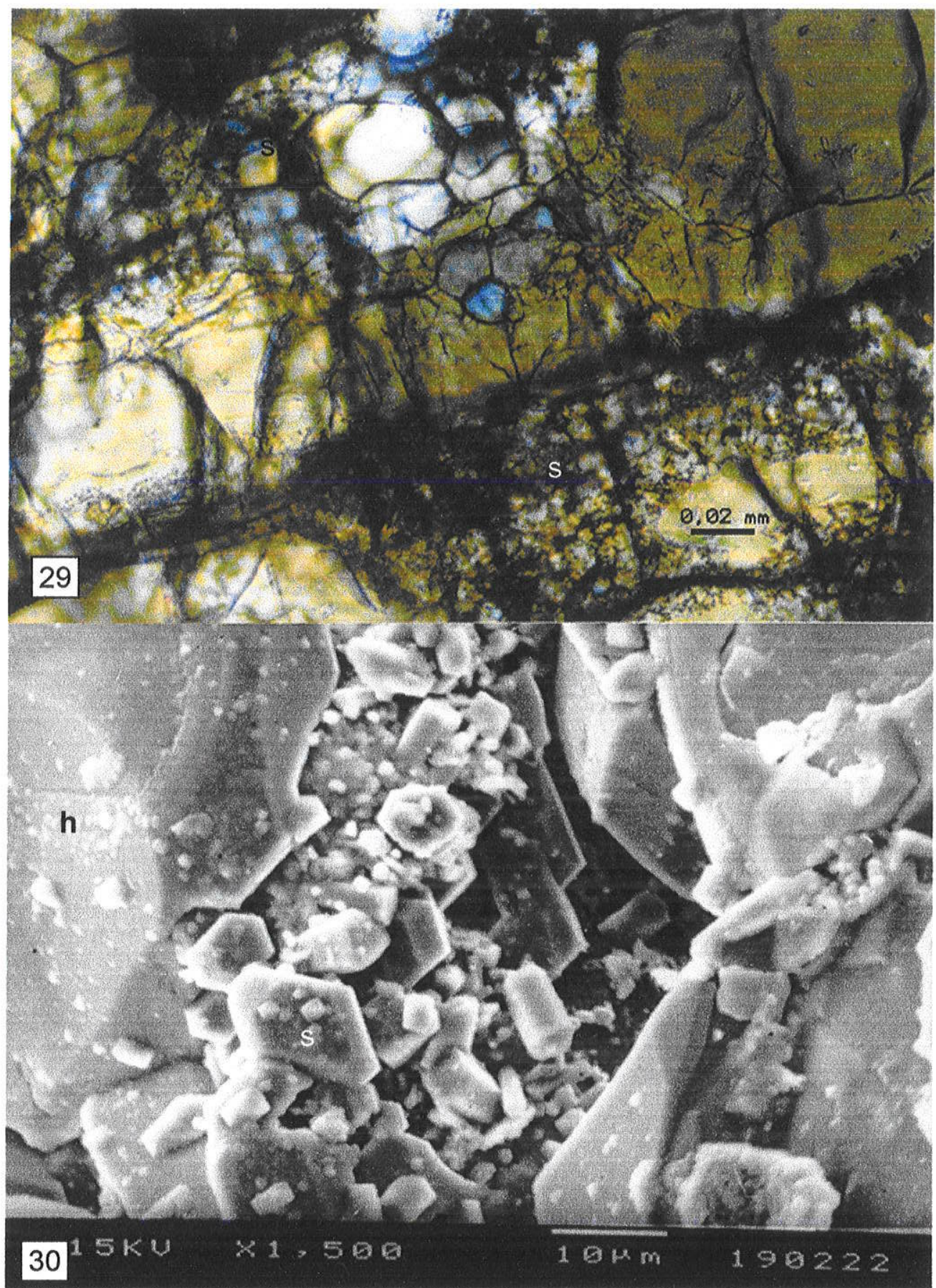

Foto 29 Cristais de apatita prismática supérgena, em pavê, cristalizada entre cristais de apatita hidrotermal (h) anédrica. Tapira. Amostra TA19. MO (LN).

Foto 30 Detalhe dos cristais de apatita prismática supérgena entre grãos de apatita hidrotermal anédrica (h). Amostra TA19. Tapira. MEV (BEI). 
Como para as outras áreas, procurou-se analisar à DRX amostras contendo apenas um tipo de apatita, o que nem sempre foi possível, devido à íntima associação entre diferentes tipos na maior parte das amostras. Foram selecionadas amostras de apatita primária sã do tipo anhedral (TA-CC-3 e TA-CC-3b) e de apatita alterada anédrica: rica em ETR (TA1ap, TA3ap, TA49.4) e pobre em ETR (TA-SC-2 e TA-SC-6). A amostra TA-SC-6 também contém apatita supérgena do tipo fibrosa, difícil de ser separada. Os cálculos dos parâmetros de cela unitária foram feitos analogamente às outras áreas, pelo método dos mínimos quadrados utilizando o programa de refinamento de parâmetros de cela LCLSQ (Burnham, 1991).

O gráfico da Figura 27 mostra a distribuição dos parâmetros cristalográficos a e $c$ das amostras de apatita encontradas na rocha e na alterita mencionadas acima. Observa-se que as amostras de apatita primária apresentam parâmetros de cela unitária de a e c próximos aos das mostras de apatita supérgena e que as de apatita muito alterada apresentam valores variáveis de a e $c$ (Figura 27 e Tabela 26).

Os valores de a das amostras de apatita analisadas são ligeiramente menores do que o da hidroxiapatita (JCPDS 9-432), sendo a maior diferença encontrada na apatita primária sã e uma das amostras de apatita muito alterada TA49.1. O parâmetro $c$ é sempre maior que $O$ da fluorapatita (JCPDS 15-876) e da hidroxiapatita (JCPDS 9-432); a diferença é maior nas apatitas mais alteradas.

Os difratogramas de amostras com misturas de apatita primária e supérgena, Figura 28, mostram diferenças nas relações de intensidade em alguns picos, que poderia ser explicado pelas diferenças estruturais da fase dominante de cada amostra. A tentativa de estudar os padrões pelo método Rietveld não teve muito sucesso. 


\begin{tabular}{|c|c|c|c|c|}
\hline material & amostra & apatita & [a] $\AA$ & [c] $\AA$ \\
\hline \multirow{2}{*}{$\begin{array}{l}\text { material praticamente } \\
\text { inalterado } 1\end{array}$} & TA-CC-3* & \multirow[t]{2}{*}{ apatita primária anédrica (tipo 2) } & $9,402(2)$ & $6,890(3)$ \\
\hline & TA-CC-3b* & & $9,400(2)$ & $6,889(2)$ \\
\hline material muito alterado ? & TA-SC-2** & $\begin{array}{l}\text { apatita primária anédrica (tipo 2) } \\
\text { com apatita supérgena tipo fibrosa }\end{array}$ & $9,405(1)$ & $6,887(1)$ \\
\hline material muito alterado & TA-SC-6** & $\begin{array}{l}\text { apatita primária anédrica (tipo } 2 \text { ) } \\
\text { com apatita supérgena tipo fibrosa }\end{array}$ & $9,404(2)$ & $6,893(2)$ \\
\hline piroxenito alterado & TA49.4 & \multirow{3}{*}{ apatita primária anédrica (tipo 3) } & $9,396(2)$ & $6,900(2)$ \\
\hline \multirow[t]{2}{*}{ glimerito muito alterado } & TA1 ap & & $9,407(1)$ & $6,891(2)$ \\
\hline & TA3ap & & $9,417(1)$ & $6,896(1)$ \\
\hline \multicolumn{2}{|c|}{ Fluorapatita (JCPDS 15-876) } & & 9,368 & 6,884 \\
\hline \multicolumn{2}{|c|}{ Hidroxiapatita (JCPDS 9-432) } & & 9,418 & 6,8841 \\
\hline
\end{tabular}

* $70 \%$ de apatita primária, ${ }^{\star \star} 35 \%$ de apatita primária ${ }^{1}$ material preparado por Lenharo (1994).

Tabela 26 Parâmetros cristalográficos a e $c$ de apatitas de Tapira.

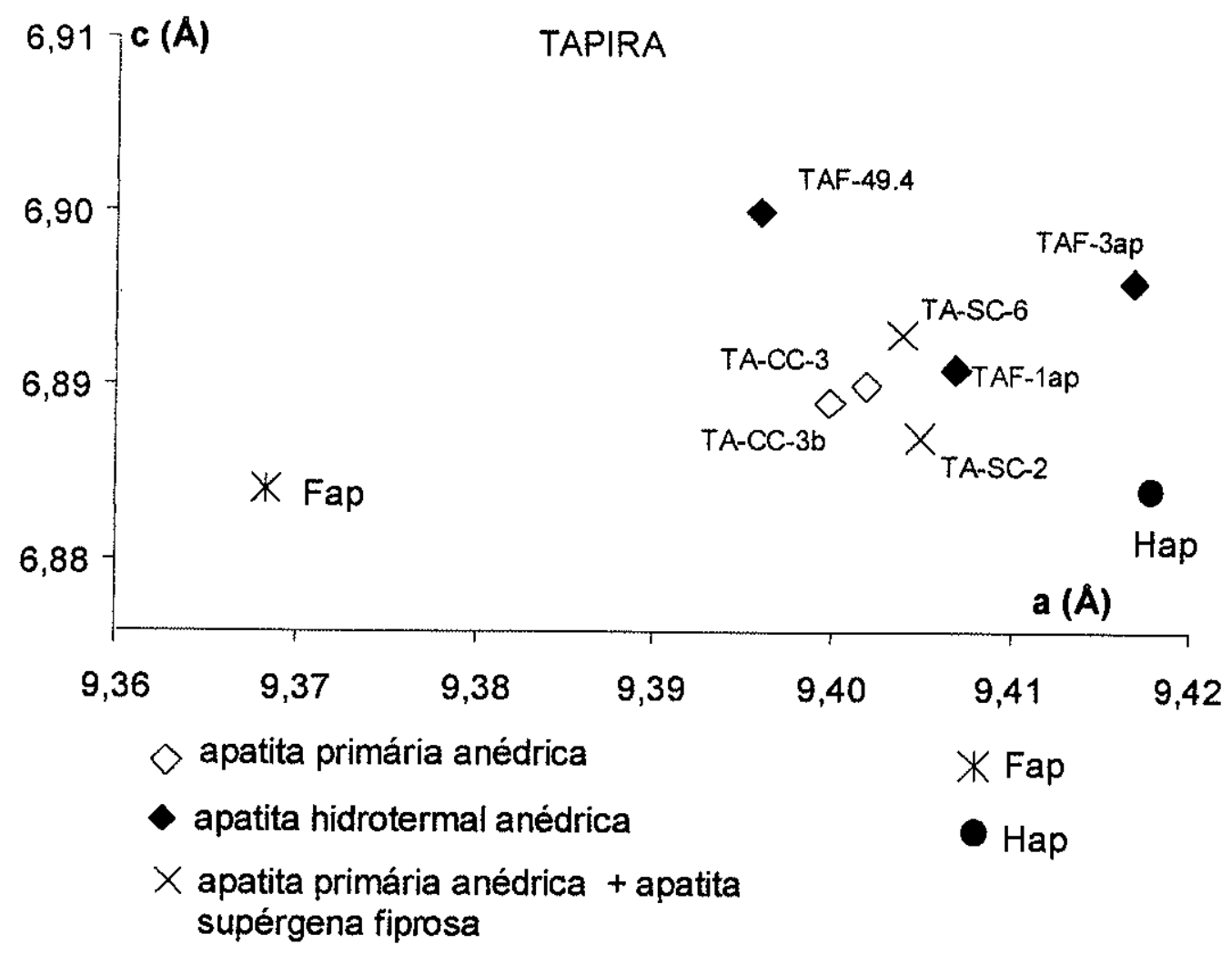

Figura 27 Variação dos parâmetros cristalográficos a e c das apatitas de Tapira, calculados pelo método dos mínimos quadrados utilizando o programa de refinamento de parâmetros de cela LCLSQ (Burnham, 1991). Fap - Fluorapatita sintética (JCPDS 15-876) Hap - Hidroxiapatita sintética (JCPDS 9-432) 


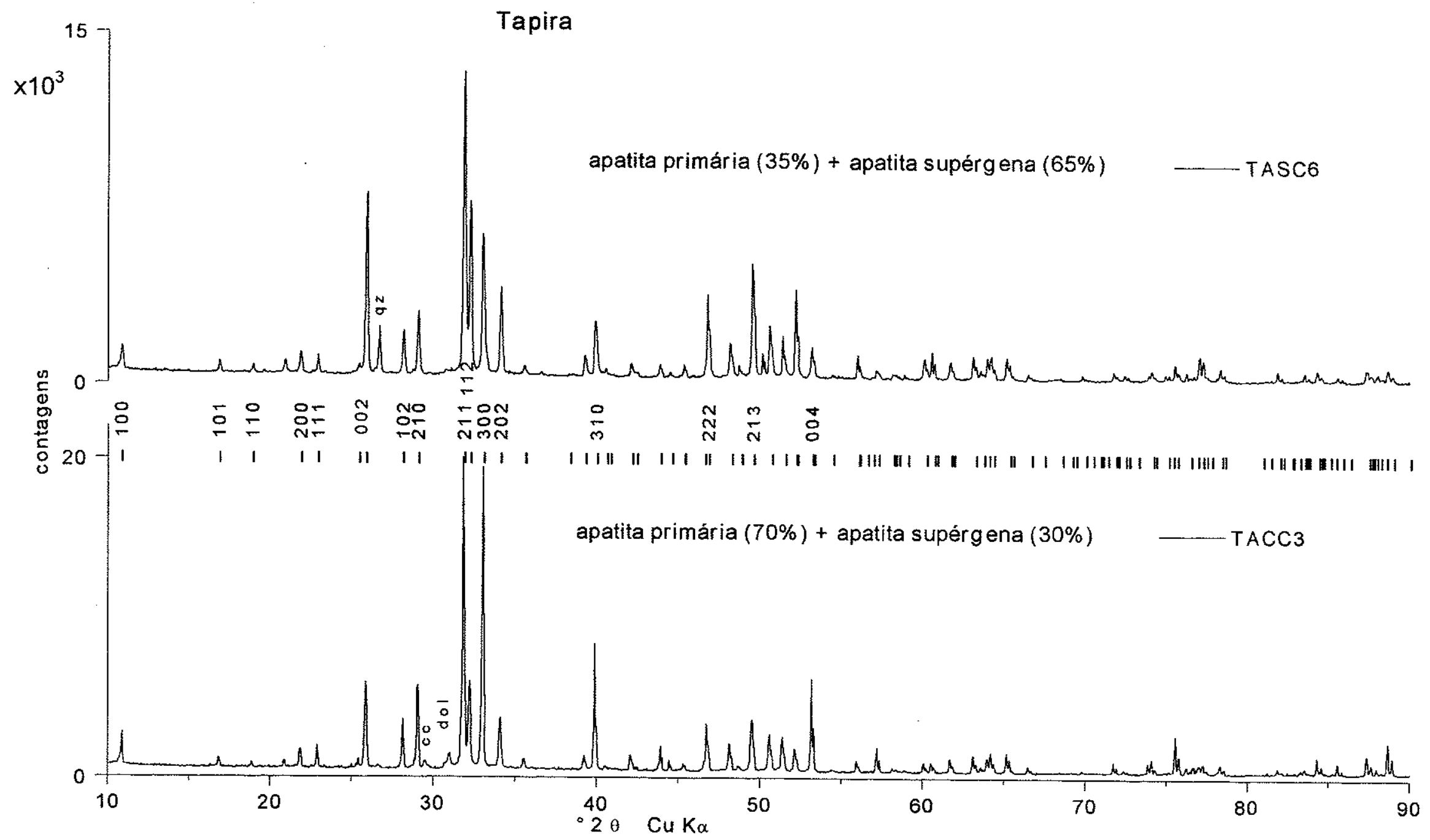

Figura 28 Difratogramas de amostras mistas de apatita primária e supérgena com diferentes porcentagens. qz: quartzo, dol: dolomita, cc: calcita, | : posiçōes das reflexōes de Bragg da apatita. 


\section{Aspectos químicos e cristaloquímicos das apatitas}

As análises à microssonda (Tabela 27, Tabela 28, Tabela 29, Figura 30, Figura 31 e Anexo 4) mostraram uma variação composicional dos diferentes tipos de apatitas de Tapira. Os valores de total das análises para a apatita primária anédrica são freqüentemente acima de $97 \%$ e atingem no máximo $99 \%$. Já o total das análises para as apatitas primárias do tipo prismático ficaram sempre abaixo de $97 \%$. As apatitas alteradas apresentaram totais de análise abaixo de $99 \%$ sendo as apatitas ricas em ETR as que apresentaram os valores mais baixos de total. Os totais obtidos nas zonas de fraturas variaram entre 93 e $97 \%$. Os totais encontrados nas apatitas supérgenas tipo prismática são maiores que $98 \%$ porém não atingem $99 \%$. Apatita supérgena do tipo fibrosa apresenta total de análises freqüentemente acima de $97 \%$ atingindo no máximo $99 \%$.

As apatitas primárias com fechamento de análise baixo em geral possuem uma razão $\mathrm{CaO} / \mathrm{P}_{2} \mathrm{O}_{5}$ mais elevada $(>1.40$ ) que a encontrada nas apatitas com total próximo a $98 \%$. Apatitas do tipo fibrosa além de possuirem fechamentos acima de $98 \%$ possuem razões $\mathrm{CaO} / \mathrm{P}_{2} \mathrm{O}_{5}$ em geral superiores a 1,40 , sendo muito similar ao encontrado na apatita supérgena prismática de Juquiá. $\mathrm{O}$ diagrama binário mostra uma correlação negativa entre os totais de análise e a razão $\mathrm{CaO} / \mathrm{P}_{2} \mathrm{O}_{5}$ apenas para os tipos apatita primária sã e apatita hidrotermal anédrica.

$\mathrm{O}$ número de átomos p.f.u. de $\mathrm{Mg}, \mathrm{Mn}, \mathrm{Fe}, \mathrm{Al}, \mathrm{Ba}$ e $\mathrm{Cl}$ das apatitas analisadas apresentaram valores muito baixos (menor que 0.02). Alguns pontos analisados na apatita primária prismática sã apresentaram valores de número de átomos p.f.u. mais elevados de $\mathrm{Mg}$ (até 0,07 ) e de $\mathrm{Fe}$ (até 0,05 ).

A apatita primária prismática sã apresentou uma quantidade de $\mathrm{Na}($ até 0,05$) \mathrm{e}$ de $\operatorname{Sr}(0,09$ a 0,20$)$ ligeiramente maior do que a maioria dos pontos analisados da apatita primária anédrica ( $\mathrm{Na:} 0,01$ a 0,07 e Sr: 0,06 a 0,16). A apatita supérgena em pavê fino apresentou valores em geral maiores de número de átomos de $\mathrm{Na}$ p.f.u. $(0,14$ a 0,19$)$ e de $\operatorname{Sr}(0,10$ a 0,14$)$. A apatita supérgena fibrosa não apresentou valores significativos de número de átomos de $\mathrm{Na}$ e $\mathrm{Sr}$ p.f.u. (ambos entre 0 e 0,02). Com exceção da apatita supérgena em todos os tipos o Sr é o principal substituinte do Ca no sítio catiônico.

Observou-se que a apatita primária anédrica apresentaram um menor número de átomos de ETR p.f.u. $(\mathrm{La}+\mathrm{Ce}$ até 0,02$)$ do que as apatitas hidrotermais anédricas ( $\mathrm{La}+\mathrm{Ce}$ entre 0,06 e 0,17 ). A riqueza em ETR destas apatitas 
supostamente está ligada ao evento hidrotermal a semelhança do $\mathrm{Na} \mathrm{e} \mathrm{Sr}$ encontrados em maior quantidade nas bordas de maior birrefringência formada por alteração hidrotermal, assim estas apatitas foram classificadas como apatitas de alteração hidrotermal (ou simplesmente apatita hidrotermal).

Os dois tipos morfológicos de apatita supérgenas se diferenciam no conteúdo de ETR, o tipo de textura fina em pavê é mais rico em $\operatorname{ETR}(0,07$ a 0,11$)$ do que o tipo fibroso $(0,00$ a 0,03$)$. A composição das apatitas supérgena parece estar relacionadas com a composição das apatitas primárias as quais estão associadas.

O Ce aparece em maior quantidade do que o La (Tabela 29 e Anexo 4) nos tipos morfológicos mais ricos em ETR. A apatita anédrica de materiais muito alterados apresentou aproximadamente a seguinte relação de teores dos ETR: Ce > La $\geq \mathrm{Nd}>\mathrm{Gd} \geq \mathrm{Sm}>\mathrm{Y} \geq$ Dy (Yb ausente) (Tabela 29)

O gráfico de variação da composição dos tipos de apatita (Figura 29) mostra que a apatita hidrotermal anédrica apresenta uma diferenciação em ETR principalmente entre a região da borda ou fratura (mais rica em ETR) e o núcleo (mais empobrecido em ETR) do grão.

O Si sempre está presente nas apatitas analisadas sendo que seu número de átomos p.f.u. no sítio aniônico do $\mathrm{PO}_{4}{ }^{3-}$ varia com o tipo morfológico. A apatita primária prismática sã apresenta valores entre 0,13 e 0,46 e a apatita primária anédrica entre 0,04 e 0,13. A região de fratura e de borda dos grãos de apatita hidrotermal anédrica apresentaram uma maior quantidade de Si (até 0,40) do que a região do núcleo (até 0,13 ). A quantidade de Si é muito pequena nos tipos de apatita supérgena fibrosa e em pavê fino (ambos entre 0 e 0,03 p.f.u.). O diagrama binário ETR x Si (Figura 30) mostra uma correlação negativa (muito pouco evidente) dos ETR com o Si para os pontos da região do núcleo da apatita hidrotermal anédrica e das apatitas supérgenas prismáticas em pavê fino. A correlação Si x ETR parece inverter (positiva) na região de borda e fraturas da apatita anédrica de materiais muito alterados.

A soma $P+$ Si mostra que todas as apatitas analisadas apresentam um déficit no sítio aniônico que pode ter várias causas (substituições do $\mathrm{PO}_{4}{ }^{3-}$ por $\mathrm{CO}_{3}{ }^{2-} \mathrm{e} \mathrm{OH}^{-}$ entre outros ânions).

A presença de $\mathrm{CO}_{2}$ foi pesquisada ao IV e MR. Ao IV, apatitas primárias anédricas apresentaram $0,61 \%$ de $\mathrm{CO}_{2}$ (TA-CC-3) e das apatitas hidrotermais anédricas $0,13 \%$ de $\mathrm{CO}_{2}$ (TA49.4). A avaliação do teor em carbonato por MR indicou 
$0 \%$ para a apatita primária hidrotermal anédrica, ao contrário do valor obtido por IV, e menos de $0,5 \%$ de $\mathrm{CO}_{2}$ para a apatita supérgena do tipo fibrosa, não analisada ao IV.

Cálculos de $\mathrm{CO}_{2}$ efetuados a partir de dados da microssonda (conforme método explicado no cap. 4) indicaram que as apatitas primárias prismáticas sãs possuem teores variáveis de $\mathrm{CO}_{2}$ com teores entre 0,57 e $3,64 \%$. As apatitas hidrotermais anédricas apresentaram uma maior variação dos teores de $\mathrm{CO}_{2}$ (entre 0,01 e $5,19 \%$ ). As apatitas supérgenas do tipo fibrosa apresentaram teores entre 0,52 e $3,12 \% \mathrm{CO}_{2}$ que são freqüentemente maiores do que as apatitas supérgenas tipo prismático em pavê fino $(0,40$ a $1,26 \%)$.

Observa-se que os valores encontrados à ME para as apatitas primárias e hidrotermais anédricas são quase sempre maiores que o encontrado ao IV e MR, havendo uma maior discrepância entre os valores encontrados à $M R(<0,5 \%)$ e à ME (entre 0,52 e 3,12\%) para as apatitas do tipo fibrosa.

O teor em flúor das apatitas do tipo fibrosa é alto com relação aos teores encontrados para as outras apatitas. Estas apatitas apresentaram razões de $\mathrm{F} / \mathrm{P}_{2} \mathrm{O}_{5}$ acima de 0,084 com alguns valores iguais a de uma fluorapatita ideal $(0,089)$.

Foram analisadas à catodoluminescência lâminas de materiais ricos em apatitas. As apatitas primárias sãs apresentaram cores de Catodo Luminescência em tonalidades azul a violeta. As apatitas alteradas, tanto por intemperismo como por processos anteriores a ele, apresentaram tons de rosa; no caso de grãos de apatita primária com sinais morfológicos de alteração intempérica (alterações de textura em cor em MO, alto grau de fissuração), houve o aparecimento de manchas rosadas dentro do grão azul-violeta. Algumas apatitas hidrotermais apresentaram manchas esverdeadas.

As apatitas supérgenas prismáticas em pavê apresentaram cor de luminescência pouco intensa chegando a mostrar tons de bege. As apatitas fibrosas supérgenas não apresentaram cor de luminescência.

No estudo dos materiais concentrados e rejeitados no processo industrial da usina de Tapira, foi verificado claramente que grãos mistos (constituídos por mais de uma geração de apatita ou por apatita primária com alteração intempérica) compõem preferencialmente as frações rejeitadas representando, assim, parte importante das perdas de $\mathrm{P}_{2} \mathrm{O}_{5}$ durante o beneficiamento (Santos, 1998 e Santos et al., 1999). 


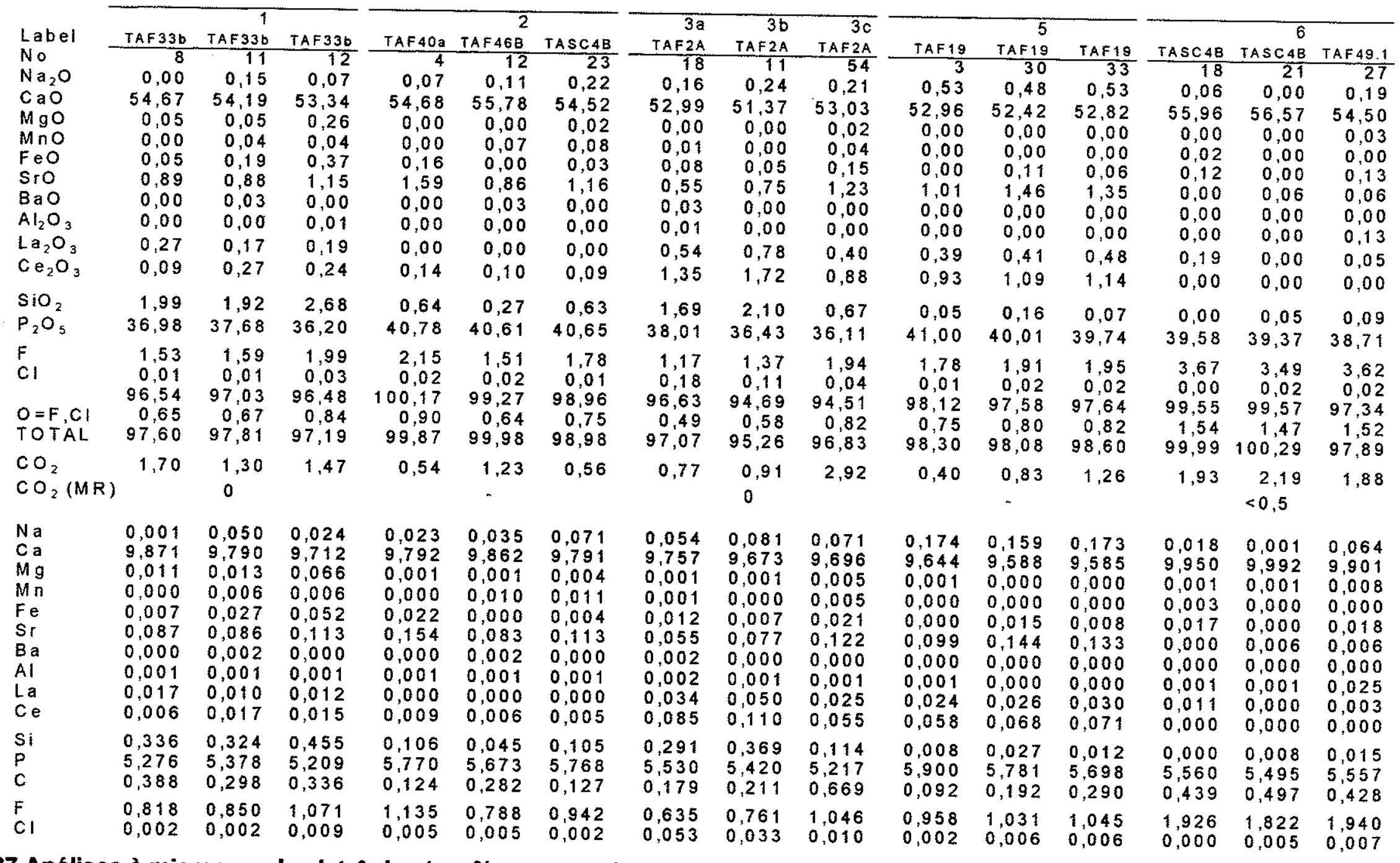

Tabela 27 Análises à microssonda eletrónica (em \% em peso dos óxidos) e cálculos de fórmulas estruturais das apatitas de Tapira.

Composição química, obtida à ME, dos diferentes tipos de apatita estudados em Tapira, expressa em \% em peso de óxidos e em número de átomos por fórmula unitária calculada na base 10 cátions. São apresentados os pontos de análise mais representativos dos tipos: 1- Apatita prismática primária, 2- Apatita primária anédrica, 3- Apatita hidrotermal anédrica (a: borda, b: próximo a fratura, c: núcleo), 5- Apatita supérgena fina em pavê intercrescida na apatita hidrotermal anédrica, 6- Apatita supérgena tipo fibrosa. A tabela completa das análises encontra-se no Anexo 4. 


\begin{tabular}{|c|c|c|c|c|c|c|c|c|c|c|c|c|c|c|c|}
\hline Label & TAF33b & $\begin{array}{c}1 \\
\text { TAF33b }\end{array}$ & TAF33b & TAF $40 a$ & $\begin{array}{c}2 \\
\text { TAF46B } \\
\end{array}$ & TASCAB & $\begin{array}{c}3 a \\
\text { TAF2A }\end{array}$ & $\begin{array}{c}3 b \\
\mathrm{AF} 49.1 \\
\end{array}$ & $\begin{array}{c}3 \mathrm{c} \\
\text { TAF2A }\end{array}$ & TAF 19 & $\begin{array}{c}5 \\
\text { TAF19 }\end{array}$ & TAF19 & TASC4B & $\begin{array}{c}6 \\
\text { TASC } 4 B \\
\end{array}$ & TAF 49.1 \\
\hline No & 8 & 11 & 12 & 4 & 12 & 23 & 18 & 26 & 54 & 3 & 30 & 33 & 18 & 21 & 27 \\
\hline $\mathrm{OH}^{\mathrm{a}}$ & 2,01 & 1,95 & 1,58 & 1,46 & 2,06 & 1,79 & 2,29 & 1,53 & 1,63 & 1,75 & 1,63 & 1,61 & 0,13 & 0,31 & 0,10 \\
\hline $\mathrm{OH}^{\mathrm{b}}$ & 2,27 & 2,15 & 1,80 & 1,54 & 2,25 & 1,87 & 2,41 & 1,72 & 2,08 & 1,81 & 1,75 & 1,80 & 0,43 & 0,64 & 0,39 \\
\hline $\mathrm{OH}^{c}$ & 2,66 & 2,45 & 2,14 & 1,66 & 2,53 & 2,00 & 2,58 & 2,02 & 2,74 & 1,90 & 1,94 & 2,09 & 0,87 & 1,15 & 0,83 \\
\hline $\mathrm{OH}^{\mathrm{a}}$ & 1,182 & 1,150 & 0,929 & 0,865 & 1,212 & 1,058 & 1,365 & 0,907 & 0,954 & 1,042 & 0,969 & 0,955 & 0,074 & 0,178 & 0,060 \\
\hline $\mathrm{OH}^{\mathrm{b}}$ & 1,337 & 1,269 & 1,064 & 0,915 & 1,325 & 1,108 & 1,436 & 1,027 & 1,221 & 1,079 & 1,045 & 1,071 & 0,250 & 0,376 & 0,231 \\
\hline $\mathrm{OH}^{\mathrm{c}}$ & 1,570 & 1,448 & 1,265 & 0,989 & 1,494 & 1,185 & 1,544 & 1,207 & 1,622 & 1,134 & 1,160 & 1,245 & 0,514 & 0,674 & 0,488 \\
\hline P.M. ${ }^{a}$ & 997 & 1001 & 1001 & 1010 & 1000 & 1006 & 1014 & 1011 & 996 & 1013 & 1013 & 1010 & 994 & 991 & 993 \\
\hline $\begin{array}{l}\text { P.M. } \\
\text { P. }\end{array}$ & 1000 & 1003 & 1003 & 1011 & 1002 & 1007 & 1015 & 1013 & 1000 & 1013 & 1015 & 1012 & 997 & 994 & 996 \\
\hline P.M. ${ }^{\mathrm{C}}$ & 1004 & 1006 & 1007 & 1012 & 1005 & 1008 & 1017 & 1016 & 1007 & 1014 & 1017 & 1015 & 1001 & 999 & 1001 \\
\hline carga $^{a}$ & 0,408 & 0,274 & 0,332 & 0,106 & 0,249 & 0,061 & 0,198 & 0,333 & 0,669 & $-0,001$ & 0,122 & 0,212 & 0,434 & 0,493 & 0,436 \\
\hline carga $^{b}$ & 0,253 & 0,155 & 0,197 & 0,056 & 0,136 & 0,010 & 0,126 & 0,213 & 0,402 & $-0,038$ & 0,045 & 0,096 & 0,258 & 0,294 & 0,265 \\
\hline $\operatorname{carga}^{c}$ & 0,021 & $-0,024$ & $-0,004$ & $-0,018$ & $-0,033$ & $-0,067$ & 0,019 & 0,033 & 0,001 & $-0,093$ & $-0,070$ & $-0,078$ & $-0,005$ & $-0,004$ & 0,008 \\
\hline $\mathrm{CaO} / \mathrm{P}_{2} \mathrm{O}_{5}$ & 1,478 & 1,438 & 1,473 & 1,341 & 1,374 & 1,341 & 1,394 & 1,370 & 1,468 & 1,292 & 1,310 & 1,329 & 1,414 & 1,437 & 1,408 \\
\hline $\mathrm{F} / \mathrm{P}_{2} \mathrm{O}_{5}$ & 0,041 & 0,042 & 0,055 & 0,053 & 0,037 & 0,044 & 0,031 & 0,052 & 0,054 & 0,043 & 0,048 & 0,049 & 0,093 & 0,089 & 0,093 \\
\hline $\mathrm{SrO} / \mathrm{P}_{2} \mathrm{O}_{5}$ & 0,024 & 0,023 & 0,032 & 0,039 & 0,021 & 0,029 & 0,014 & 0,034 & 0,034 & 0,025 & 0,036 & 0,034 & 0,000 & 0,001 & 0,001 \\
\hline
\end{tabular}

Tabela 28 Dados de quantidades de $\mathrm{OH}$ (\% em peso e átomos p.f.u.), peso molecular (PM) e carga da fórmula estrutural considerando três alternativas: a - todo flúor $(F)$ nos canais $\left(F_{p}=0\right)$, b - parte do flúor $\left(F_{p}\right)$ acompanhando o $\mathrm{CO}_{3}^{2-}\left(F_{p}=0,4 C\right)$ e $c-p a r t e$ do flúor $\left(F_{p}\right)$ acompanhando $\circ \mathrm{CO}_{3}\left(\mathrm{~F}_{\mathrm{p}}=\mathrm{C}\right)$. OH foi calculado pela diferença da fração molar no sítio dos ânions monovalentes $\left(O H=2-F-F_{p}\right)$, para cada caso a, b e c. (A partir dos dados da tabela anterior, para apatitas de Tapira)

\begin{tabular}{|c|c|c|c|c|c|c|c|c|c|c|}
\hline $\begin{array}{l}\text { tipo } \\
\text { Amostra }\end{array}$ & & & & & & $\stackrel{2}{\text { TAF } 400}$ & & & $\begin{array}{r}3 \\
\text { AF } 2 A\end{array}$ & \\
\hline No. & 1 & 2 & 3 & 4 & 13 & 14 & 15 & 1 & 2 & 3 \\
\hline $\mathrm{Y}_{2} \mathrm{O}_{3}$ & 0,00 & 0,00 & 0,00 & 0,00 & -- & -- & - & 0,01 & 0,11 & 0,09 \\
\hline $\mathrm{La}_{2} \mathrm{O}_{3}$ & 0,40 & 0,55 & 0,41 & 0,56 & 0,13 & 0,13 & 0,28 & 1,10 & 1,33 & 1,33 \\
\hline $\mathrm{Ce}_{2} \mathrm{O}_{3}$ & 0,56 & 0,69 & 0,54 & 1,53 & 0,36 & 0,31 & 0,32 & 2,67 & 2,78 & 2,44 \\
\hline $\mathrm{Nd}_{2} \mathrm{O}_{3}$ & 0,11 & 0,24 & 0,32 & 0,69 & 0,15 & 0,09 & 0,06 & 0,94 & 1,36 & 1,14 \\
\hline $\mathrm{Sm}_{2} \mathrm{O}_{3}$ & 0,05 & 0,25 & 0,02 & 0,18 & -- & - & -- & 0,31 & 0,14 & 0,23 \\
\hline $\mathrm{Gd}_{2} \mathrm{O}_{3}$ & 0,02 & 0,07 & 0,16 & 0,22 & 0,00 & 0,00 & 0,00 & 0,30 & 0,34 & 0,53 \\
\hline $\mathrm{Dy}_{2} \mathrm{O}_{3}$ & 0,10 & 0,00 & 0,00 & 0,06 & - & -- & - & 0,00 & 0,08 & 0,07 \\
\hline $\mathrm{Yb}_{2} \mathrm{O}_{3}$ & 0,00 & 0,00 & 0,00 & 0,03 & -- & - & -- & 0,00 & 0,00 & 0,00 \\
\hline
\end{tabular}

Tabela 29 Análises detalhadas de elementos terras-raras à ME (\% em peso dos óxidos) de apatitas de Tapira. 


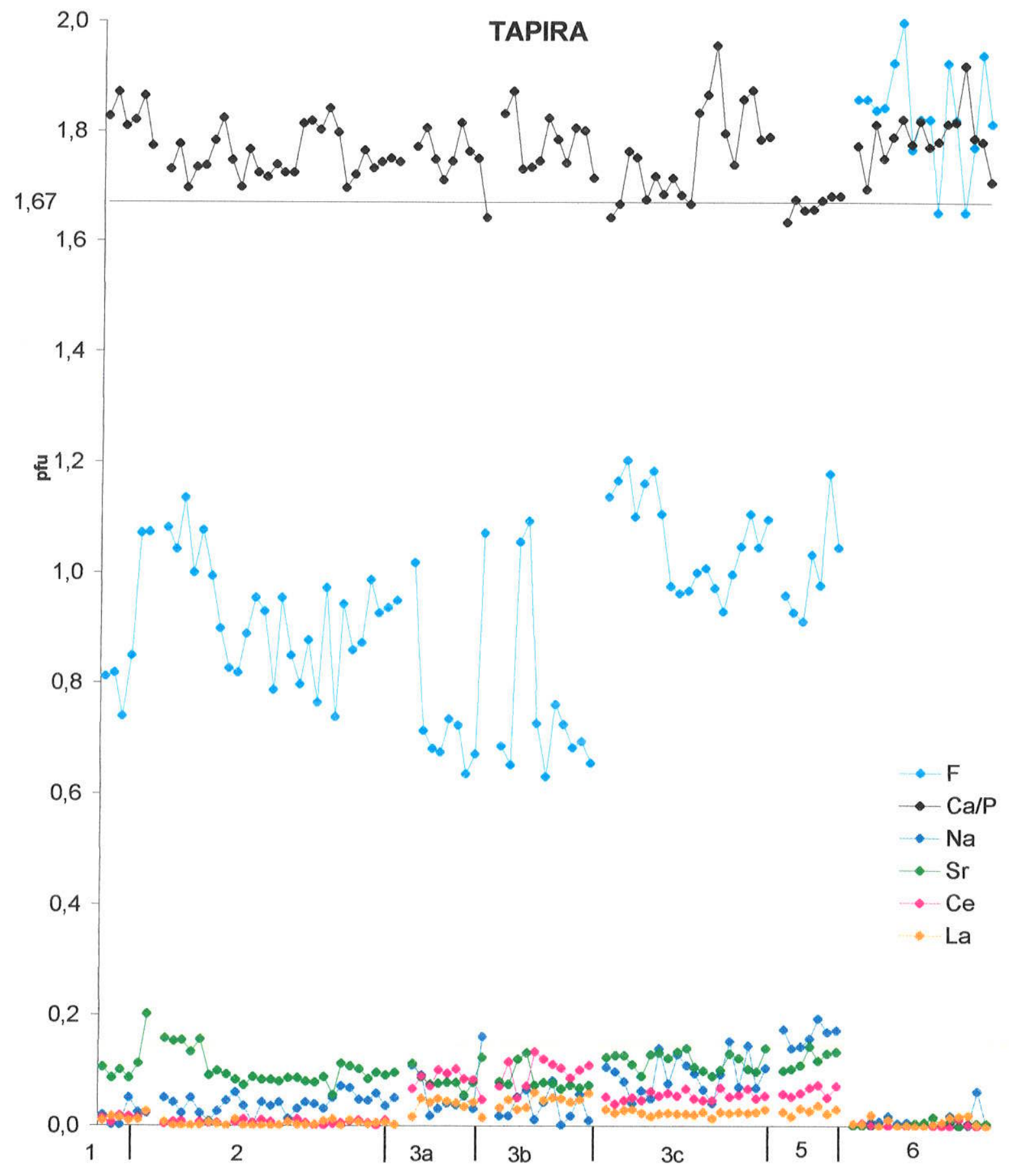

Figura 29 Gráfico da variação, em número de átomos p.f.u., dos principais cátions substituintes do cálcio, da razão $\mathrm{Ca} / \mathrm{P}$ e do $\mathrm{F}$ de diferentes tipos de apatita de Tapira. Os cálculos de fórmula estrutural foram efetuados com base em 10 cátions a partir de dados da ME.

1- Apatita prismática primária, 2- Apatita primária anédrica, 3- Apatita hidrotermal anédrica (a: borda, b: próximo a fratura, c: núcleo), 5- Apatita supérgena fina em pavê intercrescida na apatita hidrotermal anédrica, 6- Apatita supérgena tipo fibrosa. 
TAPIRA
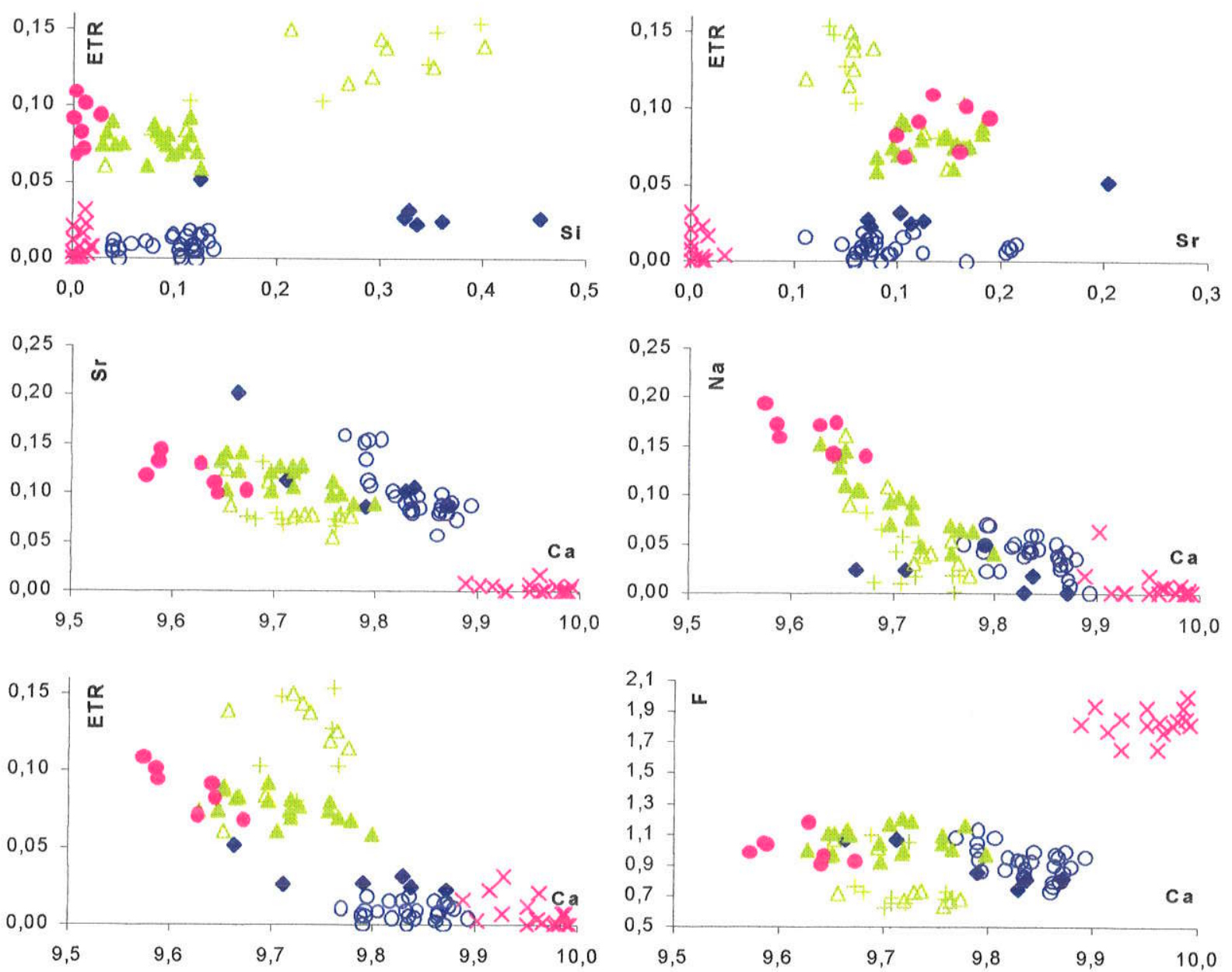

Figura 30 Diagramas binários mostrando a relação dos constituintes das apatitas de Tapira, em número de átomos p.f.u. (fórmula estrutural calculada na base 10 cátions). Legenda na próxima página. 
Figura 30 (continuação)
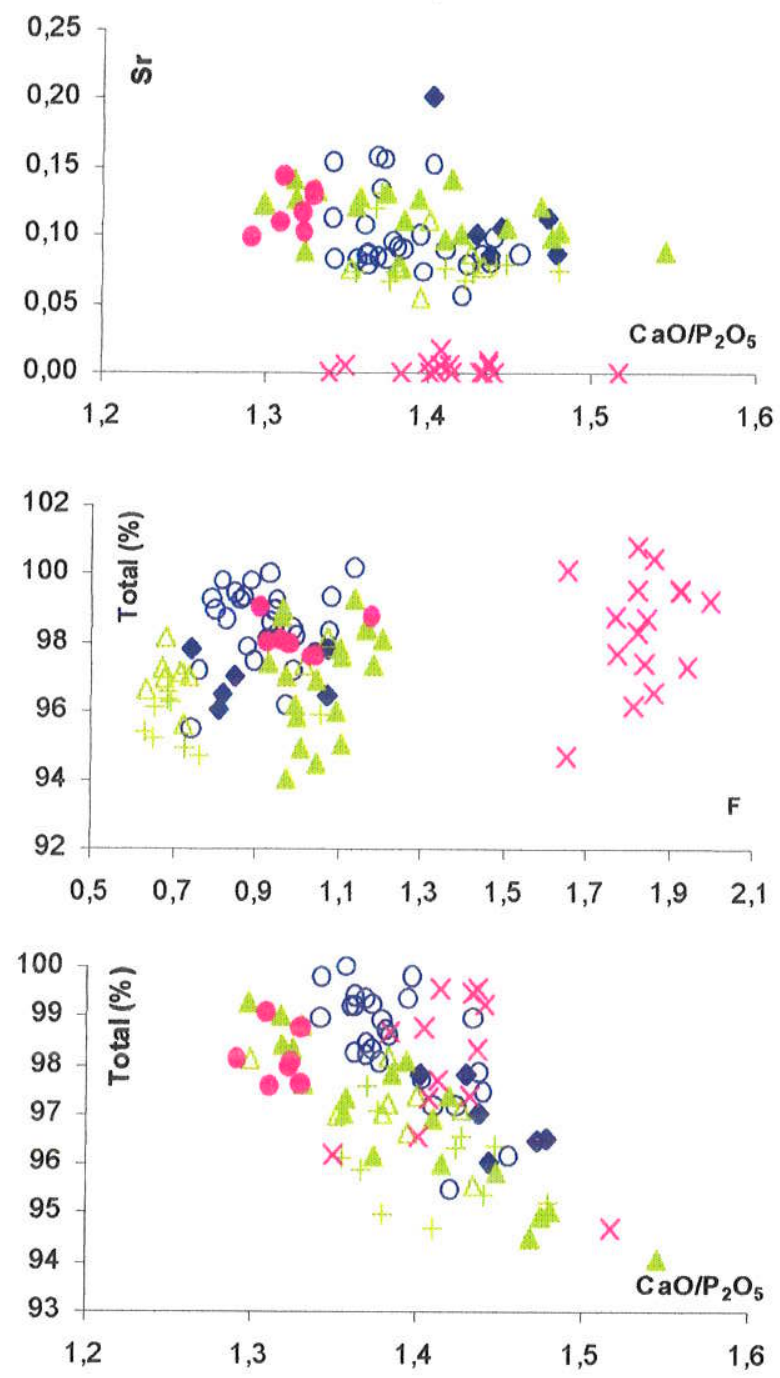

\section{TAPIRA}
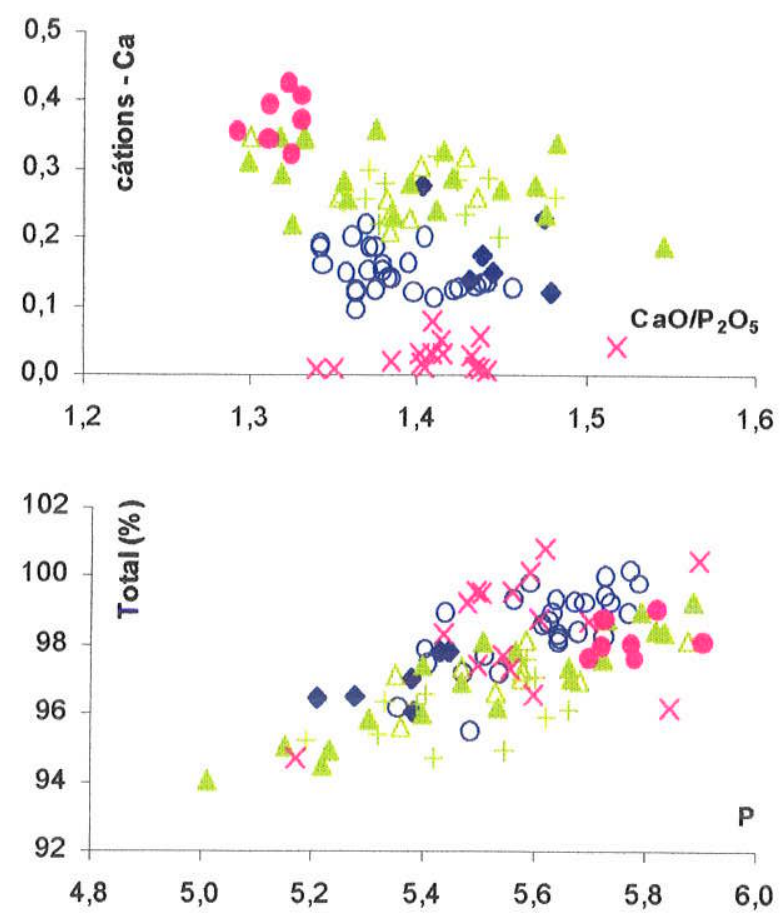

Apatita primária

- 1 - prismática

- 2 - anédrica

Apatita hidrotermal

3 - anédrica

a: borda

b: fratura

A : núcleo

Apatita supérgena

- 5 - cristais de textura fina em pavê

$\times 6$-fibrosa 

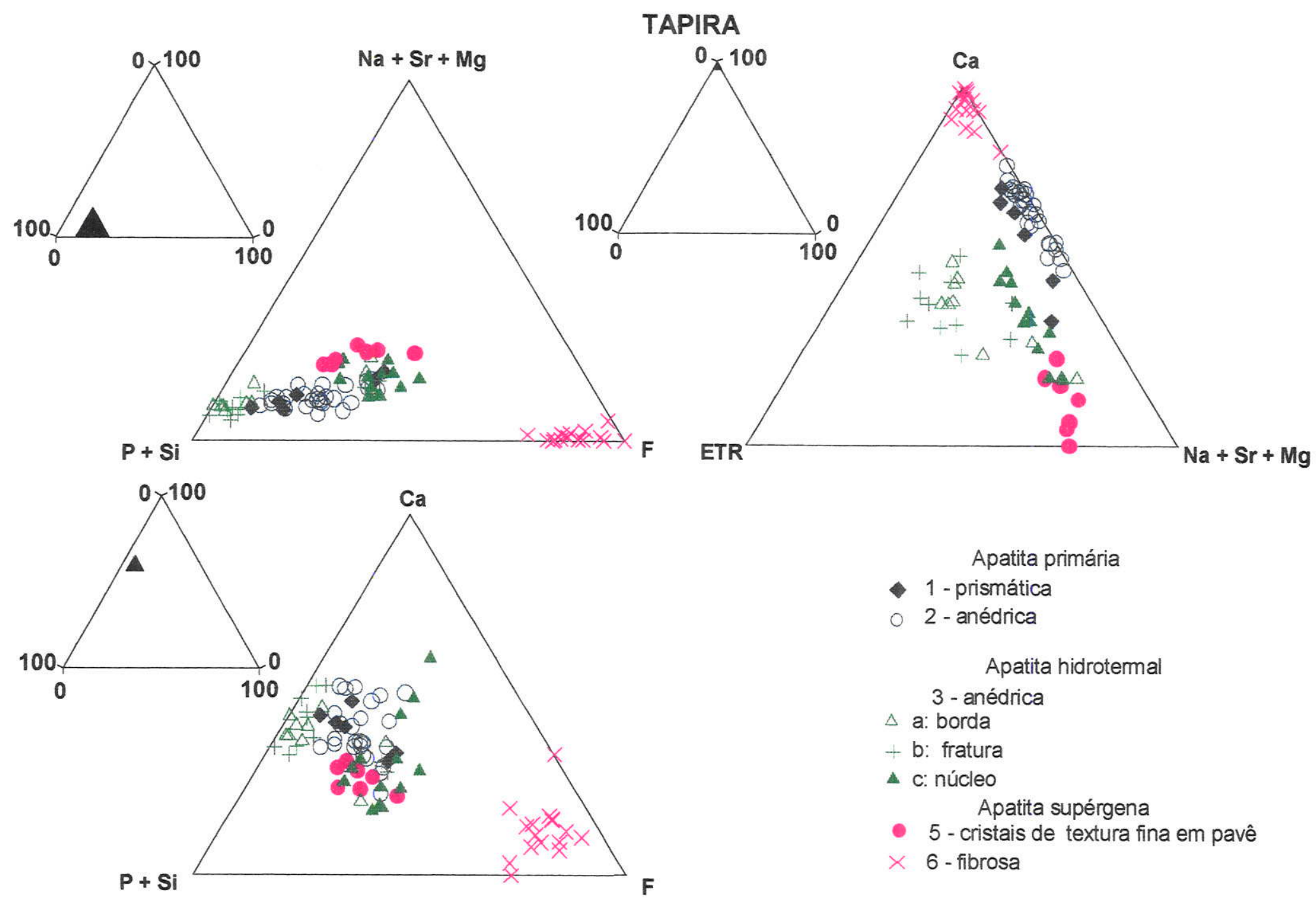

Apatita primária

- 1 - prismática

- 2 - anédrica

Apatita hidrotermal

3 - anédrica

$\triangle$ a: borda

+ b: fratura

4 c: núcleo

Apatita supérgena

5 - cristais de textura fina em pavê

$\times 6$ - fibrosa

Figura 31 Diagramas ternários mostrando as variações de conteúdo em $\mathrm{Ca} /(\mathrm{P}+\mathrm{Si}) / \mathrm{F},(\mathrm{Na}+\mathrm{Sr}+\mathrm{Mg}) /(\mathrm{P}+\mathrm{Si}) / \mathrm{F}$ e Ca / (P + Si) / ETR para os diferentes tipos de apatitas de Tapira. ETR $=\mathrm{Ce}+\mathrm{La}$. 


\subsubsection{Síntese comparativa das apatitas das três áreas Morfologia}

Morfologicamente as apatitas primárias são bem parecidas independentemente da área estudada; as características que as fazem semelhantes são a textura, dimensões dos cristais e presença de inclusões e borda de maior birrefringência (alteração hidrotermal). Os cristais de apatita primária nas três áreas estudadas apresentam textura em pavê, com granulometria milimétrica a submilimétrica. Tapira apresentou também uma outra morfologia de apatita primária que caracteriza-se por formar cristais euédricos e prismáticos. Inclusões fluidas são encontradas no núcleo de algumas apatitas do tipo anédrico em pavê em todas as áreas estudadas; em geral apresentam formas alongadas seguindo uma única direção e localizadas na porção mais interna do cristal. Estas inclusões fluídas também foram observadas em trabalhos anteriores nas áreas estudadas, mas ainda não se tem nenhum dado sobre sua composição.

A alteração hidrotermal promove a formação de borda de maior birrefringência que são melhor desenvolvidas nos materiais de Anitápolis e Juquiá. Tapira também apresentou esta borda mas com uma espessura mais fina. Em Juquiá, observou-se a formação de outros tipos de apatita hidrotermal (ou tardi-magmática): um tipo caracterizado por cristais com linhas de crescimento e formas ovóides de dimensões menores do que as apatitas primárias, podendo estar agrupados em buquê ou isolados e outro representado por uma camada muito fina de mesma morfologia e propriedades ópticas da borda de maior birrefringência, separada desta por uma zona de dissolução (tipo Ah já descrito por Walter, 1991). Em Tapira, cristais anédricos de mesma morfologia que os tipos primários foram supostamente classificados como hidrotermal por apresentarem teores elevados em ETR, nada impede que estes cristais sejam magmáticos (a classificação hidrotermal é aqui utilizada como relativa a eventos tardios ao magmatismo que deu origem a apatitas ricas em ETR).

Em todas as áreas estudadas as apatitas primárias são resistentes ao intemperismo e são residuais no manto de alteração. Alguns grãos apresentam certas caracteristicas morfológicas como um maior grau de fraturamento, superfície com feições de dissolução e revestimento ferruginoso ou por outros produtos, que podem ser interpretadas como sinais de intemperismo, visiveis nas apatitas primárias residuais de todas as áreas. A coexistência de grãos mais alterados e 
grãos praticamente sãos na mesma amostra é comum e evidencia o caráter residual deste mineral. Grãos de apatita com sinais de alteração intempérica vêm sendo observados em outras áreas no manto de intemperismo sobre complexos alcalinocarbonatíticos (Catalão: Imbernon, 1993 e Toledo, 1999, Sri Lanka: Subasinghe, 1998).

As apatitas supérgenas formam-se nos espaços inter e transminerais na forma de cristais fibrosos e agregados criptocristalinos nas três áreas estudadas; Juquiá apresentou apatitas supérgenas de formas mais variadas (microprismas e prismas milimétricos de terminação piramidal) e de distribuição bem mais extensa; a espessura destas deposições de apatita podem alcançar alguns centímetros. Os agregados criptocristalinos são mais difíceis de serem identificados ao MO, sendo sempre observados ao MEV. Seu modo de ocorrência está relacionado ao processo de precipitação nas descontinuidades das rochas em vários graus de intemperização.

A feição fibrosa das apatitas supérgenas parece comum na alteração de rochas de complexos alcalino-carbonatíticos. Toledo (1999) observou vários tipos de apatita supérgena em Catalão I, principalmente constituídos por fibras. Outros exemplos são dados, entre outros, por Torres (1997), em Araxá e Boulingui (1997), no Gabão.

\section{Parâmetros de cela unitária}

Apatitas primárias sãs apresentaram parâmetros a e $c$ similares em Anitápolis e em Juquiá $(a=9,39$ e $c=6,89 \AA)$, que se aproximam dos valores intermediários entre a fluorapatita sintética (JCPDS 155-876) e a hidroxiapatita sintética (JCPDS 9432). Apatitas primárias de Tapira apresentaram valores de $c$ próximos e de a ligeiramente maior $(9,40 \AA)$ em relação às apatitas primárias das outras áreas; estes valores se aproximam aos da hidroxiapatita sintética (JCPDS 9-432).

Apatitas supérgenas e primárias de Anitápolis apresentaram valores dos parâmetros de cela próximos entre si $(a=9,386$ e $c=6,883 \AA)$, diferindo dos valores encontrado para amostras de apatitas supérgenas de Juquiá (a entre 9,346 e 9,364

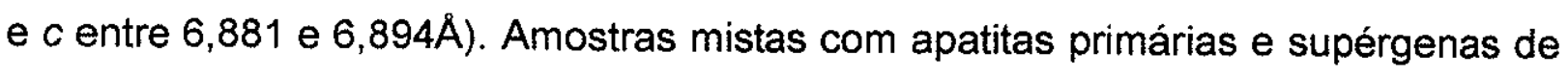
Tapira apresentaram os mesmos valores que as apatitas primárias da mesma área $(9,404$ e $6,893 \AA)$.

As apatitas das áreas estudadas já tiveram outras determinações dos parâmetros de cela. Basicamente dois métodos foram empregados nos cáiculos dos parâmetros de cela das apatitas (primárias e supérgenas) a partir de dados da DRX: 
1) Cálculo a partir das reflexões $002,210,300$ e 310 dos difratogramas de DRX utilizando as equações apresentadas por McClellan \& Lehr (1969), que relaciona os parâmetro de cela aos espaçamentos dos planos $h \mathrm{hl}\left(\mathrm{d}_{\mathrm{hk}}\right)$ para o sistema hexagonal: $\mathrm{a}=\left[\mathrm{d}_{\mathrm{hk} 0}{ }^{2} \cdot 4 / 3 .\left(\mathrm{h}^{2}+\mathrm{hk}+\mathrm{k}^{2}\right)\right]^{1 / 2}$ e $\mathrm{c}=1 . \mathrm{d}_{00 \mathrm{l}}$. Este método foi empregado por Walter, 1991 (Juquiá), Pereira, 1991, ( Anitápolis) e Girard et al., 1993 (Anitápolis e Juqiá).

2) Refinamento dos parâmetros de cela baseado no método dos mínimos quadrados (utilizando o programa de análise de dados de DRX LCLSQ, Burnham, 1991), o mesmo método aqui aplicado. Este método foi empregado por Lenharo, 1994 (Juquiá e Tapira) e por Cremillion, 1975 (Tapira).

Apatitas primárias

Em Anitápolis, Girard et al. (1993) apresentaram apatitas primárias com parâmetros de cela (a: 9,383 Å e c: 6,885 Å). Em Juquiá, Lenharo (1994) encontrou uma grande variação dos valores dos parâmetros de cela destas apatitas ( $a$ entre $9,38153 \AA$ e 9,3272 e $c$ entre $6,884 \AA$ e $6,894 \AA$ ). Na mesma área Girard et al. (1993) apresentou apatitas primárias (sem alteração hidrotermal) com valores de a $(9,3904$ e 9,3908 $\AA$ ) maior do que encontrado por Lenharo (op. cit.) para as mesmas apatitas. Ainda em Juquiá, Walter apresentou valores médios de $a=9,395$ e de $c=$ $6,89 \AA$ (apatita primária) e de $a=9,376$ e $c=6,894 \AA$ (apatita primária com borda de maior birrefringência). Em Tapira, Lenharo (1994) obteve para a apatita primária sã da amostra TA-CC-3 de valores de parâmetros a e c (a: $9,406 \AA$ e c: $6,890 \AA$ ) em acordo com o encontrado por Cremillion et. al. (1975).

Os valores dos parâmetros de cela das apatitas primárias nestes trabalhos são bem próximos dos encontrados no presente estudo para as três áreas.

Apatitas supérgenas

Determinações do parâmetros de cela de apatitas supérgenas em trabalhos anteriores nas três áreas estudadas mostram em média valores de a menores do que os encontrados nas apatitas primárias. Apatitas supérgenas de Anitápolis apresentaram parâmetros de cela $a=9,341$ e $c=6,892 \AA$ ), segundo Girard et al. (1993). Em Juquiá, observou-se uma variação dos valores dos parâmetros de cela das apatitas supérgenas, Walter (1991) obteve valores de a entre 9,3577 e 9,3679 e de $c$ entre 6,878 e $6,902 \AA$, Girard et. al. (op. cit.) obteve valores de a entre 9,3609 e $9,3690 \AA$ e de $c$ entre 6,8798 e 6,8888 $\AA$ e Lenharo (1994) apresentou valores de $a$ entre 9,335 e $9,370 \AA$ e de $c$ entre 6,881 e $6,904 \AA$. Apatitas supérgenas de Tapira foram estudadas por Lenharo (1994) que apresentou valores de a e $c$, calculados a 
partir de difratogramas de amostras mistas, TA-SC-2 $(9,377$ e 6,868 A) e TA-SC-6 $(9,368$ e $6,890 \AA)$.

No presente estudo não foi possivel confirmar os valores dos parâmetros de cela de amostras mistas de Tapira e Juquiá obtido por Lenharo (1994) aplicando o método Rietveld ou o método de refinamento de cela pelos mínimos quadrados nas mesmas amostras. A autora utilizou um passo de aquisição de dados na DRX $\left(0,01^{\circ}\right.$ 20) menor do que a utilizada aqui e adotou a retirada automática do picos $K \alpha 2$ não empregado aqui, talvez conseguindo uma maior individualização dos picos no difratograma.

Determinaçōes dos apresentaram parâmetros de cela das apatitas supérgenas de Anitápolis efetuadas no presente estudo diferem dos determinados por Girard et al. (1993) que obteve um menor valor do parâmetro a. Esta diferença pode estar ligada a presença de apatita primária na amostra estudada.

McConnell (1974) observou que substituição do Ca por cátions maiores no sítio A (como o Sr e ETR) causa um aumento simultâneo dos parâmetros de cela a e c nas apatitas e que estas substituições causam mais efeitos na estrutura do que as substituiçōes no sítio aniônico. A substituição no sítio aniônico do PO43- por CO32causa a diminuição do parâmetro a da apatita (McClellan \& Lehr, 1969 e Vignoles \& Bonel, 1978). Assim a diminuição do parâmetro a nas apatitas supérgenas está relacionada a quase ausência de substituição do $\mathrm{Ca}$ e subordinadamente pela presença do $\mathrm{CO}_{3}{ }^{2-}$ no sítio do $\mathrm{PO}_{4}{ }^{3-}$.

Liu \& Comodi (1993) observaram que o aumento de $\mathrm{OH}$ - em substituição ao $\mathrm{F}$ no sítio aniônico monovalente causa uma expansão simultânea dos parâmetros de cela . No presente estudo observou-se que as apatitas de composição próximas as da hidroxiapatita apresentaram parâmetros de cela mais elevados.

Composição Química

No estudo dos dados de composição química obtidos à $M E$, entre os parâmetros considerados, os valores de total das análises são particularmente importantes; totais baixos são indicativos, conforme já foi dito, de constituintes não analisados pela $\mathrm{ME}\left(\mathrm{CO}_{2}\right.$ e $\left.\mathrm{OH}\right)$, desde que a preparação da amostra seja boa. Altos valores para a razão $\mathrm{CaO} / \mathrm{P}_{2} \mathrm{O}_{5}$ são indicativos ou de baixa substituição do $\mathrm{Ca}$ ou de substituição do $\mathrm{PO}_{4}{ }^{3-}$ por $\mathrm{CO}_{3}{ }^{2-}$ (normalmente é isso o que ocorre) ou outro ânion. Quando uma análise apresenta simultaneamente, baixos totais e altas razões $\mathrm{CaO} / \mathrm{P}_{2} \mathrm{O}_{5}$, é mais provável que corresponda, portanto, a material com mais alta 
substituição do $\mathrm{PO}_{4}{ }^{3-}$ por $\mathrm{CO}_{3}{ }^{2-}$. Neste trabalho foi constatado que o aumento da razão $\mathrm{CaO} / \mathrm{P}_{2} \mathrm{O}_{5}$ está praticamente sempre acompanhado de um abaixamento nos totais de análise, e esta tendência refere-se sempre ou à parte alterada das apatitas primárias em relação às partes sãs ou às apatitas supérgenas quando comparadas com as primárias .

Apatitas primárias

Quando são efetuados os cálculos das fórmulas estruturais das apatitas primárias de Tapira e Juquiá observa-se que dos substituintes do $\mathrm{Ca}, \circ \mathrm{Sr}$ (entre 0,09 e 0,20 entre 0,04 e 0,09 p.f.u., respectivamente) é dominante seguido pelo $\mathrm{Na}$ (entre 0,00 e 0,05 e entre 0,01 e 0,12 p.f.u., respectivamente). As apatitas primárias de Anitápolis se diferenciaram das outras áreas por apresentarem quase sempre mais $\mathrm{Na}$ (entre 0,03 e 0,13 p.f.u.) do que $\mathrm{Sr}$ (entre 0,03 e 0,05 p.f.u.) no sítio catiônico. Os ETR apresentam em geral valores muito baixos em número de átomo p.f.u. (aproximadamente entre 0 e 0,02); em algumas das análises das apatitas de Tapira estes valores foram mais elevados (aproximadamente entre 0,02 e 0,05).

A correlação $P$ (átomos p.f.u.) e total (em \% em peso) das análises de apatita primária é positiva em todas as áreas, o que foi aqui interpretado como ligado à substituição do fósforo por algum elemento não analisado, no caso pelo $\mathrm{CO}_{3}{ }^{2-}$, substituição já admitida na estrutura de apatita em trabalhos anteriores (Nathan, 1984, Sommerauer \& Katz-Lehnert, 1985, Binder \& Troll, 1989, Hogarth, 1989, Toledo, 1999).

Outro possivel substituinte do fósforo é o Si; sua presença é mais notável nas apatitas primárias de Tapira (de 0,1 a 0,2 p.f.u.), e está praticamente ausente nas de Anitápolis (de 0 a 0,03 p.f.u.) e de Juquiá (de 0 a 0,01 p.f.u.).

Apatitas primárias das três áreas apresentaram flúor no canal aniônico, entre 0,7 e 1,3 átomos p.f.u. $\mathrm{O} \mathrm{Cl}$ é praticamente ausente nas apatitas estudadas (em geral entre 0 e 0,01 ). Os cálculos das fórmulas estruturais sempre indicaram a necessidade de uma importante quantidade de hidroxila no canal aniônico (em geral entre 0,7 e 1,4 p.f.u.) para fechamento da estequiometria das fórmulas; comparando o número de átomos de $\mathrm{OH}^{-}$com base no mesmo tipo de cálculo observa-se que Tapira apresenta pontos de composição mais hidroxilada do que apatitas de outras áreas.

A relação da composição destas apatitas com os parâmetros a e c encontrados mostra uma tendência dos tipos com maior quantidade de $\mathrm{OH}$ apresentarem um 
aumento na dimensão do eixo a, sendo a flúor-hidroxiapatita de Juquiá e Anitápolis

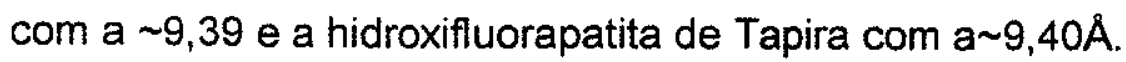

Apatitas hidrotermais

As bordas de maior birrefringência de Anitápolis e de Juquiá apresentaram um aumento do número de átomos de $\mathrm{Sr}$ e de $\mathrm{Na}$ p.f.u. quando comparadas às apatitas primárias. Os valores do número de átomos de ETR p.f.u. permaneceram os mesmos que os das apatitas primárias destas áreas. Não foi possível obter análises de boa qualidade nestas bordas nas apatitas de Tapira por sua reduzida dimensão.

Nos cálculos de fórmula estrutural da borda de maior birrefringência de apatitas primárias de Anitápolis e Juquiá o sítio do fósforo parece ser substituído por $\mathrm{CO}_{3}{ }^{2-}$ com valores de átomos de $C$ p.f.u. semelhantes (entre 0,00 e 0,02). $O$ número de átomos de Si p.f.u. é muito baixo nestas bordas. Apatitas de Anitápolis e Juquiá apresentaram bordas de maior birrefringência com valores p.f.u. de $\mathrm{OH}$ mais elevados do que os encontrados no núcleo. Anitápolis apresentaram valores de átomos de $\mathrm{OH}$ p.f.u. maiores e de F p.f.u. menores do que os de Juquiá.

Outros tipos de apatitas são ligadas a alteração hidrotermal ou evento tardimagmático como as apatitas ricas em ETR de Tapira e as apatitas anomalamente ricas em $\mathrm{Sr}$ e $\mathrm{Na}$ de Juquiá. Caracterizam-se por apresentar o sítio catiônico com substituição de $\mathrm{Sr}, \mathrm{Na}, \mathrm{Ce}$ e La nesta ordem de importância; os valores de número de átomos p.f.u. para o Ce e o La são maiores do que os encontrados em apatitas magmáticas. Apresentam-se em geral mais carbonatadas do que as apatitas primárias. Em Tapira, $\circ$ núcleo da apatita hidrotermal anédrica apresenta aproximadamente a mesma proporção $(\sim 50 \%)$ de $\mathrm{F}$ e de $\mathrm{OH}$ no canal aniônico e é levemente mais rico em $\mathrm{F}$ do que o núcleo da apatita primária anédrica.

Intemperismo das apatitas e apatitas supérgenas

Apatitas primárias residuais de todas as áreas presentes em materiais intemperizados mostraram composições próximas às das apatitas primárias sãs. As apatitas alteradas de Anitápolis apresentaram uma composição mais próxima das apatitas primárias da área podendo significar que elas sofrem poucas modificações químicas com o intemperismo. Por outro lado, em Juquiá, observou-se que as bordas dos grãos residuais apresentam um enriquecimento em $F$, sem alteração da composição do sítio catiônico porém com pouca variação do $\mathrm{CO}_{3}{ }^{2-}$ (a razão $\mathrm{CaO} / \mathrm{P}_{2} \mathrm{O}_{5}$ apresenta em média os mesmos valores). Em Tapira, só puderam ser notadas alterações na composição do grão de apatitas hidrotermais sem poder 
definir ao certo sua origem (hidrotermal, tardi-magmática ou intempérica) que apresentaram regiōes da borda e próximas a fraturas e descontinuidades com maior riqueza em ETR e em $\mathrm{F}$ e empobrecidas em $\mathrm{Sr}$, com entrada de $\mathrm{CO}_{3}$. Alguns trabalhos (como os Walter, 1991 para Juquiá e Toledo, 1999 para Catalão I) tratam do comportamento dos ETR nas apatitas e observam que a apatita sofre perda de ETR durante os processos de intemperismo. Levando isto em consideração as apatitas anédricas hidrotermais de Tapira deveriam ser originalmente mais enriquecidas em ETR, se se trata de alteração intempérica; por outro lado, pode tratar-se de alteração hipógena, o que não pôde ser completamente esclarecido.

Apatitas supérgenas de todas as áreas são em geral mais pobres em $\mathrm{Sr}, \mathrm{Na}$ e ETR do que as apatitas primárias; ou seja, são mais pobres em substituintes do Ca. Os tipos fibrosos apresentam uma maior substituição do $\mathrm{PO}_{4}{ }^{3-}$ pelo $\mathrm{CO}_{3}{ }^{2-}$ (indicado pelos cálculos da fórmula estrutural com base em 10 cátions) do que as apatitas primárias. O número de átomos de $\mathrm{F}$ p.f.u. é bem maior do que o da apatita primária. Somente Anitápolis apresentou algum $\mathrm{Cl}$ no sítio catiônico, com um número de átomos p.f.u. mais elevados do que as demais apatitas analisadas, a maioria entre 0,03 e 0,07 átomos p.f.u.

Apatitas supérgenas do tipo fibroso (e apatitas hidrotermais) nas diferentes áreas apresentaram valores mais elevados da razão $F / P_{2} \mathrm{O}_{5}$. Segundo alguns trabalhos (Regnier et al., 1994) o teor de $\mathrm{F}$ pode estar repartido entre os sítios aniônicos da estrutura da apatita, podendo estar fora dos canais no caso de uma apatita com substituição $\mathrm{PO}_{4}{ }^{3-}$ por $\mathrm{CO}_{3}{ }^{2-}$. Assim a alta razão $\mathrm{F} / \mathrm{P}_{2} \mathrm{O}_{5}$ pode significar na verdade uma carbonatoapatita ( $F$ mais elevado por acompanhar o $\mathrm{CO}_{3}{ }^{2-}$ e $\mathrm{P}_{2} \mathrm{O}_{5}$ mais baixo por estar substituído por $\mathrm{CO}_{3}{ }^{2-}$ ). Nestes casos de apatitas com substituição de fosfato por carbonato, a relação $\mathrm{F} / \mathrm{P}_{2} \mathrm{O}_{5}$, comumente utilizada para classificar fluorapatitas, pode não ser conveniente.

A catodoluminescência revelou algumas diferenças na constituição em elementos ativadores de apatitas primárias, hidrotermais ou tardi-magmáticas e supérgenas de Tapira. A atribuição de cores de luminescência a determinados elementos ativadores na apatita, aqui apresentada, é proposta por diversos autores citados por Marshall (1988).

No que diz respeito aos elementos ativadores evidenciados pela $\mathrm{CL}$ ( $\mathrm{Mn}$ e ETR) não detectados na ME cada área apresentou apatitas primárias com diferentes cores de luminescência. Materiais onde são visiveis as feições de alteração 
(hidrotermal ou intempérica) dos grãos (tais como bordas dissolvidas e fraturas) mostraram apatitas com um padrão manchado com várias cores de luminescência (ativadores $\mathrm{Sm}^{3+}, \mathrm{Dy}^{3+}$ e $\mathrm{Mn}^{2+}$ ). Apatitas supérgenas podem ou não apresentar elementos ativadores, sendo encontrados apenas nos tipos mais desenvolvidos como as camadas de apatitas fibrosas e apatitas prismáticas milimétricas (ativadores $\left.\mathrm{Eu}^{2++}, \mathrm{Dy}^{3+} \mathrm{e} \mathrm{Mn}^{2+}\right), \mathrm{Eu}^{2+}$ também foi encontrado nas apatitas hidrotermais, sendo as de Tapira a única a apresentar cor violeta (ativador $\mathrm{Ce}^{2+}$ ).

\subsection{Série da crandallita}

Os minerais da série da crandallita são os principais fosfatos supérgenos não apatítico dos mantos de alteração. Das três áreas estudadas somente Anitápolis apresentou uma ocorrência mais restrita destes minerais nos materiais estudados (de frentes de lavra experimental, de sondagens e de trincheiras).

\subsubsection{Anitápolis}

Em Anitápolis, os fosfatos da série da crandallita não puderam ser identificados apropriadamente por DRX, devido aos pequenos teores e à sua associação a richterita e apatita, que resultam em difratogramas com muita sobreposição de picos e portanto difíceis de serem interpretados. Sua presença é sugerida pelas análises de fases fosfáticas ao MEVIEDS que mostram a presença de elementos como $P, A l$, $\mathrm{Ca}, \mathrm{Sr}, \mathrm{Ba}$ (amostra AN7.4), elementos comuns aos fosfatos da série da crandallita dos materiais muito intemperizados já estudados (Toledo, 1999, Alcover Neto, 1997, Walter, 1991, entre outros), além do Fe, sempre associado às análises de EDS em materiais dos perfis de alteração. Estas fases formam microagregados que apresentam uma morfologia irregular, em agregados semelhantes a couve-flor e ocorrem na superfície de apatitas primárias residuais (Foto 31). Em MO, também não o seu reconhecimento, nem nas amostras onde a fase foi sugerida pelos estudos ao MEV-EDS; por este motivo, não há dados químicos pontuais. 


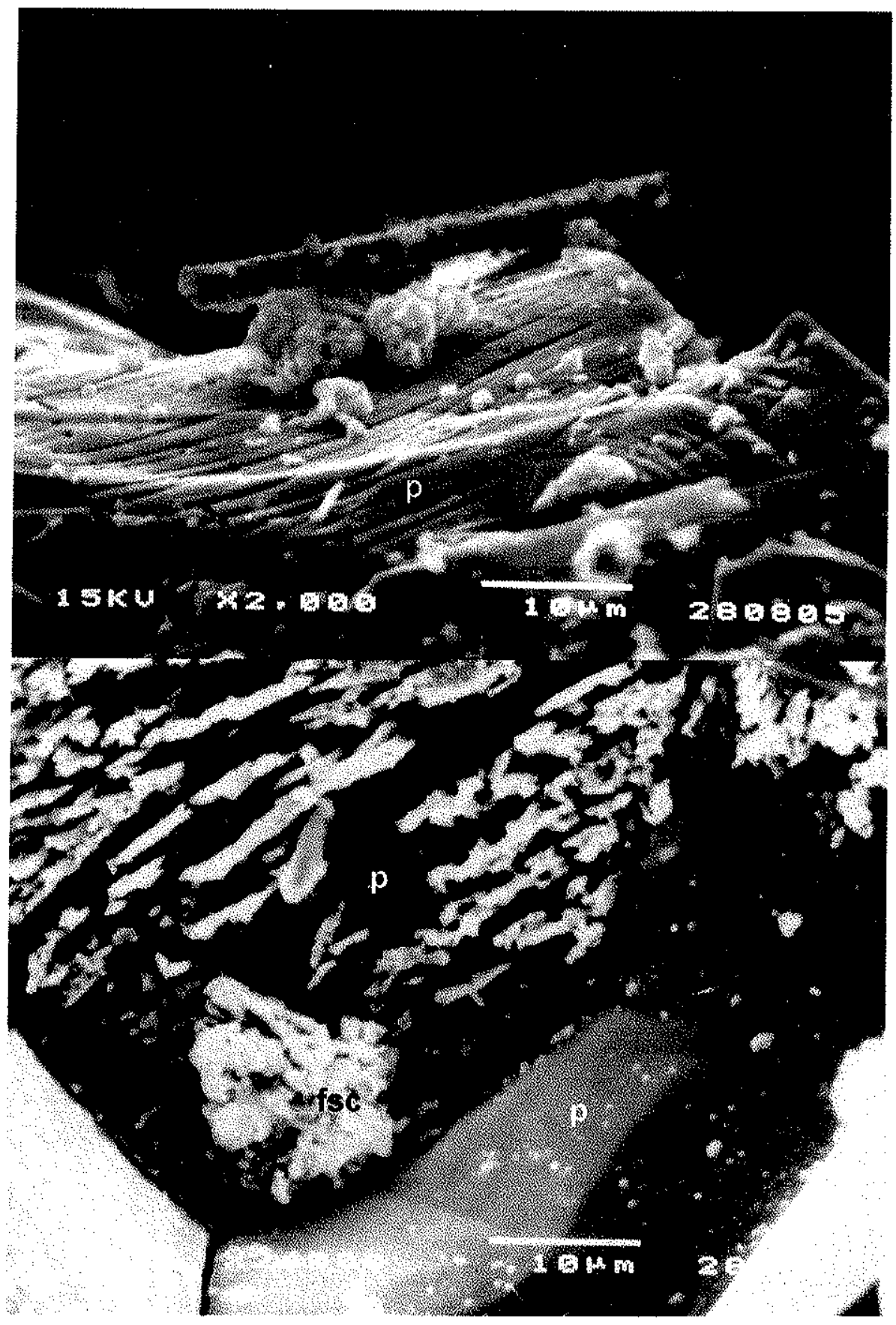

Foto 31 Fosfatos da série da crandallita (fsc) de aspecto muito fino sobre a superficie da apatita primária (p) alterada. Elementos identificados por EDS: $\mathrm{P}, \mathrm{Al}, \mathrm{Ca}, \mathrm{Sr}, \mathrm{Ba}$ e Fe. Anitápolis. Amostra AN7.4. MEV (BEI). 


\subsubsection{Juquiá}

\section{Mineralogia e micromorfologia dos fosfatos da série da crandallita}

Fosfatos da série da crandallita são encontrados em ínfimas quantidades na alterita do carbonatito e geralmente estão relacionados a pseudomorfoses de flogopita. Já na zona de transição (entre rochas alcalino-silicáticas e carbonatito) e na aloterita eles são mais abundantes, ocorrendo junto a produtos argilosos.

Cristais de fosfatos da série da crandallita ocorrem em cutãns no material argiloso ou ao redor de minerais primários residuais como apatita, bariopirocloro e flogopita alterada. Em geral estes fosfatos são globulares incolores ou amarelados, possuem um relevo baixo e estão intimamente associados a goethita e outros produtos ferruginosos. A seguir, serão apresentados os diferente tipos morfológicos e seus modos de ocorrência observados ao MEV e ao MO.

1 - Cristais microcristalinos cutânicos (JUT2BP, JU8, JUT10Ca, JUT'1.1, JUC25)

Ocorrem nas alteritas da zona de transição entre o carbonatito e as rochas alcalino-silicáticas, em várias formas cutânicas (descontinuidades intercristalinas e cavidades no plasma ferruginoso). Os cristais são trigonais e muito finos; ao MO caracterizam-se por uma cor de birrefringência baixa, formando uma fina película que contorna as descontinuidades da alterita (Foto 34). Cristais com mesmas características foram encontrados em concreções ferruginosas no nível aloterítico do perfil de intemperismo sobre carbonatito.

2 - Cristais microcristalinos em pseudomorfos micáceos (JU40, JU37.1)

Constituem as folhas dos pseudomorfos de flogopita, são em geral microcristalinos, de forma granular a triangular (MEV e MO) (Foto 35 e Foto 48). São encontrados na alterita do carbonatito.

3 - Agregados microcristalinos globulares de cor esverdeada (JU8)

Ocorrem em xenólitos de rocha alcalino-silicática estando associados a produto de alteração de flogopita, como goethita e argilominerais. Os glóbulos apresentamse coalescidos formando massas contínuas e homogêneas entre as folhas da mica (Foto 32 e Foto 33). Observa-se ao MO que os glóbulos apresentam núcleo esverdeado e borda incolor. 


\section{4 - Agregados criptocristalinos}

Ocorrem junto a apatitas supérgenas fibrosas e entre cristais de turquesa que preenchem cavidades da alterita no setor de transição. Formam uma fina camada de microcristais incolores. Quando observados ao MEV são criptocristalinos e pontualmente distribuídos na superfície da turquesa e intercrescidos com as apatitas supérgenas. O modo de ocorrência destes tipos torna impraticável a identificação à DRX (Foto 47).

5 - Agregados microcristalinos associados à alteração do pirocloro (JUT15, JUT10a)

Ocorrem na alterita do perfil de transição entre rocha carbonatítica e rocha alcalino-silicática, em pirocloros substituindo-os parcialmente, na periferia do grão. Ao MEV, observa-se uma textura granular na periferia do grão de pirocloro (Foto 36).

6 - Plasma ferruginoso gorceixítico (JUM)

Ocorre em materiais argilosos aloteríticos que recobrem a alterita do carbonatito. Ao MO e MEV não foi possível diferenciá-los da massa argilosa. Só foi possível identificá-los à $D R X$.

A DRX permitiu a identificação da gorceixita na alterita de rochas alcalinosilicáticas (JU8.3) junto aos pseudomorfos e na aloterita junto concreções ferruginosas (JUC-25) e material argiloferruginoso (JUM) (Tabela 30). Não foi identificada a presença de outro fosfato da série da crandallita.

$A$ análise dos difratogramas das amostras revelou a presença de goethita; nem todas apresentaram a presença de argilominerais (caulinita). As posições das reflexões dos planos hkl são próximas às da gorceixita (JCPDS: ficha 19-0535) como pode ser visto na Tabela 30 e Figura 32. 


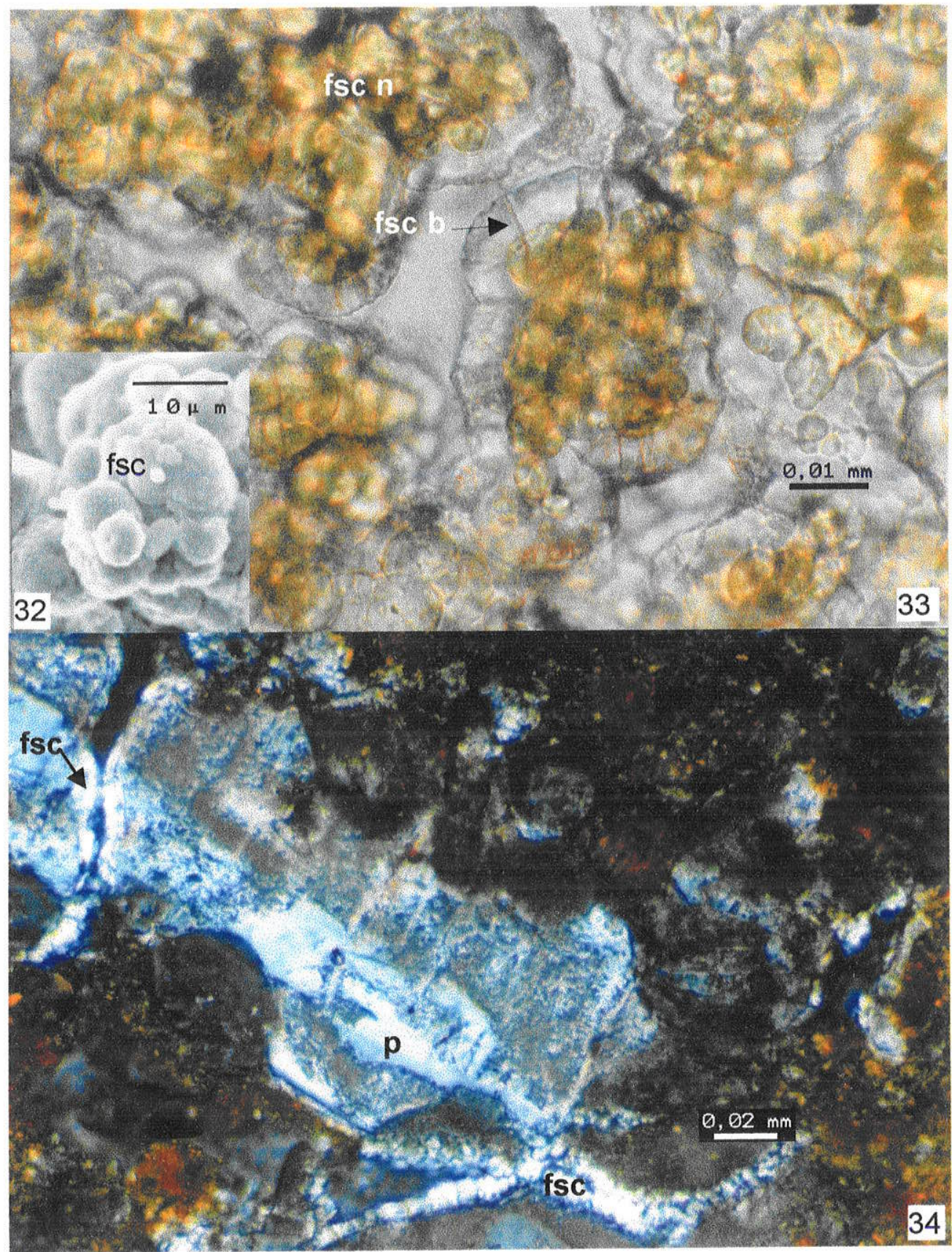

Foto 32 Agregados globulares de fosfatos da série da crandallita com núcleo mais escuro (fsc $n$ ) e bordas incolores (fsc b). Juquiá. Amostra JU8. MEV (BEI).

Foto 33 Detalhe dos agregados globulares de fosfatos da série da crandallita (fsc). Juquiá. Amostra JU8. MO (LN).

Foto 34 Apatita primária (p) alterada com fissuras (intraminerais e interminerais) revestidas por cristais de fosfatos da série da crandallita trigonais cutânicos (fsc). Juquiá. Amostra T4Agb. MO (LP). 


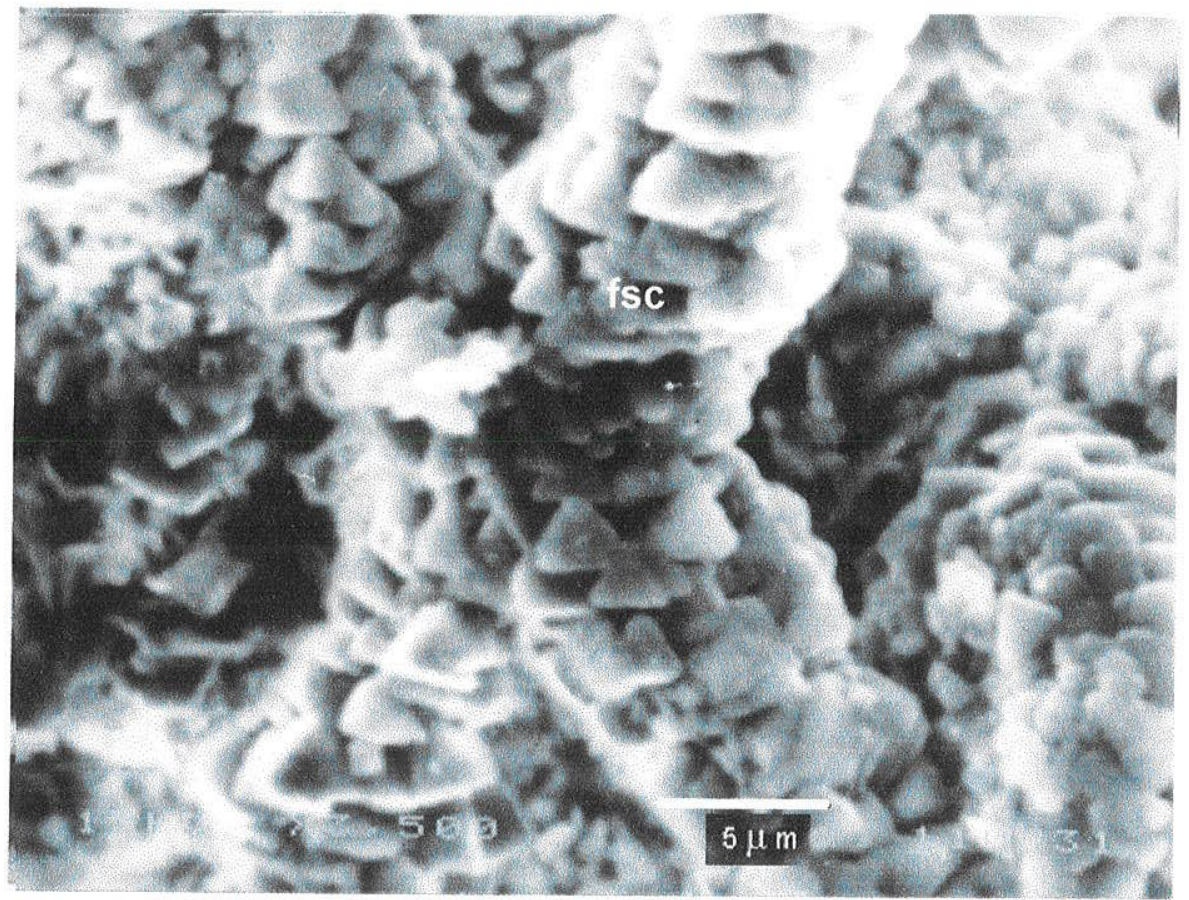

Foto 35 Agregados microcristalinos de fosfato da série crandallita (fsc) de forma granular a trigonal. Juquiá. Amostra JU40. MEV (BEI).

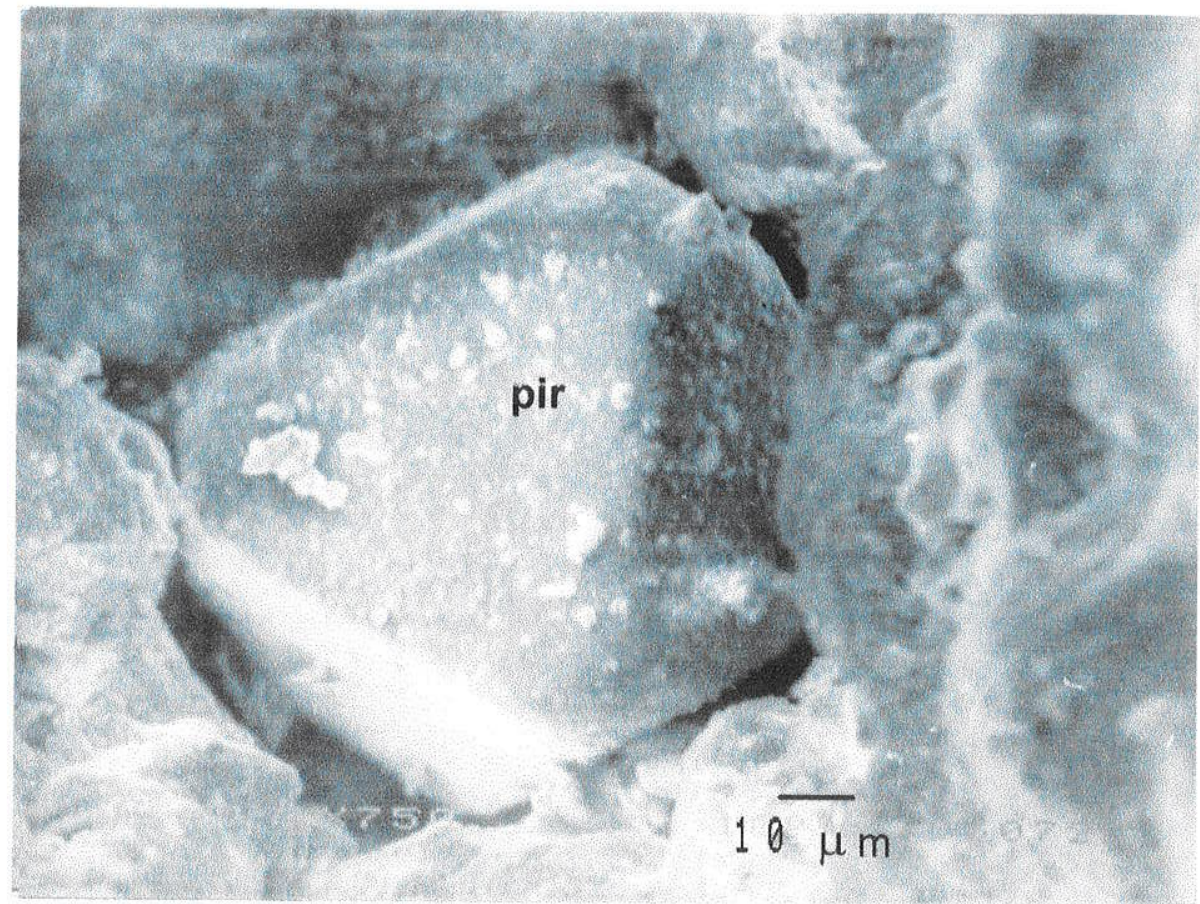

Foto 36 Cristal de pirocloro (pir) com superfície de textura granular imerso em material rico em fosfato da série crandallita. Juquiá. Amostra JU7. MEV (BEI). 
Os parâmetros a e $c$ dos fosfatos aluminosos de Juquiá e Tapira foram calculados a partir de um programa de refinamento de parâmetros de cela baseado no método dos mínimos quadrados (LCLSQ, Burnham, 1991), considerando-os do sistema romboédrico do grupo espacial R-3m e partindo de parâmetros de cela iniciais da gorceixita $\left(a_{0}=7,0363\right.$ e $\left.c_{0}=17,2819\right)$ dados por Radoslovish \& Slade (1980). Os valores obtidos para as amostras estudadas foram próximos dos encontrados para gorceixitas da literatura exceto a amostra JUT'1.1, com um valor maior do parâmetro $c(17,427 \AA \AA)$ e menor do parâmetro a $(7,004 \AA)$. Esta diferença pode estar ligada à um maior grau de hidratação ou substituições catiônicas como foi observado por Gilkes \& Palmer (1983) no estudo de crandallitas e goyazitas sintéticas.

\begin{tabular}{|c|c|c|c|c|c|c|c|c|c|c|c|c|c|}
\hline \multicolumn{8}{|c|}{ JUQUIÁ } & \multirow{2}{*}{\multicolumn{3}{|c|}{$\begin{array}{c}\text { Gorceixita } \\
\text { (Blanchard, 1989) }\end{array}$}} & \multirow{2}{*}{\multicolumn{3}{|c|}{$\begin{array}{c}\text { Gorceixita } \\
\text { JCPDS - 19-0535 }\end{array}$}} \\
\hline \multicolumn{2}{|c|}{ JUM } & \multicolumn{2}{|c|}{ JUC-25 } & \multicolumn{2}{|c|}{ JUT'-11 } & \multicolumn{2}{|c|}{ JU8.3 } & & & & & & \\
\hline d & 1/10 & & I/lo & d & I/lo & $d$ & 1/1o & hkl & $d$ & $\mathrm{I} / \mathrm{lo}$ & $d$ & $\mathrm{I} / \mathrm{lo}$ & $\mathrm{hkl}$ \\
\hline & $\begin{array}{r}100 \\
72\end{array}$ & & 95 & 260 & 89 & & 8 & 10 & 32 & & & & 101 \\
\hline 3,5099 & 72 & & 62 & 3,5709 & 31 & 3,5133 & 47 & -311 & & 56 & & & 110 \\
\hline 2,9874 & 98 & & 100 & 3,0235 & 100 & 2,9874 & 100 & -312 & & 10 & & & 113 \\
\hline 2,8640 & 17 & & 17 & 2,8591 & 13 & 2,8658 & 17 & 002 & & & & & 202 \\
\hline- & - & & 13 & 2,5076 & 17 & 2,4774 & & -222 & & 11 & & & 024 \\
\hline 4343 & 42 & & 9 & 2,4449 & 10 & & - & - & & & & & 115 \\
\hline 2798 & 22 & 2,2859 & 32 & 2,2843 & 30 &, 28 & 29 & 112 & 2,2925 & 39 & 2,271 & 50 & 211 \\
\hline- & - & - & - & - & - & - & - & - & - & - & - & & - \\
\hline- & - & - & - & - & - & & $-\pi$ & - & & & - & - & - \\
\hline 216 & 38 & & 27 & - & - & 2,2219 & 20 & -131 & 2,232 & 2 & 5 & & 121 \\
\hline 0210 & 9 & 0283 & 10 & 2,0550 & 6 & - & - & -113 & 2,0376 & 11 & & & 300 \\
\hline & - & & - & - & - & 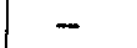 & - & - & & 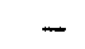 & & & \\
\hline & 32 & & 29 & 9370 & 25 & & 26 & -332 & & & & 70 & 303 \\
\hline & 30 & 1,7586 & 22 & 1,7883 & 13 & 1,7581 & 16 & -622 & 1,7626 & 20 & 1,756 & 60 & 220 \\
\hline
\end{tabular}

\begin{tabular}{|c|c|c|c|c|}
\hline $\begin{array}{l}\text { amostra } \\
\text { JU8.3 }\end{array}$ & $\begin{array}{l}\text { tipo } \\
3 \text { - Agregados microcristalinos } \\
\text { globulares de cor esverdeada e 1- } \\
\text { cristais de forma trigonal }\end{array}$ & $\begin{array}{l}a \\
7,062\end{array}$ & (1) & $\begin{array}{c}c \\
16,719\end{array}$ \\
\hline JUC25 & $\begin{array}{l}1 \text { - Cristais microcristalinos } \\
\text { cutânicos em concreções } \\
\text { ferruginosas }\end{array}$ & 7,062 & (1) & 16,707 \\
\hline JUM & 6 - Plasma ferruginoso gorceixítico & 7,061 & (1) & 16,704 \\
\hline JUT'1.1 & $\begin{array}{l}1 \text { - Cristais microcristalinos } \\
\text { cutânicos associados às apatitas } \\
\text { supérgenas } \\
\text { vio padrão }\end{array}$ & 7.004 & (1) & 17.427 \\
\hline
\end{tabular}

Tabela 30 Dados de difração de raios-X (radiação $C u K \alpha$ ) de gorceixitas de Juquiá. 


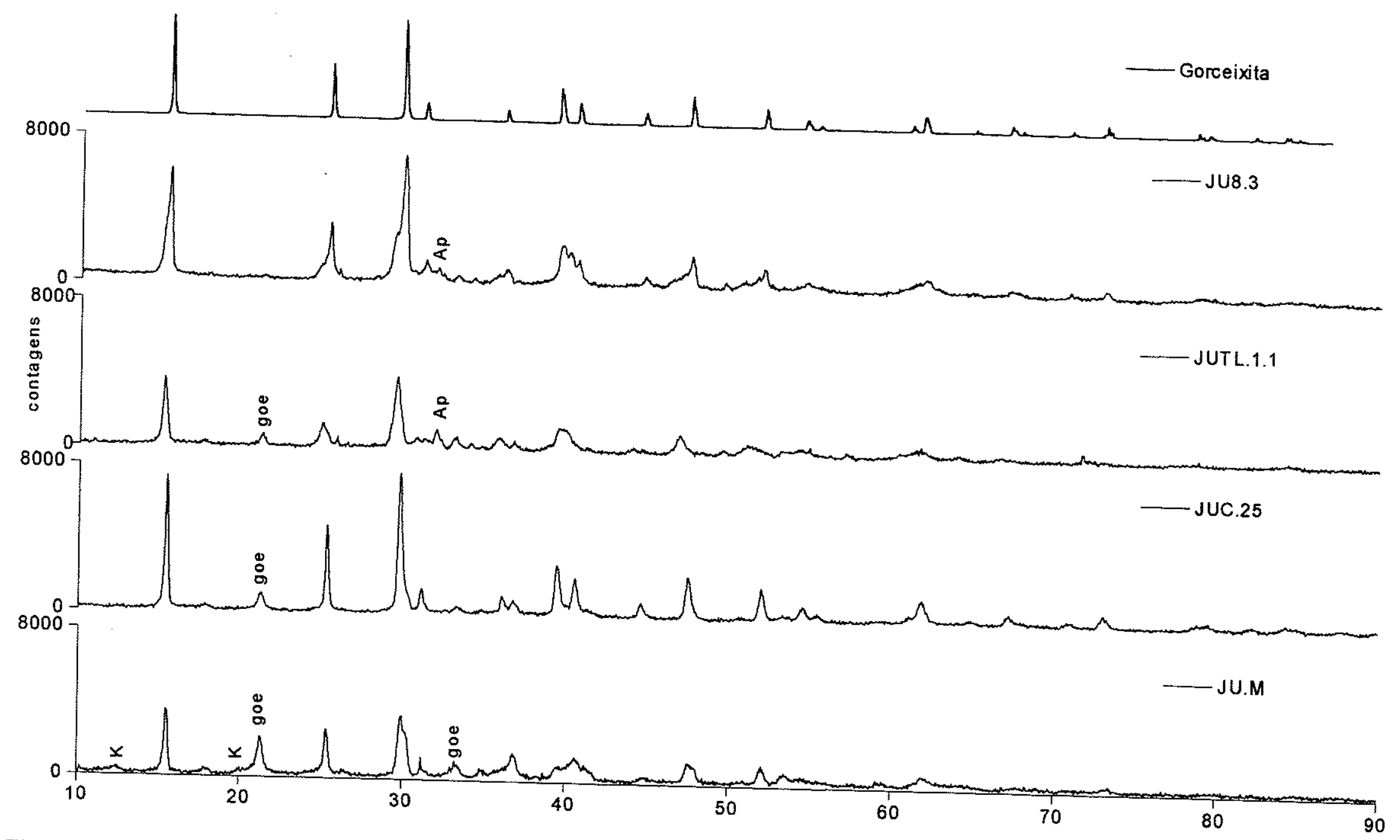

Figura 32 Difratogramas de amostras de fosfato da série crandallita de Juquiá comparado a um padrão calculado da gorceixita dada por
Radoslovich \& Slade (1980). goe: goethita, K: caulinita, Ap: apatita. 


\section{Aspectos químicos e cristaloquímicos dos fosfatos da série da crandallita de Juquiá}

A seguir serão apresentados os resultados das análises à ME dos tipos morfológicos que puderam ser identificados e discriminados ao MO e que resultaram em análises com fechamento compatível com minerais da série da crandallita $(>70 \%)$. A natureza descontínua e as dimensões reduzidas dos minerais da série da crandallita aliada à sua íntima associaçāo com outros produtos secundários resulta em número considerável de análises não aproveitáveis pelo fechamento muito baixo ou pela presença de elementos provenientes das fases associadas.

Todos os tipos de fosfatos da série da crandallita apresentaram teores muito baixos de Mn, Si e ETR. A presença do flúor foi verificada em todos os tipos sendo encontrado quase sempre baixos teores $(<0,2 \%)$.

As análises à ME revelaram uma diferenciação na composição do sítio $A$ dos fosfatos da série da crandallita de Juquiá, Tabela 31 e Figura 38 . Os microagregados cristalinos cutânicos e globulares apresentaram composição química próxima à da gorceixita, com predominância de $\mathrm{Ba}$ (entre 0,62 e 0,81 p.f.u.) em relação ao $\mathrm{Ca}$ $(\sim 0,20$ p.f.u.) e $\operatorname{Sr}(\sim 0,10$ p.f.u.), Figura 33. Os cristais de paseudomorfos micáceos apresentaram uma maior quantidade de $\mathrm{Ca}$ (entre 1,26 e 3,92 p.f.u.) em relação ao $\mathrm{Ba}(0,40$ e 0,49 p.f.u.) se diferenciando dos demais tipos, Figura 38.

Analisando os diagramas binários da Figura 34 observa-se que os tipos associados aos pseudomorfos micáceos apresentaram correlação negativa entre alguns de seus constituintes, entre $\mathrm{Ca}$ e $\mathrm{Ba}$ só observados nos cristais microcristalinos em pseudomorfos micáceos (tipo 2) e entre $\mathrm{Sr}$ e $\mathrm{Ba}$ nos cristais cristalinos cutânicos (tipo 1) e nos microagregados globulares (tipo 3). As correlações negativas entre os constituintes do sítio catiônico podem indicar substituições entre os íons dos elementos envolvidos assim o $\mathrm{Ca}$ pode ser substituído por Ba nos cristais microcristalinos cutânicos e o $\mathrm{Sr}$ substituido por Ba nos demais tipos. 
Tipo

amostra

No.

$\mathrm{CaO}$

SrO

$\mathrm{BaO}$

$\mathrm{La}_{2} \mathrm{O}_{3}$

$\mathrm{Ce}_{2} \mathrm{O}_{3}$

$\mathrm{Al}_{2} \mathrm{O}_{3}$

$\mathrm{MnO}$

$\mathrm{Fe}_{2} \mathrm{O}_{3}$

$\mathrm{SiO}_{2}$

$\mathrm{P}_{2} \mathrm{O}_{5}$

Total

Ca

Sr
Ba
La

Ce

Total sitio A

Al

$\mathrm{Fe}^{3+}$

Total sitio B

$\mathrm{Si}$

Potal sitio $X$

$\mathrm{Ca}+\mathrm{S} r+\mathrm{Ba}$

ETR

\begin{tabular}{|c|c|c|c|c|c|c|c|}
\hline & & & 1 & & & & \\
\hline JUT2BP & JU8.3 & JU8.3 & JUT2BP & JUT2BP & JUT2BP & JUT2BP & JUT2BP \\
\hline & 13 & 14 & 1 & 2 & 3 & 4 & 5 \\
\hline 1,93 & 2,54 & 2,68 & 2,79 & 2,56 & 2,42 & 2,24 & 2,47 \\
\hline 0,45 & 2,58 & 2,86 & 0,93 & 1,02 & 0,59 & 0,64 & 0,34 \\
\hline 24,63 & 18,70 & 19,66 & 23,39 & 23,49 & 24,05 & 24,06 & 24,21 \\
\hline 0,00 & 0,00 & 0,00 & 0,00 & 0,06 & 0,00 & 0,02 & 0,01 \\
\hline 0,00 & 0,18 & 0,00 & 0,29 & 0,17 & 0,00 & 0,20 & 0,00 \\
\hline 26,42 & 28,30 & 27,94 & 28,20 & 29,16 & 21,94 & 27,94 & 27,91 \\
\hline 0,04 & 0,04 & 0,00 & 0,00 & 0,00 & 0,04 & 0,00 & 0,08 \\
\hline 3,67 & 0,08 & 0,68 & 0,75 & 3,16 & 0,91 & 1,13 & 1,30 \\
\hline 0,11 & 0,11 & 0,59 & 0,05 & 0,00 & 0,11 & 0,13 & 0,08 \\
\hline 26,81 & 27,41 & 26,66 & 25,95 & 26,24 & 27,14 & 26,73 & 26,55 \\
\hline 84,06 & 79,94 & 81,07 & 82,35 & 85,86 & 77,20 & 83,09 & 82,95 \\
\hline 0,174 & 0,229 & 0,241 & 0,251 & 0,231 & 0,218 & & 0,222 \\
\hline 0,022 & 0,126 & 0,139 & 0,045 & 0,050 & 0,0 & 31 & 0,017 \\
\hline 0,811 & 0,616 & 0,648 & 0,771 & 0,774 & 0,792 & 93 & 0,798 \\
\hline 0,000 & 0,000 & 0,000 & 0,000 & 0,0 & 0,000 & & \\
\hline 0,000 & 0,004 & 0,000 & 0,007 & 0,0 & & & 0,000 \\
\hline 1,007 & 0,975 & 1,029 & 1,074 & 1,060 & 1,039 & 1,031 & \\
\hline 2,618 & 2,804 & 2,769 & 2,795 & 2,890 & 2,174 & 2,769 & 2,766 \\
\hline 0,232 & 0,005 & 0,043 & 0,048 & & 0,057 & & 0,082 \\
\hline 2,850 & & & & & & & 2,848 \\
\hline 0,009 & 0,009 & 0,050 & 0,004 & 0,000 & 0,009 & & 0,007 \\
\hline & 1,951 & 1,898 & 1,8 & 1,8 & & & \\
\hline 1,917 & & & & 1,868 & & 1,914 & \\
\hline $\begin{array}{l}1,007 \\
0,000\end{array}$ & $\begin{array}{l}0,971 \\
0,004\end{array}$ & & & & 1,03 & 1,025 & \\
\hline & & & & & & 0005 & \\
\hline
\end{tabular}

\begin{tabular}{rrr}
\hline & & \\
JU40 & JU40 & JU37.1 \\
\hline 1 & 2 & 3 \\
19,64 & 10,69 & 17,16
\end{tabular}

\begin{tabular}{rrrrr}
\hline \multicolumn{5}{c}{3} \\
\hline 8 & 9 & 11 & 12 & 15 \\
1,26 & 1,08 & 3,26 & 2,37 & 1,07 \\
1,11 & 1,02 & 3,22 & 2,38 & 0,71 \\
23,53 & 23,68 & 18,75 & 20,18 & 23,63 \\
0,08 & 0,00 & 0,00 & 0,02 & 0,03 \\
0,00 & 0,14 & 0,00 & 0,19 & 0,05 \\
11,23 & 9,43 & 24,81 & 16,77 & 10,57 \\
0,09 & 0,15 & 0,02 & 0,06 & 0,15 \\
19,45 & 21,87 & 6,57 & 15,72 & 22,93 \\
0,42 & 0,36 & 0,15 & 0,46 & 0,10 \\
24,74 & 24,50 & 26,82 & 25,35 & 24,77 \\
81,91 & 82,23 & 83,60 & 83,50 & 84,01 \\
& & & & \\
0,113 & 0,097 & 0,294 & 0,213 & 0,096 \\
0,054 & 0,050 & 0,157 & 0,116 & 0,035 \\
0,775 & 0,780 & 0,618 & 0,665 & 0,778 \\
0,002 & 0,000 & 0,000 & 0,001 & 0,001 \\
0,000 & 0,003 & 0,000 & 0,004 & 0,001 \\
0,945 & 0,931 & 1,068 & 0,999 & 0,912 \\
1,113 & 0,935 & 2,459 & 1,662 & 1,048 \\
1,231 & 1,384 & 0,416 & 0,994 & 1,451 \\
2,344 & 2,318 & 2,875 & 2,656 & 2,498 \\
0,035 & 0,031 & 0,013 & 0,039 & 0,008 \\
1,761 & 1,744 & 1,909 & 1,805 & 1,763 \\
1,796 & 1,774 & 1,922 & 1,844 & 1,772 \\
0,943 & 0,927 & 1,068 & 0,994 & 0,910 \\
0,003 & 0,003 & 0,000 & 0,005 & 0,002
\end{tabular}

Tabela 31 Composição química dos fosfatos da série da crandallita de Juquiá, expressa em \% em peso dos b́xidos e em número de átomos por fórmula unitária na base de 10,50.

Onde: 1 - cristais microcristalinos cutânicos, 2- cristais microcristalinos em pseudomorfos micáceos e 3- agregados microcristalinos e globulares em pseudomorfos micáceos 

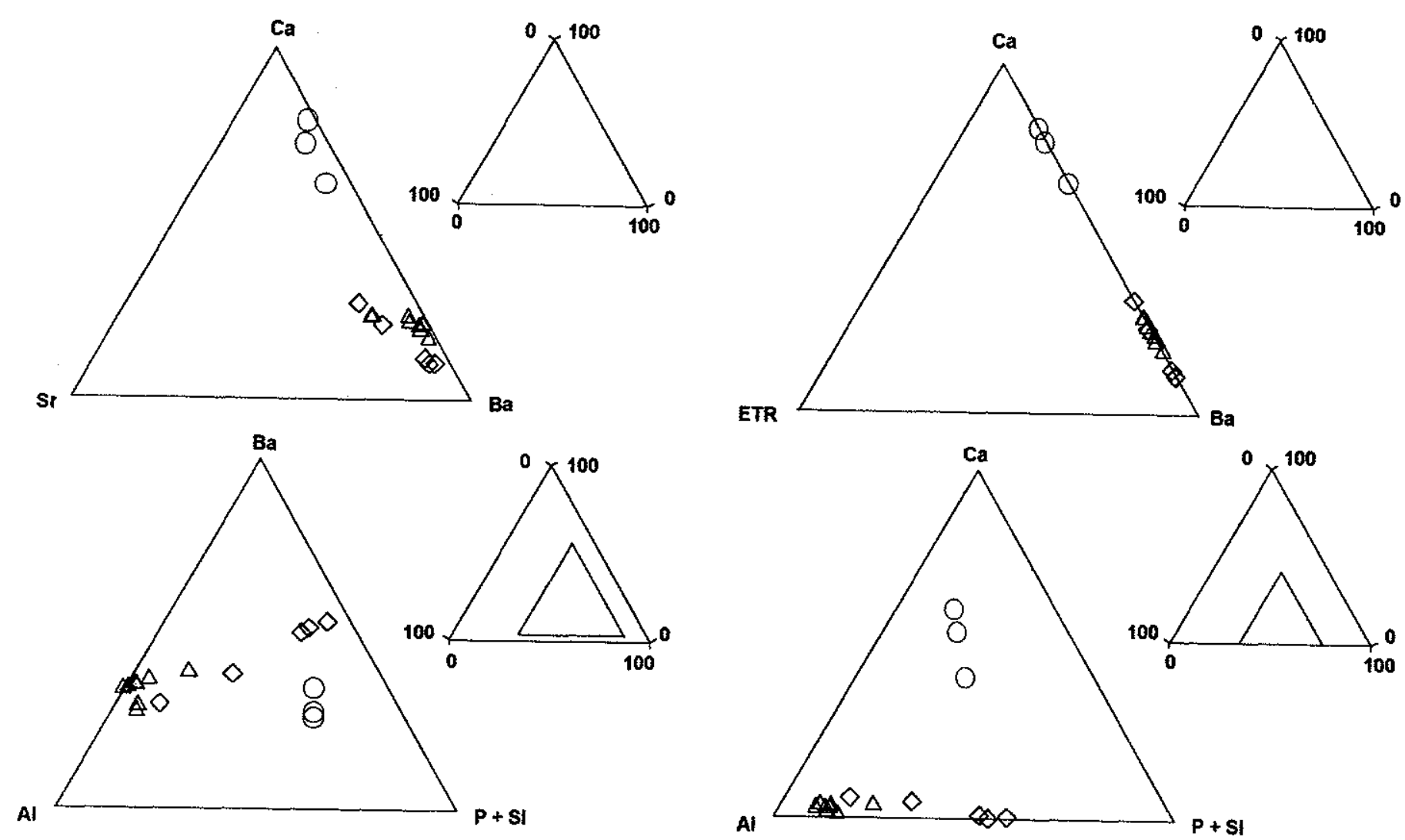

SÉRIE DA CRANDALLITA

$\triangle$ 1- Cristais microcristalinos cutânicos

$\diamond$ 3- Agregados microcristalinos globulares de cor esverdeada

2- Cristais microcristalinos em pseudomorfos micáceo

Figura 33 Diagramas ternários mostrando as variaçóes de conteúdo em $\mathrm{Ca} / \mathrm{Sr} / \mathrm{Ba}, \mathrm{Ba} / \mathrm{Al} /(\mathrm{P}+\mathrm{Si}), \mathrm{Ca} / \mathrm{ETR}$ / Ba e Ca / Al / P+Si de fosfatos não apatíticos de Juquiá. (fórmula estrutural calculada na base 10,50 para fórmula da crandallita anidra) 

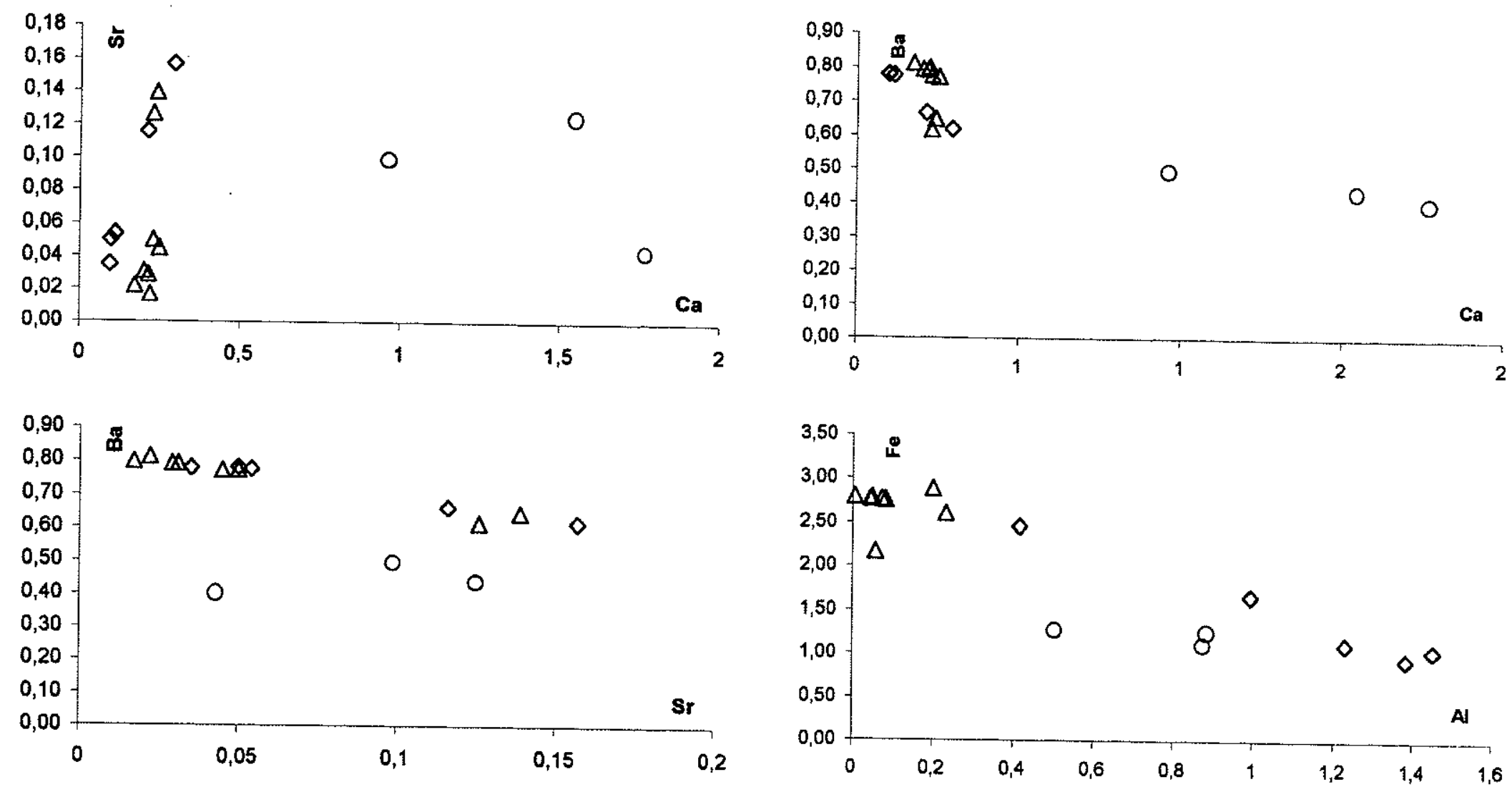

SÉRIE DA CRANDALLITA

$\triangle$ 1- Cristais de forma trigonal

$\diamond$ 3- agregados microcristalinos

2- Agregados microcristalinos em globulares de cor esverdeada

Figura 34 Diagramas binários mostrando a relação dos constituintes dos fosfatos da série da crandallita de Juquiá, em número de átomos p.f.u. (fórmula estrutural calculada na base 10,50 para fórmula da crandallita anidra). 
As ocupações do sítio $A$ também variou observando um ligeiro excesso do tipo cristalino cutânico (até $4 \%$ ), um excesso bem maior nos cristais de paseudomorfos (até $100 \%$, bem acima do encontrado na literatura, indicando problemas de contaminação da análise) e um déficit considerável no tipo microglobular (até $9 \%$ ). Sabe-se que as composições de fosfatos da série da crandalita quase sempre apresentam problemas na fórmula estrutural que na maioria das vezes são atribuidos a vacância, ao grau de hidratação ou substituiçōes, como observado por Mckie (1962), Greiffo et al. (1984), Lottermoser (1990). No caso de Juquiá ainda não se pode afirmar qual a causa da irregularidade na ocupação do sítio $\mathrm{A}$ (supondo não haver contaminação de outras fases).

No sítio B o Fe foi considerado um dos substituintes do Al como aceito para os fosfatos da série (Jambor \& Birch, 1993). Quantidades maiores de ferro nos cristais de pseudomorfos micáceos $(0,51$ a 0,88 p.f.u.) e nos agregados microglobulares $(0,42$ a 1,45 p.f.u.) em relação ao tipo cutânico (até 0,23 p.f.u.) que apresenta cristais mais desenvolvidos. Pode-se atribuir parte do $\mathrm{Fe}$ analisado a uma possível contaminação por fases visto suas dimensões reduzidas e intrínseca relação com materiais ferruginosos.

A ocupação do sítio B é deficitária em todos os tipos analisados sendo maior nos cristais do pseudomorfo micáceo. As deficiências no sítio B $(>30 \%)$ aliadas a uma riqueza em $\mathrm{Fe}$ nos remete novamente a idéia de que parte do ferro atribuido aos tipos analisados está em outra fase mineral. Mesmo as fases pobres em $\mathrm{Fe}$ apresentaram déficit (<7\%) no sítio $B$, a explicação deste fato ainda não pode ser definida.

No sítio $X$ o Si sempre ocorre como traço em todos os tipos analisados. A ocupação do sítio é irregular sendo na maior parte das vezes levemente deficitária (<11\%). Deficiências no sítio $X$ foram observados por Lottermoser (1990). Toledo (1999) também observou em Catalão deficiências nas gorceixitas de alteração das flogopitas, deficiências estas menores do que as encontradas em Juquiá.

Estudos termo-gravimétricos das amostras que puderam ser purificadas mostram pouca variação do comportamento térmico todos dentro do esperado para os fosfatos da série da crandalita. O tipo cutânico associado à apatita (JUT'1.1) apresentou uma temperatura de efeito endotérmico à 535 e perda de massa $16,9 \%$. O tipo cutânico associado às concreções ferruginosas (JUC25) apresentou uma temperatura de efeito endotérmico à $526^{\circ} \mathrm{C}$ e perda de massa de $16,5 \%$. Amostras 
mistas com os tipos 1 e 3 (JU8.3) apresentou uma temperatura de efeito endotérmico à $552^{\circ} \mathrm{C}$ e perda de massa de $16,3 \%$. Observa-se que a perda de massa variou muito pouco nos tipos analisados (entre 16,3 a 16,9\%) a temperatura do efeito térmico mais baixo foi a da amostra relacionada às concreções ferruginosas e a mais alta a da amostra de cristais cutânicos e microcristalino globular. Os valores de perda de massa estão em geral em acordo com os fechamentos das análise aqui encontradas.

\subsubsection{Tapira}

\section{Mineralogia e micromorfologia dos fosfatos da série da crandallita}

Os fosfatos da série da crandallita foram encontrados em amostras ricas em anatásio e produtos ferruginosos presentes no topo da alterita (TA8.1) e em amostras de material isalterítico rico em apatitas primárias alteradas e flogopitas vermiculitizadas e anatásio (TA1A e TA49.1).

Com base nas características micromorfológicas dos materiais estudados puderam ser diferenciados os seguintes tipos:

1- Agregados microcristalinos junto ao plasma ferruginoso associado ao anatásio (TA8.1):

Formam agregados de textura muito fina, estando freqüentemente misturados aos produtos ferruginosos em materiais muito alterados ricos em anatásio (Foto 39 ).

2- Cristais romboédricos a tetraédricos revestindo cavidades do plasma ferruginoso associado ao anatásio (TA8.1, TA50C1)

Apresentam-se como cristais trigonais que se desenvolvem nas descontinuidades da alterita rica em anatásio e produtos ferruginosos (Foto 37 , Foto 38, Foto 39 e Foto 40).

3- Agregados microcristalinos nas fraturas da apatita (TA1A, TA49.1):

Agregados microcristalinos de cor acinzentada (ao MO) revestem a superfície e fraturas de grãos ainda não totalmente alterados ou formam paredes nas bordas das cavidades antes ocupadas por apatitas (Foto 41, Foto 22 e Foto 42). Os cristais integrantes destes agregados podem apresentar formas trigonais ou granulares. As paredes muitas vezes são incrustadas por pequenos cristais de forma granular ou alongada (Foto 43). 
4- Microglóbulos associados ao plasma de alteração de micas entre cristais de apatita (TA49.1)

Estes microglóbulos estão intrinsecamente associados ao plasma de alteração de micas formando massas microgranulares de escura (ao MO) localizadas nos espaços entre os grãos residuais de apatita (Foto 22 e Foto 23).

O estudo dos dados de DRX (Tabela 32) mostrou que os cristais trigonais e agregados microcristalinos, presentes no plasma ferruginoso de materiais do topo do perfil de alteração, apresentam uma estrutura distinta daqueles associados a materiais isalteríticos rico em apatitas primárias, na base do perfil. $O$ primeiro material (amostra TA8.1) apresentou uma estrutura entre a florencita e a crandallita. O outro (amostra TA1), apresentou reflexões mais próximas da gorceixita.

\begin{tabular}{|c|c|c|c|c|c|c|c|c|c|c|c|c|}
\hline \multicolumn{2}{|l|}{ TA8.1 } & \multicolumn{2}{|l|}{ TA1 } & \multicolumn{3}{|c|}{$\begin{array}{c}\text { Florencita } \\
\text { JCPDS 15-0320 }\end{array}$} & \multicolumn{3}{|c|}{$\begin{array}{c}\text { Crandallita } \\
\text { JCPDS 25-1457 }\end{array}$} & \multicolumn{3}{|c|}{$\begin{array}{c}\text { Gorceixita } \\
\text { JCPDS - 19-0535 }\end{array}$} \\
\hline $\begin{array}{l}d \\
5,7081\end{array}$ & $\begin{array}{l}\mid / / 0 \\
86\end{array}$ & $\begin{array}{l}d \\
5,665 t\end{array}$ & $\begin{array}{l}1 / 10 \\
55\end{array}$ & $\underset{5,710}{d}$ & $\begin{array}{l}\text { 1/lo } \\
70\end{array}$ & $\begin{array}{l}\text { hkl } \\
101\end{array}$ & $\underset{5,73}{d}$ & $\begin{array}{l}\text { I/lo } \\
90\end{array}$ & $\begin{array}{l}\mathrm{hkl} \\
101\end{array}$ & $\underset{5,700}{d}$ & $\begin{array}{r}1 / 10 \\
34\end{array}$ & $\begin{array}{l}\mathrm{hkl} \\
101\end{array}$ \\
\hline- & - & - & - & 4,910 & 30 & 012 & - & - & - & 4,870 & 29 & 012 \\
\hline 3,507 & 72 & $3,490:$ & 49 & 3,500 & 70 & 110 & 3,52 & 80 & 110 & 0 & 35 & 110 \\
\hline 2,963 & 100 & $2,972 i$ & 22 & 950 & 100 & 113 & 2,978 & $100 \mathrm{t}$ & 113 & 2,983 & 50 & 021 \\
\hline- & - & 2,934: & 10 & & - & - & - & - & - & 2,941 & 100 & 113 \\
\hline 2,846 & 13 & - & - & 2,840 & 10 & 202 & 2,855 & 30 & 202 & 2,858 & 6 & 015 \\
\hline- & - & - & - & 2,746 & 10 & 006 & - & - & - & 2,699 & 17 & 006 \\
\hline- & - & - & - & 2,439 & 10 & 024 & 2,475 & 20 & 024 & 2,430 & 4 & 024 \\
\hline- & - & - & - & - & - & - & 2,449 & 30 & 115 & - & - & - \\
\hline- & - & - & - & 2,259 & 10 & 211 & 2,271 & 50 & 211 & - & - & - \\
\hline- & - & $2,200 i$ & 21 & 2,198 & 70 & 122 & - & - & - & 2,207 & 16 & 122 \\
\hline 2,210 & 48 & - & 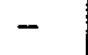 & - & - & - & 2,215 & 60 & 121 & - & - & - \\
\hline- & - & - & - & 2,146 & 10 & 116 & - & -- & - & 2,162 & 36 & 107 \\
\hline $2,011:$ & 7 & 2,168: & 25 & 2,013 & 10 & 300 & 2,021 & 30 & 300 & 1,996 & 2 & 214 \\
\hline- & - & & & - & - & - & 2,013 & 30 & 301 & - & - & - \\
\hline 1,897 & 35 & 1,941: & 33 & 1,890 & 50 & 303 & 1,905 & 70 & 303 & 1,896 & 27 & 303 \\
\hline- & - & - & - & - & - & - & - & - & - & 1,842 & 6 & 027 \\
\hline 1,752 & 31 & - & - & 1,745 & 30 & 220 & 1,756 & 60 & 220 & - & - & - \\
\hline
\end{tabular}

\begin{tabular}{|llllll|}
\hline Amostra & Tipo & a & & c & \\
\hline TA1cr & 3- Agregados microcristalinos & 7,0253 & (5) & 16,2533 & (7) \\
& $\begin{array}{l}\text { nas fraturas da apatita e 4- } \\
\text { Agregados microcristalinos de }\end{array}$ & & & & \\
TA8.1 & $\begin{array}{l}\text { cor marrom ao redor de apatita } \\
\text { 1- Agregados microcristalinos } \\
\text { junto ao plasma ferruginoso e }\end{array}$ & 7,0149 & (4) & 16,2282 & (6) \\
$\begin{array}{l}\text { 2- Cristais romboédricos a } \\
\text { tetraédricos revestindo as } \\
\text { cavidades do plasma } \\
\text { ferruginoso }\end{array}$ & & & & \\
\hline
\end{tabular}

Tabela 32 Dados de difração de raios-X (radiação $\mathrm{Cu} K \alpha$ ) de fosfatos da série da crandallita de Tapira. 

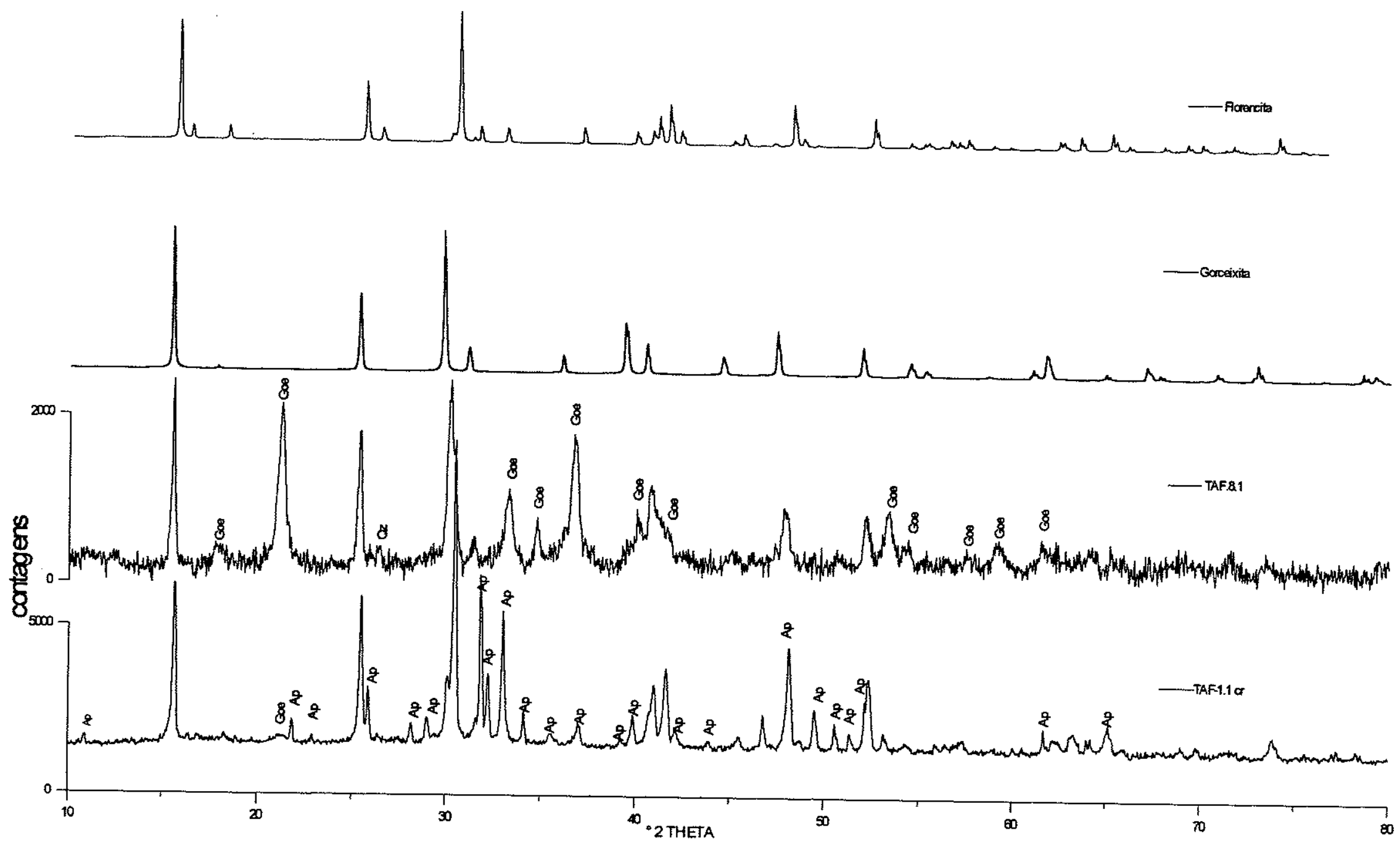
Figura 35 Difratogramas das amostras com fosfatos da série da crandallita de Tapira em comparação com padrōes da gorceixita e da
florencita. 


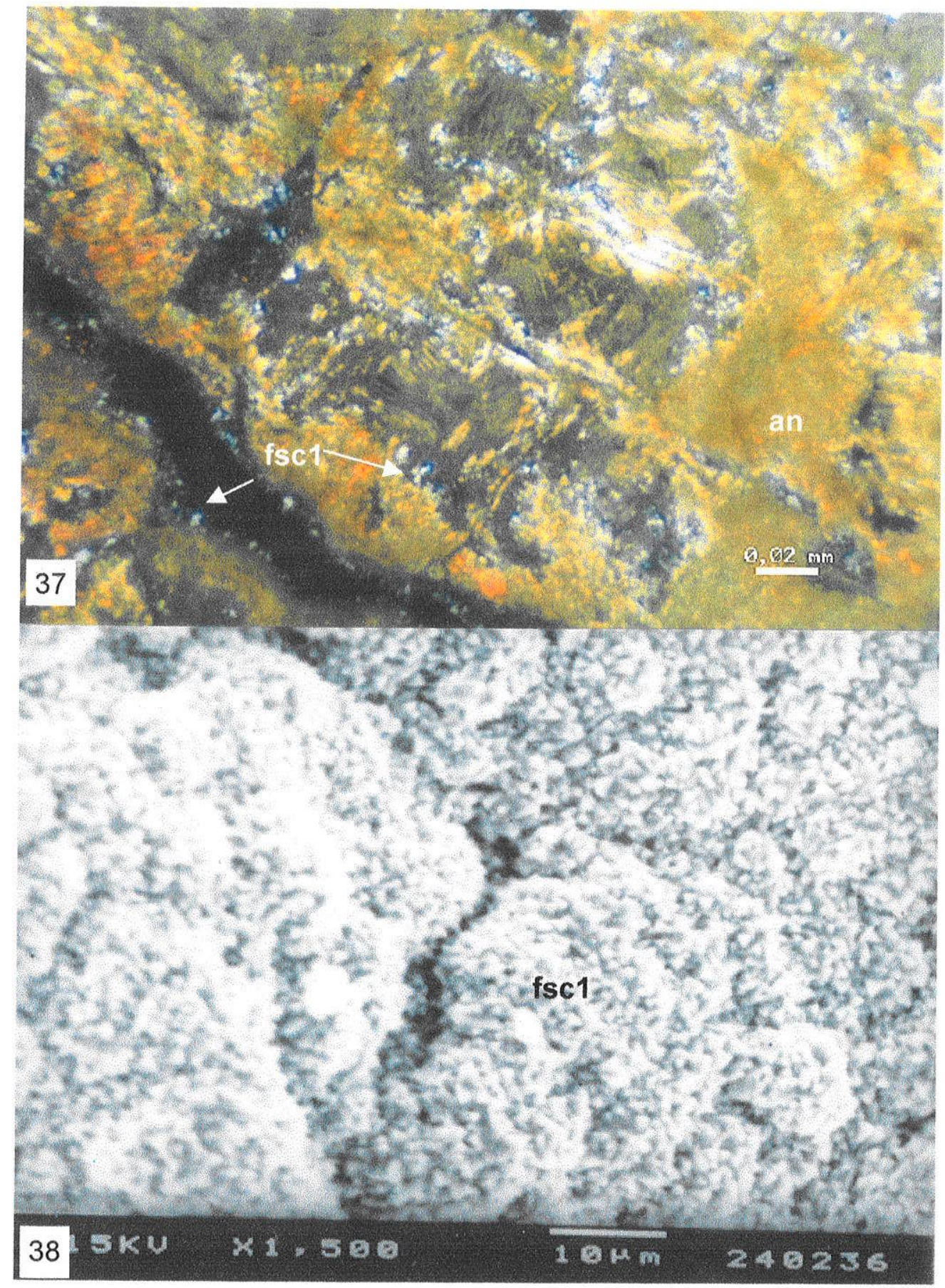

Foto 37 Cristal de anatásio alterado com fissuras revestidas por fosfato da série da crandallita (fsc1) microcristalino cor de birrefringência cinza esbranquiçada. Tapira. Amostra TA50c1. MO (LP).

Foto 38 Detalhe do material de fosfato da série crandallita (fsc1) que reveste as fissuras do anatásio. Tapira. Amostra TA50c1. MEV (BEI). 


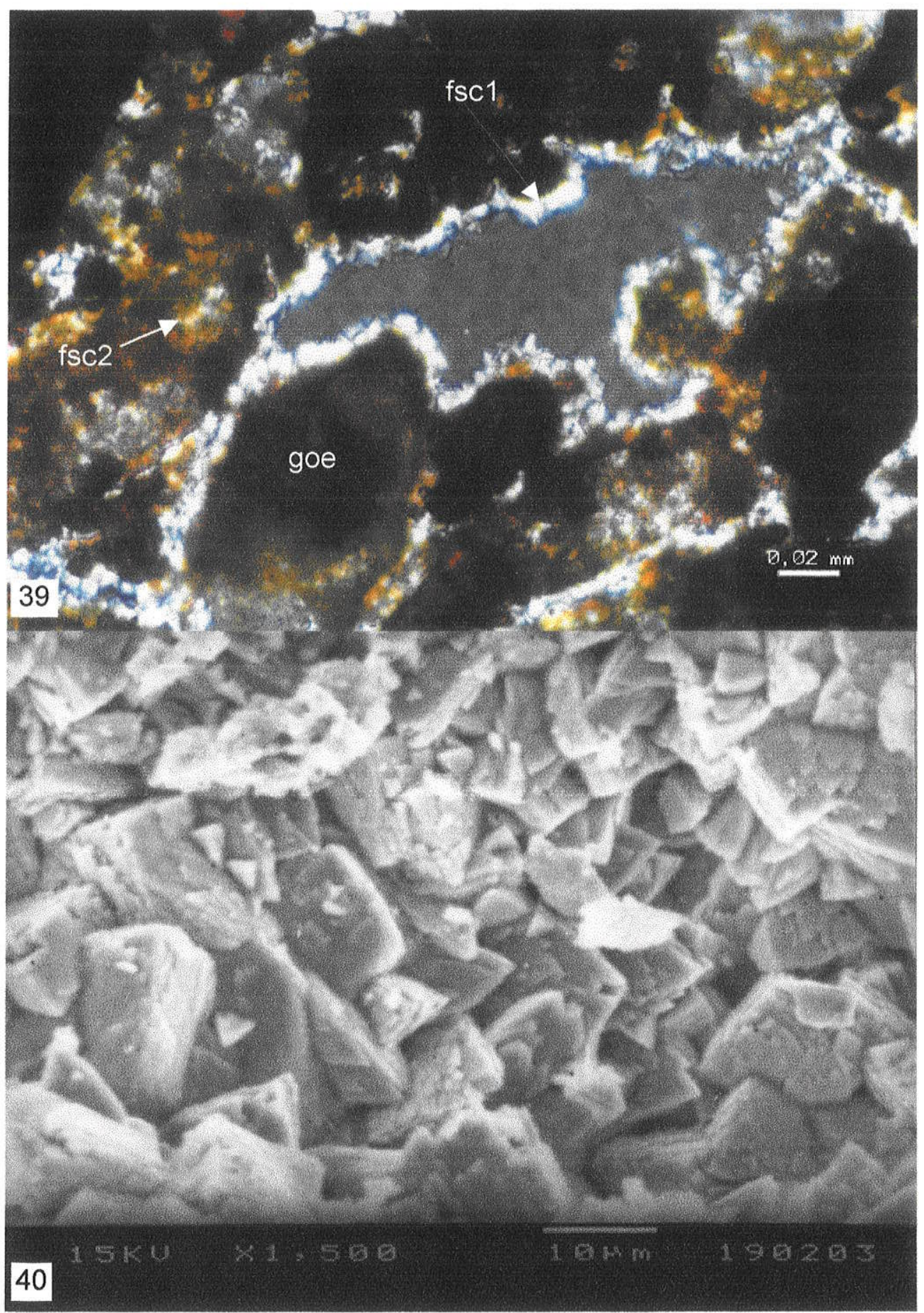

Foto 39 Revestimento cutânico de fosfato da série da crandallita (fsc1) em descontinuidades do plasma goethítico (goe) e agregados microcristalinos misturado ao plasma ferruginoso (fsc2). Tapira. Amostra TA8.1. MO (LP).

Foto 40 Detalhe do material cutânico constituído por cristais romboédricos a tetraédricos de fosfato da série da crandallita (fsc). Tapira. Amostra TA8.1. MEV (BEI). 


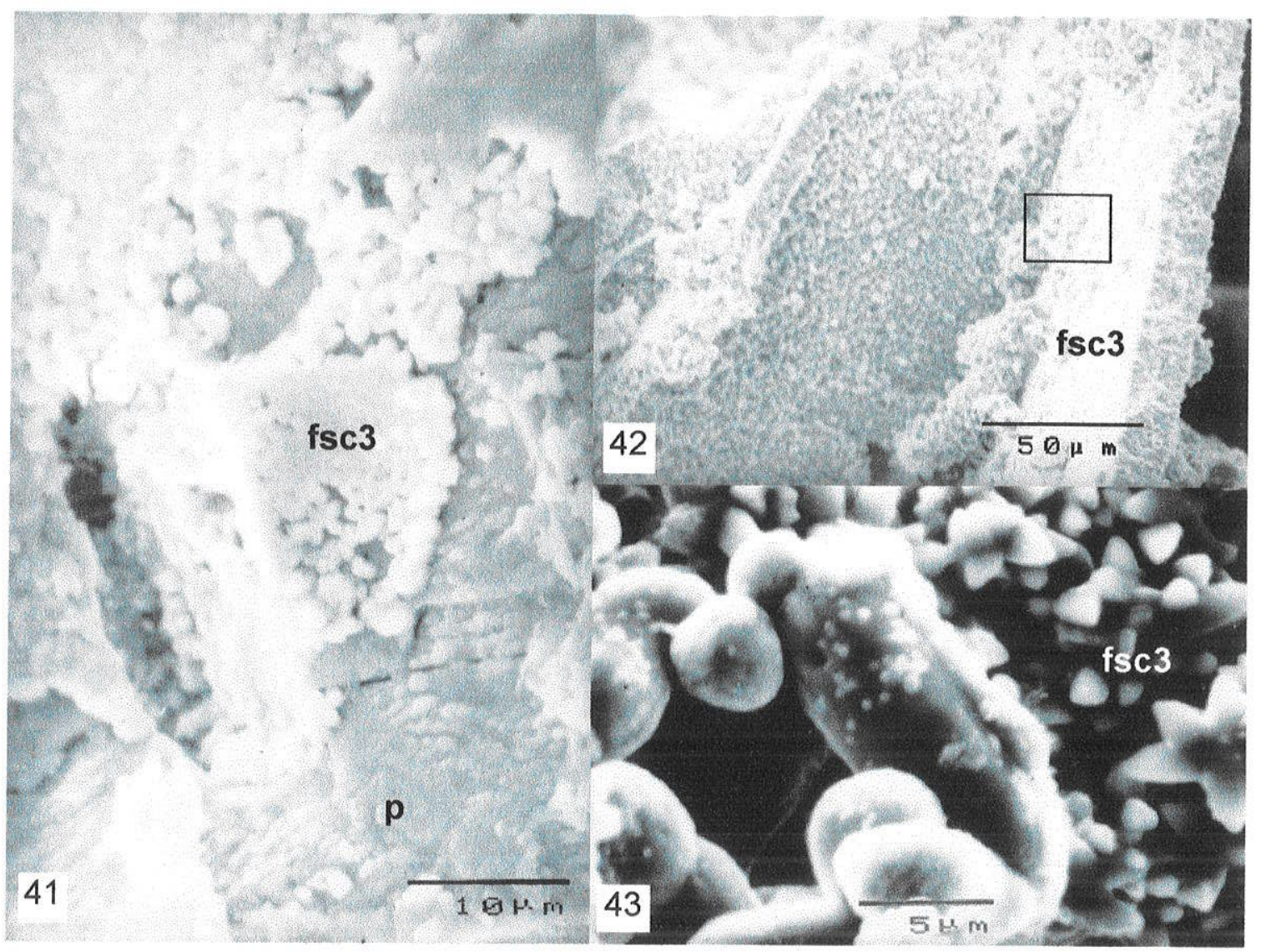

Foto 41 Apatita primária (p) com superficie revestida por fosfatos da série da crandallita (fsc3) enriquecidos em ETR. Tapira. Amostra TA5.1. MEV (BEI).

Foto 42 Feição "box-work" dos fosfatos da série da crandallita (fsc3) rico em ETR. Tapira. Amostra TA1.2. MEV (BEI).

Foto 43 Detalhe da parede do box-work (região do retângulo na foto 42 ), onde aparecem cristais fusiformes e globulares sobre a parede de cristais em roseta todos fosfatos da série crandallita com ETR. Tapira. Amostra TA1.2. MEV (BEI). 


\section{Aspectos químicos e cristaloquímicos dos fosfatos da série da crandallita de Tapira}

As análises dos fosfatos da série da crandallita de Tapira (Figura 36 e Tabela 33) revelaram um maior teor em ETR que as análises sobre os minerais similares que ocorrem em Juquiá. Os cálculos de fórmula estrutural foram efetuados na base de 10,5 O por fórmula unitária da crandallita anidra $\left(\mathrm{AB}_{3}\left(\mathrm{XO}_{4}\right)_{2}\right.$, como apresentado por Taylor et al. (1984) e Lottermoser (1990). As fórmulas assim calculadas permitiram classificar os tipos morfológicos segundo a dominância nos sítio catiônico $\mathrm{A}(\mathrm{Ba}, \mathrm{Ca}, \mathrm{Sr}, \mathrm{ETR})$ de suas estruturas, e observar os possíveis déficit nos sítios $X$ $\left(\mathrm{PO}_{4}, \mathrm{SiO}_{4}\right)$ e $\mathrm{B}\left(\mathrm{Al}^{3+}\right.$ e $\left.\mathrm{Fe}^{3+}\right)$. O Fe foi considerado nos cálculos mesmo sabendo que ele pode não estar na estrutura mineral.

As fases ligadas aos plasmas ferruginosos (tipos 1 e 2) apresentaram em geral maiores quantidades de $\mathrm{Sr}$ no sítio catiônico, a maioria dos valores próximos de 0,3 p.f.u., em relação às das fases ligadas às apatitas (tipos 3 e 4) com valores próximos a 0,1 átomos p.f.u. Todas as fases analisadas apresentaram quantidades importantes de Ba no sítio catiônico, mas quase sempre mais baixas do que as do termo gorceixítico da série da crandallita ( tipo 1: 0,24 e 0,27 ; tipo 2:0,22 e 0,74 tipo3: 0,30 e 0,37 e tipo 4: 0,27 e 0,37, todos em átomos p.f.u.). O tipo 2 apresentou alguns pontos de composição gorceixítica $(0,66$ e 0,73 átomos p.f.u.) e uma maior variação de $\mathrm{Ba}$ do que os outros tipos. Os totais de ETR são maiores nas fases associadas aos plasmas ferruginosos (atinge 0,21 p.f.u.) que nas fases junto às apatitas primárias (entre 0,04 e 0,07). O Ca é mais elevado nas fases ligadas às apatitas (entre 0,53 e 0,65 p.f.u.) do que nas outras fases (entre 0,20 e 0,29 p.f.u.).

A comparação das composições do sítio $A$ das fases estudadas com as encontradas na literatura permitiu dividi-las em dois grupos composicionais. Um representado pelas fases associadas aos plasmas ferruginosos (de alteração de piroxênio e micas) que apresentam uma maior heterogeneidade com predomínio das composições próximas à gorceixita e goyazita (Ca e ETR quase sempre aparecem em menor quantidade no sítio catiônico). Outro representado pelas fases ligadas às apatitas (tipo 3 e tipo 4) que apresenta composições muito próximas entre si, podendo ser classificado como um tipo intermediário entre a crandallita e a gorceixita.

Os tipos 1, 3 e 4 apresentaram um excesso no sítio A (entre 2 e 17\%) e o tipo 1 apresentou um ligeiro déficit (entre 1 e 4\%), Figura 38. Lottermoser (1990) encontrou 
fosfatos da série crandallita com excessos no sítio $A$ em lateritas sobre carbonatito de Mt. Weld (Austrália). A maior parte das gorceixitas de Catalão apresentadas por Toledo (1990) mostram um excesso na ocupação do sítio A a semelhança do encontrado em alguns tipos de Tapira.

Os teores de Al são ligeiramente mais elevados (entre 3,00 e 3,35 p.f.u.) nos tipos ligados a apatita em relação aos outros tipos (entre 2,61 e 2,97 p.f.u.). O Fe apresenta um comportamento inverso, as fases ligadas aos plasmas ferruginosos apresentaram maiores quantidades de $\mathrm{Fe}(1,44$ a 3,69 p.f.u.) em relação às fases ligadas às apatitas $(0,38$ a 1,60 p.f.u.). Ambas as fases apresentaram problemas na ocupação do sítio $B$ sendo as fases ligadas às apatitas (mais aluminosas) as que tem um excesso e às ligadas ao plasma ferruginoso um déficit (Figura 39).

Déficit no sítio $B$ aliado a um maior teor de $\mathrm{Fe}$ pode significar uma contaminação das fases ferruginosas vizinhas durante a análise à ME. Fases intimamente associadas, como goethita e gorceixita, podem ser atingidas simultaneamente pelo feixe de elétrons (de alguns micrômetros de profundidade) resultando em composições não estequiométricas. Os cristais trigonais cutânicos encontrados no plasma ferruginoso apresentaram teores mais variados de $\mathrm{Fe}$ do que os tipos mais finos misturados ao plasma ferruginoso, talvez por apresentarem cristais maiores que favorecem, em alguns locais, a análise de um único cristal sem a presença de produtos ferruginosos.

Deve-se então tomar cuidado na hora de atribuir o ferro na estrutura destes minerais, a confirmação do ferro é possível com a análise de amostras previamente deferruginizadas utilizando técnicas como espectroscopia Mössbauer que infelizmente não pode ser efetuada no presente estudo.

$O$ excesso na ocupação do sítio $B$ das fases associadas às apatitas e os teores elevados de Al podem significar também uma contaminação, análoga à do $\mathrm{Fe}$, desta vez com produtos aluminosos provenientes da alteração das micas.

No sítio $X \circ$ Si sempre ocorre em pequena quantidade. Quase todos os tipos apresentaram um excesso de ocupação no sítio $X$ (entre 2 e $9 \%$ ) em relação ao encontrado na crandalita estequiométrica Figura 39. Excesso no sítio $X$ não foram encontrados nos trabalhos consultados, a causa deste excesso ainda não está esclarecida.

O flúor aparece em pequenas quantidades $(0,74$ a $0,99 \%)$ nas fases analisadas, não sendo dosado nas fases microcristalinas junto a produtos 
ferruginosos pois esta dosagem exige maior tempo de contagem sob $\circ$ feixe eletrônico, o que destruiria sistematicamente o local analisado.

As análises à ME mostraram que o Mn ocorre como elemento traço nos minerais da série crandallita analisados (que em alguns pontos podem estar próximo ou abaixo do limite de deteç̧ão).

Estudos termo-gravimétricos em amostras previamente deferruginizadas revelaram uma diferença no comportamento térmico entre as amostras TA1, cristais em pseudomorfos da apatita e TA8.1, cristais cutânicos do plasma ferruginoso. A amostra TA1 apresentou um efeito endotérmico a $535^{\circ} \mathrm{C}$ e a TA8.1 a $593^{\circ} \mathrm{C}$ ambas com $14 \%$ de perda de massa. A perda de massa em geral não confirma os baixos totais encontrados nas análises destes minerais, sua causa não pôde ser esclarecida .

\begin{tabular}{|c|c|c|c|c|c|c|c|c|c|}
\hline \multirow{3}{*}{$\begin{array}{l}\text { Tipo } \\
\text { Amostra } \\
\text { No. } \\
\text { CaO }\end{array}$} & \multicolumn{3}{|c|}{$\begin{array}{c}1 \\
\text { TA8.1 } \\
\end{array}$} & \multicolumn{6}{|c|}{$\begin{array}{c}2 \\
\text { TA8.1 } \\
\end{array}$} \\
\hline & 2 & 3 & 4 & 5 & 6 & 8 & 9 & 2 & 12 \\
\hline & 2.29 & 2.34 & 2.30 & 0.76 & 1.06 & 2.96 & 2.53 & 2.35 & 2.01 \\
\hline Sro & 5.40 & 5.26 & 5.81 & 6.41 & 1.78 & 5.54 & 6.10 & 4.97 & 1.93 \\
\hline $\mathrm{BaO}$ & 7.63 & 6.86 & 6.71 & 18.62 & 18.94 & 6.28 & 9.46 & 8.49 & 20.62 \\
\hline $\mathrm{La}_{2} \mathrm{O}_{3}$ & 3.64 & 3.17 & 2.10 & 1.09 & 0.22 & 2.79 & 2.17 & 1.93 & 0.08 \\
\hline $\mathrm{Ce}_{2} \mathrm{O}_{3}$ & 3.31 & 4.05 & 4.52 & 1.42 & 1.55 & 2.39 & 1.74 & 3.07 & 0.38 \\
\hline $\mathrm{Al}_{2} \mathrm{O}_{3}$ & 24.47 & 25.20 & 24.77 & 27.37 & 27.72 & 24.40 & 26.16 & 24.33 & 26.53 \\
\hline MnO & 0.08 & 0.04 & 0.00 & 0.01 & 0.01 & 0.07 & 0.01 & 0.00 & 0.00 \\
\hline $\mathrm{Fe}_{2} \mathrm{O}_{3}$ & 3.66 & 2.48 & 2.90 & 1.44 & 3.69 & 2.14 & 2.01 & 2.81 & 2.29 \\
\hline $\mathrm{SiO}_{2}$ & 0.12 & 0.17 & 0.10 & 0.10 & 0.12 & 0.17 & 0.11 & 0.19 & 0.08 \\
\hline $\mathrm{P}_{2} \mathrm{O}_{5}$ & 26.01 & 25.41 & 25.26 & 27.31 & 25.90 & 26.96 & 27.01 & 27.20 & 26.79 \\
\hline Total & 76.61 & 74.98 & 74.47 & 84.53 & 80.99 & 73.70 & 77.30 & 75.34 & 80.71 \\
\hline $\mathrm{Ca}$ & 0.224 & 0.229 & 0.224 & 0.074 & 0.104 & 0.289 & 0.248 & 0.230 & 0.197 \\
\hline $\mathrm{Sr}$ & 0.285 & 0.278 & 0.307 & 0.339 & 0.094 & 0.293 & 0.323 & 0.263 & 0.102 \\
\hline $\mathrm{Ba}$ & 0.273 & 0.245 & 0.240 & 0.665 & 0.677 & 0.224 & 0.338 & 0.303 & 0.737 \\
\hline La & 0.123 & 0.107 & 0.070 & 0.037 & 0.008 & 0.094 & 0.073 & 0.065 & 0.003 \\
\hline $\mathrm{Ce}$ & 0.083 & 0.101 & 0.113 & 0.035 & 0.039 & 0.060 & 0.043 & 0.077 & 0.009 \\
\hline Total sitio A & 0.987 & 0.960 & 0.956 & 1.151 & 0.921 & 0.960 & 1.025 & 0.937 & 1.048 \\
\hline $\mathrm{Al}$ & 2.630 & 2.708 & 2.662 & 2.942 & 2.979 & 2.623 & 2.812 & 2.615 & 2.852 \\
\hline $\begin{array}{l}\mathrm{Fe}^{3+} \\
\text { Total sítio B }\end{array}$ & $\begin{array}{l}0.251 \\
2.881\end{array}$ & $\begin{array}{l}0.170 \\
2.878\end{array}$ & $\begin{array}{l}0.199 \\
2.861\end{array}$ & $\begin{array}{l}0.099 \\
3.041\end{array}$ & $\begin{array}{l}0.254 \\
3.232\end{array}$ & $\begin{array}{l}0.147 \\
2.770\end{array}$ & $\begin{array}{l}0.138 \\
2.950\end{array}$ & $\begin{array}{l}0.193 \\
2.808\end{array}$ & $\begin{array}{l}0.157 \\
3.009\end{array}$ \\
\hline $\begin{array}{l}\text { Si } \\
\mathbf{P} \\
\text { Tota }\end{array}$ & $\begin{array}{l}0.011 \\
2.008 \\
2.019\end{array}$ & $\begin{array}{l}0.015 \\
1.962 \\
1.977\end{array}$ & $\begin{array}{l}0.009 \\
1.950 \\
1.960\end{array}$ & $\begin{array}{l}0.009 \\
2.108 \\
2.118\end{array}$ & $\begin{array}{l}0.011 \\
2.000 \\
2.011\end{array}$ & 0.016 & 0.010 & $\begin{array}{l}0.017 \\
2.100\end{array}$ & $\begin{array}{l}0.007 \\
2.069\end{array}$ \\
\hline $\begin{array}{l}\mathrm{Ca}+\mathrm{S} r+\mathrm{Ba} \\
\mathrm{ETR}\end{array}$ & $\begin{array}{l}0.782 \\
0.210\end{array}$ & $\begin{array}{l}0.752 \\
0.210\end{array}$ & $\begin{array}{l}0.772 \\
0.180\end{array}$ & $\begin{array}{l}1.079 \\
0.070\end{array}$ & $\begin{array}{l}0.874 \\
0.050\end{array}$ & $\begin{array}{l}0.806 \\
0.150\end{array}$ & $\begin{array}{l}0.908 \\
0.120\end{array}$ & $\begin{array}{l}0.796 \\
0.140\end{array}$ & $\begin{array}{l}1.036 \\
0.010\end{array}$ \\
\hline
\end{tabular}

Tabela 33 Composição química dos fosfatos da série da crandallita de Tapira, expressa em \% em peso dos óxidos e em número de átomos por fórmula unitária na base de 10,5 0 .

Onde: 1- Agregados microcristalinos junto ao plasma ferruginoso associado ao anatásio, 2- Cristais romboédricos a tetraédricos revestindo cavidades do plasma ferruginoso associado ao anatásio. 
Tabela 33 (continuação)

\begin{tabular}{|c|c|c|c|c|c|c|c|c|c|}
\hline \multirow{2}{*}{$\begin{array}{l}\text { Tipo } \\
\text { Amostra } \\
\text { No. }\end{array}$} & \multicolumn{4}{|c|}{$\begin{array}{c}3 \\
\text { TA49.1 } \\
\end{array}$} & \multicolumn{5}{|c|}{$\begin{array}{c}4 \\
\text { TA49.1 } \\
\end{array}$} \\
\hline & 2 & 3 & 4 & 2 & 5 & 6 & 7 & 8 & 3 \\
\hline $\mathrm{CaO}$ & 5.86 & 6.51 & 5.82 & 6.18 & 5.63 & 6.39 & 5.92 & 5.42 & 6.64 \\
\hline SrO & 2.07 & 2.12 & 1.98 & 2.28 & 1.97 & 1.61 & 2.09 & 1.61 & 1.72 \\
\hline $\mathrm{BaO}$ & 9.25 & 9.79 & 8.26 & 10.32 & 10.21 & 9.02 & 9.58 & 10.01 & 7.63 \\
\hline $\mathrm{La}_{2} \mathrm{O}_{3}$ & 0.58 & 0.60 & 1.00 & 0.88 & 0.43 & 0.73 & 0.71 & 0.56 & 0.79 \\
\hline $\mathrm{Ce}_{2} \mathrm{O}_{3}$ & 1.49 & 2.09 & 0.86 & 0.54 & 1.27 & 1.37 & 1.56 & 1.22 & 1.54 \\
\hline $\mathrm{Al}_{2} \mathrm{O}_{3}$ & 29.52 & 27.98 & 30.24 & 30.13 & 29.12 & 30.14 & 31.18 & 29.10 & 28.34 \\
\hline Mno & 0.03 & 0.01 & 0.00 & 0.05 & 0.04 & 0.08 & 0.00 & 0.14 & 0.17 \\
\hline $\mathrm{Fe}_{2} \mathrm{O}_{3}$ & 1.02 & 1.20 & 1.01 & 0.39 & 0.84 & 0.38 & 0.60 & 1.60 & 0.48 \\
\hline $\mathrm{SiO}_{2}$ & 0.07 & 0.15 & 0.86 & 0.20 & 0.29 & 0.15 & 0.08 & 0.62 & 0.25 \\
\hline $\mathrm{P}_{2} \mathrm{O}_{5}$ & 27.72 & 27.93 & 27.72 & 26.74 & 25.90 & 26.36 & 27.06 & 27.53 & 27.36 \\
\hline Total & 77.61 & 78.38 & 77.75 & 77.71 & 75.70 & 76.23 & 78.78 & 77.81 & 74.92 \\
\hline $\mathrm{Ca}$ & 0.573 & 0.636 & 0.569 & 0.604 & 0.550 & 0.624 & 0.578 & 0.530 & 0.648 \\
\hline $\mathrm{Sr}$ & 0.109 & 0.112 & 0.105 & 0.121 & 0.104 & 0.085 & 0.111 & 0.085 & 0.091 \\
\hline $\mathrm{Ba}$ & 0.330 & 0.350 & 0.295 & 0.369 & 0.365 & 0.322 & 0.342 & 0.358 & 0.273 \\
\hline La & 0.020 & 0.020 & 0.034 & 0.030 & 0.014 & 0.025 & 0.024 & 0.019 & 0.027 \\
\hline $\mathrm{Ce}$ & 0.037 & 0.052 & 0.022 & 0.013 & 0.032 & 0.034 & 0.039 & 0.031 & 0.039 \\
\hline Total sítio A & 1.070 & 1.170 & 1.024 & 1.137 & 1.065 & 1.091 & 1.095 & 1.022 & 1.077 \\
\hline Al & 3.173 & 3.007 & 3.250 & 3.238 & 3.129 & 3.240 & 3.351 & 3.128 & 3.046 \\
\hline $\begin{array}{l}\mathrm{Fe}^{3+} \\
\text { Total sítio B }\end{array}$ & $\begin{array}{l}0.070 \\
3.243\end{array}$ & $\begin{array}{l}0.083 \\
3.090\end{array}$ & $\begin{array}{l}0.069 \\
3.319\end{array}$ & $\begin{array}{l}0.026 \\
3.265\end{array}$ & $\begin{array}{l}0.058 \\
3.187\end{array}$ & $\begin{array}{l}0.026 \\
3.266\end{array}$ & $\begin{array}{l}0.041 \\
3.392\end{array}$ & $\begin{array}{l}0.109 \\
3.237\end{array}$ & $\begin{array}{l}0.033 \\
3.079\end{array}$ \\
\hline $\begin{array}{l}\mathbf{S i} \\
\mathbf{P} \\
\text { Total sítio X }\end{array}$ & $\begin{array}{l}0.007 \\
2.140 \\
2.147\end{array}$ & $\begin{array}{l}0.014 \\
2.156 \\
2.170\end{array}$ & $\begin{array}{l}0.078 \\
2.140 \\
2.218\end{array}$ & $\begin{array}{l}0.018 \\
2.064 \\
2.082\end{array}$ & $\begin{array}{l}0.027 \\
2.000 \\
2.026\end{array}$ & $\begin{array}{l}0.014 \\
2.035 \\
2.048\end{array}$ & $\begin{array}{l}0.008 \\
2.089 \\
2.097\end{array}$ & $\begin{array}{l}0.057 \\
2.125 \\
2.182\end{array}$ & $\begin{array}{l}0.023 \\
2.112 \\
2.136\end{array}$ \\
\hline $\begin{array}{l}\mathrm{Ca}+\mathrm{Sr}+\mathrm{Ba} \\
\mathrm{ETR}\end{array}$ & $\begin{array}{l}1.013 \\
0.060\end{array}$ & $\begin{array}{l}1.098 \\
0.070\end{array}$ & $\begin{array}{l}0.969 \\
0.060\end{array}$ & $\begin{array}{l}1.094 \\
0.040\end{array}$ & $\begin{array}{l}1.019 \\
0.050\end{array}$ & $\begin{array}{l}1.032 \\
0.060\end{array}$ & $\begin{array}{l}1.031 \\
0.060\end{array}$ & $\begin{array}{l}0.973 \\
0.050\end{array}$ & $\begin{array}{l}1.012 \\
0.070\end{array}$ \\
\hline
\end{tabular}

Onde: 3- Agregados microcristalinos nas fraturas da apatita, 4- Microglóbulos associados ao plasma de alteração de micas entre cristais de apatita. 

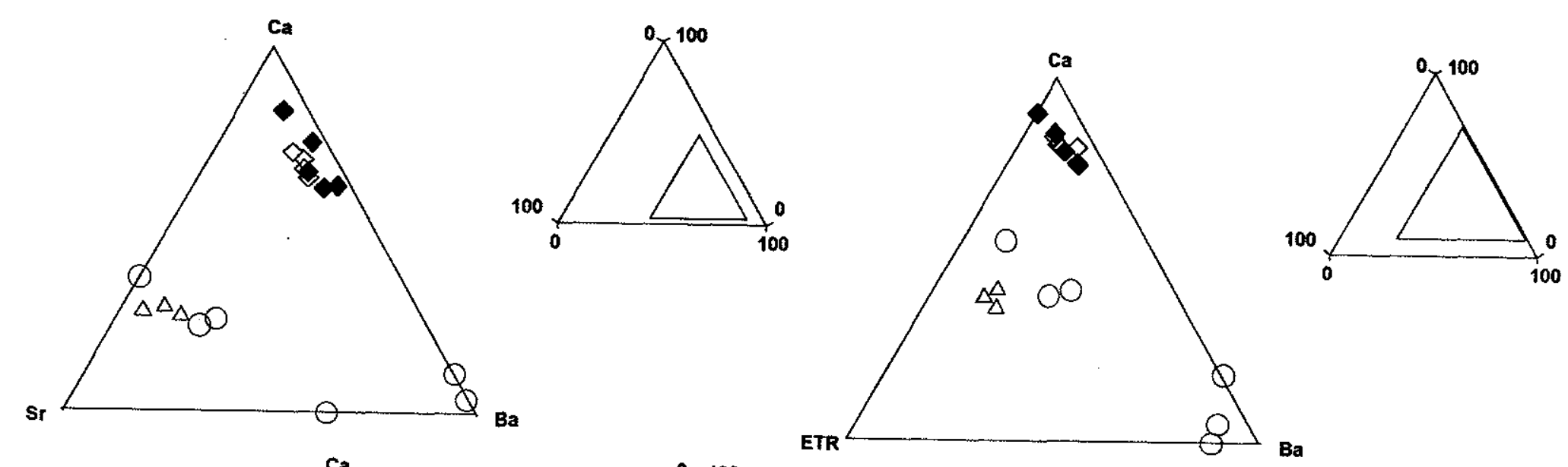

Al
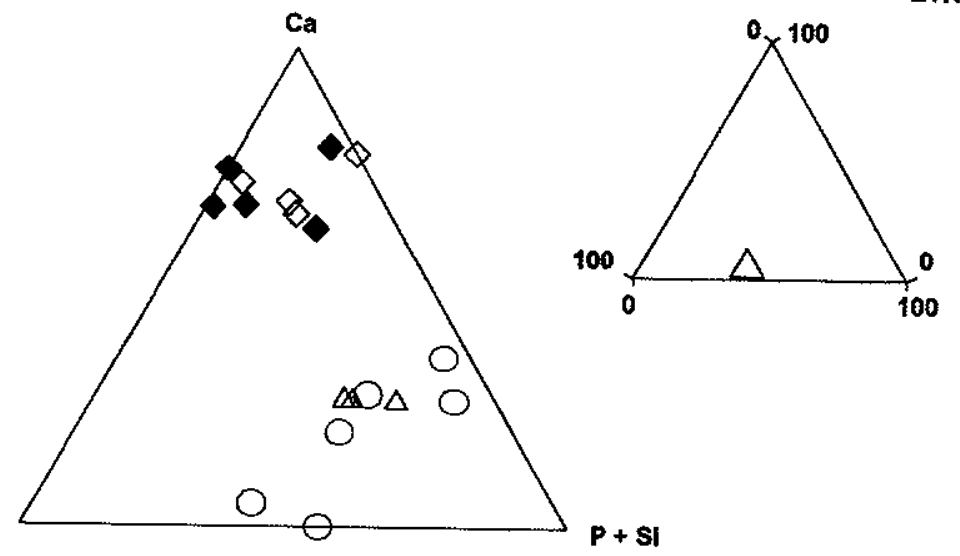

A)

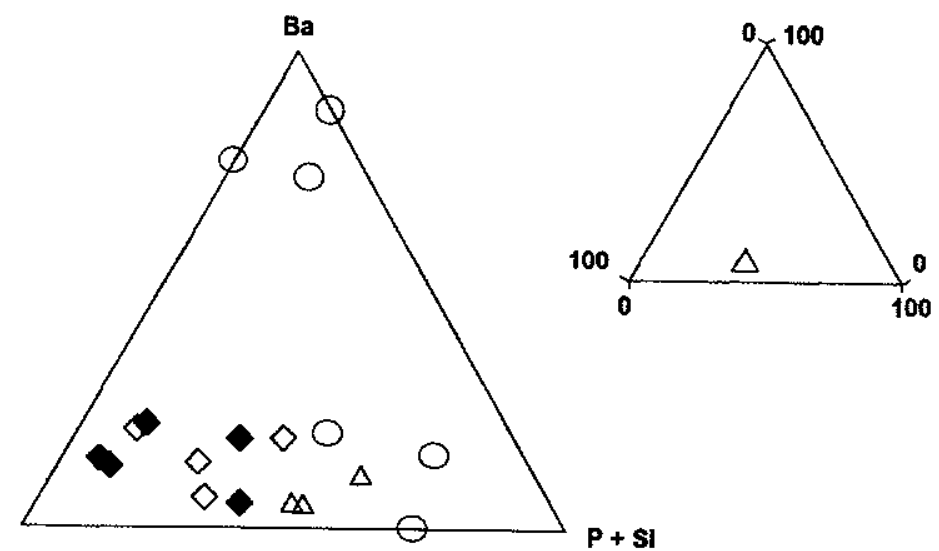

SÉRIE DA CRANDALLITA

$\triangle$ 1- Agregados microcristalinos junto ao plasma ferruginoso associado ao anatásio

$\diamond 3$ - Agregados microcristalinos nas fraturas da apatita

- 2-Cristais romboédricos a tetraédricos

revestindo cavidades do plasma ferruginoso associado ao anatásio

4. Microglóbulos associados as plasma de

alteração de micas entre cristais de apatitas

Figura 36 Diagramas ternários mostrando as variaçóes de conteúdo em $\mathrm{Ca}$ / P / Al, Ca / ETR / BaO e Ca / Sro / Ba de fosfatos não apatíticos de Tapira. (fórmula estrutural calculada na base $10,5 \mathrm{O}$ para formula da crandallita anidra) 

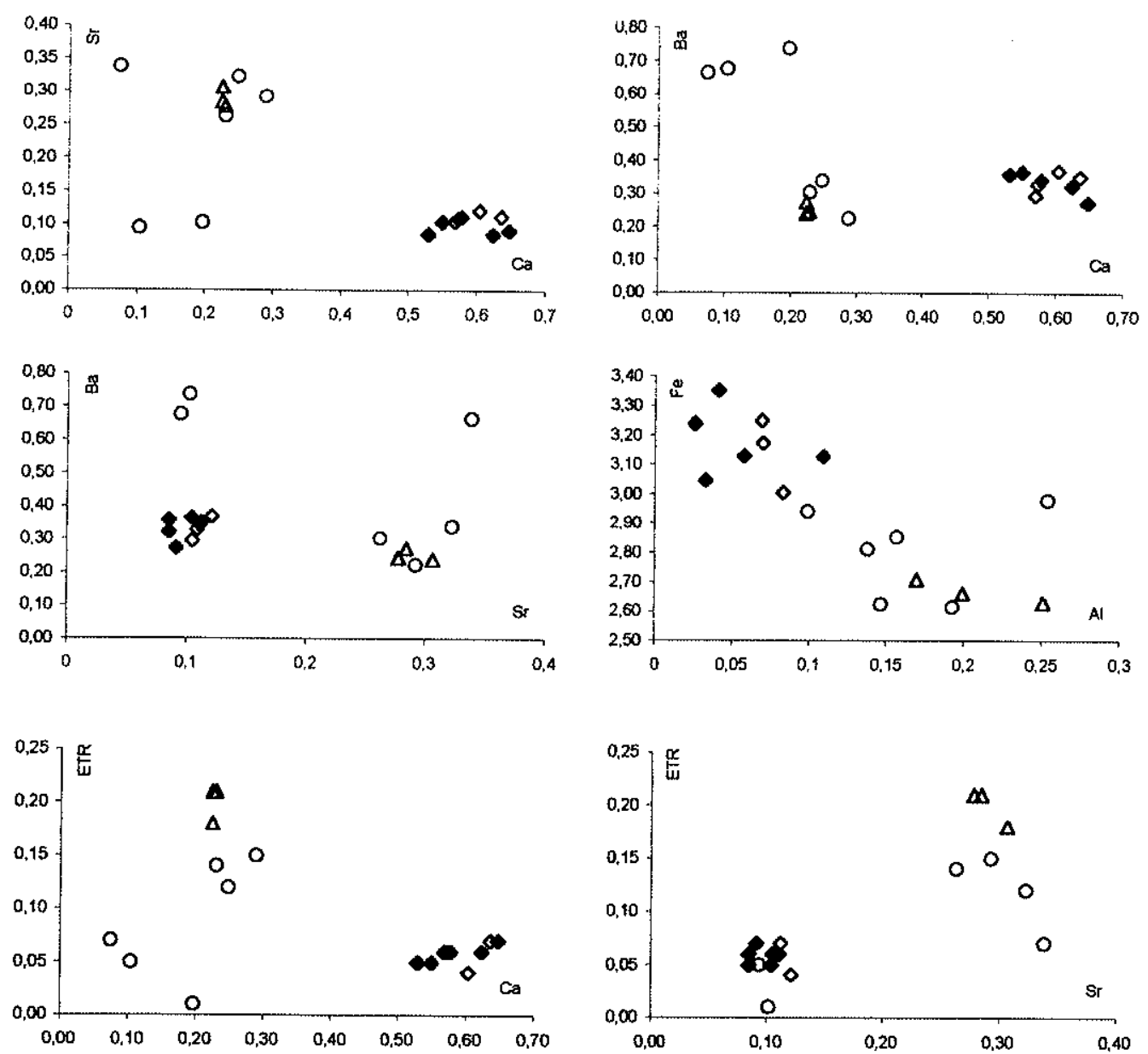
$\triangle 1$ - Agregados microcristalinos junto ao plasma ferruginoso associado ao anatásio
O 2 - Cristais romboédricos a tetraédricos revestindo cavidades do plasma fermuginoso associado ao anatásio
$\diamond 3$ - Agregados microcristalinos nas fraturas da apatita
- 4 - Microglóbulos associados ao plasma de alteraçăo de micas entre cristais de apattas

Figura 37 Diagramas binários mostrando as relações dos constituintes dos fosfatos da série da crandallita de Tapira, em número de átomos p.f.u. (fórmula estrutural calculada na base 10,5 0 para fórmula da crandallita anidra). 
Sítio A
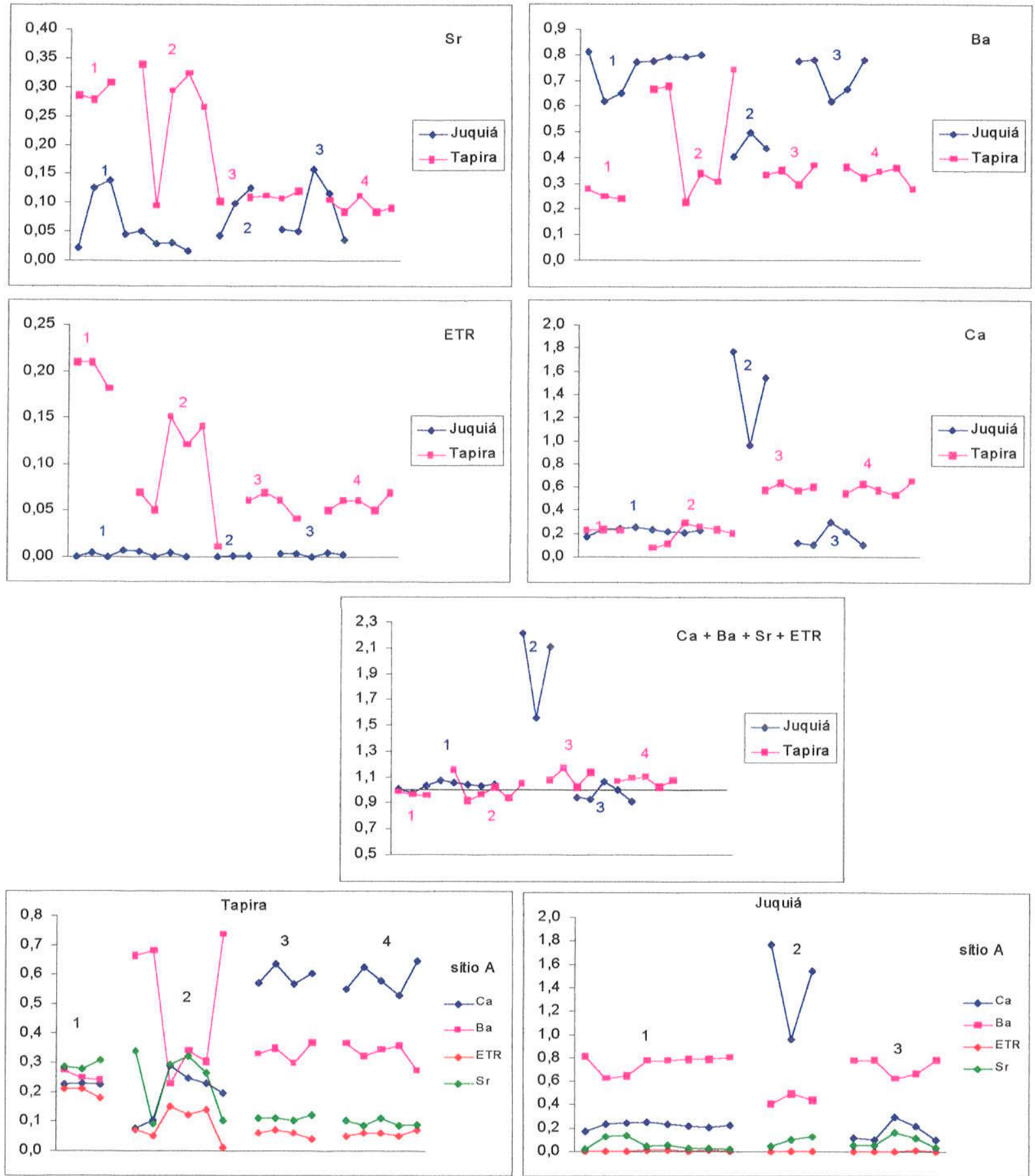

Figura 38 Gráficos de variação dos teores em principais elementos e ocupações do sítios cristaloquímicos A dos fosfatos da série da crandallita de Juquiá e Tapira (dados da tabela 32), em número de átomos p.f.u.

Juquiá: 1- cristais microcristalinos cutânicos, 2- cristais microcristalinos em pseudomorfos micáceos e 3- agregados microcristalinos e globulares em pseudomorfos micáceos.

Tapira: 1- Agregados microcristalinos junto ao plasma ferruginoso associado ao anatásio, 2- Cristais romboédricos a tetraédricos revestindo cavidades do plasma ferruginoso associado ao anatásio, 3- Agregados microcristalinos nas fraturas da apatita e 4- Microglóbulos associados ao plasma de alteração de micas entre cristais de apatita. 
Sítio B
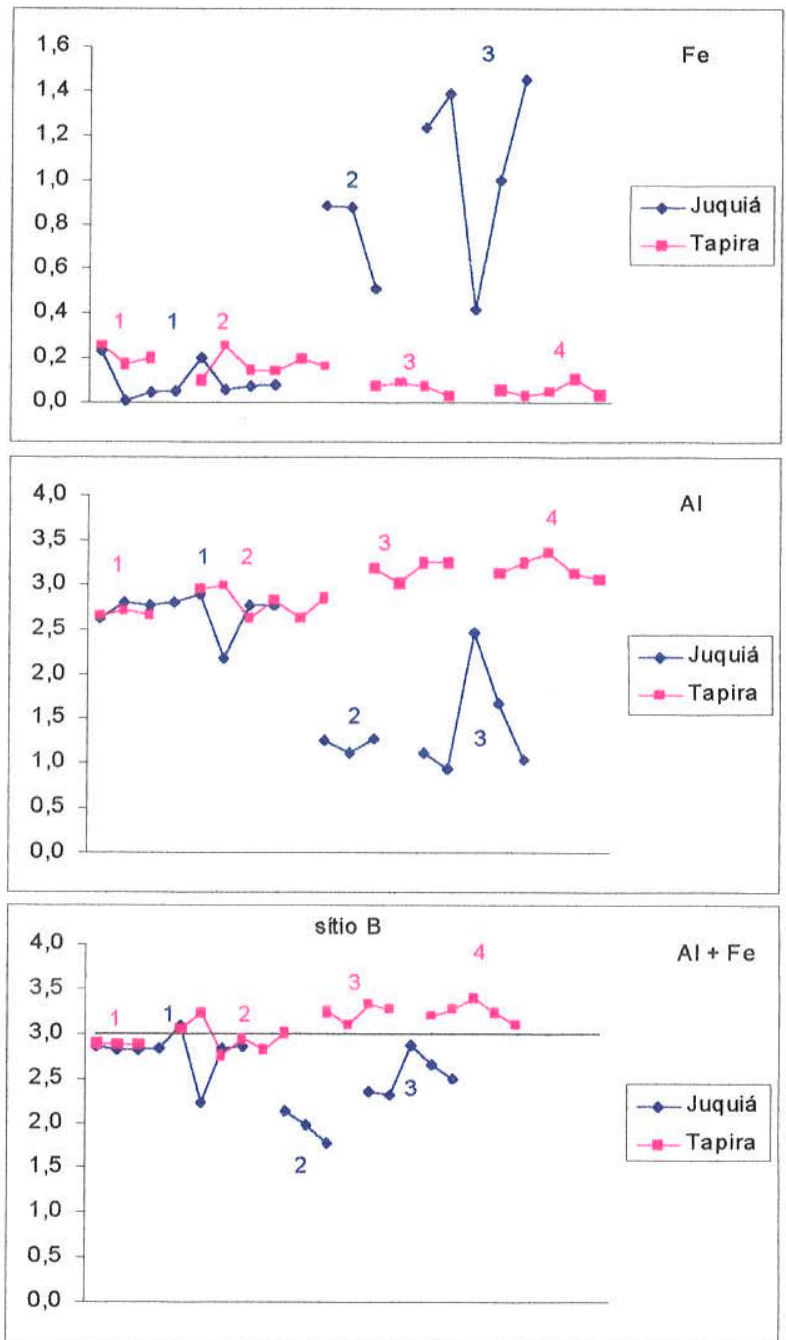

Sítio $X$
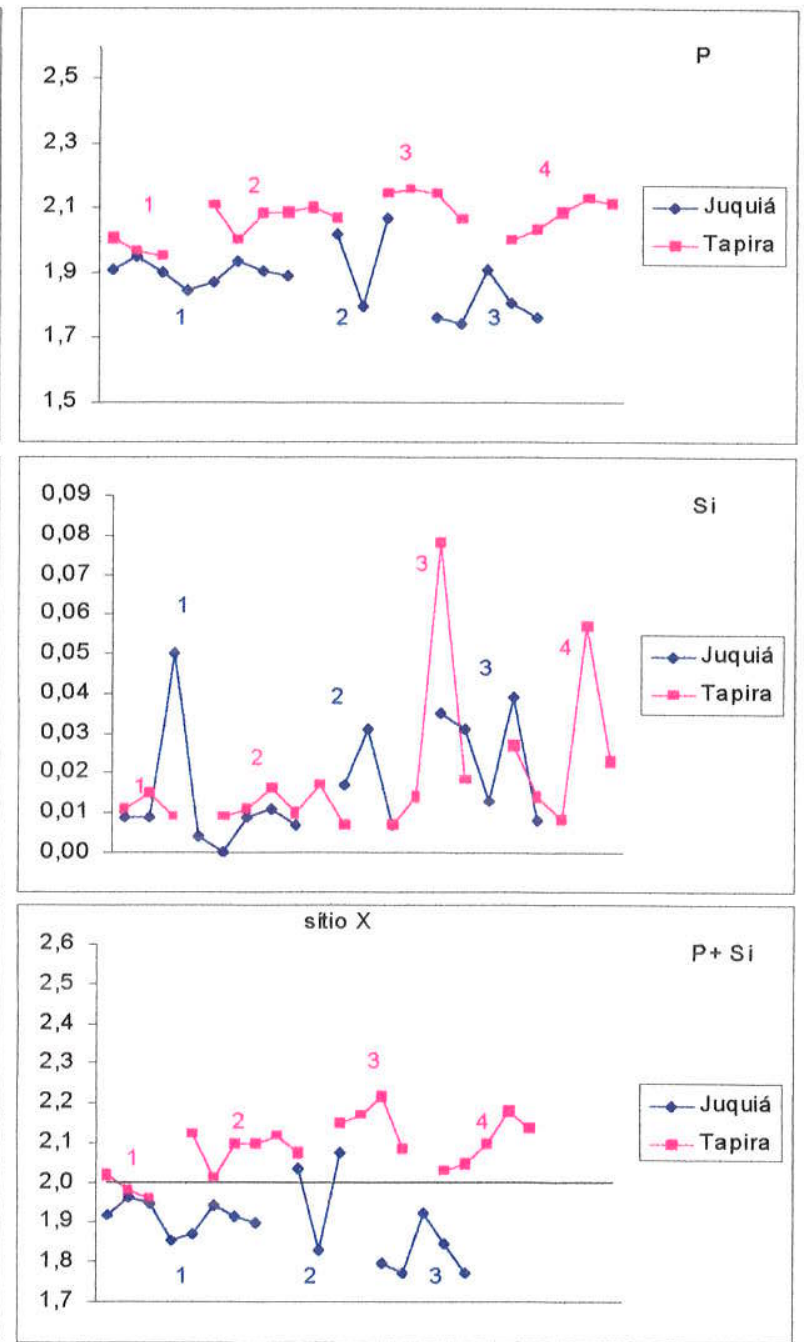

Figura 39 Gráficos de variação dos teores dos principais elementos e ocupações dos sítios cristaloquímicos $\mathrm{X}$ e $\mathrm{B}$ dos fosfatos da série da crandallita de Juquiá e Tapira, (dados da tabela 32), em número de átomos p.f.u.

Juquiá: 1- cristais microcristalinos cutânicos, 2- cristais microcristalinos em pseudomorfos micáceos e 3- agregados microcristalinos e globulares em pseudomorfos micáceos.

Tapira: 1- Agregados microcristalinos junto ao plasma ferruginoso associado ao anatásio, 2- Cristais romboédricos a tetraédricos revestindo cavidades do plasma ferruginoso associado ao anatásio, 3- Agregados microcristalinos nas fraturas da apatita e 4- Microglóbulos associados ao plasma de alteração de micas entre cristais de apatita. 


\subsubsection{Síntese comparativa \\ Morfologia}

Fosfatos da série da crandallita foram encontrados principalmente em Juquiá e Tapira. Foram encontrados apenas indícios não muito freqüentes de sua presença em Anitápolis durante as análises ao MEV-EDS, sem confirmação difratométrica. Nos trabalhos anteriores sobre o manto de intemperismo do complexo alcalinocarbonatítico de Anitápolis também não foi comprovada a sua presença.

O estudo micromorfológico dos fosfatos da série da crandallita de Juquiá permitiu diferenciar os seguintes tipos: 1- cristais microcristalinos cutânicos, 2cristais microcristalinos em pseudomorfos micáceos, 3- agregados microcristalinos e globulares em pseudomorfos micáceos, 4- agregados criptocristalinos, 5- agregados microcristalinos associados à alteração do pirocloro e 6-plasma ferruginoso gorceixítico.

Em Tapira, foram observados os seguintes tipos micromorfológicos: 1Agregados microcristalinos junto ao plasma ferruginoso , 2- Cristais romboédricos a tetraédricos revestindo cavidades do plasma ferruginoso associado ao anatásio, 3Agregados microcristalinos nas fraturas da apatita, 4- Microglóbulos associados ao plasma de alteração de micas entre cristais de apatita. Alguns tipos morfológicos são comuns às duas áreas como os agregados microcristalinos (tipos 1 e 3 de Tapira assemelham-se ao tipo 2 de Juquiá) e os cristais com formas trigonais (tipo 1) de Juquiá assemelha-se ao tipo 2 de Tapira. Agregados microcristalinos globulares (tipo 3) só foram encontrados em Juquiá.

Em Juquiá, Alcover Neto \& Toledo (1993) descreveram dois modos de ocorrência para os fosfatos crandalíticos: cristais romboédricos sobre apatita primária parcialmente dissolvida, morfologias muito finas em porosidades, em micas alteradas e misturados aos produtos argilosos. Walter (1991) também identificou a gorceixita em pseudomorfos micáceos e na matriz que engloba apatita, barita, magnetita e mineral micáceo. Estas morfologias são semelhantes às encontradas no presente estudo.

Em Tapira, Soubiès et al. (1991) observaram a presença de cristais de formas romboédricas formando microgeodos associados ao anatásio ou aos depósitos ferruginosos muito similares ao tipo 2 aqui estudado. Os autores observaram que estes fosfatos ocorrem em materiais de estágio final da alteração onde as apatitas já 
foram totalmente dissolvidos, a semelhança dos materiais em que ocorrem os tipos 1 e 2. Os autores não mencionaram a outros tipos de ocorrência (associados a apatitas). Quash (1987) não encontrou fosfatos da série crandallita nos produtos de intemperismo de rochas piroxeníticas e não cita a presença do anatásio nos materiais estudados, ao contrário do que foi observado no presente estudo.

\section{Composição Química}

Os cálculos de fórmula estrutural com base nas análises à microssonda mostram que no sítio $A$ dos fosfatos da série da crandallita de Juquiá predomina o Ba enquanto em Tapira além do Ba pode também predominar o Ca (tipos 3 e 4) e o Sr (tipo 1).

Observou-se uma variação no conteúdo de Ca nos sítios dos tipos analisados das duas áreas. O tipo 2 de Juquiá e os tipos 3 e 4 de Tapira são os que apresentaram os maiores teores de $\mathrm{Ca}$. Em Tapira, a riqueza de $\mathrm{Ca}$ em uma variedade associada a pseudomorfose de apatita mostra bem a relação estre a composição dos minerais primários e a dos produtos supérgenos.

Em Juquiá, os valores do número de átomos de Ba p.f.u. são maiores nos tipos 1 e 3 (0,62 e 0,81 p.f.u.) do que no tipo 2 (0,40 e 0,49 p.f.u.). Em Tapira, estes valores são em geral mais baixos do que Juquiá e sem muita diferenciação entre os tipos morfológicos (dos pontos analisados do tipo 2 somente dois apresentaram valores de Ba p.f.u. próximos aos de Juquiá).

Em Juquiá, os valores de número de átomos de Sr p.f.u. não se diferenciaram nos tipos morfológicos e apresentaram na maior parte das análises valores muito baixos (aproximadamente entre 0 e 0,05 p.f.u.) e em poucas análises valores mais elevados (entre 0,10 e 0,16 p.f.u.). Em Tapira, duas composições foram encontradas: uma mais pobre em $\mathrm{Sr}$ (próximo de 0,10 p.f.u.) e outra mais rica em $\mathrm{Sr}$ (entre 0,25 e 0,35 p.f.u).

Em Juquiá, apenas o tipo 2 apresentou teores consideráveis de $\mathrm{Ca}$ (1 a 1,80 p.f.u.) um pouco mai elevado do que os tipos 3 e 4 de Tapira.

Os ETR são quase inexistentes na estrutura dos fosfatos da série crandallita de Juquiá (valores entre 0,00 e 0,01). Estes fosfatos em Tapira são mais enriquecidos em ETR e apresentaram duas composições entre 0,04 e 0,08 (alguns pontos do tipo 2 e todos dos tipos 3 e 4) e entre 0,12 e 0,21 (tipo 1 e pontos do tipo 2). A ocupação do sítio $A$ destes minerais é irregular nas duas áreas. 
Foram encontrados três conjuntos de valores de no. de átomos de Al p.f.u.: 1) representado pelo tipo 1 de Juquiá e pelos tipos 1 e 2 de Tapira, com valores mais elevados sendo a maioria entre 2,50 e $3,00,2$ ) representado pelos tipos 3 e 4 de Tapira com valores entre 3,00 e 3,25 e, 3) representado pelos tipos 2 e 3 de Juquiá com valores mais baixos em geral entre 0,80 e 1,25.

Observa-se que o $\mathrm{Fe}$ a grosso modo está correlacionado negativamente com Al assim os tipos menos aluminosos são os mais ricos em Fe (tipos 2 e 3 , entre 0,40 a 1,4 p.f.u.) e os mais aluminosos os mais empobrecidos em Fe (Juquiá o tipo 1 e Tapira os tipos 1 e 2 seguidos pelo tipo 3, valores entre 0,03 e 0,25 p.f.u.).

$O$ sítio $X$ apresenta-se aproximadamente completo nos tipos morfológicos de Tapira ( $P$ entre 1,95 a 2,16 átomos p.f.u.) e mais incompleto em alguns pontos analisados do tipos 1, 2 e 3 de Juquiá ( $P$ entre 1,74 e 1,93 p.f.u.). Nas duas áreas o número de átomos de Si p.f.u. é sempre baixo (entre 0,00 e 0,08 p.f.u.).

Walter analisou as fosfatos da série da crandallita de Juquiá associados aos pseudomorfos foliáceos, obtendo composições próximas a da gorceixita com pouca substituição do $\mathrm{Ba}$ pelo $\mathrm{Ca}$ e $\mathrm{Sr}$, os cálculos de fórmula estrutural aplicando o mesmo método no presente estudo mostra uma ocupação irregular de todos os sítios (excesso e deficiências) similares ao aqui encontrado.

Fosfatos da série crandallita já foram analisados anteriormente em Tapira, Soubiès et al. (1990 e 1991) estudaram a composição de morfologias similares ao tipo 2 obtendo uma composição diferente da aqui encontrada por apresentar quantidades menores de $\mathrm{Ba}$, e maiores de $\mathrm{Ca}$ e ETR (mineral de composição intermediária entre a florencita e a crandallita). Esta diferença pode estar ligada a heterogeneidade das composições das soluções que deram origem a estes minerais.

Em Juquiá,os parâmetros de cela unitária dos tipos 1, 3 (nas concreçōes ferruginosas) e 6 são muito próximos. $O$ tipo 3 que ocorre junto a apatitas primárias apresentou um aumento do valor do parâmetro $c$. $O$ tipo 3 é encontrado na amostra JUT2BP analisada à ME, observa-se na Tabela 31 que este tipo é ligeiramente mais rico em $\mathrm{BaO}$ apresentando valores de $\mathrm{BaO} / \mathrm{P}_{2} \mathrm{O}_{5}$ mais elevados. Não existem trabalhos anteriores com determinações de parâmetros de cela dos fosfatos da série nas áreas estudadas que possam ser aqui comparados. Toledo obteve para as gorceixitas de Catalão parâmetros mais próximos ao encontrados em Juquiá com dimensão do eixo a ligeiramente menor do que a do tipo 3. 


\section{Parâmetros de cela}

Os parâmetros de cela de fosfatos da série da crandallita de Juquiá estão muito próximos dos apresentados por Radoslovich \& Slade (1980) e Schwab et al. (1990) para o termo da gorceixita da série. Tapira apresentou parâmetro de a que se aproxima do termo da crandalita estudada por Gilkes \& Palmer (1983) e do termo da florencita (Ce) apresentada por Schwab et al. (1990b).

\section{Características térmicas}

As amostras analisadas nas duas áreas apresentaram minerais da série da crandallita com valores de temperatura de efeito endotérmico distintos. Os tipos 1 e 2 de Tapira apresentaram um valor de temperatura mais elevado $\left(593^{\circ} \mathrm{C}\right)$, intermediário entre os valores dos minerais sintéticos da série da crandallita com ETR $\left(600-640^{\circ} \mathrm{C}\right.$, Schwab et al., 1990a) e o da gorceixita sintética $\left(560^{\circ} \mathrm{C}\right.$, Schwab et al., 1990b), em acordo com a composição encontrada. Os tipos 3 e 4 de Tapira e todos os tipos de Juquiá (entre 526 e $552^{\circ} \mathrm{C}$ ) apresentaram valores de temperatura intermediários entre os valores da crandallita $\left(530^{\circ} \mathrm{C}\right.$, Blanchard, 1972) e da gorceixita sintética $\left(560^{\circ} \mathrm{C}\right.$, Schwab et al., 1990b).

Os valores de perda de massa dos fosfatos da série da crandallita são maiores em Juquiá (entre 16,3 e 16,9\%) do que em Tapira (14\%). Dentro de uma mesma área o valor de perda de massa não variou significativamente. A perda de massa, que reflete principalmente a quantidade de $\mathrm{OH}^{-}$e $\mathrm{H}_{2} \mathrm{O}$ destes minerais, e somente está de acordo com os fechamentos encontrados nas análises de Juquiá .

Sabe-se que composição dos fosfatos da série da crandallita podem afetar os parâmetros de cela e a temperatura de desidratação como observado em trabalhos de sínteses (Gilkes \& Palmer, 1983, Menchetti \& Sabelli, 1976), ainda não se pode afirmar quais as causas das diferenças aqui encontradas pois são comuns as substituições isomórficas nestes minerais.

\subsection{Outros fosfatos}

Além dos fosfatos da série da crandallita foram encontrados nos perfis lateríticos estudados a wavellita, a turquesa (Juquiá) e os fosfatos de ETR (monazita, rhabdofânio e fase com P e ETR não identificada mineralogicamente em Anitápolis, Juquiá e Tapira). 


\subsubsection{Anitápolis}

Em Anitápolis, foi observada, ao MEV, a presença de fosfatos de ETR junto a cristais de apatita e de piroxênio (Foto 44). Formam agregados criptocristalinos com ETR, $\mathrm{P}$ e apresentam baixos teores de Si e Al, conforme avaliação dos espectros qualitativos de EDS. A falta de análises difratométricas impede a identificação do mineral. Outros fosfatos não foram encontrados nas amostras analisadas, embora Costa (1987) tenha encontrado wavellita nos materiais do perfil de intemperismo semelhantes aos aqui estudados.

\subsubsection{Juquiá}

Foram encontrados cristais de wavellita e turquesa em amostras do perfil de transição, junto a produtos argilosos que preenchem cavidades da alterita do carbonatito. Compostos fosfáticos com ETR, sem identificação difratométrica, foram encontrados junto a micas alteradas na alterita do carbonatito.

\section{Wavellita}

A wavellita foi identificada à DRX utilizando a técnica de câmera Debye Scherrer, que apresentou reflexões próximas da estrutura da wavellita de encontrados nos fosfatos lateríticos de Trauira estutados por Costa et al. (1980), Tabela 35. Os parâmetros de cela, calculados pelo método dos mínimos quadrados, foram refinados considerando o grupo espacial PMMN e os parâmetros iniciais de uma wavellita padrão $\left(a_{0}: 9,621, b_{0}: 17,363\right.$ e $\left.c_{0}: 6,994 \AA \AA\right)$. Os valores encontrados ficaram próximos aos encontrados por Correia Neves et al. (1976), são eles 9,6433 (8)Å, 17,3509(15)Å e 7,0032 (6) A para os parâmetros a, b e c respectivamente.

A wavellita ocorre de forma disseminada no perfil da zona de transição tanto em cavidades fissurais do material argiloferruginoso como no material apatítico. Forma cristais freqüentemente aciculares incolores podendo ocorrer intercrescido junto à turquesa. Suas acículas são bem desenvolvidas e podem aparecer soltas ou agregadas em feixes. O comprimento e a espessura das aciculas variam, como pode ser visto nas imagens ao MO e ao MEV (Foto 45 e Foto 46). A wavellita foi identificada também por Walter (1991) que a encontrou revestindo fissuras da rocha alterada com mesma morfologia da aqui descrita, a autora não apresentou a composição química deste mineral.

As proporções molares obtidas a partir de dados da ME (Tabela 34), calculadas na base $\mathrm{Al}+\mathrm{Fe}=3$ e adotando a fórmula estrutural da wavellita $(\mathrm{Al}, \mathrm{Fe})_{3}(\mathrm{OH}, \mathrm{F})_{3}\left(\mathrm{PO}_{4}\right)_{2} .5 \mathrm{H}_{2} \mathrm{O}$, mostram um excesso no sítio do $\mathrm{P}$. Um comportamento 
similar foi encontrado nas wavellitas naturais apresentadas por Correia Neves et al. (1976). Quase todos os pontos analisados mostram pouca substituição do $\mathrm{Al}$ por $\mathrm{Fe}$ e a presença de $F$ no sítio aniônico monovalente. O F é comum nestes minerais, mas pode em menor quantidade do que a observada (Correia Neves et al., 1976).

\begin{tabular}{lrrrrrrrr} 
Amostra & JUT15 & JUT15 & JUT15 & JUT10a & JUT10a & JuT10A & JUT10a & JUT10Ca \\
\cline { 2 - 8 } $\mathrm{No}$. & 1 & 2 & 3 & 5 & 6 & 23 & 33 & 20 \\
$\mathrm{CaO}$ & 0.04 & 0.02 & 0.08 & 0.02 & 0.04 & 0.06 & 0.07 & 0.03 \\
$\mathrm{SrO}$ & 0.03 & 0.03 & 0.00 & 0.02 & 0.00 & 0.10 & 0.00 & 0.00 \\
$\mathrm{BaO}$ & 0.00 & 0.00 & 0.06 & 0.00 & 0.01 & 0.00 & 0.00 & 0.00 \\
$\mathrm{La}_{2} \mathrm{O}_{3}$ & 0.00 & 0.06 & 0.00 & 0.01 & 0.09 & 0.02 & 0.00 & 0.04 \\
$\mathrm{Ce}_{2} \mathrm{O}_{3}$ & 0.00 & 0.03 & 0.00 & 0.00 & 0.00 & 0.04 & 0.00 & 0.06 \\
$\mathrm{Al}_{2} \mathrm{O}_{3}$ & 34.91 & 35.48 & 36.62 & 35.23 & 34.41 & 36.83 & 34.96 & 37.97 \\
$\mathrm{Fe}_{2} \mathrm{O}_{3}$ & 0.00 & 0.02 & 0.17 & 0.21 & 0.61 & 0.13 & 3.10 & 0.44 \\
$\mathrm{SiO}_{2}$ & 0.01 & 0.00 & 0.04 & 0.11 & 0.27 & 0.09 & 0.22 & 0.07 \\
$\mathrm{P}_{2} \mathrm{O}_{5}$ & 35.49 & 33.99 & 34.80 & 35.20 & 34.87 & 34.15 & 35.68 & 35.68 \\
$\mathrm{~F}$ & 2.36 & 2.26 & 2.52 & 2.30 & 2.36 & - & - & - \\
$\mathrm{F}=\mathrm{O} 2$ & 0.99 & 0.95 & 1.06 & 0.97 & 0.99 & - & - & - \\
$\mathrm{Soma}$ & 71.86 & 70.95 & 73.23 & 72.14 & 71.67 & 71.42 & 74.04 & 74.31 \\
$\mathrm{Al}$ & & & & & & & & \\
$\mathrm{Fe}{ }^{3+}$ & 3.000 & 2.999 & 2.996 & 3.000 & 2.983 & 2.997 & 2.917 & 2.989 \\
$\mathrm{Si}$ & 0.000 & 0.001 & 0.004 & 0.006 & 0.017 & 0.003 & 0.083 & 0.011 \\
$\mathrm{P}$ & 0.000 & 0.000 & 0.003 & 0.008 & 0.020 & 0.006 & 0.016 & 0.005 \\
$\mathrm{~F}$ & 2.191 & 2.064 & 2.045 & 2.153 & 2.171 & 1.996 & 2.139 & 2.018 \\
$\mathrm{Al} / \mathrm{P}$ & 0.544 & 0.513 & 0.553 & 0.525 & 0.549 & - & - & - \\
$\mathrm{Tab}$ & 1.369 & 1.453 & 1.465 & 1.393 & 1.374 & 1.501 & 1.364 & 1.481
\end{tabular}

Tabela 34 Composição química das wavellitas de Juquiá, em \% em peso dos óxidos e em número de átomos por unidade de fórmula estrutural na base $\mathrm{Al}+\mathrm{Fe}=3$. 


\begin{tabular}{|c|c|c|c|c|}
\hline \multicolumn{2}{|c|}{ Juquiá } & \multicolumn{3}{|c|}{ Trauira } \\
\hline $\mathrm{d} \AA$ & $1 / 10$ & $d \AA$ & l/lo & hkl \\
\hline 8,731 & 100 & 8,61 & 90 & 020 \\
\hline 8,461 & 100 & 8,35 & 100 & 110 \\
\hline 5,710 & 60 & 5,64 & 35 & 101 \\
\hline \multirow[t]{2}{*}{5,376} & 40 & 5,36 & 10 & 111 \\
\hline & & 4,93 & 14 & 130 \\
\hline \multirow[t]{2}{*}{4,830} & 50 & 4,79 & 30 & 200 \\
\hline & & 4,33 & 3 & 040 \\
\hline \multirow[t]{4}{*}{4,042} & 60 & 4,03 & 7 & 131 \\
\hline & & 3,949 & 7 & 201 \\
\hline & & 3,854 & 3 & 211 \\
\hline & & 3,49 & 4 & 002 \\
\hline \multirow[t]{2}{*}{3,424} & 80 & 3,42 & 22 & 141 \\
\hline & & 3,26 & 5 & 231 \\
\hline \multirow[t]{2}{*}{3,235} & 80 & 3,21 & 60 & 240 \\
\hline & & 3,14 & 10 & 051 \\
\hline 3,086 & 50 & 3,07 & 7 & 122 \\
\hline \multirow[t]{3}{*}{2,938} & 50 & 2,95 & 10 & 151 \\
\hline & & 2,918 & 7 & $\begin{array}{lll}3 & 0 & 1\end{array}$ \\
\hline & & 2,887 & 3 & 060 \\
\hline \multirow[t]{2}{*}{2,799} & 50 & 2,796 & 16 & 212 \\
\hline & & 2,597 & 7 & 331 \\
\hline \multirow[t]{2}{*}{2,590} & 60 & 2,57 & 3 & 161 \\
\hline & & 2,536 & 3 & 232 \\
\hline 2,372 & 30 & 2,393 & 4 & 152 \\
\hline
\end{tabular}

Tabela 35 Dados de difração de raios-X (radiação $\mathrm{Cu} K \alpha$ ) da wavellita de Juquiá comparada com a wavellita de Trauira (Costa et al., 1980).

\section{Turquesa}

A turquesa, assim como a wavellita, foi identificada à DRX utilizando a técnica de câmera Debye - Scherrer, que apresentou reflexões próximas da estrutura da turquesa padrão (Tabela 37). Os parâmetros de cela calculados pelo método dos mínimos quadrados e refinados a partir do grupo espacial $\mathrm{P}_{1}$ (triclínico) e dos parâmetros iniciais de uma turquesa padrão (JCPDS 6-214), com $a_{0}=7,52, b_{0}$ : $10,24, c_{0}=7,70 \AA, \alpha=111,3 \beta=115,12$ e $\gamma=69,32$.

Os parâmetros de cela assim obtidos ficaram próximos aos da turquesa padrão com valores 7,511 (2) $\AA$, 10,286(2) $\AA$ e 7,678 (2) $\AA$ para os parâmetros a, b e c respectivamente e $\alpha: 111,8^{\circ}(3) \beta: 115,13^{\circ}$ (2) e $\gamma: 69,12(2)^{\circ}$. Este mineral ainda não havia sido encontrado em Juquiá.

De ocorrência muito localizada, foi encontrada apenas no setor de transição em fissuras da rocha apatítica em Juquiá e, em geral, associada à wavellita. Ocorre como massas esverdeadas podendo formar pequenas rosetas. Aparece intercrescida com cristais de wavellita. Os cristais de turquesa apresentam forma 
achatada e terminada em pontas, formando pacotes empilhados em todas as direções (Foto 47).

As proporções molares obtidas a partir de dados da ME, (Tabela 36), foram calculadas considerando a fórmula geral da turquesa $A B_{6}\left[(O H)_{2} / X_{4}\right]_{4} \cdot 4 \mathrm{H}_{2} \mathrm{O}, A=$ $\mathrm{Cu}^{2+}, \mathrm{Ca}^{2+}, \mathrm{Sr}^{2+}$ e $\mathrm{Ba}^{2+} ; \mathrm{B}=\mathrm{Al}^{3+}, \mathrm{Fe}^{3+}$ eX $=\mathrm{P}$, Si, e a base de 6 átomos no sítio $\mathrm{B}$. $\mathrm{O}$ $\mathrm{Fe}^{2+}$ não foi considerado por tratar-se de mineral formado em ambiente supérgeno (meio oxidante).

Quando comparadas à turquesa estequiométrica, as análises revelaram uma riqueza em $\mathrm{Fe}$ e baixos teores de $\mathrm{Cu}$ indicando uma possível substituição do $\mathrm{Fe}$ pelo $\mathrm{Cu}$ (Tabela 36). As razões $\mathrm{Al} / \mathrm{P}$ das turquesas analisadas são quase sempre menores do que a da turquesa estequiométrica sugerindo que o $\mathrm{Fe}^{3+}$ pode também estar presente no sítio do alumínio.

\begin{tabular}{|c|c|c|c|c|}
\hline \multirow[t]{2}{*}{ Amostra } & \multicolumn{4}{|c|}{ JUT'15 } \\
\hline & 4 & 5 & 6 & 8 \\
\hline $\mathrm{CaO}$ & 0.34 & 0.27 & 0.21 & 0.33 \\
\hline SrO & 0.00 & 0.01 & 0.02 & 0.00 \\
\hline $\mathrm{BaO}$ & 0.51 & 0.39 & 0.51 & 0.39 \\
\hline CuO & 4.82 & 4.74 & 5.10 & 5.68 \\
\hline $\mathrm{La}_{2} \mathrm{O}_{3}$ & 0.00 & 0.02 & 0.00 & 0.00 \\
\hline $\mathrm{Ce}_{2} \mathrm{O}_{3}$ & 0.40 & 0.12 & 0.23 & 0.56 \\
\hline $\mathrm{Al}_{2} \mathrm{O}_{3}$ & 27.54 & 32.92 & 25.39 & 26.15 \\
\hline $\mathrm{Fe}_{2} \mathrm{O}_{3}$ & 10.88 & 8.99 & 5.62 & 15.45 \\
\hline $\mathrm{SiO}_{2}$ & 1.23 & 0.00 & 0.03 & 0.12 \\
\hline $\mathrm{P}_{2} \mathrm{O}_{5}$ & 33.08 & 32.28 & 32.77 & 31.79 \\
\hline$F$ & $\begin{array}{r}0.45 \\
79.26\end{array}$ & $\begin{array}{r}0.46 \\
80.23\end{array}$ & $\begin{array}{r}0.56 \\
70.45\end{array}$ & $\begin{array}{r}0.49 \\
80.96\end{array}$ \\
\hline $\mathrm{F}=0$ & 0.19 & 0.19 & 0.24 & 0.21 \\
\hline Total & 79.07 & 80.03 & 70.21 & 80.75 \\
\hline $\mathrm{Ca}$ & 0.054 & 0.038 & 0.039 & 0.049 \\
\hline $\mathrm{Sr}$ & 0.000 & 0.001 & 0.002 & 0.000 \\
\hline $\mathrm{Ba}$ & 0.029 & 0.020 & 0.035 & 0.022 \\
\hline $\mathrm{Cu}$ & 0.538 & 0.471 & 0.676 & 0.607 \\
\hline La & 0.000 & 0.001 & 0.000 & 0.000 \\
\hline $\mathrm{Ce}$ & 0.022 & 0.006 & 0.015 & 0.029 \\
\hline Al & 4.791 & 5.109 & 5.258 & 4.356 \\
\hline $\mathrm{Fe}^{3+}$ & 1.209 & 0.891 & 0.742 & 1.644 \\
\hline Si & 0.181 & 0.000 & 0.006 & 0.017 \\
\hline$P$ & 4.133 & 3.599 & 4.874 & 3.804 \\
\hline$F$ & 0.212 & 0.192 & 0.313 & 0.219 \\
\hline
\end{tabular}

Tabela 36 Composição química das turquesas de Juquiá expressa em \% em peso dos óxidos e em número de átomos por unidade de fórmula estrutural na base sítio $B=6$ (modelo de composição anidra: $\mathrm{A} \mathrm{B}_{6}\left(\mathrm{XO}_{4}\right)_{4} 4 \mathrm{O}^{2-}$ ). 


\begin{tabular}{|c|c|c|c|c|c|c|c|c|c|}
\hline \multicolumn{2}{|c|}{ Juquiá } & \multicolumn{8}{|c|}{ JCPDS $6-0214$} \\
\hline \multirow[t]{2}{*}{$\mathrm{d} \AA$} & \multirow[t]{2}{*}{$1 / 10$} & $\mathrm{~d} \AA$ & l/lo & \multicolumn{6}{|c|}{ hkl } \\
\hline & & 9,09 & 50 & 0 & 1 & & & & \\
\hline 6,752 & 30 & 6,73 & 50 & 0 & 1 & 0 & & & \\
\hline \multirow[t]{3}{*}{6,235} & 55 & 6,17 & 70 & 0 & 1 & 1 & -111 & & \\
\hline & & 6 & 40 & 1 & 1 & 0 & & & \\
\hline & & 5,77 & 20 & 1 & 0 & 1 & & & \\
\hline \multirow[t]{2}{*}{4,873} & 40 & 4,8 & 60 & 0 & 1 & 1 & -110 & & \\
\hline & & 4,65 & 20 & 1 & 2 & 1 & & & \\
\hline \multirow[t]{2}{*}{3,707} & 100 & 3,68 & 100 & 2 & 1 & 1 & -111 & -111 & \\
\hline & & 3,51 & 10 & 1 & 0 & 2 & -122 & & \\
\hline 3,452 & 55 & 3,44 & 70 & 2 & 0 & 1 & -221 & & \\
\hline 3,326 & 55 & 3,28 & 70 & 2 & 1 & 0 & -120 & -021 & -131 \\
\hline 3,13 & 50 & 3,1 & 40 & 0 & 2 & 2 & & & \\
\hline 2,93 & 80 & 3,05 & 20 & 0 & 3 & 1 & & & \\
\hline \multirow[t]{3}{*}{2,796} & 70 & 3 & 20 & 0 & 3 & 0 & -130 & & \\
\hline & & 2,91 & 80 & 0 & 1 & 2 & -112 & & \\
\hline & & 2,89 & 10 & & & & & & \\
\hline 2,695 & 40 & & & & & & & & \\
\hline 2,621 & 30 & & & & & & & & \\
\hline 2,535 & 60 & 2,52 & 40 & & & & & & \\
\hline \multirow[t]{3}{*}{2,487} & 40 & 2,47 & 20 & & & & & & \\
\hline & & 2,35 & 40 & & & & & & \\
\hline & & $2,32-2,29$ & 40 & & & & & & \\
\hline \multirow[t]{5}{*}{2,248} & 20 & 2,23 & 40 & & & & & & \\
\hline & & 2,19 & 20 & & & & & & \\
\hline & & 2,12 & 40 & & & & & & \\
\hline & & 2,07 & 50 & & & & & & \\
\hline & & 2,02 & 60 & & & & & & \\
\hline 1,937 & 10 & 1,903 & 40 & & & & & & \\
\hline 1,833 & 20 & 1,845 & 40 & & & & & & \\
\hline
\end{tabular}

Tabela 37 Dados de difração de raios-X (radiação $\mathrm{Cu} K \alpha$ ) da wavellita de Juquiá comparada com a turquesa da Macedônia, Grécia (Sclavounos et al, 1992 apud Foord \& Taggart, 1998, ficha JCPDS 6-214).

FTR (compostos fosfáticos com ETR não identificados mineralogicamente)

Fosfatos de elementos Terras Raras somente puderam ser identificados nos materiais de Juquiá em análises qualitativas ao MEV-EDS, formando agregados criptocristalinos misturados ao plasma de alteração de micas, constituído principalmente por gorceixitas criptocristalinas e goethita (Foto 48).

Walter (1991) não encontrou estes fosfatos enquanto Alcover Neto (1991) observou ao MEV a presença muito rara sobre o carbonato alterado de fosfato supérgeno de ETR de forma globular. É bom lembrar que estes minerais são facilmente reconhecidos ao MEV quando empregado o modo SEl, que destaca as fases ricas em elementos pesados no material alterado, principalmente quando misturados a produtos ferruginosos. 


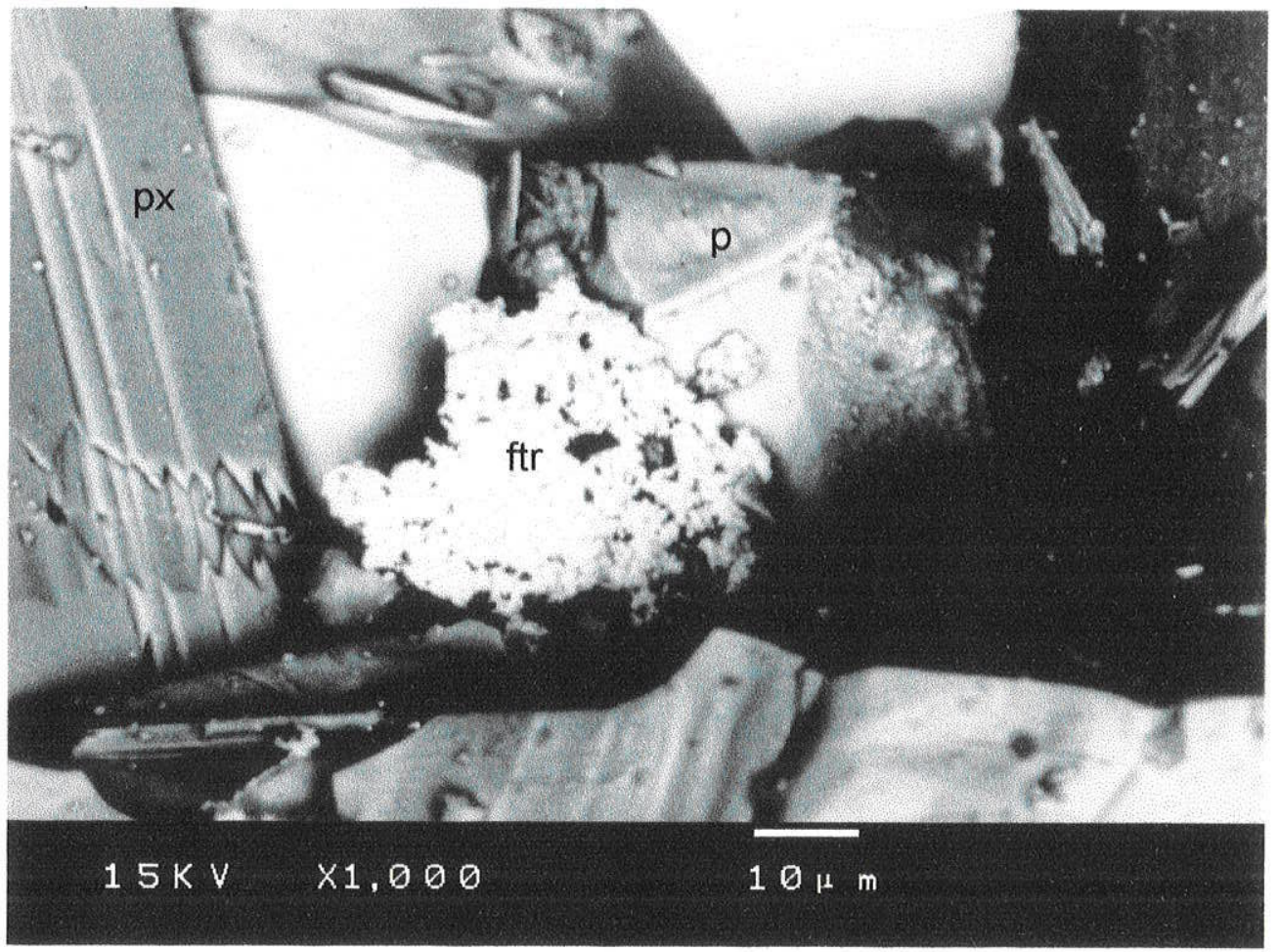

Foto 44 Agregados criptocristalinos de fosfatos de TR (ftr) entre cristais de apatita primária (p) e de piroxênio (px). Anitápolis. Amostra AN7.4. MEV (SEI).

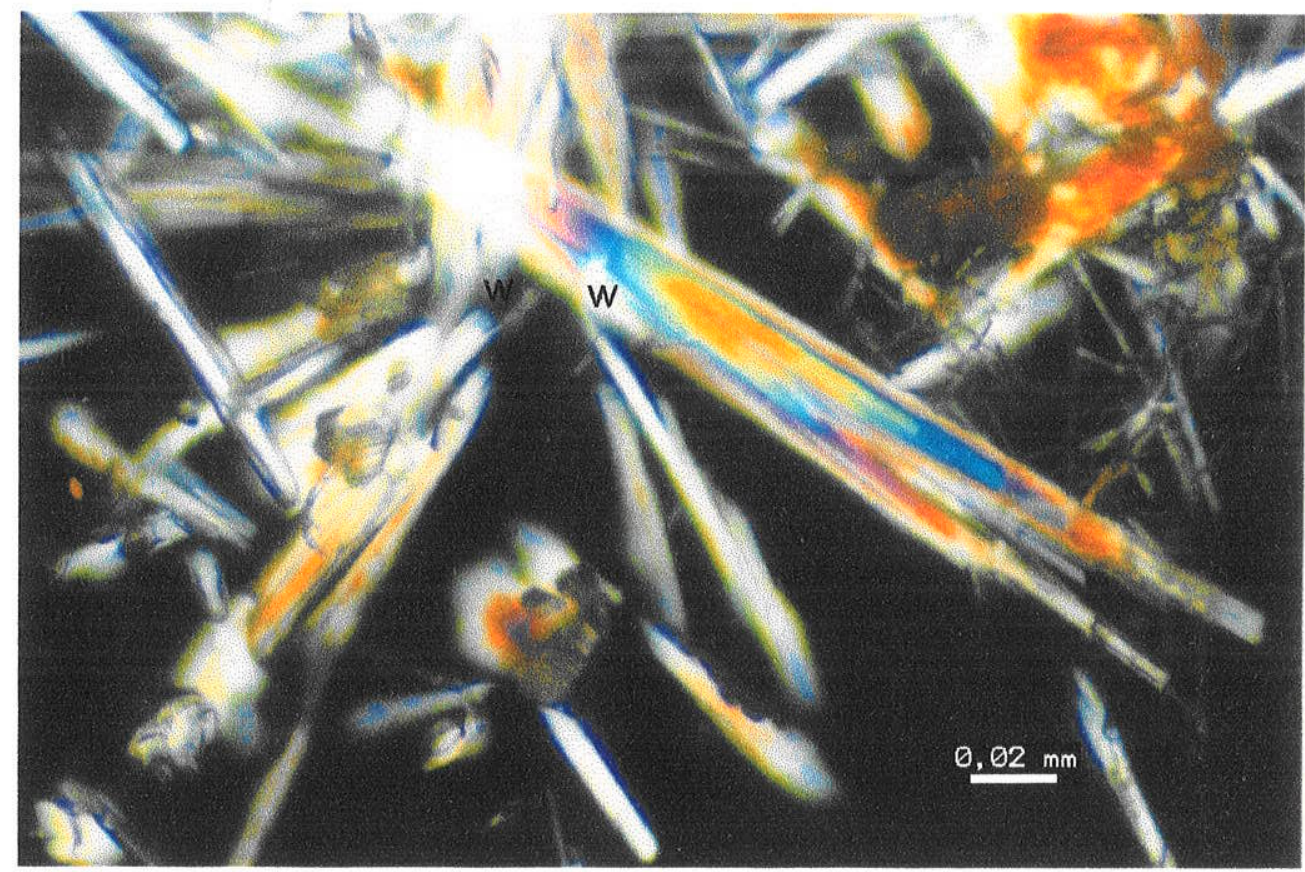

Foto 45 Wavellita acicular (w) com diferentes dimensões. Juquiá. Amostra T2Agb. MO (LP), 


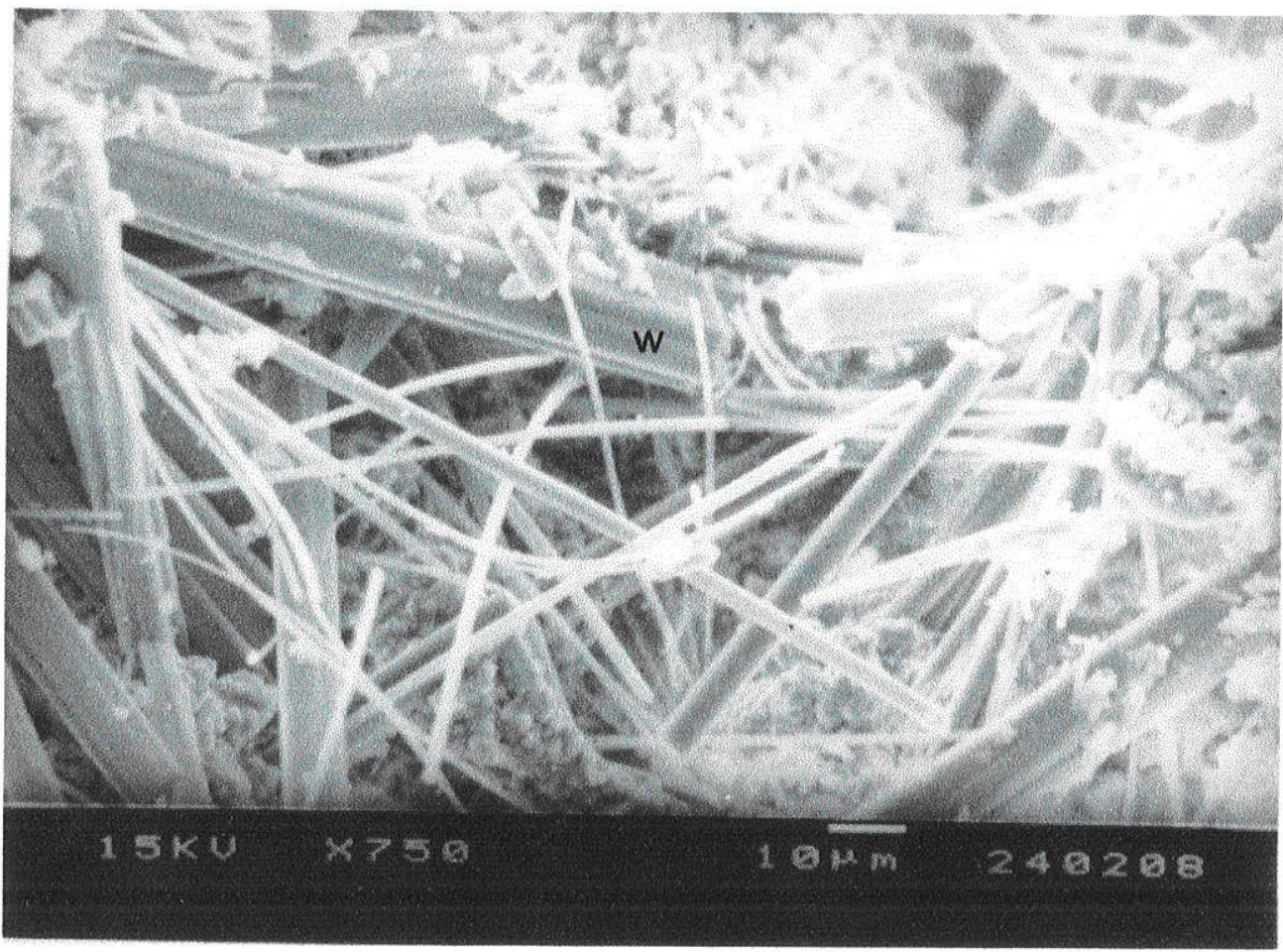

Foto 46 Wavellita acicular (w). Juquiá. Amostra JUT'15. MEV (BEI).

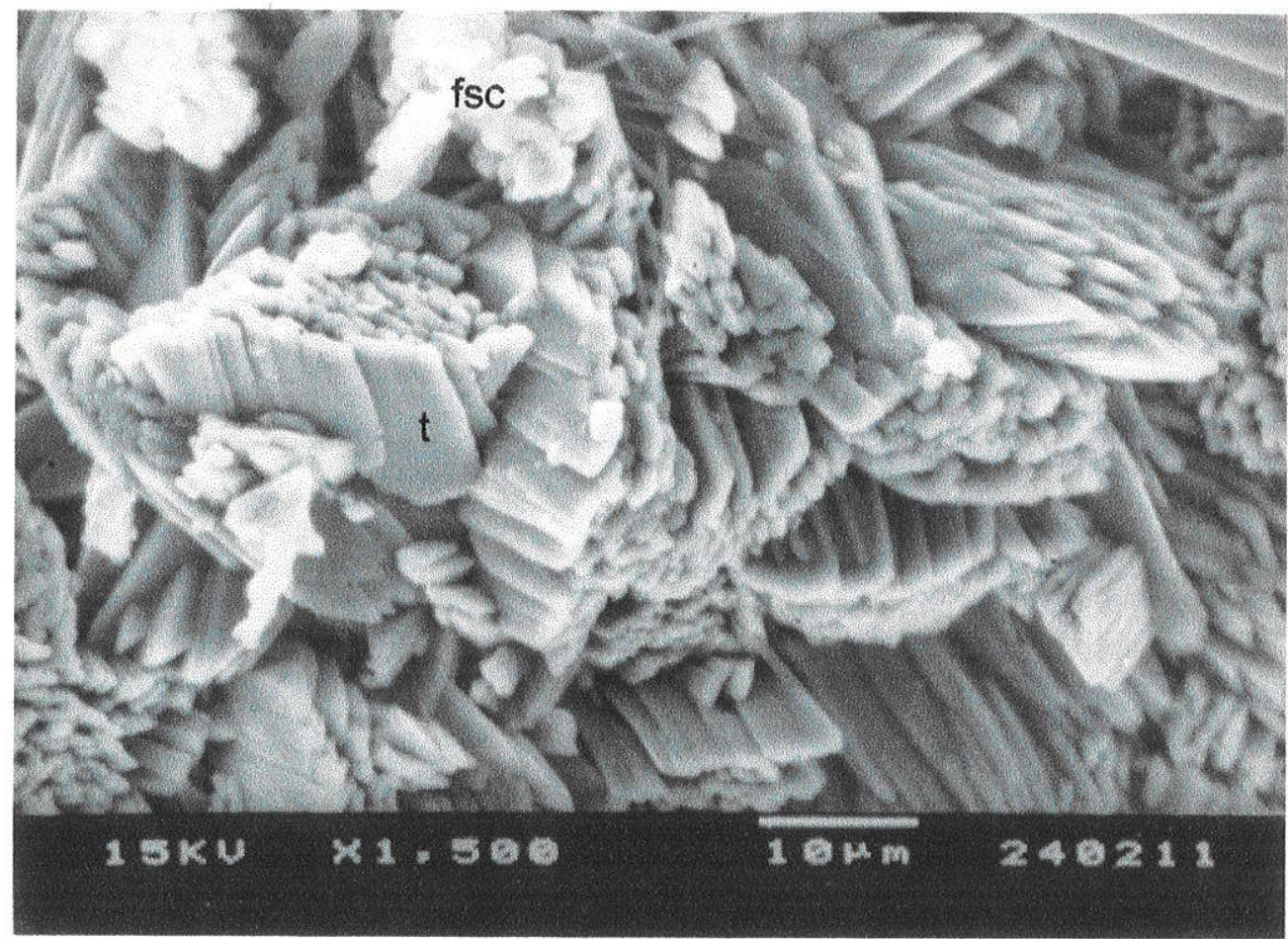

Foto 47 Cristais de turquesa $(\mathrm{t})$ associados à agregados microcristalinos de fosfato da série da crandallita (fsc). Juquiá. JUT'15. MEV (BEI). 


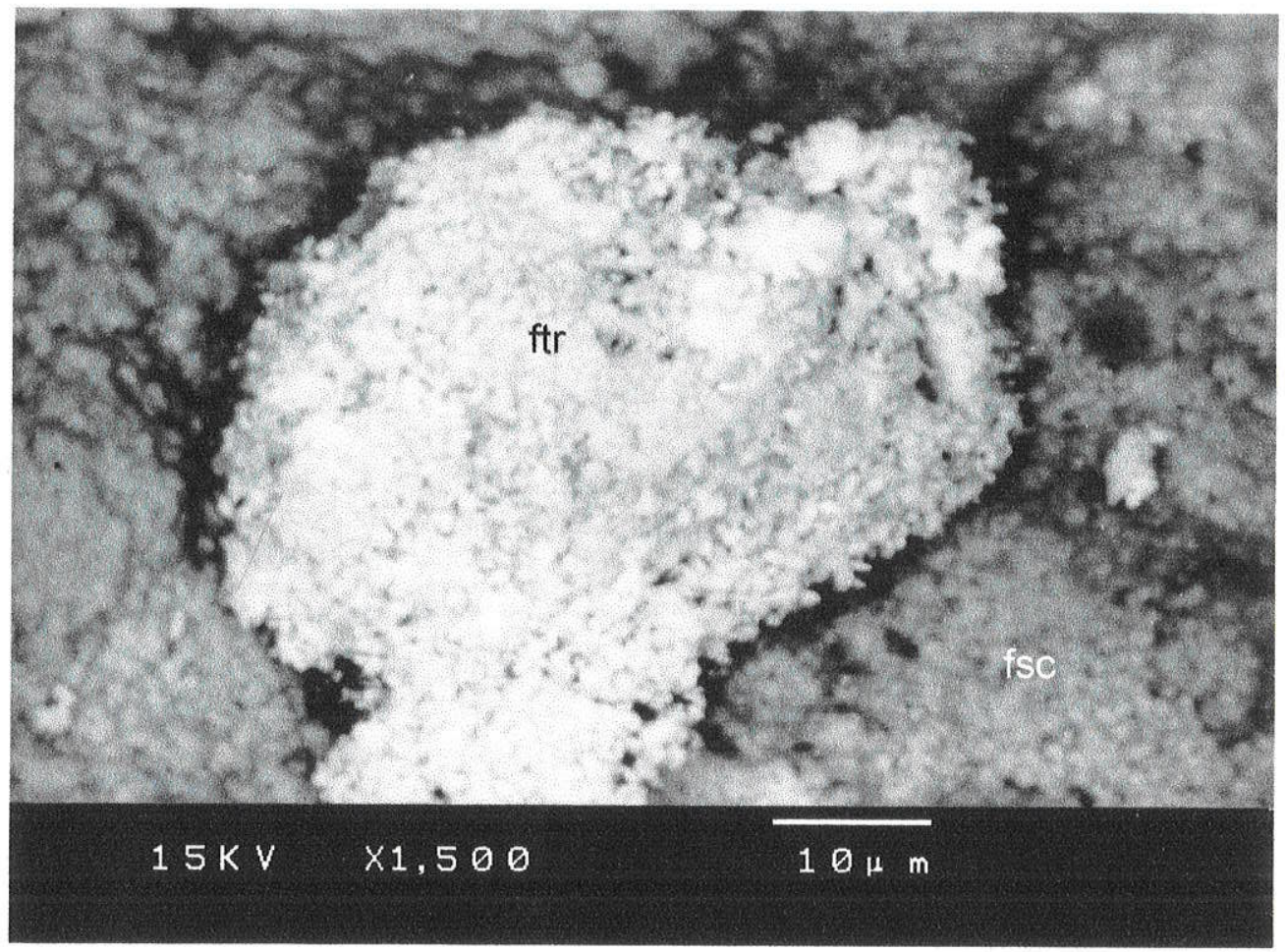

Foto 48 Agregados de cristais muito finos de fosfato de ETR associados à agregados microcristalinos de fosfato da série da crandallita (fsc) do pseudomorfo micáceo. Juquiá. Amostra JU21d. MEV (SEI).

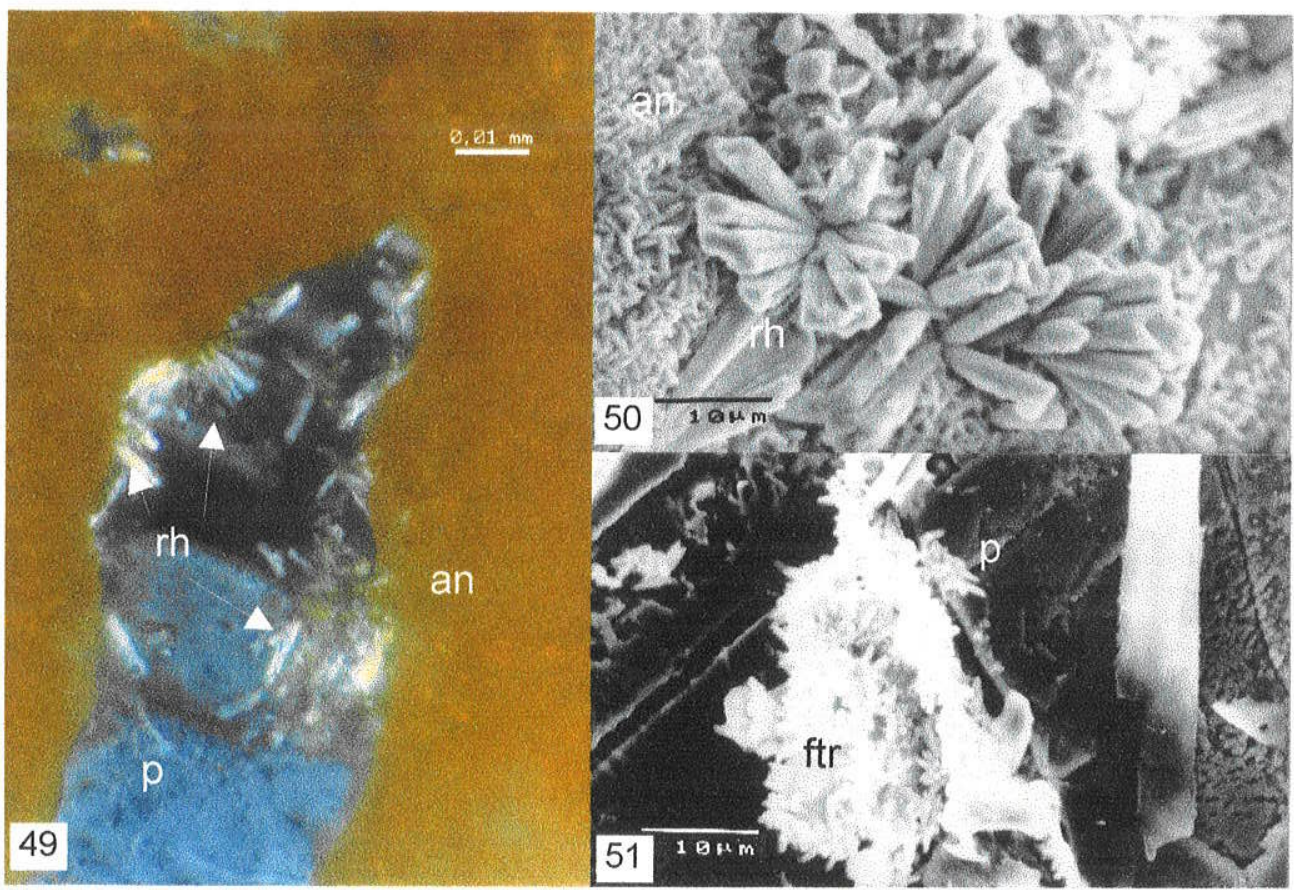

Foto 49 Apatita primária (p) inclusa em anatásio (an) e rhabdofânio (rh) no contato entre os dois minerais. Tapira. Amostra TA6.1. MO (LP).

Foto 50 Rhabdofânio (rh) crescido sobre anatásio (an). Tapira. Amostra TA2.1. MEV (BEI).

Foto 51 Fosfato de ETR (ftr) em fissura da apatita primária alterada (p). Tapira. Amostra TA6.1. MEV (SEI). 


\subsubsection{Tapira}

Em Tapira, os fosfatos com elementos terras raras são mais abundantes que nas outras áreas estudadas. São representados pelo rhabdofânio e pela monazita, sendo o primeiro identificado por DRX e passivel de ser analisado à ME por suas dimensões e grau de individualização. $O$ refinamento da estrutura do rhabdofânio feito a partir de dados da DRX utilizando o método de Rietveld revelou a presença de monazita.

\section{Rhabdofânio}

Os rhabdofânios foram encontrados em amostras ricas em anatásio representadas por piroxenitos e glimeritos alterados. Crescem nas paredes das cavidades do anatásio, formam leques ou rosetas fibrorradiais muito finas (Foto $49 \mathrm{e}$ Foto 50). Podem também ser observados em descontinuidades das apatitas. Estes minerais já foram estudados por Soubiès et al. (1990 e 1991), com mesma morfologia e modo de ocorrência dos aqui apresentados.

Como o rhabdofânio ocorre sempre associado ao anatásio é praticamente impossível obter amostras puras, utilizou-se o método de Rietveld para a separação das fases e refinamento dos parâmetros de cela. $O$ método possibilitou a identificação das reflexões referentes ao rhabdofânio que, muitas vezes, são sobrepostas às reflexões do anatásio e de outras fases como a apatita e a monazita. O método de Rietveld foi aplicado utilizando-se do programa XND (J.F. Berar, 1990) que permite um refinamento de amostras multifásicas (assim como o DBWS o faz). Os cálculos dos parâmetros de cela unitária a e c obtidos estão na Tabela $39 \mathrm{e}$ apresentaram coeficientes estatísticos razoáveis para um refinamento a partir de dados de DRX (TA3.1: Rwp = 7\% e Rp = 5\%; TA-SC-4: Rwp = 8\% e Rp = 6\%).

Para o modelo inicial do rhabdofânio foram utilizados os parâmetros estruturais dados por Mooney (1950), $a_{0}=7,005$ e $c_{0}=6,439 \AA$ do grupo espacial $P 6_{2} 22$. Outros modelos iniciais também foram considerados no refinamento: apatita (Hughes et al., 1989), crandallita (Blount, 1974), Monazita (Ni et al., 1995), Anatásio (Horn et al., 1972) .

O rhabdofânio de Tapira apresenta dimensões dos parâmetros a e $c$ da cela unitária próximos aos dos encontrados na literatura. Observa-se que as dimensões de a calculadas $(6,95$ a $6,957 \AA)$ se aproximam mais do valor obtido por Atkin et al. (1983), porém o valor de $c$ encontrado foi maior $(6,403$ a $6,414 \AA)$ do que o obtido pelo referido autor, se aproximando mais do valor do rhabdofânio de Walenta (1979). 
As análises à microssonda de rhabdofânios em materiais ricos em anatásio e apatitas (primárias e supérgenas), situados na base do perfil de alteração do minério apatítico, estão na Tabela 38.

As análises à ME aqui apresentadas foram realizadas em fase anterior ao desenvolvimento desta tese. $\mathrm{Na}$ ocasião iniciou-se analisando alguns elementos ETR () La, Ce e Nd, e depois outros foram adicionados, $\mathrm{Pr}, \mathrm{Sm}$ e Gd ao programa de análise à ME. Os totais encontrados nas análises (exceto o ponto 50) são sempre menores que os encontrados por Dorfman et al. (1988) (trabalho de referêcia da ficha JCPDS 46-1303, escrito em russo e ainda não traduzido para maiores comparações). Observa-se que os totais aumentaram quando incluiu-se outros ETR no programa de análise.

Os teores de Ca nos rhabdofânios de Tapira são geralmente muito altos, de toda a literatura consultada apenas Dorfman et al., 1988 apresentou rhabdofânios com teores próximos aos aqui encontrados. Soubiès et al. (1990) já haviam alentado para $\circ$ fato propondo uma nomenclatura para este minerais denominando-os rhabdofânio calcifero ou cálcio-rhabdofânio.

Todas as análises apresentaram teores de $\mathrm{TiO}_{2}(0,78$ a 2,66\%), que não foi dosado por Dorfman et al. (1988). Por outro lado, estes autores analisaram $\mathrm{SO}_{3}$ $(2,2 \%), \mathrm{F}(0,70 \%), \mathrm{Na} 2 \mathrm{O}(0,30 \%)$ e $\mathrm{SiO}_{2}(0,07 \%)$ que não foram dosados no programa de análise utilizado neste trabalho. Mesmo sabendo que o titânio pode estar ligado ao anatásio este foi considerado nas fórmulas estruturais (o que não foi admitido em trabalhos anteriores). A maioria das análises apresentaram teores de $\mathrm{UO}_{2}$ e $\mathrm{ThO}_{2}$ abaixo do limite de deteç̧ão.

Monazita e FTR (compostos fosfáticos com ETR não identificados mineralogicamente)

A monazita somente foi identificada ao MEV (Foto 51) e à DRX em concentrado de rhabdofânio e anatásio (prepararado manualmente retirando magnetita e apatita da amostra natural) após refinamento pelo método de Rietveld, conforme já mencionado.

A monazita ocorre em menor quantidade do que o rhabdofânio nas fissuras do anatásio. Soubiès et al. $(1990,1991)$ sugerm a formação desta monazita a partir da desidratação do rhabdofânio. 


\begin{tabular}{|c|c|c|c|c|c|c|c|c|c|c|c|}
\hline \multirow{2}{*}{$\begin{array}{l}\text { Amostra } \\
\text { No. }\end{array}$} & \multicolumn{7}{|c|}{ TAP-CSC-4 } & \multicolumn{3}{|c|}{ TAP-CSC-4D } & \\
\hline & 44 & 45 & 46 & 47 & 48 & 49 & 50 & 51 & 52 & 53 & $D$ \\
\hline & 8,08 & 7,81 & 8,28 & 8,65 & 10,11 & 9,61 & 11,26 & 10,82 & 9,22 & 10,72 & 8,50 \\
\hline $\mathrm{TiO}_{2}$ & 1,96 & 2,57 & 1,76 & 0,78 & 1,88 & 1,92 & 2,66 & 1,30 & 1,07 & 0,97 & 0,00 \\
\hline $\mathrm{Fe}_{2} \mathrm{O}_{3}$ & 0,00 & 0,07 & 0,87 & 0,00 & 0,00 & 0,01 & 0,00 & 0,00 & 0,01 & 0,04 & 0,00 \\
\hline $\begin{array}{l}\text { Sro } \\
\mathrm{BaO}\end{array}$ & $\begin{array}{l}0,34 \\
0,23\end{array}$ & $\begin{array}{l}0,26 \\
0,38\end{array}$ & $\begin{array}{l}0,35 \\
0,67\end{array}$ & $\begin{array}{l}0,33 \\
0,46\end{array}$ & $\begin{array}{l}0,19 \\
0,63\end{array}$ & $\begin{array}{l}0,57 \\
0,61\end{array}$ & $\begin{array}{l}0,06 \\
0,32\end{array}$ & $\begin{array}{l}0,21 \\
0,00\end{array}$ & $\begin{array}{l}0,08 \\
0,00\end{array}$ & $\begin{array}{l}0,21 \\
0,00\end{array}$ & $\begin{array}{l}2,20 \\
0,00\end{array}$ \\
\hline $\mathrm{La}_{2} \mathrm{O}_{3}$ & 18,77 & 18,43 & 15,80 & 11,87 & 13,54 & 12,57 & 8,65 & 9,75 & 9,40 & 9,47 & 10,30 \\
\hline $\mathrm{Ce}_{2} \mathrm{O}_{3}$ & 12,81 & 14,62 & 16,69 & 17,28 & 19,53 & 20,05 & 24,62 & 21,49 & 21,79 & 20,72 & 25,40 \\
\hline $\mathrm{Pr}_{2} \mathrm{O}_{3}$ & - & - & - & - & - & - & - & 1,02 & 1,50 & 1,61 & 1,80 \\
\hline $\mathrm{Nd}_{2} \mathrm{O}_{3}$ & 4,93 & 6,57 & 7,05 & 6,85 & 8,40 & 8,17 & 10,55 & 7,62 & 7,22 & 8,27 & 6,50 \\
\hline $\mathrm{Y}_{2} \mathrm{O}_{3}$ & 0,84 & 0,48 & 0,57 & 0,62 & 0,55 & 0,95 & 0,52 & 0,85 & 0,74 & 0,94 & 0,00 \\
\hline $\mathrm{Sm}_{2} \mathrm{O}_{3}$ & - & - & - & - & - & - & - & 0,87 & 1,08 & 1,25 & 0,80 \\
\hline $\mathrm{Gd}_{2} \mathrm{O}_{3}$ & - & - & - & - & - & - & - & 0,86 & 0,76 & 0,54 & 0,50 \\
\hline $\mathrm{Yb}_{2} \mathrm{O}_{3}$ & . & - & - & - & - & - & - & 0,00 & 0,02 & 0,05 & 0,00 \\
\hline $\mathrm{ThO}_{2}$ & 0,35 & - & - & - & - & 0,04 & - & 0,05 & 0,00 & 0,03 & 0,00 \\
\hline $\mathrm{P}_{2} \mathrm{O}_{5}$ & 29,77 & 30,20 & 29,29 & 28,22 & 31,64 & 29,96 & 32,79 & 31,63 & 31,11 & 31,30 & 28,40 \\
\hline Soma & 78,08 & 81,39 & 81,33 & 75,06 & 86,47 & 84,46 & 91,43 & 86,46 & 83,99 & 86,09 & 88,18 \\
\hline $\mathrm{TR}_{2} \mathrm{O}_{3}$ & 37,35 & 40,10 & 40,11 & 36,62 & 42,02 & 41,74 & 44,34 & 42,45 & 42,51 & 42,83 & 45,30 \\
\hline $\mathrm{Ca}$ & 0,343 & 0,327 & 0,358 & 0,388 & 0,404 & 0,406 & 0,435 & 0,433 & 0,375 & 0,433 & 0,379 \\
\hline $\mathrm{Ti}$ & 0,058 & 0,076 & 0,053 & 0,025 & 0,053 & 0,057 & 0,072 & 0,036 & 0,030 & 0,027 & 0,000 \\
\hline $\mathrm{Fe}$ & 0,000 & 0,002 & 0,026 & 0,000 & 0,000 & 0,000 & 0,000 & 0,000 & 0,000 & 0,001 & 0,000 \\
\hline $\mathrm{Sr}$ & 0,008 & 0,006 & 0,008 & 0,008 & 0,004 & 0,013 & 0,001 & 0,005 & 0,002 & 0,005 & 0,053 \\
\hline $\mathrm{Ba}$ & 0,004 & 0,006 & 0,011 & 0,008 & 0,009 & 0,009 & 0,005 & 0,000 & 0,000 & 0,00 & 0,000 \\
\hline La & 0,275 & 0,266 & 0,235 & 0,183 & 0,186 & 0,183 & 0,115 & 0,134 & 0,132 & 0,132 & 0,158 \\
\hline $\mathrm{Ce}$ & 0,186 & 0,209 & 0,246 & 0,265 & 0,267 & 0,289 & 0,325 & 0,294 & 0,303 & 0,286 & 0,387 \\
\hline $\mathrm{Pr}$ & & & & & & & & 0,014 & 0,021 & 0,022 & 0,027 \\
\hline $\mathrm{Nd}$ & 0,070 & 0,092 & 0,102 & 0,102 & 0,112 & 0,115 & 0,136 & 0,102 & 0,098 & 0,111 & 0,097 \\
\hline$Y^{Y}$ & 0,018 & 0,010 & 0,012 & 0,014 & 0,011 & 0,020 & 0,010 & 0,017 & 0,015 & 0,019 & 0,000 \\
\hline $\mathrm{Sm}$ & - & - & - & - & & 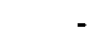 & & & 0,014 & 0,016 & 0,011 \\
\hline Gd & - & - & - & - & - & 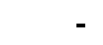 & - & 0,011 & 0,010 & 0,007 & 0,007 \\
\hline $\mathrm{Yb}$ & - & - & - & - & - & & - & 0,000 & 0,000 & 0,001 & 0,000 \\
\hline $\mathrm{Th}$ & 0,003 & - & & - & - & 0,00 & - & & 0,000 & 0,0 & 0,000 \\
\hline$P$ & 1.000 & 1.000 & 1.000 & 1.000 & 1.000 & 1.000 & 1.000 & 1.000 & 1.000 & 1.000 & 1.000 \\
\hline
\end{tabular}

Tabela 38 Variação da composição química (em \% em peso dos óxidos) de rhabdofânios de Tapira analisados a microssonda eletrônica e suas fórmulas estruturais, calculadas na base $P=1$ (base de cálculo adotada por Soubiès et. al.,
1991).

** outros elementos dosados (em \%) analisados por Dorfman et al., 1988 (D): F: 0,$70 ; \mathrm{NaO}: 0,30 ; \mathrm{SiO}_{2}: 0,07 ; \mathrm{Dy}_{2} \mathrm{O}_{3}: 0,70$. De 44 a 53: Análises cedidas por François Soubiès

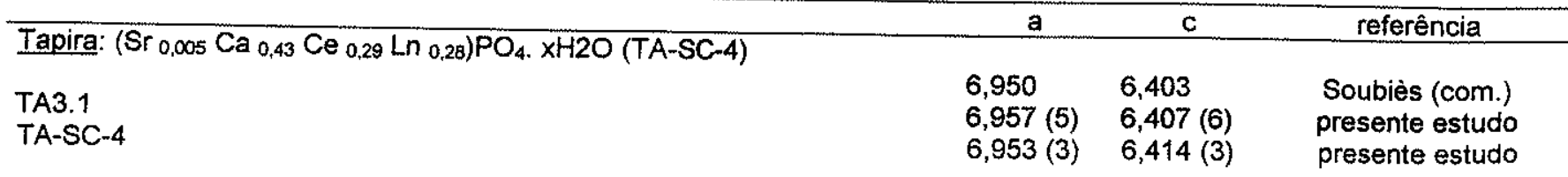

Referências

$\left(\mathrm{Na}_{0,02} \mathrm{Sr}_{0,05} \mathrm{Ca}_{0,43} \mathrm{Ce} 0,34 \mathrm{Ln} 0.29\right)\left(\mathrm{P}_{0.94} \mathrm{~S}_{0,06}\right)\left(\mathrm{O}_{3.93} \mathrm{~F}_{0,07}\right) .1 .55 \mathrm{H}_{2} \mathrm{O}^{*} \quad 7,03 \quad 6,44 \quad$ Dorfman et al., 1988

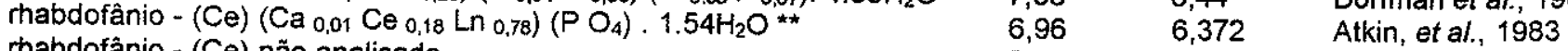
rhabdofânio - $(\mathrm{Ce})$ não analisado

$7,01 \quad 6,40 \quad$ Walenta, 1979

Ln: Iantanídios ( $\mathrm{La}, \mathrm{Ce}, \mathrm{Pr}, \mathrm{Nd}, \mathrm{Sm}, \mathrm{Ga}, \mathrm{Dy}, \mathrm{Ho}$; * estrutura refinada por $\mathrm{DRX}$ **calculo da fórmula estrutural a partir dos dados de
microssonda efetuados a base $\mathrm{P}=1$.

Tabela 39 Parâmetros cristalográficos a e c do rhabdofânio de Tapira comparado aos de outros rhabdofánios da literatura. 


\section{Considerações finais}

Variação morfológica, química dos fosfatos das áreas estudadas

a) Apatitas

O estudo das apatitas das três áreas permite esboçar um quadro de variação morfológica e química entre as gerações de apatitas.

Basicamente existe uma constância nas morfologias das apatitas primárias e supérgenas. A apatita primária apresenta cristais de dimensões submilimétricas a milimétricas e formas anédricas imbricados em texrtura pavê, tais morfologias já foram descritas por autores como Walter (1991) e Alcover Neto \& Toledo (1993), para Juquiá, Pereira (1991), para Anitápolis e Soubiès et al. (1990), para Tapira. Algumas delas apresentam bordas de maior birrefringência de espessura variável aqui atribuída a uma alteração anterior ao intemperismo (hidrotermal ou tardimagmática). Em alguns casos (Tapira e Juquiá) esta alteração não é distinguível ao microscópio óptico e só é indicada após as análises químicas (riqueza maior em substituintes do cálcio como $\mathrm{Sr}$, $\mathrm{Na}$ e ETR). Algumas gerações de apatitas encontradas em Juquiá apresentam cristais menores, ovóides e com linhas concêntricas de crescimento, morfologia diferente da encontrada para a apatita primária magmática; estas gerações foram agrupadas nos tipos formados por alteração hidrotermal, por sua ocorrência nas rochas sãs ou pouco alteradas, mostrando serem frágeis perante o intemperismo, e por apresentarem composições químicas mais próximas às da borda de maior birrefringência, provavelmente formadas em meio não tão aberto e lixiviante como os perfis de intemperismo estudados.

Apatitas supérgenas podem em geral apresentar diferentes morfologias como fibrosa (todas as áreas estudas), prismática (Juquiá e Tapira) e microgranular (Juquiá), esta última a mais difícil de ser identificada por estar misturada a produtos ferruginosos. Os tipos morfológicos assim classificados não deixam dúvidas de sua origem ligada ao intemperismo, devido ao seu modo de ocorrência nos perfis.

O estudo da composição química mostra que as apatitas primárias têm alguma substituição no sítio do cálcio, principalmente por $\mathrm{Sr}$ e $\mathrm{Na}$, em proporções molares não ultrapassando 0,02; há pouca substituição do $\mathrm{PO}_{4}$ tanto por $\mathrm{SiO}_{4}$ como por $\mathrm{CO}_{3}$ principalmente em Anitápolis e Juquiá, onde estas apatitas são em geral hidroxifluorapatitas, concordando com trabalhos já efetuados (Girard et al., 1995 e Pereira, 1991, no caso de Anitápolis e Lenharo, 1994, e Walter, 1991, no caso de 
Juquiá). Em Tapira, observou-se uma maior presença de carbonato tomando composições mais próximas de uma flúor-hidroxicarbonatoapatita em acordo com Soubiès et al. (1991) e Cremillion et al., (1975) e que diferem da encontrada por Lenharo (1994), que chegou a composições similares às de Juquiá.

As apatitas primárias, quando atingidas pelo intemperismo, apresentaram alterações composicionais: perda de $\mathrm{Na}$, $\mathrm{Sr}$ e ETR e ganho de $\mathrm{CO}_{3}$ e F. Estas alterações parecem cer mais importantes em Juquiá e Tapira. Em Anitápolis embora os grãos apresentem feições de alteração a variação de composição não é muito evidente.

Os tipos cronologicamente posteriores (ou seja, de alteração anterior ao intemperismo) e os supérgenos são diferentes, indicando a influência específica das condições de cada ambiente, em cada época.

A alteração anterior ao intemperismo é uma alteração em meio mais fechado e com soluções menos diluídas; resultando na modificação de apatitas primárias ou na formação de novas apatitas com composiçōes ricas em substituintes principalmente no sítio do cálcio. Assim, estas apatitas contêm certas quantidades de $\mathrm{Na}$, Sr e ETR, maiores que as apatitas primárias e que as apatitas supérgenas.

A alteração supérgena, além de empobrecer a apatita primária em seus substituintes catiônicos, como dito acima, forma apatitas supérgenas mais puras neste sítio, e com maior quantidade de $\mathrm{CO}_{3}{ }^{2-}$ substituindo o $\mathrm{PO}_{4}{ }^{3-}$. Também contêm mais $\mathrm{F}$, por vezes em excesso estequiométrico, o que está relacionado à possível compensação de cargas pela substituição do ânion fosfato já discutida na revisão bibliográfica. Uma exceção, em Juquiá, nos é dada pela apatita supérgena de melhor cristalização encontrada nas áreas de estudo, a do tipo prismático hialino, que não apresenta teores importantes de carbonato em substituição ao fosfato, dado confirmado tanto pela ME (totais próximos a $100 \%$ ), como por por MR e por IV. Ainda não foi encontrada explicação para esta diferença em relação a todas as outras apatitas supérgenas, que está evidentemente ligada a peculiaridades de sua cristalização.

Quando é feita a comparação entre os parâmetros cristalográficos e a composição das apatitas observa-se que as apatitas mais ricas em carbonato apresentam valores do parâmetro a maiores do que aquelas pobres em carbonato. O parâmetro $c$ varia pouco e parece não estar relacionado com o grau de carbonatação. Os trabalhos consultados (LeGeros, 1965, apud Nelson \& Williamson, 
1982, McClellan \& Lehr, 1969 e Vignoles \& Bonel, 1978) mostram que entrada do carbonato no lugar do fosfato provoca a diminuição do eixo a, em acordo com o que foi observado aqui. A entrada do $\mathrm{OH}^{-}$nos canais da estrutura das apatitas parece causar a expansão do eixo a e não afetar a dimensão do eixo $c$, que pode ser observado nas apatitas primárias de Tapira mais hidroxiladas que as apatitas de Juquiá e apresentam valores do parâmetro de cela mais elevados. Estas observações estão de acordo com o observado por Liu \& Comodi (1993). Segundo LeGeros \& Legeros (1984) a entrada de cátions como o $\mathrm{Sr}$ pode causar um mesmo efeito que o observado com a entrada de $\mathrm{OH}^{-}$. Quando entram na estrutura da apatita simultaneamente cátions e ânions é mais difícil saber qual foi a causa das mudanças observadas, assim só é possivel a comparação de tipos de composição menos complexa.

- estudo detalhado das características morfológicas, químicas e cristaloquímicas de minerais de minério, de forma acadêmica como foi feito nesta pesquisa, pode contribuir aos estudos de caracterização tecnológica, feitos normalmente de forma mais qualitativa, mas utilizando outro método, aplicado a amostras compostas ou de frações separadas e deformadas .

O avanço no conhecimento dos minerais de minério pode fornecer subsídios para a otimização dos processos industriais, bem como indicar a qualidade esperada dos produtos (Sant'Agostino \& Kahn, 1997, Barros, 1997 e Kahn, 1988).

No caso específico dos minérios apatíticos, a existência de diferentes gerações de apatitas, com composições e morfologias diferenciadas, e, principalmente os resultados da alteração intempérica sobre as apatitas primárias residuais presentes no manto de alteração são feições responsáveis por perturbações no seu comportamento frente aos processos industriais de concentração. Isto é bem conhecido dos profissionais de tratamento de minérios e foi mostrado de forma bem evidente no estudo de catodoluminescência de apatitas presentes no rejeito e no concentrado de Tapira, conforme o trabalho de formatura de Santos (1998) realizado de forma integrada com esta pesquisa de doutoramento. Como já foi mencionado, as apatitas presentes no rejeito, responsáveis por importantes perdas de $\mathrm{P}_{2} \mathrm{O}_{5}$, eram apatitas que apresentaram diversas feições de alteração e associações de materiais diferenciados das apatitas presentes no concentrado, livres de alteração, com cor de catodoluminescência azul-violeta. 


\section{b) Fosfatos aluminosos crandallíticos}

Os fosfatos aluminosos da série da crandalita são os fosfatos supérgenos mais abundantes nas áreas estudadas. Formam-se desde o início da desestabilização das apatitas, desde que haja disponibilidade em alumínio, o que não ocorre sempre. O estudo mineralógico e geoquímico dos fosfatos nos perfis estudados em cada área mostrou algumas similaridades e diferenças, que estão relacionadas às condições ambientais em cada área.

O melhor exemplo da atuação dos controles na distribuição dos tipos de fosfatos supérgenos formados ocorre em Juquiá, onde há uma clara relação entre a composição química dos materiais de origem, o comportamento dos elementos envolvidos e o tipo de fosfato encontrado nos produtos de alteração intempérica. Nos setores do manto de alteração onde dominam rochas carbonatíticas, os fosfatos supérgenos formados são apatíticos; onde ocorrem materiais com alumínio, por exemplo nas inclusões micáceas ou nos xenólitos silicáticos dentro do carbonatito, são encontrados fosfatos aluminosos. Assim, a presença original do alumínio determina as zonas onde o fosfato supérgeno formado será aluminoso, no caso das áreas em questão, do tipo crandallítico; aí, a preferência desta estrutura mineral pelo bário permite que parte do cálcio seja lixiviada e que o bário presente nas soluções percolantes (proveniente da alteração de barita comumente presente nestes complexos) seja fixado. Já a ausência do alumínio resulta na retenção do cálcio proveniente da alteração da apatita, com a formação de fosfato supérgeno do tipo apatítico. A existência de várias fases de fosfatos apatíticos e não apatíticos (aluminosos crandallíticos, principalmente, mas também não crandallíticos) mostra a reciclagem tanto do fósforo como do alumínio nos perfis.

Nas outras áreas, as diferenças na fosfatogênese supérgena estão ligadas às diferenças apresentadas em relação aos mesmos fatores de controle da alteração de Juquiá. Em Anitápolis, os fosfatos aluminosos crandallíticos ocorrem mais raramente sendo apenas sugerida a sua presença no piroxenito alterado. Em Tapira, são bem mais abundantes e relacionados a materiais de alteração intempérica, formando microgeodos em cavidades dos produtos argiloferruginosos associados ao anatásio (minério de Fosfato e de Titânio) e formam pseudomorfos de apatita (minério apatítico). 
A diversificação dos fosfatos dentro da série da crandallita é controlada não apenas pelas disponibilidades geoquímicas mas pelo comportamento dos elementos químicos envolvidos e sua adequação à estrutura cradallítica. Conforme apresentado na revisão bibliográfica sobre estes minerais, o Ba é o elemento mais adequado para estabilizar a estrutura da crandallita, entre os possiveis de ocuparem a posição $A$ na fórmula, pelo seu raio iônico mais elevado. Assim, em todas as áreas, muito embora $\mathrm{Ca}, \mathrm{Sr}$, e ETR sejam relativamente abundantes nos materiais em alteração, os fosfatos crandallíticos são predominantemente do tipo gorceixita, ou seja, com Ba como elemento principal no sítio A. Alguns casos fogem a esta regra como em ambientes mais confinados ou soluções empobrecidas em $\mathrm{Ba}$ e mais rica em outros cátions. No caso de Juquiá fosfatos associados a pseudomorfos de flogopita apresentaram riqueza em $\mathrm{Ca}$ assim como o tipo associado ao minério apatítico de Tapira. O Sr pode as vezes suplantar o Ba nos tipos associados ao anatásio. Todos os tipos de Tapira são mais ricos em ETR que os tipos de Juquiá, e esta riqueza deve estar relacionada com a presença de minerais primários portadores de ETR, favorecendo sua presença no perfil de intemperismo. A formação de fostatos crandallíticos com dominância de ETR, Sr e Ca no sítio A ao invés do Ba pode ser favorecida pelas dificuldades de circulação e homogeneização das soluções, o que ocorreu em Tapira mas não em Juquiá, onde a distribuição litológica e, conseqüentemente, das disponibilidades geoquímicas é muito mais simples.

Com a alteração da apatita e dos silicatos aluminosos elementos como $\mathrm{P}$, ○ Al e alcalis são liberados para as soluções podendo se combinar e formar inicialmente os fosfatos crandallíticos nas descontinuidades da alterita. Notou-se em Juquiá e Tapira que cristais cutânicos formados nos estágios finais de alteração são mais ricos em Ba que os encontrados em pseudomorfos de flogopita nos estágios iniciais da alteração quando ainda estão presentes as apatitas primárias. Os ETR inicialmente são também fixados no perfil pelos fosfatos de ETR (rhabdofânio e monazitas) e, mais tardiamente, pelos fosfatos da série da crandallita. Em Tapira observou-se que em materiais muito evoluídos em presença do anatásio (ou produto de sua alteração) formam-se variedades mais ricas em ETR (florencita/crandallita), apresentando teores maiores de ETR e de Ba que aquelas encontradas junto às apatitas que são mais ricas em $\mathrm{Ca}$. 
Os minerais da série da crandallita são relativamente abundantes nas formações superficiais, tanto formadas pelo intemperismo sobre rochas com alguma disponibilidade em fósforo, como em depósitos sedimentares, conforme mencionado anteriormente, na revisão bibliográfica. Formam materiais que, apesar de não terem aplicação prática no Brasil, foram considerados como fonte de fósforo para a fabricação de fertilizantes e constituem estruturas cristaloquímicas muito estáveis e abertas, podendo apresentar potencialidade para outras aplicações, o que justifica o seu estudo detalhado.

A presença de ferro foi observada em todos os fosfatos aluminosos supérgenos, como os fosfatos gorceixíticos, a turquesa e, em pequenas quantidades, na wavellita. Sua presença na estrutura destes fosfatos, descartando a hipótese de contaminação, ainda não está totalmente confirmada, mas existem indícios fortes de que, pelo menos nos fosfatos da série da crandallita, o ferro esteja substituindo o alumínio. Não foram, contudo, encontrados nos perfis estudados minerais de fosfato de ferro, tais como a estrengita e a variscita.

\section{c)Fosfatos aluminosos não crandallíticos}

Embora em materiais de alteração sobre depósitos fosfáticos de origem sedimentar a presença de várias espécies minerais aluminofosfáticas seja comum, como senegalita, augelita, millisita, ao contrário, nas áreas estudadas, a exemplo de outras áreas similares com carbonatitos, a situação é outra. A seqüência evolutiva dos fosfatos descrita anteriormente não atinge seus estágios mais evoluídos de maneira ampla. Os fatores que levaram este truncamento nesta seqüência ainda não puderam ser definidos.

Fosfatos essencialmente aluminosos foram encontrados somente em Juquiá, representados pela wavellita; turquesa também foi encontrada, de forma muito localizada. Ocorrem nos perfis desenvolvidos sobre rochas alcalino-silicáticas, onde há a presença de alumínio em maior quantidade. É importante ressaltar que não foi detectada a presença de gibbsita nem de qualquer outro oxihidróxido de alumínio, o que mostra o papel importante da presença do fósforo na determinação da fase supérgena formada pelo alumínio após sua liberação dos minerais primários que o continham. 
d) Fosfatos de ETR (monazita, rhabdofânio)

Os fosfatos de ETR ocorrem na forma de precipitados junto aos produtos de alteração de diferentes minerais. Foram encontrados em Anitápolis, nas fraturas da apatita primária de materiais pouco alterados e em Juquiá junto a pseudomorfose gorcexítica de micas. Sua mineralogia e composição não puderam ser definidas (grupo do rhabdofânio e da monazita).

Em Tapira o rhadofânio, identificado à DRX, ocorre em fissuras de anatásio. Outros FTR apenas identificados ao MEV e apresentando as mesmas morfologias do rhabdofânio foram encontrados em descontinuidades da apatita. O rhabdofanio presente no anatásio apresentou uma riqueza em Ca o que não é comum para estes minerais, composição semelhante foi observada por Dorfman et al. (1983). Esta pode ser uma nova variedade no grupo do rhabdofânio, em acordo com o que sugere Soubiès et al. $(1990,1991)$.

\section{A fosfatogênese supérgena e sua relação com os climas e os controles} do intemperismo

Os produtos de alteração intempérica sobre os maciços alcalino-carbonatíticos são influenciados por fatores ligados ao grau de individualização dos carbonatitos em relação às rochas alcalinossilicáticas dos maciços de carbonatítico (que determina a disponibilidade de alumínio para certos setores do manto de alteração ou para todo ele), à associação litológica da apatita primária (que determina o meio geoquímico onde se altera e onde o fósforo se disponibiliza para neoformações) e às condições climáticas e topográficas.

Em Juquiá, as apatitas estão associadas ao carbonatito (ao contrário das outras áreas estudadas), cuja ocorrência é contínua (cerca de $2 \mathrm{~km}^{2}$ na exposição atual do relevo), também ao contrário da situação das outras áreas, onde as apatitas estão associados às rochas alcalinas que são aluminossilicátias. Observa-se em Juquiá que o Al das rochas silicáticas não migra para os materiais de alteração dos carbonatitos, onde são formados apenas os fosfatos supérgenos apatíticos (sem Al), enquanto que o $\mathrm{P}$ do carbonatito pode migrar para os materiais de alteração das rochas alcalinossilicáticas, onde são formados os fosfatos secundários crandallíticos; esta observação está em acordo com as características de mobilidade em ambiente superficial tropical destes elementos.

Tapira e Anitápolis apresentam um domínio de rochas aluminossilicáticas cortadas por veios de carbonatito; o meio geoquímico apresenta uma composição 
mais heterogênea e o Al, pouco móvel nestes meios de tendência laterítica, está disponivel de forma mais homogênea por todo o perfị!

Assim, Jưuiá terịa condições favoráveis para a formação de apatitas supérgenas e Tapira e Anitápolị seriam áreas potencialmente sujeitas à formação de fosfatos aluminosos (principalmente crandallíticos); tanto Juquiá como Tapira apresentam uma abundância de fosfatos crandalliticos, que ocorrem com maior frequência nas rochas aluminossilicáticas, onde o aluminio é diponivel para se combinar com o P (proveniente da alteração da apatita)

Todas as áreas estão submetidas atualmente a um clima tropical úmido, sendo que a região onde se insere Tapira apresenta uma estação seca bem definida e a região de Anitápolis apresenta temperaturas médias anuais mais baixas em relação às outras áreas. A alternância de estações secas e chuvosas observada em Tapira pode favorecer a precipitação dos minerais supérgenos a partir de soluções ricas em cátions ( $\mathrm{Ba}, \mathrm{Ca}, \mathrm{Sr}, \mathrm{ETR}$ ), em acordo com o que foi observado.

Modelos paleoclimáticos existentes na literatura mostraram que o clima do Eoceno Médịo nas regiões estudadas não foi muito diferente do atual, tropical úmido (Juquiá e Anitápolis) ou tropical com estações contrastadas (Tapira). Durante o Quaternário ocorreram as glaciações nestas regiōes, marcadas pela alternância de períodos áridos e frios. A formação de bauxita seria favorecida por clima mais úmịno enqu!anto que a formação de ferricretes seria favorecida por um clima com estações bem contrastantes. Isto é aplicado a materiais de alteração sobre rochas silicáticas, nas alteritas de rochas apatíticas a presença do fósforo muda o comportamento do Al que, preferencialmente, participa na formação dos fosfatos aluminosos.

Tapira e Juquiá apresentam um relevo positivo e uma maior resistência das rochas, favorecendo a formação de fosfatos supérgenos, em acordo com o que foi encontrado. Estes fatores estão relacionados a mineralogia dos materiais de alateração que no caso destas áreas são especialmente ricos em apatita. Tapira apresentou também materiais silissificados e um espesso manto lateritico que são também bastantes resistentes a alteração. O complexo de Anitápolis ocorre em uma zona de depressão do relevo originado pela erosão mecânica das rochas; nesta área de muita remobilização e com erosão dos materiais mais evoluídos, seria mais dificil formarem-se os fosfatos crandalliticos, não haveria tempo para que eles fossem formados o que explicaria a sua escassez na alteração de rnchạs alcalinosilicáticas ricas em apatita. 
Num sentido globa!, os materiais dos mantos de intemperismo estudados seguem a evolução laterítica, caracterizada pela perda de álcalis e retenção de $\mathrm{Al}$ e Fe. Este comportamento é parcialmente modificado em presença do $P$, que, não sendo lixiviado e formando estruturas supérgenas, retém alguns destes álcalis, principalmente $\circ \mathrm{Ba}$ e também $\circ \mathrm{Ca}$ e $\mathrm{Sr}$ nas partes com influência do $\mathrm{Al}$; ou somente ○ Ca com a formação das apatitas onde o $\mathrm{Al}$ não está disponivel. O Al, portanto, não forma seus minerais próprios comuns nas condições lateríticas (gibbsita principalmente) mas é utilizado na formação dos fosfatos aluminosos crandallíticos (em presença do $\mathrm{Al}$ ).

Após a exposição das rochas dos complexos estudados possivelmente no Terciário uma sucessão de climas se deu até os dias de hoje. As variações paleoclimáticas que determinam as formações de ferricretes ou bauxitas nas rochas aluminossilicáticas, conforme discutido anteriormente, parecem ser menos influentes na formação dos fosfatos supérgenos do que os outros controles, ou seja, associações litológicas, mineralógicas e relevo, ligado a eventos de erosão, que determinaram, nas áreas estudadas, certas diferenças na fosfatogênese supérgena. 


\section{Bibliografia}

AB'SABER, A.N. (1977) Espaços ocupados pela expansão dos climas secos na América do Sul, por ocasião do períodos glaciais quaternários, Inst. Geoc. Univ. São Paulo, Brasil. Paleoclimas, 3 : $1-18$.

ALCOVER NETO, A. (1991) Evolução supérgena das rochas carbonatíticas ricas em apatita do complexo alcalino de Juquiá (SP). Dissertação de Mestrado, Instituto de Geociências - USP, São Paulo, 131p.

ALCOVER NETO, A. \& TOLEDO, M.C.M. (1993) Evolução supérgena do carbonatito de Juquiá (SP). Rev. Inst. Geol., 14(1):31-43.

ALCOVER NETO, A. \& TOLEDO-GROKE, M.C. (1989) Caracterização preliminar da evolução supérgena das rochas carbonatíticas do complexo alcalino-carbonatítico de Juquiá (SP), com enriquecimento em fosfatos. In. CONGR. BRAS. GEOQ., 2, Rio de Janeiro, 1989. Anais... Rio de Janeiro, p. 479-486.

ALMEIDA, F.F.M. de (1983) Relações tectônicas das rochas alcalinas da região meridional da Plataforma Sul-Americana. Rev. Brasil. de Geoc., 13(3): 139-158.

ALTSCHULER, Z.S. (1973) The weathering of fosfate deposits - Geochemical and environmental aspects. Environmental Phosphorus Handbook. Ed Griffith, E.J., Beeton, A. Spencer, J.M. and Mitchell, D.T. - John Wiley \& Sons, cap. 3, p. 33-95.

AMARAL, G.; BUSHEE, J.; CORDANI, U.G.; KAWASHITA, K. \& REYNOLDS, J.H. (1967) Potassiumargon ages of alkaline rocks from southern Brazil. Geoch. Cosmoch. Acta, 31:117-142.

ANDERSON, W.R.; STRINGHAM, B. \& WHELAN, J.A. (1962) Secondary phosphates from Bingham, Utah. Am. Min., 47:1303-1309.

ARENDS, J. \& DAVIDSON, C.L. (1975) $\mathrm{HPO}_{4}{ }^{2-}$ content in enamel and artificial carious lesions. Calcif. Tiss. Res., 18: 65-79.

ATENCIO, D. \& CLARK, A.M. (1996) Ferrazite is identical to gorceixite. Min. Mag. 60:841-842.

ATKIN, D.; BASHAM, I.R. \& BOWLES, J.F.W. (1983) Tristamite, a new calcium uranium phosphate of the rhabdophane group. Min. Mag., 47, 393-396.

BANFIELD, J.F. \& EGGLETON, R.A. (1989) Apatite replacement and rare earth mobilization, fractionation, and fixation during wheathering. Clays and Clay Min., 37(2):113-127.

BARDOSSY, G. \& ALEVA, G.J.J (1990) Lateritic bauxites. Developments in economic geology 27. Elsevier, Amsterdam, $624 \mathrm{pp}$.

BARROS, L.A.F. DE (1997) Flotação da apatita da jazida de Tapira (MG). Dissertação de Mestrado, Escola Politécnica, USP, 10-6p.

BÉRAR, J.F. (1990) Reduction of the number of parameters in real time Rietveld refinements. I. U. Cr. Sat. Meeting "Powder Diffractometry", Toulouse, July 1990.

BERNER, R.A. \& LASAGA, A.C. \& GARRELS, R.M. (1983) The Carbonate-Silicate Geochemical Cycle And Its Effect on Atmospheric Carbon Dioxide Over The Past 100 Million Years. Americam Journal of Science, Vol. 283, September, p. 641-683.

BINDER, G. \& TROLL, G. (1989) Coupled anion substitution in natural carbon-bearing apatites. Contr. Miner. and Petrol., 101:394-401. 
BLACKBURN, W.H.; DENNEN, W.H. (1997) Encyclopedia of Mineral Names. Special Publication 1 of The Canadian Mineralogist, Mineralogical Association of Canada. $360 \mathrm{p}$.

BLANCHARD, F.N. (1972) Physical and Chemical data for crandallite from Alachua County, Florida. Am. Miner., 57: $473-484$.

BLANCHARD, F.N. (1989) New X-Ray powder data for gorceixite, $\mathrm{BaAl}_{3}\left(\mathrm{PO}_{4}\right)_{2} \cdot \mathrm{H}_{2} \mathrm{O}$, an evaluation of d-spacings and intensites, pseudosymetry and its influence on the figure of merit. Powder Diffraction, 4, 227-30.

BLOUNT, A.M. (1974) The crystal structure of crandallite. Am. Min., 59: 41-47.

BORN, H. (1971) O complexo alcalino de Juquiá, São Paulo. Tese de Doutoutorado, Instituto de Geociências - USP, São Paulo, 180 p.

BOTINELLY, T. (1976) A review of the minerals of the alunite-jarosite, beudantite, and plumbogummite groups. J. Res. USA Geol. Surv., 4(2): 213-216.

BOULINGUI, B. (1997) Minéralogie et géochimie du gisement résiduel de phosphore et niobium de Mabounié (Moyen-Ogooue, Gabon). Thèse Docteur, Institut National Polytechnique de Lorraine, 134p.

BOWLES, J.F.W. \& MORGAN, D.J. (1984) The composition of rhabdophane. Min. Mag., 48:146-148.

BRAGG, SIR L.; CLARINGBULL \& TAYLOR, W.H. (1965) Crystal structures of minerals. G. Bell and Sons, London, $409 \mathrm{pp}$.

BROD, J. A. (1993) Química mineral de calcitas e dolomitas dos carbonatitos de Tapira - MG. In: CONGR. BRAS. DE GEOQ., 4. Cidade, 1993. Anais..., cidade, organizador, p. 64-66.

BUDYKO, M.I (1977) Climatic Changes. Am. Geophys. Union (Russian translation), $261 \mathrm{p}$.

BURNHAM, C.W. (1991) LCLSQ: Latice parameter refinement using correction terms for systematic errors. Am. Miner., 76:663-664.

CAMPBELL, S. \& HENDERSON, P. (1997) Apatite paragenisis in Obo REE-Nb-Fe ore deposit, Inner, Mongolia, China. Lithos, 42:89-103.

CARVALHO, F. M. DE S. (1996) Refinamento da estrutura cristalina de quartzo, corindon e criptomelana utilizando o metodo de rietveld. Dissertação de Mestrado, Instituto de Geociências - USP, São Paulo, 73p.

CLAPPERTON, C. (1993) Quaternary Geology an Geomorphology of South America. Elsevier. $779 \mathrm{p}$.

COOK, P.J. (1984) Spatial and temporal controls on the formation of phosphate deposits - A review. In: Nriagu \& Moore eds., Phosphate Minerals, Springer-Verlag, p. 242-274.

CORREIA NEVES, J.M.; CARDOSO, R.N. \& BRICHTA, A. (1976) Geologia e mineralogia de depósitos de wavellita e turquesa da região de Conselheiro Mata, Diamantina - Minas Gerais. In: CONGR. BRAS. DE GEOL., 29. Cidade, 1976. Anais..., cidade, organizador, p. 207-217.

COSTA, M.L. \& SIQUEIRA, N.V.M. (1988) Correlações geoquímicas entre apatita e crandalita. Revista da Escola de Minas, UFOP. II Simpósio brasileiro de Geoquímica. Ano LII, 41(1-4 231-239.

COSTA, M.L. (1987): Uma contribuição geoquímica do desenvolvimento intempérico de Anitápolis SC. In: CONGR. BRAS. GEOQ., 1, Porto Alegre, 1987. Anais ..., Porto Alegre, SBG, v. 2, p. $17-34$. 
COSTA, M.L.; COSTA W.A.M. \& SCHWAB, R.G. (1980) Mineralogia das ocorrências de fosfatos lateríticos do Pará e Maranhão (Brasíl). In: CONGR. BRAS. GEOL., 31. Balneário de Camboriú, 1980. Anais..., Baineário de Camboriú, SBG, v. 4, p. 1982-1996.

COUTINHO, J.M.V.; ATENCIO, D. \& COIMBRA, A.M. (1999) Gorceixite, a singular product of replacement in fossil bones from the Bauru Basin, Brazil. Can. Min., 37:895:890.

COWGILL, U.M. \& HUTCHINSON, G.E. (1963) An apparently triclinic dimorph of crandallite from a tropical swamp sediment in El Peten, Guatemala. Am. Min., 48:114-1153.

CREMILLION, L.R.; MCCLELLAN, G.H. \& LEHR, J.R. (1975). Characterization of thwelve phosphate rock concentrates from Tapira, Brazil. (Rel. Int.) Tennessee Valey Authority, Alabama.

CRUZ, F.F. \& CHENEY, T.M. (1976): Recursos de fosfato no complexo carbonatítico de Tapira, Minas Gerais. In: CONGR. BRAS. GEOL., 29, Ouro Preto, 1976. Anais ... Ouro Preto, SBG, v.1, p.89-107.

DAWSON, J.B., STEELE, I.M. SMITH, J.V. \& RIVERS, M.L. (1996) Minor and trace element chemistry of carbonates, apatites and magnetites in some African carbonatites. Min. Mag., 60:415-425.

DORFMAN-M-D; GORSHKOV-A-I; NECHELYUSTOV-G-N; PILOYAN-G-O (1988) Osobennosti mineraloobrazovaniya $v$ kore vyvetivaniya apatitovykh porod na Mushugay-Khuduke $v$ Mongolii. Trad. do título: Mineral formation in the apatite weathering crust in MushugayKhuduk, Mongolia. Novye Dannye o Mineralah SSSR. 35; Pages 113-128.

EL-FEKl, H.; SAVARIAULT, J.M. \& BEN-SALAH, A. (1999) Structure refinements by the Rietveld method of partially substituted hydroxyapatite: $\mathrm{Ca}_{9} \mathrm{Na}_{0.5}\left(\mathrm{PO}_{4}\right)_{4.5}\left(\mathrm{CO}_{3}\right)_{1.5}(\mathrm{OH})_{2}$. J. Alloys Compd., 287, 114-120.

ELLIOT, J.C.; HOLCOMB, D.W. \& YOUNG, R.A. (1985) Infrered determination of the degree of substitution of hydroxyl by carbonate ions in human dental enamel. Calcif. Tissue Int. 37: 372 375.

FARRUGIA, L.J. (1997) J. appl. Crist. 30, 565.

FELISSíSSIMO JR. , J. (1976): The Juquiá Alkalic district, Morro do Serrote, São Paulo. In: Simpósio Internacional de Carbonatitos, 1, Poços de Caldas, 1976. Anais Poços de Caldas, 1976, p. 263-274.

FLEET, M.E. \& PAN, Y. (1994) Site preference of Nd in fluorapatite [Ca10(PO4)6F2]. Journal of solid State Chemistry, 111, 78-81.

FLEET, M.E. \& PAN, Y. (1995a) Crystal chemistry of rare-earth elements in fluorapatite and some calc-silicates. Eur. J. Mineral., 7:591-605.

FLEET, M.E. \& PAN, Y. (1995b) Site preference of rare earth elements in fluorapatite. Am. Min., 80:329-335.

FLEET, M.E. \& PAN, Y. (1997) Site preference of rare earth elements in fluorapatite: binary (LREE+HREE)-substituted crystals. Am. Min. 82:870-877.

FLEISCHER, M. (1962) New data on rhabdophane group. Am. Min., 47:419-420.

FLICOTEAUX, R. \& LUCAS, J. (1984): Weathering of phosphate minerals. In: Nriagu \& Moore eds., Phosphate Minerals, Springer-Verlag, 292-317.

FLICOTEAUX, R. \& WALTER, A-V (1988) Altération météorique de la carbonatite de Juquiá (S.P., Brésil). Comparation avec l'altération des complexes alcalinsa à carbonates d'Anitapolis (S.C.) 
et de Tapira (M.G.). Pétrographie, minéralogie, premiers résultats cristallochimiques. In: Programme PIRAT, PIR "Geodynamique des milieux intertropicaux periatlantiques". ATP Laterites. Paris, 1988. CNRS, p. 29-31.

FLICOTEAUX, R.; WALTER, A.-V.; BONNOT-COURTOIS, C. \& TOLEDO-GROKE, M.C. (1990) Transformation and precipitation of phosphates during weathering: characterization by REE distributions. Chem. Geol., 84:365-367.

FLORÊNCIO, R.V. de S. \& TOLEDO, M.C.M. de (1997) Estudo da alteração intempérica sobre rochas ricas em apatita no maciço Alcalino-carbonatitico de Ipanema, SP. Geoquímica Brasiliensis, 11(3):

FOORD, E.E. \& TAGGART JR., J.E. (1998) A reexamination of the turquoise group: the mineral aheilite, planerite (redefined), turquoise and coeruleolactite. Min. Mag., 62(1), pp. $93-111$.

FRANSOLET, A.M. \& DELIENS, M. (1997) Crandallite et wardite dans les filons de quartz du Massif de Stavelot, Belgique. Bull. de l'Inst. Royal des Sci. Nat. de Belgique. Sci. de la Terre 67: 189194.

FREUND, F. \& KNOBEL, R. M. (1977) Distribuition of fluoruine in hydroxyapatite studied by infrared spectroscopy. J. C.S. Dalton, p. 1136-1140.

FRONDEL, C. (1958) Geochemical scavenging of strontium. Science, 128: 1623-1624.

FURTADO, S.M.A. (1989) Petrologia do maciço alcalino de Anitápolis, SC. São Paulo, Curso de PósGraduação em Geociências. Tese Doutorado, IG - USP, 245 p., São Paulo.

FURTADO, S.M.A.; GOMES, S.B. \& SCHEIBE, L.F. (1989) Ocorreência de foscoritos no maciço alcalino de Anitápolis, SC. In: CONGR. BRAS. GEOL., 34, Goiânia, 1986. Anais... Goiânia, SBG, v.4, p. 1604-1614.

GEISEL SOBRINHO, E. (1974) Prospecção de urânio na chaminé alcalina de Tapira - Minas Gerais. Brasil, CNEN/DEXM, Bol. 10, Rio de Janeiro, CNEN, 1974, p.1-16.

GILKES, R.J. \& PALMER, B. (1983) Synthesis, properties and dehydroxylation of members of the crandallite-goyazite series. Min. Mag., 47: 221-227.

GOMES, C. S. F. (1968) Mineralogia da parte fosfatada de fosforito de Cabinda (Angola). Bolletim dos Serviços de Geologia e Minas, no. 18, p. 17-27.

GOREAUD, M. \& RAVEAU, B. (1980) Alunite and crandalite: a structure derived from that of pyrochlore. Am. Min. 65: 953-956.

GREIFFO, W.; HERMANN, K; M JLLER, G.; STRAUSS. W. (1984) Sr-gorceixite, a weathering product in rich iron ores from the Córrego do Feijão, Minas Gerais, Brazil. Contributions Mineralogy Petrology, v.87, n. 4, p. 418-419.

GROSSI-SAD, J.H. \& TORRES, N. (1971) Geologia e recursos minerais do complexo de Tapira, Minas Gerais, Brasil. Belo Horizonte, GEOSOL, 68 p..

GUSEV, G.M.; ZANIN, YU.N.; KRIVOLUTSKAYA, L.M.; LEMINA, N.M. \& YUSUPOV, T.S. (1976): Transformation of apatite during weathering and leaching. Doklady Akad. Nauk SSSR, 229:146-148.

HASUI, Y. \& CORDANI, U.G. (1968): Idades Potássio-Argônio de rochas eruptivas mesozóicas do oeste mineiro e sul de Goiás. In: CONGR. BRAS. GEOL., 32., Belo Horizonte. 1968. Anais ... Belo Horizonte, SBG, p. 139-43. 
HORN, M.; SCHWERDTFEGER, C.F. \& MEAGHER, E.P. (1972) Refinement of the structure of anatase at several temperatures. Z. Kristallogr. Bd. 136 (3/4): 273-281.

HUGHES, J.M., CAMERON, M. \& CROWLEY, K.D. (1989) Structural variations in natural $F, O H$, and $\mathrm{Cl}$ apatites. Am. Min., 74: 870-876.

HUGHES, J.M., CAMERON, M. \& CROWLEY, K.D. (1990) Crystal structures of natural ternary apatites: Solid solution in the $\mathrm{Ca}_{5}\left(\mathrm{PO}_{4}\right)_{3} \mathrm{X}(\mathrm{X}=\mathrm{F}, \mathrm{OH}, \mathrm{Cl})$ system. Am. Min., 75: 295-304.

HUGHES, J.M.; CAMERON, M. \& CROWLEY, K.D. (1991) Ordering of divalent cations in the apatite structure: Crystal structure refinements of natural Mn- and Sr-bearing apatite. Am. Miner., 76 : $1857-1862$.

HUGHES, J.M., CAMERON, M. \& MARIANO, A.N. (1991) Rare-earth element ordering and structural variations in natural rare-earth-bearing apatites. Am. Min., 76: 1165-1173.

IMBERNON, R.A.L (1993) Evolução geoquímica e mineralógica dos produtos de alteração intempérica sobre rochas do complexo Alcalino-Carbonatítico de Catalão I (GO). Dissertação de Mestrado, Instituto de Geociências - USP, São Paulo, 131p.

JAMBOR, J. \& BIRCH, B. (1993) Nomenclature in "Beudandite-group minerals and related alunitetype species. CNMMN/IMA, $6 \mathrm{p}$. (relatório intermo).

KATO, T. (1971) The crystal structures of goyazite and woodhouseite. N. Jb. Min. Mh., H6: 241-246.

KAHN, H. (1988) Caracterização mineralógica e tecnológica da jazida de fosfato do Maciço de Anitápolis, SC. São Paulo. Dissertação de Mestrado, Instituto de Geociências - USP, São Paulo, 219p.

KLUG, H.P. \& ALEXANDER, L.E. (1974) X-Ray Diffraction Procedures, $2^{\text {nd }}$ ed., pp. 656 et seq. Wyley (Interscience), New York.

KRAUS, W. \& NOLZE, G. (1996) POWDER CELL - a Program for the Representation and Manipulation of Crystal Structures and Calculation of the Resulting X-ray Powder Patterns. J. Appl. Cryst.. 29, pp. 301-303.

LARSON, A.C. \& VON DREELE, R.B. (1987) GSAS - Generalized Crystal Structure Analysis System. Los Alamos National Lab. Rpt. (LA-UR-86-748).

LATIL, C. \& MAURY, R. (1977) Contribution à l'étude des échanges d'ions $\mathrm{OH}^{-}, \mathrm{Cl}^{-}$et $\mathrm{F}^{-}$et leur fixations dans les apatites hydrotermales. Bull. Soc. Fr. Minéral. Cristallogr., 100: 246-250.

LEFEBVRE, J.J. \& GASPARRINI, C. (1980) Florencite, an ocurrence in the zairian copperbelt. Can. Min., vol. 18: 301-311.

LEGEROS, R. \& LEGEROS, J.P (1984) Phosphate minerals in human tissues. In: Nriagu \& Moore eds., Phosphate Minerals, Springer-Verlag, p. 351-385.

LEGEROS, R.Z.; TRAUTZ, O.R.; LEGEROS, J.P. \& KLEIN, E. (1968) Carbonate substituition in the apatite structure. Bulletin de la Societé Chimique de France, p.1712-1717.

LEHR, J.R; MCCLELLAN, G.H.; SMITH, J.P. \& FRAZIER, A.W. (1968) Characterization of apatites in commercial phosphate rocks In: Colloque International sur les Phosphates Minéraux Solides, Toulouse, p.29-44.

LENHARO, S.L.R. (1994): Caracterização mineralógica/tecnológica das apatitas de alguns depósitos brasileiros de fosfato. Dissertação de Mestrado, Instituto de Geociências - USP, São Paulo, $131 \mathrm{p}$.

LINDENMAYER, Z.G., (1978) A chaminé carbonática de Tapira e sua mineralização a titânio, fosfato e nióbio. Salvador, UFBa. 37 p. (Doc. mimeografado). 
LENHARO, S.L.R. (1994): Caracterização mineralógica/tecnológica das apatitas de alguns depósitos brasileiros de fosfato. Dissertação de Mestrado, Instituto de Geociências - USP, São Paulo, $131 p$.

LINDENMAYER, Z.G., (1978) A chaminé carbonática de Tapira e sua mineralização a titânio, fosfato e nióbio. Salvador, UFBa. 37 p. (Doc. mimeografado).

LIU, Y, \& COMODI, P. (1993) Some aspects of the crystal-chemistry of apatites. Mineralogical Magazine, 57:709-719.

LOTTERMOSER, B.G. (1990): Rare-Earth element mineralization within the Mit. Weld carbonatite laterite, Western, Australia. Lithos, 24:151-67.

LUCAS, J.; FLICOTEAUX, R.; NATHAN, Y.; PRÉVÔT, L. \& SHAHAT, Y. (1980): Different aspects of phosphorite weathering. SEPM Special Publication No. 29, p. 41-51.

MACCIOTTA, G.; BARBIERI, M.; BECCALUVA, L.; BORN, H.; BROTZU, P.; CONTE, A.; GARBARINO, C.; GOMES, C.B.; MORBIDELLI, L.; RUBERTI, E.; SCIENA, F. \& TRAVERSA, G. (1988): Petrological and geochemical studies of alkaline rocks from continental Brazil. The Juquiá intrusive alkaline-carbonatite complex state of São Paulo. In: International Conference "Geochemical evolution of the continental crust". Poços de Caldas, 1988. Abstracts. Poços de Caldas, p. 92-97.

MACKIE, P.E. \& YOUNG, R.A. (1973) Location of Nd dopant in Fluorapatite, $\mathrm{Ca}_{5}\left(\mathrm{PO}_{4}\right)_{3} \mathrm{~F}: \mathrm{Nd}$. J. Appl. Cryst., 6: 26-31.

MAKSIMOVIÉ, Z. \& PANTÓ, Gy. (1985) Neodymian goyazite in the bauxite deposit of Vlasenica, Yugoslavia. TMPM Tschermaks Min. Petr. Mitt., 34: 159-165.

MANABE, S. \& STOUFFER, R. J. (1980) Sensitivity of a global climate model to an increase of $\mathrm{CO}_{2}$ concentration in the atmosphere: Jour. Geophys. Research, v. 85, p. 5529-5554.

MARSHALL, D.J. (1988) Cathodoluminescence of geological materials with a chapter contributed by Anthony N. Mariano. Unwin Hyman, Boston. 139 p.

MASSUYES, M.; TROMBE, J.C.; BONEL, G. \& MONTEL, G. (1969) Étude par spectrometrie d'absorption dans l'infrarouge de l'ion carbonate dans quelques apatites calciques preparées à haute temperature. C. R. Acad. Sc. Paris, 268C:941-944.

MAYER, I., VOEGEL, J.C., BRES, E.F. \& FRANK, R.M. (1988) The release of carbonate during the dissolution of synthetic apatites and dental enamel. Journal of Crystal Growth, 87:129-136.

MCARTHUR, J.M. (1978) Systematic variations in the contents of $\mathrm{Na}, \mathrm{Sr}, \mathrm{CO}_{3}$ and $\mathrm{SO}_{4}$ in marine carbonate-fluorapatite and their relation to weathering. Chemical Geology 21(1-2):89-112.

MCARTHUR, J.M. (1985) Francolite geochemistry - compositional controls during formation, diagenesis metamorphism and weathering. Geochimica and Cosmochimica Acta, 49:23-45.

MCCARTHY WHITE, W.B. \& PFOERTSCH, D.E. (1978) Synthesis of nuclear waste monazites, ideal actinide host for geological disposal. Mat. Res. Bull. 13: 1239-1245.

McCLELLAN, G. (1980) Mineralogy of carbonate fluorapatites. J. Geol. Soc. London, 137:6175-6181.

MCCLELLAN, G.H. \& LEHR, J.R. (1969) Crystal chemical investigation of natural apatites. Am. Min., 54:1374-1391.

MCCONNELL (1973) Apatite its crystal chemistry, mineralogy, utilization and biologic and geologic occurences. Wien, New York, Springer Verlag, 111p. 
MCCONNELL (1974) The crystal chemistry of apatite. Bull. Soc. Fr. Minéral. Cristallogr. 97:237-240.

McKIE, D. (1962) Goyazite and florencite from two African carbonatites. Min. Mag., 33: 281-297.

MEHMEL, M. (1930) The structure of apatite. Z. Kristallogr. Mineral., 75: 323-331.

MELFI, A.J.; SOUBIÈS, F. \& TOLEDO-GROKE, M.C. (1991) Comportamento do nióbio nas alterações das rochas do complexo alcalino-carbonatítico de Tapira, Minas Gerais. In: CONGR. BRAS. GEOQ., 3., São Paulo, 1991. Anais ... São Paulo, SBGq, V.1, p. 85-87.

MENCHETTI, S. \& SABELLI, C. (1976) Crystal chemistry of the alunite series: crystal structure refinement of alunite and synthetic jarosite. N. Jb. Min. Mh., H9: 406-417.

MONTEL, G. (1968) Conceptions nouvelles sur la physico-chimie des phosphates de structure apatitique. In: Colloque International sur les Phosphates Minéraux Solides, 1967, Toulouse. Bulletin de la Societé Chimique de France, 1968, numero special, p. 1693-1700.

MONTEL, J.M.; LHOTE, F. \& CLAUDE, J.M. (1989) Monazite end members and solid solutions: synthesis, unit-cell characteristics, and utilization as microprobre standards. Min. Mag., 53: $120-123$.

MOONEY, R.C.L. (1950) X-Ray diffraction study of cerous phosphate and related crystals. I. Hexagonal modification. Acta Cryst., 3:337-340.

MURRAY, J.R. \& ORESKES, N. (1997) Uses and limitations of cathodoluminescence in the study of apatite paragenesis. Econ. Geol., 92: 368-376.

NARAY-SZABO, S. (1930) The structure of apatite $(\mathrm{CaF}) \mathrm{Ca}_{4}\left(\mathrm{PO}_{4}\right)_{3}$. Z Kristallogr. 75:387-388.

NASRAOUI, M. (1996) Le gisement de niobium de Lueshe (nord est de Zairre): évolutions géochimique et minéralogique d'un complexe carbonatitique en contextes hydrothermal et supergène. Thèse Docteur, École Nat. des Mines de Paris et École Nat. Sup. des Mines de St. Etienne, 230p.

NATHAN, Y. (1984) The mineralogy and geochemistry of phosphorites. In: Nriagu \& Moore eds., Phosphate Minerals, Springer-Verlag, p. 275-291.

NELSON, D.G.A. \& WILLIAMSON, B.E. (1982) Low-temperature laser Raman spectroscopy of synthetic carbonated apatites and dental enamel. Aust. J. Chem., 35:715-727.

NI, Y.; HUGHES, J.M. \& MARIANO, A.N. (1995) Crystal chemistry of the monazite and xenotime structures. Am. Miner., 80:21-26.

NOUNAH, A.; SZILAGYI, J. \& LACOUT, J.L. (1990) La substitution calcium-cadmium dans les hydroxyapatites. Ann. Chim. Fr., 15:409-419.

PARRISH, J.T. \& ZIEGLER, A.M. \& SCOTESE, C.R. (1982) Rainfall pattems and the distribution of coals and evaporites in the Mesozoic and Cenozoic. Palaeogeography, Palaeoclimatology, Palaeoecology, 40: 67-101.

PARSEVAL, P.; FONTAN, F. \& AIGOUY, T. (1996) Composition chimique des minéraux de terres rares de Trimouns (Ariège, France). C.R. Acad. Sci. Paris, 324, serie II a: 625-630.

PAWLEY, G.S. (1981) Unit-cell refinement from powder diffraction scans. J.Cryst. (14):357-361.

PENEL, G.; LEROY, G.; REY, C. \& BRES, E. (1998) MicroRaman spectral study of carbonated apatites, enamel, dentine and bone. Calc. Tis. Intern., 63:475-481. 
PENEL, G.; LEROY, G.; REY, C.; SOMBRET, B.; HUVENNE, J.P. \& BRES, E. (1997) Infrared and Raman microspectrometry study of fluor-hydroxyapatite powders. Journal of materials Science: Materials in Medicine 8:271-276.

PEREIRA, V.P. (1991) Alteração das rochas no Maciço Alcalino de Anitápolis - SC. Porto Alegre, Curso de Pós-Graduação em Geociências. Dissertação de Mestrado, Instituto de Geociências - UFRGS, Porto Alegre, $199 \mathrm{p}$.

PEREIRA, V.P.; FORMOSO, M.L.L. \& TOLEDO, M.C.M (1997): Aspectos da alteração hidrotermal e intempérica no Maciço Alcalino-Carbonatítico de Anitápolis. Geochimica Brasiliensis, 11(2): 187-205.

POULIOT, G. \& HOFMAN, H.J. (1981) Florencite: a first ocurrence in Canada. Can. Min., 19: 535-540.

POZZA, E.V. \& GARCIA, P.F. (1974): Projeto Anitápolis: Conv. Com. Nac. Energia Nuclear/Comp. Pesq. Rec. Minerais (CNEN/CPRM), Porto Alegre, 89p. (inédito).

PRING, A.; BIRCH, W.D.; DAWE, J.; TAYLOR, M.; DELIENS, M. \& WALENTA, K. (1995) Kintoreite, $\mathrm{PbFe}(\mathrm{PO}) 2(\mathrm{OH}, \mathrm{H} 2 \mathrm{O}) 6$, a new mineral of the jarosite-alunite family, and lusungite discredited. Min. Mag., 59: 143-148.

PROBST, J.L. \& TARDY, Y. (1989) Global runoff fluctuations during the last 90 years in relation to world temperature change. American Journal of Science, Vol. 289, pp. 267-285.

QUASH, N. (1987) Les concentrations phosphatées de complexes alcalin a carbonatites 1- étude bibliographique 2- un exemple lié à la alteration supergène le gisement de Tapira (M.G. Brésil). DEA de Géologie. Universites d'Aix-Marseille III, Nice et Perpignan. 83p.

RADOSLOVICH, E. W. \& SLADE, P. G. (1980) Pseudo-trigonal symmetry and the structure of gorceixite. $N J$ b. Miner. $M, 4: 157-170$.

RADOSLOVICH, E. W. (1982) Refinement of gorceixite structure in Cm. $N J b$ Miner. M., 10: 446-464.

REGNIER, P.; LASAGA, A.C.; BERNER, R.A.; HAN, O.H. \& ZILM, K.W. (1994) Mechanism of $\mathrm{CO}_{3}{ }^{2-}$ substitution in carbonate-fluorapatite: Evidence from FTIR sectrospcopy, 13C NMR, and quantum mechanical calculations. Am. Min., 79: 809-818.

RIETVELD, H.M. (1967) Line profiles of neutron powder-diffraction peaks for structure refinement. Acta Cryst., 22: 151-152.

RIETVELD, H.M. (1969) A profile refinement method for nuclear and magnetic structures. J. Appl. Cryst., 2: 65-71.

RODRIGUES, C.S. \& LIMA, P.R.A.S.L. (1984): Complexos carbonatíticos do Brasil. In: Companhia Brasileira de Metalurgia e Mineração. Complexos carbonatíticos do Brasil: geologia. São Paulo, CBMM. Departamento de Geologia, p. 3-17.

RODRIGUES, E.P. (1985) O Complexo Alcalino Anitápolis - um estudo poetrológico Dissertação de Mestrado, Instituto de Geociências - USP, São Paulo, 131p., 174p.

RODRIGUES, E.P.; OLIVEIRA, M.C.B.; COUTINHO, J.M.V.; GOULART, E.P.; ENS, H.H.; TADDEO, J.S. \& MORAES, M.C. (1986) Mineralogia e petrologia do Complexo Alcalino de Anitápolis S.C. In: CONGR. BRAS. GEOL., 34, Goiânia, 1986,. Anais... Goiânia, SBG, vol. 4. p. 15081525. 
ROEDER, P.L., MCARTHUR, D., MA, X.P., PALMER, G.R. \& MARIANO, A.N. (1987) Cathodoluminescence and microprobe study of rare-earth elements in apatite. Am. Miner., 72:801-811.

ROGERS, K.D. (1997) Initial Rietveld characterization of biological calcifications. Powder Diffr., 12(3):175-179.

RøNSBO, J.G. (1989) Coupled substitution involving REEs and $\mathrm{Na}$ and $\mathrm{Si}$ in apatites in alkaline rocks from the llimaussaq intrusion, South Greenland, and the petrological implications. Am. Miner., 74:896-901.

SANT'AGOSTINO, L.M. \& KAHN, H. (1997) Metodologia para a caracterização de matérias primas minerais. Boletim Técnico da Escola Politécnica. BTPMI-069, 29p.

SANTOS, C.O.P. (1990) Estudos de cerâmicas piezoelétricas pelo método de Rietveld com dados de Difração de Raios-X. Tese de Doutorado, I. Física e Química de S. Carlos, USP, 153p.

SANTOS, C.N.; FERRARI, V.C.; TOLEDO, M.C.M. \& KAHN, H. (1999) Aspectos geoquímicos mineralógicos e tecnológicos das apatitas de Tapira (MG). $V$ Cong. Geoq. dos Países de Lingua Portuguesa e VII Cong. Brasil. Geoq.. Porto Seguro (BA). Anais.... p. 415-417.

SANTOS, R.V. \& CLAYTON, R.N. (1995) The carbonate content in high temperature apatite: an analytical method applied to apatite from the Jacupiranga alkaline complex. Am. Miner., 80:336-344.

SCHEIB, R.; THRASHER, R.D. \& LEHR, J.R. (1984) Chemical composition determination of francolite apatites by Fourier Transfor Infrared (FTIR) spectroscopy. SPIE, 1981, vol. 289:289-291.

SCHWAB, R.G.; HEROLD, H.; COSTA, M.L. \& OLIVEIRA, N.P. (1989) The formation of aluminous phosphates through lateritic weathering of rocks. In: Balasubramanian, K.S. \& Evangelov, V.P. (Eds. - Weathering: its products and deposits. Athens, Theophrastus. v. 2, p. 369-386.

SCHWAB, R.G.; HEROLD, H.; GÖTZ, C. \& OLIVEIRA, N.P. (1990) Compounds of the crandallite type: Synthesis and properties of pure goyazite, gorceixite and plumbogummite. N. Jb. Miner. Mh., Jg., 1990, H.3:113-126.

SCHWAB, R.G.; HEROLD, H.; GOTZ, C. \& OLIVEIRA, N.P. (1990) Compounds of the crandallite type: Synthesis and properties of pure Rare Earth Element-phosphates. N. Jb. Miner. Mh., Jg. 1990, H.6: 241-254.

SCOTT, K.M. (1987) Solid solution in, and classification of, gossan-derived members of the alunitejarosite family, northwest Queensiand, Australia. Am. Min., vol. 72: 178-187.

SIMONE, C.A. (1983) Refinamento de estruturas cristalinas por Difração de Raios-X pelo método de mínimos quadrados, utilizando dados de amostras policristalinas. Dissertaçăo de Mestrado, I. Física e Química de S. Carlos, USP.

SLANSKY, E. (1977) Plumboghummite from Ivanhoe mine, Northern territory, Australia. N. Jb. Miner. Mh., 45-53.

SOMMERAUER, J. \& KATZ-LEHNERT (1985) A new partial substitution mechanism of $\mathrm{CO}_{3}{ }^{2-}$ $/ \mathrm{CO}_{3} \mathrm{OH}^{3-}$ and $\mathrm{SiO}_{4}{ }^{4-}$ for the $\mathrm{PO}_{4}{ }^{3-}$ group in hydroxyapatite from the Kaisersthult alkaline complex (SW-Germany). Contr. to Miner. and Petrol., 91:360-368.

SOUBIĖS, F.; MELFI, A.J. \& ALTEFAGE, F. (1990): Le comportement des Terres-Rares dans les laltérites du gite de Tapira (M.G., Brésil): mise en évidence du rôle des phosphates. In: 
Séminaire Orstom, 1990: Organization et fonctionnement des altérites et des sols, p. 241-73. Ed. Orstom, Paris, $334 \mathrm{p}$.

SOUBIĖS, F.; MELFI, A.J. \& AUTEFAGE, F. (1991): Comportamento geoquímico dos elementos terras raras nos alteritos da jazida de fosfato e titânio de Tapira (Minas Gerais, Brasil): A importancia dos fosfatos. Rev. Bras. Geoc., 21(1):3-16.

SOUBIĖS, F.; MELFI, A.J.; AUTEFAGE, F. \& FONTAN, F. (1992): Deux phosphates secondaires des alterations du Complexe ultramaphique-alcalin de Tapira, Minas Gerais, Brésil: Calcorhabdophane et kolbeckite. In: Reunion SFMC. Orléans, 1992.

SUBASINGHE, N. D. (1998) Formation of secondary Phosphates by weathering of apatite-rich carbonatite - An exemple from Sri Lanka. Thesis. University of Reading, UK, 261p.

SUDARSANAN, K; MACKIE, P.E. \& YOUNG, R.A. (1972) Mater. Res. Bull. 7, 1331 - 1338.

TARDY, Y \& KOBILSEK, B \& PAQUET, H (1991) Mineralogical composition and geographical distribution of African and Brazilian periatlantic laterites. The influence of continental drift and tropical paleoclimates during past 150 million years and implications for India and Australia. Journal of African Earth Sciences, Vol. 12,No. 1/2,pp.283-295.

TAYLOR, M.; SMITH, R.W. \& AHLER, B.A. (1984) Gorceixite in topaz greisen assemblage, Silvermine area, Missouri. Amer. Miner. 69:984:986.

TOLEDO, M.C.M. DE (1999) Mineralogia dos principais dos principais fosfatos do maciço Alcalinocarbonatítico de Catalão I (GO) e sua evoluçăo no perfil laterítico. Tese de Livre Docência, IGc-USP, São Paulo.

TOLEDO, M.C.M. de, DE PERSEVAL, PH.; FONTAN, F.; LEROY, G. \& RIBEIRO, C.C. (1968) Caracterization des apatites de diferentes génerations du Massif Alcan-carbonatitique de Catalão I (Goiás, Brésil)" Bol. Soc. Esp. de Mineralogia, 21-A: 202-203.

TORRES, (1997) M.G. (1996) Caracterização mineralógica do minério fosfático da Arafértil S.A. no Complexo carbonatítico do Barreiro, Araxá, MG. Dissertação de Mestrado 112, UnB, 149p.

TROMBE, J.C. \& MONTEL, G. (1980) Sur lintroduction d'ions sulfate dans les tunnels ou réseau des apatites phosphocalciques. Ann. Chim. Fr., 5:443-459.

TSUDA, H. \& ARENDS, J. (1994) Orientational micro-Raman Spectroscopy on hydroxyapatite single crystals and human enamel cristallites. J. Dent. Res. 73(11):1703-1710.

ULBRICH, H. H. G.J. \& GOMES, C.B. (1981) Alkaline rocks from continental Brazil. Earth Science Reviews, v.17, p.135-54.

VAZ DE MELO, M. T. (1983) Depósitos minerais associados ao complexo alcalino-carbonatítico de Tapira (MG). doc. int.. CVRD, 39p.

VERGARA, V.D. (1979/1980): Pesquisa de fosfato em Anitápolis; relatório final. ILM, Porto Alegre, (inédito).

VERGARA, V.D. (1980): Pesquisa geológica no Complexo Alcalino de Anitápolis. In: Congr. Brasil. Geol., 31, Camboriú, 1980. Anais... Camboriú, SBG, V. 4, p. 2502-2517.

VIEILLARD, P. (1978): Géochimie des Phosphates. Etude thermodynamique. Application à la genèse et à l'altération des apatites. Sci. Geol. Mém. Estrasburgo, 51:1-181. 
VIEILLARD, P.; TARDY, Y. \& NAHON, D. (1979): Stability fields and aluminum phosphates: parageneses in lateritic weathering of argilaceous phosphatic sediments. Am. Min., 64:626634.

VIEIRA, M. A. de M. (1997) Complexo alcalino de Tapira, Minas Gerais : mineralogia e geoquímica da distribuição de terras raras no perfil de intemperismo. Dissertação de Mestrado, Instituto de Geociências - UFMG, Belo Horizonte, 131p.

VIGNOLES \& BONEL, G. (1978) Sur la localisation des ions fluorure dans les carbonato-apatites de type B. C. R. Acad. Sc. Panis, 287, serie C: 321-324.

VISSER, D; FELIUS, R.O. \& MOREE, M. (1997) Augelite and cerian crandallite in dumortierite quartzites, Vaca Morta quarry, Vereda range, Macaúbas, Bahia, Brasil. Min. Mag., 61: 607609.

WALENTA, Von K. (1979) Chukhrovite-(Ce) und Rhabdophan-(Ce) aus der Grube Clara bei Oberwolfach im mittleren Schwarzwald. Cem.. Erde, 38:331-339.

WALTER, A.V. (1991): Caractérization géochimique et minéralogique de l'altération de la carbonatite du Complexe Alcalin de Juquiá (Brésil) - Compartement des Terres Rares dans les mineraux phosphatés. Thèse, Univ. d'Aix Marseille, $247 \mathrm{p}$.

WALTER, A.-V.; FLICOTEAUX R.; GIRARD, J.P.; LOUBET, M. \& NAHON D. (1990) REE patern in apatites from the Juquiá carbonatite, Brazil. In: Geochemistry of the earth'ssurface and of mineral formation. $2^{\text {nd }}$ International Symposium, 1991, Aix en Provence, France. p. 378-380.

WALTER, A.-V.; FLICOTEAUX, R.; PARRON, C.; LOUBET, M. \& NAHON, D. (1995) Rare-earth elements and isotopes $(\mathrm{Sr}, \mathrm{Nd}, \mathrm{O}, \mathrm{C})$ in minerals from Juquiá carbonatite (Brazil): tracers of a multiusage evolution. Chemical Geology 120: 27-44.

WALTER, A.-V.; LOUBET, M.; FLICOTEAUX, R.; TOLEDO-GROKE, M.C. \& NAHON, D. (1989): Mineralogical and geochemical variations along the alteration profiles of Juquiá Carbonatite (Brazil). Terra Abstracts, Journal of the European Union of Geociences (EUGV), Strasbourg, 1(1), março, 1989.

WILSON, A.J.C. (1992) ed. International Tables for crystallography, Vol. C: Mathematical, physical and chemical Tables. Kluwer Academic Publishers, Dordrecht, The Neatherlands.

WILSON, R.M.; ELLIOTT, J.C. \& DOWKER, S.E.P. (1999) Rietveld refinement of the crystallographic structure of human dental enamel apatites. Am. Min., 84:1406-1414.

YOUNG, R.A. \& MACKIE, P.E. (1980) Crystallography of human tooth enamel: initial structure refinement. Mater. Res. Bull., 15:17-29.

YOUNG, R.A. (1993) Editor. The Rietveld methode. Oxford University Press. 298 p..

YOUNG, R.A; MACKIE, P.E. \& VON DREELE, R.B. (1977) Application of the Pattern Fitting Structure-Refinement Method to X-ray Powder Diffractometer Patterns. J. Appl. Cryst., 10:262-269.

YOUNG, R.A.; SAKWIVEL, A.; MOSS, T.S. \& PAIVA-SANTOS, C.O. (1995) DBWS-9411. an Upgrade of the DBWS*.* Programs for Rietveld Refinement with PC and Mainframe Computers. $J$. Appl. Cryst. 28: 366-367. 
ZANIN, YU.N. (1989): Phosphate-bearing weathering crusts and their related deposits. Weathering: its products and deposits. vol. II. Products - Deposits - Geotechnics, p. 321-367, Theophrastus Publications, S.A.. Zographon, Athens, Greece.

ZIESEMER, L. \& KAHN, H. (1980): O minério da jazida de Anitápolis, SC. Anais... Camboriú, SBG, V. 4, p. 2376-2390. 


\section{ANEXO 1}

Método de Rietveld aplicado à difração de raios-X 
Num experimento de difração de raios- $X$ do pó cada partícula pode ser considerada como um pequeno cristal, caracterizado por uma rede periódica tridimensional de planos reticulares (hkl) que são separados por uma distância $\mathrm{d}_{\mathrm{hkl}}$. $O$ feixe que incide sobre o cristal é difratado segundo a lei de Bragg

$$
2 d_{h k l} \operatorname{sen} \theta_{h k l}=n \lambda
$$

onde $\theta_{h k l}$ é ângulo entre os planos reticulares e o feixe difratado e $n$ é um número inteiro, $\lambda$ o comprimento de onda da radiação.

Cada átomo do cristal ao ser atingido por uma radiação pode absorve-la ou emitir uma nova radiação com a mesma amplitude de onda, fenômeno denominado espalhamento atômico. Este fenômeno é verificado nos padrões de difração de raios-X pela variação da intensidade integrada nas direção [hkl] da estrutura cristalina. A função desta intensidade é dada por (Klug \& Alexander, 1974):

$$
I_{h k l}=\left(\frac{1}{2 \mu V^{2}}\right) K m_{h k l} J_{h k l} L_{p}\left(\theta_{h k l}\right)\left|F_{h k l}\right|^{2}
$$

onde:

$\mu$ : coeficiente de absorção linear do cristal

$V=a b c(1-\cos 2 \alpha-\cos 2 \beta-\cos 2 \gamma+2 \cos \alpha \cos \beta \cos \gamma)$ o volume da cela unitária,

$$
K=\frac{I_{o} \lambda^{3} e^{4}}{32 \pi r m_{e} c^{4}}: \text { constante instrumental }
$$

onde

$I_{o}: \quad$ intensidade da radiação incidente

$r: \quad$ raio do difratômetro (distância amostra-detector)

$c: \quad$ velocidade da luz

e e $m_{\mathrm{e}}$ : carga e a massa do elétron.

$m_{h k l}: \quad$ multiplicidade da reflexão

$J_{h k l}$ : fator de orientação preferencial.

$L_{p}\left(\theta_{h k l}\right)=\frac{1+\cos ^{2} 2 \theta_{h k l} \cos ^{2} 2 \theta_{m}}{\operatorname{sen}^{2} \theta_{h k l} \cos \theta_{l k l}}$ : fator de Lorentz-polarisation (incluindo a correção para o feixe monocromador), onde $\theta_{m}$ é o ângulo de Bragg do cristal monocromador. 


$$
F_{h k l}=\sum_{j} n_{j} f_{j} e^{2 \pi i\left(h x_{j}+k y_{j}+l z_{j}\right)} \text { : função do fator de estrutura, que resulta do }
$$

espalhamento de cada átomo da estrutura na $i^{\text {esima }}$ posição onde: $h, k$ e 1 são os inteiros denominados índices de Miller; $\mathrm{x}_{j}, \mathrm{y}_{j}$ e $z_{j}$ são as coordenadas fracionárias do átomo j na malha; $n$ é o número de átomos na posição $\left(x_{j}, y_{j}, z_{j}\right), f_{j}$ é o fator de espalhamento do átomo $j$. Este último é descrito: $f_{j}=f_{o j} e^{\left(-B_{j} \operatorname{sen}^{2}\left(\theta / \lambda^{2}\right)^{2}\right)}$ onde $f_{o j}$ é o fator de espalhamento do átomo $j$ a temperatura de zero absoluto e $\beta_{j}$ é o fator Debye-Waller do átomo $j$. Os fatores de espalhamento $f_{o j}$ são tabulados na forma de polinômios do quinto grau e estão nas Tabelas Internacionais de Cristalografia (Wilson, 1992). O fator Debye-Waller $\left(\beta_{j}\right)$ está relacionado à amplitude média da ligação perpendicular a direção da difração, seu valor depende essencialmente da temperatura, da massa do ion (ou átomo) vibrante e a natureza das ligações que the pertencente.

Vários são os métodos de se obter informações dos difratogramas, que ajudam na determinação das fases de uma mistura, suas proporções percentuais, parâmetros de rede cristalina, e num estudo mais aprofundado, atualmente já bastante difundido, de extração das posições atômicas, coeficientes térmicos e proporção molar dos elementos.

O método de ajuste do padrão global segue duas linhas de resolução: decomposição em perfis individuais sem referência a um modelo estrutural (Pawley, 1981) e uso de um modelo de ajuste estrutural (Rietveld, 1967, 1969).

No método de decomposição são refinados o número de picos, localização e intensidade das reflexões de Bragg, o refinamento chega ao fim quando não se distinguir mais a diferença entre o padrão calculado e o observado. Para o ajuste as intensidades integradas (intensidade $X$ largura) das reflexões de Bragg são medidas e convertidas em fatores de estrutura, e só então parte-se para a solução e refinamento da estrutura por ajuste das posições atômicas. Para refinar os perfis dos picos de Bragg são usadas diferentes funções de perfil. O método de decomposição (ou intensidade integrada) foi aplicado por Simone (1983), trabalho pioneiro aqui no Brasil.

Este método se adapta bem a estruturas simples de alta simetria, que apresentam poucas sobreposições de picos. Para as estruturas complexas de baixa simetria, os diagramas podem conter centenas de sobreposições de picos que 
impedem a decomposição do diagrama em reflexões discretas de Bragg. Torna-se então muito difícil e quase impossível de aplicar este método numa mistura de fases.

No método de Rietveld contrariamente ao método de decomposição não se utiliza as intensidades integradas das reflexões de Bragg mas a totalidade do difratograma. Segundo esta aproximação, cada intensidade do ponto $2 \theta_{\mathrm{i}}$ de difratograma constitui um dado, e é simulado. O refinamento Rietveld consiste em ajustar os parâmetros estruturais (posições atômicas, fatores de ocupação dos sítios), os parâmetros da rede e os parâmetros dos perfis de pico, com ajuda de um algoritmo de mínimos quadrados até que o difratograma calculado reproduza ao máximo o difratograma experimental.

A quantidade minimizada no refinamento é dada por uma equação residual de mínimos quadrados:

$R=\sum_{i} w_{i}\left(Y_{o b s}\left(\theta_{i}\right)-Y_{\text {calc }}\left(\theta_{i}\right)\right)^{2}$

onde

$w_{i}=1 / Y_{\text {obs }}\left(\theta_{i}\right)$ peso

$Y_{o b s}\left(\theta_{i}\right)$ intensidade observada no ângulo $\theta$ do $i$ ésimo passo

$Y_{\text {catc }}\left(\theta_{i}\right)$ intensidade calculada no ângulo $\theta$ do $i$ ésimo passo

Em cada fase do padrão, a intensidade a cada passo i é dada pela somatória da contribuição do ruído de fundo e toda a vizinhança da reflexão de Bragg, assim a equação (2) pode ser escrita como:

$$
Y_{c a l c}\left(\theta_{i}\right)=Y_{r}\left(\theta_{i}\right)+S \sum_{h k l} m_{h k l} J_{h k l} L p_{h k l}\left|F_{h k l}\right|^{2} G\left(\theta_{i}-\theta_{h k l}\right),
$$

onde $S$ é o fator de escala, para cada intensidade integrada com a correção do ruído de fundo temos:

$S=\left(\frac{1}{2 \mu V^{2}}\right) K$,

onde

$Y_{r f}(\theta i)$ e $Y_{\text {calc }}\left(\theta_{i}\right)$ são respectivamente a intensidade do ruído de fundo e a intensidade do padrão calculado na vizinhança do ângulo de Bragg da reflexão [hkl].

$G\left(\theta_{i}-\theta_{h k l}\right)$ é a função de perfil (Gausiana, Lorentziana, pseudo-Voigt, Pearson VIl e modificada Thompson-Cox-Hastings, Young, 1993). As funções do perfil permitem modelar os efeitos como os dubletos $K_{\alpha 1}$ e $K_{\alpha 2}$ a assimetria do pico gerada pela fenda divergente, e tamanho dos cristalitos. Estas funções estão relacionadas 
ao ângulo de incidência $\theta$ e à largura a meia altura dos picos que é dada pela equação (Caglioti et al., 1958, apud Young, 1993):

$H^{2}=U \tan ^{2} \theta+V \tan \theta+W$, sendo $U, V$ e W parâmetros variáveis

Durante o refinamento são utilizados critérios numéricos para avaliar o seu desenvolvimento. No método Rietveld os critérios reprodutividade $(R)$ mais utilizados são:

$$
\begin{aligned}
& R_{F}=\frac{\sum\left|\sqrt{I_{K(" o b s ")}}-\sqrt{I_{k(c a l c)}}\right|}{\sum \sqrt{I_{K(" o b s ")}}} \text { Fator } \mathrm{R} \text { de estrutura } \\
& R_{F}=\frac{\sum\left|I_{K(\text { "obs" }}-I_{k(\text { calc })}\right|}{\sum I_{K(\text { obs" })}} \text { Fator R de Bragg } \\
& R_{w p}=\frac{\sum w_{i}\left[y_{l(o b s)}-y_{i(c a l c)}\right]^{k}}{\sum w_{i}\left[y_{(o b s)}\right]^{2}} R \text { do padrão pesado }
\end{aligned}
$$

Onde $I_{k}$ é a intensidade atribuída a $\mathrm{k}$ ésima reflexão de Bragg no final do ciclo de refinamento( calc: calculada e obs: observada). Como a intensidade de Bragg observada não é obtida diretamente, "obs" é colocado entre aspas. $y_{i}$ é a intensidade no passo i do padrão.

Outro critério muito útil é o índice $\mathrm{S}$ que é dado por:

$$
S=\left[S_{y} /(N-P)\right]^{1 / 2}=R_{w p} / R_{e} \text { onde: } R_{e}=\left[(N-P) / \sum w_{i} y_{i}\right]^{\prime 2}
$$

Onde: $\mathrm{N}$ é o número de pontos analisados e $\mathrm{P}$ é o número de parâmetros refinados.

Estes critérios podem indicar a qualidade do ajuste e seus valores podem ser comparados a outros refinamentos da literatura. Entretanto os critérios numéricos não substituem a visualização gráfica que mostra melhor o estado do refinamento e quais parâmetros devem ainda ser refinados.

O modelo estrutural com ajuste global do padrão foi inicialmente usado para uma comparação visual entre o padrão calculado e o esperado, esta comparação passa a ser melhor aproveitada com a rotina computacional de Rietveld (1967, 1968). Este modelo e variaçōes deste tem sido usadas com grande sucesso na difração de neutrons, para a qual foi especialmente escrita, e na difração de raios-X.

O refinamento Rietveld se aplica especialmente a materiais onde não é possivel a amostragem de monocristais. Existem muitos exemplos do sucesso da aplicação do método utilizando dados da difração de raios-X do pó de apatitas 
(Wilson et al., 1999, Young et al., 1977, El-Feki et al. (1999), Rogers (1997), Young e Mackie, 1980).

No Brasil refinamentos de estrutura pelo método Rietveld foram feitos em outros materiais, como cerâmicas (Santos, 1990) e criptomelana, coríndon e quartzo (Carvalho, 1996).

Para o êxito da aplicação do método de Rietveld na difração de materiais policristalinos, alguns cuidados precisam ser tomados. Experimentais, como preparação dos materiais e modo de aquisição dos dados e operacionais do refinamento, como modelo estrutural inicial bem próximo ao padrão e escolha acertada dos parâmetros a serem refinados.

O sucesso do refinamento depende do modelo inicial adotado que deve ser o mais próximo do padrão observado pois o método trata de um refinamento e não uma solução da estrutura cristalina. Em muitos trabalhos o método de Rietveld faz parte do conjunto de procedimentos que levam a determinação de estrutura. Antes de refinar uma estrutura deve-se colher muitas informações do material (análises químicas, identificação das fases, modelos iniciais de estrutura...).

\section{Refinamento da estrutura das apatitas}

A determinação da estrutura das apatitas avançou muito com as técnicas de difratometria, sobretudo as aplicadas a monocristais a partir de dados de raios- $X$. Com o método de Rietveld torna-se possivel o refinamento da estrutura de apatita utilizando-se técnicas a difração de neutrons e raios- $X$ do pó.

DRX de monocristal é a técnica mais adequada ao estudo da estrutura da apatita; exemplos de refinamentos de monocristais de apatitas são numerosos. Grande parte dos trabalhos são voltados a caracterização dos mecanismos de substituição iônica utilizando métodos que refinam as posições atômicas, parâmetros térmicos anisotrópicos e ocupação dos sítios. Exemplos da aplicação da técnica bem como os coeficientes de confiabilidade dos refinamentos ( $R$ ou $R_{B}$ ) são dados a seguir.

Sudarsanan et al. (1972) observaram que a estrutura da fluorapatita natural difere da fluorapatita sintética relacionando o fato a possível presença de impurezas ou vacâncias na estrutura da fluorapatita natural. Foi utilizado o programa XFLS e os valores finais de de $R$ foram 2,9 e $1,6 \%$ para apatita mineral e sintética respectivamente. 
Mackie \& Young (1973) estudaram apatitas em experiência de síntese dopando-as com $\mathrm{Nd}$. Verificaram as ocupações dos sítios (razão $\mathrm{Ca} / \mathrm{P}$ ) e modificações ligações propondo mecanismos de substituição (locais preferenciais, reações...). Foi utilizado o programa XFLS e os valores $R$ finais ficaram entre $1,6 \mathrm{e}$ $1,8 \%$.

Hughes et al. (1989, 1990 e 1991a e 1991b) apresentaram uma série de trabalhos visando o estudo da estrutura das apatitas naturais. Hughes et al. (1989, 1990) estudaram sobretudo a solução sólida entre a fluorapatita, hidroxiapatita e cloroapatita, propondo que os termos extremos da série são imissíveis e que apatitas ternárias e binárias devem apresentar modificações nas distâncias interatômicas, na simetria (hexagonal para monoclínica) ou desordens aniônicas quando comparadas aos termos extremos da série. Hughes (1991 e 1991b) estudaram os mecanismos de substituição do $\mathrm{Ca}$ por $\mathrm{Mn}, \mathrm{Sr}, \mathrm{Na}$ e ETR, propondo sítios preferenciais para esta substituição. Foi utilizado o programa SDP-Plus e os valores finais de $\mathrm{R}$ foram: 2,5\% (Fap), 1,6\% (OHAp), 2,0 (ClAp), 1,5\% (apatita ternária hexagonal), 4,7\% (monoclínica), 2,0 e 2,1\% (apatitas com Mn 2,3 e 2,6\%) (apatitas com Sr) e 1,5 a 1,9\% (apatitas com ETR).

Fleet \& Pan (1995b e 1997) estudaram os mecanismos de substituição do $\mathrm{Ca}$ pelos ETR em apatitas sintéticas. Os valores finais de $R$ ficaram entre 1,5 e $2,4 \%$.

Liu \& Comodi (1993) estudaram a cristaloquímica de apatitas naturais carbonatadas de várias procedências. Os resultados dos refinamentos confirma a substituição de $\mathrm{CO}_{3}$ por $\mathrm{PO}_{4}$, com o aumento de $\mathrm{CO}_{3}$ o sítio tetraédrico do diminui de tamanho e aumenta sua distorção o angular. Ainda que observaram que o Sr e ETR estariam preferencialmente no sítio do $\mathrm{Ca}$. Utilizaram o pacote de programas XELX76 e os valores de $R$ ficaram entre 1,7 e $2,5 \%$

A estrutura da apatita refinada pelo método de Rietveld a partir de dados da difração do pó resultou em poucos trabalhos, Young et al. (1977) observaram a reprodutividade dos resultados quando aplicaram o método na fluorapatita utilizando diferentes funções de perfil de pico: a Gausiana $\left(R_{w p}=13,9\right.$ e $\left.R_{B}=9,4\right)$ e a de Cauchy $\left(R_{\mathrm{wp}}=12,1\right.$ e $\left.R_{\mathrm{B}}=8,2\right)$. Porém não conseguiram comprovar a existência da pseudo simetria $\left(\mathrm{P} 2_{1} / \mathrm{b}\right)$ e nem definir a posição do $\mathrm{CO}_{3}$ (diferentes modelos com o mesmo $R_{p}=23 \%$ ) quando aplicaram o método na carbonatoapatita do tipo $A$.

Nounah et al. (1992) estudaram fluorapatitas e hidroxiapatitas portadoras de $\mathrm{Cd}$ sintéticas, refinaram os fatores de ocupação atômica para localizar o Cd nestas 
apatitas usando o método Rietveld utilizaram o programa DBWS. Os valores finais de $R_{w p}$ ficaram entre 11 e $15,2 \%$ e os de $R_{B}$ entre 5,2 e $6,7 \%$.

Rogers (1997) estudou apatitas de calcificações biológicas e observou a dificuldade em se precisar a relação $\mathrm{Ca} / \mathrm{P}$ da estrutura, esta relação seria afetada parcialmente pela substituição do carbonato no sítio $B$ e pela incerteza dos valores de ocupação do $\mathrm{Ca}$ e $\mathrm{P}$. Os autores consideram os valores das ocupações atômicas obtidos com o método de Rietveld pouco precisos pois os parâmetros termais não puderam ser liberados no refinamento. Usaram os programa LS1 e GSAS. Os valores finais de $R_{B}$ ficaram entre 3,04 e $8,38 \%$ e os de $R_{w p}$ entre 3,75 e $9,72 \%$

El-Feki et al. (1999) estudaram hidroxiapatitas sintéticas com substituição parcial no sítio do cálcio, os modelos iniciais foram construídos com base em análises químicas difração de raios- $X$ e espectrometria ao infravermelho. Foi utilizado o programa FULLPROF e refinados os parâmetros estruturais, inclusive os fatores $\beta$. No refinamento puderam confirmar a existência de vacâncias no sítio do cálcio e situar $\circ \mathrm{CO}_{3}$ nas duas faces de um vazio tetraédrico no sítio do $\mathrm{PO}_{4}$. Observaram também que a posição do $\mathrm{OH}$ é afetada pela substituição no sítio do cálcio. Os valores finais de $R_{B}$ e $R_{w p}$ foram de $9,1 \%$ e 5,6\%, respectivamente.

Wilson et al. (1999) apresentaram o refinamento de amostras de carbonato hidroxiapatita de esmalte de dente humano. Os dados foram coletados em um difratômetro com detector sensitivo a posição. Utilizaram o programa GSAS e fixaram os fatores de temperatura anisotrópica obtidos para a hidroxiapatita, considerando pequenos erros na ocupação de sítio. Para corrigir estes erros foram refinadas apatitas estequiométricas sintéticas, obtendo fatores de correção para os valores de ocupação dos sítios do $\mathrm{Ca}_{2}, \mathrm{O}_{\mathrm{OP}}, \mathrm{O}_{\mathrm{H}}$ e P. Os valores da ocupação (igual a 1) do $\mathrm{Ca} 1$ foram mantidos constantes durante o refinamento. $O$ modelo inicial foi baseado em um refinamento a partir de dados de difração de neutrons (Sudarsanan \& Young, 1969, apud Wilson et al., 1999). Os valores de $R_{w p}$ ficaram entre $4,6 \%$ a $10 \%$ (os valores de $R_{B}$ não foram dados).

Observa-se que existem um grande número de programas de refinamento da estrutura cristalina aplicado a DRX, dentre eles foram aqui testados os programas GSAS (Larson \& Von Dreele, 1987) e DBWS (Young et al., 1995), sendo o último escolhido para o refinamento dos parâmetros de cela, das ocupações e posições atômicas. O GSAS é um programa mais completo que foi utilizado nas fases finais do refinamento, sobretudo na checagem dos modelos gerados no DBWS. 


\section{ANEXO 2}

Composição química das apatitas de Anitápolis obtida à ME e expressa em \% em óxidos e em número de átomos por fórmula unitária

$\mathrm{OH}$ (\% em peso e átomos p.f.u.), peso molecular (PM) e carga da fórmula estrutural calculados considerando três alternativas: $a$ - todo flúor $(F)$ nos canais $\left(F_{p}=0\right), b$ parte do flúor $\left(F_{p}\right)$ acompanhando $\circ \mathrm{CO}_{3}{ }^{2-}\left(F_{p}=0,4 C\right)$ e $\mathrm{C}$ - parte do flúor $\left(F_{\mathrm{p}}\right)$ acompanhando o $\mathrm{CO}_{3}\left(\mathrm{~F}_{\mathrm{p}}=\mathrm{C}\right)$. $\mathrm{OH}$ foi calculado pela diferença da fração molar no sítio dos ânions monovalentes $\left(\mathrm{OH}=2-\mathrm{F}-\mathrm{F}_{\mathrm{p}}\right)$, para cada caso $\mathrm{a}$, b e $\mathrm{c}$.

Tipos: 1-apatita primária sã, 2-apatita primária alterada a- fraturada e b- estriada, 3borda de maior birrefringência, 4- apatita supérgena fibrorradial. 


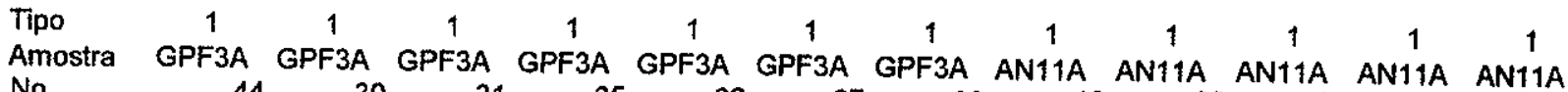

$\begin{array}{lrrrrrrrrrrrrr}\mathrm{No} & 44 & 30 & 31 & 35 & 36 & 37 & 38 & 19 & 20 & 21 & 22 & 27 \\ \mathrm{Na}_{2} \mathrm{O} & 0,29 & 0,33 & 0,22 & 0,20 & 0,15 & 0,17 & 0,26 & 0,26 & 0,10 & 0,17 & 0,42 & 0,17 \\ \mathrm{CaO} & 54,80 & 55,76 & 55,20 & 55,05 & 55,67 & 55,56 & 55,84 & 54,79 & 55,69 & 55,02 & 55,41 & 54,88 \\ \mathrm{MaO} & 0,00 & 0,00 & 0,00 & 0,04 & 0,00 & 0,00 & 0,00 & 0,01 & 0,03 & 0,02 & 0,10 & 0,06 \\ \mathrm{MnO} & 0,12 & 0,00 & 0,12 & 0,00 & 0,03 & 0,05 & 0,00 & 0,14 & 0,09 & 0,00 & 0,06 & 0,08 \\ \mathrm{FeO} & 0,06 & 0,00 & 0,00 & 0,00 & 0,08 & 0,02 & 0,09 & 0,08 & 0,00 & 0,00 & 0,08 & 0,03 \\ \mathrm{SrO} & 0,45 & 0,57 & 0,43 & 0,43 & 0,46 & 0,37 & 0,40 & 0,27 & 0,36 & 0,36 & 0,40 & 0,36 \\ \mathrm{BaO} & 0,00 & 0,01 & 0,06 & 0,00 & 0,00 & 0,00 & 0,00 & 0,00 & 0,00 & 0,04 & 0,00 & 0,00 \\ \mathrm{Al}_{2} \mathrm{O}_{3} & 0,00 & 0,00 & 0,00 & 0,00 & 0,02 & 0,00 & 0,00 & 0,00 & 0,00 & 0,00 & 0,00 & 0,00 \\ \mathrm{La}_{2} \mathrm{O}_{3} & 0,05 & 0,07 & 0,00 & 0,00 & 0,20 & 0,06 & 0,00 & 0,04 & 0,00 & 0,08 & 0,13 & 0,01 \\ \mathrm{Ce}_{2} \mathrm{O}_{3} & 0,00 & 0,00 & 0,14 & 0,09 & 0,21 & 0,03 & 0,21 & 0,00 & 0,07 & 0,17 & 0,01 & 0,04 \\ \mathrm{SiO}_{2} & 0,05 & 0,09 & 0,02 & 0,05 & 0,19 & 0,13 & 0,09 & 0,09 & 0,08 & 0,10 & 0,21 & 0,09 \\ \mathrm{P}_{2} \mathrm{O}_{5} & 41,30 & 41,29 & 41,03 & 41,23 & 39,15 & 40,50 & 41,22 & 39,45 & 40,35 & 41,14 & 40,42 & 41,44 \\ \mathrm{~F} & 1,96 & 1,96 & 2,30 & 1,84 & 1,86 & 1,87 & 2,02 & 1,74 & 1,85 & 1,80 & 1,77 & 1,60 \\ \mathrm{Cl} & 0,06 & 0,03 & 0,00 & 0,00 & 0,00 & 0,00 & 0,00 & 0,01 & 0,00 & 0,00 & 0,00 & 0,00 \\ & 98,87 & 99,79 & 99,33 & 98,73 & 97,87 & 98,60 & 99,88 & 96,62 & 98,54 & 98,74 & 98,59 & 98,60\end{array}$

$\begin{array}{rrrrrrrrrrrr}\text { TOTAL } & 98,04 & 98,97 & 98,36 & 97,95 & 97,08 & 97,82 & 99,03 & 95,89 & 97,76 & 97,98 & 97,84\end{array}$

$\begin{array}{llllllllllllll}\mathrm{CO}_{2} & 0,60 & 1,02 & 0,91 & 0,64 & 2,13 & 1,23 & 1,04 & 1,67 & 1,38 & 0,62 & 1,45 & 0,40 \\ \mathrm{OH}^{\mathrm{a}} & 1,63 & 1,66 & 1,34 & 1,74 & 1,76 & 1,74 & 1,61 & 1,84 & 1,75 & 1,77 & 1,84\end{array}$

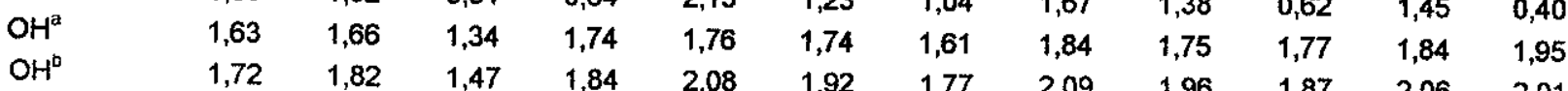

$\begin{array}{llllllllllll}\mathrm{OH}^{\mathrm{c}} & 1,85 & 2,05 & 1,68 & 1,98 & 2,56 & 2,20 & 2,00 & 2,08 & 2,27 & 2,01 & 2,39\end{array}$

$\begin{array}{lllllllllllll}\mathrm{Na} & 0,094 & 0,106 & 0,072 & 0,065 & 0,049 & 0,055 & 0,082 & 0,085 & 0,032 & 0,056 & 0,134 & 0,054 \\ \mathrm{Ca} & & 9,832 & 9,834 & 0,855 & 0,077 & 9,807 & 9,893 & 9,854 & 9,854 & 9,08 & 9,886 & 9,777\end{array}$

$\begin{array}{lllllllllllll}\mathrm{Ca} & \mathbf{9 , 8 3 2} & \mathbf{9 , 8 3 4} & \mathbf{9 , 8 5 5} & \mathbf{9 , 8 7 7} & \mathbf{9 , 8 6 7} & \mathbf{9 , 8 9 3} & \mathbf{9 , 8 5 4} & \mathbf{9 , 8 5 4} & \mathbf{9 , 9 0 8} & \mathbf{9 , 8 8 6} & \mathbf{9 , 7 7 7} & \mathbf{9 , 8 7 7}\end{array}$

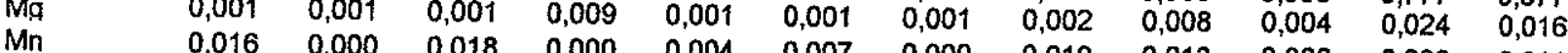

Fe $\quad \begin{array}{llllllllllllll} & 0,009 & 0,000 & 0,000 & 0,000 & 0,004 & 0,007 & 0,000 & 0,019 & 0,013 & 0,000 & 0,008 & 0,011\end{array}$

$\begin{array}{llllll}\mathrm{Sr} & 0,044 & 0,054 & 0,042 & 0,042 & 0,044\end{array}$

$\begin{array}{llllllllllllll}\text { Ba } & 0,000 & 0,001 & 0,004 & 0,000 & 0,000 & 0,000 & 0,000 & 0,000 & 0,000 & 0,035 & 0,038 & 0,035\end{array}$

Al $\quad \begin{array}{llllllllllllll} & 0,001 & 0,001 & 0,001 & 0,001 & 0,004 & 0,001 & 0,001 & 0,001 & 0,001 & 0,001 & 0,001 & 0,001\end{array}$

$\begin{array}{lllllllllllll}\text { La } & 0,003 & 0,004 & 0,000 & 0,000 & 0,012 & 0,004 & 0,000 & 0,003 & 0,000 & 0,005 & 0,008 & 0,000\end{array}$

Ce $\quad \begin{array}{lllllllllllll}0,000 & 0,000 & 0,009 & 0,005 & 0,013 & 0,002 & 0,013 & 0,000 & 0,004 & 0,010 & 0,001 & 0,003\end{array}$

$\begin{array}{llllllllllllll}\text { Si } & 0,008 & 0,014 & 0,004 & 0,008 & 0,032 & 0,021 & 0,014 & 0,015 & 0,014 & 0,017 & 0,034 & 0,016\end{array}$

$\begin{array}{lllllllllllll}\text { C } & \quad 0,136 & 0,232 & 0,707 & 0,147 & 0,483 & 5,698 & 5,748 & 5,606 & 5,672 & 5,840 & 5,636 & 5,893\end{array}$

F $\quad \begin{array}{lllllllllllll} & 1,040 & 1,021 & 1,213 & 0,975 & 0,975 & 0,081 & 1,055 & 0,926 & 0,974 & 0,955 & 0,924 & 0,848\end{array}$

$\begin{array}{lllllll}0,981 & 1,055 & 0,926 & 0,974 & 0,955 & 0,924 & 0,848\end{array}$

$\begin{array}{lllllllllllll}\mathrm{OH}^{\mathrm{a}} & 0,944 & 0,970 & 0,786 & 1,025 & 1,025 & 1,018 & 0,945 & 1,072 & 1,026 & 1,045 & 1,076 & 1,152\end{array}$

$\begin{array}{lllllllll}1,025 & 1,025 & 1,018 & 0,945 & 1,072 & 1,026 & 1,045 & 1,076 & 1,152\end{array}$

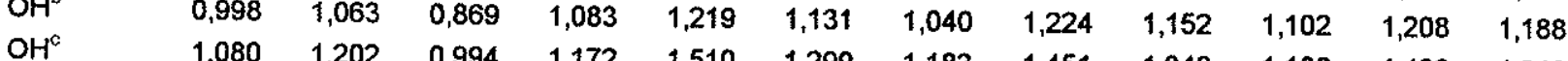

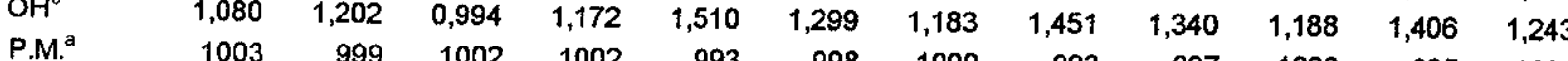

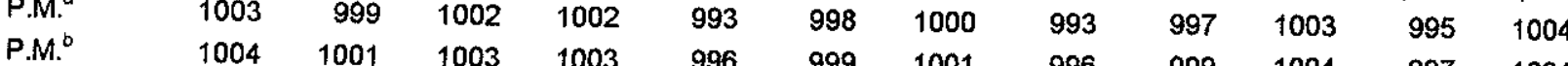

$\begin{array}{llllllllllll}\text { P.M. }^{C} & 1005 & 1003 & 1005 & 1005 & 1001 & 1002 & 1004 & 1000 & 1002 & 1006 & 1000\end{array}$

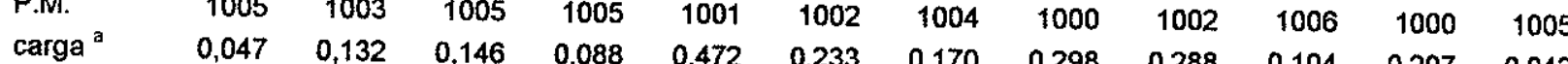

$\begin{array}{ccccccccccccc}\text { carga }^{b} & -0,008 & 0,039 & 0,063 & 0,030 & 0,278 & 0,121 & 0,075 & 0,147 & 0,163 & 0,047 & 0,075 & 0,005\end{array}$

$\begin{array}{llllllllllllll}\text { carga }^{\circ} & -0,090 & -0,100 & -0,061 & -0,058 & -0,013 & -0,048 & -0,068 & -0,080 & -0,026 & -0,039 & -0,124 & -0,049\end{array}$

$\begin{array}{lllllllllllll}\mathrm{CaO} / \mathrm{P}_{2} \mathrm{O}_{5} & 1,327 & 1,350 & 1,345 & 1,335 & 1,422 & 1,372 & 1,355 & 1,389 & 1,380 & 1,338 & 1,371 & 1,324\end{array}$

$\begin{array}{lllllllllllll}\mathrm{F} / \mathrm{P}_{2} \mathrm{O}_{5} & 0,048 & 0,047 & 0,056 & 0,045 & 0,048 & 0,046 & 0,049 & 0,044 & 0,046 & 0,044 & 0,044 & 0,038\end{array}$

$\begin{array}{lllllllllllll}\mathrm{SrO} / \mathrm{P}_{2} \mathrm{O}_{5} & 0,011 & 0,014 & 0,011 & 0,011 & 0,012 & 0,009 & 0,010 & 0,007 & 0,009 & 0,009 & 0,010 & 0,009\end{array}$ 
Tipo

Amostra AN11A AN11A AN11A$$
\mathrm{Na}_{2} \mathrm{O}
$$

\section{$\mathrm{CaO}$}

$\mathrm{MgO}$

$\mathrm{MnO}$

$\mathrm{FeO}$

SrO

$\mathrm{BaO}$

$\mathrm{Al}_{2} \mathrm{O}_{3}$

$\mathrm{La}_{2} \mathrm{O}_{3}$

$\mathrm{Ce}_{2} \mathrm{O}_{3}$

$\mathrm{SiO}_{2}$

$\mathrm{P}_{2} \mathrm{O}_{5}$

$F$

Cl

$\mathrm{O}=\mathrm{F}, \mathrm{Cl}$

TOTAL

$\mathrm{CO}_{2}$

$\mathrm{OH}^{2}$

$\mathrm{OH}^{\mathrm{C}}$

$\mathrm{Na}$

$\mathrm{Ca}$

$\mathrm{Mn}$

$\mathrm{Fe}$

Sr

$\mathrm{Bl}$

La

$\mathrm{Si}$

Sì

C

$\mathrm{F}$

$\mathrm{Ol}$

$\mathrm{OH}^{\circ}$

$\mathrm{OH}^{\mathrm{c}}$

P.M.

P.M

P.M.

carga $^{a}$

carga $^{b}$

carga $^{c}$

$\mathrm{CaO} / \mathrm{P}_{2} \mathrm{O}_{5}$

$\mathrm{F} / \mathrm{P}_{2} \mathrm{O}_{5}$

$\mathrm{SrO} / \mathrm{P}_{2} \mathrm{O}_{5}$ $\begin{array}{lll}28 & 29 & 30\end{array}$

$0,07 \quad 0,00 \quad 0,00$

$0,10 \quad 0,00 \quad 0,04$

$0,00 \quad 0,00$

$0,34 \quad 0,46$

0,06

$\begin{array}{ll}0,00 & 0,00 \\ 0,00 & 0,00\end{array}$

0,00

$0,00 \quad 0,03$

0,00

$0,05 \quad 0,00 \quad 0,06$

0,06

$0,10 \quad 0,14 \quad 0,15$

$41,06 \quad 41,68 \quad 40,83$

$\begin{array}{rrr}0,02 & 0,05 & 0,02 \\ 98,73 & 99,14 & 98,44\end{array}$

$\begin{array}{lll}0,112 & 0,075 & 0,065 \\ 9,820 & 9,878 & 9,887\end{array}$

$\begin{array}{lll}9,018 & 0,001 & 0,001\end{array}$

$\begin{array}{lll}0,014 & 0,000 & 0,006\end{array}$

$0,000 \quad 0,000 \quad 0,009$

$0,033 \quad 0,045 \quad 0,030$

$\begin{array}{lll}0,000 & 0,000 & 0,000\end{array}$

$0,001 \quad 0,001 \quad 0,001$

$\begin{array}{lll}0,000 & 0,002 & 0,000\end{array}$

$0,003 \quad 0,000 \quad 0,004$

$0,017 \quad 0,024$

0,026

0,910

$0,799 \quad 1,029$

$\begin{array}{lll}1002 & 1005 & 1004\end{array}$

$\begin{array}{lll}0,107 & 0,016 & 0,117\end{array}$

$\begin{array}{rrr}0,021 & -0,019 \quad 0,047\end{array}$

$\begin{array}{cccccc}2 a & 2 a & 2 a & 2 a & 2 a & 2 a\end{array}$ AN10C AN10C AN10C AN10C AN10C AN10C AN10C AN9E AN9E

$\begin{array}{rrr}0,35 & 0,23 & 0,20 \\ 55,23 & 55,25 & 55,02\end{array}$

1
0,23

$$
0,29
$$
0,40

$\begin{array}{lll}54,93 & 54,89 & 54,58\end{array}$

$\begin{array}{lll}1,73 & 1,51 \quad 1,94\end{array}$

0,15

0,15

0,00

0,04

0,13

0,00

$0,02 \quad 0,07$

$0,12 \quad 0,03$

$0,02 \quad 0,00$

$\begin{array}{ll}0,42 & 0,47\end{array}$

$0,00 \quad 0,00$

$0,00 \quad 0,00$

$0,00 \quad 0,07$

$0,00 \quad 0,00$

$$
\begin{array}{r}
4 \\
0,23
\end{array}
$$

0,23

$\begin{array}{rr}54,35 & 55,45 \\ 0,09 & 0,05\end{array}$

$0,10 \quad 0,09$

$0,06 \quad 0,08$

$0,48 \quad 0,50$

0,00

0,00

0,00

0,00

0,00

0,08 6
0,37
55,52

0,18

$0,21 \quad 0,31$

$\begin{array}{lll}0,23 & 0,52 & 0,28\end{array}$

0,11

0,00

0,02

0,05

0,05

0,56

0,00

0,01

$55,42 \quad 55,02 \quad 55,37$

$\begin{array}{lll}0,00 & 0,07 & 0,00\end{array}$

$\begin{array}{llll}41,91 & 40,95 & 38,75 & 39,05\end{array}$

0,04

0,00

$0,00 \quad 0,00 \quad 0,00$

2,20

$\begin{array}{llll}2,20 & 2,14 & 1,94 & 1,93 \\ 0,03 & 0,02 & 0,01 & 0,02\end{array}$

$0,02 \quad 0,01 \quad 0,02$

$40,19 \quad 37,58$

2,07

1,95

$0,03 \quad 0,01$

96,49

98,82

0,93

0,90

0,82

0,81

0,87

96,19

$99,35 \quad 98,21$

95,39

$\begin{array}{lll}0,94 & 0,38 & 0,77 \\ 1,86 & 2,03 & 1,65 \\ 2,00 & 2,09 & 1,77\end{array}$

$0,17 \quad 0,49$

$1,42 \quad 1,47$

1,4

1,48

1,54

$1,67 \quad 1,65$

$1,97 \quad 1,90$

2,43

2,28

$0,075 \quad 0,094$

$9,825 \quad 9,839$

0,129

$0,074 \quad 0,075$

0,002

0,022

0,017

9,799

$0,021 \quad 0,003$

$0,048 \quad 0,041$

0,000

0,008

0,008

0,000

0,038

5,923

0,039

0,000

0,000

$\begin{array}{ll}0,000 & 0,001\end{array}$

$0,000 \quad 0,000$

$0,086 \quad 0,047$

$5,801 \quad 5,496$

$\begin{array}{ll}0,113 & 0,457\end{array}$

$9,827 \quad 0,835$

$\begin{array}{ll}0,023 & 0,013 \\ 0,014 & 0,012\end{array}$

$0,008 \quad 0,011$

$0,047 \quad 0,048$

$0,000 \quad 0,000$

$0,001 \quad 0,001$

$0,000 \quad 0,005$

$0,007 \quad 0,000$

0,048

5,579

0,045

5,633

$0,373 \quad 0,322$

0,82

0,79

99,20

$\begin{array}{rr}0,78 & 0,74 \\ 97,99 & 97,14\end{array}$

1,160

0,008

$1,135 \quad 1,030$

1,032

1,084

0,006

0,009

0,832

0,860

0,002

0,962

0,907

$1,111 \quad 1,036$

0,847

$0,905 \quad 1,152$

$0,973 \quad 1,426$

1,335

1005

1003990

995

1,229

$1005 \quad 1004$

$1005 \quad 1005$

993

997

997

$999 \quad 988$

$3,13 \quad 0,58$

$0,99 \quad 1,73$

$-0,005 \quad 0,021$

998

1001

999

2,89

1,95

2,11

2,49

$\begin{array}{llll}0,119 & 0,057 & 0,068 & 0,099\end{array}$

$\begin{array}{llll}9,802 & 9,858 & 9,824 & 9,832\end{array}$

$\begin{array}{llll}0,005 & 0,001 & 0,017 & 0,001\end{array}$

$\begin{array}{llll}0,007 & 0,006 & 0,020 & 0,013\end{array}$

$\begin{array}{llll}0,006 & 0,000 & 0,020 & 0,000\end{array}$

$\begin{array}{llll}0,053 & 0,065 & 0,038 & 0,040\end{array}$

$\begin{array}{llll}0,000 & 0,000 & 0,000 & 0,000\end{array}$

$\begin{array}{llll}0,002 & 0,001 & 0,001 & 0,001\end{array}$

$\begin{array}{llll}0,006 & 0,000 & 0,008 & 0,002\end{array}$

$\begin{array}{llll}0,002 & 0,013 & 0,005 & 0,014\end{array}$

$\begin{array}{llll}0,051 & 0,009 & 0,001 & 0,010\end{array}$

$\begin{array}{llll}5,242 & 5,860 & 5,773 & 5,597\end{array}$

$\begin{array}{llll}0,707 & 0,132 & 0,226 & 0,393\end{array}$

$\begin{array}{llll}1,015 & 0,979 & 0,981 & 0,926\end{array}$

$\begin{array}{llll}0,002 & 0,002 & 0,002 & 0,002\end{array}$

$\begin{array}{llll}0,983 & 1,019 & 1,017 & 1,071\end{array}$

$-0,021-0,024$

0,334

0,307

0,254

0,254

0,158

$-0,069$

$-0,044 \quad-0,092$

$-0,123$

$-0,065$

1,380

$1,311 \quad 1,340$

1,409

1,392

0,051

$0,052 \quad 0,052 \quad 0,050$

0,049

0,012

1,265

$\begin{array}{lll}1,071 & 1,107 & 1,228\end{array}$ 


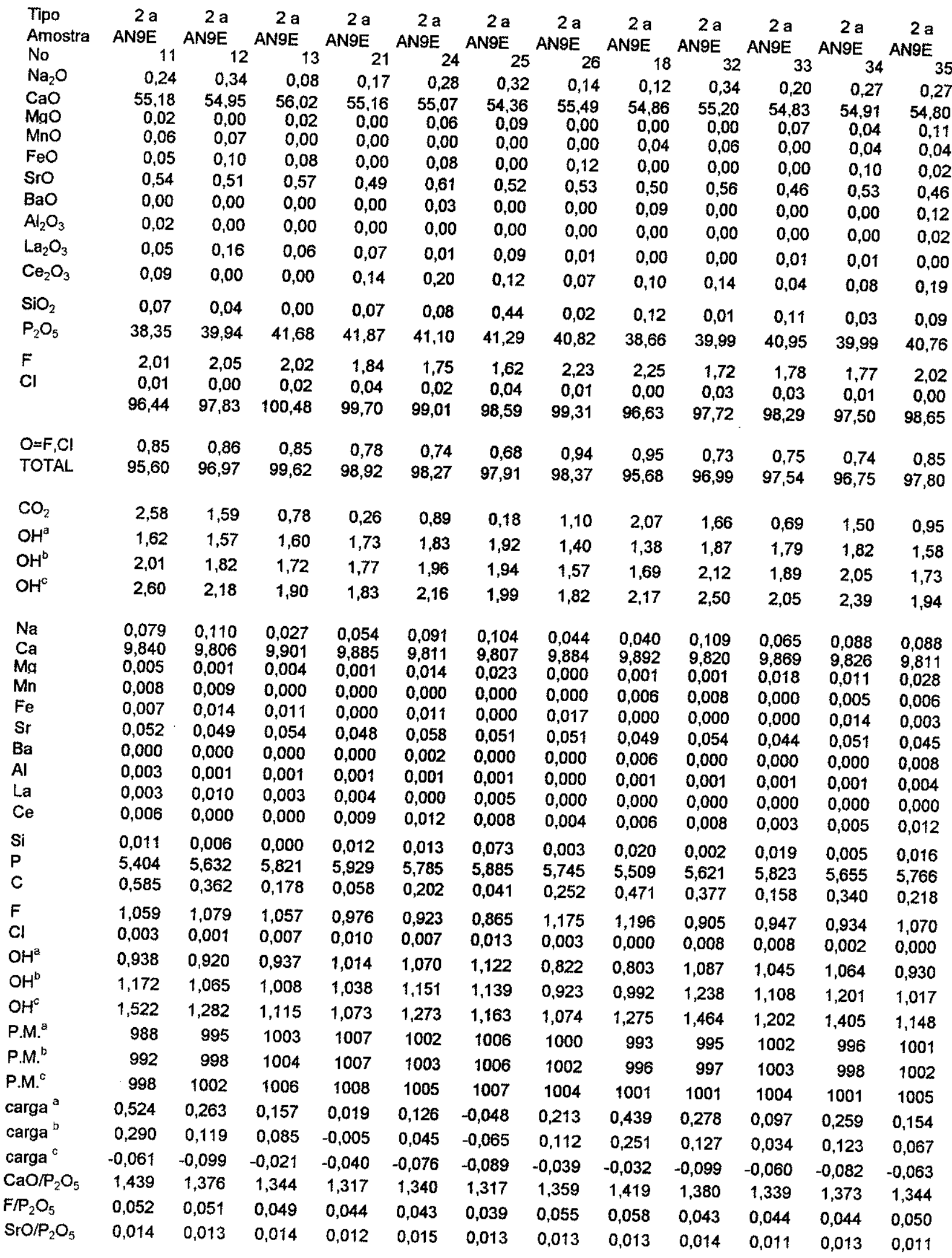




\begin{tabular}{|c|c|c|c|c|c|c|c|c|c|c|c|c|}
\hline $\begin{array}{l}\text { Tipo } \\
\text { Amostra } \\
\text { No }\end{array}$ & $\begin{array}{c}2 \mathrm{a} \\
\underset{36}{\text { TGB5B }}\end{array}$ & $\begin{array}{c}2 \mathrm{a} \\
\text { TGB5B } \\
37\end{array}$ & $\begin{array}{c}2 a \\
\text { TGB5B } \\
38\end{array}$ & $\begin{array}{c}2 \mathrm{a} \\
\text { TGB5B } \\
39\end{array}$ & $\begin{array}{c}2 a \\
\text { TGB5B } \\
20\end{array}$ & $\begin{array}{c}2 a \\
\text { TGB5B } \\
21\end{array}$ & $\begin{array}{c}2 a \\
\text { TGB5B } \\
22\end{array}$ & $\begin{array}{c}2 a \\
\text { TGB5B } \\
23\end{array}$ & $\begin{array}{c}2 a \\
\text { TGB5B } \\
24\end{array}$ & $\begin{array}{c}2 a \\
\text { TGB5B } \\
25\end{array}$ & $\begin{array}{c}2 a \\
\text { TGB5B } \\
26\end{array}$ & $\begin{array}{c}2 a \\
\text { TGB5B } \\
27\end{array}$ \\
\hline $\mathrm{Na}_{2} \mathrm{O}$ & 0,35 & 0,23 & 0,24 & 0,29 & 0,22 & 0,24 & 0,19 & 0,29 & 0,32 & 0,24 & 0,15 & 0,07 \\
\hline $\begin{array}{l}\mathrm{CaO} \\
\mathrm{MaO} \\
\mathrm{MnO}\end{array}$ & $\begin{array}{r}54,90 \\
0,07 \\
0,15\end{array}$ & $\begin{array}{r}55,17 \\
0,04 \\
0,06\end{array}$ & $\begin{array}{r}55,31 \\
0,07 \\
0,16\end{array}$ & $\begin{array}{r}55,82 \\
0,08 \\
0,05\end{array}$ & $\begin{array}{r}55,60 \\
0,07 \\
0,09\end{array}$ & $\begin{array}{r}55,32 \\
0,00 \\
0,19\end{array}$ & $\begin{array}{r}55,05 \\
0,03 \\
0,00\end{array}$ & $\begin{array}{r}55,21 \\
0,00 \\
0,14\end{array}$ & $\begin{array}{r}54,47 \\
0,00 \\
0,16\end{array}$ & $\begin{array}{r}55,33 \\
0,00 \\
0,09\end{array}$ & $\begin{array}{r}54,82 \\
0,04 \\
0,16\end{array}$ & $\begin{array}{r}55,48 \\
0,00 \\
0,00\end{array}$ \\
\hline $\mathrm{FeO}$ & 0,03 & 0,16 & 0,11 & 0,00 & 0,00 & 0,00 & 0,00 & 0,00 & 0,03 & 0,00 & 0,11 & 0,48 \\
\hline SrO & 0,40 & 0,39 & 0,57 & 0,57 & 0,53 & 0,46 & 0,48 & 0,52 & 0,52 & 0,48 & 0,63 & 0,51 \\
\hline $\mathrm{BaO}$ & 0,00 & 0,00 & 0,00 & 0,00 & 0,09 & 0,00 & 0,03 & 0,00 & 0,00 & 0,00 & 0,00 & 0,00 \\
\hline $\mathrm{Al}_{2} \mathrm{O}_{3}$ & 0,03 & 0,00 & 0,00 & 0,01 & 0,00 & 0,00 & 0,03 & 0,00 & 0,07 & 0,00 & 0,00 & 0,00 \\
\hline $\mathrm{La}_{2} \mathrm{O}_{3}$ & 0,08 & 0,00 & 0,14 & 0,00 & 0,06 & 0,00 & 0,00 & 0,06 & 0,08 & 0,00 & 0,07 & 0,00 \\
\hline $\mathrm{Ce}_{2} \mathrm{O}_{3}$ & 0,34 & 0,00 & 0,16 & 0,05 & 0,10 & 0,23 & 0,22 & 0,03 & 0,15 & 0,10 & 0,20 & 0,16 \\
\hline $\mathrm{SiO}_{2}$ & 0,03 & 0,07 & 0,07 & 0,06 & 0,06 & 0,01 & 0,07 & 0,00 & 0,14 & 0,09 & 0,08 & 0,05 \\
\hline $\mathrm{P}_{2} \mathrm{O}_{5}$ & 38,45 & 38,31 & 39,93 & 40,56 & 41,85 & 41,36 & 42,59 & 42,03 & 41,85 & 41,99 & 41,60 & 41,31 \\
\hline$F$ & 1,86 & 1,65 & 1,77 & 1,77 & 2,01 & 1,76 & 2,14 & 2,06 & 2,10 & 1,99 & 1,93 & 1,71 \\
\hline $\mathrm{Cl}$ & 0,01 & 0,02 & 0,02 & 0,00 & 0,00 & 0,00 & 0,02 & 0,00 & 0,04 & 0,03 & 0,06 & 0,02 \\
\hline & 96,34 & 95,89 & 98,30 & 98,99 & 100,48 & 99,33 & 100,68 & 100,07 & 99,62 & 100,11 & 99,69 & 99,74 \\
\hline $\begin{array}{l}\text { O=F,Cl } \\
\text { TOTAL }\end{array}$ & $\begin{array}{r}0,78 \\
95,56\end{array}$ & $\begin{array}{r}0,70 \\
95,20\end{array}$ & $\begin{array}{r}0,74 \\
97,56\end{array}$ & $\begin{array}{r}0,74 \\
98,24\end{array}$ & $\begin{array}{r}0,84 \\
99,63\end{array}$ & $\begin{array}{r}0,74 \\
98,59\end{array}$ & $\begin{array}{r}0,90 \\
99,78\end{array}$ & $\begin{array}{r}0,87 \\
99,20\end{array}$ & $\begin{array}{r}0,89 \\
98,73\end{array}$ & $\begin{array}{r}0,84 \\
99,27\end{array}$ & $\begin{array}{r}0,81 \\
98,88\end{array}$ & $\begin{array}{r}0,72 \\
99,02\end{array}$ \\
\hline $\mathrm{CO}_{2}$ & 2,57 & 2,58 & 1,76 & 1,54 & 0,62 & 0,82 & $-0,19$ & 0,38 & 0,11 & 0,32 & 0,41 & 0,85 \\
\hline $\mathrm{OH}^{\mathrm{a}}$ & 1,76 & 1,95 & 1,84 & 1,85 & 1,61 & 1,83 & 1,46 & 1,55 & 1,49 & 1,61 & 1,65 & 1,87 \\
\hline $\mathrm{OH}^{b}$ & 2,15 & 2,34 & 2,11 & 2,08 & 1,71 & 1,95 & 1,43 & 1,61 & 1,51 & 1,66 & 1,71 & 2,00 \\
\hline $\mathrm{OH}^{\circ}$ & 2,74 & 2,92 & 2,50 & 2,43 & 1,85 & 2,14 & 1,39 & 1,70 & 1,53 & 1,73 & 1,81 & 2,19 \\
\hline $\begin{array}{l}\mathrm{Na} \\
\mathrm{Ca} \\
\mathrm{Mg}\end{array}$ & $\begin{array}{l}0,114 \\
9,780 \\
0,017\end{array}$ & $\begin{array}{l}0,075 \\
9,846 \\
0,010\end{array}$ & $\begin{array}{l}0,077 \\
9,796 \\
0,018\end{array}$ & $\begin{array}{l}0,091 \\
9,823 \\
0,021\end{array}$ & $\begin{array}{l}0,070 \\
9,832 \\
0,018\end{array}$ & $\begin{array}{l}0,078 \\
9,836 \\
0,001\end{array}$ & $\begin{array}{l}0,062 \\
9,867 \\
0,007\end{array}$ & $\begin{array}{l}0,093 \\
9,830 \\
0,001\end{array}$ & $\begin{array}{l}0,104 \\
9,804 \\
0,001\end{array}$ & $\begin{array}{l}0,077 \\
9,857 \\
0,001\end{array}$ & $\begin{array}{l}0,049 \\
9,827 \\
0,010\end{array}$ & $\begin{array}{l}0,024 \\
9,850 \\
0,001\end{array}$ \\
\hline$M n$ & 0,021 & 0,009 & 0,022 & 0,007 & 0,013 & 0,027 & 0,000 & 0,020 & 0,023 & 0,012 & 0,022 & 0,000 \\
\hline $\mathrm{Fe}$ & 0,004 & 0,022 & 0,015 & 0,000 & 0,000 & 0,000 & 0,000 & 0,000 & 0,005 & 0,000 & 0,015 & 0,067 \\
\hline Sr & 0,039 & 0,038 & 0,054 & 0,054 & 0,051 & 0,044 & 0,047 & 0,050 & 0,050 & 0,046 & 0,061 & 0,049 \\
\hline $\mathrm{Ba}$ & 0,000 & 0,000 & 0,000 & 0,000 & 0,006 & 0,000 & 0,002 & 0,000 & 0,000 & 0,000 & 0,000 & 0,000 \\
\hline Al & 0,006 & 0,001 & 0,001 & 0,002 & 0,001 & 0,001 & 0,007 & 0,001 & 0,013 & 0,001 & 0,001 & 0,001 \\
\hline La & 0,005 & 0,000 & 0,008 & 0,000 & 0,004 & 0,000 & 0,000 & 0,004 & 0,005 & 0,000 & 0,004 & 0,000 \\
\hline $\mathrm{Ce}$ & 0,021 & 0,000 & 0,009 & 0,003 & 0,006 & 0,014 & 0,014 & 0,002 & 0,009 & 0,006 & 0,012 & 0,010 \\
\hline $\mathrm{Si}$ & 0,005 & 0,012 & 0,012 & 0,010 & 0,010 & 0,002 & 0,011 & 0,000 & 0,024 & 0,015 & 0,013 & 0,009 \\
\hline$P$ & 5,412 & 5,403 & 5,588 & 5,640 & 5,848 & 5,810 & 6,032 & 5,913 & 5,951 & 5,912 & 5,893 & 5,796 \\
\hline C & 0,583 & 0,585 & 0,400 & 0,350 & 0,142 & 0,188 & $-0,043$ & 0,087 & 0,025 & 0,074 & 0,094 & 0,195 \\
\hline $\begin{array}{l}\mathrm{F} \\
\mathrm{Cl}\end{array}$ & $\begin{array}{l}0,977 \\
0,003\end{array}$ & $\begin{array}{l}0,871 \\
0,005\end{array}$ & $\begin{array}{l}0,924 \\
0,005\end{array}$ & $\begin{array}{l}0,918 \\
0,000\end{array}$ & $\begin{array}{l}1,047 \\
0,000\end{array}$ & $\begin{array}{l}0,922 \\
0,000\end{array}$ & $\begin{array}{l}1,133 \\
0,007\end{array}$ & $\begin{array}{l}1,082 \\
0,000\end{array}$ & $\begin{array}{l}1,117 \\
0,012\end{array}$ & $\begin{array}{l}1,048 \\
0,008\end{array}$ & $\begin{array}{l}1,021 \\
0,016\end{array}$ & $\begin{array}{l}0,897 \\
0,007\end{array}$ \\
\hline $\mathrm{OH}^{\mathrm{a}}$ & 1,020 & 1,123 & $\uparrow, 071$ & 1,082 & 0,952 & 1,078 & 0,860 & 0,917 & 0,871 & 0,945 & 0,963 & 1,096 \\
\hline $\mathrm{OH}^{b}$ & 1,253 & 1,357 & 1,231 & 1,222 & 1,009 & 1,153 & 0,860 & 0,952 & 0,881 & 0,974 & 1,001 & 1,174 \\
\hline $\mathrm{OH}^{\circ}$ & 1,603 & 1,708 & 1,471 & 1,432 & 1,095 & 1,265 & 0,860 & 1,004 & 0,896 & 1,018 & 1,057 & 1,291 \\
\hline P.M. ${ }^{a}$ & 988 & 986 & 995 & 995 & 1004 & 1002 & 1011 & 1005 & 1009 & 1005 & 1007 & 1003 \\
\hline P.M. ${ }^{b}$ & 992 & 990 & 998 & 997 & 1005 & 1003 & 1011 & 1005 & 1009 & 1006 & 1008 & 1004 \\
\hline P.M. ${ }^{c}$ & 998 & 996 & 1002 & 1001 & 1006 & 1005 & 1010 & 1006 & 1009 & 1007 & 1009 & 1006 \\
\hline carga $^{a}$ & 0,514 & 0,512 & 0,343 & 0,269 & 0,084 & 0,125 & $-0,072$ & 0,000 & $-0,024$ & 0,004 & 0,064 & 0,183 \\
\hline carga $^{b}$ & 0,281 & 0,278 & 0,183 & 0,129 & 0,027 & 0,050 & $-0,072$ & $-0,034$ & $-0,034$ & $-0,025$ & 0,026 & 0,105 \\
\hline carga $^{c}$ & $-0,069$ & $-0,073$ & $-0,057$ & $-0,081$ & $-0,059$ & $-0,063$ & $-0,072$ & $-0,086$ & $-0,049$ & $-0,069$ & $-0,030$ & $-0,012$ \\
\hline $\mathrm{CaO} / \mathrm{P}_{2} \mathrm{O}_{5}$ & 1,428 & 1,440 & 1,385 & 1,376 & 1,328 & 1,338 & 1,292 & 1,314 & 1,302 & 1,317 & 1,318 & 1,343 \\
\hline $\mathrm{F} / \mathrm{P}_{2} \mathrm{O}_{5}$ & 0,048 & 0,043 & 0,044 & 0,044 & 0,048 & 0,042 & 0,050 & 0,049 & 0,050 & 0,047 & 0,046 & 0,041 \\
\hline $\mathrm{SrO} / \mathrm{P}_{2} \mathrm{O}_{5}$ & 0,011 & 0,010 & 0,014 & 0,014 & 0,013 & 0,011 & 0,011 & 0,012 & 0,012 & 0,011 & 0,015 & 0,012 \\
\hline
\end{tabular}




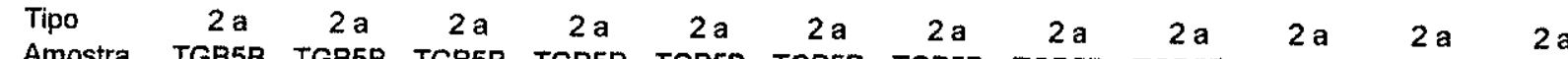
$\begin{array}{lrrrrrrrrrrrrr}\text { Amostra } & \text { TGB5B } & \text { TGB5B } & \text { TGB5B } & \text { TGB5B } & \text { TGB5B } & \text { TGB5B } & \text { TGB5B } & \text { TGB5B } & \text { TGB5B } & \text { TGB5B } & \text { TGB5B } & \text { TGB5B } \\ \text { No } & 28 & 29 & 30 & 31 & 32 & 33 & 34 & 35 & 36 & 37 & 38\end{array}$

\begin{tabular}{|c|c|c|c|c|c|c|c|c|c|c|c|c|}
\hline No & 28 & 29 & 30 & 31 & 32 & 33 & 34 & 35 & 36 & 37 & 38 & 39 \\
\hline $\mathrm{Na}_{2} \mathrm{O}$ & 0,13 & 0,27 & 0,04 & 0,36 & 0,33 & 0,21 & 0,15 & 0,09 & 0,33 & 0,28 & 0,28 & 0,23 \\
\hline $\begin{array}{l}\mathrm{CaO} \\
\mathrm{MqO}\end{array}$ & $\begin{array}{r}55,43 \\
0,00\end{array}$ & $\begin{array}{r}54,90 \\
0,00\end{array}$ & $\begin{array}{r}55,48 \\
0,00\end{array}$ & $\begin{array}{r}55,21 \\
0,05\end{array}$ & $\begin{array}{r}54,82 \\
0,04\end{array}$ & $\begin{array}{r}55,46 \\
0,00\end{array}$ & $\begin{array}{r}54,73 \\
0,00\end{array}$ & $\begin{array}{r}54,75 \\
0,03\end{array}$ & $\begin{array}{r}55,18 \\
0,02\end{array}$ & $\begin{array}{r}55,04 \\
0,04\end{array}$ & $\begin{array}{r}54,09 \\
0,02\end{array}$ & $\begin{array}{r}55,20 \\
0,02\end{array}$ \\
\hline $\mathrm{MnO}$ & 0,05 & 0,18 & 0,11 & 0,01 & 0,06 & 0,00 & 0,00 & 0,20 & 0,01 & 0,11 & 0,10 & 0,05 \\
\hline $\mathrm{FeO}$ & 0,05 & 0,00 & 0,05 & 0,03 & 0,14 & 0,00 & 0,01 & 0,00 & 0,00 & 0,00 & 0,00 & 0,01 \\
\hline SrO & 0,52 & 0,50 & 0,51 & 0,57 & 0,52 & 0,61 & 0,45 & 0,60 & 0,62 & 0,47 & 0,56 & 0,48 \\
\hline $\mathrm{BaO}$ & 0,09 & 0,00 & 0,00 & 0,05 & 0,01 & 0,00 & 0,00 & 0,00 & 0,00 & 0,00 & 0,00 & 0,00 \\
\hline $\mathrm{Al}_{2} \mathrm{O}_{3}$ & 0,00 & 0,02 & 0,00 & 0,00 & 0,00 & 0,00 & 0,04 & 0,00 & 0,02 & 0,00 & 0,06 & 0,03 \\
\hline $\mathrm{La}_{2} \mathrm{O}_{3}$ & 0,00 & 0,00 & 0,20 & 0,00 & 0,08 & 0,00 & 0,05 & 0,08 & 0,00 & 0,10 & 0,07 & 0,08 \\
\hline $\mathrm{Ce}_{2} \mathrm{O}_{3}$ & 0,11 & 0,27 & 0,00 & 0,23 & 0,17 & 0,09 & 0,17 & 0,00 & 0,03 & 0,16 & 0,05 & 0,02 \\
\hline $\mathrm{SiO}_{2}$ & 0,06 & 0,06 & 0,07 & 0,06 & 0,07 & 0,03 & 0,08 & 0,28 & 0,09 & 0,11 & 0,11 & 0,06 \\
\hline $\mathrm{P}_{2} \mathrm{O}_{5}$ & 42,08 & 41,51 & 41,27 & 40,75 & 41,19 & 42,38 & 41,27 & 39,77 & 41,02 & 40,83 & 41,64 & 40,63 \\
\hline$F$ & $\begin{array}{l}1,91 \\
0,04\end{array}$ & $\begin{array}{l}1,87 \\
0.01\end{array}$ & $\begin{array}{l}2,05 \\
0,00\end{array}$ & 2,10 & 1,86 & 1,78 & 2,16 & 1,78 & 1,92 & 1,74 & 1,92 & 2,14 \\
\hline & 100,35 & 99,32 & $\begin{array}{r}0,00 \\
99,75\end{array}$ & $\begin{array}{r}0,00 \\
99,04\end{array}$ & $\begin{array}{r}0,00 \\
98.96\end{array}$ & $\begin{array}{r}0,00 \\
0\end{array}$ & $\begin{array}{r}0,02 \\
98,99\end{array}$ & 0,01 & $\begin{array}{r}0,00 \\
0,00\end{array}$ & 0,00 & 0,00 & 0,04 \\
\hline
\end{tabular}

$\begin{array}{lrrrrrrrrrrrr}\text { O=F,Cl } & 0,80 & 0,79 & 0,86 & 0,88 & 0,78 & 0,75 & 0,91 & 0,75 & 0,81 & 0,73 & 0,81 & 0,90 \\ \text { TOTAL } & 99,55 & 98,53 & 98,89 & 98,16 & 98,18 & 99,61 & 98,08 & 98,76 & 98,10 & 97,88 & 97,82 & 97,85\end{array}$

\begin{tabular}{|c|c|c|c|c|c|c|c|c|c|c|c|c|}
\hline $\mathrm{CO}_{2}$ & 0,27 & 0,54 & 0,74 & 1,21 & 0,77 & 0,16 & 0,41 & 1,26 & 0,94 & 0,99 & 0,02 & 1,12 \\
\hline $\mathrm{OH}^{\mathrm{a}}$ & 1,68 & 1,71 & 1,56 & 1,53 & 1,73 & 1,80 & 1,43 & 1,79 & 1,69 & 1,84 & 1,64 & 1,48 \\
\hline $\mathrm{OH}^{b}$ & 1,72 & 1,79 & 1,67 & 1,72 & 1,85 & 1,82 & 1,49 & 1,98 & 1,83 & 1,99 & 1,64 & 1,66 \\
\hline$O H^{c}$ & 1,78 & 1,91 & 1,84 & 2,00 & 2,02 & 1,86 & 1,59 & 2,27 & 2,05 & 2,21 & 1,64 & 1,91 \\
\hline $\begin{array}{l}\mathrm{Na} \\
\mathrm{Ca} \\
\mathrm{Ma}\end{array}$ & $\begin{array}{l}0,041 \\
9,881 \\
0,001\end{array}$ & $\begin{array}{l}0,087 \\
9,821 \\
0,001\end{array}$ & $\begin{array}{l}0,014 \\
9,902 \\
0,001\end{array}$ & $\begin{array}{l}0,115 \\
9,797 \\
0,012\end{array}$ & $\begin{array}{l}0,105 \\
9,789 \\
0,011\end{array}$ & $\begin{array}{l}0,067 \\
9,868 \\
0,001\end{array}$ & $\begin{array}{l}0,050 \\
9,889 \\
0,001\end{array}$ & $\begin{array}{l}0,030 \\
9,870 \\
0,007\end{array}$ & $\begin{array}{l}0,108 \\
9,823 \\
0,005\end{array}$ & $\begin{array}{l}0,090 \\
9,822 \\
0,010\end{array}$ & $\begin{array}{l}0,091 \\
9,825 \\
0,006\end{array}$ & $\begin{array}{l}0,074 \\
9,860 \\
0,004\end{array}$ \\
\hline $\mathrm{Mn}$ & 0,007 & 0,026 & 0,015 & 0,001 & 0,009 & 0,000 & 0,000 & 0,028 & 0,002 & 0,015 & 0,015 & 0,007 \\
\hline $\mathrm{Fe}$ & 0,007 & 0,000 & 0,007 & 0,005 & 0,020 & 0,000 & 0,002 & 0,000 & 0,000 & 0,000 & 0,000 & 0,001 \\
\hline Sr & 0,050 & 0,048 & 0,050 & 0,054 & 0,051 & 0,058 & 0,044 & 0,059 & 0,060 & 0,045 & 0,055 & 0,046 \\
\hline $\mathrm{Ba}$ & 0,006 & 0,000 & 0,000 & 0,003 & 0,001 & 0,000 & 0,000 & 0,000 & 0,000 & 0,000 & 0,000 & 0,000 \\
\hline Al & 0,001 & 0,004 & 0,001 & 0,001 & 0,001 & 0,001 & 0,009 & 0,001 & 0,003 & 0,001 & 0,012 & 0,006 \\
\hline La & 0,000 & 0,000 & 0,012 & 0,000 & 0,005 & 0,000 & 0,003 & 0,005 & 0,000 & 0,006 & 0,005 & 0,005 \\
\hline $\mathrm{Ce}$ & 0,007 & 0,016 & 0,000 & 0,014 & 0,010 & 0,005 & 0,011 & 0,000 & 0,002 & 0,010 & 0,003 & 0,001 \\
\hline Si & 0,010 & & 0,011 & 0,010 & 0,012 & 0,005 & 0,013 & 0,048 & 0,015 & 0,018 & 0,019 & 0,011 \\
\hline$P$ & 5,928 & 5,867 & 5,820 & 5,713 & 5,812 & 5,959 & 5,893 & 5,665 & 5,770 & 5,757 & 5,976 & 5,734 \\
\hline C & 0,062 & 0,123 & 0,169 & 0,277 & 0,177 & 0,036 & 0,094 & 0,287 & & 0,225 & 0,005 & 0,255 \\
\hline $\begin{array}{l}\mathrm{F} \\
\mathrm{CI}\end{array}$ & $\begin{array}{l}1,006 \\
0,010\end{array}$ & $\begin{array}{l}0,989 \\
0,002\end{array}$ & $\begin{array}{l}1,080 \\
0,000\end{array}$ & $\begin{array}{l}1,099 \\
0,000\end{array}$ & $\begin{array}{l}0,980 \\
0,001\end{array}$ & $\begin{array}{l}0,935 \\
0,000\end{array}$ & $\begin{array}{l}1,153 \\
0,005\end{array}$ & $\begin{array}{l}0,948 \\
0,004\end{array}$ & $\begin{array}{l}1,007 \\
0,000\end{array}$ & $\begin{array}{l}0,918 \\
0,000\end{array}$ & $\begin{array}{l}1,030 \\
0,000\end{array}$ & $\begin{array}{l}1,127 \\
0,010\end{array}$ \\
\hline $\mathrm{OH}^{\mathrm{a}}$ & 0,984 & 1,008 & 0,920 & 0,901 & 1,020 & 1,065 & 0,842 & 1,048 & 0,993 & 1,082 & 0,969 & 0,863 \\
\hline $\mathrm{OH}^{\mathrm{b}}$ & 1,009 & 1,058 & 0,988 & 1,012 & 1,090 & 1,079 & 0,879 & 1,163 & 1,079 & 1,172 & 0,971 & 0,965 \\
\hline $\mathrm{OH}^{\circ}$ & 1,047 & 1,132 & 1,089 & 1,178 & 1,196 & 1,101 & 0,936 & 1,335 & 1,208 & 1,307 & 0,974 & 1,118 \\
\hline P.M. ${ }^{a}$ & 1007 & 1005 & 1004 & 999 & 1002 & 1007 & 1006 & 999 & 1000 & 1000 & 1008 & 999 \\
\hline P.M. ${ }^{b}$ & 1008 & 1006 & 1005 & 1001 & 1003 & 1007 & 1007 & 1001 & 1001 & 1002 & 1008 & 1001 \\
\hline P.M. ${ }^{\mathrm{C}}$ & 1008 & 1007 & 1007 & 1003 & 1005 & 1007 & 1008 & 1004 & 1003 & 1004 & 1008 & 1004 \\
\hline $\operatorname{carga}^{a}$ & 0,030 & 0,064 & 0,169 & 0,177 & 0,088 & $-0,023$ & 0,084 & 0,264 & 0,118 & 0,153 & $-0,044$ & 0,205 \\
\hline $\operatorname{carga}^{\circ}$ & 0,005 & 0,015 & 0,102 & 0,067 & 0,017 & $-0,038$ & 0,046 & 0,149 & 0,032 & 0,063 & $-0,046$ & 0,103 \\
\hline carga $^{c}$ & $-0,032$ & $-0,059$ & 0,000 & $-0,099$ & $-0,089$ & $-0,059$ & $-0,011$ & $-0,023$ & $-0,097$ & $-0,073$ & $-0,049$ & $-0,050$ \\
\hline $\mathrm{CaO} / \mathrm{P}_{2} \mathrm{O}_{5}$ & 1,317 & 1,323 & 1,344 & 1,355 & 1,331 & 1,308 & 1,326 & 1,377 & 1,345 & 1,348 & 1,299 & 1,359 \\
\hline$=/ P_{2} O_{5}$ & 0,045 & 0,045 & 0,050 & 0,051 & 0,045 & 0,042 & 0,052 & 0,045 & 0,047 & 0,043 & 0,046 & 0,053 \\
\hline $\mathrm{SrO} / \mathrm{P}_{2} \mathrm{O}_{5}$ & 0,012 & 0,012 & 0,012 & 0,014 & 0,013 & 0,014 & 0,011 & 0,015 & 0,015 & 0.012 & 0,013 & 0,012 \\
\hline
\end{tabular}




\begin{tabular}{|c|c|c|c|c|c|c|c|c|c|c|c|}
\hline $\begin{array}{l}\text { Tipo } \\
\text { Amostra } \\
\text { No }\end{array}$ & $\underset{40}{2 a}$ & $\begin{array}{c}2 \mathrm{a} \\
\text { TGB5B } \\
42\end{array}$ & $\begin{array}{c}2 \mathrm{a} \\
\text { TGB5B } \\
43\end{array}$ & $\begin{array}{c}2 \mathrm{a} \\
\mathrm{TGB5B} \\
44\end{array}$ & $\begin{array}{c}2 \mathrm{a} \\
\mathrm{TGB5B} \\
45\end{array}$ & $\begin{array}{c}2 \mathrm{a} \\
\text { TGB5B } \\
46\end{array}$ & $\begin{array}{c}2 \mathrm{~b} \\
\text { TGB5B } \\
\\
\end{array}$ & $\begin{array}{c}2 b \\
\text { TGB4A }\end{array}$ & $\begin{array}{c}2 \mathrm{~b} \\
\text { TGB4A }\end{array}$ & $\begin{array}{c}2 \mathrm{~b} \\
\text { TGB4A } \\
\end{array}$ & $\begin{array}{c}2 \mathrm{~b} \\
\mathrm{TGB} 4 \mathrm{~A}\end{array}$ \\
\hline $\mathrm{Na}_{2} \mathrm{O}$ & 0,18 & 0,11 & 0,21 & 0,31 & 0,13 & 0,23 & 0,14 & 0,31 & 0,21 & 0,03 & 0,15 \\
\hline $\begin{array}{l}\mathrm{CaO} \\
\mathrm{MgO}\end{array}$ & $\begin{array}{r}54,97 \\
0,00\end{array}$ & $\begin{array}{r}55,67 \\
0,09\end{array}$ & $\begin{array}{r}55,60 \\
0,00\end{array}$ & $\begin{array}{r}55,53 \\
0,00\end{array}$ & $\begin{array}{r}55,60 \\
0,01\end{array}$ & $\begin{array}{r}55,18 \\
0,00\end{array}$ & $\begin{array}{r}54,85 \\
0,00\end{array}$ & $\begin{array}{r}54,64 \\
0,00\end{array}$ & $\begin{array}{r}55,50 \\
0,00\end{array}$ & $\begin{array}{r}55,58 \\
0,00\end{array}$ & $\begin{array}{r}55,25 \\
0,00\end{array}$ \\
\hline $\mathrm{MnO}$ & 0,00 & 0,00 & 0,00 & 0,02 & 0,00 & 0,00 & 0,10 & 0,00 & 0,00 & 0,11 & 0,00 \\
\hline $\mathrm{FeO}$ & 0,09 & 0,05 & 0,04 & 0,00 & 0,00 & 0,15 & 0,00 & 0,04 & 0,00 & 0,06 & 0,00 \\
\hline Sro & 0,43 & 0,46 & 0,53 & 0,54 & 0,48 & 0,46 & 0,55 & 0,50 & 0,45 & 0,51 & 0,45 \\
\hline $\mathrm{BaO}$ & 0,00 & 0,00 & 0,00 & 0,00 & 0,00 & 0,00 & 0,00 & 0,00 & 0,00 & 0,00 & 0,00 \\
\hline $\mathrm{Al}_{2} \mathrm{O}_{3}$ & 0,01 & 0,00 & 0,00 & 0,00 & 0,05 & 0,02 & 0,00 & 0,07 & 0,00 & 0,00 & 0,02 \\
\hline $\mathrm{La}_{2} \mathrm{O}_{3}$ & 0,02 & 0,02 & 0,06 & 0,03 & 0,01 & 0,00 & 0,02 & 0,00 & 0,00 & 0,00 & 0,10 \\
\hline $\mathrm{Ce}_{2} \mathrm{O}_{3}$ & 0,18 & 0,05 & 0,08 & 0,10 & 0,26 & 0,10 & 0,30 & 0,08 & 0,00 & 0,13 & 0,04 \\
\hline $\mathrm{SiO}_{2}$ & 0,05 & 0,08 & 0,03 & 0,11 & 0,06 & 0,06 & 0,13 & 0,14 & 0,16 & 0,20 & 0,12 \\
\hline $\mathrm{P}_{2} \mathrm{O}_{5}$ & 40,15 & 40,29 & 41,04 & 41,93 & 41,90 & 42,17 & 40,73 & 40,35 & 40,43 & 41,03 & 40,47 \\
\hline$F$ & 2,07 & 2,03 & 1,87 & 2,05 & 2,10 & 1,89 & 2,24 & 2,20 & 1,90 & 2,21 & 2,18 \\
\hline \multirow[t]{2}{*}{$\mathrm{Cl}$} & 0,02 & 0,02 & 0,00 & 0,04 & 0,04 & 0,01 & 0,00 & 0,04 & 0,00 & 0,00 & 0,03 \\
\hline & 97,98 & 98,76 & 99,26 & 100,36 & 100,53 & 100,03 & 98,93 & 98,07 & 98,47 & 99,84 & 98,68 \\
\hline $\mathrm{O}=\mathrm{F}, \mathrm{Cl}$ & 0,87 & 0,85 & 0,79 & 0,86 & 0,89 & 0,79 & 0,94 & 0,93 & 0,80 & 0,93 & 0,92 \\
\hline TOTAL & 97,11 & 97,91 & 98,47 & 99,49 & 99,64 & 99,23 & 97,99 & 97,14 & 97,67 & 98,92 & 97,76 \\
\hline $\mathrm{CO}_{2}$ & 1,29 & 1,46 & 1,07 & 0,50 & 0,44 & 0,18 & 0,82 & 1,03 & 1,24 & 0,82 & 1,10 \\
\hline $\mathrm{OH}^{a}$ & 1,54 & 1,60 & 1,73 & 1,57 & 1,51 & 1,70 & 1,37 & 1,41 & 1,71 & 1,42 & 1,44 \\
\hline $\mathrm{OH}^{b}$ & 1,73 & 1,82 & 1,90 & 1,65 & 1,58 & 1,73 & 1,50 & 1,57 & 1,90 & 1,55 & 1,60 \\
\hline $\mathrm{OH}^{c}$ & 2,03 & 2,15 & 2,14 & 1,76 & 1,68 & 1,77 & 1,69 & 1,80 & 2,18 & 1,7 & 1,9 \\
\hline $\begin{array}{l}\mathrm{Na} \\
\mathrm{Ca} \\
\mathrm{Ma}\end{array}$ & $\begin{array}{l}0,059 \\
9,874 \\
0,001\end{array}$ & $\begin{array}{l}0,034 \\
9,887 \\
0,023\end{array}$ & $\begin{array}{l}0,069 \\
9,865 \\
0,001\end{array}$ & $\begin{array}{l}0,101 \\
9,836 \\
0,001\end{array}$ & $\begin{array}{l}0,043 \\
9,891 \\
0,001\end{array}$ & $\begin{array}{l}0,074 \\
9,853 \\
0,001\end{array}$ & $\begin{array}{l}0,045 \\
9,867 \\
0,001\end{array}$ & $\begin{array}{l}0,101 \\
9,839 \\
0,001\end{array}$ & $\begin{array}{l}0,068 \\
9,887 \\
0,001\end{array}$ & $\begin{array}{l}0,008 \\
9,909 \\
0,001\end{array}$ & $\begin{array}{l}0,048 \\
9,898 \\
0,001\end{array}$ \\
\hline $\mathrm{Mn}$ & 0,000 & 0,000 & 0,000 & 0,003 & 0,000 & 0,000 & 0,014 & 0,000 & 0,000 & 0,016 & 0,000 \\
\hline $\mathrm{Fe}$ & 0,012 & 0,007 & 0,006 & 0,000 & 0,000 & 0,022 & 0,000 & 0,006 & 0,000 & 0,009 & 0,000 \\
\hline$S t$ & 0,041 & 0,044 & 0,051 & 0,052 & 0,047 & 0,044 & 0,054 & 0,048 & 0,044 & 0,049 & 0,044 \\
\hline $\mathrm{Ba}$ & 0,000 & 0,000 & 0,000 & 0,000 & 0,000 & 0,000 & 0,000 & 0,000 & 0,000 & 0,000 & 0,000 \\
\hline $\mathrm{Al}$ & 0,002 & 0,001 & 0,001 & 0,001 & 0,010 & 0,003 & 0,001 & 0,014 & 0,001 & 0,001 & 0,004 \\
\hline La & 0,001 & 0,001 & 0,004 & 0,002 & 0,001 & 0,000 & 0,001 & 0,000 & 0,000 & 0,000 & 0,006 \\
\hline $\mathrm{Ce}$ & 0,011 & 0,003 & 0,005 & 0,006 & 0,016 & 0,006 & 0,019 & 0,005 & 0,000 & 0,008 & 0,002 \\
\hline Si & 0,008 & 0,014 & 0,004 & 0,017 & 0,009 & 0,009 & 0,023 & 0,024 & 0,027 & 0,033 & 0,020 \\
\hline$P$ & 5,699 & 5,654 & 5,753 & 5,868 & 5,891 & 5,950 & 5,790 & 5,740 & 5,691 & 5,780 & 5,730 \\
\hline c & 0,294 & 0,332 & 0,243 & 0,115 & 0,100 & 0,041 & 0,188 & 0,236 & 0,282 & 0,187 & 0,250 \\
\hline $\begin{array}{l}\mathrm{F} \\
\mathrm{Cl}\end{array}$ & $\begin{array}{l}1,098 \\
0,005\end{array}$ & $\begin{array}{l}1,063 \\
0,005\end{array}$ & $\begin{array}{l}0,981 \\
0,000\end{array}$ & $\begin{array}{l}1,073 \\
0,012\end{array}$ & 1,106 & 0,995 & $\begin{array}{l}1,189 \\
0,001\end{array}$ & $\begin{array}{l}1,172 \\
0,013\end{array}$ & $\begin{array}{l}0,998 \\
0,000\end{array}$ & 1,161 & 1,156 \\
\hline $\mathrm{OH}^{\mathrm{a}}$ & 0,897 & 0,931 & 1,019 & $\begin{array}{l}0,012 \\
0,914\end{array}$ & 0,012 & $\begin{array}{l}0,002 \\
1,004\end{array}$ & $\begin{array}{l}0,001 \\
0,810\end{array}$ & 0,815 & 1,001 & $\begin{array}{l}0,001 \\
0,838\end{array}$ & 0,009 \\
\hline $\mathrm{OH}^{\mathrm{b}}$ & 1,015 & 1,064 & 1,116 & 0,960 & $\begin{array}{l}0,003 \\
0,923\end{array}$ & $\begin{array}{l}1,004 \\
1,020\end{array}$ & $\begin{array}{l}0,810 \\
0,885\end{array}$ & $\begin{array}{l}0,815 \\
0,910\end{array}$ & 1,114 & $\begin{array}{l}0,838 \\
0,913\end{array}$ & $\begin{array}{l}0,836 \\
0,936\end{array}$ \\
\hline $\mathrm{OH}^{\circ}$ & 1,191 & 1,263 & 1,262 & 1,029 & 0,983 & 1,045 & 0,998 & 1,051 & 1,283 & $\begin{array}{l}0,913 \\
1,025\end{array}$ & $\begin{array}{l}0,936 \\
1,086\end{array}$ \\
\hline P.M. ${ }^{a}$ & 998 & 996 & 1000 & 1004 & 1007 & 1006 & 1004 & 1000 & 997 & 1003 & 1000 \\
\hline P.M. ${ }^{b}$ & 1000 & 999 & 1001 & 1005 & 1007 & 1007 & 1005 & 1002 & 999 & 1004 & 1002 \\
\hline P.M. ${ }^{C}$ & 1003 & 1002 & 1004 & 1006 & 1008 & 1007 & 1007 & 1004 & 1002 & 1006 & 1004 \\
\hline $\operatorname{carga}^{a}$ & 0,253 & 0,303 & 0,185 & 0,023 & 0,105 & $-0,018$ & 0,164 & 0,181 & 0,216 & 0,188 & 0,223 \\
\hline carga $^{b}$ & 0,136 & 0,171 & 0,087 & $-0,023$ & 0,065 & $-0,035$ & 0,089 & 0,087 & 0,103 & 0,113 & 0,123 \\
\hline carga $^{c}$ & $-0,041$ & $-0,028$ & $-0,058$ & $-0,091$ & 0,005 & $-0,059$ & $-0,024$ & $-0,055$ & $-0,066$ & 0,001 & $-0,027$ \\
\hline $\mathrm{CaO} / \mathrm{P}_{2} \mathrm{O}_{5}$ & 1,369 & 1,382 & 1,355 & 1,324 & 1,327 & 1,309 & 1,347 & 1,354 & 1,373 & 1,355 & 1,365 \\
\hline $\mathrm{F} / \mathrm{P}_{2} \mathrm{O}_{5}$ & 0,052 & 0,050 & 0,046 & 0,049 & 0,050 & 0,045 & 0,055 & 0,055 & 0,047 & 0,054 & 0,054 \\
\hline $\mathrm{SrO} / \mathrm{P}_{2} \mathrm{O}_{5}$ & 0,011 & 0,011 & 0,013 & 0,013 & 0,012 & 0,011 & 0,013 & 0,012 & 0,011 & 0,01 & 0,01 \\
\hline
\end{tabular}




\begin{tabular}{|c|c|c|c|c|c|c|c|c|c|c|c|}
\hline $\begin{array}{l}\text { Tipo } \\
\text { Amostra } \\
\text { No }\end{array}$ & $\begin{array}{c}2 \mathrm{~b} \\
\text { TGB4A } \\
\\
6\end{array}$ & $\begin{array}{c}2 b \\
\text { TGB4A }\end{array}$ & $\begin{array}{c}2 b \\
\text { TGB4A } \\
\end{array}$ & $\stackrel{2 b}{T G B 4 A}$ & ${ }^{2 b}{ }_{10}^{T}$ & ${ }^{2 \mathrm{~b}}$ & $\begin{array}{c}3 \\
\text { GPF3A } \\
26\end{array}$ & $\begin{array}{c}3 \\
\text { GPF3A } \\
27\end{array}$ & $\begin{array}{c}3 \\
\text { GPF3A G } \\
28\end{array}$ & $\begin{array}{c}3 \\
\text { GPF3A } \\
29\end{array}$ & $\begin{array}{c}3 \\
\text { GPF3A } \\
32\end{array}$ \\
\hline $\mathrm{Na}_{2} \mathrm{O}$ & $\begin{array}{r}0,17 \\
5575\end{array}$ & $\begin{array}{r}0,24 \\
55,68\end{array}$ & 0,22 & 0,14 & 0,13 & 0,21 & 3,44 & 3,28 & 2,65 & 3,62 & 3,61 \\
\hline $\begin{array}{l}\mathrm{CaO} \\
\mathrm{MaO}\end{array}$ & $\begin{array}{r}55,75 \\
0,01\end{array}$ & $\begin{array}{r}55,68 \\
0,00\end{array}$ & $\begin{array}{r}55,34 \\
0,00\end{array}$ & $\begin{array}{r}55,45 \\
0,00\end{array}$ & $\begin{array}{r}55,60 \\
0,00\end{array}$ & $\begin{array}{r}54,76 \\
0,00\end{array}$ & $\begin{array}{r}48,46 \\
0,02\end{array}$ & $\begin{array}{r}48,74 \\
0,06\end{array}$ & $\begin{array}{r}50,16 \\
0,09\end{array}$ & $\begin{array}{r}47,30 \\
0,03\end{array}$ & $\begin{array}{r}48,00 \\
0,00\end{array}$ \\
\hline $\mathrm{MnO}$ & 0,00 & 0,00 & 0,00 & 0,00 & 0,01 & 0,00 & 1,23 & 0,87 & 1,11 & 1,02 & 1,13 \\
\hline $\mathrm{FeO}$ & 0,09 & 0,00 & 0,00 & 0,00 & 0,06 & 0,00 & 0,85 & 1,08 & 0,57 & 0,63 & 0,78 \\
\hline SrO & 0,44 & 0,60 & 0,46 & 0,59 & 0,39 & 0,55 & 0,83 & 1,08 & 0,92 & 0,97 & 1,06 \\
\hline $\mathrm{BaO}$ & 0,07 & 0,08 & 0,00 & 0,05 & 0,00 & 0,00 & 0,41 & 0,19 & 0,33 & 0,11 & 0,45 \\
\hline $\mathrm{Al}_{2} \mathrm{O}_{3}$ & 0,00 & 0,00 & 0,05 & 0,00 & 0,00 & 0,00 & 0,00 & 0,00 & 0,01 & 0,00 & 0,04 \\
\hline $\mathrm{La}_{2} \mathrm{O}_{3}$ & 0,10 & 0,00 & 0,00 & 0,06 & 0,02 & 0,10 & 0,02 & 0,00 & 0,00 & 0,00 & 0,00 \\
\hline $\mathrm{Ce}_{2} \mathrm{O}_{3}$ & 0,04 & 0,00 & 0,00 & 0,11 & 0,01 & 0,00 & 0,30 & 0,00 & 0,02 & 0,19 & 0,08 \\
\hline $\mathrm{SiO}_{2}$ & 0,12 & 0,26 & 0,18 & 0,22 & 0,11 & 0,20 & 0,03 & 0,01 & 0,04 & 0,10 & 0,05 \\
\hline $\mathrm{P}_{2} \mathrm{O}_{5}$ & 41,09 & 40,60 & 38,47 & 39,52 & 40,37 & 39,13 & 34,75 & 34,23 & 35,76 & 34,01 & 34,21 \\
\hline$F$ & 2,08 & 2,12 & 2,08 & 2,28 & 2,02 & 1,93 & 0,86 & 0,89 & 0,97 & 0,75 & 0,82 \\
\hline \multirow[t]{2}{*}{$\mathrm{Cl}$} & 0,04 & 0,01 & 0,06 & 0,04 & 0,00 & 0,02 & 0,04 & 0,02 & 0,00 & 0,00 & 0,01 \\
\hline & 99,84 & 99,37 & 96,66 & 98,33 & 98,60 & 96,70 & 87,81 & 87,17 & 89,97 & 85,12 & 86,65 \\
\hline $\mathrm{O}=\mathrm{F}, \mathrm{Cl}$ & 0,88 & 0,89 & 0,88 & 0,96 & 0,85 & 0,81 & 0,36 & 0,37 & 0,41 & 0,32 & 0,35 \\
\hline TOTAL & 98,97 & 98,47 & 95,78 & 97,37 & 97,75 & 95,89 & 87,45 & 86,80 & 89,56 & 84,81 & 86,30 \\
\hline $\mathrm{CO}_{2}$ & 1,01 & 1,21 & 2,38 & 1,75 & 1,30 & 1,73 & 5,32 & 5,64 & 4,66 & 5,29 & 5,56 \\
\hline $\mathrm{OH}^{\mathrm{a}}$ & 1,55 & 1,52 & 1,55 & 1,37 & 1,60 & 1,66 & 2,76 & 2,75 & 2,64 & 2,86 & 2,80 \\
\hline $\mathrm{OH}^{b}$ & 1,70 & 1,70 & 1,92 & 1,63 & 1,80 & 1,92 & 3,57 & 3,60 & 3,35 & 3,66 & 3,64 \\
\hline $\mathrm{OH}^{\circ}$ & 1,9 & 2,0 & 2,5 & 2,0 & 2,1 & 2,3 & 4,76 & 4,86 & 4,39 & 4,84 & 4,88 \\
\hline $\begin{array}{l}\mathrm{Na} \\
\mathrm{Ca} \\
\mathrm{Ma}\end{array}$ & $\begin{array}{l}0,055 \\
9,873 \\
0,003\end{array}$ & $\begin{array}{l}0,076 \\
9,860 \\
0,001\end{array}$ & $\begin{array}{l}0,070 \\
9,884 \\
0,001\end{array}$ & $\begin{array}{l}0,046 \\
9,882 \\
0,001\end{array}$ & $\begin{array}{l}0,041 \\
9,909 \\
0,001\end{array}$ & $\begin{array}{l}0,069 \\
9,870 \\
0,001\end{array}$ & $\begin{array}{l}1,090 \\
8,494 \\
0,006\end{array}$ & $\begin{array}{l}1,042 \\
8,560 \\
0,014\end{array}$ & $\begin{array}{l}0,842 \\
8,796 \\
0,022\end{array}$ & $\begin{array}{l}1,174 \\
8,472 \\
0,008\end{array}$ & $\begin{array}{l}1,149 \\
8,450 \\
0,001\end{array}$ \\
\hline $\mathrm{Mn}$ & 0,000 & 0,000 & 0,000 & 0,000 & 0,001 & 0,000 & 0,171 & 0,121 & 0,153 & 0,144 & 0,158 \\
\hline $\mathrm{Fe}$ & 0,013 & 0,000 & 0,000 & 0,000 & 0,008 & 0,000 & 0,117 & 0,148 & 0,078 & 0,088 & 0,107 \\
\hline $\mathrm{Sr}$ & 0,042 & 0,058 & 0,044 & 0,057 & 0,038 & 0,054 & 0,079 & 0,103 & 0,087 & 0,094 & 0,101 \\
\hline $\mathrm{Ba}$ & 0,005 & 0,005 & 0,000 & 0,003 & 0,000 & 0,000 & 0,027 & 0,012 & 0,021 & 0,007 & 0,029 \\
\hline Al & 0,001 & 0,001 & 0,010 & 0,001 & 0,001 & 0,001 & 0,001 & 0,001 & 0,002 & 0,001 & 0,007 \\
\hline La & 0,006 & 0,000 & 0,000 & 0,004 & 0,001 & 0,006 & 0,001 & 0,000 & 0,000 & 0,000 & 0,000 \\
\hline $\mathrm{Ce}$ & 0,003 & 0,000 & 0,000 & 0,007 & 0,000 & 0,000 & 0,018 & 0,000 & 0,001 & 0,012 & 0,005 \\
\hline $\mathrm{Si}$ & 0,020 & 0,043 & 0,031 & 0,037 & 0,019 & 0,033 & 0,005 & 0,001 & 0,007 & 0,017 & 0,008 \\
\hline$P$ & 5,750 & 5,682 & 5,429 & 5,565 & 5,684 & 5,573 & 4,813 & 4,750 & 4,955 & $4,8+3$ & 4,759 \\
\hline C & 0,230 & 0,275 & 0,540 & 0,399 & 0,297 & 0,394 & 1,182 & 1,249 & 1,039 & 1,169 & 1,232 \\
\hline $\begin{array}{l}\mathrm{F} \\
\mathrm{Cl}\end{array}$ & 1,089 & 1,109 & 1,096 & 1,200 & 1,062 & 1,029 & 0,445 & 0,460 & 0,502 & 0,397 & 0,429 \\
\hline $\mathrm{Cl}$ & 0,011 & 0,004 & 0,016 & 0,011 & 0,000 & 0,006 & 0,011 & 0,005 & 0,000 & 0,000 & 0,004 \\
\hline $\mathrm{OH}^{\mathrm{a}}$ & 0,901 & 0,887 & 0,888 & 0,789 & 0,938 & 0,965 & 1,544 & 1,535 & 1,497 & 1,603 & 1,567 \\
\hline $\mathrm{OH}^{b}$ & 0,992 & 0,997 & 1,104 & 0,949 & 1,057 & 1,122 & 2,017 & 2,034 & 1,913 & 2,070 & 2,060 \\
\hline $\mathrm{OH}^{\circ}$ & 1,130 & 1,162 & 1,428 & 1,188 & 1,235 & 1,359 & 2,726 & 2,784 & 2,536 & 2,772 & 2,800 \\
\hline P.M. ${ }^{a}$ & 1001 & 999 & 989 & 996 & 997 & 994 & 958 & 954 & 964 & 954 & 955 \\
\hline P.M. ${ }^{b}$ & 1003 & 1000 & 993 & 999 & 999 & 997 & 966 & 962 & 971 & 962 & 963 \\
\hline P.M. ${ }^{c}$ & 1005 & 1003 & 998 & 1003 & 1002 & 1001 & 978 & 975 & 982 & 974 & 976 \\
\hline carga $^{a}$ & 0,185 & 0,201 & 0,499 & 0,365 & 0,259 & 0,333 & 0,112 & 0,209 & 0,203 & 0,009 & 0,109 \\
\hline carga $^{b}$ & 0,093 & 0,091 & 0,283 & 0,205 & 0,140 & 0,175 & $-0,360$ & $-0,291$ & $-0,212$ & $-0,459$ & $-0,384$ \\
\hline carga $^{c}$ & $-0,045$ & $-0,074$ & $-0,041$ & $-0,034$ & $-0,038$ & $-0,061$ & $-1,069$ & $-1,040$ & $-0,836$ & $-1,160$ & $-1,123$ \\
\hline $\mathrm{CaO} / \mathrm{P}_{2} \mathrm{O}_{5}$ & 1,357 & 1,371 & 1,438 & 1,403 & 1,377 & 1,399 & 1,394 & 1,424 & 1,403 & 1,391 & 1,403 \\
\hline $\mathrm{F} / \mathrm{P}_{2} \mathrm{O}_{5}$ & 0,051 & 0,052 & 0,054 & 0,058 & 0,050 & 0,049 & 0,025 & 0,026 & 0,027 & 0,022 & 0,024 \\
\hline $\mathrm{SrO} / \mathrm{P}_{2} \mathrm{O}_{5}$ & 0,01 & 0,01 & 0,01 & 0,01 & 0,01 & 0,01 & 0,024 & 0,032 & 0,026 & 0,029 & 0,031 \\
\hline
\end{tabular}




\begin{tabular}{|c|c|c|c|c|c|c|c|c|c|c|c|}
\hline $\begin{array}{l}\text { Tipo } \\
\text { Amostra } \\
\text { No }\end{array}$ & $\begin{array}{c}3 \\
\text { GPF3A } \\
33\end{array}$ & $\begin{array}{c}3 \\
1 A 7\end{array}$ & $\begin{array}{c}4 \\
\text { ANGE }\end{array}$ & $\stackrel{4}{\text { ANgE }}$ & ${ }_{\text {ANOE }}^{4}$ & $\stackrel{4}{\text { ANgE }_{19}}$ & ${ }_{22}^{4}$ & $\stackrel{\substack{4 \\
\text { AN9E } \\
23}}{ }$ & AN9E $_{24}^{4}$ & AN9E $_{25}^{4}$ & $\begin{array}{c}{ }_{\text {AN9E }}^{4} \\
27\end{array}$ \\
\hline $\mathrm{Na}_{2} \mathrm{O}$ & 3,80 & 1,90 & 0,00 & 0,14 & 0,09 & 0,08 & 0,15 & 0,22 & 0,18 & 0,22 & 0,19 \\
\hline $\begin{array}{l}\mathrm{CaO} \\
\mathrm{MgO} \\
\mathrm{MnO}\end{array}$ & $\begin{array}{r}48,23 \\
0,04 \\
1,06\end{array}$ & $\begin{array}{r}51,99 \\
0,06 \\
0,43\end{array}$ & $\begin{array}{r}46,48 \\
0,01 \\
0,00\end{array}$ & $\begin{array}{r}46,09 \\
0,00 \\
0,06\end{array}$ & $\begin{array}{r}48,81 \\
0,00 \\
0,00\end{array}$ & $\begin{array}{r}47,59 \\
0,04 \\
0,04\end{array}$ & $\begin{array}{r}47,97 \\
0,06 \\
0,01\end{array}$ & $\begin{array}{r}43,91 \\
0,00 \\
0,00\end{array}$ & $\begin{array}{r}49,90 \\
0,00 \\
0,04\end{array}$ & $\begin{array}{r}51,41 \\
0,00 \\
0,04\end{array}$ & $\begin{array}{r}44,97 \\
0,09 \\
0,00\end{array}$ \\
\hline $\mathrm{FeO}$ & 0,91 & 0,61 & 0,09 & 0,19 & 0,35 & 0,17 & 0,27 & 0,27 & 0,42 & 0,30 & 0,22 \\
\hline SrO & 0,94 & 1,60 & 0,18 & 0,23 & 0,20 & 0,08 & 0,22 & 0,17 & 0,14 & 0,27 & 0,15 \\
\hline $\mathrm{BaO}$ & 0,34 & 0,00 & 0,00 & 0,06 & 0,00 & 0,13 & 0,00 & 0,00 & 0,00 & 0,00 & 0,00 \\
\hline $\mathrm{Al}_{2} \mathrm{O}_{3}$ & 0,00 & 0,00 & 0,23 & 0,29 & 0,22 & 0,20 & 0,18 & 0,27 & 0,16 & 0,17 & 0,24 \\
\hline $\mathrm{La}_{2} \mathrm{O}_{3}$ & 0,06 & 0,00 & 0,00 & 0,00 & 0,00 & 0,00 & 0,04 & 0,00 & 0,11 & 0,00 & 0,00 \\
\hline $\mathrm{Ce}_{2} \mathrm{O}_{3}$ & 0,13 & 0,01 & 0,00 & 0,05 & 0,00 & 0,01 & 0,00 & 0,03 & 0,00 & 0,14 & 0,05 \\
\hline $\mathrm{SiO}_{2}$ & 0,08 & 0,06 & 0,14 & 0,48 & 0,67 & 0,24 & 0,03 & 0,20 & 0,07 & 0,19 & 0,08 \\
\hline $\mathrm{P}_{2} \mathrm{O}_{5}$ & 34,38 & 38,60 & 32,44 & 31,35 & 33,89 & 32,36 & 31,29 & 28,46 & 34,13 & 36,07 & 29,57 \\
\hline $\begin{array}{l}\mathrm{F} \\
\mathrm{Cl}\end{array}$ & $\begin{array}{r}0,87 \\
0,01 \\
87,06\end{array}$ & $\begin{array}{r}0,73 \\
0,00 \\
94,09\end{array}$ & $\begin{array}{r}2,82 \\
0,12 \\
82,51\end{array}$ & $\begin{array}{r}2,93 \\
0,47 \\
82,21\end{array}$ & $\begin{array}{r}2,94 \\
0,23 \\
87,33\end{array}$ & $\begin{array}{r}3,03 \\
0,17 \\
84,05\end{array}$ & $\begin{array}{r}3,22 \\
0,09 \\
83,37\end{array}$ & $\begin{array}{r}2,85 \\
0,09 \\
76,24\end{array}$ & $\begin{array}{r}2,75 \\
0,02 \\
87,74\end{array}$ & $\begin{array}{r}3,10 \\
0,01 \\
91,71\end{array}$ & $\begin{array}{r}2,44 \\
0,06 \\
77,87\end{array}$ \\
\hline $\begin{array}{l}\mathrm{O}=\mathrm{F}, \mathrm{Cl} \\
\text { TOTAL }\end{array}$ & $\begin{array}{r}0,37 \\
86,70\end{array}$ & $\begin{array}{r}0,31 \\
93,79\end{array}$ & $\begin{array}{r}1,19 \\
81,32\end{array}$ & $\begin{array}{r}1,24 \\
80,97\end{array}$ & $\begin{array}{r}1,24 \\
86,09\end{array}$ & $\begin{array}{r}1,28 \\
82,78\end{array}$ & $\begin{array}{r}1,36 \\
82,02\end{array}$ & $\begin{array}{r}1,20 \\
75,04\end{array}$ & $\begin{array}{r}1,16 \\
86,58\end{array}$ & $\begin{array}{r}1,31 \\
90,40\end{array}$ & $\begin{array}{r}1,03 \\
76,84\end{array}$ \\
\hline $\mathrm{CO}_{2}$ & 5,67 & 2,92 & 2,11 & 2,63 & 1,95 & 2,77 & 4,05 & 4,05 & 2,94 & 2,25 & 3,87 \\
\hline $\mathrm{OH}^{\mathrm{a}}$ & 2,77 & 2,81 & 0,37 & 0,25 & 0,41 & 0,24 & 0,08 & 0,20 & 0,68 & 0,42 & 0,73 \\
\hline $\mathrm{OH}^{b}$ & 3,63 & 3,25 & 0,69 & 0,66 & 0,71 & 0,67 & 0,71 & 0,83 & 1,14 & 0,77 & 1,33 \\
\hline $\mathrm{OH}^{\circ}$ & 4,90 & 3,91 & 1,2 & 1,3 & 1,2 & 1,3 & 1,64 & 1,76 & 1,81 & 1,29 & 2,22 \\
\hline $\begin{array}{l}\mathrm{Na} \\
\mathrm{Ca} \\
\mathrm{Ma}\end{array}$ & $\begin{array}{l}1,199 \\
8,400 \\
0,010\end{array}$ & $\begin{array}{l}0,600 \\
9,089 \\
0,015\end{array}$ & $\begin{array}{l}0,001 \\
9,960 \\
0,003\end{array}$ & $\begin{array}{l}0,054 \\
9,867 \\
0,001\end{array}$ & $\begin{array}{l}0,031 \\
9,891 \\
0,001\end{array}$ & $\begin{array}{l}0,030 \\
9,905 \\
0,010\end{array}$ & $\begin{array}{l}0,056 \\
9,855 \\
0,018\end{array}$ & $\begin{array}{l}0,088 \\
9,843 \\
0,000\end{array}$ & $\begin{array}{l}0,062 \\
9,845 \\
0,000\end{array}$ & & $\begin{array}{l}0,074 \\
9,839 \\
0,027\end{array}$ \\
\hline $\mathrm{Mn}$ & 0,146 & 0,059 & 0,000 & 0,011 & 0,000 & 0,006 & 0,001 & 0,000 & 0,006 & 0,007 & 0,000 \\
\hline $\mathrm{Fe}$ & 124 & 0,084 & 0,015 & 0,032 & 0,055 & 0,028 & 0,043 & 0,047 & 0,065 & 0,045 & 0,038 \\
\hline $\mathrm{Sr}$ & 089 & 0,152 & 1,020 & 0,027 & 0,022 & 0,009 & 0,024 & 0,021 & 0,015 & 0,028 & 0,018 \\
\hline $\mathrm{Ba}$ & 0,022 & 0,000 &, 000 & 0,004 & 0,000 & 0,010 & 0,000 & 0,000 & 0,000 & 0,000 & 0,000 \\
\hline Al & 0,001 &, 001 & 054 & 0,068 & 0,050 & 0,046 & 0,040 & 0,066 & 0,035 & 0,035 & 0,057 \\
\hline $\begin{array}{l}\mathrm{La} \\
\mathrm{Ce}\end{array}$ & 0,004 & 1,000 & & 0,000 & 0,000 & 0,000 & 0,003 & 0,000 & 0,007 & 0,000 & 0,000 \\
\hline $\mathrm{Ce}$ & 0,008 & 0,000 & 0,000 & 0,004 & 0,000 & 0,001 & 0,000 & 0,002 & 0,000 & 0,009 & 0,004 \\
\hline C & $\begin{array}{l}0,013 \\
4,732 \\
1,255\end{array}$ & $\begin{array}{l}0,009 \\
5,332 \\
0,658\end{array}$ & & $\begin{array}{l}0,096 \\
5,303 \\
0,602\end{array}$ & $\begin{array}{l}0,127 \\
5,427 \\
0,445\end{array}$ & $\begin{array}{l}0,047 \\
5,323 \\
0,630\end{array}$ & $\begin{array}{l}0,006 \\
5,079 \\
0,915\end{array}$ & $\begin{array}{l}0,042 \\
5,041 \\
0,916\end{array}$ & $\begin{array}{l}0,013 \\
5,320 \\
0,666\end{array}$ & $\begin{array}{l}0,034 \\
5,453 \\
0,513\end{array}$ & $\begin{array}{l}0,016 \\
5,111 \\
0,873\end{array}$ \\
\hline $\begin{array}{l}\mathrm{F} \\
\mathrm{Cl}\end{array}$ & $\begin{array}{l}0,448 \\
0,002\end{array}$ & $\begin{array}{l}0,379 \\
0,000\end{array}$ & $\begin{array}{l}1,785 \\
0,041\end{array}$ & $\begin{array}{l}1,851 \\
0,159\end{array}$ & $\begin{array}{l}1,761 \\
0,075\end{array}$ & $\begin{array}{l}1,860 \\
0,055\end{array}$ & $\begin{array}{l}1,953 \\
0,028\end{array}$ & $\begin{array}{l}1,886 \\
0,031\end{array}$ & $\begin{array}{l}1,604 \\
0,006\end{array}$ & $\begin{array}{l}1,753 \\
0,004\end{array}$ & $\begin{array}{l}1,578 \\
0,020\end{array}$ \\
\hline $\mathrm{OH}^{\mathrm{a}}$ & 1,549 & 1,620 & 0,174 & 0,000 & 0,164 & 0,086 & 0,019 & 0,083 & 0,390 & 0,243 & 0,402 \\
\hline $\mathrm{OH}^{b}$ & 2,051 & 1,884 & 0,366 & 0,231 & 0,342 & 0,338 & 0,385 & 0,449 & 0,656 & 0,448 & 0,751 \\
\hline $\mathrm{OH}^{\mathrm{C}}$ & 2,804 & 2,279 & 0,654 & 0,592 & 0,609 & 0,716 & 0,934 & 0,999 & 1,056 & 0,756 & 1,275 \\
\hline P.M. ${ }^{a}$ & 952 & 981 & 995 & 996 & 997 & 990 & 979 & 979 & 986 & 992 & 979 \\
\hline P.M. ${ }^{\mathrm{b}}$ & 961 & 985 & 998 & 1000 & 1000 & 994 & 985 & 985 & 991 & 996 & 985 \\
\hline P.M. ${ }^{c}$ & 973 & 992 & 1003 & 1006 & 1005 & 1001 & 994 & 994 & 998 & 1001 & 994 \\
\hline $\operatorname{carga}^{a}$ & 0,069 & 0,060 & 0,643 & 0,745 & 0,564 & 0,739 & 0,982 & 1,027 & 0,717 & 0,553 & 0,974 \\
\hline $\operatorname{carga}^{b}$ & $-0,433$ & $-0,204$ & 0,451 & 0,514 & 0,386 & 0,487 & 0,616 & 0,661 & 0,451 & 0,348 & 0,625 \\
\hline carga $^{c}$ & $-1,186$ & $-0,599$ & 0,162 & 0,153 & 0,119 & 0,109 & 0,067 & 0,111 & 0,051 & 0,040 & 0,101 \\
\hline $\mathrm{CaO} / \mathrm{P}_{2} \mathrm{O}_{5}$ & 1,403 & 1,347 & 1,433 & 1,470 & 1,440 & 1,470 & 1,533 & 1,543 & 1,462 & 1,425 & 1,521 \\
\hline$=/ P_{2} O_{5}$ & 0,025 & 0,019 & 0,087 & 0,093 & 0,087 & 0,093 & 0,103 & 0,100 & 0,081 & 0,086 & 0,083 \\
\hline $\mathrm{SrO} / \mathrm{P}_{2} \mathrm{O}_{5}$ & 0,027 & 0,042 & 0,005 & 0,007 & 0,006 & 0,002 & 0,007 & 0,006 & 0,004 & 0,008 & 0,005 \\
\hline
\end{tabular}




\section{ANEXO 3}

Composição química das apatitas de Juquiá obtida à ME e expressa em \% em óxidos e em número de átomos por fórmula unitária

$\mathrm{OH}$ (\% em peso e átomos p.f.u.), peso molecular (PM) e carga da fórmula estrutural calculados considerando três alternativas: $a$ - todo flúor $(F)$ nos canais $\left(F_{p}=0\right), b$ parte do flúor $\left(F_{\mathrm{p}}\right)$ acompanhando o $\mathrm{CO}_{3}{ }^{2-}\left(\mathrm{F}_{\mathrm{p}}=0,4 \mathrm{C}\right)$ e $\mathrm{c}$ - parte do flúor $\left(\mathrm{F}_{\mathrm{p}}\right)$ acompanhando $\circ \mathrm{CO}_{3}\left(\mathrm{~F}_{\mathrm{p}}=\mathrm{C}\right)$. $\mathrm{OH}$ foi calculado pela diferença da fração molar no sítio dos ânions monovalentes $\left(\mathrm{OH}=2-\mathrm{F}-\mathrm{F}_{\mathrm{p}}\right)$, para cada caso $\mathrm{a}$, b e $\mathrm{c}$.

Tipos: 1- Apatita tipo pavê em rocha sã, 2 a- borda da apatita tipo pavê em material alterado, 2 b- núcleo da apatita tipo pavê em material alterado 3- Apatita tipo pavê em material muito alterado, 4 a- Apatita prismática com linhas de crescimento carbonatito são, 4 b- Apatita prismática com linhas de crescimento carbonatito alterado, 5- Apatita recristalizada na superfície da apatita tipo pavê (com $\mathrm{Sr}$ alto), 6- Borda de maior birrefringência ao redor da apatita tipo pavê, 7- Apatita supérgena tipo microprismático, 8 a- Apatita supérgena tipo fibroso leitosa, 8 b- Apatita supérgena tipo fibrorradial, 9 a- Apatita supérgena tipo prismática sobre a apatita fibrosa brotrioidal de fissuras, 9 b- Apatita supérgena tipo prismática milimétrica em fissuras não revestidas por apatita tipo fibroso leitosa 
JUQUIÁ - APATITAS

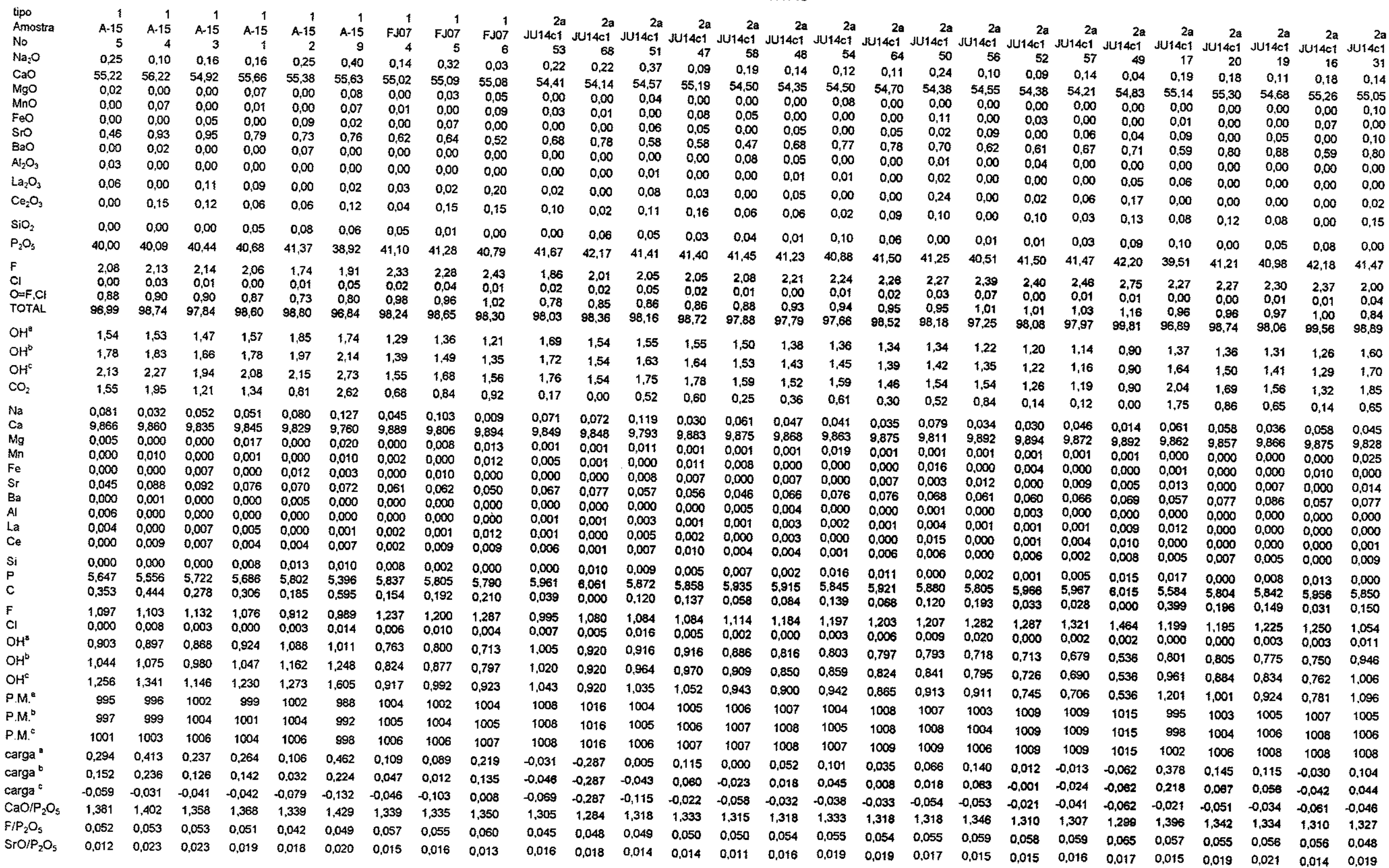


JUQUIA - APATITAS

\begin{tabular}{|c|c|c|c|c|c|c|c|c|c|c|c|c|c|c|c|c|c|c|c|c|c|c|c|c|c|c|c|}
\hline mo & $\begin{array}{r}2 a \\
J 14 c 1 \\
33 \\
0.17\end{array}$ & $\begin{array}{r}2 a \\
\text { JU14c1 } \\
32\end{array}$ & $\begin{array}{r}2 a \\
J u 4 c 1 \\
34\end{array}$ & $\begin{array}{r}2 a \\
\text { JU14c1 } \\
35\end{array}$ & $\begin{array}{r}2 a \\
\text { JU14c1 } \\
37\end{array}$ & $\begin{array}{r}2 a \\
F J 42 a \\
10\end{array}$ & $\begin{array}{r}2 a \\
F J 42 a \\
2\end{array}$ & $\begin{array}{r}2 a \\
F 342 a \\
1\end{array}$ & $\begin{array}{r}2 b \\
J U 14 c 1 \\
21\end{array}$ & $\begin{array}{r}2 b \\
J U 14 c 1 \\
23\end{array}$ & $\begin{array}{r}2 b \\
\text { JU14c1 } \\
59\end{array}$ & $\begin{array}{c}2 b \\
J U i 4 c 1 \\
60\end{array}$ & $\begin{array}{r}2 b \\
14 c 1 \\
66\end{array}$ & $\begin{array}{r}2 b \\
14 c 1 \\
62\end{array}$ & $\begin{array}{c}2 b \\
14 c_{65}\end{array}$ & $\begin{array}{c}2 \mathrm{bb} \\
14 \mathrm{ct} \\
55\end{array}$ & $\begin{array}{c}2 b \\
J U 14 c 1 \\
67\end{array}$ & $\begin{array}{r}2 b \\
3 U 14 c 1 \\
61\end{array}$ & $\begin{array}{r}26 \\
\text { FJ88 } \\
24\end{array}$ & $\begin{array}{r}2 b \\
\text { Fus8 } \\
25\end{array}$ & $\begin{array}{r}3 \\
\text { JU17 } \\
55\end{array}$ & $\begin{array}{r}3 \\
\text { JU17 } \\
50\end{array}$ & $\begin{array}{r}3 \\
\text { Ju17 } \\
49\end{array}$ & $\begin{array}{r}3 \\
\text { JU17 } \\
45\end{array}$ & $\begin{array}{r}3 \\
.417 \\
40\end{array}$ & $\begin{array}{r}3 \\
\text { Ju17 } \\
41\end{array}$ & 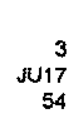 \\
\hline $\begin{array}{l}\mathrm{Na}_{2} \mathrm{O} \\
\mathrm{CaO}\end{array}$ & $\begin{array}{r}0,17 \\
54,77\end{array}$ & 0.00 & 0,23 & 0,27 & $\begin{array}{r}0.15 \\
5,33\end{array}$ & $\begin{array}{r}0,05 \\
56,50\end{array}$ & $\begin{array}{r}0.16 \\
55.17\end{array}$ & $\begin{array}{r}0,18 \\
55,02\end{array}$ & $\begin{array}{r}0,14 \\
5591\end{array}$ & 0,07 & 0,14 & 0,02 & 0,23 & 0,36 & 0,25 & 0,24 & 0,26 & 0,10 & 0,09 & 0,04 & 0.16 & 0,09 & 0,24 & 0,16 & 0,13 & 0.19 & 0.19 \\
\hline & & & & $\begin{array}{r}55,72 \\
0,00\end{array}$ & $\begin{array}{r}55,33 \\
0,00\end{array}$ & $\begin{array}{r}56,50 \\
0,00\end{array}$ & $\begin{array}{r}55,17 \\
0,04\end{array}$ & & $\begin{array}{r}55,91 \\
0,00\end{array}$ & $\begin{array}{r}55,15 \\
0,04\end{array}$ & $\begin{array}{r}54,07 \\
0,00\end{array}$ & $\begin{array}{r}54,99 \\
0,00\end{array}$ & $\begin{array}{r}54,37 \\
0,00\end{array}$ & $\begin{array}{r}53,49 \\
0,00\end{array}$ & $\begin{array}{r}54,98 \\
0,00\end{array}$ & $\begin{array}{r}53,93 \\
0,00\end{array}$ & $\begin{array}{r}54,20 \\
0,00\end{array}$ & & $\begin{array}{r}54,94 \\
0,00\end{array}$ & $\begin{array}{r}54,59 \\
0,00\end{array}$ & $\begin{array}{r}55,57 \\
0,01\end{array}$ & $\begin{array}{r}55,08 \\
0,00\end{array}$ & & $\begin{array}{r}55,09 \\
0,03\end{array}$ & 54,87 & 55,01 & $\begin{array}{r}55,08 \\
0,00\end{array}$ \\
\hline & $\begin{array}{l}0,00 \\
0,00\end{array}$ & $\begin{array}{l}0,01 \\
0,00\end{array}$ & & $\begin{array}{l}0,00 \\
0,00\end{array}$ & 0.04 & $\begin{array}{l}0,0 \\
0,0\end{array}$ & & & & & 0.16 & & 0,0 & 0,0 & 0,03 & 0,00 & & 0.0 & & & & 0,04 & 0,00 & 0,00 & 1,000 & 0,05 & 30 \\
\hline & $\begin{array}{l}0,60 \\
0,73\end{array}$ & $\begin{array}{l}0,00 \\
0,80\end{array}$ & & $\begin{array}{l}0,00 \\
0,74\end{array}$ & & $\begin{array}{l}0,00 \\
0,53\end{array}$ & $\begin{array}{l}0,0 \\
0,7\end{array}$ & & & & 0,10 & & 0,07 & 0,0 & & $0, \infty 0$ & & & 0,0 & 0.06 & 0,04 & 0.00 & & 0,00 & 0,04 & 0,02 & \\
\hline & 0,00 & 0.00 & 0,00 & 0,00 & 0,04 & 0,00 & 0,00 & 0,10 & 0,00 & $\begin{array}{l}0,32 \\
0,06\end{array}$ & $\begin{array}{l}0,34 \\
0,00\end{array}$ & & 06 & & & 1,12 & 091 & & 0,7 & 0.7 & & & & & 0,79 & & 0,64 \\
\hline $\mathrm{A}_{2} \mathrm{O}_{3}$ & 0,00 & 0,00 & 0,00 & 0,00 & $0, \infty 0$ & 0,00 & 0.00 & 0,00 & 0,00 & 0,00 & 0,44 & 0,00 & 0,00 & $\begin{array}{l}0,00 \\
0,00\end{array}$ & $\begin{array}{l}0,00 \\
0,00\end{array}$ & $\begin{array}{l}0,00 \\
0,00\end{array}$ & $\begin{array}{l}0.03 \\
0,00\end{array}$ & . & & 0,07 & & & 0,00 & 0,00 & 0,00 & , & 0,08 \\
\hline $\mathrm{L}_{2} \mathrm{O}_{3}$ & 0,08 & 0.00 & 0,13 & 0,11 & 0,21 & 0,02 & 0,05 & 0,09 & 0,00 & 0,08 & 0,00 & 0.00 & $0, \infty$ & 0,00 & & 0,00 & 0,00 & 0,00 & 0,00 & 0,03 & 0,03 & 0.01 & 0,00 & 0,02 & 0,00 & 0,00 & 0,00 \\
\hline $\mathrm{Ce}_{2} \mathrm{O}_{3}$ & 0,18 & 0,06 & 0,09 & 0,00 & 0.06 & 0,10 & .06 & & & $\infty$ & 0,03 & 0,00 & 1,07 & & & & 0,10 & 0,00 & 0,00 & 0.00 & 0,00 & 0,29 & 0,07 & 0,00 & 0,06 & 0.04 & 0.18 \\
\hline $\mathrm{SiO}_{2}$ & 0,05 & 0,06 & 0,00 & 0,00 & 0,11 & 0.01 & 0,02 & 0,01 & 0,04 & 01 & 0,10 & 0.01 & & & & & 0,00 & 0,00 & 0,30 & 0,01 & 0,13 & 0.00 & 0,16 & 0,19 & 0,05 & 0,03 & 0.01 \\
\hline${ }_{2} \mathrm{O}_{5}$ & 41,96 & 41,76 & 41,91 & 41,94 & 41,05 & 41,68 & 40,57 & 41,12 & 1,55 & & 107 & & & 0,06 & 0.01 & 0,00 & 0,00 & 0,04 & 0,02 & 0,07 & 0,04 & 0,05 & 0,04 & $0, \infty$ & 0,00 & 0,08 & 0.09 \\
\hline & 2,14 & 2,16 & 2,30 & & 2,27 & 2,09 & 2,18 & 2,03 & 305 & 0,09 & & 93 & 41,98 & 41,24 & 41,87 & 40,12 & 41,00 & 41,29 & 40,69 & 40,43 & 41,47 & 41,95 & 42,00 & 42,49 & 41,76 & 41,75 & 41,92 \\
\hline & & & & & & & & & & & $\begin{array}{l}2,82 \\
0,07\end{array}$ & & $\begin{array}{l}3,00 \\
0,03\end{array}$ & & & $\begin{array}{l}3,07 \\
0,00\end{array}$ & & & & & & & 2,20 & 2,32 & 2,11 & 2,11 & 2,24 \\
\hline & & & & & & & & & & & & & 1,26 & 1,27 & & & & & & & & & 02 & & & & 0,00 \\
\hline תו & & & & 99,83 & $-0,96$ & 100,06 & 97,93 & 98,42 & 100,01 & 97,66 & 97,96 & 98,91 & 98,88 & 97,73 & 99,60 & 97,13 & 98,04 & 98,36 & & & $\begin{array}{r}0,92 \\
99,40\end{array}$ & $\begin{array}{r}0,99 \\
99,41\end{array}$ & $\begin{array}{l}0,93 \\
99,29\end{array}$ & 100,00 & & & $\begin{array}{l}0,944 \\
99,44\end{array}$ \\
\hline $\mathrm{OH}^{2}$ & 1.45 & 1,44 & 1,34 & 1,37 & 1,36 & 1,55 & 1,45 & 1,57 & $0, \infty$ & 0,80 & 0,81 & 0,75 & 0.87 & 0,64 & 0,67 & 0,60 & 0,59 & 0,51 & 0,84 & 0,72 & 1,44 & 1,26 & 1,42 & 1,30 & 1,48 & 1.50 & 138 \\
\hline $\mathrm{OH}^{\mathrm{b}}$ & 47 & 1,47 & 1,41 & 1,47 & 1,50 & 1,70 & 1,63 & 1,69 & 0,82 & 1.01 & 0.85 & 0,75 & 0.67 & 0,67 & 0,73 & 0,76 & 0,68 & 0,55 & 0,89 & 0,86 & 1,57 & 1,29 & 1,46 & 1,30 & 1,53 & 1.55 & 1.43 \\
\hline $\mathrm{DH}^{4}$ & 50 & 1,52 & & 32 & 1 & 1.91 & 1,90 & 37 & 1,01 & 1,32 & 0.91 & & & & & $1, \infty$ & & 0.61 & 1,20 & 1,06 & 1,75 & 1,33 & 1,52 & 1.30 & 1,60 & 1,64 & 1,49 \\
\hline $\mathrm{O}_{2}$ & 0,11 & 0,23 & 0,49 & 0,66 & 0,88 & 0,93 & 1,18 & 0,79 & 0,83 & 1,37 & 0,26 & 0,00 & 0.00 & 0,18 & 0,36 & 1,04 & 0,57 & 0,28 & 0,94 & 0,87 & 0,80 & 0,18 & 0,26 & 0,00 & 0,30 & 0,38 & 0,29 \\
\hline Ce & & & & & & & & & & & & & & & & & & $\begin{array}{l}0,032 \\
9,893 \\
0,001 \\
0,010 \\
0,001 \\
0,057 \\
0,005 \\
0,001 \\
0,000 \\
0,000\end{array}$ & & & $\begin{array}{l}0,051 \\
9,854 \\
0,002 \\
0,006 \\
0,006 \\
0,073\end{array}$ & & & $\begin{array}{l}0,052 \\
9,850 \\
0,007 \\
0,000 \\
0,000 \\
0,079 \\
0,000 \\
0,004 \\
0,000 \\
0,012\end{array}$ & $\begin{array}{l}0,042 \\
9,864 \\
0,000 \\
0,004 \\
0,006 \\
0,077 \\
0,000 \\
0,000 \\
0,004 \\
0,003\end{array}$ & $\begin{array}{l}, 061 \\
, 037 \\
, 002 \\
, 007 \\
, 003 \\
, 0079 \\
0,000 \\
0,002 \\
0,002\end{array}$ & $\begin{array}{l}0,061 \\
9,840 \\
0,000 \\
0,014 \\
0,006 \\
0,062 \\
0,005 \\
0,000 \\
0,011 \\
0,001\end{array}$ \\
\hline & & & & & & & & & & & & & & & & & & $\begin{array}{l}0,007 \\
5,930 \\
0,064\end{array}$ & & & & & & & $\begin{array}{l}0,000 \\
5,932 \\
0,068\end{array}$ & $\begin{array}{l}0,013 \\
5,899 \\
0,088\end{array}$ & $\begin{array}{l}0,015 \\
5,917 \\
0,068\end{array}$ \\
\hline & & & & & & & $\begin{array}{l}1,150 \\
0,000\end{array}$ & & & $\begin{array}{l}1,532 \\
0,011\end{array}$ & $\begin{array}{l}1,520 \\
0,019\end{array}$ & .000 & & & & $\begin{array}{l}1,646 \\
0,000\end{array}$ & $\begin{array}{l}1,648 \\
0,000\end{array}$ & $\begin{array}{l}1,700 \\
0,008\end{array}$ & $\begin{array}{l}1,503 \\
0,000\end{array}$ & 0,011 & 0,011 & $\begin{array}{l}1,251 \\
0,006\end{array}$ & $\begin{array}{l}.161 \\
.006\end{array}$ & $\begin{array}{l}1,225 \\
0,006\end{array}$ & $\begin{array}{l}1,120 \\
0,003\end{array}$ & $\begin{array}{l}\{, 114 \\
0,011\end{array}$ & $\begin{array}{l}1,182 \\
0,000\end{array}$ \\
\hline $\mathrm{H}^{\mathrm{2}}$ & 0.863 & 0,852 & 792 & 0,812 & 0,806 & 0,916 & 0,850 & 0.927 & 0,408 & 0,468 & 0,480 & 0,448 & 0,397 & 0,378 & 0,398 & 0,354 & 0.352 & 0,300 & 0,497 & 0,427 & 0,853 & 0,749 & 0,839 & 0,775 & 0,880 & 0,886 & 0,818 \\
\hline$H^{\circ}$ & 373 & 0,873 & 0,837 & 0,872 & 0.886 & 1,001 & 58 & 000 & 483 & 0,593 & 0,505 & 0,448 & 0,397 & 0,396 & 0,431 & 0,449 & 0,404 & 0,325 & 0.583 & 0,507 & 0,926 & 0,765 & 0,863 & 0,775 & 0,807 & 0,921 & 0,845 \\
\hline & 0,889 & 0,905 & 0,904 & 0.962 & 1,008 & 1,129 & 1,120 & 1,108 & 0,596 & 0.781 & 0,541 & 0,448 & 0,397 & 0,421 & 0,480 & 0,593 & 0,483 & 0,363 & 0.712 & 0.626 & 1,036 & 0,790 & 0,899 & 0,775 & 0,948 & 0,974 & 0,886 \\
\hline $\mathrm{M}^{.}$ & 1009 & 1009 & 1005 & 1004 & 1004 & 1002 & 1000 & 1005 & 1003 & 999 & 1009 & 1009 & 1011 & 1009 & 1008 & 1004 & 1006 & 1008 & 1004 & 1005 & 1004 & 1009 & 1008 & 1011 & 1008 & 1007 & 1008 \\
\hline P.M. & 1010 & 1009 & 1006 & 1005 & 1005 & 1003 & 1002 & 1006 & 1005 & 1001 & 1010 & 1009 & 1011 & 1010 & 1008 & 1006 & 1007 & 1009 & 1006 & 1006 & 1005 & 1010 & 1008 & 1011 & 1008 & 1008 & 1008 \\
\hline$M^{c}$ & 1010 & 1009 & 1007 & 1006 & 1007 & 1005 & 1004 & 1008 & 1006 & 1004 & 1011 & 1009 & 1011 & 1010 & 1008 & 1008 & 1009 & 1009 & 1008 & 1008 & 1007 & 1010 & 1009 & 1011 & 1009 & 1009 & 1009 \\
\hline arga & $-0,013$ & 056 & & 0,070 & 0,167 & 0,204 & 0,225 & 131 & 0,141 & 0,283 & 0,261 & $-0,019$ & $-0,106$ & -0,076 & 0,020 & 0,173 & 0,054 & 0,025 & 0,204 & 0,193 & 0,146 & 0,030 & $-0,000$ & $-0,042$ & 0,030 & 0,019 & 0,018 \\
\hline 9 & $-0,024$ & 0,035 & 0.006 & 010 & 087 & & 0.117 & 159 & 66 & 0,158 & 0,237 & $-0,019$ & $-0,106$ & $-0,093$ & $-0,013$ & 0,077 & 0,002 & 0,000 & 0,118 & 0,114 & 0.073 & 0.013 & $-0,033$ & $-0,042$ & 0,003 & $-0,016$ & 0,009 \\
\hline & 039 & 04 & $-0,061$ & $-0,080$ & $-0,035$ & $-0,009$ & & & & & & & $-0,106$ & $-0,118$ & $-0,062$ & $-0,066$ & $-0,077$ & & & & & $-0,011$ & -0.069 & $-0,042$ & $-0,038$ & $-0,068$ & $-0,050$ \\
\hline & & & & & 1,348 & 1,356 & 1,360 & 1,338 & 1,346 & 1,376 & & & 1,295 & 1,297 & 1,313 & 1,344 & 1,322 & 1,318 & 1,350 & 1,350 & 1,340 & 1,313 & 1,307 & 1,297 & 1,314 & 1,318 & 1,314 \\
\hline$P_{2} \mathrm{C}$ & 0.051 & & & & & & 0,054 & 0,049 & 0,073 & 0,072 & .069 & 0,069 & 0,071 & 0,073 & 0,072 & 0,076 & 0.075 & 0,077 & 0,070 & 0,073 & 0,053 & 0,056 & 0,052 & 0,055 & 0.051 &, 051 & 0,053 \\
\hline $\mathrm{O} / \mathrm{P}_{2} \mathrm{O}_{5}$ & 0.017 & 0,019 & 0,013 & 0.018 & 018 & 0,013 & 0,018 & 0,017 & 0,018 & 0,008 & 0,008 & 0.006 & 0.015 & 0,028 & 0.014 & 0,028 & 0,022 & 0,014 & 0,018 & 0,019 & 0,018 & 0,014 & 0,016 & 0.019 & 0,019 & 0,020 & 0,015 \\
\hline
\end{tabular}


JUQUIÁ - APATITAS

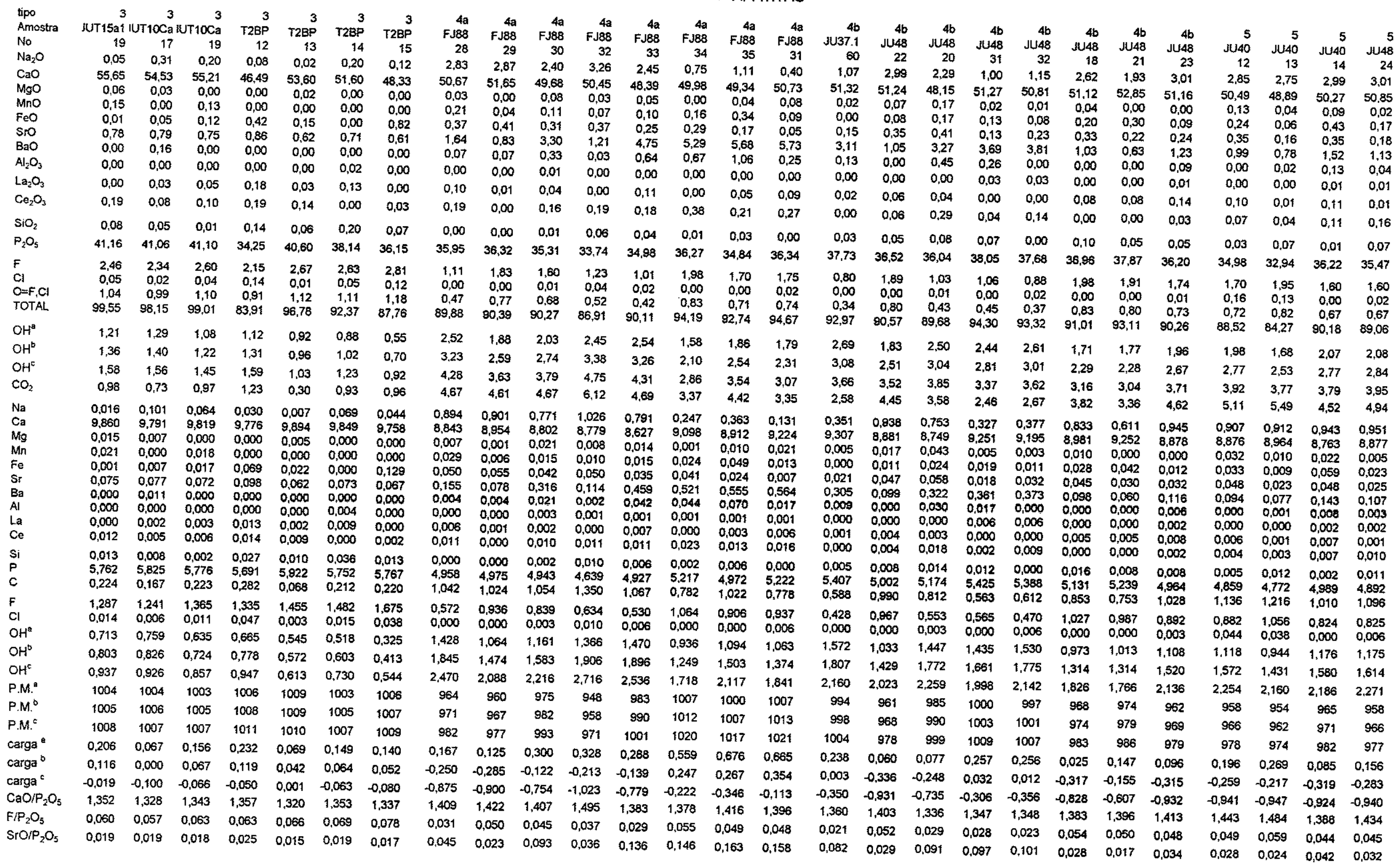


JUQUIÁ - APATITAS

\begin{tabular}{|c|c|c|c|c|c|c|c|c|c|c|c|c|c|c|c|c|c|c|c|c|c|c|c|c|c|c|c|}
\hline $\begin{array}{l}\text { tipo } \\
\text { Amostra } \\
\mathrm{No} \\
\mathrm{Na}_{2} \mathrm{O}\end{array}$ & $\begin{array}{r}5 \\
\text { U4 } 48 \\
26 \\
1.18\end{array}$ & $\begin{array}{r}5 \\
\text { JU48 } \\
27\end{array}$ & $\begin{array}{r}5 \\
\mathrm{JU} 48 \\
34\end{array}$ & $\begin{array}{r}5 \\
\text { JU48 } \\
35\end{array}$ & $\begin{array}{r}5 \\
J U 48 \\
25 \\
2,33\end{array}$ & $\begin{array}{r}5 \\
J U 48 \\
29 \\
2,38\end{array}$ & $\begin{array}{r}6 \\
\text { A-15 } \\
6 \\
2,79\end{array}$ & $\begin{array}{r}6 \\
\text { FJ88 } \\
26 \\
3.60\end{array}$ & $\begin{array}{r}6 \\
F 588 \\
28\end{array}$ & $\begin{array}{r}6 \\
F J 42 a \\
3\end{array}$ & $\begin{array}{r}6 \\
\text { FJ42a } \\
11\end{array}$ & $\begin{array}{r}6 \\
\text { F } 307 \\
1\end{array}$ & $\begin{array}{r}6 \\
F 307 \\
2\end{array}$ & $\begin{array}{r}6 \\
\text { FJo7 } \\
3\end{array}$ & $\begin{array}{r}7 \\
\text { Ju10b } \\
12\end{array}$ & $\begin{array}{r}{ }^{7} \\
\mathrm{JU} 10 \mathrm{~b} \\
5\end{array}$ & $\begin{array}{r}{ }^{7} \\
\text { Ju10b } \\
8\end{array}$ & $\begin{array}{r}7 \\
\text { Ju43b } \\
15\end{array}$ & $\begin{array}{r}7 \\
3410 b \\
14\end{array}$ & $\begin{array}{r}7 \\
\text { JU1Ob } \\
15\end{array}$ & $\begin{array}{r}7 \\
\mathrm{JU} 10 \mathrm{~b} \\
16\end{array}$ & $\begin{array}{r}7 \\
J U 10 b \\
17\end{array}$ & $\begin{array}{r}8 \mathrm{a} \\
\mathrm{JU} 37.1 \\
47\end{array}$ & $\begin{array}{r}8 \text { a } \\
\mathrm{JU} 37.1 \\
48\end{array}$ & $\begin{array}{r}8 \mathrm{a} \\
\mathrm{JU} 37.1 \\
49\end{array}$ & $\begin{array}{r}8 \mathbf{a} \\
\mathrm{J}+37.1 \\
50\end{array}$ & $\begin{array}{r}\text { JU37.1 } \\
57\end{array}$ \\
\hline $\begin{array}{l}\mathrm{Na}_{2} \mathrm{O} \\
\mathrm{CaO}\end{array}$ & $\begin{array}{r}1,18 \\
51,13\end{array}$ & $\begin{array}{r}0.89 \\
47,91\end{array}$ & $\begin{array}{r}0,97 \\
47,48\end{array}$ & $\begin{array}{r}2,41 \\
52,69\end{array}$ & $\begin{array}{r}2,33 \\
53,37\end{array}$ & $\begin{array}{r}2,38 \\
51,73\end{array}$ & $\begin{array}{r}2,79 \\
51,56\end{array}$ & $\begin{array}{r}3,60 \\
49,07\end{array}$ & $\begin{array}{r}3,46 \\
49,57\end{array}$ & 1,09 & 2,93 & $\begin{array}{r}2,39 \\
51,92\end{array}$ & $\begin{array}{r}2,79 \\
\end{array}$ & 2,56 & 0,13 & 0,11 & 0,07 & 0.12 & 0,13 & 0,09 & 0,08 & 0,10 & 0,07 & 0,19 & 0,00 & 0,03 & 0,09 \\
\hline CaO & $\begin{array}{r}51,13 \\
0,05 \\
0,00\end{array}$ & $\begin{array}{r}47,91 \\
0,00 \\
0,18\end{array}$ & $\begin{array}{r}47.48 \\
0,05\end{array}$ & $\begin{array}{r}52,69 \\
0,00 \\
0,07\end{array}$ & $\begin{array}{r}53,37 \\
0,00\end{array}$ & $\begin{array}{r}1,1,13 \\
0,02 \\
0,17\end{array}$ & & $\begin{array}{r}49,07 \\
0,00 \\
0,10\end{array}$ & $\begin{array}{r}49,57 \\
0,05 \\
0.08\end{array}$ & $\begin{array}{r}53,77 \\
0,02\end{array}$ & $\begin{array}{r}51,76 \\
0,09\end{array}$ & $\begin{array}{r}51,92 \\
0,03\end{array}$ & $\begin{array}{r}50,08 \\
0,18\end{array}$ & $\begin{array}{r}51,27 \\
0,05\end{array}$ & $\begin{array}{r}55,69 \\
0,09\end{array}$ & $\begin{array}{r}54,73 \\
0,03\end{array}$ & $\begin{array}{r}55,28 \\
0,04\end{array}$ & $\begin{array}{r}54,45 \\
0,05\end{array}$ & $\begin{array}{r}54,13 \\
0,04\end{array}$ & $\begin{array}{r}52,61 \\
0,00\end{array}$ & & & & & $\begin{array}{r}55,13 \\
0,27\end{array}$ & $\begin{array}{r}55.23 \\
0.19\end{array}$ & $\begin{array}{r}55,28 \\
0,11\end{array}$ \\
\hline & $\begin{array}{l}0 \\
0\end{array}$ & $\begin{array}{l}0.18 \\
0.25\end{array}$ & $\begin{array}{l}0 \\
0\end{array}$ & $\begin{array}{l}0,07 \\
0,17\end{array}$ & $\begin{array}{l}0,03 \\
0,23\end{array}$ & & & & $\begin{array}{l}0,08 \\
0,43\end{array}$ & $\begin{array}{l}0,06 \\
0,03\end{array}$ & $\begin{array}{l}0,16 \\
0.32\end{array}$ & 0,02 & 0,09 & 0,14 & 0,02 & 0,00 & 0,03 & 0,05 & 0,06 & $\begin{array}{l}0,00 \\
0,01\end{array}$ & $\begin{array}{l}0,07 \\
0,00\end{array}$ & & $0,0,00$ & & 02 & 106 &, 00 \\
\hline & 4 & $\begin{array}{l}0,25 \\
5,99\end{array}$ & $\begin{array}{l}0,27 \\
7,95\end{array}$ & $\begin{array}{l}0,17 \\
0,93\end{array}$ & & & & $\begin{array}{l}0,31 \\
1,32\end{array}$ & $\begin{array}{l}0,43 \\
1,20\end{array}$ & $\begin{array}{l}0,03 \\
1,46\end{array}$ & $\begin{array}{l}0,32 \\
1,07\end{array}$ & $\begin{array}{l}0,32 \\
1,11\end{array}$ & $\begin{array}{l}0,32 \\
1,28\end{array}$ & $\begin{array}{l}0,27 \\
0,75\end{array}$ & $\begin{array}{l}0,05 \\
0,50\end{array}$ & 0,00 & 0,21 & 0,17 & 0,48 & 0,20 & 0,95 & & 0,08 & & & 09 & \\
\hline & 0,00 & 0,87 & 1,16 & 0,00 & 0,00 & 0,0 & 0,00 & 0,18 & 0,29 & 0,09 & 0,13 & 0,00 & $\begin{array}{l}1,28 \\
0, \infty 0\end{array}$ & $\begin{array}{l}0,75 \\
0,00\end{array}$ & $\begin{array}{l}0,50 \\
0,00\end{array}$ & $\begin{array}{l}0,61 \\
0,00\end{array}$ & $\begin{array}{l}0,50 \\
0,00\end{array}$ & $\begin{array}{l}0,47 \\
0,26\end{array}$ & 0,43 & & & 0,31 & & 0,21 & & 67 & 0,55 \\
\hline $\mathrm{Al}_{2} \mathrm{O}_{3}$ & 0,00 & 0,01 & 0,00 & 0,00 & 0,00 & 0,00 & 0,00 & 0,00 & 0,02 & 0,00 & 0,00 & 0,00 & 0,00 & 0,03 & 0,00 & 0,00 & 0,06 & $\begin{array}{l}0,26 \\
0,00\end{array}$ & $\begin{array}{l}0,00 \\
0,91\end{array}$ & & 0,00 & 0,0 & 0,00 & 0,00 & &, 08 & 0,02 \\
\hline $\mathrm{La}_{2} \mathrm{O}_{3}$ & 0,03 & 0,05 & 0,00 & 0,00 & 0,10 & 0,03 & 0,00 & 0,11 & 0.00 & 0,01 & 0.00 & 0,00 & 0,00 & 0,08 & 0,18 & 0,05 & 0,12 & & 0,91 & 1,01 & 0,52 & 0,00 & 0,00 & 0,00 & 0,01 & 0,03 & 0,03 \\
\hline $\mathrm{Ce}_{2} \mathrm{O}_{3}$ & 0,05 & 0,28 & 0,23 & $0, \infty$ & 0,03 & 0,14 & 0,00 & 0,13 & 0,14 & 0,06 & 0,00 & 0,00 & 0.05 & 0,0 & 0,00 & & & 0,15 & 0,08 & 0,08 & 0,00 & 0,05 & 0,06 & 0,00 & 0,02 & 0,00 & 0,03 \\
\hline $\mathrm{SiO}_{2}$ & 0.01 & 0.10 & 0,06 & 0,04 & 0,03 & 0,00 & 0,06 & 0,04 & 0,00 & 0,04 & 0,08 & 0,00 & & & & & & 0,14 & 0,00 & 0,09 & 0,08 & 0,06 & 0,01 & 0,13 & 0.09 & 0,06 & 0,00 \\
\hline $\mathrm{P}_{2} \mathrm{O}_{5}$ & 38,20 & 36,27 & 35,91 & 37,34 & 37,60 & 37,07 & 33,97 & 33,56 & 13,35 & 8,74 & 36,03 & & 3554 & 0,05 & 0,11 & 0,04 & 0,03 & 0,06 & 0,59 & 0,93 & 0,58 & 0.04 & 0,05 & 0,04 & 0,07 & 0,00 & 0,09 \\
\hline & 0,75 & 1,53 & 1,61 & 1,77 & 1,59 & 1,72 & 1,49 & 1,84 & & & S, & 5.93 & 35,54 & 36,03 & 36,86 & 36,37 & 36,86 & 37,74 & 36,19 & 35,82 & 35,10 & 36,08 & 40,42 & 38,92 & 39,99 & 36,80 & 37,57 \\
\hline & & & & & & & & & $\begin{array}{l}1,52 \\
0,00\end{array}$ & $\begin{array}{l}1,61 \\
0,02\end{array}$ & & $\begin{array}{l}2,14 \\
0,00\end{array}$ & $\begin{array}{l}1,92 \\
0,00\end{array}$ & $\begin{array}{l}2,19 \\
0,00\end{array}$ & $\begin{array}{l}3,25 \\
0,00\end{array}$ & $\begin{array}{l}2,98 \\
0,01\end{array}$ & $\begin{array}{l}3,01 \\
0,00\end{array}$ & & $\begin{array}{l}3,02 \\
0,00\end{array}$ & $\begin{array}{l}3,48 \\
0,01\end{array}$ & $\begin{array}{l}3,07 \\
0,03\end{array}$ & $\begin{array}{l}3,04 \\
0,00\end{array}$ & $\begin{array}{l}3.45 \\
0.02\end{array}$ & $\begin{array}{l}3,60 \\
0,02\end{array}$ & $\begin{array}{l}3,45 \\
300\end{array}$ & 3,20 & 3,47 \\
\hline TOTAL & 94,15 & 92,80 & $\begin{array}{r}94,13 \\
\end{array}$ & 92,28 & $\begin{array}{r}93,48 \\
\end{array}$ & 1,59 & & & & & & & & & 1,37 & 1,25 & 1,27 & & & & 1,29 & $\begin{array}{l}1,28 \\
1,28\end{array}$ & $\begin{array}{l}0,02 \\
1,45\end{array}$ & & & & \\
\hline $\mathrm{OH}^{\mathrm{a}}$ & 2.73 & 1,93 & 1.87 & 1,93 & 2.10 & & & 86,15 & 85,99 & 95,23 & 90,34 & 90,56 & 88,67 & 90,00 & 95,38 & 93,69 & 95,00 & 95,51 & 94,66 & 93,35 & 93,25 & 93,19 & 98,69 & 97.74 & $\begin{array}{l}1,46 \\
97,60\end{array}$ & $\begin{array}{l}1,35 \\
1,06\end{array}$ & $\begin{array}{r}1,46 \\
95,77\end{array}$ \\
\hline $\mathrm{OH}^{\circ}$ & 11 & 2,35 & 2 & 2,53 & 2,73 & $\begin{array}{l}1,95 \\
2,54\end{array}$ & $\begin{array}{l}2.21 \\
3.14\end{array}$ & 1,87 & 2.18 & 2,00 & 2,54 & 1,58 & 4.76 & 1,52 & 0,52 & 0,71 & 0,71 & 0,37 & 0,65 & 0,13 & 0,61 & 0,65 & 0,33 & 0,23 & 0,28 & 0,55 & 0,29 \\
\hline $\mathrm{OH}^{\mathrm{c}}$ & 3,68 & 2,96 & 3,12 & 3,43 & & & $\begin{array}{l}3,14 \\
4,49\end{array}$ & 2,81 & 3.14 & 2,40 & 3,29 & 2,29 & 2.46 & 2,19 & 1,08 & 1,26 & f,26 & 0,78 & 1,13 & 0,48 & 1,19 & 1,22 & 0,54 & 0,64 & 0,49 & 1.10 & 0,75 \\
\hline $\mathrm{CO}_{2}$ & 2,53 & 2,70 & 3,28 & 3,96 & 4,08 & 3,88 & $\begin{array}{l}4,49 \\
6,03\end{array}$ & & $\begin{array}{l}4,55 \\
6,28\end{array}$ & & & 3,34 & 3,50 & 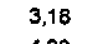 & 1,92 & 2,07 & 2,06 & 1,39 & 1,85 & 1,02 & 2,05 & 2,06 & 0,87 & 1,24 & 0.79 & 1,93 & 1,44 \\
\hline & & 0,301 & 0,323 & 0,755 & 0.721 & 75 & & & & & & & & & & 3,54 & 3,51 & 2,65 & 3,12 & 2,31 & 3,76 & 3,68 & 1,40 & 2,62 & 1,32 & 3,60 & 2.99 \\
\hline & & & & & & & & & & & & $\begin{array}{ll}7585 \\
085\end{array}$ & $\begin{array}{l}0,896 \\
8,877\end{array}$ & & & .036 & $\begin{array}{l}0,023 \\
9870\end{array}$ & 0,039 & $\begin{array}{l}0,041 \\
9885\end{array}$ & 0,030 & 0.028 & 0,031 & 0,022 &, 060 & 0,000 & 0,010 & 0,029 \\
\hline & & & & & & & & & & & & & & & 022 & 008 & $\begin{array}{l}870 \\
010\end{array}$ & & & & & & & & & & \\
\hline & & & & & & & & & & & & & & & & & & & & & & & & & & & \\
\hline & & & & & & & & & & & & & & & & & & & & & & & & & & & \\
\hline & & & & & & & & & & & & & & & & & & & & & & & & & & & \\
\hline & & & & & & & & & & & & & & & & & & & & & & & & & & & 053 \\
\hline & & & & & & & & & & & & & & & & & & & & & & & & & & & \\
\hline & & 0,018 & & & & & & & & & & & & & & & & & & & & & & & & & \\
\hline & & & & & & & 000 & 0,008 &, 007 &, 004 & 0,000 & $0, \infty 00$ & & 00 & & & & 009 & 0,000 & .006 & 0,005 & 1,004 & $0, \infty 1$ & 0,008 & & & ,002 \\
\hline & & & & $\begin{array}{l}5,110 \\
0,884\end{array}$ & & & & & & & & $\begin{array}{l}0.000 \\
4,968\end{array}$ & & & & & & & 0,100 & 0,162 & & & $\begin{array}{l}0,008 \\
5,673\end{array}$ & & & & \\
\hline & & & & & 0,912 & 868 & 334 & 1,339 & & & & & & & 82 & 0,802 & 0,795 & 603 & .710 & 0,528 & 0,854 & 833 & 0,319 &, 593 &, 301 & 0,815 & 0,679 \\
\hline & & & & & & & & $\begin{array}{l}0,954 \\
0,000\end{array}$ & $\begin{array}{l}0,786 \\
0,000\end{array}$ & $\begin{array}{l}0,839 \\
0,006\end{array}$ & $\begin{array}{l}0,568 \\
0,014\end{array}$ & $\begin{array}{l}1.105 \\
0,001\end{array}$ & $\begin{array}{l}1,004 \\
0,000\end{array}$ & &, 7000 & $\begin{array}{l}1,589 \\
0,003\end{array}$ & $\begin{array}{l}1,587 \\
0,000\end{array}$ & $\begin{array}{l}1,781 \\
0,011\end{array}$ & $\begin{array}{l}1,621 \\
0,0000\end{array}$ & $\begin{array}{l}1,926 \\
0,004\end{array}$ & $\begin{array}{l}1,649 \\
0,009\end{array}$ & 6028 & $\begin{array}{l}1,809 \\
0,006\end{array}$ & $\begin{array}{l}1,867 \\
0,006\end{array}$ & 1,833 & $\begin{array}{l}1,685 \\
0,000\end{array}$ & $\begin{array}{l}1,831 \\
0,011\end{array}$ \\
\hline $\mathrm{OH}^{\mathrm{a}}$ & 1,602 & 1,156 & 126 & 1,095 & 1,197 & 1,110 & 237 & 1,046 & 1,214 & 1,161 & 1,432 & 0,895 & 0,996 & 0,860 & 0,300 & 0,411 & 0,413 & 0,219 & 0,379 & 0.074 & 0,351 & 0,372 & 0,191 & 0,133 & 0,167 & 0,315 & 0,169 \\
\hline $\mathrm{OH}^{\mathrm{b}}$ & .834 & 1,408 & 1,434 & 1,449 & 1,562 & 1,457 & 770 & 1,582 & 1,768 & 1,399 & 1,870 & 1,308 & 1.403 & 1,250 &, 628 & 0,731 & 0.731 & 0,460 & 0,663 & 0,285 & 0,693 & 0,705 & 0,318 & 0,370 & 0,287 & 0,641 & 0,440 \\
\hline 0 & 181 & 1,785 & 1,897 & 1,979 & 2,109 & 1,978 & 2,570 & 2,385 & 2,599 & 1,755 & 2,527 & 1,927 & 2,014 & 1,835 & 1.121 & 1,213 & 1,208 & 0,822 & 1,089 & 0,602 & 1,206 & 1.205 & 0,510 & 0,726 & 0,468 & 1,130 & 0,847 \\
\hline P.M. ${ }^{9}$ & 998 & 1016 & 1021 & 967 & 968 & 970 & 951 & 950 & 947 & 987 & 958 & 963 & 961 & 963 & 981 & 882 & 983 & 892 & 990 & 999 & 984 & 980 & 996 & 987 & 997 & 982 & 886 \\
\hline P.M. ${ }^{b}$ & 1002 & 1021 & 1026 & 973 & 974 & 976 & 960 & 959 & 957 & 991 & 965 & 970 & 968 & 970 & 987 & 988 & 989 & 996 & 995 & 1002 & 990 & 986 & 999 & 991 & 999 & 988 & 991 \\
\hline P.M. ${ }^{c}$ & 1007 & 1027 & 1034 & 982 & 983 & 985 & 973 & 972 & 971 & 997 & 977 & 980 & 979 & 980 & 995 & 996 & 997 & 1002 & 1002 & 1007 & 999 & 994 & 1002 & 997 & 1002 & 996 & 998 \\
\hline carga & 0,195 & 0,356 & 0,454 & & 0,198 & 0,124 & 0,458 & 0,210 & 0,307 & 0,244 & 0,170 & 0,273 & 0,126 & 0,184 & 0,791 & 0,774 & 0,823 & 0.570 & 1,219 & 1,128 & 1,138 & 0,808 & 0,295 & 0,535 & 314 & 0,827 & 0,658 \\
\hline & ,037 & 0,104 & 0,146 & $-0,230$ & $-0,167$ & 224 & .076 & $-0,326$ & $-0,247$ & 0,007 & $-0,268$ & $-0,139$ & $-0,282$ & $-0,206$ & 0,462 & 0.453 & 0,505 & 0,329 & 0,935 & 0,917 & 0,796 & 0,475 & 0,168 & 0.298 & 193 & .501 & 0,386 \\
\hline carga $^{c}$ & & $-0,274$ & $-0,317$ & $-0,761$ & $-0,714$ &, 744 & & & & & -0.925 & $-0,759$ & $-0,893$ & $-0,791$ & $-0,031$ & $-0,028$ & 0,028 & $-0,033$ & .509 & .600 & 0,283 & $-0,025$ & $-0,024$ & $-0,058$ & 013 & .012 & $-0,021$ \\
\hline $\mathrm{CaO} / \mathrm{P}_{2} \mathrm{O}_{5}$ & & & & & 19 & 1 & 518 & 1,462 & 1,486 & 1,388 & 1,437 & & 1.409 & & 1,511 & 1,505 & 1,500 & 1.443 & 1,496 & 1,469 & .528 & 1.517 & 1,364 & 1,438 & 1,379 & 1,501 & 1,471 \\
\hline $\mathrm{F} / \mathrm{P}_{2} \mathrm{O}_{5}$ & 0,020 & 0,042 & 0,045 & & & & .044 & 0,055 & 0,046 & 0,042 & 0,031 & 0,060 & 0,054 & 0,061 & . 088 & 0,082 & 0,082 & 0.089 & 0,084 & 0,097 & 0,087 & 0.084 & 0,085 & 0.082 &, 086 & 0,087 & 0,092 \\
\hline $\mathrm{O} / \mathrm{P}_{2} \mathrm{O}_{5}$ & 0,106 & 0,165 & 0,221 & 0,025 & 0,030 & 0,029 & 0,039 & 0,039 & 0,036 & 0,038 & 0,030 & 0,031 & 0,036 & 0,021 & 0,014 & 0,017 & 0,014 & 0,012 & 0,012 & 0,016 & 0,014 & 0,009 & 0,009 & 0,005 & 0,000 & 0,018 & 0,015 \\
\hline
\end{tabular}


JUQUIÁ - APATITAS

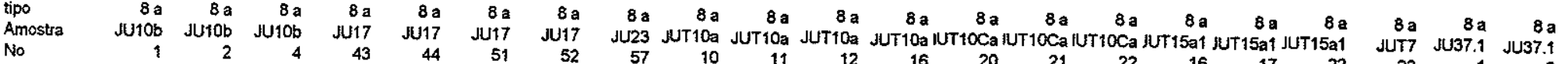

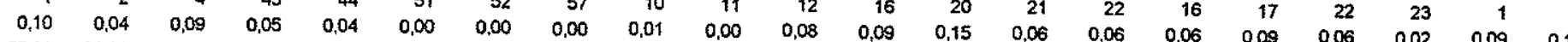

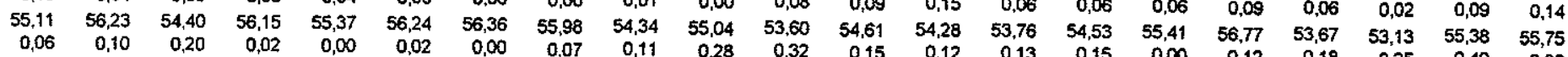

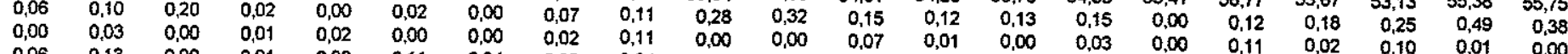

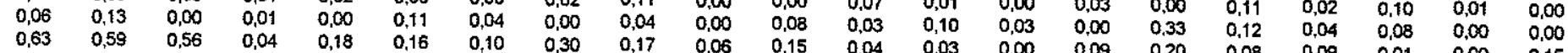

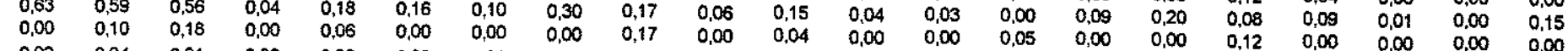

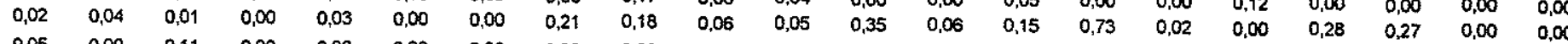

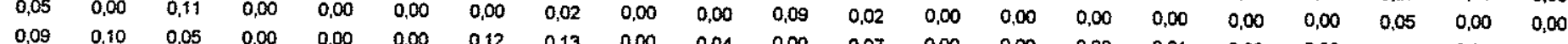

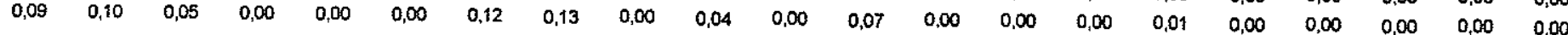
$\begin{array}{llllllllllllllllllllll}0,00 & 0,00 & 0,04 & 0,00 & 0,15 & 0,05 & 0,07 & 0,00 & 0,15 & 0,11 & 0,04 & 0,02 & 0,02 & 0,00 & 0,11 & 0,07 & 0,10 & 0,82 & 0,54 & 0,08 & 0,00\end{array}$

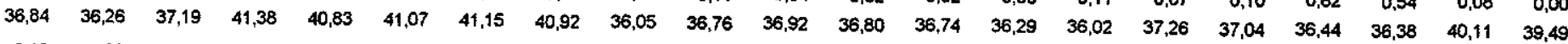

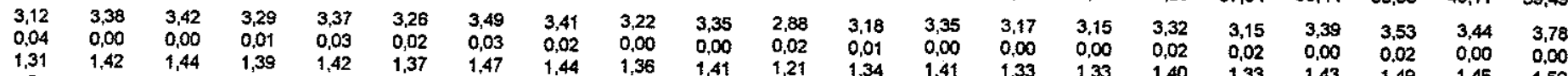

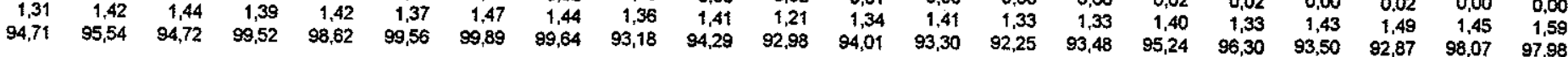
$\begin{array}{lllllllllllllllllllll}0,60 & 0,43 & 0,30 & 0,47 & 0,36 & 0,50 & 0,30 & 0,36 & 0,46 & 0,38 & 0,75 & 0,51 & 0,34 & 0,47 & 0,53 & 0,43 & 0,66 & 0,26 & 0,10 & 0,33 & 0,05\end{array}$

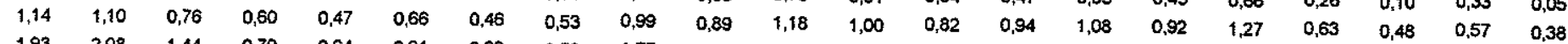

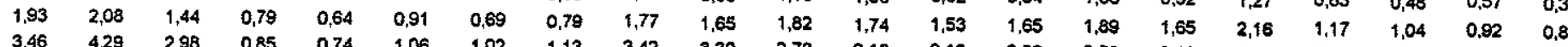

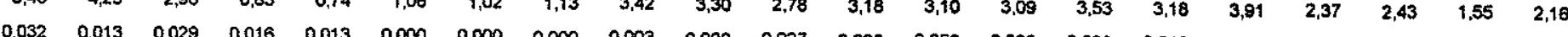

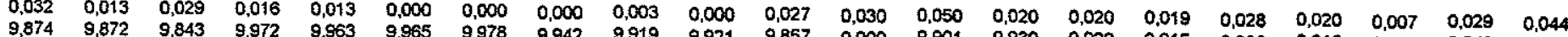

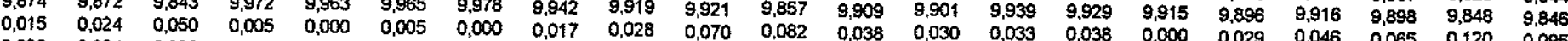

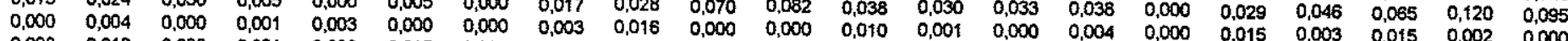

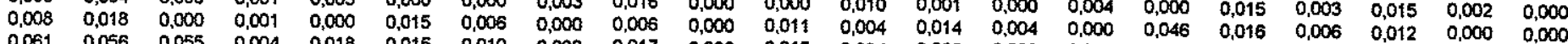

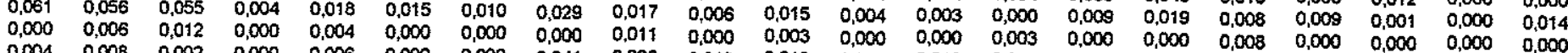

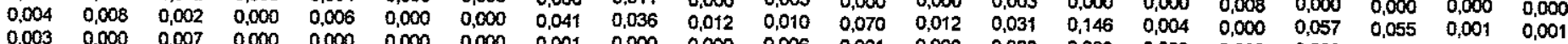

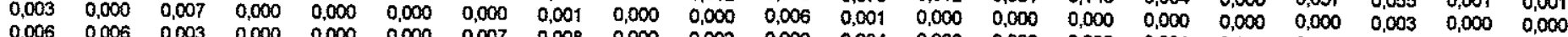

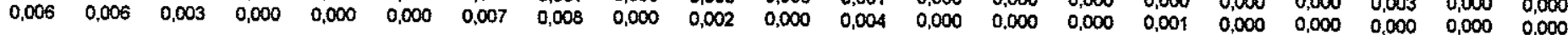

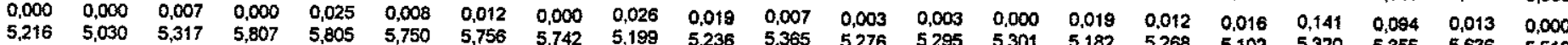

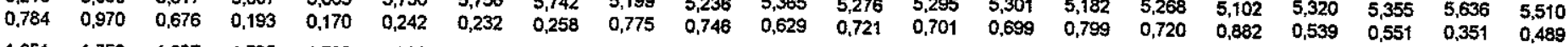
$\begin{array}{lllllllllllllllllllll}1,651 & 1,752 & 1,827 & 1,725 & 1,790 & 1,705 & 1,824 & 1,788 & 1,735 & 1,783 & 1,564 & 1,704 & 1,804 & 1,730 & 1,694 & 1,754 & 1,621 & 1,849 & 1,942 & 1,808 & 1,972 \\ 0,011 & 0,000 & 0,000 & 0,003 & 0,009 & 0,006 & 0,008 & 0,006 & 0,000 & 0,000 & 0,006 & 0,003 & 0.000 & 0,000 & 0,000 & 0,006 & 0,000 & 0,000 & 0,006 & 0,000 & 0,060\end{array}$

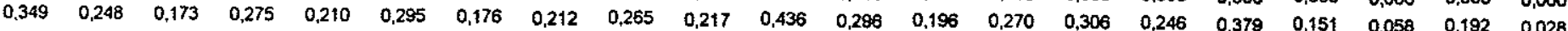

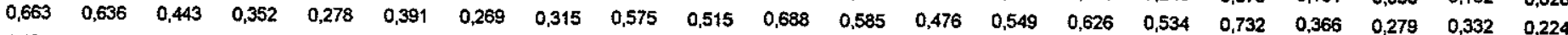

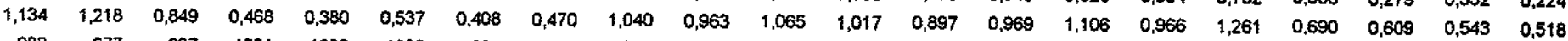

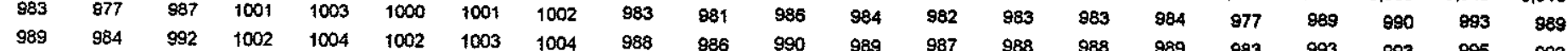

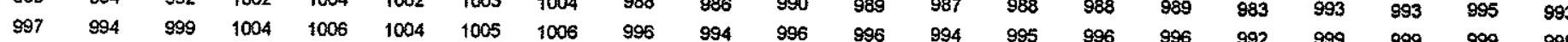
$\begin{array}{lllllllllllllllllllll}0,761 & 0,986 & 0,663 & 0,174 & 0,166 & 0,237 & 0,231 & 0,384 & 0,880 & 0,784 & 0,632 & 0,903 & 0,688 & 0,770 & 1,218 & 0,708 & 0,848 & 0,690 & 0,708 & 0,323 & 0,446\end{array}$ \begin{tabular}{lllllllllllllllllllll}
0,447 & 0,598 & 0,392 & 0,097 & 0,098 & 0,140 & 0,138 & 0,281 & 0,570 & 0,486 & 0,381 & 0,515 & 0,407 & 0,491 & 0,898 & 0,420 & 0,495 & 0,474 & 0,487 & 0,183 & 0,251 \\
\hline
\end{tabular} \begin{tabular}{lllllllllllllllllllllll} 
carga $^{c}$ & $-0,023$ & 0,016 & $-0,014$ & $-0,019$ & $-0,004$ & $-0,006$ & $-0,001$ & 0,127 & 0,105 & 0,038 & 0,004 & 0,183 & $-0,013$ & 0,071 & 0,419 & $-0,013$ & $-0,034$ & 0,151 & 0,157 & $-0,028$ & $-0,043$ \\
\hline
\end{tabular}

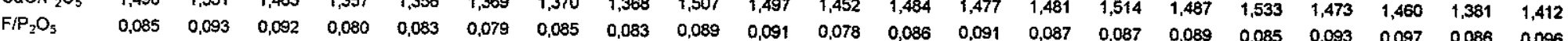
$\begin{array}{lllllllllllllllllllllll}\mathrm{SrO} / \mathrm{P}_{2} \mathrm{O}_{5} & 0,017 & 0,016 & 0,015 & 0,001 & 0,004 & 0,004 & 0,002 & 0,007 & 0,005 & 0,002 & 0,004 & 0,001 & 0,001 & 0,000 & 0,002 & 0,005 & 0,002 & 0,002 & 0,000 & 0,000 & 0,004\end{array}$

$\begin{array}{rrrrrrr}8 \mathrm{~b} & 8 \mathrm{~b} & 8 \mathrm{~b} & 8 \mathrm{~b} & 8 \mathrm{~b} & 8 \mathrm{~b} & 8 \mathrm{~b} \\ \mathrm{FJ} 42 \mathrm{a} & \mathrm{FJ42a} & \mathrm{FJ42a} & \mathrm{JU} 37.1 & \mathrm{JU} 37.1 & \mathrm{JU} 37.1 & \text { FJ42a } \\ 4 & 5 & 6 & 51 & 52 & 53 & 7\end{array}$ $\begin{array}{llllllll}0,11 & 0,12 & 0,17 & 0,00 & 0,06 & 53 & 7\end{array}$ \begin{tabular}{rrrrrrr}
$\mathbf{5 3 , 1 1}$ & $\mathbf{5 5 , 3 7}$ & $\mathbf{5 4 , 3 6}$ & $\mathbf{5 5 , 4 9}$ & $\mathbf{5 6 , 9 7}$ & $\mathbf{5 5 , 0 5}$ & $\mathbf{5 5 , 0 0 0}$ \\
\hline & 0,52 & 0,03 & 0,00 & 0,09 & 0,11 & 0,900
\end{tabular} $\begin{array}{lllllll}0,43 & 0,36 & 0,31 & 0,08 & 0,09 & 0,11 & 0,19 \\ 0,00 & 0,05 & 0,01 & 0,00 & 0,02 & 0,00 & 0,00\end{array}$

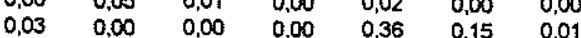
$\begin{array}{lllllll}0,32 & 0.19 & 0.17 & 0,56 & 0,63 & 0,61 & 0,30\end{array}$ $\begin{array}{lllllll}0,00 & 0,02 & 0,00 & 0,00 & 0,00 & 0,00 & 0,00\end{array}$ $\begin{array}{lllllll}0,00 & 0,00 & 0,01 & 0,00 & 0, \infty & 0,00 & 0,00\end{array}$ $\begin{array}{lllllll}0,00 & 0.01 & 0,00 & 0.17 & 0,06 & 0,00 & 0,00\end{array}$ $\begin{array}{lllllll}0,00 & 0,09 & 0,00 & 0,00 & 0,00 & 0,10 & 0,00\end{array}$ $\begin{array}{lllllll}0,06 & 0,00 & 0,07 & 0,08 & 0,00 & 0,06 & 0,07\end{array}$ $\begin{array}{lllllll}35,26 & 37,46 & 37,26 & 35,70 & 37,09 & 36,77 & 38,30\end{array}$ $\begin{array}{lllllll}2,99 & 3,04 & 3,37 & 3,16 & 3,12 & 3,21 & 3,25 \\ 0,00 & 0,03 & 0,00 & 0,02 & 0,03 & 0,00 & 0,04\end{array}$ $\begin{array}{lllllll}1,26 & 1,28 & 1,42 & 1,33 & 1,31 & 1,35 & 1,37\end{array}$ $\begin{array}{lllllll}0,64 & 0,70 & 0,34 & 0,58 & 0,71 & 0,55 & 0,49\end{array}$ $\begin{array}{lllllll}1,22 & 1,21 & 0,79 & 1,23 & 1,35 & 1,13 & 0,89\end{array}$ $\begin{array}{llllllll}2,07 & 1,96 & 1,46 & 2,19 & 2,30 & 1,88 & 1,47 \\ 3,73 & 3,28 & 2,90 & 4,19 & 4,14 & 3,71 & 2,56\end{array}$ $\begin{array}{lllllll}0,037 & 0,039 & 0,056 & 0,000 & 0,019 & 0,016 & 0,000\end{array}$ $\begin{array}{llllllll}\mathbf{9 , 8 1 6} & 9,840 & 9,848 & 9,915 & 9,846 & 9,871 & 9,922 \\ 0.111 & 0,089 & 0,078 & 0,020 & 9,022 & 0,027 & 0,047\end{array}$ $\begin{array}{llllllll}0,111 & 0,089 & 0,078 & 0,020 & 0,022 & 0,027 & 0.047\end{array}$ $\begin{array}{llllllll}0,000 & 0,007 & 0,001 & 0,000 & 0,003 & 0,000 & 0,000 \\ 0 & 0,000 & 0,000 & 0,000 & 0,049 & 0,021 & 0,001\end{array}$ $\begin{array}{lllllll}0,004 & 0,000 & 0,000 & 0,000 & 0,049 & 0,021 & 0.001 \\ 0,032 & 0,018 & 0,017 & 0,054 & 0,059 & 0,059 & 0,029\end{array}$ $\begin{array}{lllllll}0,032 & 0,018 & 0,017 & 0,054 & 0,059 & 0,059 & 0,029 \\ 0,000 & 0,001 & 0,000 & 0,000 & 0,000 & 0,000 & 0,000\end{array}$ $\begin{array}{llllllll}0,000 & 0,000 & 0,002 & 0,000 & 0,000 & 0,000 & 0,000\end{array}$ $\begin{array}{lllllll}0,000 & 0,001 & 0,000 & 0,010 & 0,004 & 0,000 & 0,000 \\ 0,000 & 0,005 & 0,000 & 0,000 & 0,000 & 0,006 & 0,000\end{array}$ $\begin{array}{lllllll}0,010 & 0,000 & 0,012 & 0.013 & 0,000 & 0.010 & 0,012\end{array}$ $\begin{array}{llllllll}0,840 & 0,740 & 0,655 & 0,946 & 0,0655 & 5,152 & 5,408 \\ 0,838 & 0,580\end{array}$ $\begin{array}{lllllll}1,632 & 1,595 & 1,803 & 1,667 & 1,592 & 1,681 & 1,715\end{array}$ $\begin{array}{llllllll}0,368 & 0,405 & 0,197 & 0,333 & 0,408 & 0,319 & 0,285\end{array}$ $\begin{array}{lllllll}0,704 & 0,701 & 0,459 & 0,711 & 0,782 & 0,655 & 0,517\end{array}$ $\begin{array}{llllllll}1,209 & 1,145 & 0,852 & 1,279 & 1,343 & 1,158 & 0,865\end{array}$ $\begin{array}{lllllll}977 & 981 & 983 & 978 & 978 & 981 & 988\end{array}$ $\begin{array}{lllllll}983 & 986 & 988 & 984 & 984 & 987 & 992\end{array}$ $\begin{array}{lllllll}991 & 994 & 994 & 994 & 994 & 995 & 998\end{array}$ $\begin{array}{lllllll}0,803 & 0,699 & 0,605 & 0,951 & 0,912 & 0,828 & 0,569\end{array}$ $\begin{array}{llllllll}0,467 & 0,403 & 0,343 & 0,573 & 0,538 & 0,493 & 0,337\end{array}$ $\begin{array}{llllllll}-0,037 & -0,041 & -0,050 & 0,005 & -0,023 & -0,010 & -0,011\end{array}$ $\begin{array}{lllllll}1,506 & 1,478 & 1,459 & 1,554 & 1,536 & 1,514 & 1,450 \\ 0,085 & 0,081 & 0,090 & 0,089 & 0,084 & 0,087 & 0,005\end{array}$ $\begin{array}{lllllll}0,009 & 0,005 & 0,005 & 0,016 & 0,017 & 0,017 & 0,008\end{array}$ 
JUQUIA - APATITAS

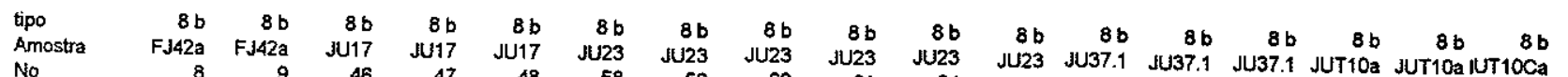

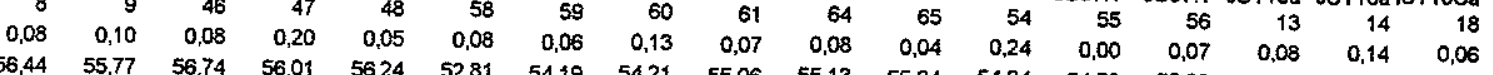
$\begin{array}{rrrrrrrrrrrrrrrrr}56,44 & 55,77 & 56,74 & 56,01 & 56,24 & 52,81 & 54,19 & 54,21 & 55,06 & 55,13 & 55,94 & 54,34 & 54,52 & 55,38 & 54,39 & 55,86 & 54,86 \\ 0,07 & 0,24 & 0,03 & 0,06 & 0,07 & 0,17 & 0,23 & 0,29 & 0,18 & 0,23 & 0,02 & 0,12 & 0,11 & 0,15 & 0,20 & 0,27 & 0,25\end{array}$ $\begin{array}{lllllllllllllllll}0,00 & 0,00 & 0,07 & 0,00 & 0,07 & 0,17 & 0,23 & 0,29 & 0,18 & 0,23 & 0,02 & 0,12 & 0,11 & 0,15 & 0,20 & 0,27 & 0,25 \\ 0,00 & 0,00 & 0,05 & 0,00 & 0,03 & 0,00 & 0,00 & 0,01 & 0,02 & 0,06 & 0,04 & 0,07 & 0,00\end{array}$ $\begin{array}{lllllllllllllllll}0,00 & 0,00 & 0,20 & 0,00 & 0,22 & 0,20 & 0,23 & 0,12 & 0,22 & 0,21 & 0,00 & 0,15 & 0,02 & 0,17 & 0,00 & 0,07 & 0,00 \\ 0,12 & 0,29 & 0,37 & 0,53 & 0,58 & 0,73 & 0,80 & 0,93 & 0,76 & 0,75 & 0,62 & 0,67 & 0,82 & 0,87 & 0,10 & 0,03 & 0,09\end{array}$ $\begin{array}{lllllllllllllllll}0,00 & 0,01 & 0,24 & 0,07 & 0,14 & 0,01 & 0,17 & 0,30 & 0,33 & 0,10 & 0,03 & 0,14 & 0,23 & 0,87 & 0,10 & 0,03 & 0,09 \\ 0,02 & 0,00 & 0,00 & 0,00 & 0,00 & 0,02 & 0,04 & 0,03 & 0,00 & 0,01 & 0,00 & 0,00 & 0,00 & 0,00 & 0,01 & 0,18 & 0,00\end{array}$ $\begin{array}{lllllllllllllllll}0,00 & 0,00 & 0,07 & 0,15 & 0,15 & 0,01 & 0,00 & 0,00 & 0,10 & 0,00 & 0,00 & 0,00 & 0,00 & 0,00 & 0,01 & 0,18 & 0,06 \\ 0,0,00 & 0,00 & 0,15 & 0,00 & 0,00\end{array}$ $\begin{array}{lllllllllllllllll}0,03 & 0,00 & 0,05 & 0,13 & 0,12 & 0,25 & 0,09 & 0,07 & 0,11 & 0,18 & 0,09 & 0,04 & 0,00 & 0,00 & 0,15 & 0,00 & 0,00 \\ 0,01 & 0,06 & 0,08 & 0,00\end{array}$ $\begin{array}{lllllllllllllllll}0,09 & 0,03 & 0,05 & 0,05 & 0,02 & 0,02 & 0,02 & 0,00 & 0,05 & 0,02 & 0,00 & 0,03 & 0,12 & 0,00 & 0,00 & 0,11 & 0,10\end{array}$ $\begin{array}{lllllllllllllllll}39,65 & 36,82 & 37,79 & 38,85 & 38,03 & 34,92 & 36,08 & 36,90 & 36,85 & 36,34 & 36,30 & 36,26 & 36,63 & 35,85 & 35,57 & 36,62 & 35,85\end{array}$ $\begin{array}{lllllllllllllllll}3,50 & 3,52 & 3,06 & 3,39 & 3,04 & 2,95 & 3,11 & 3,14 & 3,13 & 3,23 & 3,04 & 3,13 & 3,40 & 3,35 & 2,75 & 3,13 & 2,89 \\ 0,05 & 0,00 & 0,04 & 0,00 & 0,06 & 0,01 & 0,01 & 0,00 & 0,01 & 0,04 & 0,00 & 0,00 & 0,00 & 0,00 & 0,00 & 0,00 & 0,02\end{array}$ $\begin{array}{rrrrrrrrrrrrrrrrr}1,47 & 1,48 & 1,29 & 1,43 & 1,28 & 1,24 & 1,31 & 1,32 & 1,32 & 1,36 & 1,28 & 1,32 & 1,43 & 1,41 & 1,16 & 1,32 & 1,22 \\ 98,50 & 95,20 & 97,42 & 97,81 & 97,39 & 90,93 & 93,71 & 94,67 & 95,51 & 94,88 & 94,76 & 93,61 & 94,53 & 94,56 & 92,14 & 95,04 & 93,07\end{array}$ $\begin{array}{lllllllllllllllll}0,31 & 0,28 & 0,74 & 0,41 & 0,74 & 0,66 & 0,59 & 0,57 & 0,62 & 0,53 & 0,71 & 0,58 & 0,32 & 0,43 & 0,21 & 0,64 & 0,81\end{array}$ $\begin{array}{lllllllllllllllll}0,62 & 0,86 & 1,28 & 0,82 & 1,23 & 1,26 & 1,17 & 1,09 & 1,17 & 1,14 & 1,34 & 1,15 & 0,82 & 1,10 & 1,52 & 1,24 & 1,41\end{array}$

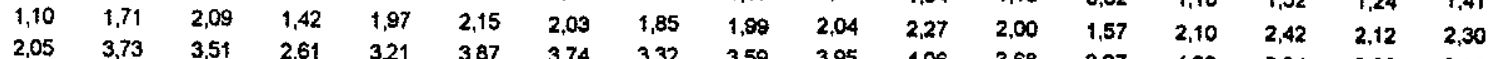
$\begin{array}{rllllllllllllllll}0,026 & 0,032 & 0,025 & 0,064 & 0,016 & 0,027 & 0,020 & 0,042 & 0,023 & 0,026 & 0,013 & 0,078 & 0,000 & 0,022 & 0,94 & 3,86 & 3,90\end{array}$ $\begin{array}{lllllllllllllllll}0,026 & 0,032 & 0,025 & 0,064 & 0,016 & 0,027 & 0,020 & 0,042 & 0,023 & 0,026 & 0,013 & 0,078 & 0,000 & 0,022 & 0,026 & 0,045 & 0,020 \\ 9,944 & 9,880 & 9,873 & 9,850 & 9,857 & 9,799 & 9,788 & 9,754 & 9,791 & 9,799 & 9,915 & 9,790 & 9,855 & 0,910 & 9002 & 0,070 & 9,885\end{array}$ $\begin{array}{lllllllllllllllll}0,017 & 0,059 & 0,007 & 0,015 & 0,017 & 0,044 & 0,788 & 9,754 & 9,791 & 9,799 & 9,915 & 9,790 & 9,865 & 9,816 & 9,892 & 9,870 & 9,885 \\ 0,0,073 & 0,045 & 0,057 & 0,005 & 0,030 & 0,028 & 0,037 & 0,051 & 0,065 & 0,063\end{array}$

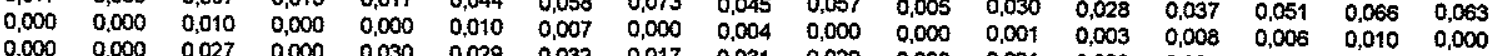
$\begin{array}{lllllllllllllllll}0,011 & 0,028 & 0,035 & 0,050 & 0,055 & 0,029 & 0,032 & 0,017 & 0,031 & 0,029 & 0,000 & 0,021 & 0,003 & 0,024 & 0,000 & 0,001 & 0,024\end{array}$ $\begin{array}{lllllllllllllllll}0,000 & 0,001 & 0,015 & 0,005 & 0,009 & 0,001 & 0,011 & 0,020 & 0,021 & 0,007 & 0,060 & 0,065 & 0,080 & 0,084 & 0,010 & 0,003 & 0,009\end{array}$ $\begin{array}{lllllllllllllllll}0,004 & 0,000 & 0,000 & 0,000 & 0,000 & 0,004 & 0,008 & 0,006 & 0,000 & 0,002 & 0,000 & 0,000 & 0,000 & 0,000 & 0,002 & 0,000 & 0,000 \\ 0 & 0,000 & 0,012\end{array}$

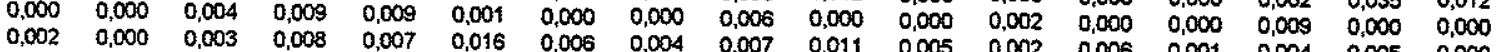
$\begin{array}{lllllllllllllllll}0,002 & 0,000 & 0,003 & 0,008 & 0,007 & 0,016 & 0,006 & 0,004 & 0,007 & 0,011 & 0,005 & 0,002 & 0,006 & 0,001 & 0,004 & 0,005 & 0,000\end{array}$ $\begin{array}{lllllllllllllllll}0,015 & 0,005 & 0,008 & 0,008 & 0,003 & 0,003 & 0,003 & 0,000 & 0,008 & 0,003 & 0,000 & 0,005 & 0,020 & 0,000 & 0,000 & 0,018 & 0,017 \\ \mathbf{5}, 520 & 5,154 & 5,196 & 5,398 & 5,266 & 5,120 & 5,149 & 5,248 & 5,178 & 5,103 & 5,004 & 5,162 & 5,237 & 5,021 & 5,112 & 5,113 & 5,104\end{array}$

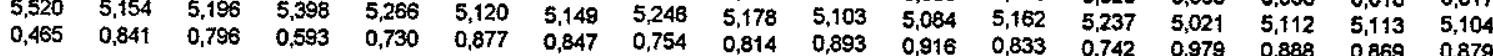
$\begin{array}{lllllllllllllllll}1,821 & 1,841 & 1,572 & 1,760 & 1,573 & 1,616 & 1,659 & 1,668 & 1,643 & 1,695 & 1,591 & 1,665 & 1,817 & 1,753 & 1,477 & 1,633 & 1,538 \\ 0,014 & 0,000 & 0,011 & 0,000 & 0,017 & 0,003 & 0,003 & 0,000 & 0,003 & 0,011 & 0,000 & 0,000 & 0,000 & 0,000 & 0,000 & 0,000 & 0,006\end{array}$ $\begin{array}{lllllllllllllllll}0,179 & 0,159 & 0,428 & 0,240 & 0,427 & 0,384 & 0,341 & 0,332 & 0,357 & 0,305 & 0,409 & 0,335 & 0,183 & 0,247 & 0,523 & 0,367 & 0,462\end{array}$ $\begin{array}{lllllllllllllllll}0,365 & 0,495 & 0,746 & 0,477 & 0,719 & 0,734 & 0,680 & 0,634 & 0,682 & 0,662 & 0,775 & 0,668 & 0,480 & 0,638 & 0,879 & 0,715 & 0,814\end{array}$ $\begin{array}{lllllllllllllllll}0,645 & 1,000 & 1,224 & 0,833 & 1,157 & 1,260 & 1,189 & 1,086 & 1,171 & 1,198 & 1,325 & 1,168 & 0,926 & 1,226 & 1,411 & 1,236 & 1,342\end{array}$ $\begin{array}{rlllllllllllrrrrr}992 & 978 & 984 & 990 & 987 & 981 & 983 & 986 & 985 & 981 & 978 & 981 & 987 & 978 & 977 & 977 & 976\end{array}$

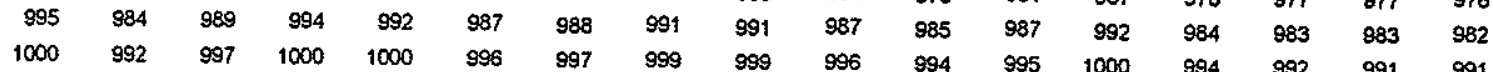
$\begin{array}{rrlllllllllllllll}0,439 & 0,809 & 0,767 & 0,547 & 0,714 & 0,876 & 0,854 & 0,734 & 0,802 & 0,873 & 0,909 & 0,760 & 0,748 & 0,957 & 092 & 991 & 991\end{array}$ $\begin{array}{lllllllllllllllll}0,253 & 0,472 & 0,449 & 0,309 & 0,422 & 0,525 & 0,515 & 0,432 & 0,476 & 0,516 & 0,542 & 0,427 & 0,451 & 0,566 & 0,526 & 0,587 & 0,538\end{array}$ $\begin{array}{lllllllllllllllll}-0,026 & -0,032 & -0,029 & -0,047 & -0,016 & -0,001 & 0,007 & -0,020 & -0,013 & -0,020 & -0,007 & -0,073 & 0,006 & -0,022 & -0,007 & 0,065 & 0,010\end{array}$ $\begin{array}{lllllllllllllllll}1,423 & 1,515 & 1,501 & 1,442 & 1,479 & 1,512 & 1,502 & 1,469 & 1,494 & 1,517 & 1,541 & 1,499 & 1,488 & 1,545 & 1,529 & 1,525 & 1,530\end{array}$ $\begin{array}{lllllllllllllllllll}\mathrm{F}_{\mathrm{P}} \mathrm{O}_{5} & 0,088 & 0,096 & 0,081 & 0,087 & 0,080 & 0,084 & 0,086 & 0,085 & 0,085 & 0,089 & 0,084 & 0,086 & 0,093 & 0,093 & 0,077 & 0,085 & 0,081\end{array}$ $\begin{array}{lllllllllllllllllll}\mathrm{SrO}_{2} \mathrm{P}_{2} \mathrm{O}_{5} & 0,003 & 0,008 & 0,010 & 0,014 & 0,015 & 0,021 & 0,022 & 0,025 & 0,021 & 0,021 & 0,017 & 0,018 & 0,022 & 0,024 & 0,003 & 0,001 & 0,003\end{array}$

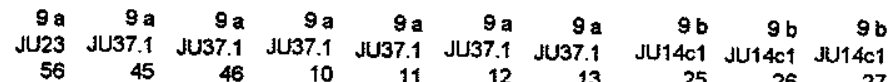

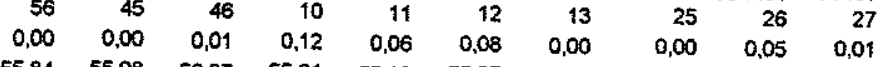
$\begin{array}{rrrrrrrrrr}55,84 & 55,98 & 56,07 & 55,01 & 55,19 & 55,27 & 55,18 & 55,86 & 0,05 & 0,01 \\ 0,50 & 55,80\end{array}$

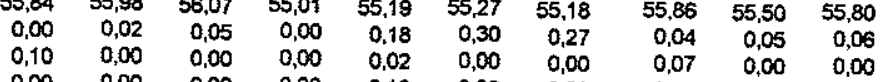
$\begin{array}{lllllllllll}0,00 & 0,00 & 0,00 & 0,00 & 0,12 & 0,00 & 0,00 & 0,00 & 0,00 & 0,00 \\ 0,29 & 0,03 & 0,12 & 0,75 & 1,05 & 0,00 & 0,70 & 0,05 & 0,07 & 0,00\end{array}$ $\begin{array}{lllllllllll}0,29 & 0,23 & 0,12 & 0,75 & 1,05 & 0,86 & 0,76 & 0,05 & 0,27 & 0,16 \\ 0,00 & 0,09 & 0,00 & 0,00 & 0,00 & 0,00 & 0,00 & 0,00 & 0,00 & 0,19\end{array}$ $\begin{array}{lllllllllll}0,00 & 0,00 & 0,00 & 0,00 & 0,00 & 0,00 & 0,00 & 0,00 & 0,00 & 0,19 \\ 0,00 & 0,01 & 0,00\end{array}$ $\begin{array}{llllllllll}0,00 & 0,05 & 0,00 & 0,00 & 0,00 & 0,00 & 0,06 & 0,13 & 0,05 & 0,00\end{array}$

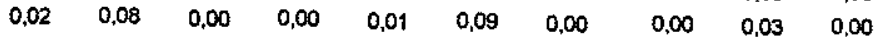
$\begin{array}{llllllllll}0,01 & 0,14 & 0,06 & 0,07 & 0,03 & 0,00 & 0,07 & 0,00 & 0,04 & 0,04\end{array}$ $\begin{array}{llllllllll}41,96 & 41,45 & 41,42 & 41,31 & 40,81 & 39,71 & 40,20 & 41,23 & 41,58 & 41,62\end{array}$ $\begin{array}{llllllllll}3,01 & 3,61 & 3,62 & 3,65 & 3,50 & 3,59 & 3,85 & 3,39 & 3,43 & 3,37 \\ 0,01 & 0,03 & 0,05 & 0,05 & 0,00 & 0,04 & 0,00 & 0,00 & 0,00 & 0,00\end{array}$ $\begin{array}{rrrrrrrrrr}1,27 & 1,52 & 1,53 & 1,54 & 1,47 & 1,51 & 1,62 & 1,43 & 1,00 & 0,00 \\ 99,97 & 100,16 & 99,86 & 99,31 & 99,44 & 98,35 & 98,76 & 99,44 & 9,52 & 9,42\end{array}$ $\begin{array}{llllllllll}0,70 & 0,18 & 0,17 & 0,10 & 0,28 & 0,20 & -0,05 & 0,36 & 0,31 & 0,38\end{array}$ $\begin{array}{llllllllll}0,76 & 0,28 & 0,28 & 0,18 & 0,45 & 0,49 & 0,16 & 0,49 & 0,39 & 0,47\end{array}$ $\begin{array}{llllllllll}0,85 & 0,43 & 0,45 & 0,30 & 0,71 & 0,83 & 0,48 & 0,68 & 0,50 & 0,59 \\ 0,38 & 0,68 & 0,74 & 0,53 & 1,14 & 1,89 & 1,38 & 0,82 & 0,48 & 0,55\end{array}$ $\begin{array}{lllllllllll}0,000 & 0,000 & 0,003 & 0,039 & 0,018 & 0,025 & 0,000 & 0,000 & 0,016 & 0,003\end{array}$ $\begin{array}{llllllllll}\mathbf{9 , 9 5 7} & \mathbf{9 , 9 5 9} & \mathbf{9 , 9 7 3} & \mathbf{9 , 8 8 8} & \mathbf{8 , 8 1 5} & \mathbf{9 , 8 1 3} & \mathbf{9 , 8 5 5} & \mathbf{9 , 0 0 0 7} & \mathbf{9 , 0 1 6} & 0,003 \\ \mathbf{9} & \mathbf{9}, 940 & \mathbf{9 , 9 5 4}\end{array}$

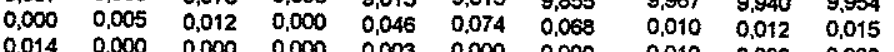
$\begin{array}{llllllllll}0,014 & 0,000 & 0,000 & 0,000 & 0,003 & 0,000 & 0,000 & 0,010 & 0,000 & 0,000\end{array}$ $\begin{array}{llllllllll}0,000 & 0,000 & 0,000 & 0,000 & 0,017 & 0,000 & 0,000 & 0,000 & 0,000 & 0,000\end{array}$ $\begin{array}{llllllllll}0,028 & 0,022 & 0,012 & 0,073 & 0,101 & 0,083 & 0,073 & 0,005 & 0,026 & 0,015 \\ 0,000 & 0,006 & 0,000 & 0,000 & 0,000 & 0,000 & 0,000 & 0,000 & 0,000 & 0,012\end{array}$ $\begin{array}{llllllllll}0,000 & 0,000 & 0,000 & 0,000 & 0,000 & 0,000 & 0,000 & 0,000 & 0,000 & 0.012 \\ 0 ., 000 & 0,000 & 0,000 & 0,000 & 0,002 & 0,000\end{array}$ $\begin{array}{llllllllll}0,000 & 0,003 & 0,000 & 0,000 & 0,000 & 0,000 & 0,000 & 0,000 & 0,002 & 0,000 \\ 0,0,000 & 0,0003 & 0,000\end{array}$ $\begin{array}{llllllllll}0,001 & 0,005 & 0,000 & 0,000 & 0,000 & 0,005 & 0,000 & 0,000 & 0,003 & 0,000 \\ 0,0,000 & 0,000\end{array}$ $\begin{array}{llllllllll}0,002 & 0,023 & 0,010 & 0,012 & 0,005 & 0,000 & 0,011 & 0,000 & 0,007 & 0,007\end{array}$ $\begin{array}{llllllllll}0,087 & 0,150 & 0,169 & 0,120 & 0,260 & 0,430 & 0,316 & 0,813 & 5,884 & 5,866 \\ & 0,109 & 0,127\end{array}$ $\begin{array}{lllllllllll}1,585 & 1,896 & 1,901 & 1,940 & 1,838 & 1,882 & 2,030 & 1,786 & 1,814 & 1,775\end{array}$ $\begin{array}{lllllllllll}0,415 & 0,104 & 0,099 & 0,060 & 0,162 & 0,118 & -0,030 & 0,214 & 0,186 & 0,225\end{array}$ $\begin{array}{llllllllll}0,450 & 0,164 & 0,168 & 0,108 & 0,266 & 0,290 & 0,098 & 0,289 & 0,230 & 0,278\end{array}$ $\begin{array}{lllllllllll}0,502 & 0,254 & 0,268 & 0,181 & 0,423 & 0,548 & 0,286 & 0,401 & 0,295 & 0,352\end{array}$ $\begin{array}{llllllllll}1006 & 1005 & 1003 & 1007 & 1003 & 996 & 1000 & 1002 & 1005 & 1005\end{array}$ $\begin{array}{llllllllll}1006 & 1006 & 1004 & 1008 & 1004 & 999 & 1002 & 1003 & 1006 & 1006\end{array}$ $\begin{array}{llllllllll}1007 & 1008 & 1006 & 1009 & 1007 & 1003 & 1005 & 1005 & 1007 & 1007\end{array}$ $\begin{array}{llllllllll}0,085 & 0,150 & 0,152 & 0,067 & 0,242 & 0,400 & 0,320 & 0,195 & 0,104 & 0,124\end{array}$ $\begin{array}{lllllllllll}0,050 & 0,090 & 0,084 & 0,019 & 0,138 & 0,228 & 0,194 & 0,120 & 0,060 & 0,073\end{array}$ $\begin{array}{llllllllll}-0,002 & -0,001 & -0,017 & -0,053 & -0,018 & -0,030 & 0,004 & 0,008 & -0,005 & -0,003\end{array}$ $\begin{array}{llllllllll}1,331 & 1,351 & 1,354 & 1,332 & 1,352 & 1,392 & 1,373 & 1,355 & 1,335 & 1,341\end{array}$ $\begin{array}{lllllllllll} & 1,0,089 & 0,089 & 0,087 & 0,088 & 0,086 & 0,090 & 0,096 & 0,082 & 0,082 & 0,081\end{array}$ $\begin{array}{llllllllll}0,007 & 0,006 & 0,003 & 0,018 & 0,026 & 0,022 & 0,019 & 0,001 & 0,006 & 0,004\end{array}$ 


\begin{tabular}{|c|c|c|c|c|}
\hline $\begin{array}{l}\text { tipo } \\
\text { Amostra } \\
\text { Noo }\end{array}$ & $\begin{array}{r}9 \mathrm{~b} \\
\mathrm{JU} 14 \mathrm{c} \\
28\end{array}$ & $\begin{array}{r}9 b \\
\text { Jบ14ci } \\
29\end{array}$ & $\begin{array}{r}9 b \\
\mathrm{JU} 14 c 1 \\
30\end{array}$ & $\begin{array}{r}96 \\
\mathrm{JU} 40\end{array}$ \\
\hline $\mathrm{Na}_{2} \mathrm{O}$ & $\begin{array}{r}28 \\
0,00\end{array}$ & $\begin{array}{r}29 \\
0,06\end{array}$ & $\begin{array}{r}30 \\
0.01\end{array}$ & $\begin{array}{r}8 \\
0.83\end{array}$ \\
\hline $\mathrm{CaO}$ & 55,56 & 55,59 & 54,69 & $\begin{array}{r}0,83 \\
53,90\end{array}$ \\
\hline Mgo & 0,03 & 0,09 & 0,08 & $0, \infty$ \\
\hline Mno & 0,00 & 0,00 & 0,00 & 0,18 \\
\hline $\mathrm{FeO}$ & 0,13 & 0,00 & 0,05 & 0,17 \\
\hline Sro & 0,02 & 0,17 & 0,13 & 0.53 \\
\hline $\mathrm{BaO}$ & 0,00 & 0,10 & 0,00 & 0,31 \\
\hline $\mathrm{Al}_{2} \mathrm{O}_{3}$ & 0,00 & 0,00 & 0,01 & 0,04 \\
\hline $\mathrm{La}_{2} \mathrm{O}_{3}$ & 0,01 & 0,00 & 0,02 & 0,02 \\
\hline $\mathrm{Ce}_{2} \mathrm{O}_{3}$ & 0,00 & 0,05 & 0,00 & 0,15 \\
\hline $\mathrm{SiO}_{2}$ & 0,02 & 0,02 & 0,05 & 0,44 \\
\hline $\mathrm{P}_{2} \mathrm{O}_{5}$ & 41,48 & 41,88 & 41,68 & 38,19 \\
\hline $\begin{array}{l}\mathrm{F} \\
\mathrm{Cl}\end{array}$ & $\begin{array}{l}3,22 \\
0,02\end{array}$ & $\begin{array}{l}3,26 \\
0,00\end{array}$ & $\begin{array}{l}3,39 \\
0,00\end{array}$ & $\begin{array}{l}2,99 \\
0,02\end{array}$ \\
\hline $\mathrm{O}=\mathrm{F}, \mathrm{Cl}$ & 1,36 & 1,37 & 1,43 & 1,26 \\
\hline TOTAL & 99,13 & 99,79 & 98,68 & 95,68 \\
\hline $\mathrm{OH}^{\mathrm{a}}$. & 0,50 & 0,47 & 0,30 & 0,73 \\
\hline $\mathrm{OH}^{b}$ & 0,57 & 0,53 & 0,30 & 9,11 \\
\hline $\mathrm{OH}^{\circ}$ & 0,69 & 0,62 & 0,30 & 1,67 \\
\hline $\mathrm{CO}_{2}$ & 0,50 & 0,37 & 0,00 & 2,43 \\
\hline $\mathrm{Na}$ & 0,000 & 0,019 & 0,003 & 0,268 \\
\hline $\mathrm{Ca}$ & 9,972 & 9,932 & 9,955 & 9,602 \\
\hline Mg & 0,007 & 0,022 & 0,020 & 0,000 \\
\hline $\mathrm{Mn}$ & 0,000 & 0,000 & 0,000 & 0,025 \\
\hline $\mathrm{Fe}$ & 0,018 & 0,000 & 0,007 & 0,024 \\
\hline Sr & 0,002 & 0.016 & 0,013 & 0,051 \\
\hline Ba & 0,000 & 0,007 & 0,000 & 0,020 \\
\hline$A^{3}$ & 0,000 & 0,000 & 0,002 & 0,008 \\
\hline La & 0,001 & 0,000 & 0,001 & 0,001 \\
\hline Ce & 0,000 & 0,003 & 0,000 & 0,009 \\
\hline $\begin{array}{l}\text { Si } \\
\mathrm{P}\end{array}$ & $\begin{array}{l}0,003 \\
5.883\end{array}$ & 0,003 & 0,008 & 0,073 \\
\hline $\begin{array}{l}P \\
C \\
C\end{array}$ & $\begin{array}{l}5,882 \\
0,114\end{array}$ & $\begin{array}{l}5,912 \\
0,084\end{array}$ & $\begin{array}{l}5,996 \\
0,000\end{array}$ & $\begin{array}{l}5,375 \\
0,551\end{array}$ \\
\hline$F$ & 1,706 & 1,720 & 1,822 & 1,573 \\
\hline $\mathrm{Cl}$ & 0,006 & 0,000 & 0,000 & 0,006 \\
\hline $\mathrm{OH}^{\mathrm{a}}$ & 0,294 & 0,280 & 0,178 & 0,427 \\
\hline $\mathrm{OH}^{\mathrm{b}}$ & 0,339 & 0,314 & 0,178 & 0,648 \\
\hline $\mathrm{OH}^{\mathrm{c}}$ & 0,408 & 0,365 & 0,178 & 0,979 \\
\hline P.M. ${ }^{a}$ & 1004 & 1006 & 1009 & 990 \\
\hline$P . M^{0}$ & 1005 & 1006 & 1009 & 993 \\
\hline P.M..$^{c}$ & 1006 & 4007 & 1009 & 999 \\
\hline carga " & 0,109 & 0.068 & $-0,010$ & 0,312 \\
\hline carga ${ }^{\circ}$ & 0,064 & 0,034 & $-0,010$ & 0,091 \\
\hline carga c & $-0,005$ & $-0,016$ & $-0,010$ & $-0,239$ \\
\hline $\mathrm{CaO} / \mathrm{P}_{2} \mathrm{O}_{5}$ & 1,339 & 1,327 & 1,312 & 1,411 \\
\hline $\mathrm{F} / \mathrm{P}_{2} \mathrm{O}_{5}$ & 0,078 & 0,078 & 0,081 & 0,078 \\
\hline $\mathrm{SrO} / \mathrm{P}_{2} \mathrm{O}_{5}$ & 0,000 & 0,004 & 0,003 & 0,014 \\
\hline
\end{tabular}




\begin{abstract}
ANEXO 4
Composição química das apatitas de Tapira obtida à ME e expressa em \% em óxidos e em número de átomos por fórmula unitária

$\mathrm{OH}$ (\% em peso e átomos p.f.u.), peso molecular (PM) e carga da fórmula estrutural calculados considerando três alternativas: a - todo flúor $(F)$ nos canais $\left(F_{p}=0\right), b$ parte do flúor $\left(F_{p}\right)$ acompanhando o $\mathrm{CO}_{3}{ }^{2-}\left(F_{p}=0,4 C\right)$ e $c$ - parte do flúor $\left(F_{p}\right)$ acompanhando o $\mathrm{CO}_{3}\left(F_{\mathrm{p}}=\mathrm{C}\right)$. $\mathrm{OH}$ foi calculado pela diferença da fração molar no sítio dos ânions monovalentes $\left(\mathrm{OH}=2-\mathrm{F}-\mathrm{F}_{\mathrm{p}}\right)$, para cada caso $\mathrm{a}$, b e $\mathrm{c}$.
\end{abstract}

Tipos: 1- Apatita prismática primária, 2- Apatita primária anédrica, 3- Apatita hidrotermal anédrica (a: borda, b: próximo a fratura, c: núcleo), 5- Apatita supérgena fina em pavê intercrescida na apatita hidrotermal anédrica, 6- Apatita supérgena tipo fibrosa. 


\begin{tabular}{|c|c|c|c|c|c|c|c|c|c|c|c|c|c|c|c|}
\hline & 1 & $i$ & 1 & 3 & $\mathrm{~T}$ & 1 & 2 & 2 & 2 & 2 & 2 & 2 & 2 & 2 & \\
\hline Label & $4 F 33 b$ & TAF33b & TAF33b & TAF33b & TAF33b & TAF33b & TAF40a & TAF40a & TAF40a & TAF40a & TAF40a & TAF60 & TAF60 & & \\
\hline & 1 & 8 & 10 & 11 & 12 & 14 & 2 & 3 & 4 & 5 & 6 & 57 & 58 & 60 & \\
\hline$a_{2} \mathrm{O}$ & 0,06 & 0,00 & 0,00 & 0,15 & 0,07 & 0,07 & 0,16 & 0,13 & 0,07 & 0,15 & 0,07 & 0,03 & 0,08 & 0,14 & \\
\hline $\mathrm{CaO}$ & 53,69 & 54,67 & 54,52 & 54,19 & 53,34 & 53,54 & 54,66 & 54,38 & 54,68 & 54,38 & 54,28 & 54,89 & 55,50 & 55,31 & \\
\hline $\mathrm{MgO}$ & 0,00 & 0,05 & 0,02 & 0,05 & 0,26 & 0,00 & 0,00 & 0,01 & 0,00 & 0,00 & 0,00 & 0,00 & 0,00 & 0,01 & \\
\hline $\mathrm{MnO}$ & 07 & 00 & .00 & 04 & 0,04 & 0,08 & 0,08 & 0,04 & 0,00 & 0,11 & 0,05 & 0,00 & 0,01 & 0,18 & \\
\hline eO & 03 & 0,05 & 0,22 & 0,19 & 0,37 & 0,33 & 0,00 & 0,00 & 0,16 & 0,06 & 0,00 & 0,10 & 0,00 & 0,00 & \\
\hline Sro & 1,07 & 0,89 & 1,04 & 0,88 & 1,15 & 2,07 & 1,63 & 1,57 & 1,59 & 1,38 & 1,59 & 0,93 & 1,03 & 0,96 & \\
\hline $\mathrm{BaO}$ & &, 00 & 0,04 & & 0,00 & & & & & 0,01 & 0,00 & 0,00 & 0,00 & 0,00 & \\
\hline & & & 00 & 00 & 01 & 0,00 &, 00 & 0,00 & 0,00 & 0,00 & 0,00 & 0,00 & 0,03 & 0,00 & \\
\hline $\mathrm{La}_{2} \mathrm{O}_{3}$ & & 0,27 & 0,23 & 0,17 & 0,19 & 0,43 & 0,11 & 0,00 & 0,00 & 0,01 & 0,04 & 0,11 & 0,06 & 0,00 & \\
\hline $\mathrm{Ce}_{2} \mathrm{O}_{3}$ & 23 & 0,09 & 0,28 & 0,27 & 0,24 & 0,40 & 0,06 & 0,11 & 0,14 & 0,00 & 0,10 & 0,09 & 0,08 & 0,00 & \\
\hline $\mathrm{SiO}_{2}$ & & & 1,95 & 1,92 & 2,68 & & 0,81 & 0,83 & & 0,72 & 0,69 & 0,24 & 0,48 & 0,65 & \\
\hline $\mathrm{P}_{2} \mathrm{O}_{5}$ & 37,17 & 36,98 & 38,13 & 37,68 & 36,20 & 38,19 & 39,95 & 38,74 & 40,78 & 39,68 & 39,54 & 38,95 & 38,52 & 40,04 & 11 \\
\hline$F$ & & 53 & 1,39 & 1,59 & 1,99 & $2,0 t$ & 2,05 & & 2,15 & 1,88 & 2,02 & 1,87 & 1,71 & 1,57 & \\
\hline \multirow[t]{2}{*}{$\mathrm{Cl}$} & 0,02 & 0,01 & 0,00 & 0,01 & 0,03 & 0,00 & 0,00 & 0,07 & 0,02 & 0,00 & 0,02 & 0,00 & 0,02 & 0,00 & 01 \\
\hline & 96,04 & 96,54 & 97,82 & 97,03 & 96,48 & 97,81 & 99,37 & 97,71 & 100,17 & 98,23 & 98,34 & 97,19 & 97,46 & 98,74 & 9,82 \\
\hline$=F, C l$ & & & 59 & 0,67 & 0,84 & 0,85 & 0,86 & 0,83 & 0,90 & 0,79 & 0,85 & 0,79 & 0,72 & 0,66 & 6 \\
\hline TOTAL & 96,60 & 97,60 & 98,29 & 97,81 & 97,19 & 98,89 & 99,64 & 98,55 & 99,87 & 98,62 & 98,61 & 98,29 & 99,06 & 99,39 & 99,76 \\
\hline $\mathrm{OH}^{\mathrm{a}}$ & 2,01 & 2,01 & 2,13 & 1,95 & 1,58 & 1,57 & 1,55 & 1,63 & 1,46 & 1,70 & 1,56 & 1,72 & 1,89 & 1,99 & 1,99 \\
\hline $\mathrm{OH}^{b}$ & 2,19 & 2,27 & 2,29 & 2,15 & 1,80 & 1,85 & 1,70 & 1,86 & 1,54 & 1,85 & 1,72 & 2,00 & 2,23 & 2,17 & 2,0 \\
\hline $\mathrm{OH}^{c}$ & & 66 & 2,53 & 2,45 & 2,14 & 2,27 & 1,92 & 2,21 & 1,66 & & 1,9 & 2,42 & 2,74 & 44 & \\
\hline $\mathrm{O}_{2}$ & & 70 & 05 & & 1 & & & & & 1,0 & 1,05 & 1,86 & 25 & 1,17 & \\
\hline & & & 101 & 150 & 0,024 & 0,02 & & & & 0,050 & 0,022 & & & & \\
\hline $\mathrm{C}$ & 9 & 371 & 9,828 & 90 & 9,712 & 9,664 & 9,769 & 9,7 & 9,78 & 9,790 & 9,805 & 9,874 & 9,864 & & 9,836 \\
\hline & 001 & 011 & 004 & 013 & 0,066 & 0,001 & 0,001 & & 0,00 & 0,0 & 0,0 & 0,001 & 0,001 & 02 & 0,001 \\
\hline & & 0,000 & 200 & 066 & 0,006 & 0,01 & & 0,0 & 0,000 & 0,0 & 0,007 & 0,000 & 02 & 25 & 0,000 \\
\hline & 104 & 0,007 & 31 & 27 & 0,052 & 0,047 & 000 & 0,0 & 0,022 & 0,0 & 0,000 & 0,014 & 0,000 & & 0,003 \\
\hline & 06 &, 087 & & 86 & 0,113 & 0,202 & & & 4 & & & 0,090 & 99 & & 0,083 \\
\hline & 100 & 000 & 03 & 002 &, 000 & 0,000 &, 000 & & 0,000 & 0,00 & 0,000 & 0,000 & 0,000 & 00 & 0,000 \\
\hline & & 001 & 001 & 001 & 001 & 0,001 & 001 & 0,001 & 0,001 & 0.00 & 0,001 & 0,001 & 0,006 & & 0,001 \\
\hline & & 017 & 014 & 10 & 0,012 & 0,027 & 0,007 & 00 & 0,000 & 0,0 & 0,0 &, 007 & 0,004 & & 0,011 \\
\hline $\mathrm{Ce}$ & 014 & 0,006 & 0,017 & 0,017 & 0,015 & 0,025 & 0,004 & 0,007 & 0,009 & 0,000 & 0,006 & 0,005 & 0,005 & 0,000 & 0,006 \\
\hline & & & & & & & & & & & & & & & \\
\hline & & & 31 & 378 & 5,209 & 0,441 & & & & & 5,643 & 5,536 & 5,410 & 25 & 5,789 \\
\hline & 0,259 & 0,388 & 0,241 & 0,298 & 0,336 & 0,427 & 0,224 & 0,351 & 0,124 & 0,235 & 0,241 & 0,423 & 0,511 & 0,268 & 0,096 \\
\hline & & & & & & & & & & 0,999 & 1,0 & & 898 & & \\
\hline & 0,005 & 002 &, 000 & 0,002 & 0,009 & 0,000 & 0,001 & 0,019 & 0,005 & 0,000 & 0,006 & 0,000 & 0,007 & 0,000 & 0,004 \\
\hline $\mathrm{OH}^{\mathrm{a}}$ & 1,188 & 1,182 & 1,260 & 1,150 & 0,929 & 0,928 & 0,919 & 0,958 & 0,865 & 1,001 & 0,924 & 1,008 & 1,102 & 1,173 & 1,181 \\
\hline $\mathrm{OH}^{\mathrm{b}}$ & 1,292 & 1,337 & 1,356 & 1,269 & 1,064 & 1,099 & 1,008 & 1,099 & 0,916 & 1,095 & 1,020 & 1,177 & 1,307 & 1,280 & 1,220 \\
\hline $\mathrm{OH}^{\mathrm{c}}$ & 1,448 & 1,570 & 1,501 & 1,448 & 1,265 & 1,355 & 1,142 & 1,309 & 0,989 & 1,236 & 1,165 & 1,431 & 1,614 & 1,441 & 1,277 \\
\hline P.M. ${ }^{a}$ & 1003 & 997 & 1005 & 1001 & 1001 & 1006 & 1006 & 1001 & 1010 & 1003 & 1006 & 997 & 993 & 1000 & 1007 \\
\hline P.M. ${ }^{b}$ & 1005 & 1000 & 1006 & 1003 & 1003 & 1009 & 1007 & 1004 & $101 \uparrow$ & 1005 & 1007 & 1000 & 997 & 1002 & 1007 \\
\hline P.M. ${ }^{\mathrm{c}}$ & 1007 & 1004 & 1009 & 1006 & 1007 & 1013 & 1010 & 1007 & 1012 & 1007 & 1010 & 1004 & 1002 & 1005 & 1008 \\
\hline carga ${ }^{a}$ & 0,262 & 0,408 & 0,274 & 0,274 & 0,332 & 0,457 & 0,185 & 0,298 & 0,106 & 0,186 & 0,222 & 0,428 & 0,505 & 0,223 & 0,051 \\
\hline & 158 & 0,253 & 0,177 & 0,155 & 0,197 & 0,286 & 0,095 & 0,157 & 0,056 & 0,092 & 0,126 & 0,259 & 0,300 & 0,116 & 0,013 \\
\hline carga $^{c}$ & 002 & 0,021 & 0,032 & $-0,024$ & $-0,004$ & 0,029 & $-0,039$ & $-0,053$ & $-0,018$ & $-0,048$ & $-0,019$ & 0,005 & $-0,007$ & $-0,045$ & $-0,044$ \\
\hline & & & & & & & & & & & & & & & 0,018 \\
\hline & & & & & & 1,402 & & & 1,341 & 1,370 & 1,373 & & 441 &, 381 & 1,342 \\
\hline $\mathrm{P}_{2} \mathrm{O}_{5}$ & 0,040 & 0,041 & 0,036 & 0,042 & 0,055 & 0,053 & 0,051 & 0,051 & 0,053 & 0,047 & 0,051 & 0,048 & 0,044 & 0,039 & 0,038 \\
\hline $\mathrm{O} / \mathrm{P}_{2} \mathrm{O}_{5}$ & 0,029 & 0,024 & 0,027 & 0,023 & 0,032 & 0,054 & 0,041 & 0,040 & 0,039 & 0,035 & 0,040 & 0,024 & 0,027 & 0,024 & 0,021 \\
\hline
\end{tabular}




\begin{tabular}{|c|c|c|c|c|c|c|c|c|c|c|c|c|c|c|c|c|}
\hline Tipo & 2 & 2 & 2 & 2 & 2 & 2 & 2 & 2 & 2 & 2 & 2 & 2 & 2 & 2 & 2 & \\
\hline Label & TAF46B & TAF46B T & TAF46B & TAF46B & TAF46B & TACC3 & TACC3 & TACC3 & TACC3 & TACC3 & TACC3 & TASCAB & TASC4B & TASC4B & TASC4BT & TASC4B \\
\hline No & 8 & 9 & 11 & 12 & 13 & 20 & 21 & 22 & 23 & 24 & 25 & 23 & 24 & 25 & 18 & 19 \\
\hline $\mathrm{Na}_{2} \mathrm{O}$ & 0.11 & 0,01 & 0,13 & 0,11 & 0,13 & 0,04 & 0,10 & 0,13 & 0,12 & 0,10 & 0,16 & 0,22 & 0,21 & 0,15 & 0,14 & 0,18 \\
\hline $\mathrm{CaO}$ & 56,33 & 55,42 & 55,59 & 55,78 & 54,92 & 55,30 & 56,35 & 55,59 & 55,31 & 55,11 & 54,32 & 54,52 & 54,92 & 55,55 & 54,77 & 54,77 \\
\hline $\mathrm{MgO}$ & 0,00 & 0,00 & 0,06 & 0,00 & 0,00 & 0,04 & 0,00 & 0,02 & 0,03 & 0,00 & 0,00 & 0,02 & 0,03 & 0,00 & 0,05 & 0,00 \\
\hline MnO & 0,00 & 0,08 & 0,07 & 0,07 & 0,00 & 0,00 & 0,00 & 0,11 & 0,00 & 0,00 & 0,00 & 0,08 & 0,00 & 0,00 & 0,00 & 0,00 \\
\hline $\mathrm{FeO}$ & 0,00 & 0,00 & 0,01 & 0,00 & 0,00 & 0,00 & 0,00 & 0,11 & 0,07 & 0,06 & 0,11 & 0,03 & 0,00 & 0,10 & 0,04 & 0,00 \\
\hline SrO & 0,77 & 0,91 & 0,86 & 0,86 & 0,81 & 0,90 & 0,90 & 0,84 & 0,82 & 0,90 & 0,57 & 1,16 & 1,11 & 1,07 & 0,88 & 0,99 \\
\hline $\mathrm{BaO}$ & 0,00 & 0,00 & 0,12 & 0,03 & 0,14 & 0,03 & 0,00 & 0,00 & 0,00 & 0,00 & 0,03 & 0,00 & 0,05 & 0,08 & 0,00 & 0,00 \\
\hline $\mathrm{H}_{2} \mathrm{O}_{3}$ & 00 & 0,00 & 0,00 & 0,00 & 0,00 & 0,00 & 0,00 & 0,00 & 0,00 & 0,00 & 0,00 & 0,00 & 0,00 & 0,00 & 0,00 & 0,03 \\
\hline $\mathrm{La}_{2} \mathrm{O}_{3}$ & 0,00 & 0,00 & 0,00 & 0,00 & 0,00 & 0,11 & 0,03 & 0.03 & 0,02 & 0,12 & 0,19 & 0,00 & 0,15 & 0,10 & 0,06 & 0,07 \\
\hline $\mathrm{Ce}_{2} \mathrm{O}_{3}$ & 0,18 & 0,08 & 0,15 & 0,10 & 0,00 & 0,13 & 0,20 & 0,07 & 0,01 & 0,00 & 0,06 & 0,09 & 0,14 & 0.15 & 0,09 & 0,00 \\
\hline $\mathrm{SiO}_{2}$ & 0,44 & 0,24 & 0,35 & 0,27 & 0,26 & 0,67 & 0,60 & 0,73 & 0,64 & 0,23 & 0,58 & 0,63 & 0,80 & 0,78 & 0,71 & 0,72 \\
\hline $\mathrm{P}_{2} \mathrm{O}_{5}$ & 40,34 & 40,67 & 40,98 & 40,61 & 40,31 & 40,60 & 39,32 & 38,67 & 38,84 & 37,86 & 38,24 & 40,65 & 40,36 & 39,84 & 39,99 & 39,75 \\
\hline$F$ & 1,72 & 1,81 & 1,78 & 1,51 & 1,80 & 1,61 & 1,54 & 1,68 & 1,45 & 1,84 & 1,38 & 1,78 & 1,63 & 1,67 & 1,86 & 1,74 \\
\hline \multirow[t]{2}{*}{$\mathrm{Cl}$} & 0,03 & 0,00 & 0,04 & 0,02 & 0,01 & 0,03 & 0,00 & 0,02 & 0,00 & 0,04 & 0,03 & 0,01 & 0,01 & 0,04 & 0,00 & 0,02 \\
\hline & 99,82 & 99,21 & 100,01 & 99,27 & 98,27 & 99,43 & 98,96 & 97,85 & 97,20 & 96,18 & 95,50 & 98,96 & 99,22 & 99,37 & 98,44 & 98,10 \\
\hline $\mathrm{O}=\mathrm{F}, \mathrm{Cl}$ & 0,72 & 0,76 & 0,75 & 0,64 & 0,76 & 0,68 & 0,65 & 0,71 & 0,61 & 0,77 & 0,58 & 0,75 & 0,69 & 0,70 & 0,78 & 0,74 \\
\hline TOTAL & 100,69 & 99,44 & 100,34 & 99,98 & 98,66 & 99,50 & 100,43 & 99,36 & 98,57 & 98,17 & 96,91 & 98,98 & 99,53 & 100,16 & 98,68 & 98,58 \\
\hline $\mathrm{OH}^{\mathrm{a}}$ & 1,89 & 1,77 & 1,81 & 2,06 & 1,78 & 1,94 & 2,06 & 1,92 & 2,11 & 1.77 & 2,16 & 1,79 & 1,93 & 1,92 & 1,72 & 1,82 \\
\hline $\mathrm{OH}^{\mathrm{b}}$ & 2,12 & 1,92 & 1,96 & 2,25 & 1,93 & 2,05 & 2,37 & 2,24 & 2,40 & 2,17 & 2,43 & 1,87 & 2,05 & 2,12 & 1,85 & 1,98 \\
\hline $\mathrm{OH}^{\mathrm{c}}$ & 2,45 & 2,15 & 2,17 & 2,53 & 2,16 & 2,21 & 2,82 & 2,71 & 2,82 & 2,78 & 2,85 & 2,00 & 2,23 & 2,43 & 2,06 & 2,22 \\
\hline $\mathrm{CO}_{2}$ & 48 & 0,98 & 0,94 & 1,23 & 1,02 & 0,71 & 2,02 & 2,08 & 1,85 & 2,67 & 1,83 & 0,56 & 0,78 & 1,35 & 0,88 & 1,03 \\
\hline $\mathrm{Na}$ & 336 & 0,002 & 0,043 & 0,035 & 0,043 & 0,014 & 0,030 & 0,042 & 0,039 & 0,032 & 0,051 & & 0,069 & 0,047 & 0,045 & 0,059 \\
\hline $\mathrm{Ca}$ & 9,879 & 9,893 & 9,833 & 9,862 & 9,868 & 9,872 & 9,869 & 9,836 & 9,862 & 9,864 & 9,860 & 9,791 & 9,794 & 9,816 & 9,843 & 9,840 \\
\hline $\mathrm{Mg}$ & 0,001 & 0,001 & 0,014 & 0,001 & 0,001 & 0,011 & 0,001 & 0,006 & 0,009 & 0,001 & 0,001 & 0,004 & 0,008 & 0,001 & 0,011 & 0,000 \\
\hline $\mathrm{Mn}$ & 0,000 & 0,012 & 0,009 & 0,010 & 0,000 & 0,000 & 0,000 & 0,015 & 0,000 & 0,000 & 0,000 & 0,011 & 0,000 & 0,000 & 0,000 & 0,000 \\
\hline $\mathrm{Fe}$ & 0,000 & 0,000 & 0,001 & 0,000 & 0,000 & 0,000 & 0,000 & 0,015 & 0,010 & 0,008 & 0,015 & 0,004 & 0,000 & 0,013 & 0,006 & 0,000 \\
\hline Sr & 0,073 & 0,088 & 0,083 & 0,083 & 0,079 & 0,087 & 0,086 & 0,080 & 0,079 & 0,088 & 0,056 & 0,113 & 0,108 & 0,102 & 0,085 & 0,096 \\
\hline $\mathrm{Ba}$ & 0,000 & 0,000 & 0,008 & 0,002 . & 0,009 & 0,002 & 0,000 & 0,000 & 0,000 & 0,000 & 0,002 & 0,000 & 0,003 & 0,005 & 0,000 & 0,000 \\
\hline $\mathrm{Al}$ & 0,001 & 0,001 & 0,001 & 0,004 & 0,001 & 0,001 & 0,001 & 0,001 & 0,001 & 0,001 & 0,001 & 0,001 & 0,001 & 0,001 & 0,000 & 0,005 \\
\hline La & 0,000 & 0,000 & 0,000 & 0,000 & 0,000 & 0,007 & 0,002 & 0,002 & 0,001 & 0,007 & 0,012 & 0,000 & 0,009 & 0,006 & 0,004 & 0,004 \\
\hline $\mathrm{Ce}$ & 0,011 & 0,005 & 0,009 & 0,006 & & & & 0,004 & 0,001 & 0,000 & 0,004 & 0,005 & 0,009 & 0,009 & 0,005 & 0,000 \\
\hline 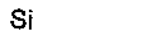 & & 0,040 & 158 & 0,045 & 0,044 & 0,112 & 0,098 & 0,120 & 0,106 & 0,039 & 0,099 & 0,105 & 0,133 & & & \\
\hline$P$ & 5,591 & 5,736 & 5,727 & 5,673 & 5,723 & 5,726 & 5,442 & 5,406 & 5,472 & 5,355 & 5,485 & 5,768 & 5,687 & 5,563 & 5,678 & 5,643 \\
\hline 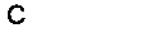 & 0,338 & 0,224 & 0,215 & 0,282 & 0,232 & 0,162 & 0,460 & 0,474 & 0,422 & 0,606 & 0,416 & 0,127 & 0,179 & 0,309 & 0,202 & 0,236 \\
\hline & 0,889 & 0,954 & 0,929 & 0,788 & 0,953 & 0.850 & 0,797 & 0,877 & 0,764 & 0,972 & 0,739 & 0,942 & 0,859 & 0,872 & 0,985 & 0,926 \\
\hline $\mathrm{Cl}$ & 0,009 & 0,000 & 0,012 & 0,005 & 0,004 & 0,009 & 0,000 & 0,005 & 0,000 & 0,012 & 0,009 & 0,002 & 0,004 & 0,010 & 0,000 & 0,007 \\
\hline $\mathrm{OH}^{\mathrm{a}}$ & 1,111 & 1,046 & 1,071 & 1,212 & 1,047 & 1,150 & 1,203 & 1,123 & 1,236 & 1,028 & $\uparrow, 261$ & $\uparrow, 058$ & 1,141 & 1,128 & 1,015 & 1,074 \\
\hline $\mathrm{OH}^{\mathrm{b}}$ & 1,246 & 1,136 & 1,157 & 1,325 & 1,140 & 1,215 & 1,387 & 1,313 & 1,405 & 1,271 & 1,428 & 1,108 & 1,212 & 1,252 & 1,095 & 1,169 \\
\hline $\mathrm{OH}^{c}$ & 1,449 & 1,270 & 1,286 & 1,494 & 1,279 & 1,312 & 1,663 & 1,598 & 1,658 & 1,635 & 1,678 & 1,185 & 1,320 & 1,437 & 1,217 & 1,311 \\
\hline P.M. ${ }^{a}$ & 998 & 1003 & 1003 & 1000 & 1002 & 1005 & 994 & 993 & 994 & 990 & 995 & 1006 & 1005 & 1001 & 1003 & 1002 \\
\hline P.M. ${ }^{b}$ & 1000 & 1004 & 1005 & 1002 & 1003 & 1007 & 997 & 996 & 997 & 994 & 997 & 1007 & 1006 & 1003 & 1004 & 1003 \\
\hline$P \cdot M^{c}$ & 1004 & 1007 & 1007 & 1005 & 1006 & 1008 & 1002 & 1001 & 1001 & 1000 & 1002 & 1008 & 1008 & 1006 & 1006 & 1006 \\
\hline $\operatorname{carga}^{a}$ & 0,305 & 0,228 & 0,171 & 0,249 & 0,188 & 0,155 & 0,445 & 0,435 & 0,386 & 0,572 & 0,373 & 0,061 & 0,125 & 0,269 & 0,166 & 0,190 \\
\hline carga $^{b}$ & 0,170 & 0,139 & 0,085 & 0,136 & 0,095 & 0,090 & 0,261 & 0,245 & 0,218 & 0,329 & 0,207 & 0,010 & 0,054 & 0,145 & 0,085 & 0,096 \\
\hline $\operatorname{carga}^{\circ}$ & $-0,033$ & 0,004 & $-0,044$ & $-0,033$ & $-0,045$ & $-0,007$ & $-0,015$ & $-0,039$ & $-0,035$ & $-0,034$ & $-0,043$ & $-0,067$ & $-0,054$ & $-0,040$ & $-0,036$ & $-0,046$ \\
\hline & & 0,005 & & 0,006 & 0,000 & 0,015 & 0,014 & 0,006 & 0,002 & 0,007 & 0,015 & 0,005 & 0,018 & & & \\
\hline 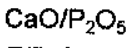 & 1,396 & 1,363 & 1,357 & 1,374 & 1,362 & 1,362 & 1,433 & 1,438 & 1,424 & 1,456 & 1,420 & 1,341 & 1,361 & 4,394 & 1,370 & 1,378 \\
\hline $\mathrm{F} / \mathrm{P}_{2} \mathrm{O}_{5}$ & 0,043 & 0,044 & 0,043 & 0,037 & 0,045 & 0,040 & 0,039 & 0,043 & 0,037 & 0,049 & 0,036 & 0,044 & 0,040 & 0,042 & 0,046 & 0,044 \\
\hline $\mathrm{SrO} / \mathrm{P}_{2} \mathrm{O}_{5}$ & 0,019 & 0,022 & 0,021 & 0,021 & 0,020 & 0,022 & 0,023 & 0,022 & 0,021 & 0,024 & 0,015 & 0,029 & 0,028 & 0,027 & 0,022 & 0,025 \\
\hline
\end{tabular}


Label

No

$\mathrm{Na}_{2} \mathrm{O}$

$\mathrm{CaO}$

$\mathrm{MgO}$

$\mathrm{MnO}$

$\mathrm{FeO}$

Sro

$\mathrm{BaO}$

$\mathrm{Al}_{2} \mathrm{O}_{3}$

$\mathrm{La}_{2} \mathrm{O}_{3}$

$\mathrm{Ce}_{2} \mathrm{O}_{3}$

$\mathrm{SiO}_{2}$

$\mathrm{P}_{2} \mathrm{O}_{5}$

$\mathrm{F}$

CI

$\mathrm{O}=\mathrm{F}, \mathrm{C}$

TOTAL

$\mathrm{OH}^{\mathrm{a}}$

$\mathrm{OH}^{\mathrm{b}}$

$\mathrm{OH}^{\mathrm{C}}$

$\mathrm{CO}_{2}$

$\mathrm{Na}$

$\mathrm{Ca}$

$\mathrm{Mg}$

$\mathrm{Mn}$

$\mathrm{Fe}$

$\mathrm{Sr}$

$\mathrm{Ba}$

Al

La

$\mathrm{Ce}$

$\mathrm{Si}$

$P$

C

F

CI

$\mathrm{OH}^{\circ}$

$\mathrm{OH}^{\circ}$

P.M. ${ }^{\text {a }}$

P.M. ${ }^{b}$

P.M. ${ }^{\mathrm{c}}$

carga a

carga $^{b}$

carga $^{\circ}$

ETR

$\mathrm{CaO} / \mathrm{P}_{2} \mathrm{O}_{5}$

$\mathrm{F} / \mathrm{P}_{2} \mathrm{O}_{5}$

$\begin{array}{lll}\mathrm{SrO}_{2} \mathrm{P}_{2} \mathrm{O}_{5} & 0,024 & 0,025\end{array}$

0,11

$0,000 \quad 0,000$

$0,009 \quad 0,002$

$0,125 \quad 0,120$

$5,614 \quad 5,630$

$0,262 \quad 0,251$

$0,936 \quad 0,949$

$0,005 \quad 0,012$
222

3a 3

TASC4BTASC4B TAF2A TAF2A TAF2A TAF2A TAF2A TAF2A TAF2A TAF2A TAF49.

$54,95 \quad 55,10$

$0,00 \quad 0,00$

$0,06 \quad 0,08$

$0,16 \quad 0,13$

$0,94 \quad 1,00$

$0,00 \quad 0,00$

$0,00 \quad 0,00$

$0,09 \quad 0,04$

$0,15 \quad 0,03$

$0,75 \quad 0,72$

$39,72 \quad 39,98$

$1,77 \quad 1,80$

$0,02 \quad 0,04$

$98,60 \quad 98,93$

$0,75 \quad 0,76$

$99,11 \quad 99,42$

$1,81 \quad 1,78$

$1,98 \quad 1,95$

$2,24 \quad 2,20$

$1,14 \quad 1,10$

$\begin{array}{rrrr}43 & 1 & 3 & \\ 0,33 & 0,28 & 0,06 & 0,09\end{array}$

$\begin{array}{lllll}0,11 & 0,16 & 0,09 & 0,49\end{array}$

$\begin{array}{lllllllll}0,00 & 0,00 & 0,00 & 0,00 & 0,00 & 0,00 & 0,00 & 0,00 & 0,00\end{array}$

$\begin{array}{llllllllll}0,00 & 0,01 & 0,00 & 0,06 & 0,02 & 0,00 & 0,01 & 0,00 & 0,00\end{array}$

$\begin{array}{lllllllll}0,00 & 0,16 & 0,11 & 0,09 & 0,02 & 0,07 & 0,08 & 0,00 & 0,00\end{array}$

$\begin{array}{lllllllll}1,15 & 0,89 & 0,77 & 0,76 & 0,78 & 0,78 & 0,55 & 0,78 & 1,25\end{array}$

$\begin{array}{lllllllll}0,01 & 0,00 & 0,00 & 0,00 & 0,01 & 0,00 & 0,03 & 0,00 & 0,00\end{array}$

$\begin{array}{lllllllll}0,00 & 0,04 & 0,00 & 0,09 & 0,00 & 0,00 & 0,01 & 0,02 & 0,07\end{array}$

$\begin{array}{lllllllll}0,26 & 0,79 & 0,69 & 0,77 & 0,68 & 0,65 & 0,54 & 0,66 & 0,22\end{array}$

$\begin{array}{llllllllll}1,10 & 1,44 & 1,16 & 1,58 & 1,50 & 1,62 & 1,35 & 1,32 & 0,75\end{array}$

$\begin{array}{lllllllll}0,65 & 2,34 & 1,58 & 1,22 & 1,77 & 1,73 & 1,69 & 2,03 & 0,18\end{array}$

$\begin{array}{lllllllll}1,91 & 1,33 & 1,27 & 1,23 & 1,35 & 1,33 & 1,17 & 1,23 & 1,99\end{array}$

$\begin{array}{lllllllll}0,00 & 0,14 & 0,08 & 0,11 & 0,04 & 0,05 & 0,18 & 0,00 & 0,02\end{array}$

$\begin{array}{lllllllll}97,39 & 97,13 & 98,17 & 96,98 & 97,02 & 95,59 & 96,63 & 97,24 & 98,14\end{array}$

$\begin{array}{lllllllll}0,81 & 0,56 & 0,53 & 0,52 & 0,57 & 0,56 & 0,49 & 0,52 & 0,84\end{array}$

$\begin{array}{lllllllll}98,75 & 97,93 & 98,32 & 97,01 & 97,09 & 96,62 & 97,07 & 97,12 & 98,21\end{array}$

$\begin{array}{lllllllll}1,67 & 2,16 & 2,21 & 2,21 & 2,11 & 2,15 & 2,29 & 2,22 & 1,56\end{array}$

$\begin{array}{llllllllll}1,95 & 2,32 & 2,30 & 2,28 & 2,19 & 2,37 & 2,41 & 2,27 & 1,62\end{array}$

$\begin{array}{lllllllll}2,36 & 2,57 & 2,45 & 2,38 & 2,31 & 2,71 & 2,58 & 2,33 & 1,72\end{array}$

$\begin{array}{lllllllll}1,83 & 1,09 & 0,63 & 0,46 & 0,52 & 1,48 & 0,77 & 0,30 & 0,42\end{array}$ $\begin{array}{lllllllll}38,46 & 37,09 & 38,83 & 38,72 & 38,17 & 36,71 & 38,01 & 38,27 & 40,74\end{array}$

$0,036 \quad 0,051$

$9,828 \quad 9,819$

$\begin{array}{lllllllll}0,109 & 0,091 & 0,018 & 0,032 & 0,040 & 0,038 & 0,054 & 0,032 & 0,161\end{array}$

$\begin{array}{llllllllll}9,694 & 9,657 & 9,774 & 9,720 & 9,736 & 9,729 & 9,757 & 9,764 & 9,652\end{array}$

$\begin{array}{lllllllll}0,001 & 0,001 & 0,001 & 0,001 & 0,001 & 0,001 & 0,001 & 0,001 & 0,001\end{array}$

$\begin{array}{lllllllll}0,000 & 0,002 & 0,000 & 0,008 & 0,003 & 0,000 & 0,001 & 0,000 & 0,000\end{array}$

$\begin{array}{llllllllll}0,000 & 0,022 & 0,016 & 0,013 & 0,003 & 0,011 & 0,012 & 0,000 & 0,000\end{array}$

$\begin{array}{llllllllll}0,112 & 0,088 & 0,076 & 0,077 & 0,078 & 0,078 & 0,055 & 0,078 & 0,124\end{array}$

$\begin{array}{llllllllll}0,000 & 0,000 & 0,000 & 0,000 & 0,001 & 0,000 & 0,002 & 0,000 & 0,000\end{array}$

$0,006 \quad 0,002$

$\begin{array}{llllllllll}0,001 & 0,008 & 0,001 & 0,019 & 0,001 & 0,001 & 0,002 & 0,004 & 0,014\end{array}$

$\begin{array}{llllllllll}0,016 & 0,049 & 0,043 & 0,049 & 0,043 & 0,041 & 0,034 & 0,042 & 0,014\end{array}$

$0,068 \quad 0,090$

$\begin{array}{lllllllll}0,110 & 0,399 & 0,268 & 0,212 & 0,305 & 0,299 & 0,291 & 0,350 & 0,031\end{array}$

$\begin{array}{llllllllll}5,470 & 5,349 & 5,586 & 5,682 & 5,575 & 5,360 & 5,530 & 5,580 & 5,874\end{array}$

$\begin{array}{llllllllll}0,420 & 0,252 & 0,146 & 0,106 & 0,120 & 0,341 & 0,179 & 0,071 & 0,096\end{array}$

$\begin{array}{lllllllll}1,016 & 0,714 & 0,681 & 0,675 & 0,736 & 0,723 & 0,635 & 0,671 & 1,071\end{array}$

$\begin{array}{llllllllll}0,000 & 0,040 & 0,022 & 0,032 & 0,012 & 0,014 & 0,053 & 0,000 & 0,007\end{array}$

$\begin{array}{llllllllll}0,984 & 1,286 & 1,319 & 1,325 & 1,264 & 1,277 & 1,365 & 1,329 & 0,929\end{array}$

$\begin{array}{llllllllll}1,152 & 1,387 & 1,378 & 1,368 & 1,313 & 1,413 & 1,436 & 1,357 & 0,967\end{array}$

$\begin{array}{llllllllll}1,403 & 1,538 & 1,465 & 1,431 & 1,385 & 1,618 & 1,544 & 1,399 & 1,025\end{array}$

$\begin{array}{llllllllll}1003 & 1014 & 1015 & 1021 & 1018 & 1011 & 1014 & 1018 & 1013\end{array}$

$\begin{array}{llllllllll}1006 & 1016 & 1016 & 1022 & 1019 & 1013 & 1015 & 1018 & 1013\end{array}$

$\begin{array}{llllllllll}1010 & 1018 & 1018 & 1023 & 1020 & 1016 & 1017 & 1019 & 1014\end{array}$

$\begin{array}{llllllllll}0,396 & 0,284 & 0,222 & 0,250 & 0,207 & 0,434 & 0,198 & 0,177 & 0,031\end{array}$

$\begin{array}{llllllllll}0,228 & 0,184 & 0,164 & 0,208 & 0,159 & 0,297 & 0,126 & 0,149 & -0,008\end{array}$

$\begin{array}{llllllllll}-0,024 & 0,032 & 0,076 & 0,144 & 0,087 & 0,093 & 0,019 & 0,107 & -0,065\end{array}$

$\begin{array}{llllllllll}0,084 & 0,139 & 0,115 & 0,150 & 0,138 & 0,143 & 0,119 & 0,125 & 0,061\end{array}$

$\begin{array}{lllllllll}1,400 & 1,427 & 1,383 & 1,352 & 1,380 & 1,434 & 1,394 & 1,383 & 1,298\end{array}$

$\begin{array}{llllllllll}0,050 & 0,036 & 0,033 & 0,032 & 0,035 & 0,036 & 0,031 & 0,032 & 0,049\end{array}$

$\begin{array}{lllllllll}0,030 & 0,024 & 0,020 & 0,020 & 0,020 & 0,021 & 0,014 & 0,020 & 0,031\end{array}$ $\begin{array}{llll}3 b & 3 b & 3 b & 3 b\end{array}$ TAF1A TAF1A TAF49.1 TAF49.1

$\begin{array}{rrrr}17 & 19 & 29 & 26 \\ 0,05 & 0,05 & 0,16 & 0,20\end{array}$

$\begin{array}{llll}53,77 & 52,65 & 52,47 & 53,07\end{array}$

$\begin{array}{llll}0,00 & 0,01 & 0,02 & 0,00\end{array}$

$0,12 \quad 0,01 \quad 0,12 \quad 0,00$

$0,11 \quad 0,13 \quad 0,01 \quad 0,08$

$0,81 \quad 0,75 \quad 1,19 \quad 1,33$

$0,00 \quad 0,00 \quad 0,00 \quad 0,00$

$\begin{array}{llll}0,00 & 0,00 & 0,00 & 0,00\end{array}$

$\begin{array}{llll}0,51 & 0,74 & 0,46 & 0,51\end{array}$

$\begin{array}{llll}1,15 & 1,83 & 0,80 & 1,14\end{array}$

$\begin{array}{llll}1,44 & 2,28 & 0,44 & 0,67\end{array}$

$\begin{array}{llll}37,14 & 35,58 & 38,38 & 38,73\end{array}$

$\begin{array}{llll}1,28 & 1,20 & 1,93 & 2,03\end{array}$

$\begin{array}{lllll}0,01 & 0,02 & 0,05 & 0,02\end{array}$

$96,34 \quad 95,20 \quad 95,88 \quad 97,58$

$\begin{array}{llll}0,54 & 0,50 & 0,81 & 0,85\end{array}$

$\begin{array}{llll}97,71 & 96,55 & 96,54 & 98,22\end{array}$

$\begin{array}{llll}2,22 & 2,27 & 1,59 & 1,53\end{array}$

$\begin{array}{llll}2,50 & 2,54 & 1,80 & 1,72\end{array}$

$2,92 \quad 2,95 \quad 2,10 \quad 2,02$

$\begin{array}{llll}1,86 & 1,80 & 1,32 & 1,30\end{array}$

$\begin{array}{llll}0,018 & 0,018 & 0,052 & 0,065\end{array}$

$\begin{array}{lllll}9,765 & 9,721 & 9,724 & 9,688\end{array}$

$\begin{array}{lllll}0,001 & 0,004 & 0,005 & 0,001\end{array}$

$\begin{array}{lllll}0,018 & 0,001 & 0,017 & 0,000\end{array}$

$\begin{array}{lllll}0,016 & 0,019 & 0,001 & 0,011\end{array}$

$\begin{array}{lllll}0,080 & 0,075 & 0,120 & 0,132\end{array}$

$\begin{array}{lllll}0,000 & 0,000 & 0,000 & 0,000\end{array}$

$\begin{array}{lllll}0,001 & 0,001 & 0,001 & 0,001\end{array}$

$\begin{array}{lllll}0,032 & 0,047 & 0,029 & 0,032\end{array}$

$\begin{array}{lllll}0,071 & 0,116 & 0,051 & 0,071\end{array}$

$\begin{array}{llll}0,244 & 0,393 & 0,077 & 0,114\end{array}$

$\begin{array}{lllll}5,330 & 5,190 & 5,620 & 5,587\end{array}$

$\begin{array}{lllll}0,427 & 0,417 & 0,304 & 0,300\end{array}$

$\begin{array}{llll}0,687 & 0,652 & 1,054 & 1,093\end{array}$

$\begin{array}{lllll}0,002 & 0,006 & 0,015 & 0,006\end{array}$

$\begin{array}{lllll}1,313 & 1,348 & 0,946 & 0,907\end{array}$

$\begin{array}{llll}1,484 & 1,515 & 1,068 & 1,027\end{array}$

$\begin{array}{llll}1,740 & 1,765 & 1,250 & 1,207\end{array}$

$\begin{array}{llll}1004 & 1010 & 1009 & 1011\end{array}$

$\begin{array}{llll}1007 & 1012 & 1011 & 1013\end{array}$

$\begin{array}{llll}1011 & 1017 & 1014 & 1016\end{array}$

$\begin{array}{lllll}0,512 & 0,557 & 0,319 & 0,333\end{array}$

$\begin{array}{lllll}0,341 & 0,390 & 0,197 & 0,213\end{array}$

$\begin{array}{lllll}0,085 & 0,140 & 0,015 & 0,033\end{array}$

$\begin{array}{lllll}0,103 & 0,163 & 0,080 & 0,103\end{array}$

$\begin{array}{lllll}1,448 & 1,480 & 1,367 & 1,370\end{array}$

$\begin{array}{llll}0,034 & 0,034 & 0,050 & 0,052\end{array}$

$\begin{array}{lllll}0,022 & 0,021 & 0,031 & 0,034\end{array}$ 


\begin{tabular}{|c|c|c|c|c|c|c|c|}
\hline Tipo & $3 b$ & $3 b$ & $3 b$ & $3 b$ & $3 b$ & $3 b$ & \\
\hline Label & TAF2A & TAF2A & TAF2A & TAF2A & TAF2A & TAF1A & \\
\hline No & 9 & 10 & 11 & 12 & 13 & 16 & \\
\hline $\mathrm{Na}_{2} \mathrm{O}$ & 0,03 & 0,13 & 0,24 & 0,00 & 0,05 & 0,17 & \\
\hline $\mathrm{CaO}$ & 50,81 & 52,31 & 51,37 & 52,25 & 53,16 & 52,75 & \\
\hline $\mathrm{MgO}$ & 0,00 & 0,00 & 0,00 & 0,00 & 0,05 & 0,04 & \\
\hline Mno & 0,05 & 0,00 & 0,00 & 0,10 & 0,00 & 0,00 & $n$ \\
\hline $\mathrm{FeO}$ & 0,17 & 0,07 & 0,05 & 0,00 & 0,06 & 0,05 & \\
\hline SrO & 0,71 & 0,79 & 0,75 & 0,66 & 0,74 & 0,69 & 0,72 \\
\hline $\mathrm{BaO}$ & 0,09 & 0,00 & 0,00 & 0,06 & 0,00 & 0,00 & 0,18 \\
\hline $\mathrm{Al}_{2} \mathrm{O}_{3}$ & 0,00 & 0,00 & 0,00 & 0,04 & 0,00 & 0,00 & 0,00 \\
\hline $\mathrm{La}_{2} \mathrm{O}_{3}$ & 0,92 & 0,71 & 0,78 & 0,77 & 0,66 & 0,74 & 0,90 \\
\hline $\mathrm{Ce}_{2} \mathrm{O}_{3}$ & 2,05 & 1,90 & 1,72 & 1,63 & 1,37 & 1,62 & 1,68 \\
\hline $\mathrm{SiO}_{2}$ & 1,94 & 2,05 & 2,10 & 2,27 & 2,01 & 2,06 & 1,84 \\
\hline $\mathrm{P}_{2} \mathrm{O}_{5}$ & 36,83 & 36,30 & 36,43 & 37,96 & 37,25 & 37,06 & 37,93 \\
\hline$F$ & 1,29 & 1,15 & 1,37 & 1,32 & 1,26 & 1,28 & 1,17 \\
\hline \multirow[t]{2}{*}{$\mathrm{Cl}$} & 0,10 & 0,08 & 0,11 & 0,00 & 0,00 & 0,02 & 0,12 \\
\hline & 94,97 & 95,37 & 94,69 & 97,06 & 96,58 & 96,31 & 96,12 \\
\hline $\mathrm{O}=\mathrm{F}, \mathrm{Cl}$ & 0,54 & 0,49 & 0,58 & 0,55 & 0,53 & 0,54 & 0,50 \\
\hline TOTAL & 94,92 & 96,41 & 95,26 & 96,51 & 97,19 & 97,06 & 95,72 \\
\hline $\mathrm{OH}^{2}$ & 2,11 & 2,30 & 2,07 & 2,12 & 2,21 & 2,19 & 2,23 \\
\hline $\mathrm{OH}^{b}$ & 2,18 & 2,51 & 2,21 & 2,12 & 2,38 & 2,36 & 2,24 \\
\hline $\mathrm{OH}^{c}$ & 2,29 & 2,83 & 2,42 & 2,12 & 2,63 & 2,61 & 2,25 \\
\hline $\mathrm{CO}_{2}$ & 0,47 & 1,41 & 0,91 & 0,01 & 1,09 & 1,11 & 0,06 \\
\hline $\mathrm{Na}$ & 0,011 & 0,042 & 0,081 & 0,001 & 0,018 & 0,057 & 0,009 \\
\hline $\mathrm{Ca}$ & 9,682 & 9,701 & 9,673 & 9,760 & 9,759 & 9,708 & 9,708 \\
\hline $\mathrm{Mg}$ & 0,001 & 0,001 & 0,001 & 0,001 & 0,014 & 0,010 & 0,001 \\
\hline $\mathrm{Mn}$ & 0,008 & 0,000 & 0,000 & 0,014 & 0,000 & 0,000 & 0,019 \\
\hline $\mathrm{Fe}$ & 0,026 & 0,011 & 0,007 & 0,000 & 0,008 & 0,007 & 0,010 \\
\hline $\mathrm{Sr}$ & 0,073 & 0,079 & 0,077 & 0,067 & 0,074 & 0,068 & 0,074 \\
\hline $\mathrm{Ba}$ & 0,006 & 0,000 & 0,000 & 0,004 & 0,000 & 0,000 & 0,012 \\
\hline Al & 0,001 & 0,001 & 0,001 & 0,008 & 0,001 & 0,001 & 0,001 \\
\hline La & 0,060 & 0,045 & 0,050 & 0,049 & 0,042 & 0,047 & 0,058 \\
\hline $\mathrm{Ce}$ & 0,133 & 0,120 & 0,110 & 0,104 & 0,086 & 0,102 & 0,108 \\
\hline Si & 0,345 & 0,355 & 0,369 & 0,396 & 0,345 & 0,354 & 0,324 \\
\hline$P$ & 5,545 & 5,319 & 5,420 & 5,603 & 5,404 & 5,390 & 5,661 \\
\hline C & 0,110 & 0,325 & 0,211 & 0,002 & 0,252 & 0,257 & 0,015 \\
\hline$F$ & 0,726 & 0,631 & 0,761 & 0,726 & 0,683 & 0,694 & 0,654 \\
\hline $\mathrm{Cl}$ & 0,031 & 0,023 & 0,033 & 0,000 & 0,000 & 0,007 & 0,035 \\
\hline $\mathrm{OH}^{2}$ & 1,274 & 1,369 & 1,239 & 1,274 & 1,317 & 1,306 & 1,346 \\
\hline $\mathrm{OH}^{b}$ & 1,318 & 1,499 & 1,323 & 1,275 & 1,418 & 1,409 & 1,352 \\
\hline $\mathrm{OH}^{\mathrm{c}}$ & 1,384 & 1,694 & 1,450 & 1,276 & 1,569 & 1,563 & 1,361 \\
\hline P.M. ${ }^{a}$ & 1025 & 1013 & 1017 & 1024 & 1011 & 1013 & 1027 \\
\hline P.M. ${ }^{b}$ & 1026 & 1016 & 1018 & 1024 & 1013 & 1014 & 1027 \\
\hline P.M. ${ }^{c}$ & 1027 & 1019 & 1020 & 1024 & 1016 & 1017 & 1027 \\
\hline carga $^{a}$ & 0,263 & 0,427 & 0,258 & 0,179 & 0,363 & 0,342 & 0,139 \\
\hline carga $^{b}$ & 0,219 & 0,297 & 0,174 & 0,178 & 0,262 & 0,240 & 0,133 \\
\hline carga $^{c}$ & 0,153 & 0,102 & 0,048 & 0,177 & 0,111 & 0,086 & 0,124 \\
\hline ETR & 0,194 & 0,166 & 0,161 & 0,153 & 0,128 & 0,149 & 0,167 \\
\hline $\mathrm{CaO} / \mathrm{P}_{2} \mathrm{O}_{5}$ & 1,380 & 1,441 & 1,410 & 1,376 & 1,427 & 1,423 & 1,355 \\
\hline$=\mathrm{P}_{2} \mathrm{O}_{5}$ & 0,035 & 0,032 & 0,038 & 0,035 & 0,034 & 0,034 & 0,031 \\
\hline $\mathrm{irO} / \mathrm{P}_{2} \mathrm{O}_{5}$ & 0,019 & 0,022 & 0,021 & 0,017 & 0,020 & 0,018 & 0,019 \\
\hline
\end{tabular}

$3 c \quad 3 c \quad 3 c \quad 3 c \quad 3 c \quad 3 c \quad 3 c$ TAF49.1 TAF49.1 TAF49.1 TAF49.1 TAF49.1 TAF49.1 TAF49.1

$\begin{array}{rrrrrrr}34 & 35 & 36 & 37 & 38 & 31 & 33 \\ 0,32 & 0,30 & 0,24 & 0,12 & 0,19 & 0,15 & 0,43 \\ 53,16 & 53,17 & 53,99 & 53,85 & 53,36 & 52,97 & 52,93 \\ 0,00 & 0,03 & 0,00 & 0,00 & 0,00 & 0,01 & 0,00 \\ 0,00 & 0,01 & 0,00 & 0,07 & 0,00 & 0,05 & 0,00 \\ 0,11 & 0,00 & 0,00 & 0,00 & 0,00 & 0,06 & 0,00 \\ 1,25 & 1,29 & 1,30 & 1,14 & 0,90 & 1,29 & 1,34 \\ 0,11 & 0,00 & 0,03 & 0,00 & 0,00 & 0,00 & 0,07 \\ 0,00 & 0,00 & 0,00 & 0,00 & 0,00 & 0,01 & 0,00 \\ 0,46 & 0,35 & 0,44 & 0,48 & 0,35 & 0,25 & 0,33 \\ 0,85 & 0,62 & 0,75 & 0,81 & 0,72 & 0,98 & 0,86 \\ & & & & & & \\ 0,19 & 0,42 & 0,54 & 0,51 & 0,57 & 0,52 & 0,24\end{array}$

$\begin{array}{lllllll}40,96 & 40,34 & 38,74 & 38,88 & 40,29 & 39,03 & 39,75\end{array}$

$\begin{array}{lllllll}2,12 & 2,16 & 2,26 & 2,06 & 2,14 & 2,18 & 2,05\end{array}$

$\begin{array}{lllllll}0,04 & 0,03 & 0,02 & 0,01 & 0,00 & 0,02 & 0,03\end{array}$

$\begin{array}{lllllll}99,27 & 98,42 & 98,09 & 97,81 & 98,36 & 97,37 & 97,61\end{array}$

$\begin{array}{lllllll}0,89 & 0,91 & 0,95 & 0,87 & 0,90 & 0,92 & 0,86\end{array}$

$\begin{array}{lllllll}99,06 & 98,29 & 99,12 & 98,58 & 97,95 & 97,67 & 98,19\end{array}$

$\begin{array}{lllllll}1,44 & 1,40 & 1,35 & 1,52 & 1,41 & 1,37 & 1,51\end{array}$

$\begin{array}{lllllll}1,50 & 1,47 & 1,61 & 1,75 & 1,45 & 1,54 & 1,66\end{array}$

$\begin{array}{lllllll}1,58 & 1,58 & 2,01 & 2,09 & 1,52 & 1,78 & 1,89\end{array}$

$\begin{array}{lllllll}0,36 & 0,48 & 1,74 & 1,51 & 0,30 & 1,08 & 1,02\end{array}$

$\begin{array}{lllllll}0,106 & 0,098 & 0,079 & 0,041 & 0,064 & 0,048 & 0,140\end{array}$

$\begin{array}{llllllll}9,665 & 9,704 & 9,718 & 9,756 & 9,778 & 9,727 & 9,648\end{array}$

$\begin{array}{lllllll}0,001 & 0,007 & 0,001 & 0,001 & 0,001 & 0,004 & 0,001\end{array}$

$\begin{array}{lllllll}0,000 & 0,002 & 0,000 & 0,011 & 0,000 & 0,008 & 0,000\end{array}$

$\begin{array}{llllllll}0,016 & 0,000 & 0,000 & 0,000 & 0,000 & 0,008 & 0,000\end{array}$

$\begin{array}{llllllll}0,123 & 0,127 & 0,127 & 0,112 & 0,089 & 0,128 & 0,132\end{array}$

$\begin{array}{llllllll}0,007 & 0,000 & 0,002 & 0,000 & 0,000 & 0,000 & 0,004\end{array}$

$\begin{array}{lllllll}0,001 & 0,001 & 0,001 & 0,001 & 0,001 & 0,003 & 0,001\end{array}$

$\begin{array}{lllllll}0,029 & 0,022 & 0,028 & 0,030 & 0,022 & 0,016 & 0,021\end{array}$

$\begin{array}{llllllll}0,053 & 0,039 & 0,046 & 0,050 & 0,045 & 0,061 & 0,054\end{array}$

$\begin{array}{llllllll}0,032 & 0,071 & 0,091 & 0,086 & 0,097 & 0,089 & 0,041\end{array}$

$\begin{array}{llllllll}5,884 & 5,818 & 5,509 & 5,566 & 5,834 & 5,663 & 5,725\end{array}$

$\begin{array}{llllllll}0,084 & 0,111 & 0,400 & 0,348 & 0,069 & 0,248 & 0,234\end{array}$

$\begin{array}{lllllll}1,136 & 1,166 & 1,204 & 1,101 & 1,160 & 1,183 & 1,105\end{array}$

$\begin{array}{lllllll}0,013 & 0,008 & 0,007 & 0,003 & 0,000 & 0,006 & 0,008\end{array}$

$\begin{array}{llllllll}0,864 & 0,834 & 0,796 & 0,899 & 0,840 & 0,817 & 0,895\end{array}$

$\begin{array}{llllllll}0,898 & 0,878 & 0,856 & 1,038 & 0,867 & 0,916 & 0,989\end{array}$

$\begin{array}{llllllll}0,948 & 0,945 & 1,196 & 1,247 & 0,909 & 1,065 & 1,130\end{array}$

$\begin{array}{lllllll}1017 & 1013 & 1005 & 1007 & 1014 & 1011 & 1010\end{array}$

$\begin{array}{lllllll}1017 & 1014 & 1007 & 1009 & 1014 & 1013 & 1012\end{array}$

$\begin{array}{lllllll}1018 & 1015 & 1011 & 1013 & 1015 & 1015 & 1014\end{array}$

$\begin{array}{llllllll}0,049 & 0,067 & 0,389 & 0,385 & 0,074 & 0,279 & 0,162\end{array}$

$\begin{array}{llllllll}0,015 & 0,023 & 0,229 & 0,246 & 0,046 & 0,180 & 0,069\end{array}$

$\begin{array}{llllllll}-0,035 & -0,044 & -0,011 & 0,038 & 0,005 & 0,031 & -0,072\end{array}$

$\begin{array}{llllllll}0,082 & 0,061 & 0,074 & 0,080 & 0,067 & 0,077 & 0,074\end{array}$

$\begin{array}{lllllll}1,298 & 1,318 & 1,394 & 1,385 & 1,324 & 1,357 & 1,332\end{array}$

$\begin{array}{lllllll}0,052 & 0,054 & 0,058 & 0,053 & 0,053 & 0,056 & 0,052\end{array}$

$\begin{array}{lllllll}0,031 & 0,032 & 0,034 & 0,029 & 0,022 & 0,033 & 0,034\end{array}$ 


\begin{tabular}{|c|c|c|c|c|c|c|c|c|c|c|c|c|c|c|c|}
\hline Tipo & $3 c$ & $3 c$ & $3 c$ & $3 c$ & $3 c$ & $3 c$ & $3 c$ & $3 c$ & $3 c$ & $3 c$ & $3 c$ & $3 c$ & 4 & 4 & 4 \\
\hline Label & TAF49.1 & TAF19 & TAF19 & TAF2A & TAF2A & TAF2A & TAF2A & TAF2A & TAF2A & TAF2A & TAF2A & TAF2A & TAF19 & TAF19 & TAF19 \\
\hline No & 30 & 6 & 7 & 46 & 47 & 48 & 49 & 51 & 54 & 55 & 44 & 45 & 3 & 4 & 5 \\
\hline $\mathrm{Na}_{2} \mathrm{O}$ & 0,23 & 0,40 & 0,34 & 0,29 & 0,20 & 0,12 & 0,29 & 0,46 & 0,21 & 0,45 & 0,21 & 0,32 & 0,53 & 0,43 & 0,44 \\
\hline $\mathrm{CaO}$ & 53,01 & 53,66 & 53,33 & 53,79 & 53,81 & 54,33 & 54,14 & 52,97 & 53,03 & 53,81 & 53,89 & 53,12 & 52,96 & 53,57 & 53,64 \\
\hline $\mathrm{MgO}$ & 0,01 & 0,03 & 0,03 & 0,00 & 0,00 & 0,00 & 0,00 & 0,00 & 0,02 & 0,00 & 0,00 & 0,00 & 0,00 & 0,04 & 0,00 \\
\hline Mno & 0,00 & 0,00 & 0,00 & 0,00 & 0,00 & 0,09 & 0,00 & 0,10 & 0,04 & 0,05 & 0,03 & 0,02 & 0,00 & 0,00 & 0,00 \\
\hline $\mathrm{FeO}$ & 0,00 & 0,05 & 0,01 & 0,08 & 0,00 & 0,00 & 0,11 & 0,00 & 0,15 & 0,01 & 0,00 & 0,00 & 0,00 & 0,02 & 0,10 \\
\hline Sro & 1,23 & 1,38 & 1,44 & 1,08 & 1,01 & 0,92 & 1,05 & 1,33 & 1,23 & 1,07 & 0,99 & 1,43 & 1,01 & 1,06 & 1,13 \\
\hline $\mathrm{BaO}$ & 0,00 & 0,00 & 0,00 & 0,00 & 0,00 & 0,00 & 0,00 & 0,00 & 0,00 & 0,00 & 0,00 & 0,00 & 0,00 & 0,03 & 0,00 \\
\hline $\mathrm{Al}_{2} \mathrm{O}_{3}$ & 0,00 & 0,00 & 0,00 & 0,00 & 0,00 & 0,02 & 0,00 & 0,00 & 0,00 & 0,00 & 0,00 & 0,00 & 0,00 & 0,00 & 0,00 \\
\hline $\mathrm{La}_{2} \mathrm{O}_{3}$ & 0,37 & 0,34 & 0,33 & 0,33 & 0,38 & 0,21 & 0,39 & 0,35 & 0,40 & 0,36 & 0,40 & 0,46 & 0,39 & 0,27 & 0,51 \\
\hline $\mathrm{Ce}_{2} \mathrm{O}_{3}$ & 0,92 & 0,88 & 1,09 & 0,80 & 0,73 & 0,74 & $\uparrow, 11$ & 0,84 & 0,88 & 1,10 & 0,79 & 0,87 & 0,93 & 0,84 & 0,97 \\
\hline $\mathrm{SiO}_{2}$ & 0,54 & 0,29 & 0,47 & 0,72 & 0,61 & 0,74 & 0,68 & 0,17 & 0,67 & 0,23 & 0,65 & 0,48 & 0,05 & 0,03 & 0,00 \\
\hline $\mathrm{P}_{2} \mathrm{O}_{5}$ & 39,11 & 40,33 & 40,49 & 37,14 & 36,48 & 35,16 & 38,14 & 38,54 & 36,11 & 36,34 & 38,22 & 37,55 & 41,00 & 40,46 & 40,98 \\
\hline & 1,80 & 1,81 & 1,81 & 1,87 & 1,88 & 1,83 & 1,76 & 1,86 & 1,94 & 2,09 & 1,96 & 2,04 & 1,78 & 1,74 & 1,72 \\
\hline \multirow[t]{2}{*}{$\mathrm{Cl}$} & 0,03 & 0,03 & 0,00 & 0,01 & 0,00 & 0,01 & 0,02 & 0,02 & 0,04 & 0,00 & 0,00 & 0,04 & 0,01 & 0,00 & 0,02 \\
\hline & 97,03 & 98,80 & 99,00 & 95,83 & 94,92 & 94,05 & 97,41 & 96,18 & 94,51 & 95,04 & 96,93 & 96,01 & 98,12 & 98,05 & 99,08 \\
\hline $\mathrm{O}=\mathrm{F}, \mathrm{Cl}$ & 0,76 & 0,76 & 0,76 & 0,79 & 0,79 & 0,77 & 0,74 & 0,78 & 0,82 & 0,88 & 0,82 & 0,86 & 0,75 & 0,73 & 0,72 \\
\hline TOTAL & 97,55 & 99,39 & 99,13 & 97,85 & 97,24 & 97,21 & 99,09 & 97,77 & 96,83 & 98,18 & 98,16 & 97,73 & 98,30 & 98,71 & 99,58 \\
\hline $\mathrm{OH}^{\mathrm{a}}$ & 1,72 & 1,75 & 1,73 & 1,71 & 1,70 & 1,77 & 1,82 & 1,70 & 1,63 & 1,54 & 1,62 & 1,54 & 1,75 & 1,81 & 1,83 \\
\hline $\mathrm{OH}^{\mathrm{b}}$ & 1,88 & 1,90 & 1,82 & 2,09 & 2,14 & 2,36 & 2,14 & 1,99 & 2,08 & 2,08 & 1,90 & 1,88 & 1,81 & 1,96 & 1,95 \\
\hline $\mathrm{OH}^{c}$ & 2,12 & 2,11 & 1,95 & 2,67 & 2,81 & 3,22 & 2,63 & 2,42 & 2,74 & 2,89 & 2,32 & 2,39 & 1,90 & 2,18 & 2,13 \\
\hline $\mathrm{CO}_{2}$ & 1,05 & 0,96 & 0,56 & 2,52 & 2,91 & 3,81 & 2,13 & 1,90 & 2,92 & 3,56 & 1,85 & 2,26 & 0,40 & 0,97 & 0,78 \\
\hline $\mathrm{Na}$ & 0,077 & 0,129 & 0,110 & 0,094 & 0,065 & 0,040 & 0,093 & 0,153 & 0,071 & 0,146 & 0,069 & 0,104 & 0,174 & 0,140 & 0,143 \\
\hline $\mathrm{Ca}$ & 9,718 & 9,647 & 9,652 & 9,719 & 9,765 & 9,798 & 9,697 & 9,627 & 9,696 & 9,652 & 9,756 & 9,668 & 9,644 & 9,673 & 9,641 \\
\hline $\mathrm{Mg}$ & 0,002 & 0,008 & 0,008 & 0,001 & 0,001 & 0,001 & 0,001 & 0,001 & 0,005 & 0,001 & 0,001 & 0,001 & 0,001 & 0,011 & 0,001 \\
\hline $\mathrm{Mn}$ & 0,000 & 0,000 & 0,000 & 0,000 & 0,000 & 0,013 & 0,000 & 0,014 & 0,005 & 0,007 & 0,004 & 0,004 & 0,000 & 0,000 & 0,000 \\
\hline $\mathrm{Fe}$ & 0,000 & 0,007 & 0,001 & 0,011 & 0,000 & 0,000 & 0,016 & 0,000 & 0,021 & 0,001 & 0,000 & 0,000 & 0,000 & 0,002 & 0,014 \\
\hline $\mathrm{Sr}$ & 0,122 & 0,134 & 0,141 & 0,105 & 0,100 & 0,090 & 0,101 & 0,131 & 0,122 & 0,103 & 0,097 & 0,141 & 0,099 & 0,103 & 0,110 \\
\hline $\mathrm{Ba}$ & 0,000 & 0,000 & 0,000 & 0,000 & 0,000 & 0,000 & 0,000 & 0,000 & 0,000 & 0,000 & 0,000 & 0,000 & 0,000 & 0,002 & 0,000 \\
\hline Al & 0,001 & 0,001 & 0,001 & 0,001 & 0,001 & 0,003 & 0,001 & 0,001 & 0,001 & 0,001 & 0,001 & 0,001 & 0,001 & 0,001 & 0,001 \\
\hline La & 0,023 & 0,021 & 0,021 & 0,020 & 0,024 & 0,013 & 0,024 & 0,022 & 0,025 & 0,022 & 0,025 & 0,029 & 0,024 & 0,017 & 0,032 \\
\hline $\mathrm{Ce}$ & 0,058 & 0,054 & 0,067 & 0,050 & 0,045 & 0,046 & 0,068 & 0,052 & 0,055 & 0,067 & 0,049 & 0,054 & 0,058 & 0,052 & 0,059 \\
\hline $\mathrm{Si}$ & 0,093 & 0,049 & 0,079 & 0,121 & 0,103 & 0,125 & 0,114 & 0,029 & 0,114 & 0,038 & 0,109 & 0,082 & 0,008 & 0,005 & 0,000 \\
\hline J & 5,665 & 5,729 & 5,791 & 5,302 & 5,232 & 5,011 & 5,397 & 5,535 & 5,217 & 5,150 & 5,468 & 5,400 & 5,900 & 5,774 & 5,820 \\
\hline c & 0,242 & 0,222 & 0,130 & 0,577 & 0,665 & 0,865 & 0,489 & 0,436 & 0,669 & 0,812 & 0,423 & 0,518 & 0,092 & 0,222 & 0,180 \\
\hline & 0,975 & 0,961 & 0,966 & 1,000 & 1,008 & 0,972 & 0,929 & 0,997 & 1,046 & 1,105 & 1,045 & 1,095 & 0,958 & 0,928 & 0,910 \\
\hline $\mathrm{Cl}$ & 0,008 & 0,008 & 0,000 & 0,003 & 0,000 & 0,003 & 0,005 & 0,006 & 0,010 & 0,000 & 0,000 & 0,010 & 0,002 & 0,001 & 0,005 \\
\hline $\mathrm{DH}^{\mathrm{a}}$ & 1,025 & 1,039 & 1,034 & 1,000 & 0,992 & 1,028 & 1,071 & 1,003 & 0,954 & 0,895 & 0,955 & 0,905 & 1,042 & 1,072 & 1,090 \\
\hline $\mathrm{OH}^{\mathrm{b}}$ & 1,122 & 1,128 & 1,086 & 1,231 & 1,258 & 1,374 & 1,266 & 1,178 & 1,221 & 1,220 & 1,124 & 1,112 & 1,079 & 1.161 & 1,162 \\
\hline $\mathrm{DH}^{\circ}$ & 1,267 & 1,261 & 1,164 & 1,577 & 1,657 & 1,893 & 1,560 & 1,439 & 1,622 & 1,707 & 1,378 & 1,423 & 1,134 & 1,294 & 1,269 \\
\hline.$M^{\mathrm{a}}$ & 1010 & 1010 & 1015 & 996 & 993 & 985 & 1001 & 1002 & 996 & 989 & 1002 & 1001 & 1013 & 1008 & 1012 \\
\hline M. & 1012 & 1012 & 1016 & 1000 & 998 & 991 & 1005 & 1005 & 1000 & 995 & 1005 & 1005 & 1013 & 1009 & 1013 \\
\hline & 1014 & 1014 & 1017 & 1006 & 1004 & 1000 & 1010 & 1010 & 1007 & 1003 & 1009 & 1010 & 1014 & 1011 & 1015 \\
\hline arga ${ }^{a}$ & 0,240 & 0,162 & 0,110 & 0,551 & 0,670 & 0,889 & 0,484 & 0,353 & 0,669 & 0,757 & 0,430 & 0,488 & $-0,001$ & 0,151 & 0,123 \\
\hline $\mathrm{rga}^{\mathrm{b}}$ & 0,143 & 0,074 & 0,058 & 0,321 & 0,404 & 0,543 & 0,289 & 0,179 & 0,402 & 0,432 & 0,260 & 0,281 & $-0,038$ & 0,062 & 0,052 \\
\hline $\operatorname{arga}^{\circ}$ & $-0,002$ & $-0,060$ & $-0,021$ & $-0,025$ & 0,005 & 0,024 & $-0,005$ & $-0,083$ & 0,001 & $-0,055$ & 0,006 & $-0,030$ & $-0,093$ & $-0,071$ & $-0,056$ \\
\hline & 0,081 & 0,075 & 0,088 & 0,070 & 0,069 & 0,059 & 0,092 & 0,074 & 0,080 & 0,089 & 0,074 & 0,08 & 0,082 & 0,068 & 0,091 \\
\hline $\mathrm{H}_{2} \mathrm{U}_{5}$ & 1,355 & 1,330 & 1,317 & 1,448 & 1,475 & 1,545 & 1,420 & 1,374 & 1,468 & 1,481 & 1,410 & 1,415 & 1,292 & 1,324 & 1,309 \\
\hline$/ \mathrm{P}_{2} \mathrm{O}_{5}$ & 0,046 & 0,045 & 0,045 & 0,050 & 0,052 & 0,052 & 0,046 & 0,048 & 0,054 & 0,057 & 0,051 & 0,054 & 0,043 & 0,043 & 0,042 \\
\hline $\mathrm{rO} / \mathrm{P}_{2} \mathrm{O}_{5}$ & 0,031 & 0,034 & 0,035 & 0,029 & 0,028 & 0,026 & 0,027 & 0,035 & 0,034 & 0,029 & 0,026 & 0,038 & 0,025 & 0,026 & 0,028 \\
\hline
\end{tabular}




\begin{tabular}{|c|c|c|c|c|c|c|c|c|c|c|c|c|c|}
\hline Tipo & 4 & 4 & 4 & 4 & 5 & 5 & 5 & 5 & 5 & 5 & 5 & 5 & . \\
\hline Label & TAF19 & TAF19 & TAF19 & TAF19 & TAF2A & TAF2A & TAF2A & TASC4B & TASC4B & TASC4B & TASC4B & TASC $4 B$ & TASC4B \\
\hline No & 30 & 31 & 32 & 33 & 40 & 41 & 42 & 17 & 18 & 19 & 20 & 21 & \\
\hline $\mathrm{Na}_{2} \mathrm{O}$ & 0,48 & 0,59 & 0,52 & 0,53 & 0,00 & 0,00 & 0,02 & 0,03 & 0,06 & 0,01 & 0,02 & 0,00 & 0,01 \\
\hline $\mathrm{CaO}$ & 52,42 & 53,01 & 53,63 & 52,82 & 53,89 & 55,37 & 55,07 & 55,24 & 55,96 & 56,29 & 55,56 & 56,57 & 56,55 \\
\hline $\mathrm{MgO}$ & 0,00 & 0,03 & 0,00 & 0,00 & 0,03 & 0,00 & 0,00 & 0,04 & 0,00 & 0,00 & 0,00 & 0,00 & 0,10 \\
\hline $\mathrm{MnO}$ & 0,00 & 0,00 & 0,00 & 0,00 & 0,11 & 0,00 & 0,00 & 0,00 & 0,02 & 0,04 & 0,06 & 0,00 & 0,10 \\
\hline $\mathrm{FeO}$ & 0,11 & 0,00 & 0,00 & 0,06 & 0,27 & 0,02 & 0,06 & 0,00 & 0,12 & 0,00 & 0,11 & 0,00 & 0,00 \\
\hline Sro & 1,46 & 1,19 & 1,34 & 1,35 & 0,00 & 0,00 & 0,00 & 0,00 & 0,00 & 0,00 & 0,02 & 0,06 & 0,07 \\
\hline $\mathrm{BaO}$ & 0,00 & 0,00 & 0,00 & 0,00 & 0,04 & 0,00 & 0,00 & 0,00 & 0,00 & 0,00 & 0,00 & 0,00 & 0,05 \\
\hline $\mathrm{Al}_{2} \mathrm{O}_{3}$ & 0,00 & 0,02 & 0,00 & 0,00 & 0,04 & 0,02 & 0,00 & 0,00 & 0,00 & 0,01 & 0,03 & 0,00 & 0,04 \\
\hline $\mathrm{La}_{2} \mathrm{O}_{3}$ & 0,41 & 0,58 & 0,35 & 0,48 & 0,06 & 0,05 & 0,31 & 0,00 & 0,19 & 0,00 & 0,02 & 0,00 & 0,00 \\
\hline $\mathrm{Ce}_{2} \mathrm{O}_{3}$ & 1,09 & 1,18 & 0,82 & 1,14 & 0,06 & 0,07 & 0,03 & 0,00 & 0,00 & 0,00 & 0,00 & 0,00 & 0,00 \\
\hline $\mathrm{SiO}_{2}$ & 0,16 & 0,02 & 0,06 & 0,07 & 0,11 & 0,11 & 0,00 & 0,03 & 0,00 & 0,00 & 0,06 & 0,05 & 0,00 \\
\hline $\mathrm{P}_{2} \mathrm{O}_{5}$ & 40,01 & 40,09 & 40,36 & 39,74 & 38,46 & 41,35 & 38,46 & 39,92 & 39,58 & 39,08 & 39,57 & 39,37 & 40,39 \\
\hline$F$ & 1,91 & 1,83 & 2,22 & 1,95 & 3,42 & 3,49 & 3,44 & 3,46 & 3,67 & 3,81 & 3,34 & 3,49 & 3,51 \\
\hline \multirow[t]{2}{*}{$\mathrm{Cl}$} & 0,02 & 0,02 & 0,00 & 0,02 & 0,10 & 0,00 & 0,02 & 0,02 & 0,00 & 0,01 & 0,02 & 0,02 & 0,01 \\
\hline & 97,58 & 97,99 & 98,78 & 97,64 & 96,58 & 100,49 & 97,41 & 98,71 & 99,55 & 99,24 & 98,77 & 99,57 & 100,82 \\
\hline $\mathrm{O}=\mathrm{F}, \mathrm{Cl}$ & 0,80 & 0,77 & 0,94 & 0,82 & 1,44 & 1,47 & 1,45 & 1,46 & 1,54 & 1,61 & 1,41 & 1,47 & 1,48 \\
\hline TOTAL & 98,08 & 99,00 & 99,52 & 98,60 & 96,83 & 99,41 & 98,18 & 98,59 & 99,99 & 99,94 & 99,06 & 100,29 & 101,03 \\
\hline $\mathrm{OH}^{\mathrm{a}}$ & 1,63 & 1,72 & 1,39 & 1,61 & 0,24 & 0,24 & 0,28 & 0,27 & 0,13 & 0,00 & 0,40 & 0,31 & 0,30 \\
\hline $\mathrm{OH}^{b}$ & 1,75 & 1,91 & 1,56 & 1,80 & 0,50 & 0,30 & 0,62 & 0,47 & 0,43 & 0,36 & 0,66 & 0,64 & 0,57 \\
\hline $\mathrm{OH}^{\circ}$ & 1,94 & 2,18 & 1,83 & 2,09 & 0,89 & 0,39 & 1,13 & 0,77 & 0,87 & 0,89 & 1,04 & 1,15 & 0,95 \\
\hline $\mathrm{CO}_{2}$ & 0,83 & 1,20 & 1,15 & 1,26 & 1,69 & 0,38 & 2,21 & 1,30 & 1,93 & 2,29 & 1,68 & 2,19 & 1,68 \\
\hline $\mathrm{Na}$ & 0,159 & 0,193 & 0,170 & 0,173 & 0,001 & 0,001 & 0,007 & 0,009 & 0,018 & 0,004 & 0,007 & 0,001 & 0,002 \\
\hline $\mathrm{Ca}$ & 9,588 & 9,573 & 9,628 & 9,585 & 9,926 & 9,988 & 9,962 & 9,980 & 9,950 & 9,989 & 9,966 & 9,992 & 9,951 \\
\hline $\mathrm{Mg}$ & 0,000 & 0,008 & 0,000 & 0,000 & 0,008 & 0,001 & 0,001 & 0,010 & 0,001 & 0,001 & 0,001 & 0,001 & 0,023 \\
\hline $\mathrm{Mn}$ & 0,000 & 0,000 & 0,000 & 0,000 & 0,015 & 0,000 & 0,000 & 0,000 & 0,003 & 0,005 & 0,008 & 0,000 & 0,014 \\
\hline $\mathrm{Fe}$ & 0,015 & 0,000 & 0,000 & 0,008 & 0,039 & 0,003 & 0,009 & 0,000 & 0,017 & 0,000 & 0,015 & 0,000 & 0,000 \\
\hline $\mathrm{Sr}$ & 0,144 & 0,117 & 0,130 & 0,133 & 0,000 & 0,000 & 0,000 & 0,000 & 0,000 & 0,000 & 0,002 & 0,006 & 0,007 \\
\hline $\mathrm{Ba}$ & 0,000 & 0,000 & 0,000 & 0,000 & 0,003 & 0,000 & 0,000 & 0,000 & 0,000 & 0,000 & 0,000 & 0,000 & 0,003 \\
\hline Al & 0,000 & 0,004 & 0,000 & 0,000 & 0,008 & 0,004 & 0,001 & 0,001 & 0,001 & 0,002 & 0,005 & 0,001 & 0,008 \\
\hline La & 0,026 & 0,036 & 0,021 & 0,030 & 0,004 & 0,003 & 0,019 & 0,000 & 0,011 & 0,000 & 0,001 & 0,000 & 0,000 \\
\hline $\mathrm{Ce}$ & 0,068 & 0,073 & 0,050 & 0,071 & 0,004 & 0,004 & 0,002 & 0,000 & 0,000 & 0,000 & 0,000 & 0,000 & 0,000 \\
\hline $\mathrm{Si}$ & 0,027 & 0,003 & 0,011 & 0,012 & 0,018 & $0,0 \uparrow 8$ & 0,000 & 0,004 & 0,000 & 0,000 & 0,009 & 0,008 & 0,000 \\
\hline$P$ & 5,781 & 5,720 & 5,724 & 5,698 & 5,597 & 5,894 & 5,498 & 5,698 & 5,560 & 5,480 & 5,609 & 5,495 & 5,616 \\
\hline C & 0,192 & 0,276 & 0,265 & 0,290 & 0,385 & 0,088 & 0,502 & 0,297 & 0,439 & 0,520 & 0,382 & 0,497 & 0,383 \\
\hline$F$ & 1,031 & 0,977 & 1,178 & 1,045 & 1,858 & 1,858 & 1,839 & 1,844 & 1,926 & $\uparrow, 998$ & 1,767 & 1,822 & 1,822 \\
\hline $\mathrm{Cl}$ & 0,006 & 0,006 & 0,001 & 0,006 & 0,030 & 0,000 & 0,005 & 0,005 & 0,000 & 0,003 & 0,005 & 0,005 & 0,003 \\
\hline $\mathrm{OH}^{\mathrm{a}}$ & 0,969 & 1,023 & 0,822 & 0,955 & 0,142 & 0,142 & 0,161 & 0,156 & 0,074 & 0,002 & 0,233 & 0,178 & 0,178 \\
\hline $\mathrm{OH}^{b}$ & 1,045 & 1,134 & 0,928 & 1,071 & 0,296 & 0,177 & 0,362 & 0,275 & 0,250 & 0,210 & 0,386 & 0,376 & 0,332 \\
\hline $\mathrm{OH}^{\circ}$ & 1,160 & 1,299 & 1,087 & 1,245 & 0,527 & 0,230 & 0,663 & 0,453 & 0,514 & 0,522 & 0,615 & 0,674 & 0,562 \\
\hline P.M. ${ }^{a}$ & 1013 & 1010 & 1008 & 1010 & 997 & 1005 & 992 & 997 & 994 & 990 & 995 & 991 & 995 \\
\hline P.M. $^{b}$ & 1015 & 1011 & 1009 & 1012 & 1000 & 1006 & 996 & 999 & 997 & $994^{\circ}$ & 998 & 994 & 998 \\
\hline P.M. ${ }^{\mathrm{c}}$ & 1017 & 1014 & 1012 & 1015 & 1004 & 1007 & 1001 & 1002 & 1001 & 999 & 1001 & 999 & 1002 \\
\hline carga ${ }^{a}$ & 0,122 & 0,199 & 0,165 & 0,212 & 0,385 & 0,105 & 0,512 & 0,285 & 0,434 & 0,518 & 0,387 & 0,493 & 0,402 \\
\hline carga ${ }^{b}$ & 0,045 & 0,088 & 0,059 & 0,096 & 0,231 & 0,070 & 0,311 & 0,167 & 0,258 & 0,310 & 0,234 & 0,294 & 0,249 \\
\hline carga $^{c}$ & $-0,070$ & $-0,078$ & $-0,100$ & $-0,078$ & 0,000 & 0,017 & 0,010 & $-0,012$ & $-0,005$ & $-0,002$ & 0,005 & $-0,004$ & 0,019 \\
\hline ETR & 0,094 & 0,109 & 0,071 & 0,101 & 0,007 & 0,008 & 0,021 & 0,000 & 0,012 & 0,000 & 0,001 & 0,000 & 0,000 \\
\hline $\mathrm{CaO} / \mathrm{P}_{2} \mathrm{O}_{5}$ & 1,310 & 1,322 & 1,329 & 1,329 & 1,401 & 1,339 & 1,432 & 1,384 & 1,414 & 1,440 & 1,404 & 1,437 & 1,400 \\
\hline $\mathrm{F} / \mathrm{P}_{2} \mathrm{O}_{5}$ & 0,048 & 0,046 & 0,055 & 0,049 & 0,089 & 0,084 & 0,089 & 0,087 & 0,093 & 0,098 & 0,084 & 0,089 & 0,087 \\
\hline $\mathrm{SrO} / \mathrm{P}_{2} \mathrm{O}_{5}$ & 0,036 & 0,030 & 0,033 & 0,034 & 0,000 & 0,000 & 0,000 & 0,000 & 0,000 & 0,000 & 0,000 & 0,001 & 0,002 \\
\hline
\end{tabular}




\begin{tabular}{|c|c|c|c|c|c|c|c|}
\hline Tipo & 5 & 5 & 5 & 5 & 5 & 5 & \\
\hline Label & TASC4B & TASC4B & TAF2A & TAF2A & TAF2A & TAF49.1 & TAF49.1 \\
\hline No & 26 & 27 & 50 & 52 & 53 & 27 & 0 \\
\hline $\mathrm{Na}_{2} \mathrm{O}$ & 0,00 & 0,00 & 0,06 & 0,00 & 0,01 & 0,19 & \\
\hline $\mathrm{CaO}$ & 56,48 & 56,31 & 55,40 & 54,64 & 54,60 & 54,50 & 53,16 \\
\hline $\mathrm{MgO}$ & 0,04 & 0,01 & 0,05 & 0,03 & 0,09 & 0,03 & 0,00 \\
\hline $\mathrm{MnO}$ & 0,00 & 0,00 & 0,15 & 0,04 & 0,00 & 0,00 & 0,0 \\
\hline $\mathrm{FeO}$ & 0,07 & 0,00 & 0,25 & 0,18 & 0,13 & 0,13 & 0,08 \\
\hline SrO & 0,17 & 0,00 & 0,08 & 0,00 & 0,05 & 0,06 & 0,06 \\
\hline $\mathrm{BaO}$ & 0,00 & 0,05 & 0,03 & 0,00 & 0,25 & 0,00 & 0,00 \\
\hline $\mathrm{Al}_{2} \mathrm{O}_{3}$ & 0,03 & 0,00 & 0,00 & 0,10 & 0,17 & 0,13 & 0,12 \\
\hline $\mathrm{La}_{2} \mathrm{O}_{3}$ & 0,06 & 0,11 & 0,26 & 0,30 & 0,32 & 0,05 & 0,00 \\
\hline $\mathrm{Ce}_{2} \mathrm{O}_{3}$ & 0,00 & 0,00 & 0,00 & 0,21 & 0,04 & 0,00 & 0,00 \\
\hline $\mathrm{SiO}_{2}$ & 0,00 & 0,04 & 0,07 & 0,07 & 0,08 & 0,09 & 0,05 \\
\hline $\mathrm{P}_{2} \mathrm{O}_{5}$ & 40,12 & 39,28 & 38,57 & 36,03 & 38,64 & 38,71 & 39,39 \\
\hline$F$ & 3,17 & 3,68 & 3,45 & 3,08 & 3,30 & 3,62 & 3,27 \\
\hline \multirow[t]{2}{*}{$\mathrm{Cl}$} & 0,00 & 0,00 & 0,01 & 0,00 & 0,02 & 0,02 & 0,02 \\
\hline & 100,15 & 99,50 & 98,33 & 94,69 & 97,71 & 97,34 & 96,19 \\
\hline $\mathrm{O}=\mathrm{F}, \mathrm{Cl}$ & 1,34 & 1,55 & 1,45 & 1,30 & 1,39 & 1,52 & 1,38 \\
\hline TOTAL & 100,61 & 100,11 & 99,35 & 97,00 & 98,26 & 97,89 & 95,47 \\
\hline $\mathrm{OH}^{\mathrm{a}}$ & 0,59 & 0,13 & 0,31 & 0,60 & 0,39 & 0,10 & 0,32 \\
\hline $\mathrm{OH}^{b}$ & 0,87 & 0,46 & 0,68 & 1,16 & 0,69 & 0,39 & 0,42 \\
\hline $\mathrm{OH}^{\circ}$ & 1,28 & 0,96 & 1,24 & 1,98 & 1,14 & 0,83 & 0,57 \\
\hline $\mathrm{CO}_{2}$ & 1,80 & 2,16 & 2,42 & 3,61 & 1,94 & 1,88 & 0,65 \\
\hline $\mathrm{Na}$ & 0,001 & 0,001 & 0,019 & 0,001 & 0,002 & 0,064 & 0,001 \\
\hline $\mathrm{Ca}$ & 9,961 & 9,985 & 9,887 & 9,927 & 9,913 & 9,901 & 9,976 \\
\hline $\mathbf{M g}$ & 0,009 & 0,003 & 0,012 & 0,008 & 0,022 & 0,008 & 0,001 \\
\hline $\mathrm{Mn}$ & 0,000 & 0,000 & 0,022 & 0,006 & 0,000 & 0,000 & 0,002 \\
\hline $\mathrm{Fe}$ & 0,009 & 0,000 & 0,034 & 0,026 & 0,019 & 0,018 & 0,014 \\
\hline $\mathrm{Sr}$ & 0,016 & 0,000 & 0,008 & 0,000 & 0,005 & 0,006 & 0,006 \\
\hline $\mathrm{Ba}$ & 000 & 0,003 & 0,002 & $.0,000$ & 0,016 & 0,000 & 0,000 \\
\hline Al & 0,006 & 0,001 & 0,001 & 0,019 & 0,035 & 0,025 & 0,025 \\
\hline $\mathrm{La}$ & 0,004 & 0,007 & 0,016 & 0,019 & 0,020 & 0,003 & 0,000 \\
\hline $\mathrm{Ce}$ & 0,000 & 0,000 & 0,000 & 0,013 & 0,003 & 0,000 & 0,000 \\
\hline Si & 0,000 & 0,006 & 0,012 & 0,012 & 0,013 & 0,015 & 0,009 \\
\hline$P$ & 5,591 & 5,503 & 5,438 & 5,171 & 5,543 & 5,557 & 5,841 \\
\hline C & 0,409 & 0,490 & 0,551 & 0,817 & 0,444 & 0,428 & 0,150 \\
\hline$F$ & 1,653 & 1,925 & 1,820 & 1,654 & 1,771 & 1,940 & 1,813 \\
\hline $\mathrm{Cl}$ & 0,000 & 0,000 & 0,002 & 0,000 & 0,007 & 0,007 & 0,007 \\
\hline $\mathrm{OH}^{\mathrm{a}}$ & 0,347 & 0,075 & 0,180 & 0,346 & 0,229 & 0,060 & 0,187 \\
\hline $\mathrm{OH}^{\mathrm{b}}$ & 0,511 & 0,271 & 0,400 & 0,673 & 0,406 & 0,231 & 0,246 \\
\hline $\mathrm{OH}^{c}$ & 0,756 & 0,565 & 0,731 & 1,163 & 0,672 & 0,488 & 0,336 \\
\hline P.M. & 994 & 992 & 991 & 983 & 997 & 993 & 1004 \\
\hline P.M. ${ }^{b}$ & 997 & 995 & 995 & 988 & 1000 & 996 & 1005 \\
\hline P.M..$^{c}$ & 1001 & 1000 & 1000 & 997 & 1005 & 1001 & 1006 \\
\hline carga a & 0,430 & 0,498 & 0,548 & 0,906 & 0,561 & 0,436 & 0,218 \\
\hline carga b & 0,267 & 0,302 & 0,328 & 0,579 & 0,384 & 0,265 & 0,158 \\
\hline carga ${ }^{\circ}$ & 0,021 & 0,007 & $-0,003$ & 0,089 & 0,118 & 0,008 & 0,069 \\
\hline ETR & 0,004 & 0,007 & 0,016 & 0,032 & 0,023 & 0,003 & 0,000 \\
\hline $\mathrm{GaO} / \mathrm{P}_{2} \mathrm{U}_{5}$ & & 1,434 & 1,437 & 1,517 & 1,413 & 1,408 & 1,349 \\
\hline $\mathrm{F} / \mathrm{P}_{2} \mathrm{O}_{5}$ & 0,079 & 0,094 & 0,090 & 0,086 & 0,085 & 0,093 & 0,083 \\
\hline $\mathrm{SrO} / \mathrm{P}_{2} \mathrm{O}_{5}$ & 0,004 & 0,000 & 0,002 & 0,000 & 0,001 & 0,001 & 0,001 \\
\hline
\end{tabular}

